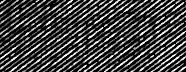

\section{(1)}




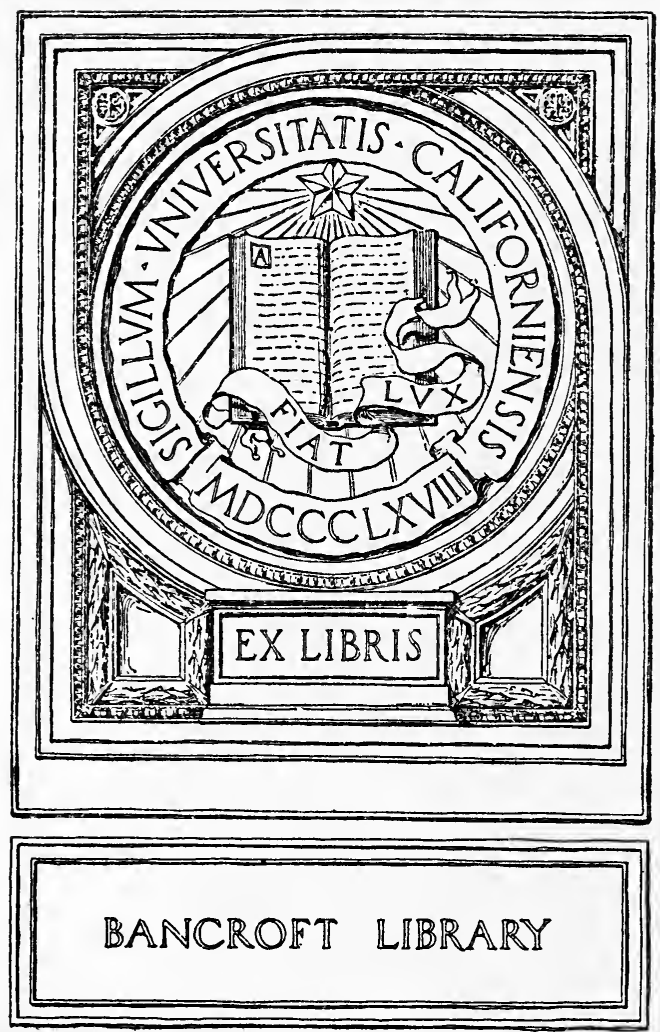






SMITHSONIAN INSTITUTION BUREAU OF AMERICAN ETHNOLOGY BULLETIN 60

\title{
HANDBOOK OF \\ ABORIGINAL AMERICAN ANTIQUITIES
}

\author{
PART I \\ INTRODUCTORY \\ THE LITHIC INDUSTRIES
}

BY

W. H. HOLMES

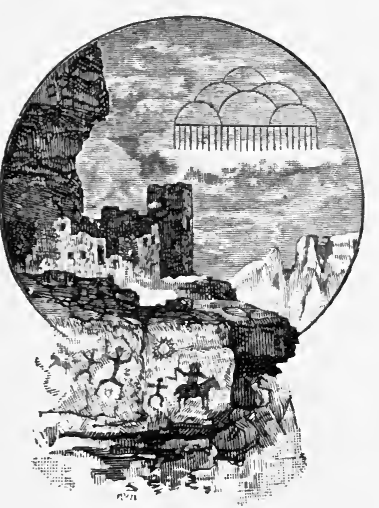





\section{LETTER OF TRANSMITTAL}

$$
\begin{aligned}
& \text { Suithisonian Institution, } \\
& \text { Bureau of American Ethnology, } \\
& \text { Washington, D. C., April 10, } 1916 .
\end{aligned}
$$

SIR: I have the honor to transmit herewith the manuscript of a memoir entitled "Handbook of Aboriginal American Antiquities, Part I," by William II. Holmes, and to recommend its publication as a bulletin of the Bureau of American Ethnology.

Very respectfully,

$$
\text { F. W. Hodge, }
$$
Ethnologist-in-Charge.

Dr. Charles D. Walcott, Secretary, Smithsonian Institution. 



\section{CONTENTS}

I. The place of archeology in human history ...................... Page

II. Resources and agencies of archeologic science................ 9

III. Progress of archeologic research....................... 13

IV. Problems of race and culture origins................. 18

V. Problems of intercontinental communication................ 32

VI. Problems of migration................................. 36

VII. Problems of culture development and mutation.............. 44

VIII. Problems of chronology ................................. 51

IX. Culture characterization areas............................ 95

1. The North Atlantic area...................... 99

2. The Georgia-Florida area...................... 102

3. The Middle and Lower Mississippi Valley area........... 105

4. The Upper Mississippi and Great Lakes area . . . . . . . . 108

5. The Great Plains and Rocky Mountain area........... 110

6. The Arid area.............................. 111

7. The California area........................... 114

8. The Columbia-Fraser area........................ 117

9. The Northwest Coast area........................ 119

10. The Arctic Coast area....................... 120

11. The Great Northern Interior area................. 123

12. The North Mexican area...................... 123

13. The Middle Mexican area . . . . . . . . . . . . . . . . . 125

14. The South Mexican area...................... 128

15. The Maya-Quiché area......................... 129

16. The Central American-Isthmian area............... . . 132

17. The North Andean-Pacific area................... 134

18. The Middle Andean-Pacific area.................. 136

19. The South Andean-Pacific area..................... 140

20. The Amazon Delta area....................... 141

21. Primitive South America ..................... 142

22. The West Indian or Antillean area................ 145

X. Classification of antiquities............................ 148

XI. Acquirement and utilization of materials................. 153

XII. Acquirement of minerals............................. 155

Quarrying and mining............................... 155

XIII. Quartzite bowlder quarries, District of Columbia.............. 159

XIV. Flint Ridge and Warsaw quarries, Ohio................. 173

Flint Ridge quarries........................... 173

Warsaw quarries............................... 181

XV. Flint quarries: West Virginia, Kentucky, Indiana............. 185

XVI. Mill Creek quarries, Illinois.......................... 187

XVII. Flint quarries near Crescent, Mo.................... 195 
XVIII. Novaculite quarries, Arkansas.............................. 196

XIX. Chert quarries of the Great Plains. . . . . . . . . . . . . . . . . . 201

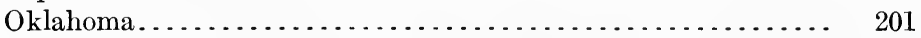

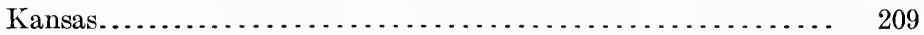

XX. Quartzite quarries, Wyoming........................... 210

XXI. Obsidian mines... . . . . . . . . . . . . . . . . . . . . . . . . 214

XXII. Steatite quarries.................................... 228

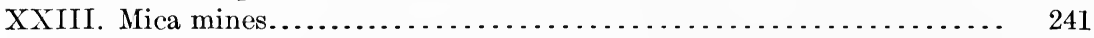

XXIV. The red pipestone quarry ............................ 253

XXV. Hematite ore and paint mine, Missouri. . . . . . . . . . . . . . . 266

XXVI. Turquoise mines. . . . . . . . . . . . . . . . . . . . . . . . . . . . 271

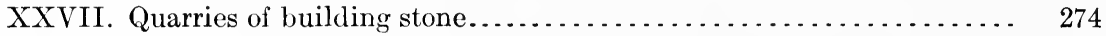

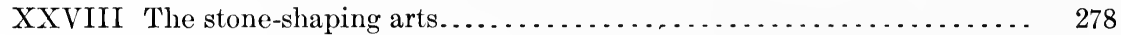

XXIX. Fracture processes..................................... . 283

Percussion fracture processes...................... 283

XXX. Pressure fracture processes. . . . . . . . . . . . . . . . . . . . . . . . . 304

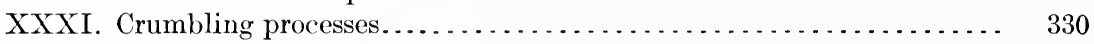

XXXII. Abrading processes.................................. . . 344

XXXIII. Incising processes................................ 358

XXXIV. Piercing processes.................................... 363

XXXV. Fire fracture processes................................. . . 364

XXXVI. Cushing's account of shaping processes . . . . . . . . . . . . . . . 366

Bibliography ......................................... 368

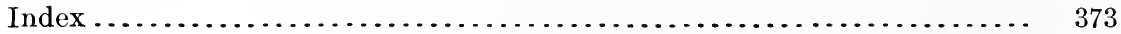




\section{ILLUSTRATIONS}

Figure 1. False relation of the historic (written) to the prehistoric (unwrit-

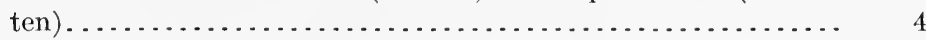

2. True relation of the historic (written) to the prehistoric (unwritten). 4

3. Relation of recorded to unrecorded history ................. 6

4. Relation of the unrecorded history to the purposely and fortuitously recorded history............................. 6

5. Relations of unrecorded history and the several forms of record...... 7

6. Relative permanency of the several forms of record........... 7

7. Ancient wheeled toy from a child's grave, Mexico............. 21

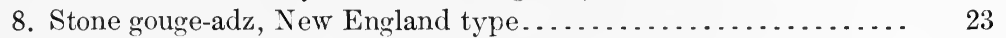

9. Stone gouge-adz, Scandinavian type..................... 23

10. Ax-shaped "banner stone," eastern United States ............ 23

11. Ax-shaped stone implement, Scandinavian type............. 23

12. Ground slate spearhead, New England type................. 25

13. Ground slate spearhead, Japanese type.................. 25

14. Ground slate spearhead, Korean type..................... 25

15. A terra-cotta head with ohlique eyes, Vera Cruz, Mexico......... 28

16. Chinese bronze axes with perforate and decorated blades.......... 29

17. $a$, Axlike stone implement with perforate blade, United States. $b$, Axlike implement of bronze with perforate and decorated blade,

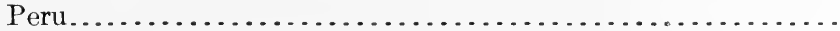

18. Antique Chilcat mask with Chinese coins set in as eyes .........

19. Stages of migration in the peopling of America from tropical Asia..

20. Jade statuette from Vera Cruz, Mexiro, with glyphic date corre-

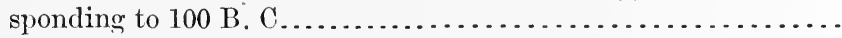

21. Map suggesting multiple origins in Asia and differentiations in

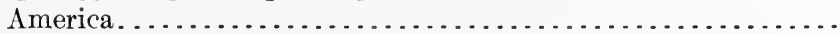

22. Section of Table Mountain showing mines penetrating to old river channels.

5

5

23. a, Fragment of stone pestle found by Clarence King embedded in gravels underlying the Table Mountain lava cap. $b$, Pestle of the prevailing type among the California tribes ...............

24. The Calaveras skull, said to have been taken from Tertiary gravels

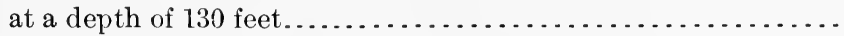

25. Types of mortars and pestles said to have come from the auriferous

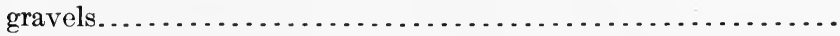

26. A ladle-like utensil from the auriferous gravels. . . . . . . . . . . .

27. Boat-shaped stones from the auriferous gravels. . . . . . . . . . . .

28. Weathered gravel wall of a gold mine 200 feet in height, with ancient village site above . .........................

29. Section showing relations of ancient village site to caved-in gold mine.

30. Obsidian blade from supposed Pleistocene deposits, Nevada...... 
Figure 31. Terra-cotta figurine reported to have come from late Tertiary or early Quaternary deposits, Idaho ......................

32. Section showing the geological position of the Lansing skeleton...

33. Frontal view of the Lansing skull, Kansas.................

34. Sand-buried Indian village, site on shore of Chesapeake Bay ......

35. Sections of gravel bank, Newcomerstown, Ohio, suggesting danger of misinterpretation of finds.......................

36. Supposed paleolithic implement from gravels at Newcomerstown, compared with rejects of blade-making from shop sites..........

37. Chipped blade from supposed glacial deposits at Loveland, Ohio.

38. Grooved ax from supposed glacial deposits, New London, Ohio...

39. Objects of chipped quartz from sand and gravel deposits at Little Falls, Minn. Probably rejectage of arrowhead making.......

40. Implement-like bits of bone from a California cave..............

41. Map of North America outlining tentative culture characterization

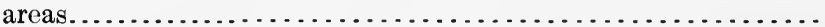

42. Map of South America outlining tentative culture characterization areas.

43. Nap of lower Piney Branch, showing position of bowlder quarries.

44. Section of bluffs showing position of bowlder quarries ...........

45. Section of bowlder quarry showing undermining and a pocket of shop refuse.

46. Section of bowlder quarry showing ordinary quarry face and

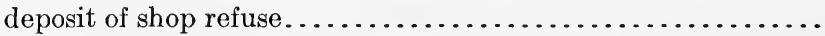

47. Character of refuse deposits exposed by trenching..............

48. Part of an extensive deposit of shop refuse near the quarry face..

49. Relation of a roughed-out, broken blade to the original bowlder..

50. Series of rejects illustrating failure at various steps of progress in

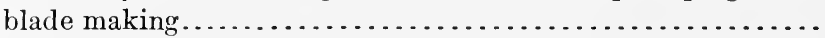

51. Examples of blades broken under the hammerstone when nearly finished.

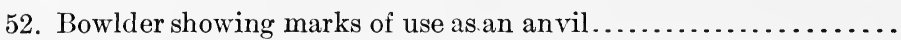

53. Examples of the blades produced in the quarry workshops.......

54. Examples of the specialized implements from village sites.......

55. Life-size group in plaster of Paris, illustrating the quarry shop-

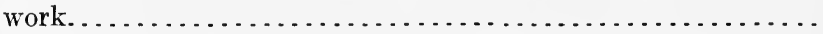

56. Map showing distribution of the several Flint Ridge quarry areas.

57. Detail map of a portion of the Flint Ridge quarries, showing dis-

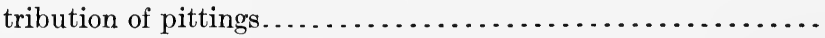

58. Section of a quarry excavation, showing work in progress.........

59. Rejects of blade making due to malformation, too great thickness

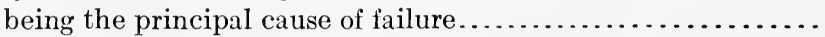

60. Examples of the hammerstones employed in blade making.......

61. Types of the blades produced in the quarry shops.............

62. Types of the implements specialized for use, one as a scraper, the

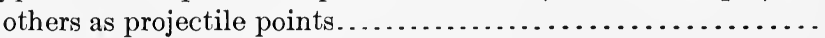

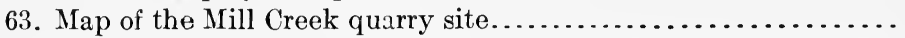

64 . Section indicating the relation of the residual nodule-bearing deposits to the limestones............................

65. Manner of occurrence of the chert concretions in the limestone

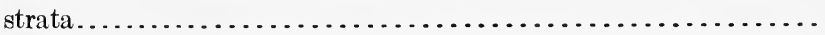

66. Examples of the flattish, irregularly shaped chert concretions

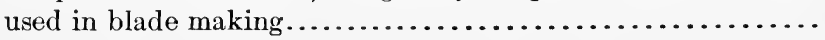


Figure 67. Section showing the ancient excavations...................

68. Clublike implement used in removing the concretions from the

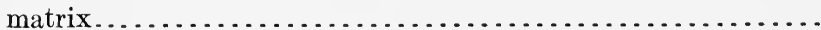

69. Suggested manner of holding the quarry implement............

70. Examples of the blades produced and ready for hafting as hoes..

71. Hoe blade specialized to facilitate hafting.................

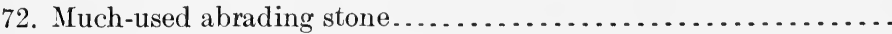

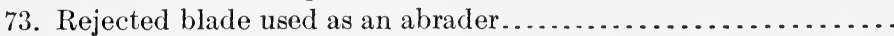

74. Chipping implements made of the base of deer antlers.........

75. Manner of using the antler hammer, unhafted................

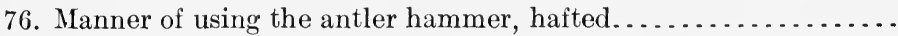

77. Sketch map of the Indian Mountain novaculite quarry.........

78. Sketch map of a small portion of the Magnet Cove novaculite

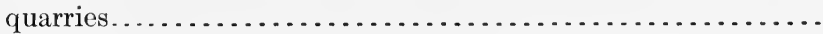

79. Section through a single quarry pit well filled with shop débris..

80. Plan of lodge shop site showing central fire pit and circle of chert

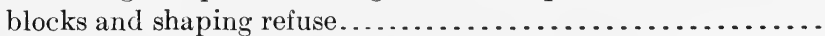

81. Workshop sites with depression in the center, probably the lodge fireplace.

82. Series illustrating the full range of quarry shop rejects.........

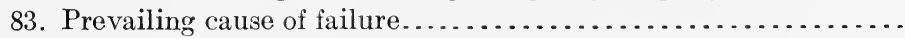

84. Comparatively thin blade found among the refuse.............

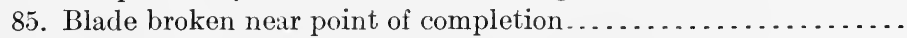

86. Slightly notched specimen, possibly used as a pick...........

87. Nucleus from which flake knives have been struck............

88. Sketch map of the Wyoming quartzite quarry area.............

89. Present appearance of the Wyoming quartzite quarries.........

90. Present appearance of the Wyoming quartzite quarries.........

91. Giant columns of impure obsidian, Obsidian Canyon, Yellowstone

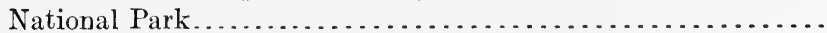

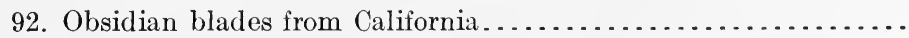

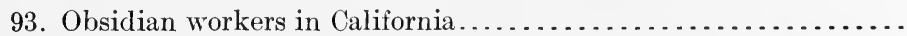

94. Great deposits of obsidian flakes and other shop refuse, Mountain

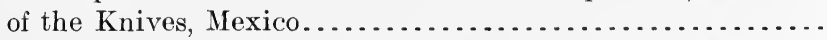

95. Section of the great deposit of flakage, obsidian mines, Mountain of the Knives, Mexico.............................

96. Hammerstones from the obsidian mines of Mexico.............

97. Roughed-out nuclei intended for blade making, rejected on account of defects of fracture, Mountain of the Knives, Mexico...

93. Exhausted or nearly exhausted nuclei from the Valley of Mexico.

99. Scraper-like objects from the refuse heaps, Mountain of the

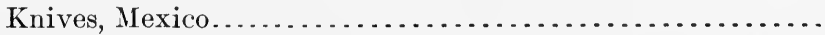

100. Large flakes slightly specialized for undetermined uses, Mountain of the Knives, Mexico........................

101. Types of implements from the fields near the obsidian mines,

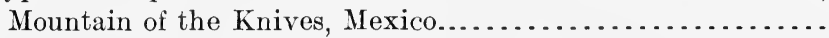

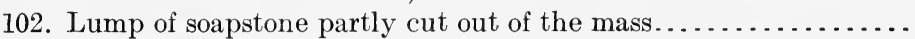

103. The stump left by breaking off the globular lump.............

104. Unfinished vessels broken during the shaping work.............

105. Rudely finished vessels from village sites ..................

106. Appearance of the Clifton quarry, Virginia, after cleaning out....

107. Chisel and pick like forms of quarry implements..............

108. Chisel and pick like forms of quarry implements..............

109. Grooved axes employed as picks in the quarry work...........

110. Grooved axes employed as picks in the quarry work........... 
Figure 111. Gouge of New England type employed in the Connecticut Avenue quarries.

112. Traces of aboriginal work in soapstone quarry, Santa Catalina Island....

113. The soapstone workers, a life-size group prepared by the writer for the Panama California Exposition and repeated in the

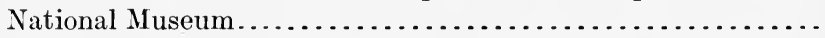

114. Stone implements from the ancient mica mines of North Carolina...

115. Stone implements from the ancient mica mines of North Carolina..

116. Sketch map showing the relation of the Robinson and Sink Hole

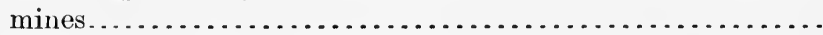

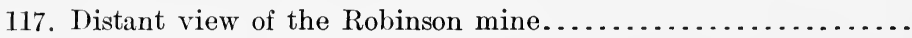

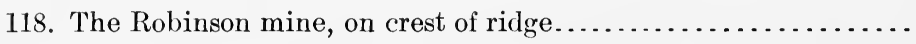

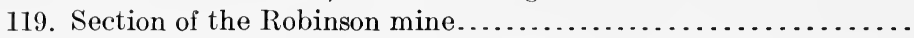

120. Sketch indicating the present appearance of the mine.........

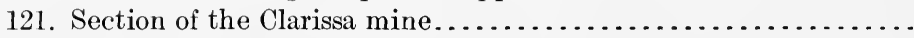

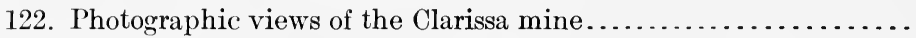

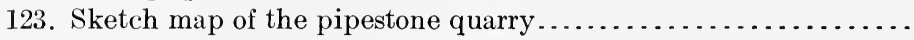

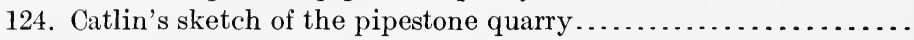

125. The almost complete obliteration of the earlier pittings. Pipe-

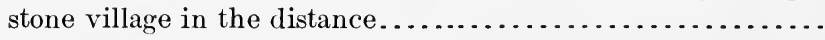

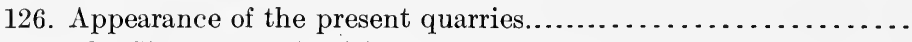

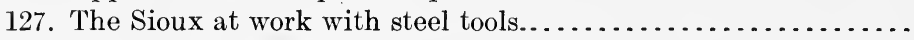

128. Indian miner breaking up the exposed margin of the pipestone

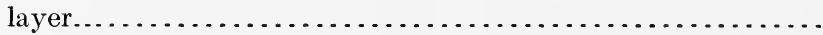

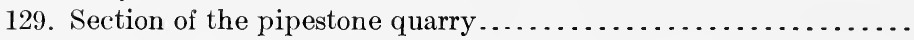

130. Hammerstones used in the quarry work before the acquirement of

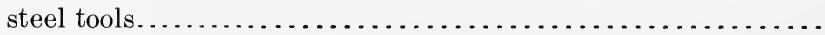

131. Grooved sledges of the Plains tribes found on the shop sites.....

132. Examples of worked bits of the pipestone from the camp sites...

133. Commercial pipe and trinket maker at work near the quarries...

134. Great granite bowlders near the quarries, brought from the far

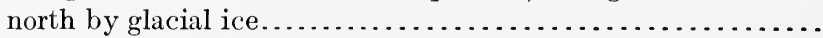

135. A heap of ancient mining tools thrown out of the quarry........

136. Examples of the stone sledge heads, picks, and hammers found in the mines........................................

137. Wall of a modern iron mine, exposing the ancient tunnels......

138. Section indicating the general character of the ancient tunneling...

139. One of the figures of the model of the hematite workers, prepared by the writer for the Panama California Exposition.....

140. Stone sledge heads from the ancient turquoise mines at Los Cerillos, N. Mex.....................................

141. The stonecutters of Yucatan. From a group in the National

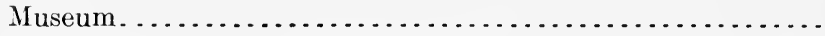

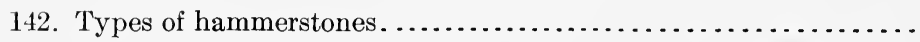

143. Pitted hammerstones employed in a wide range of uses, and of very general occurrence.................................

144. Free-hand fracture of a bowlder with a bowlder hammer.........

145. Flint working by Ishi, a Yahi Indian of California..............

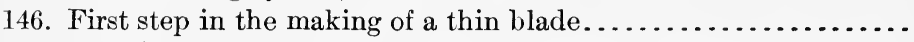

147. a, One face chipped all around but unsuccessful because not flat enough - a reject. $b$, Successful so far because flat enough to insure a thin blade, provided the other side chips equally flat.. 
Figure 148. Beginning of the chipping of the second side of the bowlder. A

pad was generally used to protect the hand .................

149. $a$, Profile of a blade, unsuccessful because too thick. $b$, Profile of a blade, successful because thin enough to serve as a knife, or as the blank form for a projectile point....................

150. Types of the blades, the blank forms of implements, produced in

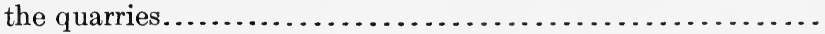

151. Example of failure in blade making due to malformation ...........

152. Example of cross fracture under the hammer near the completion

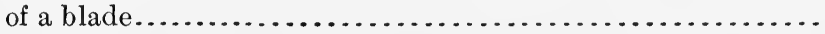

153. Cross-fractured blade, one-half of which was found, and also a dozen of the flakes struck from it with the hammer. Flakes set back into place...................................

154. Limited degree of specialization of the blades, possible by percussion with flat discoidal hammers....................

155. Large, thick, animal-shaped figure of flint, probably specialized

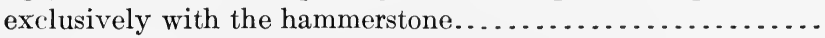

156. Flint blade the specialization of which would exceed the capacity of the hammerstone............................... 295

157. Indirect percussion; three hands employed................ 296

158. Free-hand fracture with hammer and deer-horn punch.......... 297

159. Fracture of a stone held in the hand by striking it against an anvil

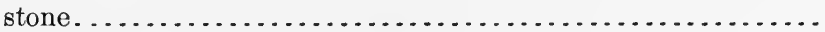

160. Fracturing a large stone with a hammerstone cast as a missile.....

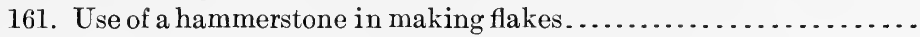

162. Shaping a blade at rest by fracture with a hammerstone.........

163. Chipping a stone held at rest by strokes of a hammerstone..........

164. Pebble from which flakes have been removed by strokes of the

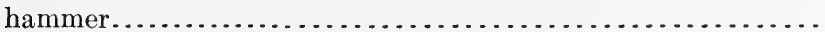

165. Hammerstones used also as anvils, as indicated by the scarring..

166. Hammerstones used also as anvils, as indicated by the scarring..

167. Flakes made from water-worn bowlders by a single stroke of the

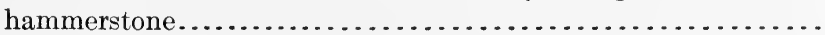

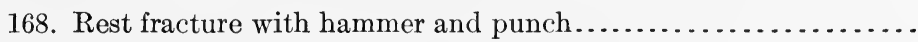

169. Fracture by resting a blade upon an anvil and tapping it from above with a hammer..............................

170. Notching a blade by resting it on a sharp-edged anvil and tapping

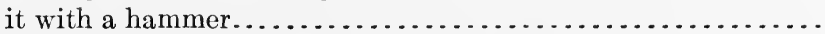

171. Free-hand pressure chipping with a bone point..............

172. Sharpening an arrow point by chipping with a bone point.........

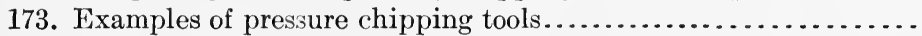

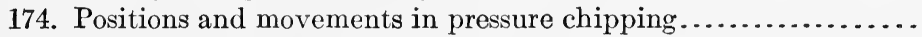

175. Paiute Indian chipping a knife blade with a bone point ...........

176. Relative position of the implements in the hands of the Paiute

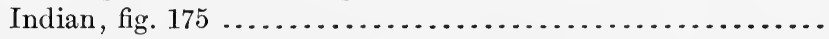

177. Free-hand pressure chipping of the Klamath Indians...........

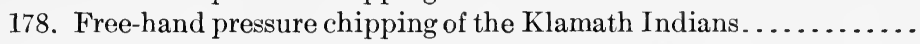

179. Position in chipping with a bone point by the Wintoons............

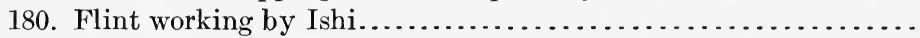

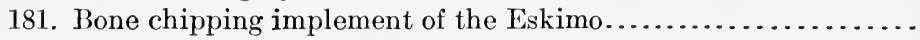

182. Method of flaking by Mexican Indians as described by Torquemada, and by western United States tribes as described by

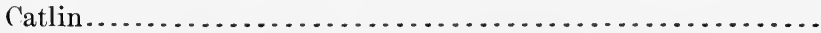


Figure 183. Australian method of chipping as described by Balfour.........

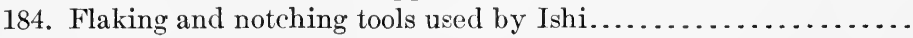

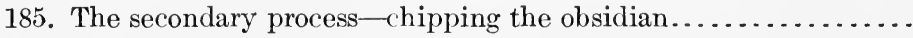

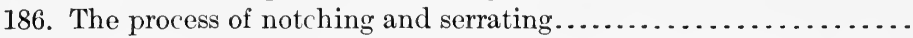

187. Shaping a stone ax by the pecking (crumbling) process.........

188. Method of holding the discoidal hammerstone................

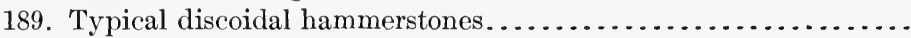

190. Stone axes in process of manufacture by pecking (crumbling)

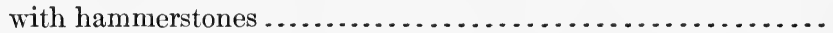

191. Incipient grooved axes showing the effects of pecking (crumbling) with a hammerstone.

192. Specimens illustrating successive steps in shaping hatchet blades

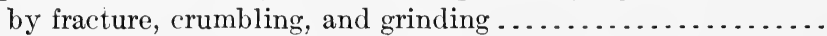

193. Carving with a pointed bit of stone held in the hand ...........

194. Probable manner of employing the chisel in carving stone......

195. A chisel-like blade of flint from Yucatan...................

196. Three forms of the crumbling-carving process-with mallet and chisel, with hafted pick, and with pick held in the hand......

197. Partially dressed blocks of stone in an ancient quarry at Mitla,

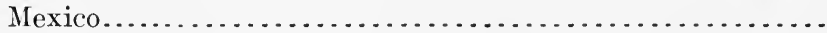

198. Rude stone-cutting (crumbling) implements found on a quarry site at Mitla, Mexico.............................

199. Marvelous mural masonry of the ancient Peruvians...........

200. Carving of the massive rock in place by the ancient Peruvians...

201. Common forms of abrading stones from the Atlantic States.....

202. Type of whetstone of jade in common use among the western

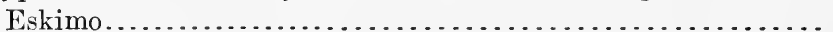

203. Grooves produced by the abrasion of implements...........

204. Series of positions illustrating abrading work with a small hand

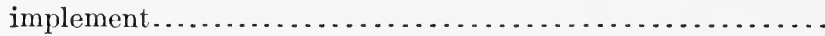

205. A California Indian grinding shell ornaments on a flat stone....

206. Traces of abrading work left in rock bodies in place...........

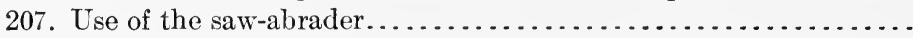

208. Showing the result of sawing from opposite sides and breaking the

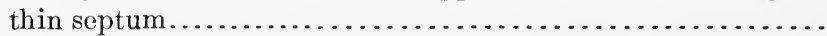

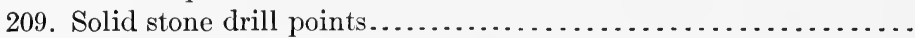

210. Drill points of chipped flint. . . . . . . . . . . . . . . . . . . .

211. Tubular drill of copper and section of bore..................

212. Bowl of travertine vase partially excavated by tubular drill.....

213. Alabaster tablet with the bone drill found in place............

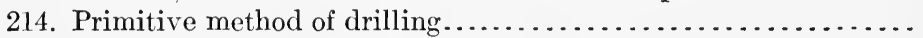

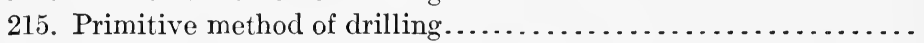

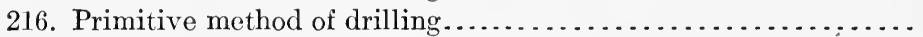

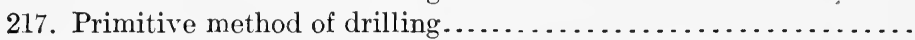

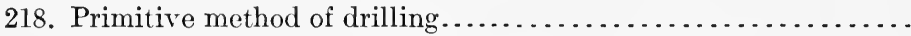

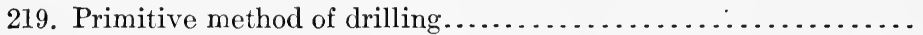

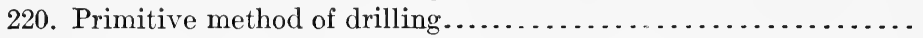

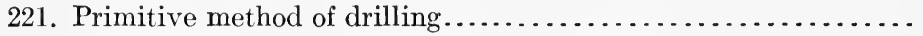

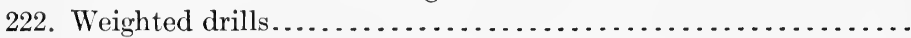

223. $a$, Use of strong strokes by a broad-pointed implement, probably hafted. $b$, Use of a narrow-pointed implement, probably

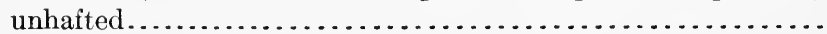




\section{PREF ACE}

7 HE present work forms one of the series of handbooks of the Bureau of American Ethnology, which was conceived as the natural and necessary outgrowth of the Handbook pleted and sent to press while the writer was Chief

The Handbook Series of the Bureau. It was planned to have a series of at least 12 separate handbooks which should cover as many grand divisions of the subject matter embodied in brief form in Bulletin 30. The first of this series to be submitted for publication was the Handbook of American Indian Languages (Bulletin 40), Part 1, and the second, the present memoir, the Handbook of American Antiquities. This work is not designed as a formal presentation of American archeology in which the antiquities are described and discussed country by country, or region by region, in geographical sequence, but rather as a reference

A Reference Work work or manual, the principal purpose of which is to assemble and present the antiquities of the continent in such a manner and order as to make them readily available to the student who shall undertake to present a comprehensive view of the erolution of culture among men.

The present volume is, in large measure, introductory to the systematic presentation of the antiquities; it deals with the scope of archeologic science, the character, extent, and classification of its subject matter, the progress of research; with the several important problems which present themselves for solution, including those of race origin, migrations, culture evolution, and chronology; with the ethnic characterization areas: with the acquirement of the substances employed in the arts; and finally with the manipulation of stone.

The second volume is to be devoted exclusively to the implements, utensils, and other minor artifacts of stone. These are given precedence over other grand divisions of the subject matter for the reason that they lie at the foundation of Stone Age culture, and, for that matter, at the foundation of all progress toward the civilized 
state, and at the same time are the chief reliance of the historian and chronologist who seeks to write the early chapters of the story of humanity. Additional volumes are expected to treat of all the remaining materials-mineral, animal, and vegetable-and it is further planned to give separate consideration to the more important arts and industries practiced by the native peoples, as building, sculpture, the textile and fictile arts, and metallurgy.

While the preliminary studies for this work were under way, the writer was called upon to take charge of the The National Collections archeological collections of the National Museum, with which he had been more or less familiar for 40 years. These collections, at the time of his transfer from the Bureau of American Ethnology to the Museum, were in process of removal from the old to the new Museum building and had to be reassembled, classified, labeled, and installed in exhibition cases designed and built for the purpose. This arduous and prolonged yet agreeable task was executed in the most painstaking manner and extended over the years 1909-1913. In this way the collections, which had accumulated in a somewhat random way during half a century, became intimately familiar to the writer, and their study led not only to a more complete understanding of the characteristics, technical history, and functions of the many classes of objects, but opened the way to suitable methods of museum presentation and to their rational application to the solution of the various problems of aboriginal history.

Dr. Charles Rau, an archeologist of exceptional acumen, was the first custodian of antiquities in the Museum and Early Publications published a number of valuable papers relating to the collection as it existed during his incumbency (1877-87), and for a number of years Mr. Frank H. Cushing was associated with him in the work, gaining a mastery of the subject which proved of great service to him in his subsequent valuable field researches among the tribes. Dr. Thomas Wilson followed Dr. Rau (1887-1902), and during his custodianship published a number of volumes, in which portions of the national collections were described and illustrated. The work of this early period was, however, in the main preliminary to a more systematic and comprehensive discussion of the materials of American archeology. An elaborate catalogue of the national collections was begun by Dr. Rau, but remained unfinished at the time of his death. Numerous excellent illustrations prepared under his direction by Mr. Charles F. Trill, a master draftsman, were utilized by Dr. Wilson, and selections from the same will appear in the present work. 
While the Museum staff during the past 50 years was gradually accumulating, studying, and installing the collections, Research Work field researches conducted by Government experts in
Under Powell various branches were actively adding new material and amassing besides a great body of information relative to the tribes and their culture, present and past. Major Powell began his epoch-making studies among the tribes of the arid region in the late sixties, and the succeeding half century witnessed the gradual building up of the Bureau of American Ethnology, which has done so much toward placing on record the present and the past of the northern aborigines. Researches carried forward by other institutions and by individuals at home and abroad during this period have aided in greatly extending our knowledge of the aboriginal culture of the entire continent, placing the science of American archeology on a substantial and permanent footing.

Many of the problems of antiquity have been solved, but still cthers remain which must await fuller investigation Unsolved Prob- than has yet been possible. Among these are the
lems origin of the native race, the period or periods of arrival in America, the routes of migration, the areas occupied by the successive incoming groups, the character and relations of the cultures introduced, the influence of environments and of successive environments on the people and their culture, and the manner in which the stages of culture supervened one upon another, together with their general chronology. Indeed, some of the questions can never be fully answered, as the solutions are unrecorded in the objective forms of art with which archeology has principally to deal. However, the deep mystery which a short time ago enshrouded some of the greater problems is now dispelled and visions of mysterious races and lost civilizations haunt the minds of those only who have failed to keep in touch with the progress of archeological research throughout America.

Archeology deals primarily with the material relics of antiquity, deriving from them what it can of the past of the Scope of the Stone Age

aborigines, but its researches extend to a much wider field, as will be shown in succeeding pages. However, it does not assume to comprise the whole of the so-called "age of stone," since our aboriginal history as a whole lies entirely within the so-called age or stage of stone. Intelligently conceived, a discussion of the Stone Age does not signify merely a study of objective antiquities but a comprehensive consideration of the whole subject matter of the aboriginal peoples and their culture. The expression "Stone Age" as applied to America has thus a wider significance than even the term "archeology," comprehending, as it does, somatology, psychology, language, religion, social systems, tech- 
nology, and esthetics, embracing in each department the problems of evolution, chronology, geography, and general history.

The ultimate purpose of the archeologist working within his special field is not merely to classify and describe the antiquiPurpose of Re- ties, but to aid in acquiring and making available search fuch full and intimate knowledge of all the phenomena of aboriginal culture as to render possible their accurate application to the elucidation of the American race and thus to the history of the human race as a whole.

In the researches of the Bureau of American Ethnology the southern limit of these activities has usually coincided Northern America with the northern boundary of Mexico, although it is probable that a more natural line of demarcation between Northern and Middle America could be drawn across northern Mexico, for it is here that there appears to be a somewhat decided break in the continuity of peoples and cultures. ${ }^{1}$ The peculiar culture of the mound-building tribes practically ends with the lower valley of the Rio Grande, but the culture characterizing the arid region extends in slightly variant forms well into Mexico. It was not in the original plan to extend the present work to Middle and South America, for the reason that until recent years Middle and South America

researches in these regions had not been carried far enough to make a reasonably well rounded presentation of southern antiquities possible, and even now the task of covering this rast ground meets with much embarrassment from lack of reliable knowledge. In these countries the early explorers have given their chief attention to the architectural and other striking and showy remains, leaving the minor relics in a large measure unobserved; however, more recently much good work, though not often fully intensive work and covering limited areas only, has been done by Middle and South American students as well as by those of Northern America and Europe.

It is well understood that the culture as well as the peoples of the West Indian Islands have kinship with the culWest Indies ture and peoples of South America rather than of

North America, but recent researches, especially those of Fewkes under the auspices of the Bureau of American Ethnology in cooperation with the staff of the Museum of the American Indian, have made the antiquities of the Antilles so well known that they can be presented with reasonable fullness.

\footnotetext{
1 It has been found convenient in presenting the materials of antiquity to refer to the continent as comprising three grand divisions, Northern, Middle, and South America, the first including North America down to middle northern Mexico and the second from this boundary to the Gulf of Darien.
} 
The Hawaiian Islands and Samoa are remote from the American shores, but a brief review of their antiquities may Hawaii and Samoa be embodied in this work for comparative purposes. It is not assumed that intimate relations existed between these and other Pacific islands and the American Continent during early or even late pre-Columbian times, but analogies are found to exist between the antiquities of the adjacent land areas and especially along the more proximate shores of the two regions which require to be explained.

The multitude of analogies between the art forms of America and those of the Stone Age peoples of the Old World Culture Analogies need not receive exhaustive attention in this work, although it is recognized that a comparative study of the entire field would be most interesting in its bearing upon the questions of parallel developments, relationships, and resemblance due to incomplete differentiations and to analogies arising from transfer of independently dereloped culture phenomena.

The researches relating to the antiquities of America and more especially of Northern America are recorded in an Literature extensive literature. Published works embodying original researches in the several ethnic areas, outlined later on, are cited in connection with the brief comparative study of these areas, and it is intended that a list of publications bearing upon the general field shall appear as an appendix in one of the subsequent volumes.

W. H. HoLires.

$38657^{\circ}-19-$ Bull. 60 , pt I- 2 



\section{HANDBOOK OF ABORIGINAL AMERICAN ANTIQUITIES}

PART I

INTRODUCTORY

THE LITHIC INDUSTRIES

By W. H. HoLmes

\section{THE PLACE OF ARCHEOLOGY IN HUMAN HISTORY}

NTHROPOLOGY, which is defined as the science of man, may $A$ be regarded as presenting two distinct phases: (a) The his1 torical phase, which deals with the present and past, and (b) the practical phase, which relates to the present and future. The former comprises all of those researches designed Human History to acquire a knowledge of the present and past of $\begin{array}{ll}\text { and Anthropology } \\ \text { Synonymous } & \text { man, and the latter all of those researches which } \\ \text { have the present and future welfare of man in view. }\end{array}$ The term "History" as applied to the human race is a comprehensive designation corresponding to the historical phase of Anthropology. According to Powell's classification, Anthropology may be considered under seven heads or departments, giving rise to as many branches of research: Somatology, the science of the human body; psychology, the science of the human mind; philology, the science of actirities designed for expression; sociology, the science of institutions; sophiology, the science of activities designed to give instruction; technology, the science of the arts and industries; esthetology, the science of activities designed to give pleasure. In working out its problems each of these branches employs every available agency of research within and without its particular field, and makes use of every kind of record in which the history of man is embodied.

The sources of information to be drawn upon in these researches are comprised under two principal heads: (I) In-

Sources of Information-Purposeful Records tentional or purposeful records, and (II) nonintentional or fortuitous records. The intentional records are of five forms, as follows: (1) Pictorial, as in pictures and pictographs; (2) major objective, as in commemorative, monumental works; (3) minor objective, as in quipu and wampum; 
(4) oral, as in tradition and lore; (5) written, as in glyphic and alphabetic characters. It should be observed that with each of these categories goes necessarily a mnemonic element-a very considerable dependence on memory.

Fortuitous records take numerous forms: (1) The great body of products of human handicraft to which no mnemonic Fortuitous Records significance has ever been attached; (2) the nonmaterial results of human activity as embodied in language, beliefs, customs, music, philosophy, etc.; (3) the ever-existing body of unpremeditated memories which accrue to each generation and are in part transmitted adventitiously; (4) the record embodied in the physical constitution of man, which, when properly read, aids in telling the story of his development from lower forms; $(5)$ the records of intellectual growth and powers to be sought in the nature and activities of the mind; (6) the environments which may be made to assist in revealing the story of the nurture and upbuilding of the race and its culture throughout the past.

It is from these diversified records, present and past, that the story of the race-of the seven grand divisions of human Relations of Ar- history-must be drawn. Archeology stands quite cheology to His- apart from this classification of the science of man,
tory since, as will be shown, it traverses in its own way the entire field of research; howbeit, it usually claims for its own more especially that which is old or ancient in this vast body of data. It is even called on to pick up the lost lines of the earlier written records, as in the shadowy beginnings of glyphic and phonetic writing, and restore them to history. It must recover the secrets of the commemorative monuments - the tombs, temples, and sculptures intended to immortalize the now long-forgotten great. It must follow back the obscure trails of tradition and substantiate or discredit the lore of the fathers. It must interpret in its way, so far as interpretation is possible, the pictorial records inscribed by Archeology the Re- the ancients on rock faces and cavern walls, these
triever of History being among the most lasting of purposeful records. All that Archeology retrieres from this wide field is restored to human knowledge and added to the volume of written history. Archeology is thus the great retriever of history.

The science of Archeology is equally useful in the field of the fortuitous records of humanity, for it reads or interprets that which was never intended to be read or interpreted. The products of human handicraft, present and past, which have automatically recorded the doings of the ages, are made to tell the story of the struggles, the defeats, and the triumphs of humanity. The fortuitous records embodied in the nonmaterial products also of man's activi- 
ties are made to cast a strong light on the history and significance of the material things of the past. Even the body of knowledge gathered from many sources and stored in the memory of the living, though untrustworthy as a record, may be made, if wisely employed, to illumine the past; and the physical and psychical man of to-day are in themselves records and may be made to tell the story of their own development, thus explaining the activities and the products of activity throughout the ages. All that Archeology gathers from this wide field of research is contributed to the Archeology the volume of written history. It is thus not only the Revealer of His- retriever of that which was treasured and lost, but
tory equally the revealer of vast resources of history of which no man had previously taken heed.

In the great work of assembling the scattered pages and completing the volume of the history of man, ArchePrehistory Sign- ology may well claim first place among the confies Merely Prewritten IIistory

tributing sciences. The range of its activities may be further defined. Since history must be regarded as embracing the entire record of the race, whatsoever form it may take, there can in reality be no such thing as "prehistory," and hence no such thing as a "prehistoric period" or "prehistoric archeology," hence these terms, if used at all, should not be employed without first fully setting forth their particular application. There can, indeed, be no satisfactory or scientifically useful classification or separation of the history of human culture as a whole or even with a single people on a basis of time or period. The beginning of Relation of Writ- the written record is not the end of the unwritten ten and Unwritten History

record either for the race as a whole or for any of the groups. We may think of a people as having a period of written history, a period dating from the beginning of writing among that people, or we may think of a people without writing, which by accident of geographical proximity has found a place in the written record of a neighboring, more advanced nation; but the unwritten phase in no case ceases with the beginning of the written phase of the history of any people; a large part of the current history in all cases, being unwritten, passes, unless temporarily conserved by tradition or by some nonpurposeful method, directly into the vast body of the subject matter of archeological science or otherwise into the great blank of oblivion.

Referring to the American Continent, and using the term "prehistoric" in the usual sense, we may think of the prehistoric period as ending and the historic as beginning with the landing of the Norsemen in the year 1000 A. D.; or, disregarding this episode as a mere negligible incident, without practical effect on the prehistoric 
status of the aborigines, we may think of the landing of Columbus as ending the prehistoric and beginning the historic period. It is customary to speak of the historic period in America as thus limited, and of the prehistoric as covering all previous time (fig. 1), but this is an unscientific classification. The Columbian discovery did not reveal the American aborigines or make known their place in history, save in the most limited way. The race and its culture continued for a long time practically within the realm of the prehistoric (the unknown and unwritten), somewhat as indicated in figure 2. The actual separation, the scientific separation, is between the written and the unwritten. As commonly expressed, the prehistoric phase of

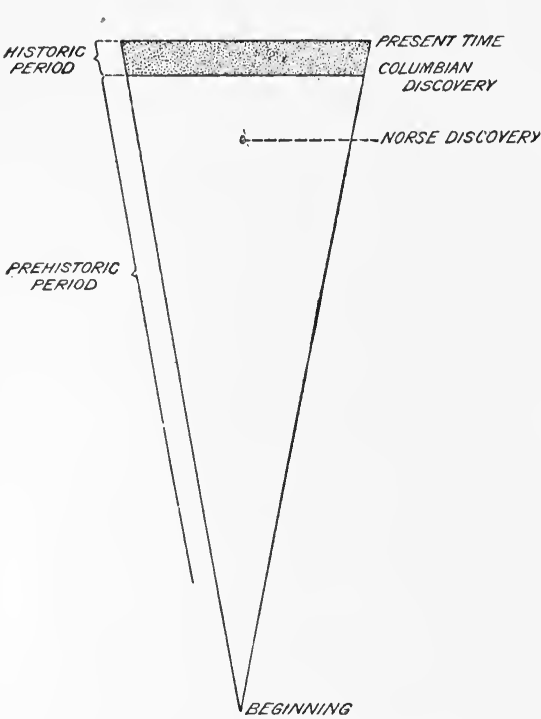

FIG. 1. False relation of the historic (written) to the prehistoric (unwritten).

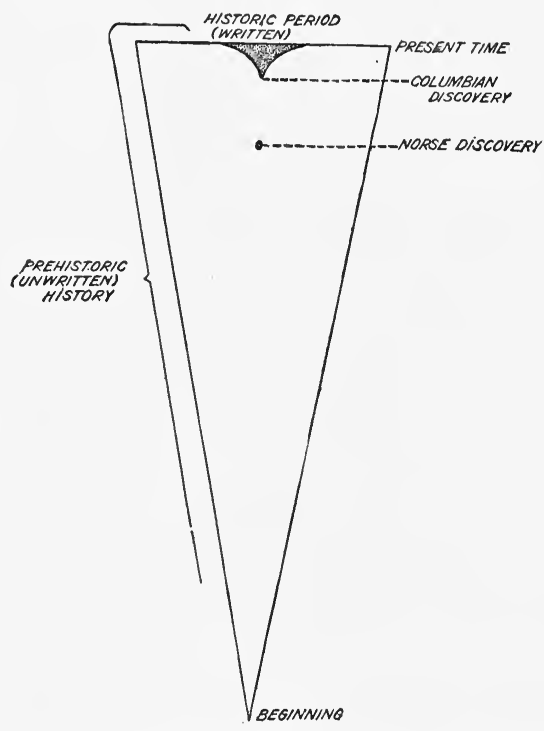

FIG. 2. True relation of the historic (written) to the prehistoric (unwritten).

the history of a particular people or ethnic group would end and the historic phase begin with the first written record of that people. Thus the prehistoric status of the Peruvians would end and the historic begin with the arrival of Pizarro, of the New Mexicans with the arrival of Fray Marcos de Niza, and of the Virginians with the landing of the Roanoke colony. The prehistoric (unwritten) period of the valley of the "River of Doubt" would end and the historic would begin when Roosevelt made his much-challenged report; the previous history of the valley, being outside of the range of historyrecording peoples, is prehistoric-that is, without designed record, and so it largely remains.

Although the first written record of a people may be regarded as marking the beginning of the period of written history of that people, the separation of the two fields is not thus correctly indi- 
cated. In each case the written record covers but a limited portion of the historical subject matter of the people of the area concerned, as indicated in figure 2. In fact, the unwritten, the true prehistoric, never ends, and the task of the archeologist has an unlimited future as it has an inexhaustible past. Concrete examples may serve further to illustrate the relation of history and the so-called prehistorythat is, of the written and the unwritten phases of the human record.

The history of Rome is recorded in a thousand volumes, yet there is much more of Roman history within the period Written and Un- of written history which can be known to the mod-
written Rome

ern world only through excavation and research, and much more still which can not be known at all. The archeological phase of the history of Rome begins practically with the present and extends backward over a succession of periods passing indefinitely beyond the dawn of its written history toward the beginning of man's career in the basin of the MediterWritten and Un- ranean. Even a modern city like Washington, now written Washing- little more than a century old, has a record of events
ton entombed beneath its pavements awaiting the pick and spade of the archeologist of the future. Resting upon a substratum filled with relics of the aborigines, the subject in recent years of extended and important research, is a layer of deposits pertaining to the British colonial régime, and a stratum superposed upon this inclosing traces of nearly a century and a half of the modern Republic. The bulk of the unwritten is by far greater than that of the written. It would seem thus that the Capital City has its unwritten record to which, however, the archeologist-historian may not need to apply, since the written record is exceptionally complete, unless, indeed, a fate like that of ancient Rome should in the fullness of time fall to her lot.

That antiquity is not a necessary attribute of the subject matter of archeologic science may be further illustrated. Archeology Not The contents of an ancient village site in Asia Minor, Limited to Antiq- for example, deserted before the beginning of the Christian era, contains ruined buildings and other works, as well as minor relics of various kinds, on and beneath the surface. All of these antiquities are properly within the purview of the archeologist, who uses them in determining people, culture, period, relations, and origins. The contents of a village site deserted by a primitive tribe in Arizona a generation ago furnishes nearly identical remains, all of which are equally well within the purview of the student of archeology, who may use them in determining the people, the culture, the period, relations, and origins as in the other case. The period does not in any way affect the status of the subject matter of the science of archeology. Events lost to memory but yesterday and 
unwritten can be restored to the realm of the known only through the agency of this science. Objects lost to sight but yesterday and unrecorded can be restored to the realm of the known only by archeological research.

The wide range of the field of Archeology may be made more fully apparent by a consideration of the accompanyDiagram of Human ing diagrams, in which the field of human history,
History represented by the space between two diverging lines, is assumed to begin at the bottom with the birth of the race, to widen with the ages, and to end at the top with the present time. On this field is laid down (fig. 3) a theoretical scheme of the relation of the wholly unrecorded $(A)$ to the whole body of recorded

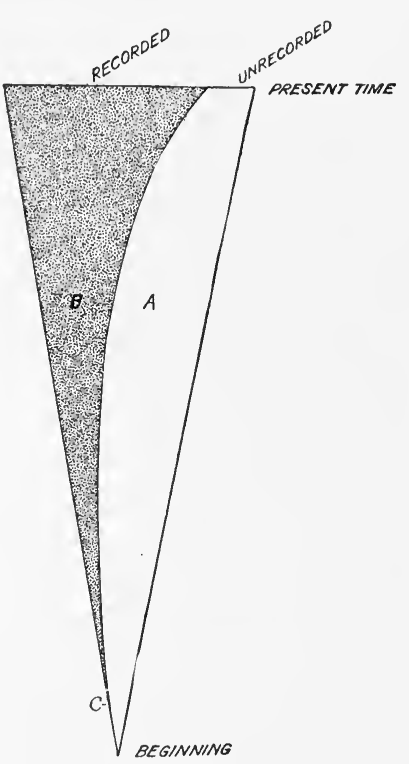

FIG. s. Relation ot recorded to unrecorded history.

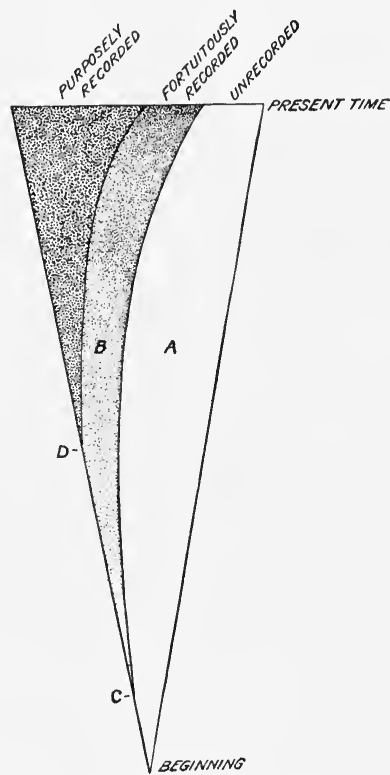

Fig. 4. Relation of the unrecorded history to the purposely and fortuitously recorded history.

history $(B)$. It is clear that in the earlier stages the wholly unrecorded must occupy a large part of the historical field, but records of a fortuitous kind, consisting of the physical remains of man and the simpler forms of his works, have been preserved under certain favorable conditions from the earliest times, as indicated at $C$. With the passing ages this area increases in importance, and new forms of record arise, gradually occupying a considerable part of the field. It is assumed that purposeful records began perhaps during the early stages of savagery (fig. $4, D$ ), the point in intellectual evolution at which the suggestion of keeping in memory past events and of fixing dates of present and future events dawned upon the mind. The five forms of purposeful record which arose-pictorial, minor 
objective, monumental, traditional, and written-had beginnings, we may say, at $D, E, F, G, I I$, respectively (fig. 5). Insignificant and of slow development at first, the purposeful records gradually expanded, as indicated in the diagram, so that to-day they occupy an important place in the historic field, the written record having increased in scope with exceptional rapidity.

It is observed that the several purposeful records, although kept up continuously from generation to generation, are All Records Fugitive

not necessarily permanent. for while additions are made to-day, the records of yesterday are being obliterated. All fade out with the passing of the years, and are lost,

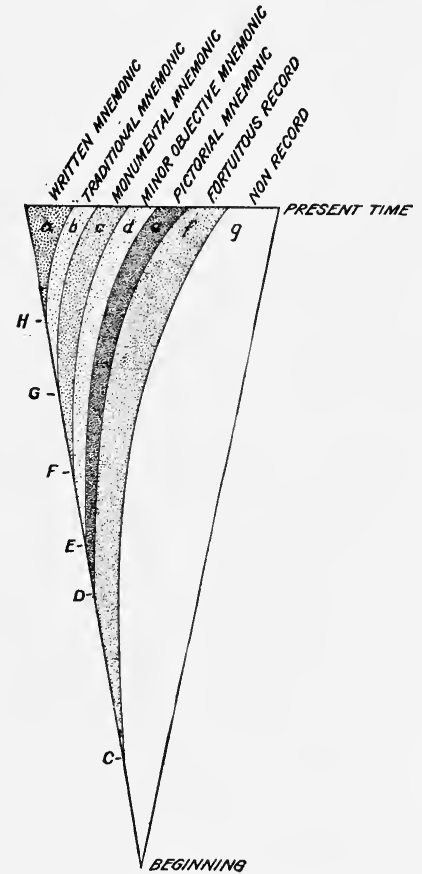

FIG. 5. Relations of unrecorded history and the severalforms of record.

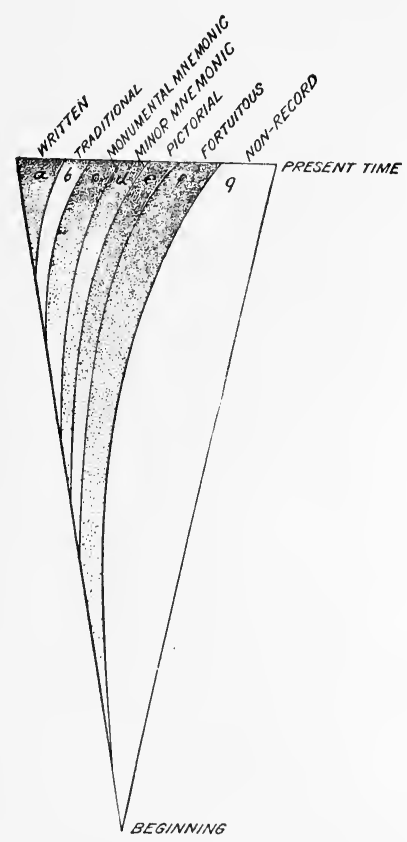

FIG. 6. Relative permanency of the sereral forms of record.

though at different rates, as indicated in figure 6 . The traditional records (b) persist for a few generations only, or at most a few centuries. The monumental mnemonic records $(c)$, of which the dolmen and the pyranid are examples, are durable as structures; they suggest their purpose and tell of the customs of the time; but the associated record, being unwritten and hence dependent on tradition, is soon wholly lost. Even the written record has in many instances lost its significance, as in the case of dead tongues, becoming thus a part of the subject matter of archeological research, and if not thus retrieved passing into oblivion. The minor mnemonic $(d)$ are hardly more permanent. The quipu, for example, dug from 
a Peruvian grave contains no hint of the record which it was intended to keep, and is without significance except such as it may acquire through the efforts of the archeologist. ${ }^{1}$

The pictorial record $(e)$ alone, while it endures, retains and conveys a considerable measure of its purpose and significance; for the story, graphically told, is intelligible in part at least to all men of all times.

It is apparent from the above that the enduring portions of all material forms of record may in time become part of the subject matter of Archeology, so, as before shown, it is plain that this science must traverse the entire field of human history, howsoever recorded, drawing its data from the whole record, purposeful and fortuitous, present and past, contributing the product to the ever-growing yet insufficient and never fully permanent body of written history.

To-day the realm of unwritten fortuitously recorded history is still vast as compared with that of written history, research having made hardly more than a beginning in its exploration of the scattered archives of past ages; but the inquisitive turn of the civilized mind respecting antiquity will have its way, and in time the story of the past of man in most of its essential details will have been, through the agencies of Archeology and contributing sciences, so fully told, though never to be completely told, as to become in its principal outlines a part of common knowledge.

Although we speak of permanent records, harboring the delusion that civilization has achieved means of perpetuating a knowledge of human events, it must be allowed that, as has been shown, no known record really perpetuates indefinitely; stone crumbles with time, and books are eaten by worms or destroyed by fire and decay. Nothing of history approaches permanency save through purposeful repetition in books and on monuments, and even this means affords but a shadow of perpetuity, since this repetition can continue only so long as a kindly nature continues to fertilize a mutable and finite world, permitting the race to survive and its higher phases of culture to flourish.

1 An extraordinary example of objective mnemonic record is furnished by the practice of the Incas of Peru. The mummied bodies of the earlier rulers were brought out at stated periods and awarded the same daily service by their descendants as when living. By this practice a body of memories relating to the most important personages and events in the history of the nation, extending over a period of several hundred years, was preserved; yet the record thus kept alive was necessarily restricted in scope and in a few generations must have become in large part vague and merged with myth. 


\section{RESOURCES AND AGENCIES OF ARCHEOLOGIC SCIENCE}

7 HE nature and extent of the wide field from which the student may gather the scattered records of human history have been suggested in the preceding section. Although the field of archeological research is generally understood to be limited

Resources of the Science

to ancient or old things, and it is with these that the archeologist has more directly to deal, yet it appears, as already indicated, that all phenomena, natural and artificial, material and immaterial, mundane and celestial, by the study of which the history of man may become better known, are, with the cooperation of auxiliary sciences, drawn upon and made to contribute to the result.

The principal sources to which the archeologist may directly appeal regarding the history of the peoples of the western world may be thought of as eightfold, as follows: (1) The living peoples, the ten or more million members of the American race distributed in numberless groups between the Arctic and the Antarctic, and presenting physical and mental traits of great interest, traits which, well understood, must assist materially in interpreting the peoples of antiquity; (2) the remains of the dead of past generations preserved in graves, tombs, and caverns, and found fossil in geological formations; and in addition the osseous remains of such genetically related forms, assuming their existence, as may have occupied the continent in past periods, from all of which sources facts of value may be gathered; (3) the various activities of the living people, which afford a key to the activities of the past; (4) the great body of material products of the arts and industries of the present aborigines, the study of which in regard to manufacture, form, use, significance, and genesis is of the utmost importance to the student of the past; (5) the vast body of monumental works (mounds, temples, fortifications, tombs, etc.) and industrial remains (mines, quarries, aqueducts, reservoirs, roads, bridges, etc.) of antiquity and the innumerable minor relics of the handicrafts obtained from graves, tombs, and caverns, scattered at random over the surface of the land, and embedded in superficial formations, upon which main reliance must be placed for a knowledge of what man has accomplished in past times and the manner of its accomplishment; (6) the literature of 400 years-a treasury of fact and a pitfall of error from which the stu- 
dent must select with proper discrimination his historical data; (7) the considerable body of current and traditional information variously acquired and conserved in the minds of the current generation, whose knowledge is not necessarily included in books but which may be often drawn upon to advantage; and (8) the diversified environments of the tribes and the nations which have served to mold both people and art and which must be understood as an essential foundation for the study of the evolution of culture.

Auxiliary agencies which may be called upon to contribute materially to the researches of the student in the great Auxiliary Agencies of Research

field thus suggested are numerous and highly important. Inspired by the hope of learning something tangible of the origin and mutations of the race, the genetic relations of man with other living forms past and present, the story of his development, and his possible destiny, the somatologist weighs and measures him, the anatomist dissects his body, the microscopist exposes the structure of his tissues, the $\mathrm{X}$ ray discovers secrets of his anatomy heretofore unrevealed, the sociologist studies him as a social being, and the psychologist seeks to comprehend his mental make-up. Still other branches of research may contribute to the result. The geologist is called on to identify the formations in which his remains occur and determine questions of age; the paleontologist digs up the fossil forms associated with the various strata, thus determining the confrères of man in the successive periods of his biotic career; the geographer stands ready to record upon the map the distribution of the diverging groups over the various land areas of the globe at all stages of his history; and even the astronomer determines the mutations of mundane and celestial forces by means of which the destinies of man as well as of all living things have been and must be determined. The science of Archeology seeks to utilize properly all of these varied sources of information and agencies in the task of restoring the past, and in proportion as its derotees are masters of the entire field will they be able to spread before the world the story of the origin, the early struggles, the comings and goings, the ups and downs of the hordes, the tribes, and the nations, and to interpret the laws responsible for the diversified results, racially and culturally.

While the resources enumerated are or may be drawn upon with gratifying results, the sources of misinformation Sources of Misin- are no less a subject of archeological concern. These
formation

comprise, referring especially to America, the misinterpretations and errors embodied in four centuries of literature, among which are the imperfect observations and erroneous deductions of a host of amateur explorers and would-be historians. Especially to be deprecated is the utilization of this class of observations 
by enthusiastic supporters of vague theories and preconceived riews, and the demand for sensational matter by the public press, a large contingent of which is ready to accept for public consumption whatever is novel or sensational, without serious regard for its verity.

The diversity of invented and exaggerated statements which find currency is, indeed, appalling. The world hears con-

False Reports stantly of the discovery of skeletons of giants and of pygmies; of caverns filled with mummified bodies and rich plunder; of ruined cities abounding in marvelous works of art; of hardened copper; of walls and buildings of astonishing magnitude; of sunken continents; of ancient races associated with extinct species of animals; of inscribed tablets of doubtful origin and extraordinary import; of low-browed crania attributed to prehistoric races but which are mere local variations or pathological freaks; of fossil bones of animals parading as the bones of man; of reputed petrified human bodies which, on inspection, turn out to be of modern cement; of faked pottery, metal work, and the like, so well wrought and so insidiously brought to the attention of scholars as to have become in certain instances the types of antiquity; of learned readings of undecipherable inscriptions; and of the remains of man and his culture from formations of all ages, dating from the present back to the Carboniferous age. The output is so great and the public mind so receptive to error that the tide of misinforTenacity of Error mation keeps steadily on, hardly reduced in bulk by the never-ceasing efforts of science. The compilations of a Bancroft, a Winsor, or a Fiske, illumined as they are by exceptional genius, could not always rise above the vitiated records upon which they drew; and our best authorities in many cases are subject to the danger of combining the original errors into new fictions so compounded and difficult of analysis as to elude the vigilance even of the critical scientific world.

From the first, potent agencies of error have conspired to obscure the aboriginal record. The attitude of the propaFanatical Destruction of Art Works

ganda of Christianity at the period of discorery was such that the first impulse of the Spanish conquerors was to destroy at once all traces of the native religion, and a rast number of important sculptures, the "idols" of the people, were mutilated or beaten to fragments, and the native books and paintings, the treasures of native learning and art, were ruthlessly destroyed. The impulse to destroy was perhaps not so strong on the part of the French and English when they reached North America, but this may have been due in part to the fact that there was little to destroy that could be regarded as dangerous to the cause of religious fanaticism. 
The loss to history through this policy of destruction is beyond compute. The thought of preserving a record of the native people and the strange cultures which they had developed seems to have entered the minds of but few until 300 years had passed, and even then it was only when questions of the geological antiquity of man came to the front in Europe that it was deemed worth while to inquire into the present or the past of the aborigines of America as scientific problems. The work of sifting the truth from the literature of this period is a task surpassed in difficulty only by that of the explorer who essays to dig his data from the ground. 


\section{PROGRESS OF ARCHEOLOGIC RESEARCH}

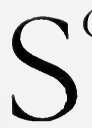

CIENTIFIC research in the domain of American archeology did not begin until well along in the nineteenth century, and for a long time the meager disquisitions respecting the remains of antiquity were colored by speculative interpretations and handicapped by the point of view imposed by Old World conditions. Gradually, however, archeologists have broken away from the thrall of the past and have exposed many of the fallacies which had grown into settled beliefs, and now the records of prehistoric times are being interpreted in the light of their own testimony. The public, however, is slow to follow and the cloud is not fully lifted from the popular mind, which seems prone, perhaps from long habit, to find error more fascinating than truth.

Among the fallacies which early took hold of the popular mind, appearing everywhere in the older literature, are Popular Fallacies those of the presence in America of civilized preIndian populations. The mound builders, so-called, were supposed to have reached a high stage of culture and to have disappeared completely as a race, a conclusion The Mound Buld- reached after superficial examination of the monu-
ers

mental remains of the Mississippi Valley. This idea has held with great tenacity notwithstanding the facts that many articles of European provenance are found in the mounds as original inclusions, indicating continuance of construction into postColumbian times, and that the aborigines in various parts of the American Continent, as in Mexico, Central America, and Peru, when first encountered by the Spanish invaders, were occupying a culture stage far in advance of anything suggested by the antiquities of the Mississippi Valley.

A fallacy similar to that regarding the mound builders fastened itself upon the ancient cliff dwellers of the arid reThe Clin Dwellers gion when traces of their interesting culture first came to light, but more recent investigation has shown that the ancient occupants of the region who built and dug their dwellings in the cliffs were in general the immediate ancestors of the Pueblo tribes which occupy the same region to-day. 
Speculation has ever been rife regarding the origin of the aborigines and supposed significant analogies have been Supposed Euro- made out with nearly every race and people of the
pean Origins

Old World. A favorite theory of the earlier students of the subject regarded them as descendants of the "lost tribes of Israel," and as a result, oddly enough, literature has been enriched by the publication of sereral valuable works on the habits and characteristics of the Indians, written with the view of establishing identities between the two races-works which otherwise would never have existed. Perhaps the most important of these works are Adair's History of the North American Indians (1775), and Lord Kingsborough's Mexican Antiquities (1830-48).

The myth of Welsh settlement in North America has also been very persistent, descendants of a colony, reputed to have been founded by Prince Madoc about 1170, having been identified, mainly on linguistic analogies, with numerous tribes, including the Tuscarora, the Mandan, the Hopi, and the Modoc. ${ }^{1}$

The literature of Middle and South America records many at. tempts to identify the native tribes with foreign peoples, the misconceptions beginning with the belief of Columbus that the people of the New World were identical with those of far Cathay; and a mythic Atlantis has had a large share in the theoretic peopling of the western world. The laborious compilations of Donnelly, though marshaling all available facts and suggestive culture analogies, fail to give this latter myth a scientific standing. The fascination of these misconceptions is well illustrated by the recent elaborate and costly staging of a play which embodied, not unknowingly, most of the errors regarding our aborigines which men of science have been combating for half a century. Fortunately, the play had but a short run, not, however, because it promulgated error, but because of other defects which the public was able to appreciate.

Among the raried misconceptions embodied in our literature is the belief that the native culture had reached before Theory of Degeneracy

the Columbian discovery its highest development and had given way to a period of general decadence, conforming thus with the fate of certain Old World civilizations. Although frequently promulgated, this theory is not fully sustained by facts with regard to the race as a whole; doubtless some advanced groups, as the Maya, had reached a climax of progress and had retrograded, but it would be difficult to prove that any of these cultures, represented as they are by important works of sculpture and architecture, were on the whole greatly superior to the culture

${ }^{1}$ Consult Mooney, The Growth of a Myth; and Bowen, America Discovered by the Welsh. 
achievements of the Aztec or the Incas at the period of discovery. Among the conciliatory offerings of Montezuma sent to the approaching conqueror of Mexico were certain works of art unsurpassed on the continent for technical perfection and esthetic refinement, and the culmination of Mayan culture development, even if decadent at the period of conquest, could not have been remote. The remarkable stucco embellishments of the city of Palenque, for example, exposed in a peculiarly destructive climate, on the pillars, roofs, and roof crests of the great buildings, are not entirely effaced to-day, and this evidence of recentness can not be fully discredited by the chronological determinations of archeologists obtained through a study of the inscriptions, since these so far as read may not represent the later stages of the local development.

It is not proposed in this connection to scan the literature of the earlier centuries for scattered allusions to the antiquities and to the pre-Columbian history of the aborigines, as this would be a work of great magnitude, but to recite in the briefest manner the beginnings and progress, especially in the north, of the scientific investigation of antiquities.

Although passing attention was paid to the great earthworks of the Mississippi Valley by numerous early settlers and Researches in explorers, no serious discussion of these antiquities North America appeared until the first quarter of the nineteenth century; the minor antiquities attracted even less attention. The earliest organized investigation of these remains was that of the American Antiquarian Society, incorporated in 1812. The first publication of this society was a paper by Caleb Atwater, which appeared in the Transactions of the society in 1812. The first contribution of particular note was that of Daniel Drake in 1815.

Well-directed and sustained research in the mound region was undertaken by Squier and Daris, 1845-47. ${ }^{1}$ The views of these authors were in general correct according to more recent interpretations, except those regarding the problem of the relation of the mound builders to the Indian tribes, the conchusion having been reached and embodied in the final pages of their great work that the mound builders were of an unidentified race of comparatively high culture and undetermined antiquity. As a record of the monuments and an interpretation of the lithic and other relics of art of the region this work takes high rank. ${ }^{2}$

During the second half of the century researches extending over a large part of the United States were rapidly initiated, and a vast body of substantial information was brought together and pub-

${ }^{1}$ See Squier and Davis, Ancient Monuments of the Mississippi Valley.

${ }^{2}$ For a notice of the numerous early contributors to the subject, see Squier and Davis, op. cit. (preface); Ilaven, Archæology of the United States.

$38657^{\circ}-19-$ Bull. 60 , pt I- -3 
lished by individuals, societies, and institutions, and by the Government. During this period a gradual change took place in the views of students regarding the mound builders, and at the close of the century there was practical unanimity in the view that the builders of the great earthworks were the ancestors of the Indian tribes found in possession of the general region, and that the culture represented is not of a grade especially higher than that of the tribes first encountered by the whites in the lower Mississippi Valley and in some of the Gulf States to the east.

Little was recorded of the important antiquities of the arid region-the ancient pueblos and cliff dwellings-until after the middle of the nineteenth century, when the Government began the work of surveying transcontinental railway lines and mapping the "Great West."

The literature of the Spanish, Portuguese, and other pioneers in the conquest and settlement of Middle and South America abounds in references to the material culture, modern and Researches in Middle and south America ancient, of the vast region occupied, but no organized researches were undertaken anterior to the expeditions of Squier in Peru and Stephens in Yucatan and Central America, and not until recently have the Latin-American countries entered on the study of the native peoples and culture in real earnest. Mexico, Argentina, Costa Rica, Brazil, Peru, and Chile have each conducted explorations and published results of great value, and foreign students, research organizations, and even foreign Governments have taken an active part in the work.

One of the most important problems of the American race, the last to be taken up in a serious manner, is that of Chronology the antiquity of the occupancy of the continent, especially that phase of it coming within the realm of geology, and the researches in this field have not as yet advanced to a stage where definite and generally accepted conclusions have been reached. This topic will be presented at some length in the section on chronology. The literature of geological chronology is already extensive but consists in so large a measure of the writings of inexperienced observers and bookmakers that it is perplexing rather than enlightening.

The most serious hindrance to progress in correctly interpreting the evidence of antiquity arose from the assumption on the part of a number of students that the course of human history in America must be parallel with that of the Old World; that occupation of the continent was indefinitely remote and that the course of cultural development must correspond in every essential respect with that of prehistoric Europe; that traces must exist, and should be found, of the initial period corresponding to the European paleolithic and the 
later stage duplicating the neolithic. This unfortunate assumption has cast a shadow over the whole American archeological field, not as yet fully dissipated. That the parallel is not complete, however, is now generally recognized, and American antiquities of all stages and types are being employed to develop the history of man in America, whether or not in accord with Old World determinations.

A large number of explorers who have conducted original researches in the field, contributing noteworthy data regarding antiquities, are cited in the section of this work devoted to an outline of the ethnic characterization areas of the continent. ${ }^{1}$

1 For extended lists of authors embodying in their works valuable data relating to the whole of the American field, consult Winsor's Narrative and Critical History of America; Bancroft's Native Races of the Pacific States; Handbook of American Indians; Hrdlička's Early Man in South America. 


\section{PROBLEMS OF RACE AND CULTURE ORIGINS}

$7 \mathrm{HE}$ archeologist, absorbed in the study of the multitude of monuments of past periods, full of interest in themselves, 1 does not lose sight of the fact that his efforts relate to these monuments not as finalities of research but as means of accomplishing a great end. He regards them as the architect regards the separate stones with which the massive structure is to be built, or as the historian or novelist regards the paragraphs and chapters by means of which his creations are given to the world. He remembers that the final aim of research is to cast stronger light into the dark places of the history of man. In contributing to this end scope of Research he goes beyond the realm of mere ancient things and seeks to understand not only the racial groups whose history he would especially reveal, but extends his view to the race as a whole and to the environments which, while limiting human achievement, have molded man into what he is.

The hypothesis of the unity - the biotic solidarity-of the human race now meets with very general acceptance, but there Unity of the Race is still much uncertainty in the minds of anthropologists regarding the time and place of origin and the partings of the racial ways. In seeking to trace the American race backward in its history, by whatsoever means, the archeologist encounters immediately the inquiry as to whether the beginnings are to be sought in the Old or in the New World. The theory of a New World origin which would make the Old World races offshoots of an American stock is held by but few and is sustained by meager evidence. To-day the consensus of opinion among students of the subject favors the view that the Old World gave birth to the human kind, and it follows that the earliest traces of his existence must be sought there, and that our researches must trend backward in that direction.

It is, indeed, incredible that the American race, repTheory of Ameri- resented at the period of its greatest expansion by can Origins Un- hardly more than fifteen or twenty million people,

and these of homogeneous physical type and imperfectly developed culture, not only should have peopled the Old World but should have peopled it with three races, the white, the yellow, and the black, highly differentiated in physical type and in culture achievement, and comprising the bulk of the world's population.

Traces of human occupancy are found in the Old World associated with geological formations which are confidently assigned to 
the beginning of the Quaternary period, hundreds of thousands of years ago, and it is incumbent on those who hold to the theory of American origin to establish an earlier occupancy of the New World. Two regions only in America have furnished testimony worthy of serious consideration in respect to this assumption-testimony which implies an antiquity so remote as to give color to the autochthonic assumption. These are the gold-bearing districts of California, where relics of advanced neolithic art are reported to have been found beneath rast flows of Quaternary lavas, and the pampas of Argentina, where even a middle Tertiary man is thought by some to have existed. The testimony in these cases is striking, and even picturesque, and is supported with enthusiasm by a few students, who are ready to stake their scientific reputations on the outcome. Recent investigations relative to North American as well as South American very early man show, however, that the testimony is really open to most serious question, and it appears that if it is to stand the test of criticism it must have much additional support. ${ }^{1}$

In riew of these considerations the theory of an autochthonous origin of the American race may be, for present Great Antiquity purposes, set aside, and the problem of the arrival
Not Proved

in the New World of racial and cultural elements originating in the Old World alone be given consideration. Not only does America furnish no tangible eridence of antiquity so great as to give support to the theory of autochthonic origin of the American race, but, as just indicated, it has failed so far to afford satisfactory evidence of the arrival of man on the continent in remote geologic time. The problems pertaining to this subject are discussed in some detail in a subsequent section deroted to chronology and may be passed over here without further consideration.

The student pursuing inquiries with regard to racial origins in America turns to the known aborigines and their Astatic Origins somatic characteristics, historic and prehistoric, and seeks to discover significant suggestions of relationship with Old World races. Heretofore, knowledge of the peoples of northeastern Asia has been so meager that satisfactory comparisons with them could not be made, but recent researches have opened up this field and have demonstrated the marked similarity of certain of the northeastern Asiatic tribes to the American Indians. This fact, taken in connection with the geographical proximity of northeastern Asia and Arctic America, would seem to offer a satisfactory solution of the question of origin.

${ }^{1}$ Holmes, Review of the Evidence Relating to Auriferous Gravel Man in California; IIrdlička, Skeletal Remains Suggesting or Attributed to Early Man in North America; Hrdlička, Early Man in South America. 
Accepting the view that America was peopled from the Old World by way of Bering Strait, it follows that the culture Culture Relations introduced would be that of the Arctic, and, so far as observed, no other than primitive forms of native culture have ever reached the shores of Bering Sea. All American culture is classed as neolithic, but the range of achievement is extremely wide, and as we pass into the south it takes forms so diversified and extraordinary that the inquiry is frequently raised as to whether the Arctic gateway has been the only means of admission to ancient America. That the civilized nations of the Old World have never been in intimate relations with the tribes of the New World is apparent from the fact that so far as the material traces show preColumbian American culture was of strictly Stone Age types. The aborigines were without Old World beasts of burden, wheeled vehicles, and sail-rigged craft-essentials of the civilized state; they had no cattle, sheep, or goats-potent factors in the development of Old World sedentary life; they had little knowledge of iron or the smelting of ores-essentials in the development of civilization; no keystone arch-a principal requirement of successful building; no wheel or glaze in the potter's art; no well-developed phonetic alphabet-the stepping stone from barbarism to civilization. Cattle, a civilizing agency of much importance in the Old World, could not have survived a long voyage, and the calendar, a device of the priestcraft, might not readily be transferred from shore to shore by occasional or chance wayfarers, but it would appear that the wheel as a means of transportation might readily appeal to the most primitive mind. That no extended contact with the civilized peoples of the Old World occurred in pre-Columbian times is strongly suggested by the fact that this device was unknown in America, except possibly as a toy. It appears in no pictographic manuscript or sculpture, the highest graphic achievements of the race. Charnay obtained from an ancient cemetery at Tenenepanco, Mexico, a number of toy chariots of terra cotta, presumably buried with the body of a child, some of which retained their wheels (fig. 7 ). ${ }^{1}$ The possibility that these toys are of post-Discovery manufacture must be taken into account, especially since mention is made of the discovery of brass bells in the same cemetery with the toys.

Have we, then, any trustworthy evidence in the whole range of prehistoric material culture of the introduction into America from transoceanic sources of elements of culture other than those which might have arrived with migrating peoples by way of Bering Strait? As the continents stand to-day, and considering primitive means of migration, there seems small chance of the arrival of wayfarers in 
any considerable numbers on the American shores except by this route, and the evidence of such arrivals, even if they actually took place, must be far to seek and difficult of evaluation. A primitive boat's crew reaching the Western Continent as voluntary voyagers or as wayfarers brought unwillingly by the winds and currents, even if hospitably received by the resident population, assuming such to have existed, could leave no physical trace of their presence that would last beyond a few generations, and the culture they happened to represent might not find even a temporary foothold. Yet germs of culture have sometimes wonderful potentialities, and a very simple device, a technical suggestion, or a tenet of belief introduced by a foreign wayfarer (regarded possibly as a superior being), might catch the primitive fancy, engraft itself upon the native culture, and in a rery short period influence the whole current of its development. However, instances of this kind have not been observed and, indeed, had they occurred,
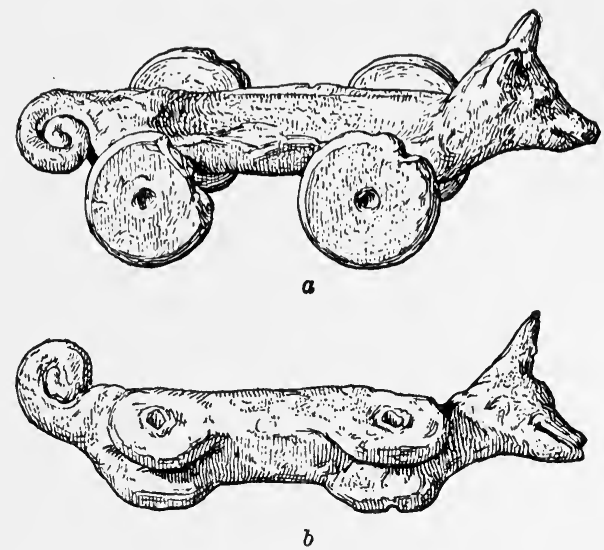

Fig. 7. Ancient wheeled toy from a child's grave, Mexico.

might be impossible of identification by means of archeologic remains alone. It may not be amiss in this place to inquire as to the kind of archeologic evidence which might be thought of as warranting the conclusion that transoceanic visitors had arrived on American shores in numbers sufficient to introduce culture germs of distinctive character. In beginning it is necessary that we exclude from the body of material to be considered all handiwork which bears the taint of post-Columbian influence. We have to consider, also, lest we misinterpret the meaning of Value of Analogies in Culture

the similarities, analogies, and identities in the culture achievements of distinct peoples which arise and, from the nature of things, must arise, as a result of the like constitution everywhere of the human body and mind and the like environment the world over. It is not wise to throw these evidences overboard entirely or too rashly, for they may possess values of very different degrees. They may range from the merest fortuitous resemblances to correspondences so close, so intimate, and so complex that actual intercourse could be safely inferred. The nature of such possible evidence may be theoretically and briefly considered. 
The student examining certain collections of primitive antiquities discorers that a particular form of flint knife blade occurs in America and also in the Old World and explains the occurrence by the oft-observed fact that with given states of culture, given needs, and given materials, men of all races reach kindred results. When, however, he observes that the blade of the knife in each case is specialized for hafting in identical ways, he wonders how such close correspondence in two important characteristics could occur. Pressing his investigation further he discovers on the two continents other knife blades of chipped flint with curved and keen points and identical specialization to facilitate hafting and a further identical elaboration for purposes of embellishment, and he begins to inquire whether the people concerned in making these two groups of artifacts are not somewhat closely related or have not in some way come in close contact. His interest is intensified when he observes that the groups of closely identical blades occur in two transoceanic areas at points of nearest approach, and also not in any case at more remote localities on the respective continents, and he is astonished to discover further that the two areas involved are connected by oceanic currents and trade winds by means of which seagoing craft could make the ocean royage from continent to continent with comparative ease. Later he finds that other objects of handicraft belonging to these adjacent areas have similar correspondences, and his previous impressions are decidedly strengthened. When, going more deeply into the investigation, he learns that analogous phenomena involving other classes of artifacts occur at other points, that in numerous localities on the shores of the one continent the culture traces have close similarities to those of the adjacent transoceanic areas, and that there are no such resemblances elsewhere, the evidence is cumulative to an overwhelming degree, and he concludes without hesitation, and concludes safely, that contact or transfers of peoples and transfers of cultures have taken place not only at one but at a number of points.

Now, this is a purely suppositional case, but it is suggestive and $\begin{aligned} & \text { Suggestive Anal- justifies further pursuit of the inquiry regarding } \\ & \text { ogies }\end{aligned}$
the significance of culture resemblances. Attention

may be drawn to certain noteworthy analogies which do occur between American and foreign archeological remains, due caution being exercised in their application. In New England and farther north is found a highly specialized form of the stone adz known as the gouge (fig. 8), The Stone Gouge which is abundant in the region mentioned, but which disappears gradually as we pass to the south and west, with rare outliers in the Carolinas, the Ohio Valley, and the Lakes region but not occurring elsewhere on the continent. It 
does appear, however, in northern Europe (fig. 9) where the Atlantic is narrowest and most nearly bridged by intervening islands. The gouge was in the Old World a practical implement devoted to ordinary uses, as in the working of wood, digging, cutting, etc. In America it was also a thing of ordinary use. Within the same region in northeast America, and thinning out as does the gouge to the south and west, is an object of rare and highly specialized form, The Banner stone an axlike implement, known as the banner stone (fig. 10) with tubular perforation for hafting and with extremely varied winglike blades. It is not found elsewhere in America. In northern Europe there is found a drilled ax (fig. 11) of similar type, and it is a noteworthy fact that this form of artifact throughout the Old World, though originally perhaps a thing of use, had wide and diversified application as a symbol. The following very interesting and suggestive statement regarding the "Amazon Axe" is quoted from Nilsson: ${ }^{1}$

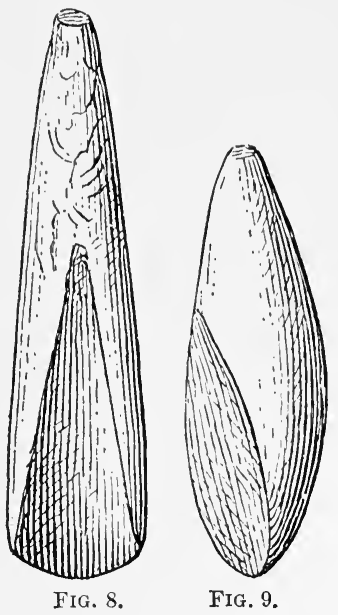

Fig. 8. Stone gouge $-\operatorname{adz}$, New England type. ( (1)

FIG.9. Stonegouge-adz, Scandinavian type. $\left(\frac{1}{4}\right)$

Stone weapons of this kind are rather variable, and the central part is often much shorter than the figure here referred to, resembling that shown in figure 174. The original of this sketch is from the south of Scania, and is preserved in my collection, but is not finished, there being no hole for the handle; but this weapon is always known by both ends being much expanded and more or less sharpened. It is exactly like the axes with which the Amazons are armed,

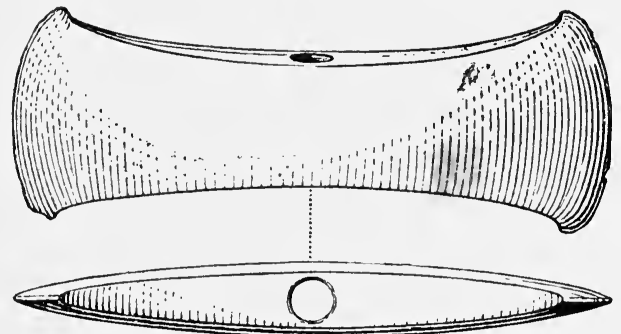

FIG. 10. Ax-shaped "banner stone," eastern United States. (1

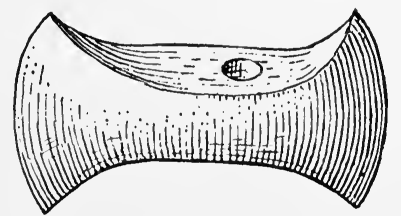

FIG. 11. Ax-shaped stone implement, Scandinavian type. ( $\left(\begin{array}{l}1 \\ 4\end{array}\right)$

wherever we see them represented. On a marble sarcophagus in the Museum of the Louvre, at Paris, bearing the inscription, "Scarcophage trouvé a Salonique en MIacédoinc," the warriors wield axes with one edge and a pointed sharp back; but all the Amazons have such two-edged axes as the one here sketched. The Amazons are represented with such axes even in other places also; for instance, on some antique friezes in the British Museum. In a treatise on "The Sword of Tiberius" (in German, 4to., with coloured engrav- 
ings), an Amazon is also represented with a similar axe. It is called "Amazon axe." Xenophon mentions it in the "Anabasis," Iv, 4; and Horace speaks of "Amazonia securis" in the Odes, Iv, 4, 20.

The American homologue certainly had no other than sacred and ceremonial functions. It may not be amiss, then, to suggest that possibly in prehistoric times examples of this type of implement were carried by some voyager across the intervening seas and that being regarded by the natives as possessed of supernatural attributes these were adopted as "great medicine," spreading to many tribes and taking a wide range of form. It does not appear an entire impossibility that a stone or bronze perforated ax of this type left by one of the Ericsson ships should have been the "ancestor" of these peculiar objects. Who will venture to say that these greatly varied, beautifully finished, and widely distributed objects may not have come into existence among the tribes during the 620 years separating the discovery of Vineland and the arrival of the English Pilgrims. This suggestion may not be worthy of serious consideration, since it is always preferable in such cases to seek origins near home. Dr. Gordon ${ }^{2}$ may well be right in his suggestion that the banner stone had its origin in northern America where among both Indians and Eskimos the whale's tail symbol was in common use, its form corresponding closely to that of the typical banner stone. Mr. Frank Cushing, a close student of such matters, is said to have advanced the view that this symbol originated in the South, and it is true that two-bitted stone axes are found in Honduras and perhaps elsewhere in Central America, but connection has not been traced.

Another example more noteworthy and of trans-Atlantic, even of world-encircling, analogy is observed in the northern Temperate and Arctic regions. A highly specialized slate spear or harpoon head (fig. 12), long, narrow, and bayonet-like, is found along with prehistoric burials in New England and neighboring sections. Nearly identical forms occur in the St. Lawrence Valley, in Greenland, and along the Arctic shores at intervals as far as Alaska, and again in Finland, Siberia, Japan (fig. 13), and Korea (fig. 14). Objects closely resembling these slate points in shape and manner of manufacture are not found, or rarely found, except along the

1 " This form of axe occurs with us during the Stone Age, not only of the full size of stone (pl. viii, figs. 173, 174), but also in the shape of small ornaments of amber for women (pl. viii, fig. 175), found also in gallery-graves in West Göthland amongst other ornaments of amber. But what appears to me to be very remarkable, in an ethnological point of view, is that exactly the same form of axe which was worn as an amber ornament by the women in the North during the Stone Age was worn by Grecian women, being, however, in that country made of gold. In the comedy of 'Rudens' (the Shipwreck), by Plautus, Act IV, Scene 4, vv, 112-116, it is said that the girl Palaestra, from Athens, amongst the ornaments given to her as a child by her parents, had also received such an axe in miniature, of gold ('securicula anceps') inscribed with her mother's name. This coincidence is very difficult to account for. It appears to me to be one of those circumstances which deserve the attention of the comparative ethnographer."

${ }^{2}$ Gordon, The Double Axe and some other Symbols. 
northern borderland on either continent. The occurrence, though noteworthy, may or may not have significant relation with the movements of races or the transfer of cultures, but the correspondences in shape, material, size, and method of manufacture form an unbroken chain of genetic, accultural, or for-

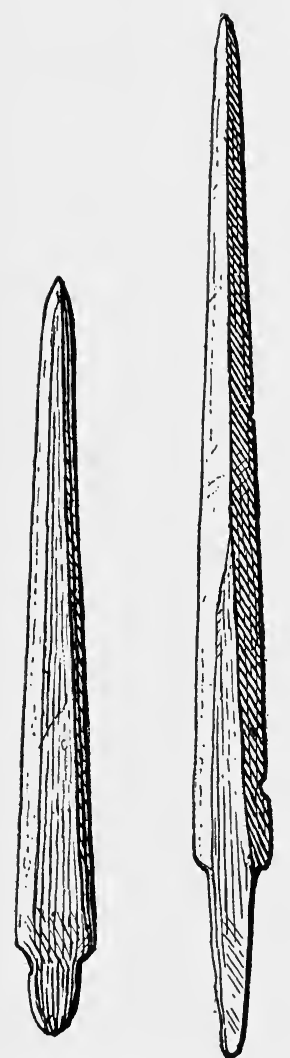

FIG. 12. Ground slate spearhead, New England type. tuitous analogies entirely encircling the globe where the land areas

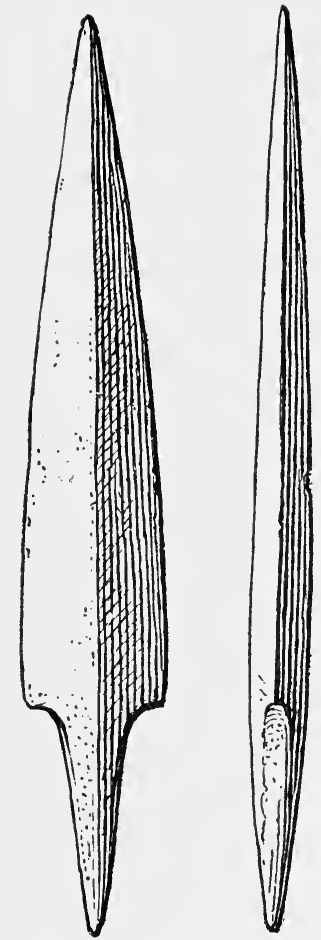

Fig. 14. Ground slate spearhead, Korean type. are most nearly continuous. Howerer, it should be noted that this particular form of implement, if it really originated in the East,
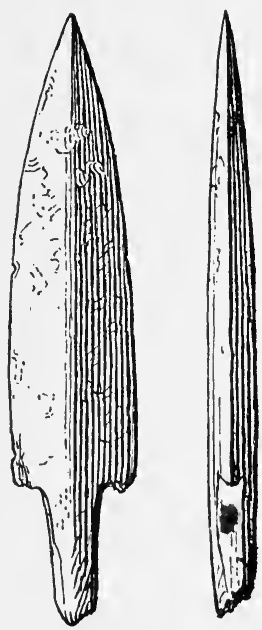

Fig.13. Ground slatespearhead, Japanese type.

may have passed from Asia to America by the Bering Strait route along with many other primitive artifacts.

Along the middle Atlantic shores of America certain forms of artifacts are found which resemble more closely the

Middle Atlantic corresponding fabrications of the Mediterranean region than do those of other parts of America. The Analogies

round-sectioned, petaloid polished celt is found in highest perfection in western Europe and in the West Indies and neighboring American areas. It is absent or rare on the opposite shores of the Pacific. In the Isthmian region we find works in gold and silver and their alloys which display technical skill of exceptional, even remarkable, kind, and it is noteworthy that the method of manufacture employed, as well as some of the forms produced, suggest strongly the wonderful metal-craft of the Nigerian tribes of old Benin; and, as possibly bearing upon this occurrence, we observe that the trade 
winds and currents of the Atlantic are ever ready to carry voyagers from the African shores in the direction of the Caribbean Sea.

It may be observed that, although we fail to reach definite conclusions as to contact or relationships, the above instances are not merely those of simple resemblances as is the case with the multitude of examples cited by Donnelly in his Atlantis, but their interest is enhanced by the fact that in most cases the resemblances are given additional support and claim to attention on account of geographical relationships. However, none of the examples measure up to the highest standard of evidence and do not, therefore, take the rank of proofs.

Even more diversified and remarkable are the correspondences existing between the architectural and sculptural Mexican Analogies remains of Middle America and those of Southeastern Asia. In both regions the chief structures of the cities are pyramids ascended by four steep stairways of stone, bordered by serpent balustrades, and surmounted by temples which employ the offset arch and have sanctuaries, symbolic altar sculptures, and inscriptions. The snouted masks of the Maya sculptures have an insinuating way of suggesting the trunk of the elephant and the upturned jaw of the mythical serpent is equally reminiscent of the treatment of the cobra jaw in the Far East. Temple walls are embellished with a profusion of carved and modeled ormaments and surmounted by roof crests and clupolas of elaborate and even pagodalike design. There are present also in Yucatan, as in Cambodia, as supports for the great stone tables, balustrades, and lintels, dwarfish Atlantean sculptured figures, and it is especially noteworthy that some of these figures on this side represent whiskered Whiskered Men in men. The true significance of all this and more has
Yucatan Carvings been sought again and again without satisfactory result. That some of these analogies should occur between works of the Antipodes renders the mystery more deep and might seem utterly to discredit the use of this class of eridences as proof of contact of peoples or close racial relationships. And yet is it an impossibility that the energetic builders of Cambodia, Java, and India, 2,000 years ago, should have had seagoing craft that might encircle the world ${ }^{1}$ We are compelled to allow that culture trans-

1 The feasibility of early south Asiatic communication with distant lands in early centuries of the Christian era, or even at an earlier date, is distinctly suggested by the story of Chau (500 A. D.). "The ships which sail the Southern Sea [Early Voyages] and south of it are Iike houses. When their sails are spread they are like great clouds in the sky. Their rudders are several tens of feet long. A single ship carries several hundred men. It has stored on board a year's supply of grain. They feed pigs and ferment liquors. There is no account of dead or living, no going back to the mainland, when once they have entered the dark blue sea. When on board the gong sounds the day, the animals drink gluttonly, guests and hosts by turn forgetting their perils. To the people on board all is hidden, mountains, landmarks, the countries of the foreigners, all are lost in space."-IIirth and Rockhill, Chau-Ju-kua, pp. 33-34. 
fer by this means may be reasonably thought of as a possibility but hesitate to allow that it is a probability.

"There is a great sea [the Mediterranean], and to the west of this sea there are countless countries, but Mu-lan-p $\mathrm{i}$

One Hundred Years Iiefore Marco Polo

[Mediterranean Spain] is the one country which is visited by the big ships . . . Putting to sea from $\mathrm{T}^{6} \mathrm{o}$-pan-ti [Suez of to-day] . . . after sailing due west for full an hundred days, one reaches this country. A single one of these (big) ships of theirs carries several thousand men, and on board they have stores of wine and provisions as well as wearing Giant Ships of the Mediterranean

looms. If one speaks of big ships, there are none so big as those of Mu-lan-pi.". . . .

"If one travels by land (from Mu-lan-p6i) 200 days' journey, the days are only six hours long." 1

In the serenth century trade was carried on between Canton, China, and the Persian Gulf, a sailing distance of 6,000 miles, and the voyage was eren continued to Japan, which would extend it to 8,000 or more miles, and so extensive was the intercourse between eastern and western Asia that by the "middle of the eighth century the Mohammedans at Canton . . . had become so numerous that in 758 they were able, for some reason which has not come down to us, to sack and burn the city and make off to sea with their loot." ${ }_{2}$ In the eighth century the ships engaged in the Chinese trade with the southern Asiatics (Hindus, Arabs, and Malays) "were very large, so high out of the water that ladders sereral tens of feet in length had to be used to get aboard. ${ }^{3}$ The Government of China took steps to encourage the trade by sea, which became extensive, and the Enperor sent a mission abroad with credentials under the imperial seal and provisions of gold and piece goods to induce "the foreign traders of the South Sea and those who went to foreign lands beyond the sea to trade" to come to China. ${ }^{4}$

It may be objected to the suggestion here made regarding the possible transfer of cultural elements by means of extended ocean voyages by the orientals, that the date is subsequent to the period of greatest American development, but who shall say that the mastery of the sea known to have been attained in the Orient 500 A. D. had not been achieved long prior to that date?

On the Pacific side of the American Continent numerous culture coincidences are noted which seem to indicate that the broad Pacific has not proved a complete bar to the intercourse of peoples of the opposing continents. It is indeed quite impossible to say with respect to the Middle American analogies whether the advanced maritime peoples of southeastern Asia one or two thousand years ago would be more likely to have reached America by way of New

${ }^{1}$ Hirth and Ro:khill, Chau Ju-kua, pp. 142-143. $\quad{ }^{2}$ Ibid., p. 15. $\quad{ }^{3}$ lbid., p. 9. $\quad{ }^{4}$ Ibid., p. 19. 
Zealand and the Easter Islands or by sailing around Africa and across the Atlantic.

It has often been remarked that the faces of modeled and sculptured figures in southern Mexico have a suggestive Mongolian cast,

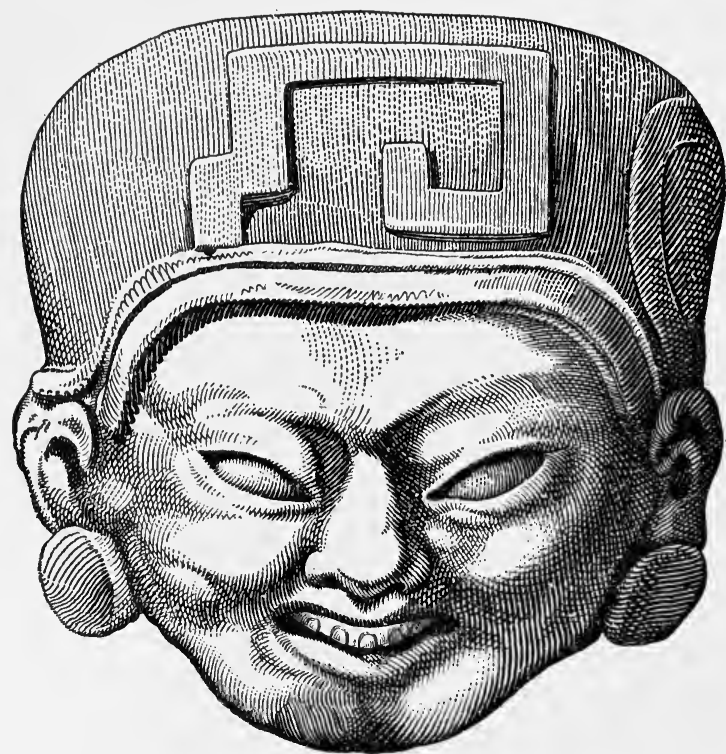

Fig. 15. A terra-cotta head with oblique eyes, Vera Cruz, Mexico. and the eyes in many cases are decidedly oblique. A pottery head from Vera Cruz, shown in figure 15 , illustrates this characteristic. Oaxaca, on the Pacific side, has supplied many striking examples of this peculiarity, and it is often remarked that the sculptured stele of Guatemala and Honduras present suggestions of facial and other analogies with the sculptures of the Far East.

Certain very remarkable Chinese axes of bronze are published by de Mortillet. ${ }^{1}$ One of these shown in figure 16 is described in the following language:

It very much resembles the polished stone axes of a type with tongue so common in Cochin China, and which have also been found in Cambodia, in the Laos, in Burma, in the Malay Peninsula, in Malaysia, in Tonkin, and in Yun-nan in the south of China... The round hole which is found in the middle of the blate does not appear to have been utilized. It rather seems to be a relic of a more ancient form, perhaps in stone, destitute of the rectangular openings just referred to and in which the bands fastening the ax to the handle had to pass through a circular opening easier to pierce. Polished stone axes [Peruvian Analogies] with tongue and round hole have also been described in North America, particularly in the south and southeast of the United States. South America, Ecuador, Peru, and Bolivia have also yielded axes thus pierced, of stone, copper, and bronze.

Another ancient Chinese ax of the same type as the preceding but larger and embellished with incised fretwork is shown in figure 16, $a, b$, and two examples of American axes of analogous form are shown in figure $17, a, b$. The most striking analogies in these cases are the occurrence of an ornamental figure or inscription on the stem 
of the Peruvian and Chinese axes and of the round hole in the stems or body of the North American and Chinese specimens.
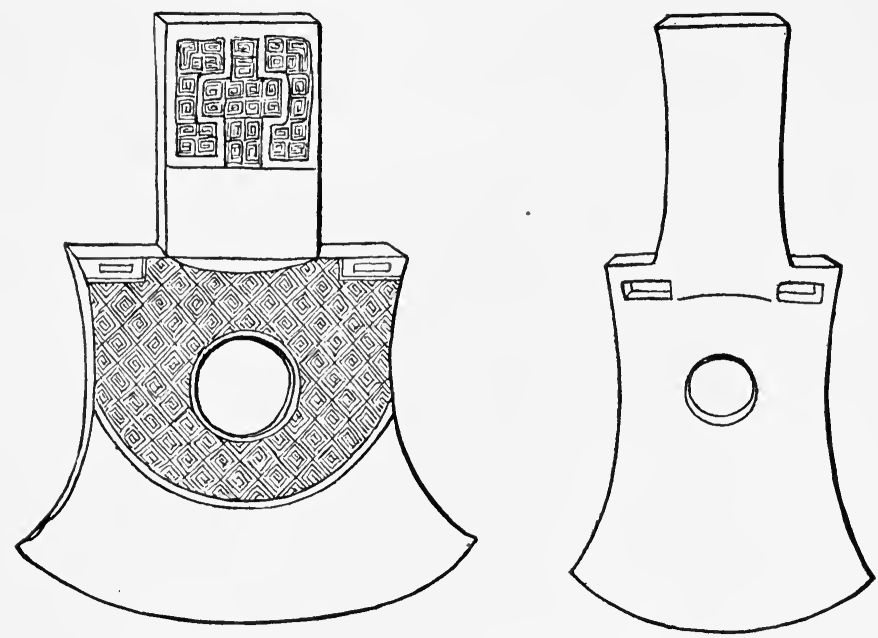

FIG. 16. Chinese bronze axes with perforate and decorated blades.

The stone adzes and pestles of the Northwest Coast resemble the adzes and pestles of the Pacific islands more closely than they do the corresponding tools of the eastern shores of America, and the

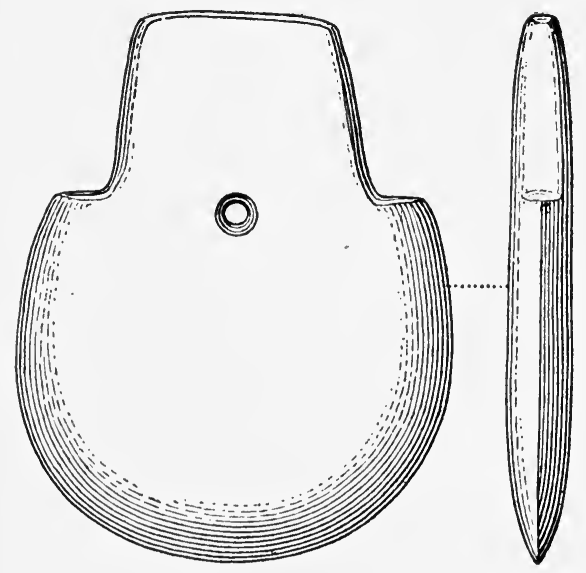

$a$ peculiar flat-bodied stone club or mere of the Samoan and other islands is dis-

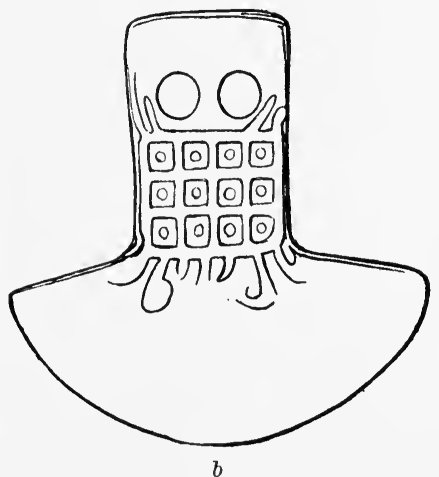

FIG. 17. $a$, Axlike stone implement with perforate blade, United States. $b$, Axlike implement of bronze with perforate and decorated blade, Peru.

tributed along the Pacific coast and scattered sparsely orer the adjacent regions to the east. With regard to relics of this general class, however, it is difficult to say whether or not the spread to America of a particular idea or form has taken place since the arrival of European ships in the Pacific. 
A good example of an art transfer which lies somewhere near the border between the historic and the pre-European $\begin{aligned} & \text { Northwest Coast invasion of the Pacific and is thus under the ban of } \\ & \text { Analogies }\end{aligned}$
a modernity is exemplified by an old Chilcat mask

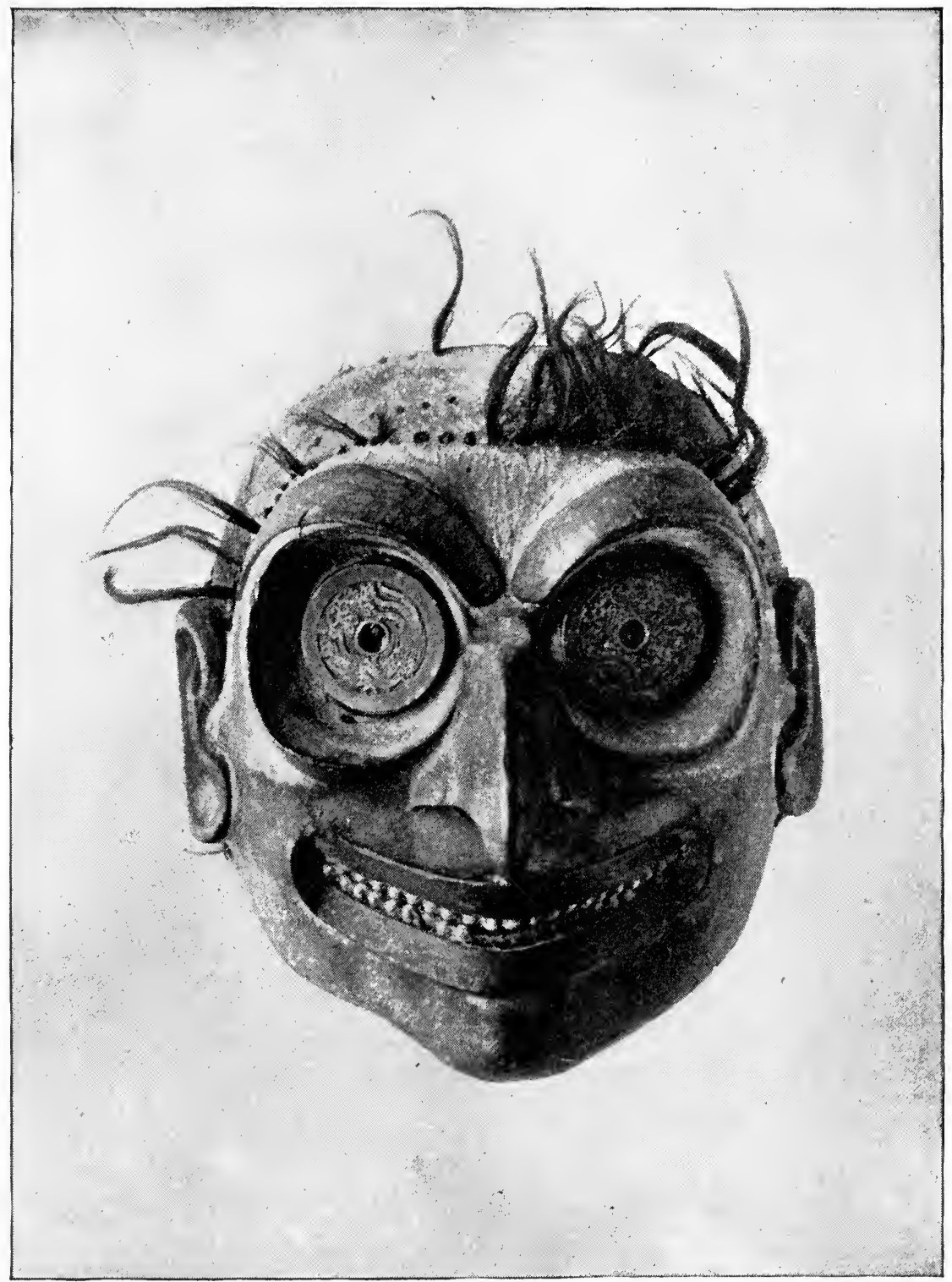

FIG. 18. Antique Chilcat mask with Chinese coins set in as eyes.

haring bronze Chinese coins set in the eye sockets (fig. 18). This specimen, which is described by Lieut. Bolles, was obtained from the grave of an old "medicine man who had flourished more than two 
hundred years ago, six successors having filled this office; each one living to a good old age." 1 The Indians were entirely ignorant of the origin and significance of the coins forming the eyes of the specimen. This and many other like occurrences are regarded as suggestive of indefinitely early intercourse between the New World and the Old World across the Pacific, but are not decisive. Passing over other instances which might be cited and many seemingly significant analogies in arts, customs, and beliefs, we find that we have completed the circle of the continent and are approaching, as has often been done before in the study of these problems, the main intercontinental thoroughfare, the proximate shores of Siberia and Alaska, at Bering Strait.

It has been sought in presenting these few of the many available examples of analogies between the material culture of the two worlds to avoid giving too much weight to simple resemblances such as are bound to develop between widely separated areas or distinct environments, and to suggest those which exhibit unusually striking analogies or which combine close analogies with suggestive geographical relationships. Although none of the examples given are found to be fully satisfactory, or free from danger of challenge for one cause or another, as proofs of culture transfer, it is quite clear that the study of these analogies with a view of determining their exact bearing upon questions of origin is not to be ignored or cast aside lightly. It is only requisite that wise discrimination be exercised and definite conclusions be avoided until the evidence has been exhaustively collected and critically scrutinized.

It appears that although derived from transoceanic sources, the race must be regarded as essentially an American race, the result of coalescence of diversified Old World strains combined and modified in various ways producing numberless new strains under the American environment, forming, however, at the period of Columbian discovery a measurably homogeneous whole. Aboriginal American culture, based on elements transferred with migrating groups, or by other agencies from the Old World, has in like manner been modified, developed, and specialized into various well Americanized. phases or forms, the result of the particular conditions under which the people lived.

${ }^{1}$ Bolles, Chinese Relies in Alaska, p. 221.

$38657^{\circ}-19-$ Bull. 60 , pt $\mathrm{I}-4$ 


\section{PROBLEMS OF INTERCONTINEN'TAL COMMUNI- CATION}

ROBLEMS of race and culture origins, discussed in some detail in the preceding section, are necessarily the subject of earnest research on the part of the archeologist, and a consideration of the first importance is that of the bridges and ferries, the probable routes by means of which the Avenues of Ap- American Continent could have been reached by
proach to America

migrating peoples from foreign shores. As the continental areas stand to-day, geographically and climatically, these possible approaches are, first, the North Atlantic chain of islands connecting northern Europe with Labrador; second, the mid-Atlantic currents setting steadily westward from the African coast to the shores of South America and the West Indies; third, the middle and southern Pacific currents traversing the vast expanse of ocean separating the Polynesian islands from South America; fourth, the Japan currents setting to the northeast from Asia and washing the shores of North America; fifth, the AleutianCommander chain of islands connecting Kamchatka with Alaska; and sixth, the well-known route by Bering Strait. Other possible connections during remote periods and under different climatic conditions are across the polar regions north and south. Geological changes within the human period even may have obliterated other thoroughfares, and all of those enumerated above may have undergone changes increasing or diminishing their availability as routes of migration. As they stand, the majority are certainly not practicable for primitive voyagers and may never have been traversed by uncivilized man unless by wayfarers drifting with the winds or currents to transoceanic shores.

It has been a favorite theory with a few writers that the North Atlantic was wholly or partly bridged by land con-

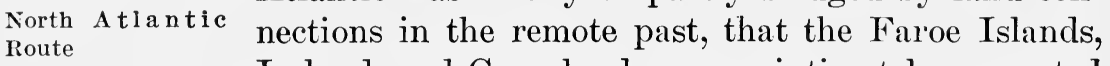

Iceland, and Greenland were so intimately connected that northern Europe could have furnished at least a part of the American population; but modern researches seem to discredit this theory, and James Geikie, one of our most learned authorities on continental evolution, does not hesitate to declare ${ }^{1}$ that " not a single 
scrap of eridence" can be adduced in support of the once generally accepted idea of a preglacial or early glacial elevation of the northern Atlantic sea bed. The elevation of this region was probably assumed by glacialists as the best means of explaining the glacial period. This route may be omitted, therefore, from consideration as a probable avenue for European migrations to America at any date decidedly more remote than the voyages of Ericsson. Highly developed water craft carrying fresh water and a food supply would be required to traverse the three formidable stretches of open sea between the Faroe Islands and Labrador. There are no currents setting in the proper direction to aid in this royage, and, besides, storm-driven mariners are hardly to be counted on as colonists.

The chance of voyagers having reached America intentionally from southern Europe with the aid of the trade Middle Atlantic winds or the mid-Atlantic currents, prior to the time
Route of Columbus, is, in the absence of evidence, perhaps too slight to call for serious consideration, although, as mentioned in the preceding section, seagoing craft sailed successfully the 2,400 miles of the Mediterranean long before the time of Columbus. The shortest possible royage between Africa and South America is upward of 1,500 miles in length, and tides, currents, and wind would afford but slight aid and that one way only. The fabled Atlantis has been regarded as a possible haven to the royager between the two continents, but geologists say that if an Atlantis ever existed it certainly disappeared long before men sailed the seas.

In the southern and middle Pacific there are thousands of miles of open sea separating South America from the nearest Pacific islands, a condition precluding the idea that very South Pacific primitive peoples could have found a thoroughfare
noute here. The early Polynesians were venturesome sailors of the Pacific and probably even reached the Easter group, but between this and South America are 1,200 miles of open sea, and geologists have discovered no evidence tending to show that this great gap was ever bridged or diminished. The same may be said of the route of the North Pacific current, which originates in the Japan Sea and sweeps the shores of North America from the Aleutian Islands to the Gulf of California. Traversing these vast wastes of ocean was hardly possible, even by drifting voyagers, until within comparatively recent times. Such royages can hardly have resulted in colonization or in seriously affecting blood or culture in regions already occupied. The story of Fusang, the land accistory of Fusang dentally reached by early Chinese voyagers, is not of consequence in this connection, since the time is recent, and since it is not at all probable that the land visited and re- 
ported by the wandering priests was America. It is well known that Japanese junks have been found floating in the near Pacific or stranded on the American shores, but this also has little bearing on the question of the peopling of America, since this continent was probably inhabited long before the Japanese junk became a seagoing ressel.

We now approach the route afforded by the festoon of islands draped like a wreath in the Pacific between KamAleutian-Com- chatka and Alaska. To-day with the boats of the mander Is land Foute primitive natives of both coasts this is a possible route, but the voyage has one great interval of 300 miles of open and generally tempestuous sea. It is not, therefore, a probable route for very primitive times. Examinations of the ancient midden heaps and other inhabited sites of the Aleutian Islands give no encouragement to the idea that this was ever a thoroughfare for migrating populations. Dr. Dall's careful explorations ${ }^{1}$ indicate that three periods of Aleutian occupancy may be distinguished, estimated to embrace in all some 3,000 years or more. The earliest period is represented by the echinus eaters, a people of the lowest culture, seemingly without fire, and, so far as the evidence goes, without implements or utensils of any kind, and necessarily without boats or any other possible means of sailing the seas. The second occupants were fish-eating tribes, who may have had craft of the simplest kind, but certainly none fitted for long voyages. The people of the third period were more advanced, approximating to the historic tribes in culture. The first and second occupants were necessarily of continental American origin, and the same statement is no doubt equally true of the third. In all the deposits not a trace was found indicating that stranger wayfarers of higher culture, or of any culture, had ever passed that way. Had this chain of islands been a thoroughfare for migrating tribes this could hardly be true. Stations would have been made on all the larger islands and some indications of their presence would remain to the present day. The Commander Islands, forming the western links of the chain, were not inhabited when first visited by civilized man, and no traces thereon of occupancy of any kind have been as yet reported. There is thus an interval of more than 300 miles on this hypothetical route in which no evidence has been found of human presence, while an expanse of a thousand miles or more shows no trace of migrating peoples. None of the native peoples of the whole North Pacific coast from Japan to California, when first known to the whites, would have ventured to navigate the broad expanse of open sea that separates the outer members of the Aleu- 
tian group from Kamchatka without stronger motives for so doing than can now be imagined, and there is no evidence that at any earlier time the people of this coast were more enterprising or skillful in boat making and navigation, or that stronger motives for attempting the royage existed than during the historic period. Trade by such peoples over such a route is not to be thought of. Neither is there evidence of the bridging of Bering Sea in this latitude by glacial or other ice, making migration feasible. It thus seems safe to conclude that the so-called Aleutian-Commander Island route can not be reckoned on as an intercontinental route of travel for primitive peoples.

Among the possible gateways to America, interest centers chiefly around that of Bering Strait. The distance from Bering strait land to land is only 40 miles, and during espe-
route cially frigid seasons ice forms a bridge so complete that crossing becomes a question only of the presence of migrating peoples and warm clothing and food supply for the journey. Here, then, supposing no important modification of geographical conditions, there has ever been an open thoroughfare from Asia to America for peoples of a culture sufficiently matured to enable them to withstand the rigors of Arctic climates. The question of complete land connection between the continents in Tertiary and Quaternary times, and especially during the warmer interglacial periods, has been much discussed, but the solution, whether for or against the connection, can not materially affect the case, since up to the present time no evidence has been found that man existed in this part of the world before or during the glacial period. 


\section{PROBLEMS OF MIGRATION}

$\mathrm{H}$

AVING adopted the view that America received its initial populations from Asia, the problems of migration present themselves for consideration. These problems are numerous and must be discussed in the main theoretically. They call for inquiries into the location and extent of the cradle of the race; the agencies and processes of dispersal; the period or periods of arrival at the gateway or gateways to the New World; the continental relations at and subsequent to the period of arrival or arrivals; the condition of the connecting bridges and intervening waters; the climate; and the distribution of the peoples throughout America at all periods down to the arrival of Europeans. Some of these problems are not susceptible of solution while others must always remain in a large measure mere matters of speculation.

The widespread dispersal of the genus IIomo over Europe in Pleistocene time is an accepted fact. Osseous traces of his presence are found associated with geological formations of this period from the Mediterranean to the North Sea and from the Atlantic to the Black Sea. His remains are associated with those of extinct species of animals, including the mastodon and mammoth, whose distribution was still wider, and we are asked whether it is not reasonable to suppose that man should have spread with these creatures during periods of mild climate as far north as the Arctic Circle and why he should not have followed them into the New World by the Bering land route, which is believed to have been more or less permanently open. That this could have happened and that it probably did happen are taken for granted by supporters of the hypothesis of the very early occupancy of the American Continent. Howsoever plausible this view may appear, it may be claimed with confidence that up to the present time the Bering region, and indeed the far north generally, have furnished no evidence of the early presence of man on the continent, and that the testimony obtained in more southern areas and outlined elsewhere in these pages, as in California, Idaho, Nerada, Brazil, and Argentina, giving man and his possible predecessors a place in Tertiary and early Quaternary times, 
is too meager and unsubstantial to be accepted as conclusive where determinations of such great importance are involved. Notwithstanding these conditions, speculation regarding the possible course of human affairs in very early times may not be entirely profitless, since in all investigations in very obscure fields the discussion of reasonable hypotheses often assists in determining profitable lines of research. Howerer, the present writer prefer's to confine his speculations to a consideration of the possible course of distribution under conditions of climate and geography corresponding somewhat closely with those of postglacial and recent time. In support of the reasonableness of this procedure it may be asked why adolescent man more than the apes and monkeys should have taken to wandering into distant and inhospitable regions. When we consider that many of the larger species of quadrupeds have a widely distributed and reliable food supply, that nature furnishes them with ample protection from cold, and that they multiply rapidly, while the precursor of man in all probability was unfitted to withstand the cold of Arctic climates or even temperate winters and subsisted on tropical fruits rather than on animal food, replenished his numbers slowly, and was not endowed with the fleetness of foot which makes seasonal migrations possible, there seems to be sufficient reason for holding that distribution to the remote, and espe-

Normal Ilabitat of Man

cially to the frigid, areas must have been much slower than would be the distribution of most mammals. He would have to become acclimated or to acquire sufficient intelligence to enable him to master the adrerse conditions of the colder climates, and it seems that only highly developed, reasoning, fire-using, implement-making, and warmly clothed man would be equal to the task. It seems reasonable, therefore, to hold that the IIominide probably did not begin to spread widely beyond their original habitat until the human status had been fully reached, nor far into inhospitable climes until a considerable degree of culture had been achiered.

It appears that under conditions of land relations and climate which are thought to have prevailed well back toward the close of the Tertiary period, America could hardly have been colonized by a people not well skilled as hunters and fishers, acquainted with fire, and supplied with suitable clothing. To-day, deprived of fire and clothing, men could not survive a year north of $30^{\circ}$ north latitude, and it does not seem probable that in earlier stages of derelopment the genus could have any greater capacity for withstanding unaccustomed environments. It is assumed that in order to reach the New World from the Old, cultureless man would require a climate at the gateway which would compare with that of southern Cali- 
fornia to-day, but even if it could be shown that the climatic conditions were favorable at a given period it would still remain to be shown that representatives of the human stock actuProof of Presence ally reached and passed the gateway at that period,
Necessary

no matter what other species of mammals accomplished the feat. The establishment of such a proposition is necessarily dependent on the discovery of traces of human remains or relics of art in the region in question and in formations which can be safely assigned to the particular time. The failure to discover traces of decidedly early forms of crania in America must be regarded as strong evidence against Tertiary or early Quaternary arrivals, and the failure to discover traces of special elementary forms of art also gives countenance to this view.

The migrations of very primitive man would be directed, no doubt, much as are those of the larger mammals, along lines Nature of Race of least resistance, as determined by such factors as
Movements multiplication of numbers, food supply, pressure of foes, geographical and climatic conditions, and instincts acquired during long periods of experience. The migratory movements of civilized man are governed more fully by well-defined ultimate considerations of welfare. The movements of the pioneers of the race would not be those of simple migration from Vicissitudes of a native seat. Each step would be the result of pres-
Migration

sure of some form which by degrees would push groups out of their original habitat, thence from environment to environment, each step requiring painful processes of exploitation and adaptation, each alike subjecting the group to danger of disaster and eren of complete annihilation. We may fairly assume, however, that the perpetual struggle for existence necessarily engaged in by migrating hordes dealing with new and perplexing conditions would develop the hardihood and the higher attributes of mind which in time came to characterize the race, making possible the conquest of the remoter parts of the world.

Considering the conditions under which dissemination is here assumed to have taken place, it seems highly improb-

Peopling of Any Land Requires Proof within the very primitive stages of culture progress, and we are bound to insist at least that early or even late peopling of any land should not be taken for granted, but that it should be established by evidence of the strongest kind. When we recall the difliculty with which the civilized nations of Europe, possessed of seagoing craft capable of carrying many hundreds of men and making sea voyages of thousands of miles, and, what is quite as essential, inspired by the passion for 
discorery and conquest, reached far lands, it should not surprise us if primitive man, without boats or with craft of the simplest kind only and without far-reaching ambitions of any kind, left some of the remoter regions of the world, as, for example, America, for a long time undiscovered. The 10,000 miles of coast connecting tropical Asia with tropical America could be travMigration Not a ersed by men afoot in a few years of continuous
Journey Journey progress, but for reasons already given we should not think of the movements that led to the peopling of America from the cradle in the Old World in the light of an ordinary journey. (Fig. 19.)

The precursor of man at the period of his specialization as man probably occupied a limited area-possibly a single homogeneous environment-as do his nearest congeners, the African anthropoids, to-day, and variations of race doubtless took place as a result of dispersal and consequent group isolation in unlike environments. We may fairly assume that the precursor, during the stage of development corresponding, say, to that of Pithecanthropus erectus, occupied some area in southern or southeastern Asia not larger, perhaps, than that occupied by the gibbon or the orang to-day. Can we imagine, under climatic conditions at all resembling those of the present period, agencies sufficiently potent to have sent such a creature in haste north ward a thousand miles, from tropical Java, for example, to the subtropical Irrawaddy, thence, later, 500 miles into the temperate Yellow River region, thence a thousand miles or more into the Amur Valley, and thence again 2,000 miles orer the icy plateaus and ranges into Siberia, across the chill and barren tundra to the Anadyr, and finally to the Arctic Cape East? Almost equally discouraging would be the coastal route, where the tortuous outline of the land or the wide separation of the chains of islands would tend constantly to retard and defeat adrance. $\Lambda$ tendency to Movements Due to Pressure

wander may be assumed, but pressure of multiplying numbers would seem to be the only adequate agency in driving peoples from a land of warmth and plenty to the inhospitable regions of the north. At best a vast amount of time necessarily would be consumed with each of these great steps. In fact, the changes would be so profound in respect to climate and food supply that the wonder is that a tropical creature should crer succeed in accomplishing the feat.

It is reasonable, then, to assume that the movements would be made gradually, that in temperate climes the elements of culture would be acquired through repeated struggles with unfriendly conditions, and that great increase in population would take place before the farther north would be penetrated. We can not conceive of men under any combination of climatic and geographic conditions known to have prevailed since the closing stages of the Pliocene 
penetrating the Arctic and passing into America without a wellassured food supply, without fire, without clothing, and without implements of the chase. Adrocates of the Tertiary or early Quaternary settlement of America may take exception to this view, since it is possible that climatic conditions were such in the later Pliocene, or possibly in certain interglacial epochs, that the far north was favorable to human occupation and that if geographical relations were favorable man may have spread to the ends of the earth. In

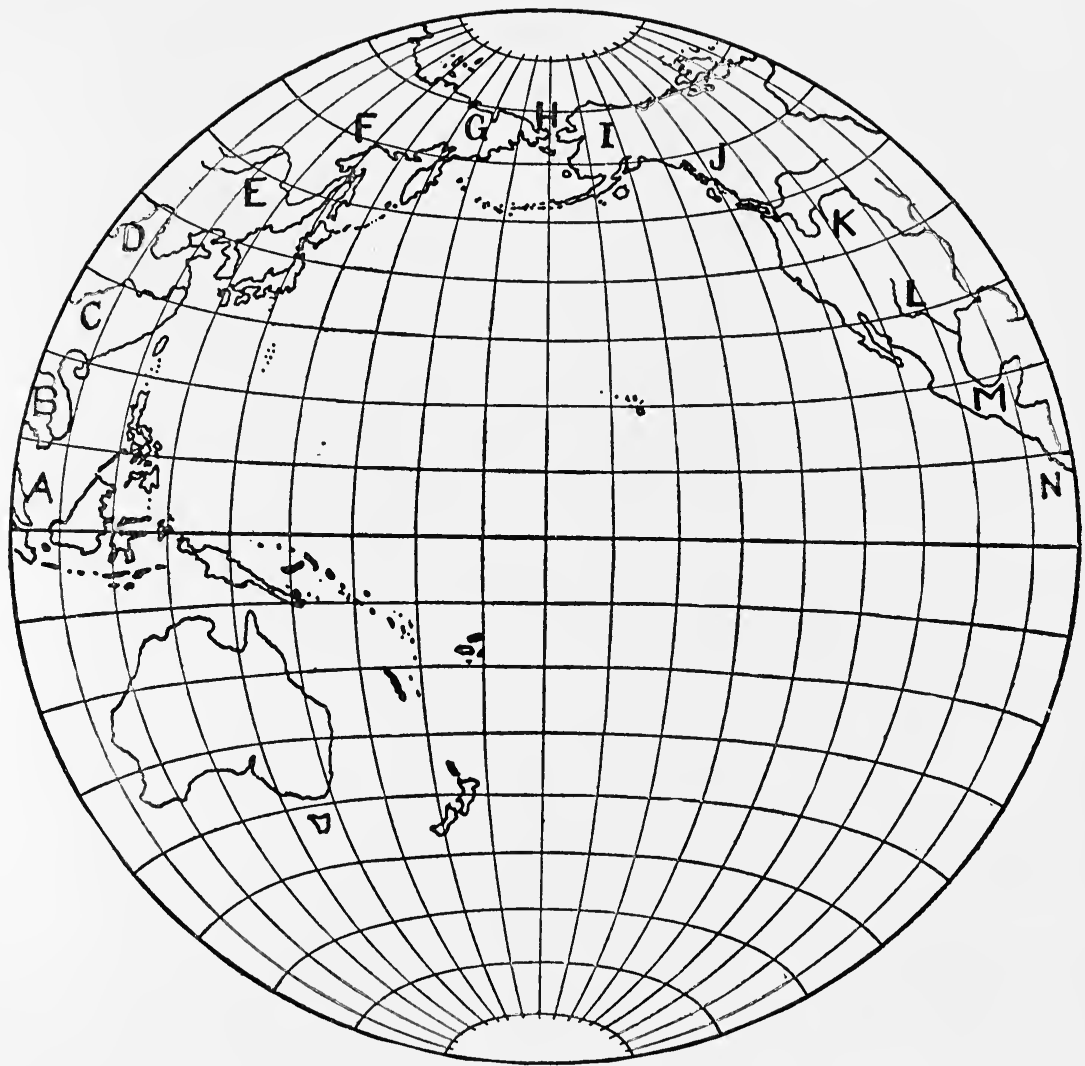

FIG. 19. Stages of migration in the peopling of America from tropical Asia.

reply it may be said that not only is the hypothesis of early general distribution under any conditions improbable in itself, but it is entirely without the support of eridence.

Figure 19 will aid in conveying a notion of the problems of migration under known post-Tertiary conditions from Effect of Migra- an Old World cradle to the New World by way of
tion on Culture

the Arctic gateway, and in suggesting the cultural transformations which would accompany each step of the process. In each successive environment from $A$ to $G$ man would come under 
the sway of new conditions, and at $G$ there would probably remain but few of his activities and possibly not a single article of food known at $A$. It is self-evident that with the progress of such a movement language, social institutions, government, religion, and all the arts of subsistence would be subject to frequent and decided modifications, and, assuming their existence at earlier stages of progress, agriculture, pastoral life, modes of transportation, metallurgy, ceramics, building arts, textiles, and religious and rsthetic art one by one would drop into disuse, passing little by little out of the knowledge of the northward migrating people; for there would be not only elimination of activities, but there would ensue quick forgettings. In one environment the preceding habitat in a few generations would surely be forgotten, and the knowledge of an art or industry based on local products and needs lost for a generation would be lost for good.

Assuming a common place of origin for the Hominide in some part of the Old World, and climates and continental Difficulty of Reaching America

relations corresponding in the main to the present, the probabilities seem favorable to the view that dispersal to distant land areas would not take place until the populations had greatly multiplied and until considerable advance had been made in the arts of humanity. Under known geographical and climatic conditions, America naturally would be the last of the great areas to be reached. As determined by the best authorities on the physical history of the Bering region, pioneer immigrants, according to the period of their arrival, might have been subject to at least three climatic periods: (1) A period of mild climate accompanied apparently by changes in the land relations of the continents at the close of the Tertiary era; (2) a long period of remarkable climatic and other changes, known as the Ice Age, which affected the northern hemisphere to an undetermined degree, and which at successive periods blocked the pathway to the east and possibly in some measure to the south, with intervening periods of mild climate favorable to distribution, at least on the Pacific side; (3) the so-called postglacial periods, which throughout have approximated the climatic conditions and geographical relations of the present day. The duration of this period was not uniform over the entire country but long or short according to the latitude, as fully explained under the heading Chronology. In the northern United States east of the Rocky Mountains the ice sheet persisted down to comparatively recent times, estimated at from 7,000 to 20,000 years ago, and would have interfered with the southern movements of population, while in the Rocky Mountain region highland and the Pacific slope the glacial occupation was less complete, and 
it is possible that passage from north to south was nerer wholly interrupted.

In the absence of definite knowledge of the period of arrival of the pioneers and the beginning of the American occupancy, and of the climatic and other conditions to which all preglacial and glacial movements would be subject, it seems vain to enter upon a prolonged theoretical discussion of the possible processes and progress of settlement during these periods. If, however, man by whatsoever routes he may have taken eventually did reach the gateway during these periods, there is no known reason why, at least during the intervals of milder climate, he should not have entered America and passed southward, if not eastward, orer the northern continent.

Tribes acclimated in Siberia would readily make a home in the valley of the Yukon, but considerable time might elapse before they would overcome the intervening difficulties and reach the valley of the Columbia, the Mississippi, or the St. Lawrence. The journey along the coast from the Aleutian Peninsula to Sitka is practically impossible for any except peoples having seagoing craft. The crossing from the headwaters of the Yukon into the forest-covered area of the Northwest Coast or into the MacKenzie Basin would meet, aside from the possible interference of glacial ice, with untold difficulties for primitive peoples.

It may be assumed that movements southward would be, at first, extremely tedious and confined to very meager bands Movements at of wanderers, but the progress could well be more
First Tedious

rapid than the spread of tropical Asiatic peoples to the north, as described in the preceding section. Instead of advancing against new and unfavorable conditions of climate, the progress in America would be constantly to milder climates and more plentiful food supply. Then, again, successive advances in culture necessarily occurring would give distinct advantage to wanderers in the new land. The spread over the Mississippi Valley to the Gulf would be quickly accomplished, and from the central area the east and the west would be occupied with comparative ease.

The passage of peoples from North into South America would present no insurmountable difficulties under geographical conditions corresponding to the present. Unoccupied, these areas would offer no resistance to the advance of the pioneers, although the Isthmus might hinder on account of its prevalent jungles, marshes, and febrific dangers.

The passage from either North or South America to the Caribbean Archipelago would probably present problems closely akin to those of the passage of Bering Strait in the present period. 
It is not apparent that intercontinental transfer has been wholly blocked at any time to migrating hordes or wandering groups, for if not bridged by land the intervening space may have been bridged by ice or may have been an easy ferry after seagoing craft came into use. The question, then, is one not of the availability of the arenues of approach at one period or another but rather that of the actual arrival of migrating groups at the gateway and of the pressure necessary to push them one step farther from the place of their nativity after the manner suggested in earlier paragraphs. The arrival of the precursors of the race during glacial or preglacial times would depend primarily on the extension of his habitat to the shores of Bering Sea, and the improbability of this, as already pointed out, must be apparent to every one who gives serious consideration to the subject. 


\section{PROBLEMS OF CULTURE DEVELOPMENT AND MUTATION}

T N THE entire field of anthropological research there occurs no such opportunity for the study of primitive life and the evolution from it of the higher forms of culture as that afforded by aboriginal America, pre- and post-Columbian. This is due largely to the facts (1) that the cultures are, in large part, living cultures, which have been the subject of observation more or

Favorable Field of Study

less intelligent for 400 years; (2) that the cultures of the Columbian and post-Columbian periods represent practically the whole range of aboriginal advancement so far as it is known, from the humblest stage of savagery to the very threshold of civilization; (3) that the prehistoric phases of these cultures are continuous with the historic and present and are thus readily interpreted in terms of the well known; (4) that the antiquities are countless and have been left in large measure undisturbed by the activities of succeeding occupants. Notwithstanding these favorable conditions the task before the historian of the race is not an easy one. The very early stages of American history, being scantily represented by art remains, must always remain obscure, and students of the subject are thus free to adopt such views as may occur to them regarding the probable course of events during the occupation and conquest of the continent. It is quite natural that views of Initial there should have arisen widely divergent views on
status status the subject, views which, however, will doubtless tend to disappear as research makes headway. The writer finds it most advantageous for present purposes to follow up the general scheme outlined in the section dealing with the culture transformations of migrating peoples in their passage from the hypothetical cradle in Asia to America. The conception is that of a people not advanced beyond the simplest known stages of hyperborean culture entering upon the heritage of a previously unclaimed continent and in course of time, by continued migrations and multiplication of numbers, occupying all habitable areas and gradually reaching the various stages of advancement which characterized America at the period of European conquest. 
Although the story of the evolution of the American peoples and cultures can of course never be known in great detail, Assumed Begin- it is to be expected that the archeologist working in
nings

unison with the ethnologist, the biologist, the geologist, and the geographer will be able to supply an approximate outline of the course of events during the prolonged interval between the arrival of the pioneer settlers and the coming of Columbus. History comes to the aid of these sciences by contributing to the post-Columbian phases of the subject. Passing for the present orer the theories (1) that the race originated in America and (2) that its arrival on the continent dates back to Tertiary or early glacial time, it is assumed that the occupation did not begin until the peoples of northeastern Asia had acquired a degree of culture development somewhat analogous to that of the more primitive hunting, fishing, fire-using, igloo-building tribes of the far north in recent times. Arriving in limited groups, the morements would be hesitating and slow; the pioneers would creep along the ocean shores, meander the river courses, and scale with much difficulty the mountain ranges and, avoiding the ice-clad and arid areas, Culture Modified by Environment

would pass gradually into the temperate and tropical climes. The culture of the groups that lingered in the north would undergo little change, and the status of those who found their way into the vast forests and the featureless plains would continue, with local changes, practically on the same level from generation to generation and century to century. The people would necessarily continue to subsist by the precarious resources of unaided nature. In regions where the supply of fish was abundant during the year there would probably result practically permanent settlement accompanied by limited progress in directions imposed by the environment, and in temperate and subtropical valleys complete sedentation would ensue and far-reaching changes would be initiated; resultant increase in numbers would gradually lead to the failure of the chase, and agriculture and domestication of animals, where tractable species were arailable, would follow and an artificial basis of food supply would be established. The hunter would lose his calling and would gradually share with the women the work of tilling the soil; new agencies of progress would come into being, new activities would arise, and specialization of labor would follow; exploitation of resources would derelop new sources of food supply and new materials for the handicrafts, and arts and industries would multiply; the textile art, pottery, mining, metallurgy, and stone building would be added; the graphic arts and pictography would lead upward toward glyphic writing; and skill in numbers and observation of the heavenly bodies would make 
accurate time keeping possible, giving rise to the calendar. Interchange of commodities with neighboring peoples would increase and extended trade, with its manifold benefits, would widen the range of interests; customs, habits, social organizations, and even religion would take on new forms; the embellishing arts and luxury would find encouragement; and commerce, war, conquest, and the command of labor would build up important nations, opening the way to civilization. From the more advanced centers of progress there would radiate in time by various agencies, germs of culture, slowly leavening the savage complex, a process still in active operation.

On this general plan it is thought to account for the greatly diversified phenomena of aboriginal culture among the historic tribes, as well as that brought to light by archeological research and, since no clear evidence is found of culture stages distinct from the well known, it is here assumed, adopting the European nomenclature, that aboriginal American culture is exclusively neolithic, and that such "paleolithic"-appearing forms of artifacts as occur are not chronologically separable. This view may be adopted and held as a working hypothesis until reliable proof to the contrary accumulates, if indeed such proof exists. All American culture rising above the level of early neolithic would thus be regarded as belonging to America, always allowing, however, for sporadic intrusions of germs of higher phases which it must be conceded are within the range of possibility, especially in the more recent millenniums.

The agencies which conspire to shape up the culture of a people to its highest state, and which from lack of sustainAgencies of Advancement, Active and I'assive

ing power permit retrogression and final obliteration, may not be fully analyzed or determined in any given case, but they are worthy of the close study which is being given them by students. The active dynamic - the subjectiveforces are to be distinguished from the contributory, passive agencies; the first law of all sentient creatures is self-preservation and with the human race the second law is the law of betterment. The first provides for the perpetuation of existence, the second for the perpetuation of progress. These are the fundamental forces responsible for all human activity and all progress; they apply alike to the individual, the family, the community, and all the larger social, political, and racial units. The contributory and passive agenContributory cies are the extremely varied constituents of environ-
Agencies

ment: (1) The diversified animal life, giving rise to the chase, which furnishes food, clothing, and shelter, and material for the arts and industries; (2) the vegetable life, supplying various alimentary needs and a vast range of materials for the arts and industries; (3) the mineral world, whose limitless riches make 
possible utilization of all the vast resources of nature. The relations of land and sea, of fertile and desert areas, and of valleys and mountain ranges may also have great influence, and climate may decide the cultural fate of peoples, confining them to the limited activities of the Arctic, stimulating them to activity in the Temperate Zone, and encouraging indolence in torrid climes.

The vast influence of environment as an agency in determining the culture of primitive peoples becomes more and more Environment in
Pueblo Culture

illustrated, for example, by the highly specialized culture of the Pueblo tribes of the southwestern United States. It is here made manifest that it is not so much the capabilities and culture heritage of the particular stock of people that determines the form of material culture as it is their local environment. Any primitive people finding its way into this land of cliffs, rock shelters, and ready-quarried building stone would soon be led under favorable stimulus to employ stone in building. The proximity of predatory peoples would bring about the building of strong pueblos in the lowlands and defensive resorts in the cliffs. The limitations of natural food resources would lead to the cultivation of the fertile spots in the isolated desert-bordered valleys. The arid conditions would make irrigation necessary and other special features of culture would perforce arise locally. The needs of transporting the produce of the fields and of the storage of water would lead to skill in basketry and pottery, and scarcity of large game yielding skins for clothing would make wearing necessary. Accommodating itself to the peculiar conditions, the social organization would take on localized forms. The mythology and forms of worship which often come up from the remote past with little change would yield to local influences and even the origin myths would derive the tribes from local sources. The modifying influences of environment are well shown by the fact that the three or four stocks which arrived in the arid region from different sources have had their cultures almost completely remodeled and unified by the exceptional local environment.

The culture of the mound-building tribes of the middle eastern United States was not widely different in degree of Environment in advancement from that of the Pueblos, yet it was in $\begin{array}{ll}\text { Mlound Builders' } \\ \text { Culture } & \text { most respects distinct in type. There were marked }\end{array}$

differences in agriculture, the building arts, sculpture, pottery, wearing, metallurgy, in implements and utensils, and in the arts of embellishment, as well as in social and religious customs-differences doubtless largely due to the impress of local conditions rather than to any extraneous or distant ancestral 
cause. A remarkable theory is advanced by Shaler regarding the seeming degeneracy of the historic culture of this ethnic area as compared with the prehistoric, which serves to emphasize the potent influence of even single features of environment. It is averred with much show of plausibility that the advent of the buffalo into the Mississippi Valley-a comparatively recent occurrence-revolutionized the culture, material and immaterial, changing it from the advanced, sedentary, agricultural type to that of seminomadic followers of the chase-a good illustration of the "call of the wild" which so readily affects eren those who claim to be civilized.

When in his eastward movement the buffalo came to the semi-civilized inhabitants of the Mississippi system of valleys, he brought a great plenty of animal food to the people, who had long been in a measure destitute of such resources, for they had no domesticated animals save the dog. Not yet firmly fixed in the agricultural art, these tribes appear, after the coming of the buffalo, to have lapsed into the pure savagery which hunting entails. To favor the pasturage of these wild herds, the Inclians adopted the habit of burning the prairies. These fires spread to the forests on the east, killing the young trees which afforded the succession of wood, gradually extending the pasturage area of the wild herds until the larger portions of the western plains eastward to central Ohio and Kentucky, probably even into the Carolinas, and southward to the Tennessee River, had been stripped of their original forests, making way for the vast throngs of these creatures which ranged the country at the time when we first knew it. With the rehabilitation of the hunter's habit, and with the nomadic conditions which this habit necessarily brings about, came more frequent contests between tribes and the gradual decadence of the slight civilization which the people had acquired. ${ }^{1}$

The highly specialized and mature culture of the Valley of Mexico may be attributed, in no small measure, to the vigor Environment in and diversified acquirements of a people which had
Aztec Culture Aztec Culture passed through successive stages of migration and conquest in an exacting climate. Allowance must be made also for the influence of the Toltec foundation on which the Nahua people began their final building; at the same time, howerer, aside from this it is clear that the influence of other features of the local environment has been profound. On account of its dimensions, physiography, climate, and natural resources the valley is the natural cradle of a culture and a nation. At the same time it is so related to surrounding areas that its people, while retaining their own autonomy, were able to lay tribute upon the cultural resources of numerous less farorably placed neighboring peoples.

The culture of the Maya-Quiché of Mexico and Central America represents the climax of aboriginal achievement. Little is definitely known, however, either of the period or the place of its earlier manifestations, and there is thus slight chance of determining the 
elements which entered into its composition or the forces which carried it forward to its exceptional position. The environments involved are so diversified and extensive that little can Environment in be said regarding the part they have taken in giving character to the culture beyond that which is made apparent locally by a study of the antiquities. The particular factors which have given Chichen Itza and Palenque, for example, some of the most striking characteristics of their material culture may be readily observed. The climate of Chichen, although subtropical, is comparatively dry, while that of Palenque is characterized by a rainy season of the most typical kind. In Chichen, as a consequence, the roofs of the buildings are flat, while those of Palenque are sloped to turn the rains, and from the crest or comb which this form of roof implies there has arisen an ornamental feature of most remarkable kind. The geological formations of the plains of Yucatan furnish soft massive limestone for building, while the formations at Palenque are hard limestones which cleave into slablike forms. In Chichen the architect, employing the massive stone, reached results impossible in Palenque. The use of large stones in building was usual in Chichen and the colonnades of a single group of buildings include upward of 600 columns, round and square, of massive stone. In Palenque the architect built his columns of rough stone and faced them with stucco, while slabs of limestone of large superficial area were used in carving the many important altar panels and glyphic inscriptions. In Chichen the decorative relief sculptures carved in stone are rigid and expressionless, while those of Palenque modeled in stucco are remarkable for spirit and for freedom in form and line. Doubtless environmental differences have similarly affected the various minor arts of these people.

The subjective-the dynamic force in culture evolution-the everpresent desire for betterment, manifests itself in two distinct ways: (1) By direct effort, as in the pursuit of activities designed to supply bodily comforts, to gain influence over environment, and to gratify esthetic longings; and (2) by indirect methods, as in appeals for assistance to the powers assumed to hold all farors at their disposal. Strangely enough, it is this indirect method, this appeal to the gods, the organized and sustained effort of the cults to promote welfare by this means, that has brought about, directly or indirectly, all that is greatest in human achievement, material and immaterial.

There can be little question that the wonderful achievements of the ancient city builders of Middle America were due to religious propagandism, that the enthusiasm engendered by supposedly inspired leadership enlisted the energies of a comparatively primitive people in the erection of the vast establishments now in complete ruin. It 
is equally apparent that the exhaustion naturally and inevitably resulting from the enormous waste of material resources and energy and the inability to sustain the burden imposed by the ruling class is responsible for the downfall, the utter ruin, and final abandonment of the great Maya cities. The house built on sand must fall, and these and other kindred results of human effort are builded on sands of the imagination. The more rapid the advance and the loftier the rise, the more certain and complete the ruin.

It is not to be forgotten that various causes, such as change of climate, encroachment of enemies, earthquakes, and other agencies may have contributed to the lamentable result. These, however, were hardly in any case more than contributory agencies. 


\section{PROBLEMS OF CHRONOLOGY}

$\mathrm{N}$ a previous section devoted to the place of archeological research in human history the distinction was made between intentional or purposeful records and fortuitous or nonpurposeful records, it being premised that all records of whatsoever kind serve the purposes of or contribute to the needs of Purposeful Records the chronologist. Purposeful records are a product of somewhat advanced culture and take different forms as advance is made toward the requirements of the highly civilized state. In the beginning memory was the only means of preserving the lore of a people, but it is assumed that material things were in time associated purposely with the memories in such a way as to assist in their preservation; then pictures took, in part, the place of things, and the pictures became conventionalized by long use into half formal and then into fully formal signs. The formal signs became symbols of things, persons, facts, events, and ideas, and finally of sounds, and then written records took up the burden of chronology, initiating a new era in human progress and exerting vast power in the world. These devices are, however, of Nonpurposeful Rec- comparatively recent origin and application, and the
ords

chronologist who would determine the place of long past events in the scale of time must resort to the study of the nonpurposeful records which are scattered along the pathway of culture progress.

The achierements of the American aborigines in building up a system of glyphic record are of much interest to the student of the evolution of civilization, but our knowledge of the subject is as yet extremely limited, notwithstanding the learned and patient researches of a number of able students, among whom are Thomas, Bowditch, Förstemann, Goodman, Seler, Brinton, Morley, and Tozzer. In the Maya system of Central America, which is the most: highly perfected, the symbols for days, months, years, and cycles are known, and dates inscribed in manuscripts and carved on monuments are in numerous cases made out with considerable facility. The earliest date yet deciphered is that engraved in glyphic characters on a small jade statuette obtained from southern Vera Cruz (fig. 20). ${ }^{1}$ The date, as read by Morley, translated into our system,

${ }^{1}$ Holmes, On a Nephrite Statuette from San Andrés Tuxtla, Vera Cruz, Mexico. 
is $100 \mathrm{~B}$. C. The next recorded date found on the small sculpture called the Leyden stone is 160 years later, or $60 \mathrm{~A}$. D.

The fact that 2,000 years ago the people of eastern Mexico had advanced so far toward the civilized state as to have Glyphic Chronology perfected a system of writing warrants the conclusion that the occupancy of the continent covers a much longer period, the length of which, however, may never be determined. Already so many of the dates have been read that the

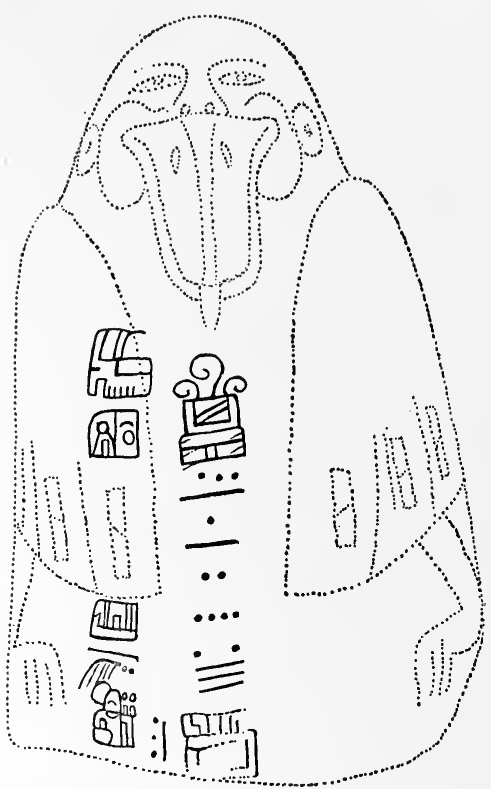

Fig. 20. Jade statuette from Vera Cruz, Mexico, with glyphic date corresponding to 100 B. C. $\left(\frac{1}{2}\right)$

periods of many of the greater cities of the olden time are known and the outlines of Maya history covering a period of 20 centuries are clearly made out. The correctness of these readings is confirmed by observed characteristics of the art of the several culture centers which indicate progressive development in close accord with the glyphic chronology. The present status of the researches in this fascinating field may be learned by reference to the works especially of Morley ${ }^{1}$ and Spinden. ${ }^{2}$

In the present work, however, it is not the purposeful records of the tribes which must receive particular attention, but rather the fortuitous records-works of the hands designed for various purposes, used and left by the wayside, and more especially those associated with geological formations. The data to be drawn upon in this field is vast in extent and of various grades of Classification of chronological value, ranging from the merely sugChronologic Data gestive to the decisive and convincing. The category of data available to the Americanist in determining measurable periods of time as well as relative antiquity may be grouped as follows:

\section{Historical (Written)}

Data embodied in written history which, with the exception of the tales of the Norsemen and meager native glyphic records, are chiefly post-Columbian.

1 Morley, An Introduction to the Study of the Maya Hieroglyphs.

2 Spinden, A Study of Maya Art. 


\section{Traditional (Mnemonic)}

Data supplied by native tradition employed by chronologists necessarily with much caution.

\section{Biological}

(a) Data derived from the growth and decay of forests.

(b) Data derived from the distribution of plant species by liuman agency.

(c) Data afforded by changes in living forms, as of shellfish, during the human period.

(d) Data based on the differentiations of the human groups and on the modification of animal species, as the llama and alpaca, through domestication.

\section{Cultural}

(a) Data derived from a consideration of the bulk of work accomplished by the tribes, as in irrigation works, mines, and architectural monuments.

(b) Data derived from a study of the culture contents of inhabited sites representing successive occupancies.

(c) Data furnished by a consideration of the time required for the evolution of various branches of culture, as language, customs, arts.

(d) Data derived from the study of migrations and the time required in completing the settlement of the several land areas of the globe.

\section{Geological}

(a) Data derived from the association of traces of man, physical and cultural, with geological formations, a chief resource of the chronologist, association being (1) with the systematic formations; (2) with river terraces, lake beds, eolian accumulations, and cave deposits, the relative, and in a measure, the actual age of which can be determined.

(b) Data furnished by changes in artifacts by weathering, sandblast, etc.

\section{Paleontological}

Data supplied by association of the remains of man and his works with fossil remains of animal and regetal life, the geological place of which has been determined.

\section{Mineralogical}

Data based on the rate of alteration which takes place in the material of antiquities and in osseous remains from decay, mineralization, and patination. 


\section{Geograpiticil}

Data furnished by a study of the relations of land and water, historic and prehistoric, with respect to distribution of peoples and faunas.

\section{Astronomical}

Data derived from changes in the relations of the earth and heavenly bodies which affect humanity at determinable periods.

The antiquity of man on the American Continent is a subject of deep interest to the student of the aborigines as well as to the historian of the human species as a whole, and the various problems which arise with respect to chronology are claiming an ever-growing amount of scientific attention. The problems may be briefly suggested in this place, and the evidence so far presented for their solution may be reviewed.

During the first centuries of European occupancy of the continent belief in the derivation of the native tribes from Passing of Biblical Old World peoples in comparatively recent times
Chronology

was very general, and, indeed, the fallacy has not yet been entirely eradicated, as pointed out in a previous section. This view was based on the apparently solid foundation of the Usher chronology, and many works have been written in the attempt to determine the particular peoples from which the American tribes sprang. The results of researches into the archeology of the Old World during the past century, however,

Old and New World Chronologies Distinct

have served to clear away the strict biblical interpretation of events and establish the fact of the great antiquity of man in the world, and to develop a clear conception of the course of events from the close of the Tertiary epoch. Later on investigations in America were taken up, and evidence was found and readily accepted, which seemed to warrant the conclusion that the course of primitive history had been about the same on both continents; but a critical examination of the testimony has shown that this is probably not the case, and the necessity of treating the evidence furnished by the two continents quite separately is made apparent.

The aborigines are usually spoken of as a distinct race, but are more properly regarded as a subrace-an ancient Diversity of Race Characters

offshoot of the yellow-brown race of Asia. Notwithstanding this, it is observed that the racial characters of the Americans are measurably distinctive and homogeneous, differing more or less from those of the better-known typical Asiatics, and some students have reached the conclusion that a long period was required to bring about these results. Again, those 
who begin with the assumption that the arrivals in America were of a single or homogeneous stock marvel at the diversity in physical characters exhibited by the tribes, and inquire whether a long period was not required to produce the differentiations; but until the character of the incoming peoples with respect to homogeneity is determined, it is practically unavailing to attempt an estimate of the chronologic significance of present similarities and differences. Although the immigrants may have reached America through a single portal they were not necessarily a homogeneous people racially. To-day the great region from which they are beliered to have been derived contains tribes exhibiting marked physical differences, diversity being the rule among primitive tribes there as elsewhere. Arrivals along the Bering shores, whether during glacial, interglacial, or postglacial time, probably included numerous tribes, or even linguistic stocks, presenting degrees of physical difference corresponding to those observed to-day among the tribes of Siberia and Mongolia, or even those of central Asia. Considering these possibilities and the extent of the American Continent over which the immigrants wandered, the similarities of group characters are perhaps quite as much to be remarked upon as the differences, and are at present equally valueless as indexes of chronology.

It does not appear that a study of the physical characters of the present tribes can serve any important purpose in considering problems of American chronology, and the evidence so far supplied by the fossil remains is without crucial value in this direction, as shown elsewhere. The various human remains of apparently low type and assumed antiquity brought to light have been, on rigid examination, eliminated, one by one, so far as their physical characters are concerned, from the field of chronologic evidence.

The cultural conditions of aboriginal America have been studied diligently with the view of obtaining further light Diversity of Lan- on questions of age. The great diversity of cultures guages in Chronology

and especially the wonderful differentiations in language are brought forward as possible proofs of great antiquity. Usually the discussion begins with the assumption that the American pioneers were one people and from one region, speaking the same or allied languages, and that the differentiations took place entirely within the New World. Referring again to those parts of the Old World from which the American race is assumed to have been derived, we find peoples speaking not a single language but languages as diversified as those of corresponding areas in America to-day, and realize that the intercontinental migrations probably involved peoples speaking radically different tongues. It would thus appear that differentiations of language can not be regarded as of great value in solving the problems of antiquity. The theory of 
multiple genesis of the languages introduced into America and of continued divergence is illustrated in figure 21. The same suggestion applies to other branches of culture and to race.

Considering all features of the research it seems probable that the immigrants to America were comparatively unifor'm in physical characters and in mental capacity, while the dialects were greatly diversified. Further and greatly accelerated differentiation must have resulted from the new and constantly changing conditions of

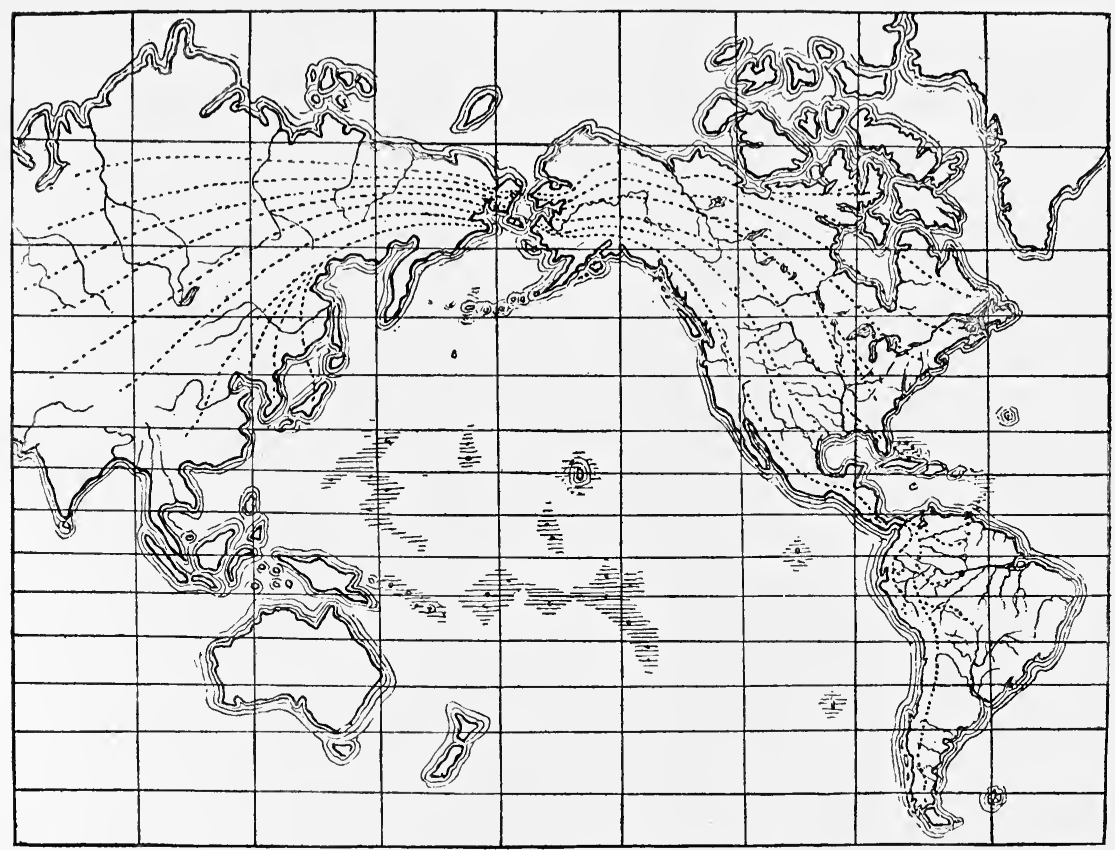

FIG. 21. Map suggesting multiple origins in Asia and differentiations in America.

environment to which the migrating peoples were necessarily subjected in passing from Arctic America toward the Equator, and thence again toward the Antarctic. Differentiating agencies corresponding to those affecting language must have affected religion, folklore, games of divination and chance, social customs, etc., of the migrating tribes, reducing to a minimum the importance of these branches of culture as aids in the study of chronology.

The diversified phenomena of material culture have been the subject of extended studies by chronologists. The evoCulture and Chro- lution of the arts and industries of primitive peoples
nology

was naturally a process involving much time, but assuming that culture development in America began with an advanced hunter-fisher stage, progress toward the higher stages, observed by the European colonists, may have been comparatively 
rapid. Traces of geologically ancient man have not been found in America as in Europe, and investigations are proceeding with painful slowness and much halting along the various lines of research, and false leads have been followed in many cases, prolonging the investigations and impeding progress. Students have sought in many ways to establish a chronology of the occupation of the continent by man. The magnitude of the work accomplished in the building of mounds and other earthworks in the Mississippi Valley has been dwelt upon at length, and the time required for the growth and decay upon these works of a succession of forests has been computed. The rast accumulations of midden deposits in both North and South America and the fact that the beds composing them seem in cases to indicate a succession of occupancies by tribes beginning in savagery and ending in well-advanced barbarism have been considered by chronologists. Striking physiographic mutations, as changes of level in coast lines and alterations in river courses since man took possession, have been taken into account. Modifications of particular species of mollusks between the time of their first use on the shell-heap sites and the present time, and the development in one or more cases of new varieties, suggest hoary antiquity, but the highest estimate of elapsed times based on these evidences does not exceed a few thousand years. After carefully weighing the evidence collected by him in Alaska, Dall reached the conclusion that the earliest midden deposits on the Aleutian Islands are probably as much as 3,000 years old. ${ }^{1}$ It is possible that, considering the character of the evidences, other students utilizing the same observations might have reached results differing from those of Dall.

We view with wonder the massive ruins left by the more cultured peoples of Middle and South America and speculate on the time required for the evolution of stone-built cities, as Tiahuanaco or Cuzco, Chichen or Copan, from villages of primitive type. Referring, however, to Old World civilizations, we discover that many of the grandest culture developments matured quickly and were short-lived, being the product of some spasm of religious enthusiasm or some abnormal derelopment of national power and enterprise. In India, for example, some of the most wonderful architectural creations of all time were built and abandoned within a few centuries. It is a well-ascertained fact that while the great architectural monuments of Java, Cambodia, and India were rising in their grandeur in the early centuries of the Christian era, the stone-built structures of America were also springing up in the forests of Yucatan and Central America. Centuries rather than millenniums have witnessed the accomplishment of the greatest material achieve-

${ }^{1}$ Dall, On Succession in the Shell-heaps of the Aleutian Islands. 
ments of humanity. Shall we then be able to predicate great antiquity for the occupation of the American Continent on the testimony furnished by the achievements of human labor or even on the length of time required for the evolution of the American cultures from the neolithic elements assumed to have been introduced from Asia?

As thus presented, the testimony of racial and cultural phenomena dissociated from geological criteria does not serve Geological $\mathrm{Chro}^{-}$to indicate clearly an antiquity for the aboriginal
nology occupancy beyond a few thousand years. Through association with geological formations, the age of which can be determined with some degree of accuracy, both cultural and somatic remains combine to extend our vision with reasonable clearness well back toward the close of the last glacial occupation of middle North America, a period whose duration is estimated by some students at from eight to twenty thousand years. Some students of the subject are satisfied that authentic evidence of man's presence during the glacial period has been obtained, others find sufficient reasons for believing in man's existence in both North and South America far back in Tertiary times, while a single bold advocate of autochthonic antiquity has promulgated the view that man originated in the western world rather than in the eastern and proceeds to identify his forbears among the American lower orders.

The geological evidence of antiquity, derived from the association of somatic and cultural remains with geological formations, that is to say, such formations, beds, layers, or strata as are due to natural as distinguished from artificial deposition, is extensive, and a full and exhaustive discussion of the subject necessarily involves the consideration of a vast body of testimony which, however, can not be more than briefly summarized in this place. The evidence will be presented, therefore, in outline merely, and the literature of original research will be cited somewhat fully for the benefit of those who may wish to pursue the subject further.

The various discoveries reported may be taken up somewhat in chronologic order, beginning with the earliest assigned date. First consideration thus falls to the testimony furnished South American by students of South American chronology, especially
Testimony

Ameghino and his associates, who have accumulated a large body of data purporting to indicate the presence of man in the pampas region of South America in remote times, the earliest traces brought forward being accumulations of cinders associated with strata assigned to the Eocene age and assumed to be due to human agency. The several periods intervening between the early Tertiary and historic times have been bridged by Ameghino by 
various discoveries of osseous remains and artifacts and by hypothetical links, and the formidable body of data collected and published has carried conviction in numerous European and American centers of research. In 1909 the writer had the opportunity of examining the various traces-cinders, fossil bones, and stone artifactsin the Museo Nacional at Buenos Aires, and portions of the material were studied in greater detail in Santiago, Chile, where the evidence was presented by Ameghino before the section of Natural Sciences of the First Pan American Scientific Congress. The various phases of the subject presented so many features of scientific interest and importance that arrangements were made later to have Dr. Aleš Hrdlička, physical anthropologist, of the United States National Museum, and Dr. Bailey Willis, geologist, of the United States Geological Survey, visit Argentina with the view of becoming more intimately acquainted with the character of the field observations and the various relics of antiquity preserved in the Argentina museums. The results of this investigation, which included a most exhaustive study of the large body of literature relating to the subject, are summarized by Dr. Hrdlička in the following paragraphs:

A conscientious, unbiased study of all the available facts has shown that the whole structure erected in support of the theory of geologically ancient man on that continent rests on very imperfect and incorrectly interpreted data and in many instances on false premises, and as a consequence of these weaknesses must completely collapse when subjected to searching criticism.

The main defects of the testimony thought to establish the presence of various representatives of early man and his precursors in South America are: (1) Imperfect geologic determinations, especially with regard to the immediate conditions under which the finds were made; (2) imperfect consideration of the circumstances relating to the human remains, particularly as to possibilities of their artificial or accidental introduction mino older terranes and as to the value of their association from the standpoint of zoopaleontology; (3) the attributing of undue weight to the organic and inorganic alterations exhibited by the human bones; and (4) morphologic consideration of the human bones by those who were not expert anthropologists, who at times were misled in the important matter of placing and orienting the specimens and who accepted mere individual variations or features due to artificial deformation as normal and specifically distinctive characters.

As to the antiquity of the various archeologic remains from Argentina attributed to early man, all those to which particular importance has been attached have been found without tenable claim to great age, while others, mostly single objects, without exception fall into the category of the doubtful.

As to the many broken, striated, grooved, and perforated animal bones, the writers have not been convinced that these are in any case necessarily the work of geologically ancient man. In those instances in which the originals were examined, the markings observed were either clearly recognized as due to gnawing rodents or to other nonhuman agencies or as of doubtful origin.

The conclusions of the writers with regard to the evidence thus far furnished are that it fails to establish the claim that in South America there have been brought forth thus far tangible traces of either geologically ancient man himself or of any precursors of the human race. 
This should not be taken as a categorical denial of the existence of early man in South America, however improbable such a presence may now appear; but the position is maintained, and should be maintained, it seems, by all students, that the final acceptance of the evidence on this subject can not be justified until there shall have accumulated a mass of strictly scientific observations requisite in kind and volume to establish a proposition of so great importance. ${ }^{1}$

The extensive literature of the subject is cited in full detail by Dr. Hrdlička in his report. The results of the present writer's examination of the large collections of stone artifacts brought back by Dr. Hrdlička, which are embodied in the same volume, serve to show that the determinations of Ameghino, drawn from the study of corresponding material in his own collections, are properly subject to critical revision. There appears to be no very cogent reason for assigning any of the cultural traces to sources other than tribes occupying the region in comparatively recent times.

Apart from the evidence obtained by Lund in Brazil and by the authorities above referred to in Argentina, considered with such acumen by Dr. Hrdlička, South America has furnished no geological data deserving of extended mention.

The very serious risk of hasty conclusions, not only by amateurs but on the part of scientific observers, respecting Risk of Hasty Con- finds of human remains in association with geologi-
clusions

cal formations is well illustrated by a recent instance furnished by the second Peruvian expedition of Prof. Hiram Bingham. The osseous remains of a human being were found by the first expedition in the vicinity of Cuzco in what were believed to be deposits of Pleistocene age, and after careful examination by the geologist of the expedition, the following announcement was made of the discovery of a fossil man of an antiquity which would have'given countenance to the questionable discoveries of Ameghino in Argentina :

From a detailed study of the geology of the upper Cuzco basin with special reference to glacial forms, it is concluded (1) that the beds belong to the I'leistocene series, (2) that the bones were deposited during a period of pronounced alluviation, and (3) that since the deposition of the bones at least 75 feet of gravel were deposited over them and later partly eroded, an erosion that is still in progress and to whose activity we owe the exposure.

It should be remembered that while compelled to refer the gravel beds of this locality to the Pleistocene series, I have yet to determine their place in that series. When this is done the antiquity of the vertebrate remains may be more safely approximated than now. A provisional estimate would hardly be less than 10.000 years; it could not exceed the maximum glaciation of the last glacial period, generally estimated at 75.000 years. $^{2}$

\footnotetext{
1 Hrdlička and others, Early Man in South America, pp. 385-386.

2 Bowman, in Bingham, Preliminary Report of the first Yale Peruvian Expedition, p. 25.
} 
Notwithstanding the adverse attitude at once assumed by skeptics, had not Professor Bingham made a second risit to the spot with the most commendable purpose of determining before it was too late the exact truth regarding the observations, the literature of American chronology would have been burdened with a most lamentable error, willingly accepted and perpetuated by the writers of books at home and abroad. The positive determination of the geologist would have carried conviction to many minds. The citation of these facts is not intended as in any sense derogatory to the explorers concerned. On the contrary, Professor Bingham is deserving of the highest commendation for his prompt action in renewing the search, thus estab-

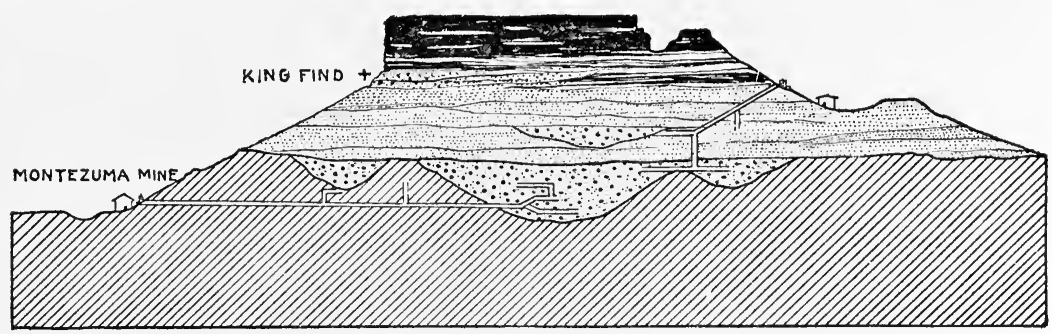

Fig. 22. Section of Table Mountain showing mines penetrating to old river channels. The position of the King pestle is shown.

lishing the truth in place of error. It is the probability that many such faulty observations are embodied undetected in archeological literature that deserves to be emphasized.

In North America during the middle decades of the nineteenth century a most imposing body of evidence relating to California Evi- the Tertiary origin of man was collected by the State
dence

Geological Survey of California in the auriferous gravel region. ${ }^{1}$ Miners working the rast deposits of gold-bearing gravels, assigned in part to Tertiary times, reported the discovery of various artifacts in the diggings, not only in the deep gravels but entombed in these gravels beneath heary sheets of lava of Tertiary age (fig. 22). This evidence has been the subject of most careful reexamination and revision, and, although it is imposing in bulk and was accepted as convincing by Professor Whitney, director of the survey, the conclusions drawn are questioned by those who realize the extreme danger of too ready acceptance of observations of geological phenomena by inexperienced observers, persons not prepared to understand the possible intrusion of recent artifacts from the surface into the deep diggings or to consider other possible risks of error. After visiting the principal sites of the alleged discoveries, the writer prepared an exhaustive review of the evidence. ${ }^{2} \perp$ brief

1 Whitney, Auriferous Gravels of the Sierra Nevada of California.

${ }^{2}$ Holmes, Revision of the Evidence Relating to Auriferous Gravel Man in California. 
summary of the arguments for and against the great antiquity of man in the gold belt, extracted from that review, is presented here for convenience of reference. The principal considerations arrayed in support of geological antiquity are as follows:

(1) During the three or four decades succeeding the discovery of gold in California the miners of the auriferous belt reported many finds of implements and human remains from the mines. The formations most prominently involved are of Neocene age; that is to say, the middle and later portions of the Tertiary.

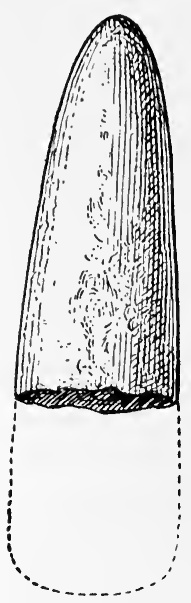

$a$

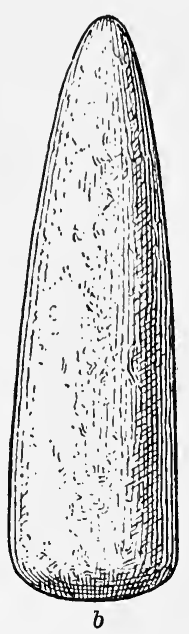

Fig.23. a, Fragment of stone pestle found by Clarence $\mathrm{K}$ ing embedded in gravels underlying the Table Mountain lava cap. $b$, Pestle of the prevailing type among the California tribes.

(2) Most of the objects came from surface mines, but some were seemingly derived from tunnels entering horizontally or obliquely and to great depths and distances beneath mountain summits capped with Tertiary lavas, a condition leading to a belief in their great age.

(3) The finds were very numerous and were reported by many persons, at various times, and from sites distributed over a vast area of country. They were made, with one exception, by inexpert observers-by miners in pursuit of their ordinary calling-but the statements made by the finders are reasonably lucid and show no indications of intentional exaggeration or attempted deception.

(4) The stories as recorded are uniform and consistent in character, and the objects preserved are, it is claimed, of a few simple types, such as might be expected of a very ancient and primitive people. The evidence, coming from seemingly unrelated sources, is described as remarkable for its coherency.

(5) The reported finding of an implement apparently in place in the late Tertiary strata of Table Mountain by Clarence King, geologist and director of the Survey of the Fortieth Parallel, is especially important and gives countenance to the reports of inexpert observers (fig. 23). It is the most important observation yet made by a geologist bearing upon the problem of man's antiquity in America. Unfortunately Mr. King failed to publish the discovery, which was made known many years later by Dr. G. F. Becker. ${ }^{1}$

Another unpublished discovery has also been made in these gravels which will be in so far more satisfactory to the members of this society that the

${ }^{1}$ Becker, Antiquities from under Tuolumne Table Mountain in California, p. 189. 
discoverer is well known personally to most of them and by reputation to every geologist. In the spring of $1869 \mathrm{Mr}$. Clirence King visited the portion of the Table Mountain which lies a couple of miles southeast of Tuttletown, and therefore near Rawhide camp, to search for fossils in the auriferous gravels. At one point, close to the high bluff of basalt capping, a recent wash had swept away all talus and exposed the underlying compact, hard, auriferous gravel beds, which were beyond all question in place. In examining this exposure for fossils he observed a fractured end of what appeared to be a cylindrical mass of stone. This mass he forced out of its place with considerable difficulty on account of the hardness of the gravel in which it was tightly wedged. It left behind a perfect cast of its shape in the matrix and proved to be a part of a polished stone implement, no doubt a pestle. It seems to be made of a fine-grained diabase. This implement was presented to the Smithsonian Institution on January 20, 1570. It is shown in the accompanying cut (fig. 1), a photo-engraving from a drawing by Mr. Wr. H. Holmes. Mr. King is perfectly sure that this implement was in place, and that it formed an original part of the gravels in which he found it. It is difficult to imagine more satisfactory evidence than this of the occurrence of implements in the auriferous, preglacial, sub-basaltic gravels. .. . That human remains are really associated with an extinct fauna in these gravels seems to me thoroughly established. ${ }^{1}$

(6) The osseous remains recovered from the gravels are, in some cases, said to be fossilized, having lost nearly all their animal matter, and some are coated with firmly adhering gravels resembling those of the ancient deposits. These conditions give rise to the impression of great age.

(7) The flora and fauna with which the human remains and relics appear to be associated indicate climatic conditions and food supply favorable to the existence of the human species. It is a noteworthy fact that in many cases the intimate association of the human remains with those of extinct animal forms is noted.

(8) The eridence as presented by Whitney and others seems abundant and convincing, and many scientific men have accepted it as satisfactory proof of a Tertiary man in America. It is clearly the strongest body of evidence yet brought together tending to connect man with any geologic formation earlier than post-glacial.

On the other hand, numerous considerations are urged against great antiquity, as follows:

(1) It is held that the strength of testimony should be proportioned directly to the magnitude of the propositions to be supported and that this particular case requires proofs of a higher order than have as yet been presented.

(2) The existence of a Tertiary man, even of the lowest grade, has not yet been fully established in any country, and this California evidence, therefore, stands absolutely alone. It requires a human race older by at least one-half than Pithecanthropus erectus 
of Dubois, which may be regarded only as possibly an incipient form of human creature. Some of the finds reported indicate a Middle Tertiary people well advanced in the elements of culture; and culture, especially in the earlier stages, is necessarily of exceedingly slow growth. The Pithecanthropus of California would have to be looked for somewhere in the early Tertiary if not in a preceding period. The burdens thus thrown on the auriferous gravel evidence are enormous.

(3) The assumption that a Tertiary man could have survived to the present time in California may well be held in abeyance. The physical and biological changes in the region have been profound
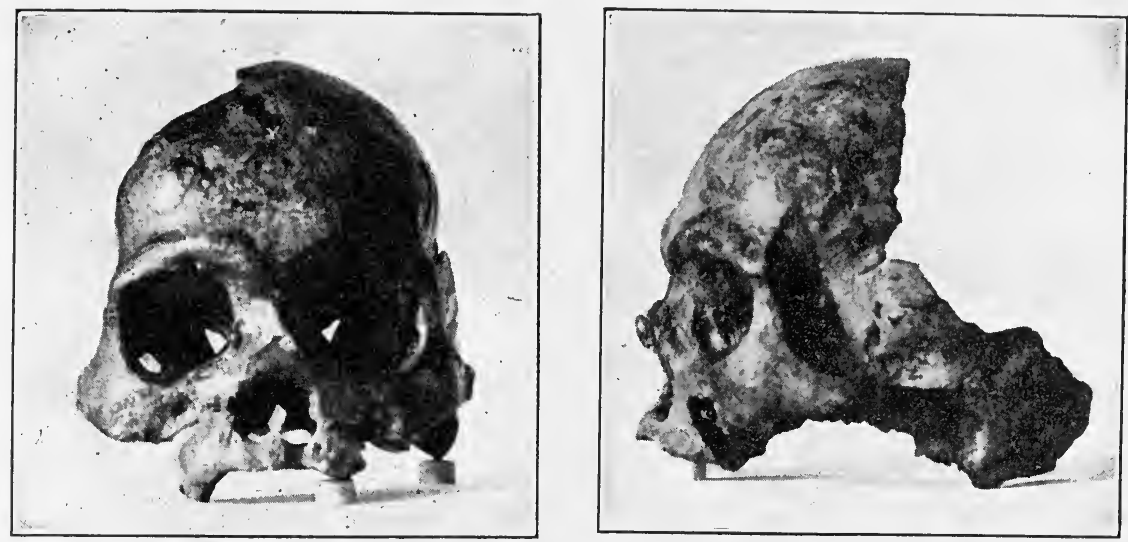

Fig. 24. The Calaveras skull, said to have been taken from Tertiary gravels at a depth of 130 feet.

and far-reaching. The western half of the continent has been twice or thrice remodeled since Middle Tertiary times, and every known species of plant and all species of the higher forms of animal life of that time are said to have been obliterated. Evidence based on random and inexpert observations is not sufficient to establish such a proposition.

(4) Could it be admitted that man did survive throughout the ages and continental transformations, it appears quite improbable that his physical characters and his culture should have remained unchanged. It seems equally unlikely that a modern race could have sprung up duplicating the man of a million years before in every essential particular.

(5) Examination of the human relics reported from the gravels fails to give support to the claim of antiquity. The fossilization, so called, of the osseous remains, upon which so much stress has been laid, may have taken place in comparatively recent times. The crania recovered are practically identical in character with those of the present tribes of California (fig. 24). 
(1) The skull presents no signs of having belonged to an inferior race. In its breatth it agrees with the other crania from California, except those of the Diggers, but surpasses them in the other particulars in which comparisons have been made. This is especially obvious in the greater prominence of the forehead and the capacity of its chamber. (2) In so far as it differs in dimensions from the other crania fron California, it approaches the Esquimaux. ${ }^{1}$

(6) Objects of art from the auriferous gravels have been described as exceptionally primitive in character and in large measure peculiar to the gravels. When critically examined, however, they are found to belong to the polished-stone stage and to duplicate modern implements in every essential respect (figs. 25-27). They
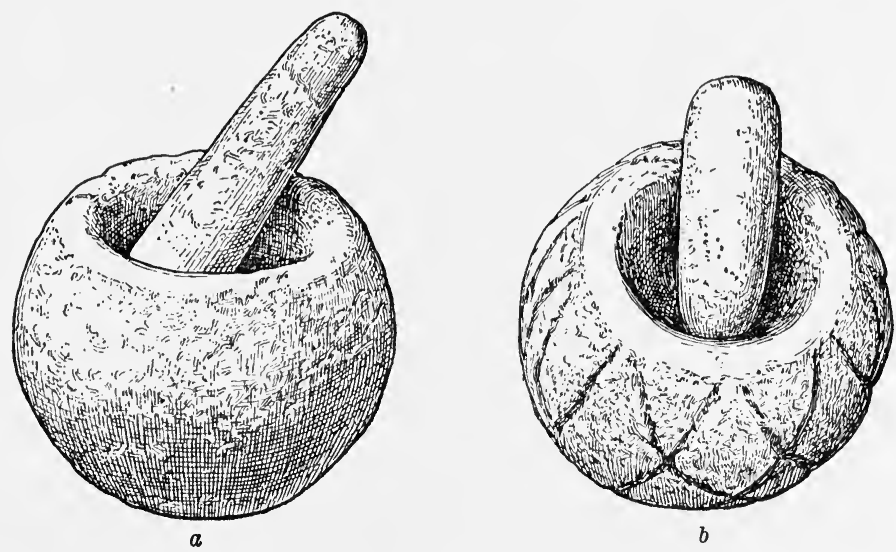

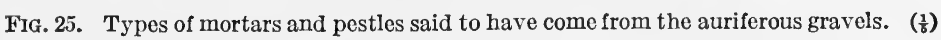

are such as may have fallen in from Indian camp sites or been carried into caverns by the Indians themselves. They are made from varieties of stone belonging to formations ranging from the oldest to the youngest found in the district, and have been shaped by the ordinary processes employed by our aborigines. They evidently served purposes identical with the corresponding implements of our Indian tribes.

(7) None of these objects show evidence of unusual age, and none bear traces of the wear and tear that would come from transportation in Tertiary torrents, nor can any reason be given why they should have been included in the beds of torrential rivers. These striking facts relative to the condition of the human and cultural remains confirm and enforce the impressions of recentness deduced from a study of the geological and biological history of the region.

(8) The case against antiquity is strengthened again by a study of the recent history of California. All, or nearly all, of the

${ }^{1}$ Whitney, Auriferous Gravels of the Sierra Nevada, p. 273; Hrdlička, Skeletal Remains Suggesting or Attributed to Early Man in North America. 
phenomena relied upon to prove antiquity can readily be accounted for withont assuming a Tertiary man. Indian tribes have occupied the region for many centuries. They buried their dead in pits, cares,

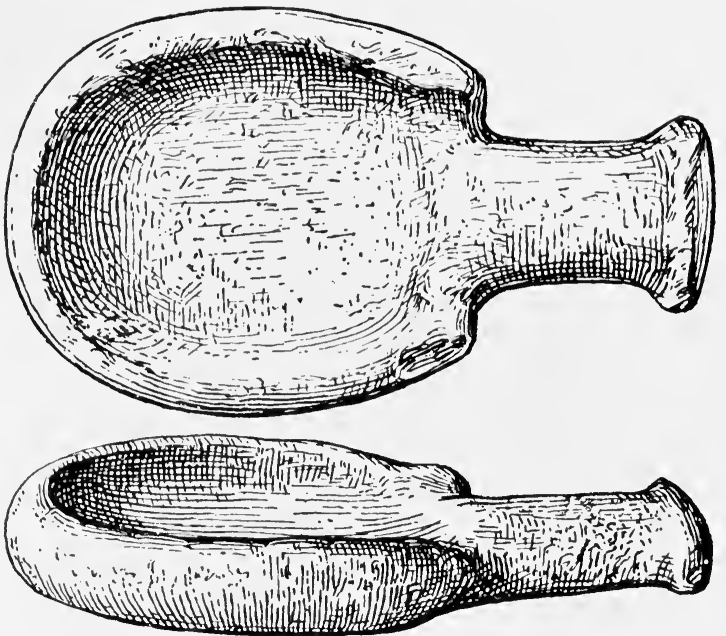

FIG. 26. A ladle-like utensil from the auriferous gravels. ( rock crevices, and deep ravines, where the remains were readily covered by accumulations of débris and of calcareous matter dèposited by water. As soon as mining operations began, the region became noted as a place of skulls.

(9) Coupled with the above is the fact that no other country in the world has been so extensively and profoundly dıg over as this same auriferous gravel region. The miners worked ont the ossuaries, and undermined the village sites, and it has been shown beyond cavil that large numbers of the native implements and utensils belonging to recent villages (figs. 28, 29)

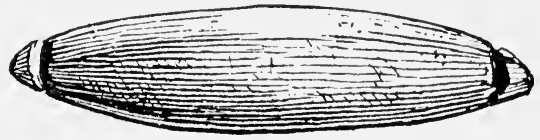

$a$

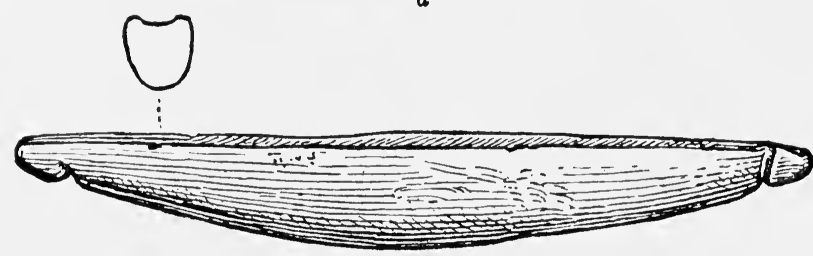

$b$

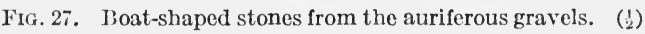

were introduced into the mines and became intermingled with the gravels while the deep placer workings were actually in progress. Implements and utensils may also, in cases, have been introduced into the deep mines by helpers in the mining work.

(10) When these articles began to be observed by the miners, individuals interested in relics commenced making collections, but neither miners nor collectors understood the need of discrimination. 
The fact that the objects came from the mines was to them satisfactory evidence that they belonged originally in the gravels.

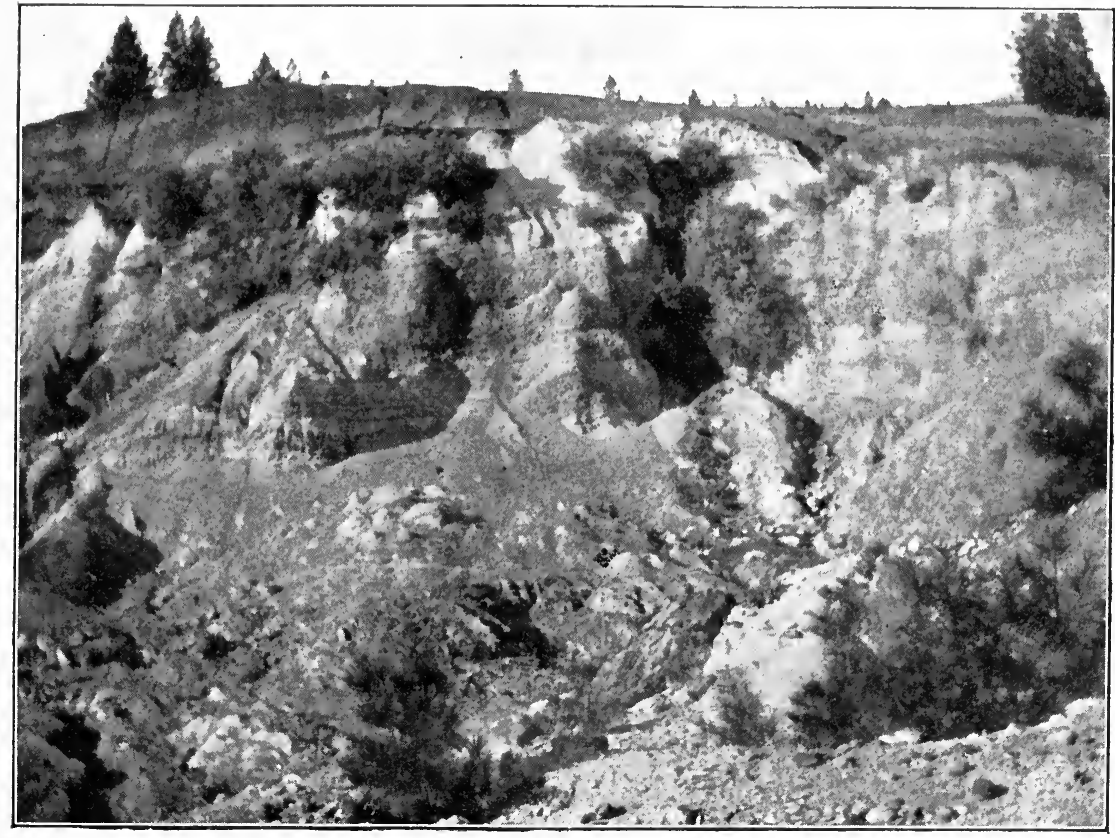

FIG. 29. Weathered gravel wall of a gold mine 200 feet in height, with ancient village site above.

(11) Again, it is possible that deception was often practiced. A mining camp is the natural home of practical joking, and the notion

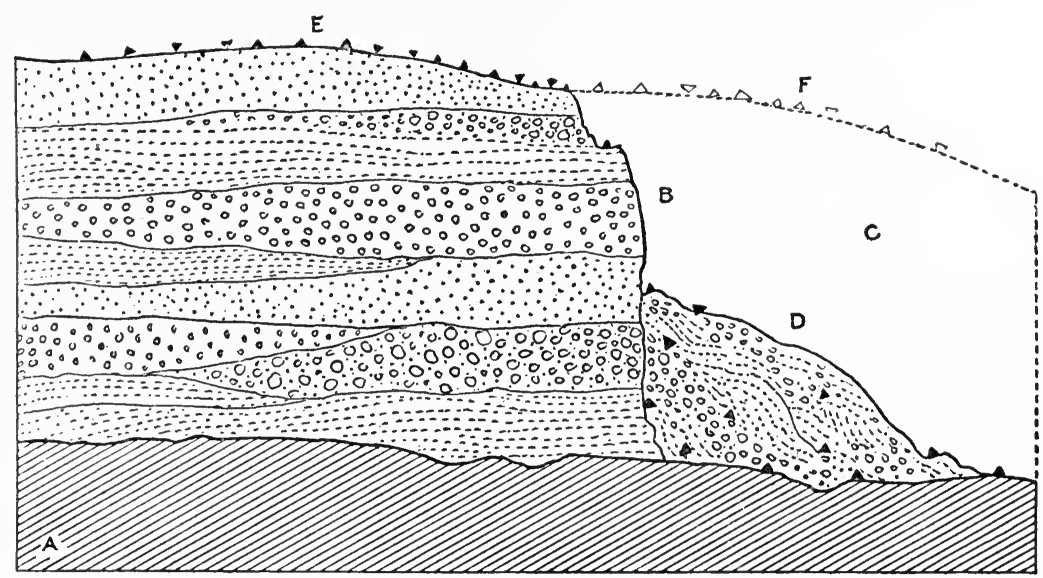

FIG. 29. Section showing relations of ancient village site to caved-in gold mine.

$A$, Auriferous slates-bed rock; $B$, auriferous gravels, 250 feet thick; $C$, great excavation made in gravels by hydraulic mining; $D$, crumbled gravels, result of caving in; $E$, ancient village site; $F$, portion of village site destroyed by mine. The dark triangular figures in the talus show the distribution of artifacts resulting from slides into the mine. 
that finds of human relics in the gravels tended to excite heated discussion would spread quickly from camp to camp until the whole region would be affected.

(12) The testimony for antiquity is greatly weakened by the facts (1) that the finds on which it depends were made almost wholly by inexpert observers, and (2) that all observations were recorded at second hand. Nothing short of abundant expert testi-

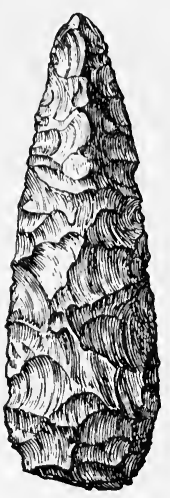

Frg. 30. Obsidian blade from supposed Pleistoceno deposits, Nerada, (McGee.) ( $\left.\frac{1}{2}\right)$ mony will convince the critical mind that a Tertiary race of men using symmetrically shaped and beautiful implements, wearing necklaces of wampum and polished beads of marble or travertine bored accurately with revolving drills, and having a religious system so highly developed that at least two forms of ceremonial stones well known among the Indian tribes were in use, could have occupied the American Continent long enough to develop this marked degree of culture without learing some really distinctive traces of its existence, something different from the ordinary belongings of our present aborigines.

Although, as thus summarized, the writer finds the weight of evidence rather against than for the great antiquity of man in California, he does not believe that the eridence recorded by Whitney and others should be disregarded. Certain portions of the deep gravels appear to have yielded traces of human occupancy of the region during the formation of these deposits and science can not afford to let the matter rest until their age is determined and the exact manner of inclusion is known; meantime chronologists can be on their guard against too hasty acceptance of conclusions not absolutely warranted by the evidence.

In 1882 Professor McGee obtained an obsidian knife blade (fig. 30) from bedded deposits of white marl of supposed The Nevada ob- Pleistocene age in Walker Valley, Nevada. The
sidian

specimen was seemingly in situ at the depth of 25 feet in the formation.

It is of massive obsidian, or volcanic glass, and quite free from superficial incrustation or disintegration. In material, size, general form, mode of chipping, and freshness in appearance it is undistinguishable from the arrow points in use to-day by the Piute Indians of the vicinity. It should be mentioned that this fresh aspect is paralleled by that of the fossil bones found in the same stratum of white silt. These bones are perfectly white, not at all mineralized and, when found in fragments not readily identifiable, may easily be discriminated from long-weathered recent bones by their greater porosity and less weight.

The upper series of Lahontan deposits within which the obsidian was found are classed as Pliocene (Equus beds) by the vertebrate paleontologist and 
later Pleistocene by the physical geologist; but this discrepancy is of no further significance than an indication that the chronologies of paleontologist and geologist do not coincide. It suffices that the later episode of cold and wet in the Lahontan basin has been demonstrated by King, Gilbert, and Russell to correspond with the second ice invasion of the glacial epoch. ${ }^{1}$

In a subsequent paragraph (pp. 306-307), speaking of the need of careful discrimination and great caution in treating of exceptional inclusions in unconsolidated geological formations, McGee makes the following most instructive and important statement:

It is a fair presumption that any unusual object found within, or apparently within, an unconsolidated deposit is an adventitious inclusion: Every cautious field geologist accustomed to the study of unconsolidated superficial deposits quickly learns to question the rerity of apparently original inclusions; he may, it is true, exhanst the entire range of hypothesis at his command without satisfying himself that the inclusion is adventitious; yet he is seldom
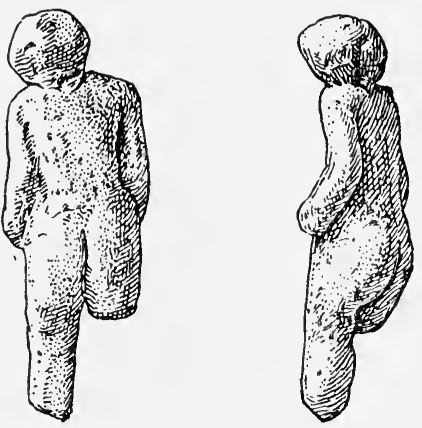

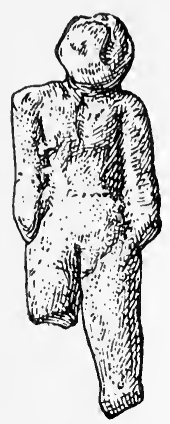

FIG. 31. Terra-cotta figurine reported to have come from late Tertiary or early Quaternary deposits, Idaho. (1) satisfied that he has exhausted the range of possible hypothesis as to the character of the inclusion, and hesitates long before accepting any unusual association as veritable. His case is not that of the invertebrate paleontologist at work in the Paleozoic rocks, to whom a single fossil may carry conviction; for not only are the possibilities of adventitious inclusion indefinitely less in solid strata, but the mineral character of the fossil is commonly identical with that of its matrix and so affords inherent evidence of the verity of the association. Nowhere, indeed, in the entire range of the complex and sometimes obscure and elusive phenomena of geology is there more reason for withholding final judgment based upon unusual association than in the unconsolidated superficial deposits of the earth; and it is only where there is collateral evidence that such testimony is acceptable to the cautious student. Now, the sediments of Lake Lahontan are generally, and in Walker River Cañon almost wholly, unconsolidated and so the probabilities are against the verity of the association.

These considerations, although bespeaking much candor on the part of McGee, do not make it imperative that an observation so carefully made and recorded should be ignored by seekers after the truth. Made by a geologist of high standing, it is the second most important observation yet recorded bearing upon the problems of 
the high geological antiquity of man in America, the Table Mountain find of King taking first rank.

Of similar import with respect to antiquity is the so-called Nampa image, a minute clay figurine supposed to represent a female, the body being quite well modeled, the head hardly more than a crude lump of clay, and the legs broken away, one above and the other below the knee (fig. 31). It is said to have been brought up by an artesian well sand-pump at Nampa, Idaho, in 1889, and derives its archeological interest from the fact that the deposits penetrated are geologically ancient. According to Emmons, ${ }^{1}$ the formation in which the pump was operating is of late Tertiary or early Quaternary age; and the apparent improbability of the occurrence of a wellmodeled human figure in deposits of such great antiquity has led to grave doubt as to its authenticity. It is interesting to note that the age of this object, supposing it to be authentic, corresponds with that of the incipient man whose bones were, in 1892, recovered by Duboise from the late Tertiary or early Quaternary formations of Java. Like the auriferous gravel finds of California, if taken at its face value the specimen establishes an antiquity for Neolithic culture in America so great that we hesitate to accept it without further confirmation. While it may have been brought up as reported, there remains the possibility that it was not an original inclusion under the lava. It is not impossible that an object of this character could have descended from the surface through some crevice or water course penetrating the lava beds and have been carried through deposits of creeping quicksand aided by underground waters to the spot tapped by the dirill.

It should be remarked, however, that forms of art closely analogous to this figure are far to seek, neither the Pacific slope on the west nor the Pueblo region on the south furnishing modeled images of the human figure of like character or of equal artistic merit. The nearest region in which work of corresponding culture grade occurs is in the middle Mississippi Valley, the period being recent. In seeking to explain the possible occurrence of this specimen several alternatives are suggested as follows: (1) That the figure is a rare and exceptional work of one of the tribes occupying the locality in recent times; (2) that it is of modern make by some distant aboriginal people of advanced culture; (3) that it is of modern make, by some designing person, introduced into the sand-pump output with intent to deceive; (4) that it is of early Quaternary age as indicated by its alleged occurrence, and the work of a people already well advanced in the Neolithic stage of culture progress.

${ }^{1}$ Emmons, in Wright, Climatic Condition of the Glacial Period: The Nampa Image, p. 432 . 
Other averred traces of geologically ancient man are few in number and in nearly all cases are lacking in anThe Lansing Man thority as chronological evidence. Perhaps the most important instance is that of the fossil man of Lansing, Kans., about which there has been much discussion, certain students assigning the remains to the Iowan phase of the glacial

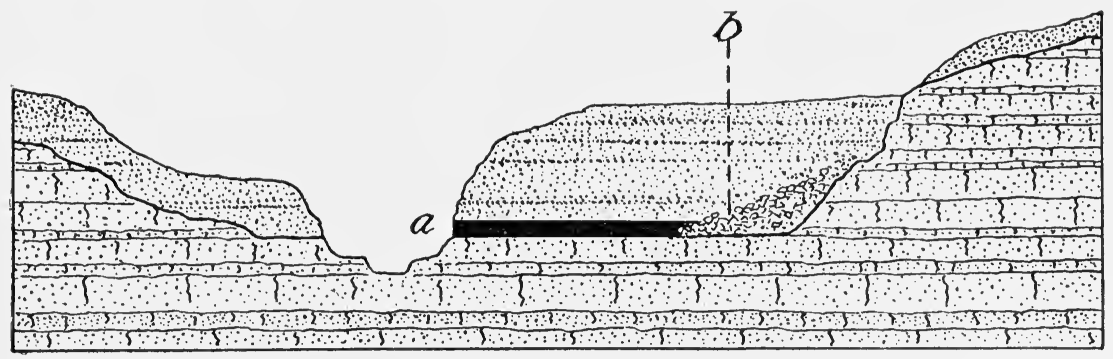

FIG. 32. Soction showing the geological position of the Lansing skeleton. $a$, Tunnel; $b$, location of find.

epoch and others advocating the view that it is probably postglacial and comparatively recent. The name is given to a partially dismembered human skeleton found in 1902 under 20 feet of undisturbed silt, 70 feet in from the face of a Missouri River bluff (fig. 32). The bones lay partly under a large limestone slab imbedded in a mass of talus at the foot of a shale and limestone cliff against which the silt had been deposited. The silt deposit was probably due to an upbuilding partly by wash, partly by winds, partly by creep from the adjacent hills, partly by sediment from the Missouri. It appears that this deposit, while possibly geologically ancient is not necessarily so and may be comparatively recent. The bones themselves do not give countenance to the theory of great antiquity. ${ }^{1}$ According to Hrdlička ${ }^{2}$ the skull is

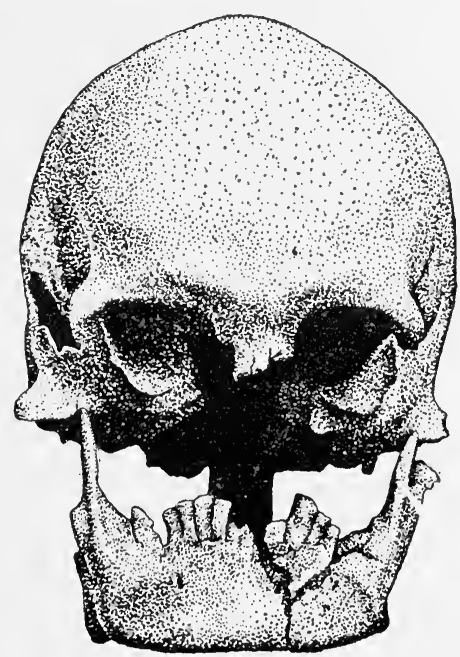

FIG. 33. Frontal view of the Lansing skull, Kansas.

not perceptibly fossilized, and is practically identical in type with crania of the historic Indians of the general region (fig. 33). It has

1 The history of the discovery of the specimen is given by Wright in Proc. Boston Soc. Nat, Hist., January, 1890, February, 1891. Emmons's statement regarding the age of the formations involved is given in the same connection. Its authenticity is questioned by Powell in Pop. Sci. Monthly, July, 1893. See also Ilandbook of American Indians, art. Nampa Image.

2 The Lansing skeleton, p. 324. 
been placed for safe keeping in the U. S. National Nuseum by its owner, Mr. M. C. Long, of Kansas City, Mo.

As the geologists who examined the site when a deep trench, cut under the direction of the writer, was open for inDifferent Interpre- spection, hold widely divergent opinions with respect tations

to the age of the formation inclosing the remains, further investigation is necessary before the question of antiquity can be safely regarded as settled. The literature of the subject is extensive and can not be more than cited in this place. Of the geologists referred to, those favoring glacial antiquity are Upham, ${ }^{1}$ Winchell, Williston, ${ }^{2}$ and Erasmus Haworth, professor of geology, University of Kansas. Those favoring a comparatively recent date are Chamberlin, ${ }^{3}$ Holmes, ${ }^{4}$ R. D. Salisbury, professor of geology, University of Chicago; Samuel Calvin, State geologist of Iowa; and Gerard Fowke, who conducted the excavations on the site.

Professor Chamberlin concludes a lengthy and most critical review of the Lansing evidence and refers also to his equally noteworthy discussion of certain discoveries at Little Falls, Minn., as follows:

The discovery of human remains under 20 feet of dibris near Lansing, Kans., has revived interest in the antiquity of man in [Chamberlin's View] America, and fortunately on more hopeful lines than heretofore, since the mode of occurrence at Lansing is more definitely determinate than in most previous cases of the kind, and the geologic elements of the problem are more declared, though, as it happens, they belong to a much overlooked yet very common type. The recent studies of Brower and Winchell on the quartz chips at Little Falls have brought that case into more definite form.

There remain about the same differences of interpretation as heretofore, but these will pass away as the specific identification of glacio-fluvial, alluvial, and sub-aërial adjustment deposits become more familiar and precise, and as their interpretation is at once given greater latitude and made more strictly dependent on discriminative criteria.

In the judgment of the writer, neither of the above cases affords any substantial ground for affirming the presence of man in America during the glacial period; but they do afford a strong presumption that man in this country has witnessed very notable progress in the deepening of the channels of the Missouri and Mississippi rivers. In time there may be found means for estimating the rate at which these rivers are lowering their channels, but at present these are wanting, and there is no trustworthy method of estimating in years the time consumed in the deepening which has taken place since the human relics were buried. ${ }^{5}$

\footnotetext{
${ }^{1}$ Upham, Man in the Ice Age at Lansing, Kansas.

${ }^{2}$ Williston, A Fossil Man from Kansas.

${ }^{3}$ Chamberlin, The Geologic Relations of the IIuman Relics of Lansing, Kansas, p. 715.

${ }^{4}$ IIolmes, Fossil IJuman Remains found near Lansing, Kansas.

5 Chamberlin, Editorial, p. 793.
} 
Professors Calvin and Salisbury agree with Professor Chamberlin in his very carefully drawn conclusions.

A large proportion of the observations relating to the geological antiquity of man in America cluster about the closSignificance of ing stages of the glacial period in the northern Terms "Glacial" and "Postglacial"

United States. It is to be noted that the expressions "glacial," "postglacial," and "close of the glacial period" need to be employed with discrimination. Referring to the American Continent as a whole, the glacial period did not close until the main body of the general ice sheet disappeared beyond the arctic shores, and the postglacial period did not begin until the ice sheet had thus disappeared. Referring, however, to particular localities or regions, the glacial period ended when the ice abandoned that locality or region and the postglacial began. If the close of the glacial period in the Ohio or Delaware valleys, for example, should be placed at 20,000 years ago, it might in the region of the Great Lakes have been 10,000 years ago, and in the Mackenzie Valley and Hudson Bay region 5,000 years ago, and so on. In employing the expression "close of the glacial period," therefore, its particular geographical application should be made clear.

If, as some hold, the continent was occupied at the period of the last great southward extension of the ice sheet, the

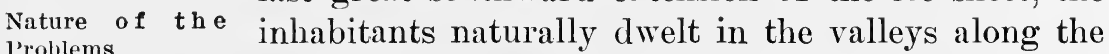
1'roblems southern border, and traces of their presence should be found there. All the peoples occupying these valleys in postglacial times down to the present would likewise leave traces of their presence-traces which would owe their characteristics to the kind of culture, the materials available for the arts, and the particular kind of occupation of the site as for hunting, fishing, war, manufacture of implements and utensils, dwelling or burial. The archeologist, no matter when the occupancy began or whether it was broken or continuous, must encounter the very exacting task of arranging chronologically the data-the material evidences available on each site and in each district-and determining their true value. Chrono logical evidence is to be sought in successive, undisturbed deposits of glacial and postglacial ages, more especially in river and lake terraces and in caverns, but the record is not easily read and the true sequence may be determined only by expert and experienced observers. Various agencies have conspired to complicate and confuse the record and to render the reading difficult. The unconsolidated deposits of post-Tertiary time conform to no uniform order of succession, as do the systematic geological formations. Torrents, the exact period of which can not be determined, have plowed up the flood-plain deposits of the rivers and intermingled them, even reversing the order of original occurrence. The winds have torn 
down and built up, in most perplexing confusion, and the ever active forces of gravity have brought about extensive changes. Forests have been uprooted, breaking up the original order of deposition, and man and beast have been continuously active in disturbing the superficial deposits in many ways. Pitfalls await the unwary rerplexing Condi- observer on every hand, and the interpretations of all
tions

fincls of artifacts attributed to unconsolidated deposits are to be accepted with due reservation. A Japanese teapot from the alluvial deposits of a Virginia valley found at a depth of 25 feet may not prove, in the hands of even the most inexpert and credulous, an element of danger, since its origin and period are not liable

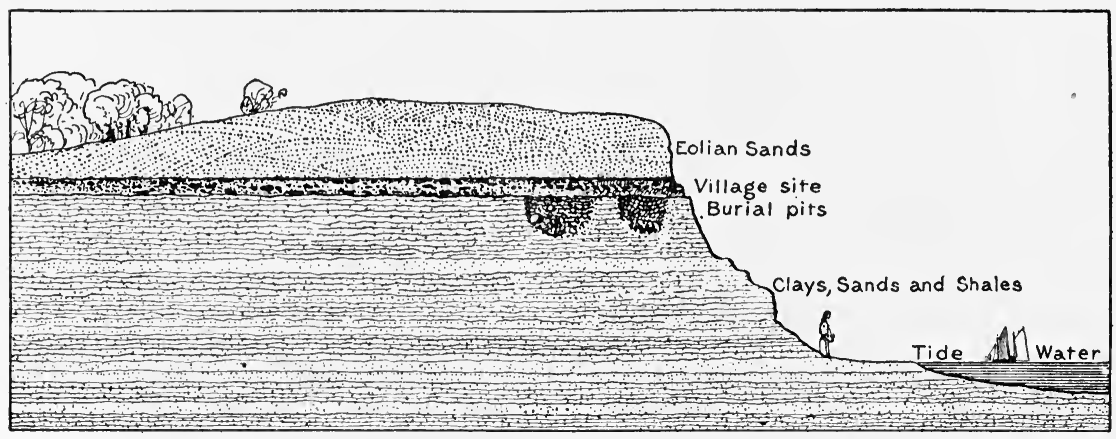

FIG. 34. Sand-buried Indian village site, on shore of Chesapeake Bay.

to misinterpretation, but a rudely shaped implement or a reject of manufacture of recent origin found at an equal depth may in incompetent hands take its place in the literature of archeology as proof of great antiquity and an unknown race low in the culture scale. An Indian village site with its normal complement of relics on the shore of a Maryland bay, buried beneath a score of feet of windblown sand, may be readily and correctly interpreted by anyone having a little knowledge of such deposits and the contents of such sites (fig. 34). But objects of rudely shaped stone, the handiwork of the modern Indian, and such as occur on thousands of sites of random manufacture, buried at corresponding depths in like deposits and unaccompanied by other relics to assist in their proper interpretation, may find ready acceptance as testimony of remote time and elementary culture status. The normal contents of a lowland village site, including implements and utensils of several kinds, may be plowed up by torrential waters, redeposited lower down, and covered deeply by other transported material without danger of leadDanger of Misin- ing to confusion on the part of expert observers, since
terpretation

the various relics included may tell the story of their neolithic origin plainly. But the rudely shaped contents of quarries and workshops occurring in like situation and in like manner plowed up and redeposited may result in serious error, especially if encoun- 
tered by incompetent enthusiasts searching for the old and the primitive and seeking evidence in support of favorite theories.

The pioneers in this perplexing field of investigation labored under numerous serious, though by them unrecognized, difficulties. They began with the assumption that the archeological conditions in America should repeat those of Europe; they began without actual knowledge of the cultural limitations and of the diversified handiwork of the recent aborigines of the region under investigation. They were unacquainted with the vital distinction to be drawn between real implements and the very abundant partially shaped refuse of implement making surrounding them on every hand; and because in Europe the ancient was rude, they adopted the idea that all in America that was rude was ancient. They were not versed in the geological formations and their numerous deceptive characteristics, and they sought in the Old World for explanations of phenomena which were much more readily explained by that which was near at hand.

It was a knowledge of these and other like misconceptions and misinterpretations which led the writer to assume a Reasons for Questioning Testimony questioning attitude toward all the evidence, expert and inexpert, brought for'ward by the earlier students of the subject of antiquity in Inerica, and especially of the testimony derived from accumulations left along the southern fringe of the ice sheets. When, at the instigation of Major Powell, the writer, then engaged in the geological survey of Colorado, and incidentally of the ancient cliff dwellings, took up the subject and began inquiries regarding evidences of the antiquity of man in America, the curator of prehistoric archeology in the U. S. National Museum was collecting rudely chipped stones by means of a widely distributed circular letter, largely mere shop rejects, which he classed and distributed as "paleolithic implements" at the rate of thousands per year; and a large collection of rude argillite objects, mostly of the shop-waster class, was exhibited in the Peabody $\mathrm{Mu}$ seum, Cambridge, labeled "Paleolithic implements."

Such was the status of the research and such the attitude of mind toward traces of antiquity in the early days that the Early Credulity as California evidence of Tertiary man and the reputed to Evidenees of finds of artifacts associated with bones of extinct ani-
Antiquity mals reported from several States were accepted without reservation, and even in recent years the astonishing announcements of Ameghino respecting his hypothesis of the origin of the human race in Argentina were welcomed with open arms by the antiquity-hungry world.

Fortunately, to-day conservatism in accepting crude and imperfectly verified observations prevails, and scientific methods are tak- 
ing their place in archeology as they have done in the older branches of research. Such of the earlier conclusions as are sound will doubtless in time be so fully supported by additional evidence as to force general recognition, while those which are wrong will die a lingering death, proportioned in duration directly to the amount of literature with which they have been bolstered up and to the continued personal support of their authors.

In a few localities, especially in the Ohio and Delaware Valleys, prolonged effort has been made to obtain evidence of Delaware valley a conclusive nature with respect to antiquity. The work at Trenton, N. J., has been more extensive than at any other station and the results have been presented to the scientific world in much detail. ${ }^{1}$ The river terraces at Trenton are composed largely of gravels accumulated at the period when the southern margin of the ice sheet was retreating to the northward in and beyond the Delaware Valley, some 10,000 or 20,000 years ago. At the points in and near Trenton where traces of man have been found, a section of these deposits shows generally a few feet of dark soil underlain by sand deposits of moderate thickness and beneath these accumulations of wind drift, while beneath again are the coarser gravels deposited by the glacial and postglacial torrents. Finds of relics in the superficial deposits, the soil and sands, appear to have little positive chronological value, since the age must always remain in a measure uncertain; they may as a whole be passed over, therefore, as probably representing the occupation of the valley by the Indian tribes. It should be noted that the site of Trenton was, doubtless, a common resort of the Indians for a long period, for hunting, fishing, dwelling, and especially for the manufacture of implements from the argillite and other water-worn stones of the outcropping gravel deposits. Relics of various classes, and especially the refuse of manufacture, were thus scattered over the surface and buried to various depths in the superficial formations by sand drift and wash at all periods subsequent to the confinement of the river to its present channel. They were also subject to introduction into these deposits by excavations such as occur in all thickly populated districts-excavations, canals, foundations for buildings, cellars, graves, cisterns, wells, and the like. Objects of art assigned to the gravels proper and obtained by competent observers from depths not usually penetrated by excavations are limited in number. A tubular fragment of bone regarded as part of a human femur and said to show traces of human handiwork was found at a depth of 21 feet beneath the surface. Other finds of relics, attributed to the gravels proper, have been adequately characterized by the present writer. ${ }^{2}$ Speaking of

\footnotetext{
${ }^{1}$ Abbott, The Stone Age in New Jersey, p. 247. Volk, The Archacology of the Delaware Valley.

2 Holmes, Are there Traces of Glacial Man in the Trenton Gravels? Primitive Man in the Delaware Valley.
} 
the Trenton gravels and relics ascribed to them, Professor McGee employs the following language:

(1) The deposits in which they (the relics) were found are either late aqueoglacial accumulations or later accumulations produced by winds or storms; while the depth at which most of the relics were found was so limited as to be within reach of surface disturbance. One of the relics, however, is of special significance because found at a considerable depth in apparently undisturbed deposits of later Glacial Age. This is a bone, apparently a human femur, which, although so far decomposed as to render the determination in some degree doubtful, appears to have been cut squarely across at one end, sharpened at the other end, and perforated about mid length. The whole appearance of the object suggests that it was artifically shaped for use as a handle for some sort of cutting implement, or for attachment to the shaft as a harpoon head or javelin point. The object is specially noteworthy as affording the most decisive bit of evidence of high human antiquity in America thus far recorded. (2) On the whole the question of the antiquity of man in America must be regarded as far from settlement. So far as occurrences of human relics in geologic deposits of known age are concerned, the evidence of high human antiquity seems less decisive now than a quarter century ago, chiefly by reason of the more critical weighing of details with increasing knowledge. ${ }^{1}$

The alleged evidence of a succession of periods of occupation and attendant progressive stages in culture in the Delaware Valley may be more readily and logically accounted for by reference to the known occupancy of the valley by the Indian tribes. It is claimed that the earlier deposits of the locality in places contain simpler forms of artifacts than do the more superficial, but this alone does not warrant the conclusion that the culture was decidedly lower, that distinct peoples were involved, or that the period was remote. A site may have been occupied at a comparatively early period by implement makers of Algonquian or other stock, who left the refuse of their operations upon the surface to be covered by deposits of soil and wind-blown sand, and later the same site may have been the resort of simple fishermen and hunters, and still later the dwelling place of well-advanced communities of the same or other people. The successive layers would thus show apparent advance in culture as well as lapse of time, yet the culture of the people as a whole may not have advanced in the least and the elapsed time may have been centuries rather than millenniums.

The fact that argillite was used exclusively or rarely on certain sites in earlier times can have little significance in its bearing upon problems of age, culture, or people. The most convenient and plentiful local materials would be used first by the occupants in any region, and argillite is the most tractable and readily acquired workable stone of the region. Afterwards through exploitation of resources and intercourse with neighboring peoples the materials used would multiply and the things made would have a wider range. Mercer, who conducted exhaustive examinations of the quarries and 
implement shops as well as of the dwelling sites of the Delaware Valley, has shown in the most satisfactory manner a principal source of the argillite, the processes employed in shaping it, and the various forms produced. He has shown beyond dispute that the well-identified Indian tribes of the valley employed argillite and produced every known form of argillite artifact. Having described his researches in the vicinity of Trenton, this author concludes with the following paragraphs:

We had learned that Lenni Lenape Indians had worked the Gaddis' Run quarry, probably as late as the year 1700 , for the purpose of making ovate blanks of argillite desirable "turtlebacks" that would work down into the broad, thin forms called "cache blades," and that in the process mamy undcsirable "turtlebacks" or wasters different in type from the characteristic Trenton specimens were produced, which, since they would not thin down into cache blades, were cast into the rubbish heap by the quarrymen.

That the same Indians had worked the riverside trimming-shop, carried thither quarry "turtlebacks" for thinning, and at the same time made riverside "turtlebacks" resembling the a verage Trenton specimens in form, on the riverside, from surface material, and for the same purpose of thinning down.

That the same Indians had occupied the upper layer of the village site at Lower Black's Edly, worked its trimming-shop, and again scattered the site with riverside "turtlebacks" made on the spot.

That another tribe of Indians, or band of the same tribe, who had probably not worked the quary, hat at a long or short time previously occupied the lower layer of the village site, where they had still strewn the ground with riverside "turtlebacks" resembling the usual Trenton forms. . . .

Thus to examine the main outcrop of argillite in the Delaware Valley was to concentrate attention upon a spot where successive argillite-using inhabitants of the region, presumably resorting to the neighborhood for blacle material, should have left traces of themselves had they existed. But the remains found were, after all, scanty. All referred to the Indian. No token of an antecedent race was discovered, either on the exposed native rock, upon the hills above, or on the beaches below.

Nor has anything yet been found anywhere else in the valley to corroborate the alleged antiquity of the chipped blades from Trenton, while, as remarked before, the Trenton case has been somewhat weakened by the appearance among the exhibited list of Drift specimens in the Peabody Museum of several blades of common Indian pattern and of certain "turtlebacks," which, judged by form, appear to have been made by Indians at the Gaddis' Run quarries. More than ever the question of Glacial man has been narrowed down to evidence produced at one site, and to a question of the correctness of observation of individuals. ${ }^{1}$

There can be no question that men have dwelt in the Delaware Valley as elsewhere in America for many centuries or even thousands of years, possibly as far back as the closing stages of the glacial perior in the northern Inited States, but the evidence thus far furnished as proof of the glacial or immediately postglacial occupancy is by no means conclusive. As to the question of a distinctive ele-

1 Mercer, Researches upon the Antiquity of Man in the Delaware Valley and the Eastern United states, pp. 84-85. 
mentary culture stage corresponding to the European paleolithic, there appears in the light of what is now known regarding the origin of rudely chipped stones generally, no good reason why it should even have been seriously raised in the Delaware Valley, or, for that matter, elsewhere in America.

In digging a well in the village of Gaines, Orleans County, N. Y., about 1858 David Tomlinson discovered what he beThe Lake Ontario Hearth

lieved to be a prehistoric hearth, and in 1886, Prof. G. K. Gilbert visited the locality for the purpose of verifying the report and determining the precise geological relations. The well was dug on the site of a spring which had dried up and at the depth of 15 to 18 feet the hearth was uncorered.

It consisted of three bowlders about one foot in diameter, lying close together in the form of a triangle, and surrounded by ashes and fragments of charcoal. Between the stones and pointing toward the central area lay sticks from one to three inches in diameter; the inner ends were charred, the outer not. Above the stones lay other branching sticks which were not charred. ${ }^{1}$

Professor Gilbert remarks further that the statement of Mr. Tomlinson needs no confirmation as to credibility other than that which pertains to all narrations from memory of events long past. The terrace on which the Tomlinson house stands, which is about 175 feet above the present level of Lake Ontario, was formed during the long p,eriod in which the lakes were held between the jce front on the north and the southern rim of the basin. When finally the basin was freed from ice, the lake outflowed via the Mohawk Valley, and the terrace in question was formed.

The local relations, taken in connection with the phenomena of the shore line as elsewhere observed, indicate that the hearth was made not long [geologi(ally speaking] after the establishment of the Mohawk outlet and during its continuance. It belongs therefore to the period of the decline of the glacial climate. If, with Prof. Chamberlin and others, we recognize two epochs of glacial climate in the district of the Great Lakes, then the date of the hearth belongs to the waning phase of the later and briefer epoch. ${ }^{2}$

It is difficult to determine just what value should be given to this evidence, and it need only be noted that the Gaines terrace was formed subsequent to the retreat of the ice from the Ontario Basin and necessarily far subsequent to the formation of the terraces of the Delaware Valley - a possible difference in time of thousands of years.

It would appear from the generally accepted estimate of such other reported traces of geologically ancient man on the Atlantic slope that they are not of sufficient importance to require extended notice.

${ }^{1}$ Gilbert, The Geologic History of a Prehistoric Hearth Found in Western New York, p. 173 .

2 Ibid., p. 174.

$38657^{\circ}-19-$ Bull. 60 , pt $\mathrm{I} \longrightarrow 7$ 
The Ohio Valley has furnished much material for controversy, and there is still apparent ground for difference of

The Newcomerstown Find opinion regarding the chronologic value of the finds. Among the more noteworthy specimens is a chipped object obtained from a gravel deposit of glacial or postglacial age at Newcomerstown, Ohio, by W. C. Mills, at a depth of about 15 feet. ${ }^{1}$ Mr. Mills was at the time not an experienced observer of geological phenomena and probably had little idea that especial importance might ever attach to the specimen, and the question is naturally raised as to whether he actually found it in its original
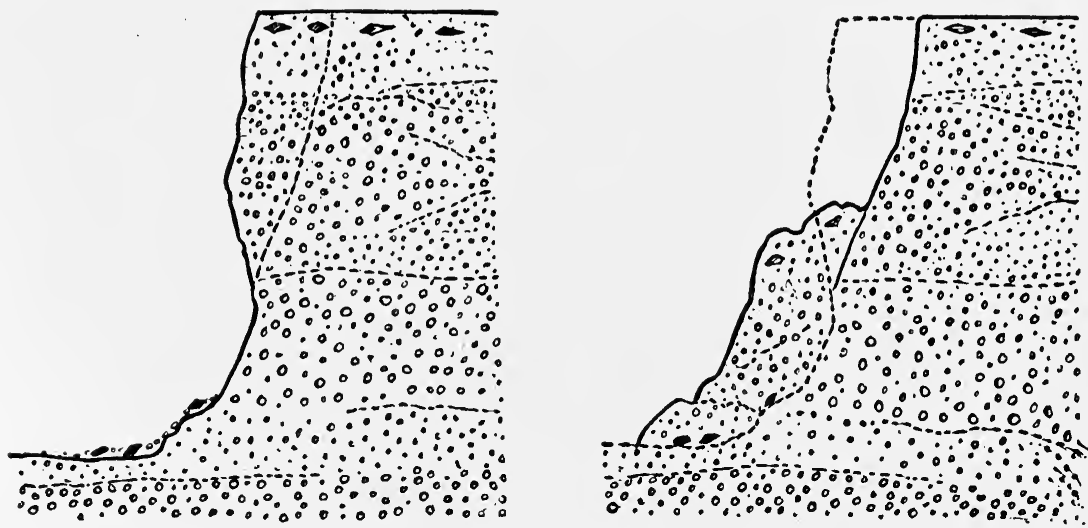

FIG. 35. Sections of gravel bank, Newcomerstown, Ohio, suggesting danger of misinterpretation of finds.

relation with the gravels at the depth noted. The treacherous nature of such formations as chronological depositories is well known, and the accompanying sketch (fig. 35) is intended to suggest the possibility of misinterpretation on the part of Mr. Mills. The excavations in the gravels made by the railroad workmen had left a vertical face some 20 feet high, and when the place was visited later by the writer large masses of the upper part had broken away and descended to different levels against the base without losing their original horizontal position. Arrowheads and splinters of flint which had fallen from the surface above were found at different levels in the slide gravels more or less firmly embedded, and the specimen obtained by Mr. Mills may similarly have descended without separation from its original bed at or near the surface to the depth of 15 feet. No trace of human handiwork of any kind was found by the writer in the entire undisturbed gravel face. ${ }^{2}$ It was observed, however, that numerous chipped flints rested on the upper surface and in the soil as if the site had been at one time occupied for dwelling or arrow-making purposes by the aborigines.

${ }^{1}$ Wright, Man and the Glacial Period, p. 251; Evidences of Glacial Man in Ohio.

2 Holmes, Traces of Glacial Man in Ohio. 
The riew that the specimen is of glacial provenance is supposed to be supported by its shape and surface appearance, these features strongly suggesting typical European paleoliths. It should be noted, however, with respect to these points that the specimen finds its
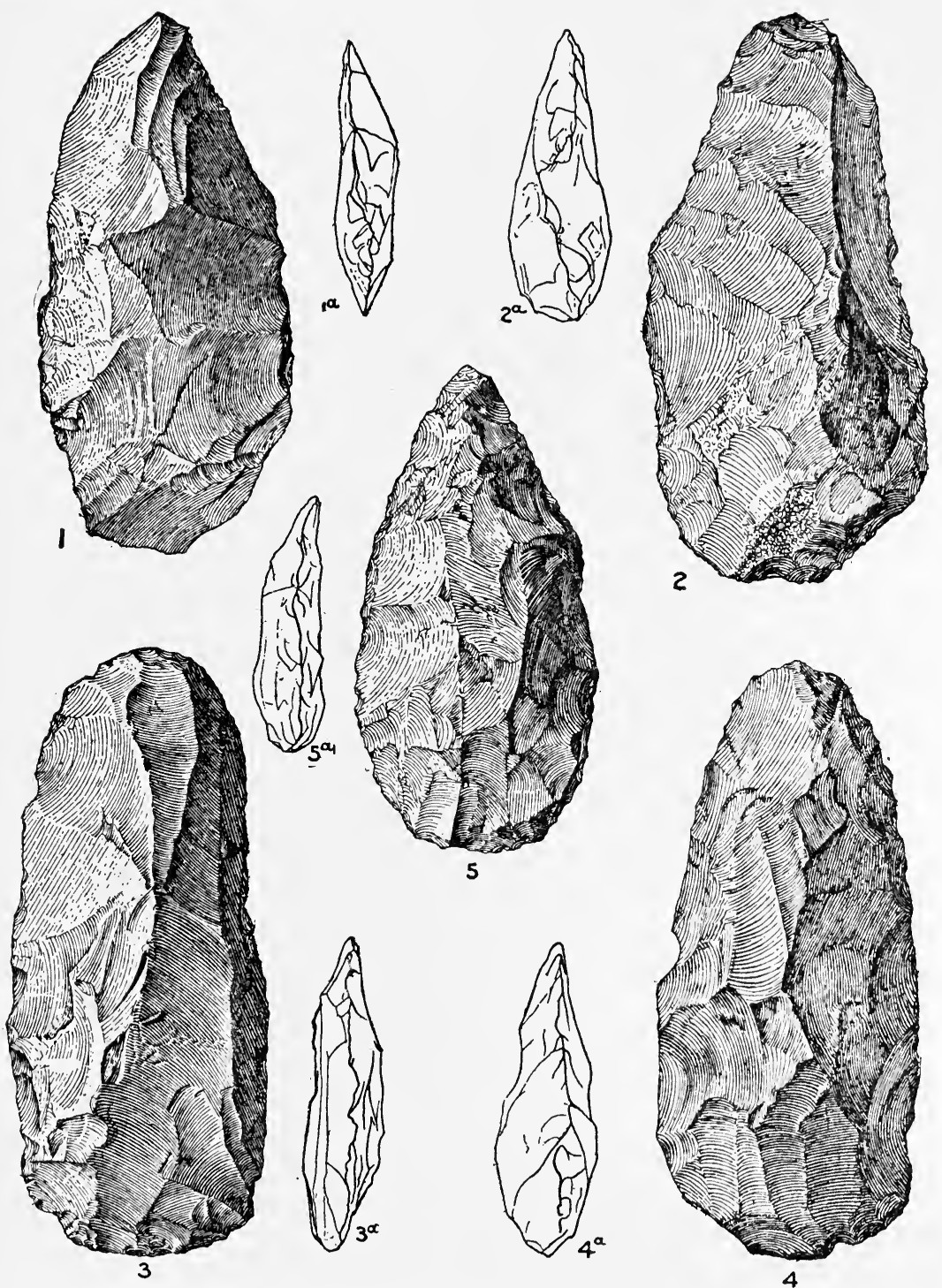

FIG.36. Supposed paleolithic implement from gravels at Newcomerstown (4), compared with rejects of blade making from shop sites $(1,2,3,5)$.

actual counterparts in the partially shaped wasters of blade making, numerous practically identical forms occurring in the flint workshops of the neighborhood. The very close analogy with shop wasters is made apparent by the drawings presented in figure 36 . 
In form the specimen is not specialized in any particular except in so far as all rejects of blade making show one heary and one somewhat tapering end, and it gives no indication of having been used; in these respects it is identical with the multitude of wasters in the blade-making shops throughout northern America. The exceptional surface polish often regarded as significant of antiquity is characteristic of some varieties of the material even when freshly chipped. Considering the above facts, it is not unreasonable that conclusions regarding the value of this specimen as evidence of antiquity and of paleolithic culture should be held in abeyance until something more trustworthy as to geological position and convincing as to characteristics of form is brought forward.
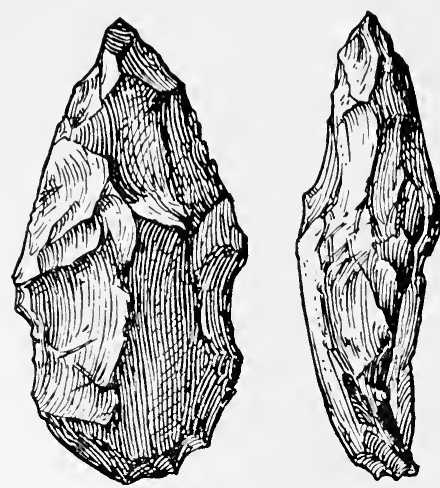

In digging a well at Madisonville, Ohio, a chipped stone was found resting on a glacial gravel surface beneath a deposit of red clay 8 feet thick. Another implement-like object was obtained from a deposit of coarse glacial débris in an excavation at Loveland, Ohio, at a depth of 20 feet (fig. 37 ). ${ }^{1}$ The present writer visited these localities in 1892 and examined the objects and sites with all possible care and in a subsequent publication raised such ques-

Fra. 37. Chipped blade from supposed tions as to the value of the evidence as glacial deposits at Loveland, Ohio. presented themselves. ${ }^{2}$ Mr. Frank Leverett, employed by the U. S. Geological Survey in the examination of the glacial formations of the Middle West, has given particular attention to these finds and concludes his study of the subject as follows:

When a question so important as that of the date of the appearance of man may depend upon the correct determination of the original position of a stone in such loose and poorly assorted gravel, it is well to withhold judgment until every line of evidence has been thoroughly worked out. As the evidence now stands, it is, in my opinion, not conclusively proven that man inhabited this portion of the Ohio valley during the glacial period. ${ }^{3}$

However, these two objects seem quite worthy of consideration as possible representatives of late glacial or early postglacial time to which the particular formations belong. The authenticity of the finds as reported may not well be questioned except on the ground that in a region in which the surface is strewn with kindred artifacts,

${ }^{1}$ Putnam, On a Collection of Palæolithic Implements. Wright, Ice Age in America, pp. 642-643.

2 Holmes, Traces of Glacial Man in Ohio, p. 147.

${ }^{3}$ Leverett, Supposed Glacial Man in Southwestern Ohio, p. 189. 
accidental associations with deep formations to which they do not pertain are likely to occur. That they represent a paleolithic culture rather than the universal neolithic of America is pure assumption. In type they agree with the rude implements and the workshop rejects of the Indian tribes.

Very interesting and important discoveries of stone implements were made in 1858 by Elmer E. Masterman at New Finds at New Lon- London, Huron County, Ohio. One of the objects
don, Ohio

was a grooved ax of greenstone encountered at a depth of 22 feet. The find has been made the subject of a special investigation and report by Prof. E. W. Claypole, a geologist of high standing, who accepted the statements of Masterman as correct in every respect.

$\mathrm{He}$ found the material penetrated by the well to be clay, becoming tougher downward and resembling the fine silt that settles from still water, and concludes that the ax was deposited there when the thin gravel bed in which it was found was formed, as it lay directly

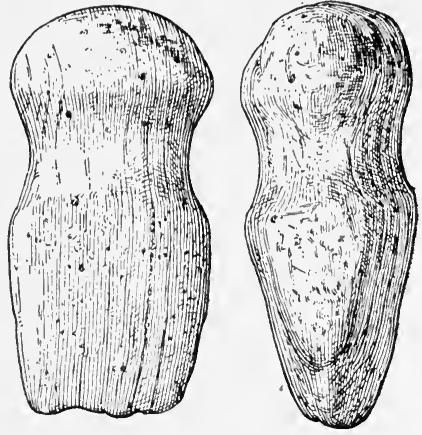

FIG. 38. Grooved ax from supposed glacial deposits, New London, Ohio. upon the bowlder clay. There is a slight suggestion of uncertainty as to the age represented in the following words: "If there is no other origin or date for the fine clay and streaks of sand that overlie it than that which assigns them to late glacial time, then the tool must be set down to the same epoch and must be considered the work of glacial man," " but subsequent statements by this author indicate full confidence in the chronologic assignment of the find.

The specimen is shown in figure 38 . It is worthy of note that several other specimens were obtained from the same formation as follows: A greenstone celt at a depth of 5 feet; a grooved ax of greenstone, at a depth of 7 feet; a chipped celt at a depth of 13 feet; a shovel-shaped specimen of slate roughly chipped around the edge at a depth of 5 feet; and a spearhead of red flint, at a depth of 7 feet. Professor Claypole, speaking of the specimens, remarks that-

The discovery of these implements in the Ohio valley, where an exclusively palaolithic regime from the close of the glacial period had become pretty firmly established, has served to open the question again and give support to the view that the rude chipper implements of so-called palaolithic type are here, as elsewhere, mere wasters of blade making by the Indian tribes. ${ }^{2}$ 


\section{The following statement will further represent his views:}

They are neolithic in pattern, whereas an opinion is somewhat prevalent that implements found in such circumstances should be of palæolithic type; at least such a conclusion may fairly be drawn from much that has been written on the subject. But this opinion can scarcely be well founded. In Europe, where later glacial, interglacial, and possibly preglacial relics of man are more or less recognized, the first mentioned are not palæolithic. This character belongs strictly to those of the second and third eras. All such are palæolithic and betray by their pattern an ancient origin. We should anticipate similar results here, and the facts above given are in accord with this view. These inplements bear every trace of comparatively recent date, and they occur mixed in the clay and gravel deposits of the melting ice-sheet. The evidence of their entombment proves that they belong to the closing years of the glacial era-at the least their inclusion in their present matrix is of that date.

Professor Claypole adds that it is at present far from certain that paleolithic man ever reached this continent at all, although he allows that doubt rests at present on merely negative evidence. He states further that-

On this side of the Atlantic the ice-sheet thus far has proved a barrier beyond which human footprints have not been found. Glacial man, and still more, interglacial man, is therefore here a shadowy, semi-mythical being of whose existence the anthropologist feels at best very uncertain.

It is true that not a few cases have been brought forward in which human relics have been found in such association with glacial deposits as to point strongly to the conclusion that both were of the same age. But in all these cases the deposits in question belong to the very latest stages of the Glacial era and were the work of the retreating ice or even of the torrents that flowed from it after the area in which the remains were found had been left bare. Consequently, if every one of these cases was logically unassailable, and its evidence positively conclusive, the only inference would be that man was a denizen of North America during the final withdrawal of the ice, that he hung Esquimaux-like on its borders and followed it as it withdrew to the northward.

Of any earlier date than this, therefore, for man in North America we have no evidence whatever, and even this has been regarded with skepticism and its value denied by men of eminence in the field of archæology. Such skepticism is wise and justifiable so long as it can be logically maintained. So important a conclusion demands support much stronger than that which would amply establish many less momentous propositions. ${ }^{2}$

At Little Falls, Minn., flood-plain deposits of sand and gravel are found to contain many artificial objects of quartz. Finds at Little This flood plain is believed by some to have been
Falls, Minn. formed and finally abandoned by the Mississippi at about the close of the glacial period in the valleys, but the question of exact age is still an open one, and to just what extent eolian deposits enter into its composition is not readily deter-

1 Claypole, Human Relics in the Drift of Ohio, p. 313.

2 Ibid., pp. 302-303. 
mined. In 1870 Miss Babbitt discorered superficial deposits of chipped quartzes at a certain level in the bluff face above the falls and without undertaking excavations reached the conclusion that they belonged to an outcropping stratum, which extended at the particular level throughout the valley. ${ }^{1}$ In 1892 the writer undertook limited excavations on the site; finding only superficial traces of objects of artificial origin, he reached the conclusion that no definite stratum containing these objects existed; that, although largely artificial, they were not implements but refuse of arrow making (fig. $39)$, the quartz used having been derived from outcropping veins in the river bank near $b^{2}{ }^{2}$ Later, more extensive excarations by Brower revealed the fact that the chipped objects were actually included in the terrace deposits at various points near the river bank. ${ }^{3}$ The initial examinations are a noteworthy case of imperfect and insufficient observation of data bearing on an obscure and difficult problem and of the futility of drawing conclusions of the broadest kind from limited resources of well ascertained fact. In this faulty work the writer had his share. It is important now that the problems be clearly stated, that the whole range of geologic and cultural phenomena be fully studied, and conclusions drawn free from the warping influence of preconceived views. The problems relate (1) to the real character of the quartz relics as products of human handiwork; (2) to the nature of their association with the flood-plain deposits; and (3) to the origin and age of the deposits in which the artifacts are embedded.

That observations of the phenomena of the site are not yet sufficiently thorough to enable students to reach harmonious conclusions is apparent, and it is the part of wisdom to regard such conclusions as may be reached as tentative and subject to revision as the problems are more critically considered.

It is observed that veins of white quartz outcrop along the river bank above the falls and that this material was probLittle Falls ably quarried or gathered and worked up at various
Quartzes Quartzes points along the margin of the terrace. It is reasonable to suppose that the torrents which swept from the river banks across the flood plain carried mainly, if not wholly, the refuse of manufacture - the fragments, chips, and partially shaped implements. The character of the finds bears out this interpretation. These relics correspond entirely with the rejectage of arrow making from quartz rock found on the sites of Indian occupation throughont the country. They do not appear to include any particular type of

${ }^{1}$ Babbitt, Vestiges of Glacial Man in Minnesota, p. 594.

${ }^{2}$ IIolmes, Vestiges of Early Man in Minnesota, p. 219.

${ }^{3}$ Brower, Kakabikansing. 
finished implement and as interpreted by the writer, whose experience in this field is wide, have no good claim to be classed as imple-

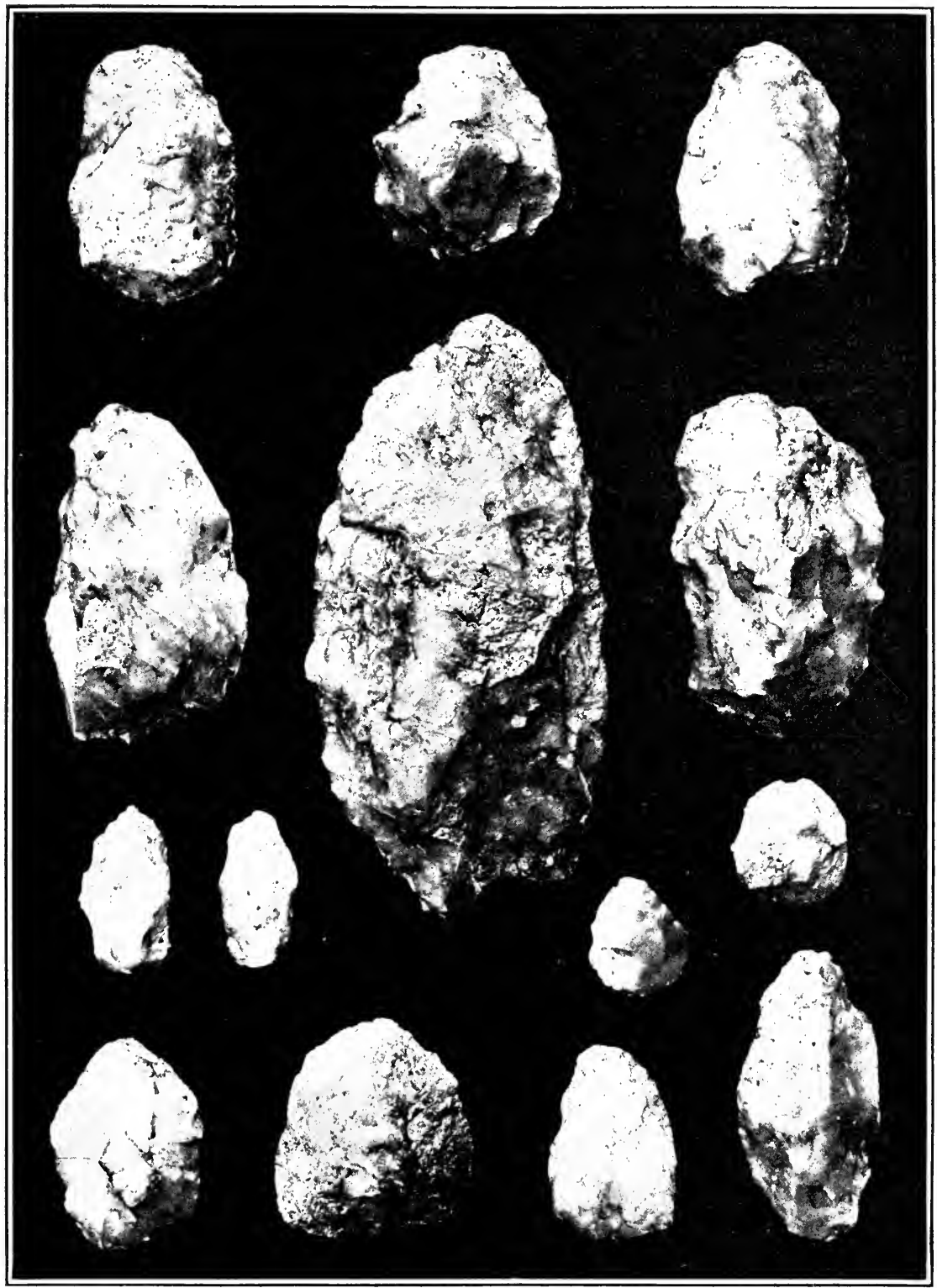

FIG. 39. Objects of chipped quartz from sand and gravel deposits at Little Falls, Minn. Probably rejectage of arrowhead making.

ments and not the least claim to be referred to as paleolithic any more than all rudely worked stones of whatsoever people or age may have such a claim. 
As indicated by the various observations, the association of the quartzes with the flood-plain deposits is that of irregular scattering such as would result from carrying and dropping by successive sandand gravel-carrying floods or by freshet-borne ice.

The period or periods represented are necessarily subsequent to the occupation of the river banks at the points of the quartz-bearing outcrop as quarry and shop sites. This time is likely to have been very long subsequent to the retreat of the ice from the immediate locality. It is hardly reasonable to suppose that it was during the immediate presence of the ice. The discriminations of Professor Chamberlin on this point in reviewing the work of Mr. Brower are worthy of the closest consideration by students of the subject. They are in part as follows:

The descriptions of Mr. Brower are apparently careful and candid, so far as intention goes, but they are obviously not those of a critical geological observer. They neglect most of the really discriminative factors and embrace much inconsequential matter. Notably also they have the trait, so common to the untrained worker, of incorporating interpretation unconsciously while insisting on "ascertained facts." "The glacial river" plays a notable part in the description of the formations, whereas the very thing to be demonstrated is the "glacial" or nonglacial character of the river at the time the formations in question were made. ...

It appears that there overspreads the plain once occupied by the Mississippi waters, but now above their reach, a surface layer of dirty pebbly sand of the typical structureless kind which usually covers abandoned flood plains of sand and gravel. This is about four feet thick and at places near the river contains many chips of white vein quartz of undoubted human origin. The source of the quartz is unquestionably the veins in the outcropping slate over which the falls are formed. This quartz-bearing slate does not now rise as high as the upper surface of the plain, and this fact has been urged by Holmes and IJershey as evidence that the quartz chippings were not taken from the parent ledge until the plain had been cut down to the requisite depth after its original completion. Mr. Brower, while not answering this objection by positive evilence, holds that the crest of the quartz-bearing ledge was exposed at seasons of low water, though covered at times of flood. It is of course probable that the crest of the ledge has been worn down where the river flows over it, but such erosive covering by the river does not fit in well with the view that this same portion was the source whence large quantities of vein quartz were quarried at the same time. It is clearly urging a bare possibility at best rather than a probable occurrence.

If, however, the case rested merely on the possibility of reaching the source of the quartz while yet the uppermost layers of the original plain were in the process of formation, it might be ungenerous to refuse to entertain the utmost possibilities of the case in favor of glacial man in America. But the facts of the case, taken just as given in this paper, do not seem to the reviewer to afford even a plausible ground for assigning the quartz chips to the glacial stage of the river. The surface deposit in which they are found, as described and illustrated in the paper, not only does not bear the characteristics of a glaciofluvial deposit, but bears quite clear evidence that it is not glacio-fluvial. The descriptions cite the fact that the surface deposit is highest near the bank of 
the present bottoms, after the common habit of existing legrading rivers. This habit is recognized and the facts are summarized in the following quotation (p. 73) : "At Little Falls, Minn., the eastern portion of the sandy plain on the east side of the Mississippi is several feet lower than the crest of the plain at the east end of the dam. That fact is important. After the great glacial river which overspread the entire plain at Little Falls had withdrawn into the narrower limits of an eroded stream bed, that river, often in freshet from the effects of the melting ice sheet, occasionally reoverflowed the entire plain, disturbing and overturning the sandy surface, mixing into its materials every chipped quartz blade or spall which had been placed by the hand of man upon the surface aljoining the newly eroded and narrower channel. The higher altitudes of the plain along the Mississippi between The Notch and the dam were caused by successive stages of recurring overflowage, creating additional surface deposits upon the plain nearest to the newly formed river bank." 'This is indeed "important," as the author himself naively remarks, since it shows, as the author also recognizes with equal unconsciousness of its real meaning, that it is the characteristic action of streams of the present nonglacial régime. It is here recognized, with undoubted correctness, that the quartzes were buried "by disturbing and overturning the sandy surface" and by "additional surface deposits." The reference of this, however, to glacial waters is wholly without evidence and quite against the probabilities. Glacial streams as a rule have the aggrading habit, and are not therefore "withdrawn into the narrower limits of an eroded stream bed," but on the contrary, are constantly shifting their courses from one point to another across their whole plain. Usually they sublivide into a complex plexus of numerous shallow shifting branches. There is, therefore, no reason whatever to suppose that the present channel of the Mississippi at Little Falls was in existence, even in its initial stages, while the river remained truly a glacial stream. The fact that the relic-bearing deposit is closely related to the present stream is evidenee that it was postglacial. The deposit that carries the relics supports the same view, for it bears the characteristics of a postglacial rather than a glacial formation. On the evidence submitted, therefore, in the paper the inference is rather imperative that the quartz chips were buried at some stage when postglacial rather than glacial conditions prevailed. . . .

Now, it seems clear from the evidence presented in the paper that the quartz chips were not spread over the plain while the clean stratified gravels were being formed, nor while the river was meandering over the plain in its transitional adjustment stage, nor in its general degradational stage, for at all of these stages, scour-and-fill should have incorporated the chins in the stratified sands and gravels. The chips were quite clearly introduced after the Mississippi had "withdrawn into the narrower limits of an eroded stream bed" and while only its flood stages overflowed the upper plain. ... As the recent cutting down of the channel has been slow on account of the slate barrier, a very considerable period has probably elapsed since the Mississippi last reached the upper plain even in its highest flood stages, except as these might be made exceptional by ice jams and similar obstructions. This gives the origin of the chips a respectable antiquity, but does not offer any presumption that it fell within the glacial period, or even very near its close. ${ }^{1}$

Considering this masterly analysis of the phenomena of postglacial river action, as applied to the Little Falls site, no other view

${ }^{1}$ Chamberlin, Review of "Kakabikansing," by J. V. Brower, pp. 794-798. 
seems reasonable than that while the inclosed artifacts correspond in age with the superficial terrace deposits, the period to which these pertain is quite imperfectly made out. To call them paleolithic because of their form is but to risk serious misinterpretation, since they appear to be nothing more than the shop refuse of the Indian arrow maker.

Cave explorations throughout America have been unfortunately limited in extent, considering the vast number known Cave Explorations to be awaiting the pick of the archeologist and geologist. It is to the caves that the archeologist naturally looks for traces of the presence of tribes of the earliest times, for these were the ready-made dwellings of primitive man; yet, in the habitable caverns throughout northern America and especially in the middle region of the United States, of which there are thousands, thus far little has been found that may not be attributed to the Indian tribes of comparatively recent times. It is this remarkable fact, together with others of similar import, which give countenance to the attitude of caution assumed by the writer and others in regard to the so-called evidence of man of geological antiquity in America. Prof. N. S. Shaler, who, as State Geologist of Kentucky, had unexampled opportunities for the study of cave phenomena, makes the following very significant statement:

Noting the fact that primitive man had extensively resorted to the caverns of the old World and had left there extensive accumulations of bones, his own and those of species on which he fed, with many other evidences of his presence, I expected to find similar deposits in our caves and rocks. A good deal of fruitless work led me to the conviction that cave dwellers never existed in the Appalachian district in the way they did in northern Europe.

In 1869 I made extensive excavations at Big Bone Lick in Kentucky, partly with the hope of finding human remains mingled with the [Ohio Valley Caves] abundant bones of extinct mammalia which occur in the deposits of mud at that point. Here again I gathered only negative evidences which went to show that primitive man never hunted the elephant, the mastodon, the Ovibos and other large animals which frequented this region about the time of the glacial period, probably when the ice lay over the region north of the Ohio. As this field would have been an excellent hunting ground for early man, as it was for their successors, the red Indians, and the frontiersmen, it seemed to me strange that I could not find a single trace of man below the level occupied by the living bison which evidently comes to this district in modern days. In this superficial layer made up mainly of bison bones, I found a number of arrow or spear heads. It also seemed to me important to trace the remains of the "mound builders" or early American Indians backward or downward to see if they graduated into those left by yet earlier varieties of man; with this idea in mind I searched the banks of the Ohio and its tributaries for a distance of a hundred miles or more to see if the sections of its alluvium might show human or art remains of another kind than those derived from the known indigenes of this country. This work also proved 
substantially fruitless. Traces of savage man appeared at many points but they were all superficial; in the deeper parts of the sections I found nothing which could fairly create a suspicion that a really ancient member of the species had dwelt in this valley. Whenever I could establish anything like time ratios they seemed to show that man had not been at work in this part of the country for more than one or two thousand years. . . . The only positive conclusion which I attained was to the effect that man had never taken to our caves or hunted our larger herbivora in the way he did in Europe, and if he occupied this part of the continent in the time when he was settled in the Old World his habits were peculiar. ... I undertook in a more general way to search for such evidence in the New England district. Here too I failed to ascertain anything which could be reckoned as proof that man had been on the ground for two thousand years; in fact I have seen nothing which raised a presumption of his presence for half that time in the region north of New York. ${ }^{1}$

The conclusions of Shaler are supported by the explorations of Mercer, who, well qualified by experience and acting under the advice of Professor Cope, made a reconnaissance of the caverns of the Ohio Valley:

We followed the New River into the Kanawha, the Kanawha through its deep gorge into the Ohio, and the Ohio nearly to its mouth in the Mississippi, examining all the caves and rock shelters by the way.

The time has not come to describe in full or fairly estimate the evidence thus collected. Suffice it here to say that as compared with prehistoric Europe everything was modern, that while in Europe you have many cave layers, here we found but one, namely, that representing the North American Indian, and, finally, that while in Europe human relics in the cave layers evidently reach back into geologically ancient times because of their association with the bones of extinct animals, here, with two exceptions, the bones of animals, cooked and eaten by the cave visitors, were modern. In other words, we had failed thus far to find any evidence of a race of mound builders antedating the Indian or any trace of the so-called Paleolithic man, who, if he existed in the eastern United States, had, strange to say, avoided these caves, which had not only given shelter to the red man, but, as bits of glass, buttons, and leather on the surface abunclantly showed, had continually tempted the ingress of the white $\operatorname{man}^{2}$

The results of cavern exploration, even though negative, must have very considerable weight in dealing with the important question of the settlement of America. Cope, a paleontologist of the highest standing, favored the view that man had probably occupied the western world at periods corresponding to the occupation of the Old World, but his excavations in the Port Kennedy cave and others, which produced the remains of many extinct species of animals of Pleistocene age, brought to light no trace of man.

Mercer's explorations of the caverns of the eastern United States have strengthened the already formidable negative evidence against

1 Shaler, Man and the Glacial Period (Antiquity of Man in Eastern North America). pp. 180-181.

Mercer, Jasper and Stalagmite Quarried by Indians in the Wyandotte Cave, pp. $397-398$. 
geological antiquity. Referring to his work in the Port Kennedy cave, Bucks County, Pa., Mercer writes as follows:

Six months' work, leaving the chasm incompletely excavated, had failed to reveal traces of humanity in the deposit. If man had [PortKennedyCave, existed at the period, we might have expected, not unreaPennsylvania]

sonably, that the waters which gathered together and poured into this tomb so many living creatures had seized him also, and that at some unexperted monent our discovery of a fragment of his skeieton, a handmade implement of bone, a potsherd, or a chip of jasper would have settled the much-vexed question of his presence in pleistocene America. But no such sign appeared, and this fact is negative evidence of weight. . . . Nevertheless, though our labor had thus no direct bearing upon anthropology, Port Kennedy must retain a strong indirect interest for the student of primitive humanity in the New World. As if preserved in a bottle the remains of so many bears, cats, herbivores, rodents, and reptiles of extinct race help to illustrate the conditions of the geological time immediately preceding the present and known as the pleistocene, the period when early man is known to have existed in Europe and in which he has been alleged to have existed in America. ${ }^{1}$

The results of Mercer's exploration of the caverns of Tennessee confirm the eridence obtained from the carerns of other sections, that the Indian tribes were the sole prehistoric occupants.

The fossil sloth bones found in Big Bone Cave, Tenn., illustrate an investigation at one of the points of contact between paleontology [Big Bone Cave, and archrology. They explain an effort made during the Tennessee]

last several years by the Department of Archæology and Paleontology of the University of Pennsylvania to settle the question of man's antiquity in North America through a study of the association of human with animal remains in caves. Turning away, for a time, from mounds, village sites, and buried cities, we have sought the help of the naturalist in a systematic attempt to penetrate the crust of recent earth under foot, to trace man through a mixture of the familiar vestiges of such animals as the deer, the bison, the bear, the beaver, the muskrat, and the wolf, still existing in the American forest, and to follow him down into that older world layer next below called the Pleistocene. There we have endeavored to find, if possible, his bones still associated with the remains of the extinct mastodon, the mammoth, the tapir, the giant beaver, and the fossil sloth. ${ }^{2}$

Peabody's explorations in a cave at Cavetown, Md., were equally unproductive of traces of early man, ${ }^{3}$ and long-continued work in a rock crevice near Cumberland, Md., by representatives of the National Museum, though fruitful in finds of fossil mammals, yielded no trace of man. Explorations in the caves of the Ozark region, Arkansas, by Peabody and of the Wyandotte cave in Indiana by Fowke were equally barren of results. It is true that Baird reported

${ }^{1}$ Mercer, The Bone Cave at Port Kennedy, Pennsylvania, and Its Partial Excavation in 1894,1895 , and 1896 , p. 285.

2 Mercer, The Finding of the Remains of the Fossil Sloth at Big Bone Cave, Tennessee, in 1896, pp. 36-37.

${ }^{3}$ Peabody, The Exploration of Bushey Cavern, near Cavetown, Maryland, p. 5. 
the discovery of remains of man associated with fossil animals in a cave on the Susquehanna, near Carlisle, $\mathrm{Pa} .{ }^{1}{ }^{1}$ and Leidy made similar observations in caves near Easton, Pa., ${ }^{2}$ but no assurance is given in either case that the association was such as to lead to the belief that the human and animal remains were of the same period. Like results have followed Mercer's explorations of the Durham cave, Bucks County, Pa., ${ }^{3}$ where ample evidence of occupancy by the Indian tribes was obtained, but no trace of an earlier or distinct tenancy.

Researches in the caves of California, entered upon with the view of determining as far as possible the value of the remarkable evidences previously obtained from the gold-bearing gravels of that region, have led to no very decisive results, although much

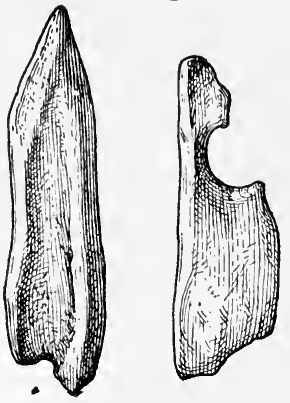

FIG. 40. Implement-like bits of bone from a California cave. more may be in store for the future explorer. Reviewing the work accomplished in the Shasta caves previous to the year 1906, Merriam states that-

The character of the pointed and polished bones figured by Dr. Sinclair in his paper is also difficult to determine with certainty [fig. 40]. These polished fragments strongly resemble many of the roughest implements found in the deposits of the shell-mounds of the Pacific coast. Possibly they have been rough bone splinters, used by man until they attained the degree of polish which we find upon them. On the other hand, it is noted that in nearly all shell-mound fragments the polish is mainly upon the pointed portion of the implement, while the portions not used for active work may be almost without smoothing or polish. In the specimens from the caves the polish is almost perfectly even over the whole surface in every case. The evenness of this polish seems to indicate that, if these objects were used as implements, special pains must have been taken to polish those portions which would in the course of ordinary use be left rough. Such smoothing as we see here may perhaps be as readily explained by the action of water as by any other means, the fragments being rubbed on all sides and evenly polished.

In other bone fragments, peculiar perforations and notches have been noted which are not easily explained by the operation of natural processes, but which could be accounted for by perforation through human agency. Of all the evidence which has been advanced in favor of the influence of man in the production of implement-like objects found in the Shasta cares, the evidence of perforation seems probably the strongest. A serious doubt must exist, however, as to whether the presence of only a few somewhat inclefinite perforations in a very small number out of several thousand of these fragments should be considered proof of the presence of man. Had a large percentage of the fragments been formed and used by man, evidence of a more definite character ought to be present in abundance.

${ }^{1}$ Baird, Bone Caves of Pennsylvania, p. 355.

${ }^{2}$ Leidy, Fossils in Caves of the Limestone Rocks of Pennsylvania, p. 3.

3 Mercer, Exploration of Durham Cave, Bucks County, Pennsylvania, p. 149. 
While it is probably true that as yet no unequivocal evidence of the agency of man in the fashioning of the bone fragments from this cave has been presented, in all fairness to those who may undertake from the study of such materials to give us something of the earliest history of the human race, we should not forget that, at the very period where the discrimination between artifacts and natural objects is most important, it becomes most difficult. In the early stages of the development of man, such implements as were used by him were probably in many cases simply special forms of natural objects which were, in their original form, weil adapted to meet his primitive needs. The earliest true artifacts were objects of this class showing only a little modification. ${ }^{1}$

Mercer searched the caves of Yucatan in vain for traces of early man $^{2}$ and others have not been more fortunate in

Yucatan Caves any part of the great Central American area in which the race has achieved its greatest cultural triumphs, and in which traces of early occupancy might reasonably be cxpected to exist.

The evidence obtained thus far from the caves of South America is not more decisive. The most important finds are Brazilian Caves those of Lund in the caves of Brazil, but Hrdlička has shown that eren this evidence, although accepted by some authorities, is not worthy of full confidence. ${ }^{3}$ His view of the evidence is expressed briefly as follows:

In view of all the above facts and considerations, it seems quite evident that the human remains from the Lagoa Santa caves ean not be accepted, without further and more conclusive proofs, as belonging to a race which lived contemporaneously with the extinct species of animals found in the same caves; and there is no reliable foundation in the remainder of the data relating to the specimens on which such geologic antiquity could be based. ${ }^{4}$

Nine categories of evidence have been mentioned as arailable to the chronologist of the race, but of these the geo-

Summary logical category alone can be expected to supply an adequate chronology of man in America. So far, however, the expectation is far from realization, the research being beset by many perplexing difficulties. The superficial formations from which the evidence has been and must be derived are treacherous custodians of the records intrusted to their keeping. The waters uncover, transport, intermingle, and redeposit the traces of man's presence; ice scores deeply into the surface, likewise destroying the normal sequence; the winds sweep the sands into deceptive semblance of stratification, burying and uncovering and burying again the relics of all periods, imposing thus on the unwary student false and confusing chronologies; gravity with persistent activity carries down

${ }^{1}$ Merriam, Recent Cave Exploration in California, pp. 224-225.

2 IIercer, The Ilili Caves of Yucatan.

${ }^{3}$ IIrdlička, Early Man in South America, p. 153.

4 Ibid., p. 184. 
and ever down, rearranging in utmost disorder; forests are uprooted, dragging up the deeply buried records and letting down the superficial into their place; and man and beast are ever at work digging and boring and preparing the ground for abundant crops of misleading observations and erroneous interpretations. It was a knowledge of these conditions that led the writer at an early date to appreciate the danger of hasty determinations respecting antiquity, based on random and unskilled observations, and to realize at the same time the futility of attempts to determine the culture status of the people merely by the form of the few random artifacts recovered. He insisted on the closest scrutiny of all discoveries supposed to bear on the problems of chronology. His restrictions, however, were regarded by some as ill-advised and as tending to embarrass or to endanger the acceptance of legitimate conclusions. The sequel seems, however, to justify the questioning attitude, since to-day, after 30 or 40 years of persistent research, a large part of the testimony adranced in support of geological antiquity is discredited and the remainder awaits a fate to be determined only by additional research. The writer has no fear that the truth can be obscured by any amount of adverse inquiry, for, if men occupied the continent at or before the final glacial retreat, the evidence of this occupancy exists and in time must be found in convincing abundance. Thus far the testimony brought forward is scattering, disconnected, and contradictory, and tells no consistent story, the manner of occurrence of the various finds being such as might be expected to result from intrusion rather than from original inclusion in the formations with which they were found associated.

The Vero, Florida, finds, brought to light since the present work was written, have been fully discussed in Bulletin 66 of the Bureau of American Ethnology. It does not appear that the evidence as published requires any modification of the above conclusions.

Considering the evidence in all its phases, it can not be allowed that the Tertiary, or even the Pleistocene, occupancy of the American Continent by the race is demonstrated, and the writer prefers to favor the view, already fully expressed, that the continent was probably not reached and occupied until after the final retreat of the glacial ice from middle North America. At the same time it must be granted that there is no apparent reason why, if already occupying northern Asia, man should not have reached American shores by way of Bering Strait during any of the periods of mild climate which preceded and interrupted the Ice Age; yet we may wisely a wait the results of further research and provide for the application to these of the severest tests that science can devise. 


\title{
IX. CULTURE CHARACTERIZATION AREAS
}

\begin{abstract}
S AN initial step in the description and interpretation of the antiquities of the continent, the archeologist observes the tribes of to-day, their cultural characteristics and environments, and acquaints himself with what is known of them historically. He finds that their achievements are greatly diversified and that certain forms and states of culture characterize particular geographical areas and realizes that environment has had a large share in determining the course of the culture evolution. He examines the antiquities and finds that analogous geographical distinctions characterize the material culture of the past and reaches the conclusion that the relations of environment to man and culture must play an important part in the prosecution of his researches and in the analysis of aboriginal history.
\end{abstract}

In the practical work of museum classification and arrangementa work which has served in part to give form to this writingarcheological materials are necessarily grouped primarily by continents and other natural divisions, and secondarily by political divisions, such as states and territories. Separation by the larger natural divisions is always necessary, but separation by ethnic areas, or areas of culture characterization, as they are sometimes called, is most advantageous. These areas may be large or small according to the understanding or the needs of the student. By their means he approximates the real or natural grouping of the material traces of human achierement and studies to advantage culture and culture relationships and the causes of the resemblances and differences everywhere met with. The geographical limitations of culture units are, as a matter of course, not usually well defined. Cultures are bound to overlap and blend along the borders and more especially along lines of ready communication. But notwithstanding this, certain characteristics of achievement or groups of culture traits within each area will be found to separate it from North American its neighbors and afford effective means of com-
Areas

parison with other culture groups. In the present work, keeping in view the archeological rather than the ethnological evidence, it is convenient to recognize 11 areas north of Mexico (fig. 41), namely: (1) The North Atlantic area; (2) the Georgia-Florida area ; (3) the Middle and Lower Mississippi Valley $38657^{\circ}-19-$ Bull. 60 , pt I -8 
area ; (4) the Upper Mississippi and Great Lakes area ; (5) the Great Plains and Rocky Mountain area; (6) the Arid area; (7) the California area; $(8)$ the Columbia-Fraser area ; $(9)$ the Northwest Coast area; (10) the Arctic Coast area; (11) the Great Northern-Interior

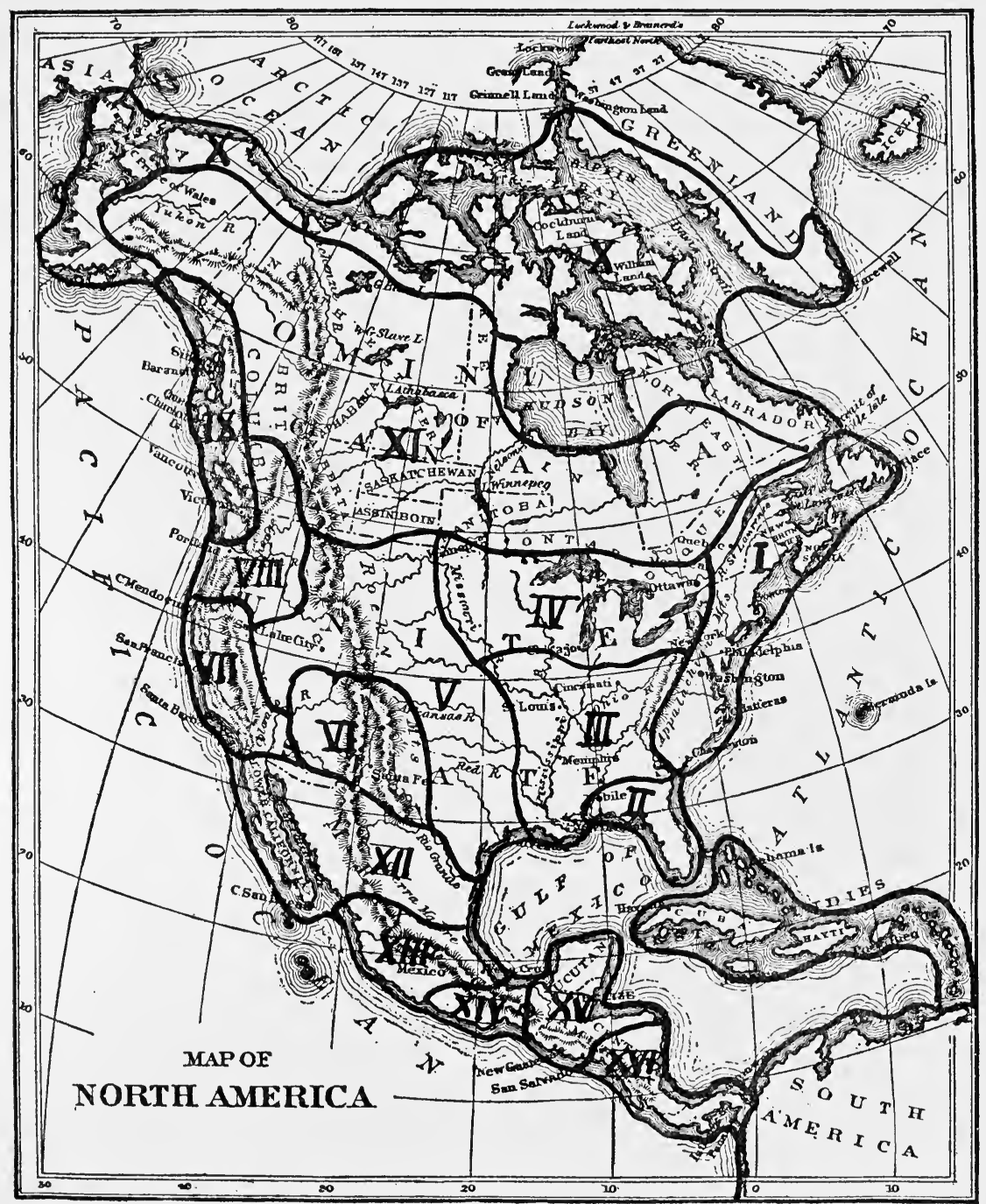

Fig. 41. Map of North America outlining tentative culture characterization areas.

area. These areas are here made as few and simple as possible to avoid too great complexity in conducting comparative studies of the several classes of antiquities.

The Middle and South American areas (fig. 42), also outlined on the broadest possible plan, are as follows: (12) The North Mexican; (13) the Middle Mexican; (14) the South Mexican; (15) the Maya- 
Quiché; (16) the Central American-Isthmian; (17) the North Andean-Pacific; (18) the Middle Andean-Pacific; (19) the South Andean-Pacific; (20) the Amazon Delta; (21) Primitive South America; (22) the West Indian or Antillean. Detailed study of the

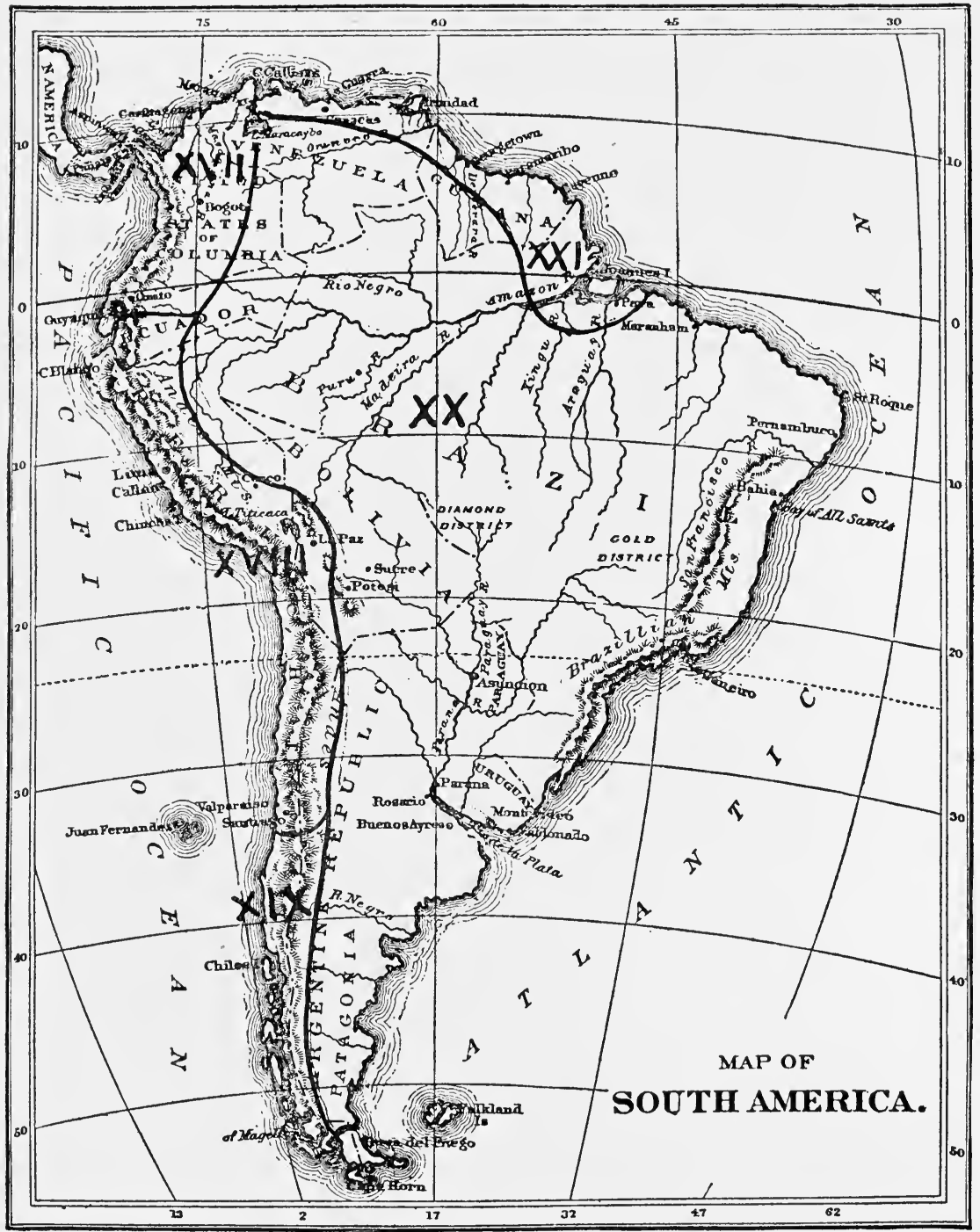

FIG. 42. Map of South A merica outlining tentative culture characterization areas.

antiquities and history of these vast regions might profit even in the initial stages of research work by further subdivision of the areas, but in the present restricted state of our knowledge this would not prove greatly advantageous, as it would prolong the summary review here contemplated without an equivalent in useful results. 
These areas in all cases are based on the more clearly manifested phases of their culture content. In some areas evidence has been reported of early cultures radically distinct from the type adopted as characteristic of the areas, and ancestral forms grading into the later and into the historic forms are thought to have been recognized. In these particular branches of the research; however, haste must be made slowly as the utmost acumen of the student is called for in making areal and chronological discriminations. It is anticipated, since the period of occupancy of the continent must have been of long duration, that not only early but more elementary cultures may in good time be identified within areas characterized by advanced cultures. Certainly the historic period furnishes many illustrations of the superposition of inferior over greatly superior advancement.

Within the region north of Mexico the culture of the most advanced communities rises high in the scale of barRange of Culture barian achievement-a status characterized by an artificial basis of subsistence, sedentary life, successful agriculture, and extensive town building, yet still far below the culture level of glyphic writing reached by the more advanced tribes of Middle America. Pictographic records carved on stone, engraved or painted on bark, and painted on surfaces of many kinds, were almost entirely pictorial or graphic, slight advance having been made in the use of purely conventional characters, except as separate symbols or as ornamental designs. The lowest stage ranges well down in savagery, where art in stone in its rudimentary forms had barely obtained a sure foothold, as with the Seri and other Lower Californians.

In Middle and especially in South America the culture contrasts are even greater, and nations standing upon the very threshold of civilization, with arts, industries, and institutions highly developed, are in close juxtaposition with utterly savage tribes to which even clothing and stable dwellings are practically unknown. With the exception of a limited group at the mouth of the Amazon, the more advanced cultures were confined to the west coast and the Andean plateaus, where forests are rare and deserts common, while the primitive status was and is yet found in places throughout the vast forest regions of the eastern slope of the Andes and the OrinocoAmazon region, in the broad pampas of Brazil, Paraguay, and Argentina, and on the entire Atlantic coastal border from Panama to Tierra del Fuego, excepting always the limited areas about the delta of the Amazon.

These differences in culture status appear to be due to a complex of causes not readily analyzed. Whatsoever the nature of the molding agencies, they have acted to diversify, differentiate, and individualize cultures in a most pronounced manner throughout the two Americas, 
and the results, as suggested by a study of the several areas, are among the most striking and scientifically important features of our aboriginal ethnology.

The following sketches do not assume to approximate complete presentation of the cultural remains of the several areas; they are merely intended to cultivate familiarity with the vast field as a whole and to lay out its great features tentatively as an aid in describing and comparing the antiquities and the cultures they represent. It is by no means assumed that the culture phenomena of any considerable area are uniform throughout. There may be much diversity, possibly great complexity of conditions. There may be a number of somewhat independent centers of development of nearly equal importance, or a single center may have spread its influence over a wide area. The mapping of the cultures will, in the end, take forms that can not now be foreseen. When all available relics of antiquity have been considered and their history and distribution recorded, discussion of the culture complex may be taken up to advantage, and, enforced by the somatic evidence and illumined by the researches of ethnology, may round out the history of man in America with gratifying fullness.

\section{The Northi Atrantic Area}

The North Atlantic characterization area, as outlined for present purposes, extends from Newfoundland and the St. Lawrence Valley on the north to Georgia on the south. It includes eastern Canada, New England, New York, Pennsylvania, Maryland, and large sections of Virginia, West Virginia, and the Carolinas. It is a region of splendid forests, rugged highlands, charming valleys, and a diversified coast line indented by many tidewater inlets. The aborigines, largely of the Algonquian, Iroquoian, and Siouan stocks, were primarily hunters and fishers, although Primitive Status agriculture was practiced successfully in many of the
of Culture

fertile valleys. The native culture of both colonial and precolonial times, so far as known, though varying with the widely distributed centers of habitation, was quite uniform in grade and general characteristics. It is well differentiated from that of the South and Middle West but passes with no abrupt change into that of the upper lakes and the great interior regions of the North. The changes from north to south were doubtless due in large measure to differences in food resources and the influence of neighboring cultures.

The use of stone in building was practically unknown, the dwellings being constructed of wattlework, bark, and mats, and stockades were relied upon for village defence. Burial mounds and other earthworks in the area are rare or insignificant in size, except where 
the influence of the Mississippi Valley culture was felt along the western border, but the shores are lined with shell heaps, many of great extent. Methods of burial were primitive and considerably varied, and the graves yield many examples of the simple artifacts employed by the people. Numerous caves and rock shelters were occupied for dwelling and burial.

The ceramic art was in a somewhat rudimentary stage, although considerable skill and taste were displayed by the Iroquois in the manufacture of culinary utensils and tobacco pipes of clay. The vessels are round bodied, often conical beneath, and adapted thus to earthen floors; they were decorated with incised lines forming simple geometric figures, with fabric or cord impressions, and many, among the Iroquois, with crude figures in relief. The tobacco pipes of this people are varied in form and elaborately embellished with modeled life forms. The Virginia clay pipe with long stem and upturned bowl, carried to England by the early colonists along with the first tobacco, gave form to the common clay pipe which prevails even to-day in the English-speaking world.

Of implements of pecked and polished stone, the grooved ax, celthatchet, chisel, pick, gouge-adz, mortar, pestle, slate knife, slate spearhead, and hammerstone are present in large numbers, and articles of faith and ornament include banner stones, bird-shaped stones, plummets, tubes, pierced gorgets, etc. Chipped implements of all ordinary types are well made and plentiful, as are also shell beads, pins, and pendent ornaments. The engraved conch-shell gorgets of Virginia and the Carolinas are of particular interest, but it is possible that these should be regarded as culture intrusions from the west.

The tribes of this region surpassed their neighbors in the manufacture of a few varieties of artifacts only; their gouge-adz takes first rank among implements of this general class. Within the area there are a number of local features of particular interest, some of which are due to the occurrence of mineral deposits of exceptional character, while others are due to ethnical conditions not at present fully determined. Maine has furnished a group of relics of exceptional character, most noteworthy of which are certain long, slender celts and gouge-adzes, and ground and polished lance heads, discovered and described by Willoughby and tentatively ascribed by him to some pre-Algonquian people. The occurrence of red oxides with the burials has led to the use of the designation "the red paint people." The resemblance of the lance heads to those of the Eskimo and even to those of northern Europe and Asia is noted. The occurrence in New England and the eastern Lakes region of examples of the ground spearhead and the broad-bladed slate knife, the woman's knife of the Arctic, is also worthy of remark. 
Deposits of soapstone occur throughout nearly all the States from Massachusetts to Georgia and were extensively worked by the aborigines for the manufacture of cooking utensils, tobacco pipes, and articles of ornament, and the stone pickaxes and chisels used in cutting out and shaping these articles constitute a unique feature in American archeology. Mica was mined extensively in Virginia and North Carolina, and quarries of argillite, jasper, and rhyolite are found in Pennsylvania, and of quartz and quartzite bowlder deposits in the District of Columbia. From the materials obtained in these quarries and from other widely distributed sources of supply vast numbers of chipped implements were made, as would be expected with a forest people devoted to war and the chase. It is stated that a single collector amassed, largely within the limits of a single county in South Carolina, 20 bushels of arrowheads. The coarse grain and refractory nature of most of the materials, however, rendered impossible the refined work which was produced in the areas to the west. Deposits or caches of large chipped blades, mostly of the narrow oblong type, have been found at many points throughout the area. The spear was not in general use on the arrival of the whites, the bow and arrow, the tomahawk (celt hatchet), and club being the principal weapons. Dugout canoes and canoes of bark were in use, and occasional examples of the former have been uncovered in recent years. Petroglyphs of primitive type are found in all sections. The most noted example is that of Dighton Rock, Massachusetts, which has greatly puzzled antiquaries and has been the subject of much controversy.

Relics of stone and bone, believed to have had their origin in glacial and early postglacial times, have been collected in the Delaware Valley and elsewhere, but geologists are not yet agreed as to the exact age of the formations with which most of the objects are said to be associated. These artifacts are not specifically different from those of the Indian tribes, and whether they represent an earlier and a distinct culture from that of the remains of the region generally seems to be an open question. The possibilities are that, howsoever ancient the older traces may be, they represent continuous occupancy of the area by the same or related tribal groups.

A few remnants of the original tribes (Algonquian and Iroquoian), mostly of mixed blood, still live within the more IIistorical Stocks easterly and southerly States, while a considerable body of the Iroquois remains in the valley of the

\section{St. Lawrence.}

That the tribes of this great region should have remained always in a state of culture so primitive while other areas witnessed advancement must be attributed in large part to the forest environment. In both physical and intellectual attributes they had few superiors on the continent. 
Explorations have been conducted in this area by numerous students, prominent among whom are Kain in New Brunswick; Boyle and Laidlaw in Canada; Willoughby, Putnam, Cushing, McGuire, and Moorehead in Maine; Putnam and Chase in Massachusetts; Perkins in Vermont; Haldeman, Mercer, Holmes, and Wren in Pennsylvania; Beauchamp, Parker, Harrington, Pepper, and Skinner in New York; Rau, Abbott, Volk, and Heye and Pepper in New Jersey; McGuire, Holmes, Fowke, Dinwiddie, Valentine, Kengla, Reynolds, and Proudfit in the District of Columbia and Virginia; Thomas, Heye, Holmes, and Bushnell in the Carolinas.

Early observers embodying in their works important data regarding the aborigines of the region are White of the Roanoke colony, Smith, Strachey, and Hariot of the Virginia colony; Burk, Beverley, Jefferson, Heckewelder, Kalm, Holm, Lawson, Adair, Bartram, and others.

\section{The Georgia-Florida Area}

This area includes the Florida peninsula and part of southern Georgia. The aboriginal occupants, so far as known historically, were mainly of the Muskhogean and Timucuan stocks, a remnant of the former only, the Seminole, remaining in the peninsula to-day; and since the antiquities show no radical diversity of characteristics they may safely be assigned, in large part, at least, to the ancestors of these groups. A colony of Cuban Arawak is said to have settled on the west coast of Florida in comparatively recent times, but no very distinctive traces of their presence have been observed. The early literature of the region, summarized by Brinton in Notes on the Floridian Peninsula, supplies many interesting details of the vanished peoples.

The antiquities of the area are somewhat distinctly set off from those of the North Atlantic area, but graduate almost imperceptibly into those of the Gulf States to the west and the great Mississippi Valley area to the northwest.

Shell heaps, many of remarkable extent, occur along the Atlantic and Gulf coasts, and on the banks of the larger rivers. Some of these remain as originally deposited, while others have been more or less remodeled for purposes of dwelling, observation, or defense by the aborigines, and have been subject to extensive disturbances and even to obliteration in cases by the present occupants of the region. Burial mounds, principally of earth and sand, are very numerous. The houses, built of poles and thatch, arranged often in circular village groups and surrounded by palisades, have left but meager traces. Communal houses mentioned by Cabeza de Vaca were so large that they "could contain more than 300 persons." The researches of Cushing demonstrated the fact that pile dwellings were in use along the Gulf coast, and also that canals and "water 
courts" were dug to accommodate the canoes of the villagers. Agriculture was practiced in favorable localities, as recorded by the early explorers.

Knowledge of the native culture is obtained largely through a study of the contents of the burial mounds and shell heaps, and more especially through a study of the earthenware, which is very plentiful and presents numerous features of interest. The forms of the ressels are often pleasing, and in the west life forms were modeled with considerable skill. The figured stamp or paddle was employed in decorating the surfaces in the east and north, while engraved and indented designs are most common in the west. Curvilinear designs and peculiarly conventionalized life forms prevail, and some of these are thought to suggest Middle American influence. The use of color was elementary. Owing to the meagerness of sculptural remains pottery takes the place in large measure of stone art as a means of determining the culture status of the people.

The remarkable finds of Cushing in an ancient village site on Key Marco, through the accidental inclusion of articles of Key Marco Culture wood, bone, and shell in deposits of muck in an old canal bed, give us a most instructive and interesting glimpse of the Gulf Coast culture of which otherwise we should have remained in almost total ignorance. The ceremonial masks, figurines, implements, and other carvings in wood, and the conventional and highly symbolic embellishments in color indicate a degree of artistic accomplishment not suggested by the few articles of stone and pottery found in the same connection or, for that matter, elsewhere in the south or west. That artistic development of such pronounced characteristics should be possible, practically without the aid of stone, is a matter of much interest to the student of culture history. It is probable that the culture was exotic in some measure. Implements of shell and sharks' teeth appear to have been a main reliance of the craftsmen of the keys.

Flint occurs in association with the extensive limestone formations of Georgia and northern-central Florida, and was utilized by the natives in the manufacture of chipped implements of all the usual varieties. Their abundance in Georgia is phenomenal. Varieties of stone usually employed in the manufacture of pecked-ground implements do not occur except in limited parts of the area, and implements of this type are comparatively rare, with the exception of the celt, which is found in large numbers in mounds and graves and on village sites; the grooved ax is of rare occurrence, a noteworthy circumstance since it is observed that this implement is abundant in the northern sections of most of the Gulf States and in intimate association with the celt. Moore's great collection of relics from the peninsular region includes hundreds of celts but not a single typical or fully specialized 
grooved ax. It is observed that while the celt is found in great numbers in the adjacent West Indies, the groored ax does not occur there, the ax of the islands being of a totally distinct type. It is further observed that the celts of the Florida region approximate more closely those of the West Indies than do those of any of the more northerly districts, suggesting intrusive influences from that direction. An examination of the material of which they are made may serve to throw needed light on their history and on the relationships of the people of the area with those of the West Indies.

Mortars and pestles of stone are of rare occurrence. Wood was in common use for these utensils, and examples of mortars and pestles, as well as dishes, stools, masks, and figurines, of this material, exceedingly well made, were recovered by Cushing from the canal muck at Key Marco.

Numerous ornaments of gold and silver have been found in the peninsula. It is quite possible that some of the more elaborate pieces reached the peninsula from Mexico or Central America subsequent to the Columbian discovery, but that the native metal workers were highly skilled is amply shown by numerous examples of the overlaying of wooden ornaments and objects of bone with sheet copper and by certain plates of sheet copper collected by Moore which display symbolic devices executed repoussé fashion with much precision.

Burial places and mounds yield a rich harvest of relics. A feature peculiar to the peninsula is the inhumation with the dead of great numbers of crudely shaped objects of baked clav, vessels of fanciful shapes, and rude images of creatures and things real and fanciful, manifestly intended for no other purpose than as mortuary offerings. Urn burial, common in Georgia, was rare on the peninsula.

There has been some discussion of certain supposed evidences of the geological antiquity of man in Florida based on the discovery of human skeletal remains, seemingly fossilized, embedded in geological formations in the western part of the State, but it has been shown that the age of these deposits is recent, the appearance of petrifaction being due to the coating and infiltration of calcareous and ferruginous matter present in solution in percolating waters. The most remarkable evidence of age is that furnished by the shell deposits, which are of great depth and horizontal extent and include varieties of shells not now prevalent on the coasts.

Decided relationships with the culture of Yucatan and the West Indies have been looked for in vain, yet certain analogies more or less pronounced do occur in pottery forms and decoration, in implements of stone and wood, and in the treatment of metals. The relationships are not intimate, but a glance at the general facies of the antiquities leaves the impression of trans-Caribbean kinship, which 
fades out as we penetrate the interior. A suggestion of cultural connection with South America is found in the frequent occurrence in this and other Gulf States of a perforated hoe-shaped stone implement which corresponds closely with a type of ax prevalent in South America. It is believed to have had only a ceremonial use north of the Gulf.

The superiority of the culture of this area over that of the North Atlantic region is manifest, especially in skill in Culture stat us Compared

the potter's art and in the manipulation of metals. On the whole, considering all branches, the material culture of typical centers differs but slightly in state of adrancement from that of corresponding centers in the Mississippi Valley. In some respects it is decidedly inferior to that of the more advanced culture centers of the West Indies.

The leading explorers of the antiquities of the Georgia-Florida area are: Brinton, Wyman, Webb, C. C. Jones, Bartram, Cushing, Moore, and members of the Museum of the American Indian.

\section{The Middle axd Lower Mississippi Valuey Area}

The very extensive interior region, which comprises the middle and lower sections of the Mississippi Valley with much outlying territory, was the seat of a remarkable group of peoples, whose culture, all things considered, stands higher than that of any other characterization area north of middle Mexico. This culture was characterized by well-established sedentary life, extensive practice of agricultural pursuits, and construction of permanent worksdomiciliary, religious, civic, defensive, and mortuary - of great magnitude and much diversity of form. The people, many if not all of whom were mound builders, were of numerous linguistic stocks, principal among which were the Siouan, Algonquian, Iroquoian, Muskhogean, Tunican, Chitimachan, and Caddoan; and these historic peoples, remnants of which are still found within the area, were doubtless preceded by other groups not of a distinct race but belonging to the same or related linguistic families. This view in recent years has gradually taken the place of the early assumption that the mound culture belonged to a people of high cultural

Mound Building attainments which had been succeeded by the Indian tribes. That mound building continued down to the period of European occupancy is a well-established fact, and many of the burial mounds contain as original inclusions articles of European make.

Traces attributed to very early occupants of the area have been reported from time to time, especially the osseous remains of man found in association with remains of the mastodon and mammoth. In nearly every instance, however, subsequent observations have 
thrown serious doubt on the theory of the original association of such remains. A human skeleton, found recently embedded in terrace deposits near Lansing, Kans., is assigned by some authorities to the Iowan phase of the glacial period, while others regard the inclusion as more recent. Certain relics of stone, attributed to glacial times, have been found in the Ohio and Mississippi Valleys; these await fuller investigation. Numerous crania of primitive type have been collected from ancient sites in the Missouri Valley and claims to geological antiquity have been promulgated, but Irdlička has shown that this type occurs among the modern tribes of the area. The region abounds in caverns, many of which contain traces of occupancy, but none so far examined seems to include in their floor deposits remains of other than the well-known culture products of the Indian tribes.

Unfortunately for the antiquarian of to-day, the peoples of this area did not construct their buildings of durable materials, and nothing is left to us of their architectural achievements except works constructed of earth and loosely laid stones. These are now mere unshapely mounds and embankments. The buildings of the Natchez and other tribes of the South have been described by early writers, though imperfectly. Many of the walls were of wattlework faced with clay, and the roofs were of bark and thatch. Little that is specific can be ascertained regarding the character of the buildings which must have crowned mounds so great as those of Cahokia and Etowah, or were associated with works so remarkable as those of Marietta, Newark, and Fort Ancient. Many stockades supplemented the embankments in defensive works and served to protect the villages from intruders. Modes of burial within the area were extremely varied, and vast numbers of the minor works of the people were deposited as offerings with the dead in ordinary cemeteries, in stone graves of several types, and in earth and stone mounds. Shell heaps, composed mainly of mussel shells, border the rivers in some sections. They contain relics of art of the varieties prevalent in the respective localities.

The lithic arts were wonderfully diversified and in some respects highly developed. Sculpture of the human figure had, however, made but slight advance, except in connection with the carved tobacco pipes, where much skill is shown. The mineral resources, in which the region is extremely rich, were well exploited and extensively utilized. Stone was employed in a limited way in building walls and fortifications and in the construction of graves, and desirable varieties were quarried on a large scale for the manufacture of implements, utensils, and objects of faith, ceremony, and ornament. Heavily bedded chert deposits were worked in Ohio, Arkansas, Kentucky, 
Georgia, and Missouri; nodular cherts in Indiana, Illinois, Kentucky, and Tennessee; and hematite ore for implements and ocher for paint in Missouri. The ice sheets of the glacial period distributed over the northern borders vast bodies of detritus from the far north, filled with fragments and rounded masses of granitic and other durable rocks, which were utilized by the inhabitants of the region. Copper from the Lake Superior mines had taken an important place in the arts, and much skill was shown in its manipulation by malleating processes. The tribes of the middle region, the greatest of the mound builders, mined mica in western North Carolina, and the evidences cf their operations are of astonishing magnitude.

As a result of the mineral riches of the area, the range of lithic artifacts is greater than in any other region north of wide $\mathrm{R}$ ange of the Lithic Arts the valley of Mexico. By the fracture processes vast numbers of cutting, scraping, boring, piercing, digging, and hammering implements were manufactured. The swordlike blades of Tennessee approach the highest place among American chipped products, and the agricultural implements of the Illinois region constitute a unique and remarkable class without parallel in any country.

The large class of implements and other articles shaped by pecking and grinding processes, often as secondary to chipping, is of great archeological interest. The grooved axes, celts, adzes, and chisels are of superior make, and the discoidal chunkey stones, tobacco pipes, banner stones, and other objects of faith and ornament are remarkable for their perfection of form and high degree of finish.

Among the specially noteworthy features of the area are the caches or hoards of stone implements employed as mortuary offerings. Perhaps the most remarkable of these hoards is a deposit of many hundreds of obsidian implements found in an Ohio mound; the beautifully made implements are of unique shapes and were not designed for use, but as offerings merely. They had been transported from unknown sources in the Rocky Mountains a thousand miles away or from California or Mexico. A single deposit in a mound at Hopewell, Ohio, contained upward of 8,000 well-made flint disks of large size. There are also the hematite objects of the central districts, the pigment palettes of Alabama, the engraved shells and the sculptured utensils and idols of the middle districts, the skillfully executed implements and ornaments of copper, and the remarkable and very puzzling repoussé figures in sheet copper obtained from mounds in Georgia and Illinois. Among the most noteworthy examples of the handiwork of the mound-building peoples are certain relics obtained by Putnam from the Turner group of mounds in Ohio. 
Some of the tribes were excellent potters, and the elaborately engraved and painted vases and effigy vessels of the middle Mississippi region and the scroll-decorated vessels of the lower Mississippi and Gulf coast evince excellent taste and great skill, falling short, however, of the achievements of the ancient tribes of the arid region in some important respects. The stamp-decorated ware of the south Appalachian region is of much interest.

It is observed that the culture of this area in certain of its typical phases extends down to the Atlantic in Georgia, Comparative Status of Culture

blending with that of the Florida area, and to the Gulf in Alabama, Mississippi, Louisiana, and Texas. It has much in common with the culture of the Upper Mississippi and Great Lakes region, and grades somewhat abruptly into the culture of neighboring areas on the east and west. Although presenting a certain degree of homogeneity throughout, this area is by no means a simple culture unit. There are a dozen or more somewhat localized centers of development and differentiation, no one of which could in the present state of our knowledge be safely selected as a type for the entire area. Aside from the more typical forms of culture, there are limited areas in which very primitive conditions seem to have prevailed down to the coming of the whites. There are some indications of culture relations with Mexico, among which are certain sculptured figures in stone, repoussé figures in copper plates, and engraved designs on shell ornaments and pottery, but as a whole the cultures stand well apart.

This area has been the field of extensive though somewhat scattered research. Some of the more important explorations are those of Tomlinson, Squier and Daris, Force, Putnam, Moorehead, Mills, Fowke, Thomas and his assistants, Phillips, Thruston, Moore, Jones, Peet, Whittlesey, MacLean, Holmes. and Metz.

\section{The Upper Mississippi and Great Lakes Area}

The Upper Mississippi and Great Lakes region is not very sharply differentiated from the neighboring areas in either its aboriginal inhabitants or its culture, ancient or modern. The historical tribes are of the Algonquian and Siouan stocks, and important communities of the former are still found within the area. The ancient culture is about on a par with that on the east and in some respects is inferior to that on the south. Hunting, fishing, and seed-gathering were the leading avocations of the people, but agriculture was practiced in favorable localities and the so-called garden beds of Michigan are among the most novel and mysterious features of our northern archeology. Burial mounds of ordinary forms are widely 
distributed and monumental features of unique type abound. The latter include groups and chains of earthworks in formal and puzzling arrangements, and numerous animal-shaped mounds, confined largely to Wisconsin, and supposed to have had some important sacerdotal function.

The area has within its borders two features of exceptional interest: the ancient copper mines of the Lake Superior Copper Mines and Catlinite Quarries region and the catlinite or red pipestone quarries of southwestern Minnesota. The sites of the copper mines are marked by extensive pittings made in exposing the copper-bearing rocks and breaking them up to release the masses of native copper. This work was accomplished mainly with heary bowlder hammers obtained from the lake shores and by the aid of fire. Thousands of these hammers are found in and about the old pits, occasional specimens being grooved for hafting. The copper was worked up into implements, ornaments, and objects of faith of great variety which are found, especially associated with burials, throughout the United States. The implements employed in quarrying the pipestone were tough fragments of quartzite rock, roughly shaped for the purpose. The old excavations extend along the narrow outcrop for nearly a mile across the smooth surface of the prairie. The articles made from the catlinite were tobacco pipes, ceremonial objects, and ornaments, and these were distributed and used, as was the copper, throughout a large part of the area now included in the United States.

The stone utensils of the area comprise rude mortars and pestles, the latter of the cylindrical type, and the pecked and ground implements include grooved axes, celts, adz blades-rarely of gouge shapetobacco pipes, tubes, and the usual range of ceremonial and talismanic objects. The fluted ax and the faceted celt are peculiar to the area. Deposits of flint were worked in many places and chipped implements of usual types are exceedingly plentiful.

Quartz veins were worked at an early period about the Little Falls of the Mississippi, and crudely chipped artifacts are found in floodplain deposits of the ricinity, which are regarded by some geologists as haring been laid down during the closing stages of the glacial period.

The pottery of the area is of distinctive types and generally more primitive in make than is the ware of the South. In some sections the pots are carefully finished and decorated with incised and indented figures, but painted specimens are rare.

A most noteworthy feature of the region is the manufacture in recent years of many false antiquities of peculiar type, purporting to represent early occupancy of the country by Old World peoples. 
Explorations have been conducted within the area by Catlin, Latham, Winchell, Brower, Brown, Hamilton, Phillips, Smith, Holmes, and many others.

\section{The Great Plains and Rocky Mountain Area}

Traces of the typical culture of the agricultural mound-building peoples of the Mississippi Valley fade out gradually as we traverse the great plains which extend westward to the Rocky Mountains. The region generally is not well suited to primitive agriculture, and, abounding in game, it encouraged a nomadic rather than a sedentary life, although several stocks-Siouan, Algonquian, Caddoan, Athapascan, Shoshonean, Kiowan, and others-claimed and permanently occupied somewhat definite areas. Agriculture was practiced in a limited way in some of the more easterly valleys. There were no buildings that could be called permanent, although many hut rings, house depressions, and small mounds, the last being the remains of earth lodges, occur on the old village sites, and burial mounds are not uncommon in some of the principal valleys. The dwellings of the less sedentary tribes were made of the dressed skins of animals, especially the buffalo, which overran the region in vast herds.

Quarries of flint with associated sites of manufacture are found in Oklahoma, Kansas, and Texas, and of quartzite and soapstone in Wyoming. Obsidian is plentiful in the Yellowstone Park and in the upper valleys of the Snake River, and was much used locally.

The obsidian implements found occasionally in the Stone Implements Eastern States may have come from this region. The population was sparse, the activities were restricted, and as a consequence the rarieties of well specialized artifacts were limited in number. The more essential stone implements of the hunter tribes-the projectile points, knives, scrapers, hammers, and club heads-are very generally distributed, while other forms are comparatively rare. An implement of much importance to the hunter tribes was the heavy grooved hammer so useful in killing and breaking the bones of large game, in driving stakes, and in pounding seeds and pemmican. It is probably the most typical and characteristic of the stone implements of the plains and mountains of the middle region. A powerful weapon was a hafted hammer, probably of somewhat recent introduction, called pogamoggan by some of the tribes. These two hammers were the principal articles of the pecked-ground variety of the region, although implements of other classes and even objects deroted to sacred and ceremonial use occur here and there in the valleys. Similar lithic conditions prevail in the mountains and valleys north of 
the arid region, west to the Sierra Nerada and indefinitely toward the north. There are some traces of the spread of the characteristic implements of the arid region, especially the metate and muller, toward the north beyond Salt Lake and to the east orer the great plains eren as far as the Ozarks, and there is a noticeable overflow of the types of artifacts characterizing the middle Pacific slope into the upper valley of the Missouri. Among these latter objects are straight, tubular stone tobacco pipes and paddle-shaped stone clubs. These intrusions are probably due to the Shahaptian stock, whose habitat extended from Oregon and Washington well over into the valley of the Missouri. Two remarkable discoveries within the region are a deposit of nearly a thousand flint implements obtained from a sulphur spring at Afton, Okla., and a cache of thousands of arrowheads in Delaware County, Okla. Large areas along the eastern border of the plains, that were formerly occupied by sedentary, mound-building peoples, had become, through the invasion of the buffalo, the hunting grounds of the so-called wild tribes. Pottery, the safest index of the stable status of a people, is somewhat rare in the area except in the more easterly valleys, and where found it is of the simplest culinary type.

Collections from this great area are comparatively limited, and large tracts of the territory have received almost no attention on the part of archeologists.

Claims to great antiquity in this grand division are based on reported finds of stone implements associated with fossil mammal remains in the loess formations, on a small figurine of baked clay known as the Nampa image found in Idaho, and on an obsidian blade from Nevada. It is a most remarkable fact that the image, which is assigned tentatively to the Tertiary or early Quaternary, is probably the most mature example of modeled human figurine yet found west of the Missouri.

Naturally the antiquities on the southwest border share numerous features with the art of the Pueblo region and in the Far West with the remains of the California and Columbia-Fraser areas, but the general state of culture has been everywhere about the same and closely akin to that of the historic and the present time in the same area.

The principal scientific explorations of the region are those of Dorsey, Smith, Holmes, Norris, Brower, Winchell, Montgomery, Leidy, and McGee.

\section{The Arid Area}

This area includes New Mexico and Arizona, and parts of Utah, Colorado, Nevada, and Texas. It is in the main a region of plateaus, canyons, and cliffs, of limited fertile areas bordering stream courses, 
and broad stretches of semidesert country. Contrasting thus strongly with neighboring areas, it has induced a culture peculiarly its own. The cliffs abound in caves and deep recesses well adapted for habitation, and the modification of these for dwellings probably led to the intelligent use of stone in building, with the result that the building arts were more highly developed than in any other section north of middle Mexico.

That the region has been occupied for a long period is amply attested by the occurrence of great numbers of ruins of substantial structures-cliff dwellings, and plateau and lowland pueblos scattered broadcast over the territory. Reservoirs and traces of extensive irrigating canals attest the enterprise of the people. That the present town-building tribes are the descendants of the ancient peoples is indicated by tradition, by skeletal eridence, and by material culture. The past connects with the present without perceptible break, and the implements and utensils of to-day are, except for the intrusive elements of white civilization, the implements and utensils of the past. It is not held, however, that the culture of the area is a close unit, and it is to be anticipated that with progress of archeological research various somewhat well differentiated cultures will be identified and their ethnic and chronologic relations made plain.

The town-building peoples belong to a number of linguistic stocks-Zuñian, Tanoan, Keresan, Shoshonean, Piman, and Iumanand aside from these a number of non-town-building tribes occupy the region - the Ute, Paiute, Navaho, and Apache-the range of whose lithic arts is quite limited, agreeing somewhat closely with that of the hunter tribes of the plains and mountains.

Four types of building are noted-concrete, as in the Casa Grande ruins in Arizona; adobe bricks, as in parts of New Mexico and Arizona; masonry, throughout the region; and excarated, as in Colorado, New Mexico, and Arizona. The cliff dwellings, which are of great interest, are as a rule single houses or small groups of houses; there are, however, villages capable of accommodating hundreds of people. Most of them occupy picturesque and almost inaccessible niches in the canyon walls. The plateau sites were often selected with a view to defence, and the lowland pueblos were practically fortifications. The outer walls were unbroken except by a single doorway, while entrance to the dwellings generally was from the inner court by way of the roofs of the first story. The estufa, or kiva, the sacred chamber, is a feature of exceptional interest. In many places steep ascents and narrow passes were defended by low walls of rude masonry, and it is assumed that the round and square towers found in some sections were designed for observation and defence. 
Apart from the buildings and excavated dwellings, other features of the lithic art of the region, although distinctive, are in no case markedly superior to corresponding features of neighboring areas. Nearly all implement types are in present use or have been in recent use by the tribes, and the practice of gathering and using stone implements from the ancient sites has been so general that the old and the new are not readily separable, and references of implements or other relics of art to particular tribes, ruin groups, or districts must be made with caution. The mealing stones, especially the metate and the muller, though plain slabs or shallow troughs, are well made, and some of the numerous small mortars and pigment plates are carved to represent serpents, birds, and other animal forms. The carving of animal fetishes is a noteworthy feature, particularly of the modern art, but the work is not of a high order of merit. Attempts at representing the human form are exceedingly crude. The most ambitious sculptural effort of the region is exemplified in the figures of two crouching mountain lions worked out life-size in the rock in place near Cochiti in the Rio Grande Valley, but these figures have been so mutilated that it is difficult to determine their original merit as works of sculpture.

Receptacles of stone, apart from the mealing stones and mortars, are rare, their place having been taken by products of the potter's art, which are abundant and of superior quality, and remarkable for varied and tasteful decoration. The potter's art had reached a degree of perfection not greatly surpassed elsewhere in America, certain groups of the ware displaying grace of form and beauty of decoration advanced seemingly far beyond the attainments of the people in other directions.

The minor stone implements of the area correspond in grade somewhat closely with those of the Middle and Eastern States and the Pacific slope, but the gouge, celt, chisel, and perhaps other forms are absent; while a few are peculiar to the area, as the spatulate celt and the sandal last. The grooved ax takes the most prominent place, and in form, finish, and effectiveness as a Stone-age cutting tool is rarely surpassed. Numerons axes of exceptional interest are quite distinct in type from the ordinary ax; these are made of fibrolite, a handsome mineral of great toughness and hardness which is rarely found elsewhere. Implements for straightening and smoothing arrow shafts are quite numerous and exceptionally varied in shape. A group of spatulate implements of jasper, resembling somewhat closely the celt of the East, is of special interest. Although it is referred to by the natives as an agricultural implement, its modern use, according to Fewkes, is entirely ceremonial. In one instance this explorer found 12 of these implements among the 
sacred paraphernalia of a Hopi altar. The present writer found one embedded in a bin of charred corn in a cliff house on the Rio Mancos. Hammerstones of all ordinary varieties are present in large numbers, and abrading stones and polishing implements are of common types. Chipped implements-arrowpoints, spearheads, knives, scrapers, and drill points-are of usual types and are not very abundant or especially noteworthy. The materials used include obsidian, jasper, and many varieties of chalcedony. Great skill was evinced in the manufacture of beads and other small trinkets, the boring being done with the pump drill. Bone was much used for awls, and shell for ornaments. The bow and arrow was the principal weapon, while the atlatl, or throw-stick, was in pretty general use.

Mines of turquoise were worked extensively in New. Mexico, Nevada, and Arizona. This semiprecious stone was used for ornaments and especially for inlay or mosaic work, some very attractive specimens of the latter having been collected, and it was distributed by trade to distant parts, even to Mexico. There are few traces of the working of metals, the silversmith's art of recent times having been introduced by Spaniards, and the copper bells occasionally found are probably of Mexican origin. The weaving arts and basketry were practiced with much skill.

In three important branches of material culture-the ceramic, the textile, and the stone-building arts-this area stands far abore any other north of middle Mexico. Little evidence of great antiquity beyond that furnished by the complex cultural conditions and innumerable deserted dwelling places and acequias has been found.

Among those who have contributed observations of scientific value regarding the antiquities are: Blake, Cope, Powell, Cushing, Fewkes, Bandelier, Matthews, Hewett, Russell, Hodge, Holmes, Hough, Jackson, the Mindeleffs, Nordenskiöld, Stephen, Pepper, the Stevensons, Wheeler, Whipple. Simpson, Abert, Morgan, Dorsey, Bartlett, Voth, Bourke, Prudden, Kidder, and N. C. Nelson.

\section{The California Area}

Notwithstanding the diversified physical characters of the State and the extraordinary assemblage of linguistic groups within its limits, the native culture of California was and is primitive. At the same time it is set off with remarkable distinctness from the equally primitive cultures of other areas, especially those of the Atlantic side of the continent. In the desert and semidesert regions of the extreme south and in northwestern Mexico, occupied mainly by the Yuman stock, an exceptionally primitive state of culture prevailed. It is observed that the Santa Barbara region, including the islands off the coast, was in early times the center of a somewhat ex- 
ceptional development in certain branches of handicraft and especially in the working of stone, while more primitive but kindred conditions prevailed to the north and east throughout California.

The lithic antiquities of the Santa Barbara district, which are attributed in large part to the Chumashan group, are Southern Cali-
fornia domestic utensils-bowl-shaped mortar's, and long, graceful pestles of sandstone, globular cooking pots, rectangular and ovoid baking or boiling plates, tubular tobacco pipes of steatite, and polished bowls and cups of serpentine. The quarries from which the materials were obtained are situated partly on the mainland, but principally, it is believed, on the islands off the coast. The shell heaps and village sites of the mainland and of the islands have been examined by Schumacher, Bowers, Nelson, and members of the War Department surveys, and the quarries of Santa Catalina Island have been described by Schumacher and the present writer. Contrasting with the thin-walled bowl-like mortars of this district and the slender, graceful pestles associated with them, are the heary, globular, conical, and cylindrical mortars, the numerous mortars and clusters of mortars worked in outcropping rock masses with their heavy cylindric pestles, and the metate slabs with their flattish mullers which occur in great numbers in many sections.

Bone was much used for piercing implements and ornaments. The beautiful shells of the coast - especially the haliotis and large clamwere a favorite material for the manufacture of personal ornaments, and the dentalium and other of the smaller shells served as ornaments and as a medium of exchange.

In the middle and northern districts obsidian is plentiful, and chipped implements made of this material are found in great numbers. The large knives, some of which measure 2 feet or more in length, are marrels of the flaking art, and are second in this respect in North America only to the slender flint blades of Tennessee. There are also superb flint blades in some localities, and arrowpoints and spearheads of exceptional beanty are found, their manufacture having continued in some sections down to the present day. Other features deserving special mention are the perforated digging weights made of numerous varieties of stone, the hook-shaped carvings and the killer-whale images of soapstone of iriddle and Northern California

the Santa Barbara region, and the plummet stones of middle California. Among the unique objects are specimens of boat-shaped amulets and banner stones (imperforate) of eastern type found in middle California. It is a remarkable fact that the grooved ax, the celt, and the gouge, implements of so much importance in eastern areas, do not occur, or are found but rarely, 
on the Pacific slope; the small adz blades take, in a measure, the place of these tools.

The dwellings were of grass, brush, bark, and earth, and in the north were to a limited extent of slabs of wood. Some of the floors were excarated to slight depths, and many of the more primitive structures were covered with earth. Absence of stone building from the area and the practical absence of pottery are in striking contrast with the well-matured state of these arts in the arid region on the east, shortcomings which, notwithstanding the well-made utensils of stone and the exquisite basketry and shell and bone work of California, place the Pueblo culture on a considerably higher plane than that of even the most advanced group of the Pacific States. The practice of agriculture gave the Pueblo people a decided advantage over the nonagricultural peoples of the coast, whose chief food resource, apart from the products of the chase, consisted of acorns, seeds, and berries.

The handiwork of the tribes of the coast merges with that of the inland valleys and ranges, and this blends in turn with the culture of the Sierra, and the basin range region to the east. The transition between the culture of southern California and that of the Pueblo region is decidedly abrupt, although the somewhat recent coastwise extension of the Shoshonean stock from the east has resulted in limited blending. The transition to the north is gradual, the disappearance of the oak being responsible for marked changes in the activities and manner of life of the people.

A most extraordinary feature of California archeology is the occurrence of articles of stone-mortars, pestles, and The Auriferous Area

other objects of kindred culture grade, as well as fossil human remains-in the gold-bearing gravels of the mountain valleys, numerous specimens having been reported as coming from beneath beds of lava of early Qunternary or late Tertiary age. That the relics are old in cases can not be doubted, but their exact chronological place and value have not as yet been ascertained.

The most niteworthy features of Californian culture are entirely its own and are manifestly due in great measure to the molding influences of the environment. The acorn is probably responsible for the wonderful development of the mortar and pestle, and deposits of soapstone have made possible the unique cooking pots and other noteworthy features of the native handicraft. The art of basketry was remarkably developed and retains its superiority to the present day. Water-tight baskets and utensils of stone took the place of earthenware.

It is interesting to note that, beginning in middle California, the status of culture as represented by art works rises gradually as we 
pass to the north through Oregon, Washington, and British Columbia, the culmination being reached with the tribes of the Northwest coast. In the south attempts to model or carve the human figure are unknown, while animal figures are of rare occurrence. As we advance toward the north sculptures, human and animal, increase in number, and in British Columbia there is an extraordinary development of the sculptor's art culminating in the remarkable grave posts, masks, and giant totem poles. That Middle America has had no influence on the culture of this coast is manifest.

Considering all phases of their culture, the achierements of the California tribes must be regarded as inferior to those of the Gulf States, the Mississippi Valley, the Pueblo region, and the Northwest coast, and possibly even to the Eskimo of Alaska.

Among those who have conducted archeological investigations in California are: Whitney, Schumacher, Yarrow, Henshaw, Powers, Bowers, Holmes, Sinclair, Meredith, Terry, Yates, Palmer, Becker, Nelson, Rust, J. C. Merriam, and Skertchley.

\section{The Columbia-Fraser Area}

The interesting region beginning in northern California and extending north to include the Columbia and Fraser Valleys presents diversified yet in a large way uniform culture phenomena. Owing to the somewhat marked differences between the coastal environment, which is moist and rich in forests, and the interior, which assumes generally a semiarid aspect, the material culture, ancient and modern, presents numerous minor differences. Naturally the inland culture graduates into that of the plateau and mountain region on the east. It is not separated very definitely from California on the south, but presents strong contrasts with the culture of the Northwest coast.

The inhabitants of recent times comprise numerous stocks and tribes of primitive culture whose chief dependence was and is hunting and fishing and the natural supply of seeds, nuts, fruits, and roots. In the south the acorn was a principal article of diet. Their hetter houses were of wood and earth and have left few traces except the shallow floor excarations with accompanying heaps and ridges of earth, and in the arid interior the earth rings which mark lodge sites. Along the shores are numerous shell heaps, the industrial contents of which agree with those of the general region except in so far as differences have resulted from differences in Ancient Earth- environment. Eells mentions burial mounds in the
works

Willamette Valley which yielded a wide range of the ordinary local relics, besides, in cases, glass beads and articles of iron. Chase examined certain mounds on the coast in southwestern Oregon, with similar results. Earthworks and simple fortifications 
are mentioned by both explorers. Numerous cemeteries have yielded many relics of art of all classes. Rock carvings are distributed generally over the area.

The relics of stone seem to tell a consistent story of ethnic conditions varying but little from that of historic times. Stone Implements Certain forms of implements and objects of sculpture characteristic of California extend to the north throughout the entire length of the area, while other forms characteristic of the Northwest coast extend far to the south. Deep globular forms of mortars prevail in some sections, and metates are found in others. The pestles in certain regions are of the oblong-club shape, many well finished and even tastefully carved, while in others they are ovoid or flattish, many being merely adapted bowlders. All were used as hammers on occasion. Tobacco pipes, straight in the south and bent tubes and other forms in the north, are mentioned. The grooved ax and celt are absent, the adz blade taking the place of these forms here as elsewhere on the Pacific slope. Dishes, slate knives, sinkers, wedges of antler, abrading stones, scrapers, drills, arrow-shaft rubbers, clubs (the latter of bone and stone), projectile points, and knives are found in numbers.

Among objects of exceptional types may be mentioned large obsidian ceremonial blades in the south, batons of stone or bone carved to suggest or represent animal shapes, weight-like stones with loop for suspension, and certain curious carved heads which have been regarded by some as intended to represent apes. The latter, although not carvings of particular note, find no counterparts in any section of North America.

Detailed study of this region would, perhaps, as in other cases, require its separation into two or more minor environments, but the blendings of the material culture are so intricate that conclusions of value can not be reached until further field investigations are made.

There appears no certain evidence of the presence in early times of peoples distinct in character and culture from those of the present. The valley of the Columbia is given an important place in the ethnic history of the continent by Morgan, who imagined it was a kind of hothouse, the multiplying peoples of which spread out over the south and east; but slight evidence has been found to support this hypothesis. Certain finds of supposed geologically ancient human remains and culture traces have been reported, but none of these have so far been fully authenticated. If, however, geologically ancient man did occupy the continent, the valley of the Columbia ought to be a very promising field for the discovery of the record.

Explorers of the region include Schumacher, Eells, Smith, Boas, Terry, Dawson, Morice, and Chase. 


\section{The Northwest Coast Area}

This area comprises a rather narrow strip of the mainland and the contiguous coastwise islands in British Columbia and Alaska, and extends from Puget Sound on the south to Mount St. Elias on the north, a distance of twelve or thirteen hundred miles. The present tribes belong to half a dozen stocks, well differentiated in physical characteristics from the Eskimo, with whom they come in contact on the north, and differing somewhat decidedly from the Indian tribes on the east and south. The material culture embodies many noteworthy and exceptional features and, as a whole, stands well apart from all other cultures of the continent. It resembles in some respects that of the coast culture on the south and that of the inland culture on the east. Hunting and especially fishing are and have always been the chief food resources of the people, agriculture being unknown. The area abounds in splendid forests, and the people have developed exceptional skill in carving wood, originally with stone tools, and later in greater elaboration with implements of iron and steel. The dugout canoes are often of great size, beauty, and seaworthiness, and are probably the world's highest achievement in this direction. Not less worthy of mention are The sculpture the substantial houses of hewn timbers, and the toten
Arts

poles, house posts, grave posts, human and animal effigies, and various utensils, masks, and other objects carved with a skill and boldness that would do credit to any people. Although it must be allowed that these results are due in a measure to the acquirement of white men's tools, it can not be denied that the people are endowed with a genius for sculpture without parallel among the tribes of northern America. Their skill in carving extended to stone, shell, bone, and horn, and to a wide range of minor articles of use, ornament, faith, and ceremony. The artifacts of stone include hammers and mauls of the highest known types, adzes, mortars, pestles, knives, batons, tobacco pipes, amulets, ornaments, and other objects, but examples of chipped stone are of rare occurrence. Pottery is unknown, vessels of wood, bone, and horn serving in its place. Slate obtained from deposits on the Queen Charlotte Islands has been much used in recent times for carving, and remarkable results are seen in miniature totem poles, boxes, dishes, pipes, and in diversified animal, human, and fanciful forms. Jade, found in the Frazer Valley and probably elsewhere, was skillfully cut by primitive abrading processes and shaped into tasteful implements and ornaments. Much taste is shown in the inlaying of ornaments of bone and stone with the brilliant nacre of shells. Petroglyphs are numerous in some sections and probably date back to very early times, although they display the peculiar character- 
istics of the graphic art of the living tribes as embodied in painting, engraving, and weaving. Copper was and still is worked with considerable skill, and although the native metal occurs within the area, it is not known to what extent it was mined and utilized before the coming of the whites. Certain features of the arts-practical, religious, and ornamental-are thought to suggest inspiration from the Pacific islands, but if this is shown to be the case we shall still be unable to say whether that influence may not have been exerted exclusively during the rather long period since modern seagoing vessels began to ply back and forth on the Pacific. Traces of advanced Asiatic art are occasionally encountered along the coast, but these may be attributed to the stranding of vessels carried across the Pacific by the Japan current rather than to purposeful voyages in prehistoric times.

The peculiar geography of the country has doubtless served in conjunction with its exceptional vegetal and animal resources to develop the unusual ability and enterprise of the people. Indeed, if a greatly diversified coast line tends, as some have held, to accelerate the culture progress of peoples, the inhabitants of this region should rank high among American nations.

The archeologist can lay little exclusive claim to the antiquities of the region, since nearly all the known forms of Scant Archeologi- native artifacts appear to have been in use since the
cal Evidence

coming of the whites, and these have given way only gradually to the encroachments of iron and steel. Scientific researches within the area have hardly touched the problems of antiquity, and no evidence serving to carry the history of man into the remote past has been obtained. The culture, so far as observed, appears to be decidedly homogeneous and with slight trace of antecedent forms of art either lower or higher than the historic. It is believed by some authorities that certain elements of the population entered the area from the highland valleys on the east. Although this region lies along the most likely trail of peoples entering America by way of Bering Strait, nothing has been observed in the culture of the people suggesting migrations from the north, and no characteristic features that might not have arisen within the local environment or from possible intrusions within a few hundred years.

Original investigators of this area who have contributed information regarding the native culture and antiquities are Vancouver, Swan, Niblack, Boas, Emmons, Smith, Swanton, Curtis, and others.

\section{The Arctic Const Area}

The arctic characterization area extends from Greenland on the east to farthest Alaska on the west, and from the tortuous northern 
shores of the continent somewhat indefinitely into the interior. Along the Atlantic and Pacific coasts the peculiar arctic culture shades off into the cultures of the south. Where not subject to the direct influence of other races, it is essentially Eskimoan in its prehistoric as well as in its historic phases, and the uniformity of the frigid environment and of the racial elements involved has resulted in marked uniformity of achievement throughout the area. Indeed, so all-impelling are boreal conditions that it would seem strange, since Bering Strait does not interfere with free intercourse between the east and the west, did this uniformity not extend practically the entire length of the Arctic Circle. The Past and Present culture of the past merges into that of the present
Merge

and archeological researches may be expected in time to contribute much of interest to the culture history of the area, at least of the more recent past. There is no doubt that marked changes have taken place in the arts and manner of life of such of the peoples as have come in close contact with the whites, but we may feel assured that their ingenuity and their exceptional dexterity in many directions are indigenous traits, developed largely as a result of long struggles with the exacting environment.

In these inhospitable regions shelter during the inclement seasons is an ever-existing necessity, but home building had its severe limitations. Houses were built of driftwood, whalebones, stone, earth, sod, and snow, and the sunken floors aided in making existence during the long winters bearable. Explorers find traces of these longdeserted structures and of storehouses and cairns scattered along thousands of miles of the frozen coast.

Fire for warmth and for cooking is a first consideration to dwellers in the arctic, and since oils and fats were the main dependence for fuel, the lamp filled an important place in every household. This useful utensil was made usually of soapstone. It is a remarkable fact that the lamp is unknown in any other part of America, while several forms are found in arctic Asia.

Hunting and fishing are and were always necessarily the almost exclusive means of subsistence of the people, and Skill in the Arts weapons and other devices for capturing game are among the most ingenious of their kind. In the west tough jades, the rare pectolites, and other hard varieties of stone were employed in making mortars, pestles, dishes, vessels or receptacles. hammers, adzes, chisels, picks, knives, whetstones, sinkers, tobacco pipes, and other implements and utensils. Hard and brittle stones, as flint and slate, were wrought and skillfully shaped by fracture processes into knives, scrapers, drills, and projectile points, and the art is by no means a lost one at the present day. It is a note- 
worthy fact that, although great skill was shown in the shaping of stone by these processes, spear and harpoon heads, knives, and especially the woman's knife, were very often shaped and sharpened by grinding. Familiarity with this process in the shaping of bone and ivory would necessarily suggest its use in working stone. The grooved ax, celt, and gouge are absent from the area.

Stone was used also in the manufacture of various personal ornaments, as labrets, beads, ear plugs, and pendants, some of these being unsurpassed for beauty of material and finish. Figurines, toys, fetishes, charms, talismans, and a multitude of other articles were also carved with great skill and in all available materials, and engraving of pictorial subjects of considerable merit is a distinctive feature of the more recent arctic art.

It is a remarkable fact that pottery was formerly in common use in the far north, especially along the coast as far east as Franklin Bay. The vessels, rather thick-walled, and generally of medium or large size, were probably intended for cooking and containing food, but are of good shape and tastefully ornamented with incised and impressed decorations. The pottery-making period is not yet determined, but the art appears not to have been practiced in recent times, except in the manufacture of lamps.

As with many of the ethnic areas of America, the material culture of the present and past blend completely. The task of determining by a study of the antiquities the changes that have been wrought falls to archeology. The shell heaps of the Aleutian Islands have yielded data of interest regarding the problems of chronology, carrying the story back perhaps thousands of years. The Bering region is believed to be pregnant with historic interest-geological, geographical, climatic, and anthropological-to hold within its soil and more recent formations solutions of many of the problems of the American race-but the inquirer must wait.

A comparison of the culture of the Eskimo race with that of the other ethnic groups of the continent must result in Culture Status giving this people an enviable place in the scale of intellectual achievement, but the environment has placed rigid limitations on the possibilities of accomplishment. However, the list of minor artifacts would probably be as long as that of any other northern American area, and many of the things are without corresponding features elsewhere.

Among the explorers who have contributed original information regarding Eskimo culture may be mentioned Dall, Murdoch, Nelson, Turner, Boas, Solberg, Rink, Mackenzie, Holm, Frobisher, Simpson, Krantz, Kane, Hoffman, Grenfell, and Stefánsson. 


\section{The Great Northern Interior Area}

Archeologically the great interior region of British America is practically a negligible quantity. It may contain traces of early occupancy of deep interest to the historian of the race, but research has as yet made slight progress within its borders. It is assumed as probable that successive installments of migrating peoples entered the gateway at the northwest and moved southward and eastward over the region, some remaining, unaware of better things, others passing on to more genial climes. None appear, howerer, to have made a perceptible impression upon the face of the northern wilderness. Over a large part of the area, at least, all traces of very early occupancy, if such there ever were, must have been wiped out by the ice sheets which, one after another, swept southward over the country, the latest invasion in the central region continuing down to the period which witnessed the building of the Egyptian pyramids. Limited areas in the west and northwest were Antiquities Rare not thus invaded, but these have, as yet, yielded nothing of particular value to archeology. The extensive operations of the gold miners of the Yukon have, during 20 years of unprecedented activity, brought to light no trace of man or his works.

That the primitive Athapascan and Algonquian stocks-the caribou-hunting peoples-have long occupied the region and have left the simple products of their handicraft on countless abandoned sites is safely to be inferred, but it is probable that past cultures did not in any instance rise above the level of the present. The researches of Mackenzie, Hearne, Morice, and others indicate the poverty of the historical tribes in manifestations of material culture, and the archeologist may expect to find little beyond artifacts of the simplest type-projectile points, knives, scrapers, abrading stones, hammerstones, boiling stones, and minor relics of other materials-merely such things as are necessary to the existence of hunter tribes. Traces of intrusive culture may be expected along the western and southern borders. The unfolding of the story of the past in this area must prove a tedious and almost thankless task. At any rate, it is apparent that in the present state of our researches this region will seldom be referred to in the discussion of the antiquities and culture history of the continent.

Explorers of this area who have made contributions to the history of early times include Mackenzie, Hearne, Morice, Hill-Tout, Dawson, and others.

\section{Time North Mexican Area}

Consideration of the culture areas of Middle and South America is here limited to the broadest possible geographical grouping. the brief sketches presented being intended merely to define the areas 
sufficiently for convenient reference in describing the antiquities and in comparing the cultures of the regions in a broad way.

In passing from the arid region of the southeastern United States into northern Mexico but slight change is observed Continuous Arid in the character of the country and in the status
Culture

of the aboriginal culture, either present or past. Similar conditions prevail over a wide zone extending from the Gulf and the Rio Grande on the east to the Pacific on the west. The prevailing arid characteristics of the country are interrupted only by the forested belt of the Sierra Madre. No very definite line can be set for the southern limit of the area until fuller studies have been made of the antiquities. The tribes of the present and of the historic past represent numerous linguistic stocksNahuatlan, Athapascan, Serian, Yuman, Janambrian, Tamaulipecan, and Pankawan. In the north, apart from the Casas Grandes group of ruins, few architectural remains worthy of particular note have been observed. The cliff dwellings of the mountain tribes correspond closely in most respects with those of the north, and numerous caves which have been used for dwelling and burial occur in the general region; from these mummies or desiccated bodies and certain primitive artifacts have been recovered. Village sites yielding the usual varieties of relics are common along the streams, more especially along those which descend from the plateau to the Gulf on the east and to the Pacific on the west. The minor relics include some crude sculptures and numerous mealing stones, axes, hammers, and other artifacts of types not differing radically from those of the northern Pueblos, yet showing in some respects the influence of the farther south. Pottery of excellent make and tasteful decoration is found in a few localities, that from the Casas Grandes in Chihuahua having exceptional interest and rivaling the best wares of Arizona. It appears, however, that over a large part of the area, especially on the east and west, culture never rose far above the primitive hunter-fisher level. This fact is graphically set forth by Father Baegert, who had a most intimate knowledge of the tribes of the California peninsula, ${ }^{1}$ and by McGee, who made valuable studies among the Seri on the island of Tiburon and the neighboring mainland. ${ }^{2}$

It is assumed that this region witnessed the passage southward of the racial currents which overspread central Mexico in prehistoric times, reaching the culmination of their advancement and power in the valley of Mexico at the period of the Spanish invasion, but it is not likely that the scattered antiquities will ever contribute mate-

1 Baegert, An Account of the Aboriginal Inhabitants of the California Peninsula.

2 McGee, The Seri Indians. 
rially to the history of these movements or to the elucidation of the events which led to Aztec domination. The Quemada in Zacatecas is the most northern of the well-known groups of architectural remains of middle Mexico. It is not likely that others of equal importance remain to be discovered. Earthenware of fine make and remarkable artistic excellence has been obtained by Hrdlička well north in the State of Durango.

Among the explorers of the region who have contributed information relating to the antiquities are Palmer, McGee, Batres, Lumholtz, Irdlička, and Archives of La Mission Scientifique, vol. III, Paris, 1867. The earlier explorers are given in Bancroft, Native Races, vol. Iv.

\section{The Middle Mexican Area}

Passing to the south beyond the limits of the arid region into middle Mexico we begin with the valley of the Rio Grande de Santiago on the Pacific side and the Rio Panuco on the Atlantic side to encounter traces of a more advanced culture, represented by ruined stone-built pueblos of remarkable type and other works and artifacts characteristic of middle Mexico. For present purposes it is convenient to include in the middle Mexican area a broad zone, limited on the north as above indicated, and on the south by a somewhat arbitrary line separating middle and southern Mexico, and extending from the Pacific to the Gulf across the States of Guerrero, Oaxaca, and Vera Cruz. This area is occupied in large part to-day by the several stocks of people encountered and conquered by the Spanish invaders 400 years ago. Although the ancient reinains of the area must, in considerable measure, be attributed to the tribes or nations known historically, it is known traditionally that successive waves of population swept the region in prehistoric times, thus complicating the culture traces and making the task of separatHistoric Tribes ing the various classes of remains ethnologically and
and Culture

chronologically a most difficult one. The Nahuatlan stock, of which the Aztec is the best-known branch, held dominion over much of the area on the arrival of the Spanish and ordinarily is given credit for the lion's share of the archeological remains, especially in the valley of Mexico. Of the other stocks the Tarascan, west of the valley, and the Huastecan and Totonacan on the east slope and Gulf shore, had developed cultures of much individuality and perhaps not inferior to that of the Aztecan, while the Otomian stock on the north has been usually ranked, seemingly with much justice, as hardly more than savage.

The Aztec were preceded in the valley by other groups of people, probably of kindred origin, the best known being the Toltec, to 
which people are ascribed the most important architectural remains of ancient Mexico. These include the ruins of San Juan Teotihuacan and Cholula. The former, situated within the northern rim of the valley, was a place of much importance, possibly the greatest of the American cities. The buildings proper are now in an advanced state of ruin, the sites being marked by many almost shapeless mounds; the only commanding features being the pyramids of the sun and moon. The latter, in the State of Puebla, is to-day represented by the greatest of the American pyramids, now a somewhat featureless mound 200 feet in height and 1,400 feet square at the base. Like nearly all of the American pyramids it was crowned originally by a temple. It is now occupied by a Catholic cathedral.

The minor relics of these and other sites attributed to the Toltec are of much scientific and esthetic interest. Our Toltec Remains knowledge of this people is extremely shadowy, the large body of tradition relating to them not yec having been sufficiently analyzed to determine its true value. It is held by some authorities that the Toltec were of kindred stock with the Nahua and that they were pushed to the south into Central America by the intrusion of that people, their descendants being known to-day as the Maya or Maya-Quiché. It is further held that the Huasteca of the State of Vera Cruz are a remnant of that people holding a small part of their original patrimony.

The Aztec, who followed the Toltec in the Valley of Mexico, have left us but meager traces of their architectural Aztec Culture achierements, their chief city, Tenochtitlan, having been obliterated by the building of the Spanish City of Mexico, but many important works of sculpture and especially a wide range of minor works in stone and clay are preserved. Among the more important sculptures brought to light within the limits of the City of Mexico are the great calendar stone, the Tizoc votive disk, often called the sacrificial stone, and the colossal composite image of a deity, probably the feathered serpent goddess Coatlicue, embodying various strange symbols and mythological conceptions strongly suggestive of the sanguinary character of the Aztec religion.

Excavations in the valley have brought to light traces of successive culture-bearing strata rich in minor artifacts of many classes, among which are tasteful and even elaborate works in clay, alabaster, obsidian, jade, and other hard stones, gold, silver, and copper. It is assumed that these remains represent in the order of their superposition successive occupancies of the valley, but up to the present time little systematic work has been done tending to solve the chronologic problems. Noteworthy advance had been made in pictographic and glyphic writing and a number of codexes of the 
early Spanish period are preserved in foreign libraries. Numerous superb examples of mosaic work preserved by the conquerors of the valley are now among the valued treasures of European libraries and museums.

A most noteworthy feature of the antiquities of the middle Mexican region are the mines of obsidian, the most im-

Obsidian Mines portant example of which is located near Pachuca, north of the Valley of Mexico. From this source the raw material, more especially in the form of nuclei or cores, from which flake knives were made in vast numbers, was obtained.

In the State of Morelos, inmediately southwest of the Valley of Mexico, architectural remains of distinctive type are encountered, the best known example of which crowns the fortified "Hill of Flowers," Xochicalco. These and other kindred ruins lie within the area occupied by the Nahua peoples, but are not with certainty attributed to the Aztec. Archeological investigations in this section of Mexico have been extremely limited, but a somewhat gradual transition of culture traits into those of southern Mexico is assumed. The Tarascans west of the valley, occupying historically the State of Michoacan and part of Guanajuato, were equal in many departments of culture to the Aztec, although little progress had been made in architecture either by these people or by earlier occupants of the region.

To the east of the Valley of Mexico, in the Huastecan and Tarascan areas, traces of culture development of most Eastern Mexico striking character are thickly distributed over the slopes of the plateau and down to the Gulf coast. The most noteworthy structure encountered is the stepped and paneled pyramid of Papantla in the State of Vera Cruz, possibly referable to the Huastecan stock. The minor relics include some remarkable works, among which are the dextrously carved collars or yokes of diorite sometimes referred to as sacrificial collars. Beautiful and equally problematical "Palmas" carvings and the gargoylelike representations of the vulture and other creatures gire a unique character to the sculpture of the region.

It appears from the character of the remains that this area must have been one of the earliest to witness advance to the higher planes of aboriginal culture, though as yet we have acquired only meager knowledge of the chronology of events and little comprehension of the causes which led to exceptional artistic developoldest Dated Relic ment. The oldest dated antiquity thus far collecter is a small jade figurine, on the front of which is the date in glyphic characters, interpreted by Morley as corresponding to 100 B. C. Passing northward of the Rio Panuco few traces of $38657^{\circ}-19-$ Bull. 60 , pt $\mathrm{I}-10$ 
aàvanced culture have been found and nothing of interest is encountered along the coastal region until we are well within the Valley of the Mississippi. Of the tribes of that valley it may be said to their credit that in the magnitude of their undertakings, as illustrated, for example, by such works as the Cahokia mound, they were close rivals of the pyramid builders of the south. Had they used stone instead of earth and wood they would probably be able to claim a much higher place in the American culture scale than is now awarded them.

Among the more recent explorers of this area are: Maudslay, Bandelier, Seler, Saville, Holmes, Tozzer, Fewkes, and Batres. Earlier authorities are giren in much detail by H. H. Bancroft in his Native Races, vol. iv, and in Walter Lehmann's Methods and Results of Mexican Research.

\section{The Soutir Mexican Area}

The South Mexican area, aside from the Yucatan Peninsula, which is properly eastern Mexico (Merida, the capital of Yucatan, being much farther north than the City of Mexico), comprises the States of Guerrero, Oaxaca, and parts of Vera Cruz. The preColumbian aborigines, represented to-day by their descendants of Zapotecan, Zoaquan, and other stocks, had reached a degree of advancement in most respects equal to, and in some respects superior to, that of middle Mexico. The culture appears, however, to be much diversified, and the antiquities present features essentially distinct from those of the areas on the north and east. There were numerous important centers of development, although there remains to-day west of the Isthmus of Tehuantepec but one well-preserved architectural group, that of Mitla, 20 miles east of the city of Oaxaca. The several buildings contain few features in common with the buildings of neighboring regions and find no close analogies, so far as determined, even in the immediately adjacent districts. Mitla can boast also of a unique type of mortuary structures unsurpassed in ornamental elaboration by any other American burial monuments.

The defensive motive would seem to have exercised in many cases an important influence on the selection of occupied sites, and the visitor to central Oaxaca is astonished to behold Antiquities of Oaxaca

the summits of lofty hills and mountain ridges notched by the ruins of pyramids and other massive structures, the most remarkable example of this class being Monte Alban, near the city of Oaxaca. The slopes of the great ridge are entirely remodeled by man and the summit, a mile in length, is leveled off and covered with a remarkable system of terraces, pyramids, and sunken areas. 
The minor artifacts present features hardly less noteworthy than do the greater works. The potter's art had an exceptional development, a group of mortuary vases standing at the head of American fictile products in bold elaboration of life forms. The lapidarian and metal work were also of a high order. It may further be stated to the credit of the south Mexicans that they can justly lay claim to foremost progress in the development of the calendar and of a system of pictographic and glyphic writing, a number of codexes attributed to them being preserved in the libraries of Europe, a claim well supported by the identical character of designs painted in rich colors on the walls of two of the principal buildings at Mitla.

Unfortunately little advance has been made in the exploration of the southern territory apart from those sections penetrated by the railways. Among the more recent explorers of the region are Maudslay, Seler, Holmes, Batres, León, and Saville. See Bancroft's Native Races for the earlier explorers.

\section{The Maya-Quiché Area}

The culmination of aboriginal American advancement was reached in the great Maya-Quiché area of Middle America, which includes Yucatan, Campeche, Tabasco, and Chiapas in Mexico, all of Gautemala and British Honduras, and large sections of Honduras and Salvador. The Maya-Quiché, or for brevity the Maya race, comprises at present the bulk of the population of the region, estimated at a million souls. The stock is believed to have occupied large areas in middle Mexico before the invasion of the Nahua, as already noted, and the Huasteca of Vera Cruz and San Luis Potosi are regarded by some as a remnant group. The culture of the Huasteca, however, appears to have been allied to that of the other peoples of middle Mexico rather than to that of the great Maya area of the east and south. In the southern part of the latter area, in western Guatemala and Salvador, a large Nahua element found lodgment in early times and has doubtless exercised a decided influence on the culture of the region, the archeological remains displaying certain affinities with that of the Aztecs.

Numerous centers of development within this area are represented to-day by ruined cities of remarkable character and Great Culture large extent, principal among which are Chichen
Centers

Itza, Isamal, Uxmal, Labna, and Mayapan, in Yucatan: Chakanputun in Campeche; Palenque in Chiapas; Tikal, Naranjo, Piedras Negras, Yaxchilan, Seibal, and Quirigua in Guatemala, and Copan in Honduras. All of these were abandoned at the time of the arrival of the Spanish invaders or soon thereafter, and, although the various agencies of destruction have been at work 
for 400 years, some of the edifices, built of massive masonry, stand almost complete to-day as noble monuments to the genius, skill, and taste of the ambitious builders.

The sculptor's art had reached a remarkable degree of perfection notwithstanding the fact that so far as has been determined tools of stone only were used in the work. Sculpture was employed extensively in the embellishment of buildings, with a freedom and effectiveness truly surprising. Where suitable stone for carving was not readily available, stucco was employed with excellent effect in surfacing and ornamenting the buildings. These builders were masters of formal geometric design, but reveled especially in the elaboration of life forms and fantastic creations of the imagination, in which work there appear many suggestions of the virile art of the Far East. Sculpture, aside from its architectural application, is displayed in monolithic monuments of large size and great beauty, as exemplified in the stelæ and altars of Copan and Quirigua, and in a multitude of minor works.

The potter's art was cultivated with marked success technically and esthetically. Among the exceptional products is a kind of glazed hard-burnt ware of unique design closely imitating copper or pewter in appearance, which is distributed, though sparsely, over a wide area. In Guatemala are found vases with polychrome designs of rare beauty embodying glyphic inscriptions. Perhaps the most remarkable product so far collected is represented by a series of artistically modeled and uniquely decorated vases, choice examples of which are preserved in the Peabody Museum. A number of interesting examples of mural painting are preserved.

The culminating achievement of the race is its highly dereloped system of ideographic writing, which it is believed Glyphic Writing was already beginning to embody certain phonetic elements, presaging the development of a phonetic system of writing. The glyphic inscriptions are represented by numerous examples sculptured in stone, modeled in stucco, and painted on walls, vases, sheets of parchment, and paper. The long sheets of the latter were folded and bound into books after the oriental fashion. Although these picture writings, in the absence of a key, can not actually be read by our scholars, much has been determined with respect to their nature and application. It appears that they are largely calendric, serving to record dates and events of importance, and in setting forth and fixing the dates of the oftoccurring observances of religion, which held a most important place in the lives of the people. The exceptional advancement of the Maya is indicated especially by their knowledge of astronomy and arithmetic and by the development of a calendric system which compares favorably with that of the Old World of corresponding centuries. 
It is much to be regretted that the minor relics of the region have not been adequately collected. The masterly products of the handicrafts might be thought to imply the employment of implements and utensils of very highly developed types, but so far as the evidence goes these do not appear to be greatly superior to those of many of the more primitive peoples of the continent. The carving of artifacts deroted to sacred and ceremonial purposes and to ornament display decided skill and taste. The lapidary expended his energies on various personal ornaments and talismanic trinkets, many of which were of jade. Although metal was scarce in the region, the goldsmith produced many articles of exceptional merit. Few traces of the textile art have been spared but, judging by the sculptural and pictorial representations, the costumes of the people were among the most elaborate that the world has ever known.

It is not easy to reach a satisfactory conclusion respecting the influences which led to the remarkable cultural deCulture History relopment of this region and of the Maya race, and no particular light is thrown upon the subject by the preserved chronicles. There are, indeed, certain features of the antiquities, especially in architecture, which suggest the introduction of foreign elements and resultant accelerated and exceptional development. This idea is somewhat enforced by the comparative absence of traces of earlier and more primitive stages of culture. This is true especially of Yucatan. However, according to the native chronicles, the Maya race did not occupy Yucatan until about the fifth century of our era. The more southern centers of Maya culture had at this period passed their culminating stage. When the time comes for the final comparison of the cultures of the several characterization areas of the continent it will appear without question that this area leads all others in progress toward the cirilized state. A culture curve or profile drawn from the Arctic to the Antarctic through the two continents would have its apex in the center of the Mayan area. To the north there would occur a slight sagging in the Tehuantepec region, a rising to a second but slightly inferior apex in the Valley of Mexico, and a gradual descent with undulations to the Arctic. On the south the curve would descend rapidly in the Isthmian region and rise gradually to another but secondary culmination in the land of the Inca, descending thence gradually to Tierra del Fuego.

Among the scientific explorers of the archeological remains of the area are Waldeck, Stevens, Le Plongeon, Charnay, Seler, Maler, 'Thompson, Holmes, Hewett, Tozzer, Saville, Maudslay, Morley, Spinden, Breton, Gordon, Bowditch, Owen, Kingsborough, Habel, Lehmann-Nitsche, and Huntington. For a bibliography of early explorers see Bancroft's Native Races, vol. iv. 


\section{6. 'The Central American-Isthumia Area}

Passing to the south of the Maya-Quiché Province into the Central American area proper, a decided step downward in the culture scale is manifest, a descent broken somewhat by the influence of Maya contact along the northern border and by the intrusion at various points of Nahua colonies. These latter were established in pre-Spanish times in southern Guatemala, Honduras, Nicaragua, and Panama. Apart from the Nahua groups, the inhabitants belonged to a large number of distinct linguistic stocks, but all are now largely blended with intrusive elements of European, African, and West Indian origin. None of these stocks could claim an especially high culture rank at the period of conquest and the majority, though practicing agriculture and the simpler forms of textile, ceramic, and other arts, rose only slightly above the status of the simple sarage.

The inferior state of pre-Columbian culture in this area is especially emphasized by the absence of architectural

Culture Inferior remains. The whole area contains, so far as reported, only very limited traces of stone building or of major antiquities of any kind. Sculpture of the human figure, of which there are many examples, was still in the primitive stage, the clumsy forms being rigid, expressionless, and inartistic, contrasting strongly with the exceptionally free and graceful treatment of the Maya-Quiché area. The apparent absence or rarity of traces of the recording arts also serves to stamp the advancement of this area as of decidedly inferior grade to that of the areas.to the north. Sculptural representations of animals correspond in character with those of the human form except as elaborated in the remarkable stool and stoollike metates found in great numbers in Costa Rica and in northern Panama. In this branch of handicraft, strange to say, the ancient Costa Ricans stand at the head of the American tribes. The elaborately carved and tastefully embellished forms suggest the extension of the function of these objects beyond ordinary practical uses into the realm of superstition and ceremony. Achievements in the potter's art also in some sections, especially on Ometepe Island and the shores of Lake Nicaragua and in Chiriqui, Panama, go far toward rescuing the ancient craftsmen from relegation to a decidedly inferior status. Indeed, there is not in America any group of ceramic products displaying a refinement of taste in modeling superior to that of Chiriqui. It is also to be observed that as metallurgists the ancient Central Americans must be accorded high rank. Countless examples of skillfully executed ornaments in gold and gold-copper alloys have been recovered from burial places in Costa Rica and Chiriqui, and the Spanish invaders reaped a rich harvest in the 
region. The minor lithic antiquities also present many features of interest. The axes, celts, and clubheads in some sections, more especially in Costa Rica, take on artistic and unique forms due doubtless to association of mythic concepts, and personal ornaments of jade and other rare stones show much taste in design and perfection of finish. The celts and chisels of Chiriqui in form, finish, and effectiveness as tools are unsurpassed anywhere. Viewed as a whole, omitting certain traces of Mayan and Nahuan influence, the antiquities of Central America are allied with those of Colombia and there is little doubt that Chibcha influence has been strongly felt, if, indeed, the Isthmian region is not the original home of this people and the birthplace of its remarkable and highly individualized culture.

Geographically, the Central American Isthmian area is a striking and significant feature of the American Continent-a Intercontin e $\mathbf{n}$ a l Thoroughfare narrow sinuous stretch of land, widening at the north, nearly 1,000 miles in length, connecting the two grand divisions. If, as is generally supposed, America was peopled from the northwest, the migrating groups had to traverse this long neck with its tropical tangles and febric danger's before the southern continent was reached, and the study of Isthmian ethnology and archeology should thus be fraught with more than usual interest. The observed ethnologic conditions give, however, no hint of the movements of tribes and stocks beyond the suggestive intrusion of the Nahua from the north and the very perplexing fact that most of the Isthmian tribes of historic times as far north as Honduras are allied linguistically, and in many features of their material culture, with the peoples of South America, just as the West Indians are connected with the South Americans of the Orinoco region. The view that the movements were from south to north is said to be supported by linguistic evidence, but this eridence is too meager to be depended upon in a matter of such moment. The archeologic remains of the narrow stretches of the Isthmus have received little attention except on the part of relic hunters lured by rich finds of mortuary gold, as in the provinces of Nicoya, Cartago, and Chiriqui, and it is thus too early to say whether or not the Isthmian highway holds identifiable material traces of the comings and goings of peoples other than the historic stocks. The opening of the canal may in time afford the opportunity of prosecuting researches in regions heretofore most difficult of access.

It is not necessary to assume that this neck of land, especially the narrow sections, though a thoroughfare for migrating tribes of early times, should have held any of these long enough or afforded 
the kind of environment required to give the genius of the people an opportunity to assert itself. As to the evidence of recent tribal movements, the original occupation of the continent is probably so remote as to have resulted in a state of migratory equilibrium many centuries or millenniums ago, so that in modern times movements may as readily have taken place toward the north as toward the south. Under these conditions the present distribution of tribes, stocks, languages, and arts can have little or no bearing on the problems of origin and primary distribution.

It is well known that the Isthmian region has undergone very radical changes in comparatively recent geological time, but there seems to be no reason for supposing that man appeared until the present configuration of the land had been permanently established. No trace of occupancy has been found which may not be safely assigned to the present geological period.

The principal explorers of the antiquities of this region are: Alfaro, Hartman, Pittier, Stevens, Zeltner, Brantsford, Bollaert, Squier, Merritt, Uhle, Seler, and Spinden. For early explorers see Bancroft's Native Races, vol. Iv.

\section{The Nortil Andeax-Pacific Area}

This extended area comprises Colombia and some adjacent territory in Venezuela and Ecuador, and its antiquities, although as yet but little studied, must prove an important aid in analyzing the apparently complex problems of the settlement and subsequent history of the regions connected by the Isthmus of Panama. A study of the strongly marked physical features of the country and its diversified products may be expected to throw much light on the problems of environmental influence.

The area was occupied in early historic times by numerous stocks and tribes, the descendants of which, although greatly scattered and intermingled, still constitute the principal body of the population.

The more advanced communities had reached a cul-

Culture Status

ture development corresponding closely in many re-

spects with that of Central America. The Chibcha and Quimbaya had made noteworthy advance in some branches of material culture, and the tribes of Ecuador, particularly in the highland and along the coast, have left traces, probably representing preInca times, of still higher achievement. The little known peoples of the north extending to the east into the drainage of Lake Maracaibo and the valleys of the Orinoco and Amazon had attained varying degrees of primitive culture, grading down to the utterly savage. Traces here and there appear suggesting considerable advancement in the arts. 
The antiquities of the area include few features clearly indicating decided superiority of the past over the historic status and suggest relationships more or less intimate with the culture of Central America on the north and the pre-Inca culture on the south. It is noteworthy, however, that much diversity is shown, especially in the more southern districts; a condition due partly, it would appear, to intrusive elements of race and culture as well as to isolation of communities by reason of the pronounced physical characteristics of the country. Architectural remains are of rare occurrence in Colombian territory. The most important traces consist of a group of stone columns, apparently the remains of an important structure in the Magdalena Valley northwest of Tunja, of a remarkable series of slab-built temples associated with colossal statues, which display certain sculptural features of much interest, in the valley of the Rio de La Plata, an affluent of the Magdalena, and far to the east in the most rugged part of the eastern Cordillera there exist, according to report, certain cyclopean edifices and subterranean temples in which are colossal statues carved from the living rock. These remains, if correctly reported, would seem to be related in some way to the advanced stone building of the Inca region to the south.

In highland Ecuador and along the coast in Esmeraldas and Manabi numerous stone-built structures are encountered, but whether of Inca or pre-Inca type is not fully determined. Some of the more advanced tribes erected burial mounds of stone and earth over their dead but rarely of any considerable architectural pretensions. Agriculture was practiced and the early historians refer to the use of irrigation works, but no trace of these has been observed in recent times. The mining of gold, silver, copper, and emeralds was carried on with much success. This consisted in washing the sands and gravels of stream beds as well as the working of vein material. The processes employed must have been exceedingly primitive, but apparently no account of these has been recorded by the historians of the region. Sculpture was in a backward state throughout the area. The examples preserved of images and kindred sculptures compare unfarorably with those of Chiriqui and Costa Rica and also with those of southern Ecuador. In minor lapidarian work considerable skill was displayed. Implements and ornaments were tastefully shaped and the carving of emeralds, a stone invested with sacred attributes by some of the tribes, was carried on with remarkable skill. The stone implements of the Ecuadorian highland are well made and display remarkably diversified characteristics.

The burial places of the people furnish most striking evidences of culture advancement in pre-Columbian times. Pottery is abun- 
dant and presents great diversity of style due to development in numerous independent culture centers. The forms are varied and the highland peoples, especially in Ecuador, displayed great skill in modeling life forms employed in decoration, the vigor and artistic character of the work reminding us strongly of the pottery of

Oaxaca. The most striking evidence of the advanceSkill in Metallurgy ment of the peoples of the region in the arts is furnished by their works in metal. They early discovered and utilized gold, silver, and copper, and employed them in the manufacture of vast numbers of articles of ornamental and sacred use, displaying a degree of skill and taste hardly to be expected of a people so backward in other branches of handicraft. The mastery displayed in the manipulation of gold is a never-failing source of wonderment to the student of American culture. So far as recorded, these tribes had not succeeded in making bronze, a fact due, possibly, to the absence of tin. Kindred skill in the metallurgic arts was displayed by the Incas, who alone made extensive use of bronze, and also by the Central Americans and Mexicans. None of these peoples were so plentifully supplied with the precious metals as were the inhabitants of Colombia.

\section{The Mindele Andean-Pacific Area}

This vast region is culturally a world in itself, and no brief sketch can convey an adequate notion of its history, traditional and written, and of its diversified and multitudinous antiquities. It extends from Middle Ecuador on the north to the valleys of the Rio Maule in Chile and the Rio Salvador in Argentina on the south.

The important linguistic stocks of the area, according to Brinton, are the Kechua, Pequina, Atacameno, Aymara, and Yunca, the

Kechua being the dominant element of Inca rule. Linguistic Stocks These peoples were bordered on the east by numerous forest tribes and on the south by the Pampean tribes of Argentina and the Araucanians of Chile, none of which were advanced decidedly beyond the simple hunter-fisher state, and many, especially on the east, had never risen above the lowest round of the culture scale.

The ethnic conditions of the area as known historically and as further revealed by the antiquities were exceedingly complex, and the earlier culture phases, representing distinct periods and peoples, are overspread more or less fully and deeply by a veneer of the Incan civilization. That numerous stages of culture supervened one upon another is clearly manifest, and some students of the subject do not 
hesitate to distinguish the successive periods and stages and even to suggest duration of time in centuries.

It is assumed on excellent grounds that the earlier cultures developed in numerous amewhat isolated centers, owing Inca Dominance to the pronounced physical barriers of the country, and that in course of time combinations took place, the stronger groups absorbing the weaker and thus forming larger social units, the process ending in the almost complete dominion of the Inca element. The archeologist essays to separate and restore the original groups by means of the antiquities, but he can never hope to reach more than tentative results. However, he may come to understand very fully the general course of history throughout the region.

It is generally agreed that although remarkable progress had been made in some branches of culture by the foremost Relative Status peoples of the area, the status as a whole takes a rank somewhat inferior to that of the more adranced nations of North America. Judged by the more delicate of tests of progress toward civilization, the advancement made in calendric knowledge, and in the recording and esthetic arts, the Incan status must be regarded as distinctly lower than the Zapotec, Aztec, and Maya. At the same time it is admitted that no other American people, so far as is known, had achieved a system of government so highly perfected as that of the Inca, and their agriculture and ceramic, textile, and metallurgic arts compare favorably with the best.

In no other area do the antiquities have so wide a range or tell so completely the story of the life and the fate of the Abundance of Antiquities

people. Above ground the more durable artifacts and works only are preserved, but in the depositories of the dead, especially in the arid districts, vast numbers of every conceivable product of handicraft are preserved almost unchanged. The entire personal and much of the household equipment is complete. From the graves of Ancon, for example, every article necessary to the building of a museum family group, showing the people in their proper costumes and embellishments and engaged in their daily arocations of a thousand years or more ago, could be assembled without difficulty. One of the most striking features of the mortuary class are the elaborately constructed and bedecked mummy packs.

Agriculture was by far the most important industry of the area and a chief concern of the Inca rulers. It was pracAgriculture ticed originally in many centers, separated more or less completely by natural barriers, but later all sections were unified by the Inca, who employed every known device and took every step calculated to increase productiveness. In arid dis- 
tricts extensive and highly dereloped systems of irrigation were devised, and the remains of the stone-built aqueducts bear evidence of engineering skill of a surprisingly high order. To increase and retain the tillable area the mountain slopes were terraced to great heights, the successive steps being faced with walls of stone, which were ascended by rude stairways. The terraces have, as a rule, been long abandoned, but the ribbed hills are to-day visible on every hand. The implements employed were hoes and sparles of primitive form made of wood armed with points or blades of stone or copper, numerous examples of these having been preserved to the present time. Storehouses were built in erery community, and doubtless traces of these are still to be found in some sections. Maize was the chief product, and the many varieties found and perpetuated even to the present time afford evidence of independent development covering a long period of time.

The archeologist must concern himself also with the zooculture of the Andean highland, this being the only American Domestic Animals region in which animals, except the dog, were domesticated and employed in transportation, as a source of food supply, and as an important source of the materials of the textile arts. The llama and alpaca, as shown by archeological as well as by biological evidence, have been subject to domestication for unnumbered centuries.

The expansion of the Inca dominion to include distant regions difficult of access led to the building of roads, and Iioads engineering achievements of remarkable character were the result. A highway extended to the north from Cuzco, traversing mountain regions of the wildest character for thousands of miles. Another extended along the coast, connecting the numerous valley pueblos, while other roads connected these two main thoroughfares. These roads, which were in use at the coming of the Spanish invaders, are well described by the early annalists, and traces remain to-day, although in the main they are obliterated by the new system of highways, which had to accommodate not only pedestrians and llama trains but wheeled vehicles as well, the latter being previously unknown to the natives.

The architectural remains of the area are of rast extent and varied in character and abound in unique features,

Architecture which find no parallel either in America or in the Old World. In plan, elevation, material, construction, and embellishment the buildings vary with the region, the people, and the period. Stone was used almost exclusively in the highlands and adobe and concrete in the coastal districts. The build- 
ings include dwellings, community houses, palaces, convents, temples, storehouses, observatories, fortifications, fortified strongholds, tombs, bridges, aqueducts, corrals, and also structures of unMegalithic Build- known use. In the Cuzco region a megalithic style, ing

probably of ancient origin, prevailed and was still in vogue in the Inca period. The fortifications of Olantaytambo and Sachsahauman are marvels of their kind, and Machu Picchu, recently explored by Bingham, is one of the most astonishing achievements in city building and fortification in the western world. Remains of stone building of less note occur throughout the Sierra region from Quito to Tucuman.

The remains of the Titicacan basin are not less noteworthy than those of Cuzco. The ruins of Tiahuanaco are among Tiahuanaco the most extraordinary achievements of American architectural genius, doubtless the result of some powerful religious impulse, which caused a comparatively primitive community to undertake a work entirely beyond the normal, reasonable requirements of such a people. In this region occur tombs called chulpas, towerlike in form, constructed of cut Chulpas stone. In the coastal centers adobe was largely employed in the construction of buildings of all classes. Some of the cities were of large size and many of the principal structures were of complicated plan and great extent.

Without a knowledge of the keystone arch the aborigines were unable to construct stone bridges of wide span, but Bridges short spans were erected by means of the offset arch. Long spans were constructed by means of cables of vines or osiers fixed to the living rock or to heary buttresses of masonry. Traces of the latter structures are still to be found.

The minor artifacts of the area-Incan, extra-Incan, and preIncan-include implements, utensils, ornaments, and problematical objects of stone, metal, clay, wood, bone, and shell in the greatest possible variety, and in metal and clay the diversity of form exceeds that of any other American area. Remarkable ability is shown in modeling in clay the human face and, indeed, almost every natural form, animal and regetable, found in the country, but this ability does not seem to have extended to sculpture except in the more minute forms of lapidarian work, in which bianch, however, superior workmanship is shown. There is nothing in the entire Incan area to compare with the masterly sculptures of Guatemala and Honduras, and the larger monuments, probably of the olden time, are extremely primitive in type.

Stone implements and utensils were necessarily a feature of great importance with a people who worked stone and metal on an exten- 
sive scale, and who were given to war and the chase. Between Quito on the north and Tucuman on the south nearly every variety of minor stone artifact known to our prehistoric peoples is found. The hammer, the little observed but omniscient engine of culture, is of shapes common the world over, and axes of every known type occur. Chipped implements, including arrow, spear, and harpoon heads, however, are comparatively rare, but those of bone and metal are of frequent occurrence. Club heads are of excellent make, many stellar in form and tastefully ornamented, and bolas stones and digging weights are found in some sections. The metal implements were modeled after corresponding implements of stone but were often elaborated in many directions into types unknown elsewhere.

The metallurgical arts were advanced to the highest American stage. Gold, silver, and copper, and alloys of these were extensively employed and with great skill in the manufacture of personal ornaments and other articles in astonishing variety.

Among the scientific explorers of this area are Squier, Bingham, Saville, Uhle, Markham, Wiener, Reiss and Stübel, Hrdlička, Dorsey, and Bandelier.

\section{The South Andean-Pacific Area}

In Chile and Argentina the wide Andean highland narrows down to a compact mountain range without high plateaus Araucanian $\mathrm{Cul}-$ or habitable valleys of any considerable extent, with
ture precipitous descent to the narrow rim of lowland along the Pacific and a more gradual descent across the pampas of middle Argentina and the broken plains and plateaus of Patagonia to the Atlantic. The sturdy Araucanian tribes of Chile were never conquered by the Inca and were never fully overcome by the Spanish, but are now being rapidly absorbed into the mixed agricultural population. They had made considerable progress in the sedentary arts and were practicing a rudimentary agriculture. On the Pacific side traces of the advanced culture characterizing northern Chile fall off abruptly south of the Maule to a culture level but little above that occupied by the Araucinians when first risited by the Spanish. In middle Chile numerous wellstone Implements fashioned implements, utensils, and other artifacts are found, seemingly in large measure free from Inca influence. Among these are mortars and pestles, axes, celts, annular digging-stick weights, net sinkers, projectile points, and tobacco pipes. Oddly enough, the digging weights duplicate those of California, while the pipes find close counterparts in the Mississippi Valley. The chipped implements-arrowheads, spearheads, knives, scrapers, and drills-are of ordinary forms. Limited traces of relics 
of corresponding forms and kindred grades are found on the Argentina side along the southern margin of the area of Incan dominance.

A noteworthy feature of the archeology of the immediate coast of the Pacific are the shell heaps, the refuse of food Shell Heaps consumption by the tribes. These shell heaps yield various primitive implements and pottery of excellent make, the latter not, however, free from characteristics that remind us of Inca work. Numerous petroglyphic inscriptions, which correspond in general type with those of primitive tribes in other localities all over South America, are found throughout Chile. The antiquities of the region as a whole indicate a state Culture Status of culture corresponding somewhat closely in grade to that of the Pacific States of North America, although investigations have not extended far enough to make accurate rating possible. Evidences of marked advancement disappear as we pass southward to the Straits of Magellan and into Southern Chile Fuegia. Southern Chile and Patagonia seem to present no trace of culture progress distinct from or superior to that of the known nomadic aborigines.

Among the authors who have prosecuted archeologic studies in this area are: Philippi, Uhle, Oyarzun, Ambrosetti, Medina, Lenz, Lehmann-Nitsche, ten Kate, Latcham, Guardia, Van Dyke, Evans, Furlong, and Boman.

\section{The Amazon Delta Area}

Pre-Columbian culture had made noteworthy adrance in certain sections of the Amazon delta region, with outliers as far north as the valley of the Couanani and as far up the Amazon as Santarem and beyond. The historic tribes include the Carib, Arawak, and Tupi. This area is represented in collections by numerous very interesting and characteristic objects of art, chiefly pottery, which is found in great plenty in mounds and burial places. The most striking objects are the large burial or cinerary vases from the island of Marajo. The advancement made by the prehistoric tribes seems remarkable, since the delta is frequently subject to inundations and must have been in the past, as now, a most uninviting place for permanent residence.

Many of the Marajo vases are of large size and are tastefully embellished with human and animal features in relief, the relief motives being elaborated in complicated and often formal designs in color. Other vases of varied shape and size are embellished with incised and carved geometrical patterns, often labyrinthine, showing excellent taste. These embellishments are distinct from those of the more southern regions as well as those of the western highlands 
but appear to resemble the decorative art of the Guianas and the Trest Indies.

A number of rery striking and handsome vessels obtained from graves and caverns in the valley of the Couanani are manifestly the work of related peoples. It is impossible at present to define fully the area over which the delta culture extends. Grotesque images in clay, of small size, representing men and animals, are of very general occurrence throughout the Arawak-Carib areas and were, doubtless, for the greater part mere embellishments for vases. Stone implements of usual southern forms and more rarely grooved axes of northern type are found within the area.

Among the explorers who have noted the archeological remains of the delta may be mentioned Brett and Lange.

\section{Primitive Soutil America}

The vast region which extends from the eastern slope of the Andes to the Atlantic Ocean, comprising three-fourths of Extent of Area the continent, may, with slight exceptions, appropriately be referred to as primitive if not as savagc South America. At its southern extremity it connects culturally and also racially across the Andes with southern Chile, and at the north the art forms grade into those of the Guiana coastal belt. This area is occupied by very many stocks and tribes of diversified physical characteristics, a few only of which have been the subject of scientific study. Aside from the limited districts orer which the Inca influence extended, it is practically without architectural remains or monuments of any kind except occasional burial mounds and shell heaps.

It is not to be understood that the whole of this region affords evidence of a uniform state of advancement pre- and Culture Status post-Columbian. There are vast areas occupied by unnumbered tribes of which little is known and of which little that is good can be said. Many of these are described as nomadic savages without permanent homes and without clothing, subsisting on fruits, fish, and game, and in cases on human flesh. These conditions are doubtless due in part to the occurrence of extensive areas of marshy lowland, barren plains, and impenetrable forests equally unfarorable to social progress. It is apparent, however, that the people as a whole do not lack in ability and in certain sections where conditions were favorable agriculture was practiced and culture rose in numerous respects above the dead level of savagery. Among the multitude of tribes belonging to the Arawak, Carib, Tupi, and other stocks very many have evinced capacity which it would seem only required favorable environment to turn them toward paths of higher culture. The Arawak of the Matto Grosso, far out in the primitive area, are spoken of in terms of praise by early missionaries. 
They were living in neat houses and cultivating the land with skill and industry. They made sugar from cane, and their cotton cloth, dyed in various hues, was highly esteemed for its texture. ${ }^{1}$ In a wide area about the delta of the Amazon, as already indicated, there are traces of a state of development considerably in advance of that of any of the historic peoples, while along the northern borcler of the continent, from the mouth of the Amazon to Lake Maracaibo, the Arawak and Carib stocks had made marked adrancement in the arts; and their implements, utensils, and personal ornaments present many features of interest, althongh the culture state as a whole appears to be considerably lower than that achiered by the same stocks in the West Indies.

Evidences of advanced culture are found along the Andean slopes of Bolivia, doubtless echoes from the highland or survivals of culture among peoples driven from the upland valleys by the Inca. There are in the upper valleys of the Rio Mamore burial mounds from which are obtained pottery and stone implements such as usually pertain to the sedentary, agricultural status, and the same is true of some parts of the valleys of the Parana and Paraguay.

Stone implements and utensils of excellent make and considerable variety are widely distributed. The total absence of Stone Implements stone from the marshy areas of the ancient lake beds and the rast alluvial areas of the lower courses of the rivers naturally interfered with progress in many branches of the arts. Stone celt-hatchet blades, where found, are identical in type with these implements in North America, and they were and in some sections still are hafted in a similar fashion. The axes are, for the greater part, South American in type, many of those of the far south having an hourglass outline, while the prevailing form in the north is notched or winged laterally. Occasional examples of the grooved $a x$ are found in different parts of the area, these being identical in type with the grooved ax of North America. The occurrence of mortars, flat rubbing stones, and well made pestles orer the region occupied historically by the bolas-using tribes of the south may be explained by assuming that these utensils served in pulverizing other food materials than maize, unless, indeed, it is conceded that agriculture was practiced in this region. Chipped implements are rare in the north but were in common use among the tribes of the south, where they include knives, scrapers, and drill and projectile points of varieties duplicating those of northern America.

Sculpture was in its infancy throughout the area and no important specimens have been reported, but occasional examples of skillful lapidarian work as well as implements and ornaments of copper and

${ }^{1}$ Brinton (quoting Hervas and Castelnau), The American Race, p. 243. $38657^{\circ}-19-$ Bull. 60 , pt $\mathrm{I}-11$ 
gold are brought to light in the Amazon Valley and along the northern border. It is regarded as probable that objects of these classes had their origin in the Andean highland.

Pottery is found in many sections of the vast area from Patagonia to the Caribbean coast, and the use of large ressels for burial purposes, observed in the east and north, indicates a stage of advancement considerably above the arerage of the area. In the middle regions and far to the south the ware is of primitive type; the forms are of the simple round-bodied pots and bowls, and the decorations consist of conventional incised and impressed figures. In the north many of the vessels are modeled to imitate or to suggest life forms and the incised and painted decorations are tasteful and elaborate.

Naturally the art of the northern margin of the continent has somewhat marked analogies with that of the West InPictographs dies, but the contrast between the art of these regions and that of northern America is very decided. Pictographs, engraved and painted, are common, especially in the north, and all appear to be of the simple type common to primitive America generally. Many represent very rudely the figures of men and animals, but the majority are formal unintelligible devices descending to mere scrawls. Kitchen middens, the refuse of food Kitchen Middens consumption, are found along the coast from the mouth of the Amazon to the Rio de la Plata, and also on the Fuegian and Chilean coasts. In cases they are of remarkable dimensions and the reports of explorers indicate that the accumulations of these extended over very considerable periods of time. They seem to owe their existence to very primitive peoples, however, since they contain but limited traces of works of art of any kind. The Tupi tribes, or, according to Church, the Tapuya, who largely occupied eastern Brazil on the arrival of the Spanish, were preceded, it is said, by the Ges stock, a very primitive people, and the middens may be attributed, at least in part, to them.

In recent years much attention has been given by anthropologists to supposed traces of early man in Brazil and ArgenAntiquity tina, but it is doubtful whether there exists sufficient reason for assuming the geological antiquity of either the osseous remains of man or the works of his hands, and there is certainly no substantial ground for assigning any of the artifacts thus far discovered to a stage of culture or to a period corresponding to the European paleolithic. No human remains have been brought forth that afford sufficient ground for assuming an early people of distinct type from the Indian, and no form of artifact has been 
found that may not be attributed to the known aborigines rather than to any hypothetical people.

The literature of this great region is naturally very extensive, but few of the explorers outside of Argentina have given close attention to the antiquities. Among the most helpful authors are: Ambrosetti, Ameghino, Lehmann-Nitsche, Moreno, Hrdlička, and Outes in the south, and Netto, Hartt, Pinot, Ernst, von Ihering, Church, Ehrenreich, Von den Steinen, im Thurn, Göldi, and Farabee in the middle and north.

\section{The West Indian or Antillean Area}

The West Indies present a most attractive field for archeological research-a field as yet touched only superficially Extent of the An- except for the recent researches of Fewkes and
tllles

de Booy. The archipelago stretches out over a length of 1,600 miles of ocean expanse, connecting by way of the Lesser Antilles somewhat closely with South America, and through the Bahamas with eastern Florida. The greatest expanse of open sea between South America and the Lesser Antilles is that separating the islands of Tobago and Grenada, a distance of some 80 miles, while the distance between the Bahamas and the Florida coast is about 60 miles, and that separating Yucatan from the Island of Cuba is 120 miles. Within historic times the inhabitants of the islands have included two great linguistic stocks-the The People Arawak and the Carib, both generally believed to have had their origin in contiguous regions of South America. The former had practical possession of the islands in late pre-Columbian times, while the latter were rapidly encroaching upon their territory and threatening their extinction at the period of discovery. Whether the Arawak were preceded by any other earlier race or stock is still a question, since no well authenticated traces of such antecedent population have been found. The aborigines decreased rapidly under the merciless rule of the conquerors, and to-day barely perceptible traces of Indian blood are to be found.

The entire material culture presents somewhat uniform characteristics and, as would be expected from known race reThe Culture

lationships, corresponds more closely with the culture of South America than with that of Florida or Yucatan, the break between these latter regions and the islands, as indicated by the antiquities, being in many respects very marked. The culture, all features considered, is quite equal to that of the southeastern United States and superior to that of northern South America. 
The greatest advancement seems to have been made in Santo Domingo and Porto Rico, but no conspicuous centers of development, as sites of large pueblos, have been observed. The islands contain no architectural remains and have but few traces of other fixed works besides kitchen middens and certain level areas believed to have been deroted to ceremonial use. Sculpture was Art in Stone in a very backward state, other than the carving of minor objects of stone, such objects comprising not only implements and utensils in large numbers, surpassing in elaboration and beauty the corresponding forms in the Southern States, but several classes of sculptures of remarkable characteristics and of undetermined purpose, except that they may with safety be regarded as having served some purpose in the religious activities of the people. Most noteworthy among these are the collars, yokes, the tripointed stones, and the maskettes. The collars are carred with wonderful skill and must have cost no end of time and labor in their manufacture. All are oval in shape, while the Mexican analogues are mostly open and at the same time display higher stages of symbolic art and esthetic appreciation. Stone mortars are not numerous but some specimens are neatly carved, and the pestles, which are of several varieties, are not equaled in elaboration of form except perhaps in Costa Rica. The hatchet blade or celt is found in large numbers, especially in Jamaica, and is unsurpassed for perfection of form and beauty of finish anywhere in the world. The same types of form occur in the Southern States, but rarely of such fine finish. Chisels resembling the celts, except in their more cylindrical bodies and narrow points, are exact duplicates of the chisels of the United States. The monolithic hatchets are of much interest, being carved, haft and blade, of a single piece of stone, thus illustrating perfectly the common manner of hafting this class of implements. One example of celt blade, still retaining the wooden handle, has been recovered. Axes, however, do not duplicate the axes of the States, but are allied in form somewhat closely with the axes of South America.

Chipped implements are of rare occurrence, a circumstance implying the use of bone for projectile points and Wood, Pottery, Shell, Bone

possibly the absence in a measure of suitable varieties of stone.

The potter's art flourished on some of the islands. Life forms were modeled and employed in embellishment. A tendency toward the grotesque is everywhere manifest, and symbolism had an important place in the painted and incised designs. The greatest advance in this branch was in middle and southern Santo Domingo. 
Shell was used for celts and gouges as well as for various minor implements and personal ornaments, and wood was carved with lemarkable skill, the anthropomorphic and animal-shaped seats being unique. Metal was scarce on the islands and the little gold found by the Spaniards, although worked into personal ornaments by the natives, seems to have been obtained by them from the far west.

Explorers of the West Indies include im Thurn, ten Kate, Ober, Explorers Branch, Montané, Duerdin, Fewkes, de Booy, Huckerby, Latimer, and others. 


\section{CLASSIFICATION OF ANTIQUITIES}

CLASSIFICATION of the material subject matter of archeological research is a necessary first step in its consideration. It appears that there are sereral arailable methods of approaching and treating the very diversified materials as a whole, among which the most practical for general purposes are the following:

(1) By geographical areas, natural and political.

(2) By culture characterization areas.

(3) By peoples, as tribes, stocks, and nations.

(4) By successive geological periods, as Tertiary, glacial, postglacial.

(5) By classes of artifacts, as implements, utensils, weapons.

(6) By the materials employed, as mineral, animal, vegetable; as stone, metal, wood, bone, shell.

(7) By arts and industries, as hunting, war, agriculture, quarrying, mining, building.

(8) By successive steps in culture derelopment, as sarage, barbarous, civilized.

(9) By function groups, as practical, ornamental, sacerdotal, diversional.

(1) The diversified materials of antiquity may be taken up and described by the greater geographical areas, as conGeographical Areas tinents, archipelagoes, islands, and political divisions, but this is entirely satisfactory for scientific purposes in cases only where the areas are measurably coextensive with those of the ethnic or culture groups. This happens in America only in the case of the continent as a whole, and in certain minor areas which happen to include well differentiated ethnic or culture units, as the arctic region, the West Indies, and the arid Southwest.

(2) The culture characterization areas, if reasonably well defined, are the natural and practical units for the presentaClassification by tion of their cultural phenomena, and they may or
Culture Areas may not correspond in their boundaries with the ordinary geographical units. The student of antiquity seeks to determine the limits of these areas and considers the subject matter included in each as a unit of research, which is to be made available for building into the historic structure as a whole. This method is 
probably better suited than any other to the systematic discussion of the antiquities of the continent, yet its exclusive adoption would prove unsatisfactory. To describe separately in full detail, by ethnic areas, the many classes of antiquities would necessitate a vast amount of useless repetition, descriptive and comparative. The necessary comparative study of the multitude of antiquities is carried out to advantage only by taking up each class of artifacts separately, area by area, as a special unit of research. The same is true of the numerous nonmaterial branches of culture, which the archeologist is expected to aid in elucidating.

(3) The culture of historical and existing peoples is readily treated by ethnic units, as by tribes, stocks, nations, and Classification by Peoples

races, according to the needs of the ethnologist, and the archeologist may join him in elaborating these units, carrying the story of particular peoples backward into the deepening shadows of antiquity; but the culture remains of the imperfectly recorded past refuse to be assigned definitely to particular peoples and the archeologist, when the ethnic connection fails, must change his point of view and so manipulate his data-the prehistoric antiquities-as to make them tell, so far as he may, the story of the groups of unnamed prehistoric peoples, applying the data more especially, however, to the solution of the broader problems of chronology and of race and culture history.

(4) It is a well-established fact that the continent has been occupied for a long though imperfectly defined period, and Classification by Time or Sequence numerous well-authenticated discoveries bearing testimony to this fact have been made, but attempts to correlate particular grades or stages of culture with geologic or other time periods have had a very small measure of success. The classification of the antiquities of the continent as a whole, or even of any large part of them, on a time basis is thus not feasible. The salient features of the chronologic record are given under the heading "Chronology."

(5) For purposes of research antiquities may be classified by kinds of artifacts and under designations originating Classification by Kind largely in common usage. Function is an important factor in determining these groups, yet the use of many kinds of artifacts of antiquity is not known, and in many cases may never be determined. This is true especially of articles of superstition and ceremony - a very numerous class - the significance of which, or the precise use of which, is not easily determined, even where found in use among living tribes. With this class of material probable function as inferred from form may serve as a means of classification and treatment. 
(6) The classes of artifacts are very numerous and are, for the greater part, presented to good advantage grouped Ciassification by Materiais

under the sereral materials of which they are made or which enter into their construction, and under these in alphabetical order, as altars, anvils, axes, batons, beads, buildings, celts, chisels, clubs, etc., and under these again by geographical distribution, by form, use, and other significant characteristics. The life history of all artifacts as such begins with the acquirement of the materials employed, and this step, represented by numerous vital industries, is followed by that of manufacture, in which the characteristics of the material have a most important part, determining the nature of the shaping processes and in a large measure the forms produced, as well as the manner and kind of use. So important are these considerations, namely, the acquirement of the materials and the characteristics which affect manufacture and utilization, that a comprehensive study of antiquities from the point of view of the materials employed is exceptionally advantageous. In extending the study of materials into the field of utilization, however, the archeologist finds that in many classes of antiquities two or more materials are combined, as in the building arts, projectile weapons, etc., and must complete his researches by resorting to other classifications, under materials, as by arts and industries, by groups of artifacts, etc.

(7) All antiquities may be assembled and described by the groups of activities concerned in their production and utiliClassification by - zation, and much of the story of the peoples and
Activities

culture of antiquity may be thus told to advantage. This method is a favorite one and serves for separate and effective treatment of various phases of ancient material culture. Of these activities the following are among the most important: (a) Foodacquiring arts-hunting, fishing, gathering, cultivating, breeding; (b) food-utilizing arts-preparing, preserving, cooking, serving; (c) material-acquiring arts-collecting, quarrying, mining, transporting; $(d)$ arts of war-the activities pertaining to offense and defense; $(e)$ the building arts-designing, constructing, decorating; $(f)$ sculptural arts-fracturing, crumbling, cutting, scraping; $(g)$ the potter's art-modeling, molding, baking, burning; $(h)$ the metalshaping arts—swaging, casting, smelting; $(i)$ tissue-working artsscraping, tanning, manipulating; $(j)$ textile arts-hackling, dyeing, spinning, netting, wearing: $(k)$ transporting arts-carrying, hauling; $(l)$ costuming arts-cutting, sewing, fitting; $(m)$ surgical artsamputating, trephining, bleeding, dentistry; $(n)$ medical arts; $(o)$ arts of music; $(p)$ arts of play; $(q)$ arts of embellishment-painting, tattooing, engraving; $(r)$ arts of superstition and magic. These activities are recorded with varying fullness in the materials of antiquity, and the culture achievements and status of the peoples become 
in large measure through their study an open book. In arid regions the most fragile and evanescent of art materials-even cotton, wool, and feathers, and fabrics made of them-are preserved from preColumbian times almost without change, as in Peru, serving to show what the peoples used, what they made, and how they made it. The story of the food-acquiring industries is told by weapons of the chase, especially those of stone, metal, and bone, and that of agriculture by the simple tools employed in cultivating the soil. The food-preparing arts are well represented by nut-cracking, mealing, and cooking utensils and by the countless tools for cutting, rubbing, and pounding. The varied activities connected with the acquirement of the materials employed in the arts and the preparation and shaping of these to serve the needs of man are amply represented. Quarrying, mining, and transporting, and the industries connected with the manufacture of implements and other articles of use and beauty, are included in this group. The activities of war are practically unceasing among primitive tribes and employ the energies of the peoples in countless ways-in the preparation of weapons and works and in expeditions of offense and the critical work of defense-and are amply illustrated by the relics and remains of antiquity. The remains of the building arts tell the story of the builder's with great clearness, more especially in the higher stages of barbarism, where stone was employed in construction; and the textile and plastic arts and the working of metals are revealed by the multitude of products obtained from occupied sites and burial places, and traces of the personal arts-clothing and embellishment-reveal a wide range of activities according to the materials used, the methods employed, the forms taken, and the esthetic treatment.

(8) Students of Old World culture have come to recognize a definite succession of progressive steps which have Classification by somewhat well-established relations with periods of
Culture Steps time. These are known as the Early Stone, the Late Stone, and the Bronze ages. In America, although the probabilities are strong that a somewhat similar succession may apply, at least in part, no lines of separation on a culture basis, except in so far as such steps may be recognized among living peoples, have been established, and classification of artifacts on the basis of culture steps is not attempted.

(9) Classification of antiquities by use brings together groups corresponding in many ways with those based on the Classification by arts and industries and on simple artifact groups,
Functions and any of these three groupings may be employed according to the needs of the student or the use to which his studies are to be devoted. Abrading implements regarded as a use group would include several artifact groups, as scrapers, grindstones, files, 
arrow-shaft straighteners, etc., and all of these and others would come under the broader group of shaping utensils or arts. Personal ornaments, a use group of wide scope and at the same time an artifact group, would embrace several subdivisions and a very large number of simple artifact groups and might conveniently be made the subject of separate and intensive study.

It would appear from the foregoing brief review of the several a vailable methods of classifying the antiquities of America for purposes of research and record that no one method is alone satisfactory for complete and exhaustive presentation; the majority are, however, well adapted for the examination of more or less important parts of the field. It is the privilege of the archeologist to adopt such classification and take such points of view as he believes will best serve his particular purpose, the broader purpose being to place the whole body of the subject matter on record in the manner best suited to the needs of the anthropologist-historian, who in due course may expect to have at his command data sufficiently complete to enable him to give to the world a well-rounded story of the American race.

For the purpose of this treatise, which is designed as a reference work or handbook, it is believed that presentation of the antiquities by groups based primarily on the materials employed will prove most satisfactory, consideration being given under each material group, first, to the activities connected with acquirement; second, to manipulation or manufacture; and third, to form and utilization. 


\section{ACQUIREMENT AND UTILIZATION OF MATERIALS}

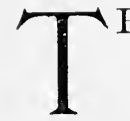

HE materials employed in the arts are derived from the three kingdoms of nature: Mineral, animal, and regetal, and the antiquities of the continent may be considered for the greater part under the three groups thus indicated, and in the order named. Their acquirement and utilization gave rise to many important activities, which differed with the nature of the material and the purposes to which the product was devoted. These activities will not be made, however, the subjects of separate treatment as a whole but will receive appropriate attention in connection with the discussion of the materials with which they are particularly concerned.

The rescurces of the mineral kingdom are located by exploration, gathered, mined, quarried, transported, and shaped Mineral Substances by diversified methods and utilized in a multitude of ways according to the requirements of the particular people.

The acquirement of the diversified resources of the animal kingdom gives rise to activities-hunting, fishing, trapAnimal Substances ping, etc.-which are less distinctive and important than those connected with minerals, for the reason that in a large measure they are by-products of the food-acquiring arts. The activities connected with the preparation and use of these materials and their employment in the arts are imperfectly illustrated in the remains of antiquity, but their character and scope may be determined in large measure through observation of the corresponding activities among living peoples.

The vegetal world supplies a rast body of material for the arts of primitive peoples, but limited evidences of the vegetal Substances activities connected with acquirement are preserved from the distant past. Is with the animal substances, the utilization of vegetal materials gave rise to numerous industries - to carving and building, to the preparation of bark, roots, and fibers, and their utilization in basketry and textiles generally.

Transportation of the materials of the arts follows their acquirement and also follows manufacture, continuing indefinitely through the whole period of utilization. The activities thus arising are of great importance in the history of all peoples, and much may be learned of their nature and extent among the aborigines by a study of the antiquities themselves as well as of the work of historic tribes. Transportation was conducted by water and by land, and man himself 
was the most important burden bearer and the mover of the great bodies of stone and wood employed in building and sculpture. $\mathrm{Nc}$ greater marvel is encountered in the history of the race than that of the transportation of the great stones built into the megalithic monuments of Peru and Bolivia and in the sculptured monuments of Central America and Mexico. The devices employed by the aborigines include water craft of simplest construction-rafts, dugout canoes, balsas, and doubtless skin and bark boats of types known historically. Domestic animals were made helpers by the more advanced peoples. Dogs dragged the travois of the plains, dogs and caribou drew the sledges of the Arctic, and the llama in Peru had acquired a high degree of importance as a burden bearer. Growing out of the exigencies of transportation were the industries connected with road building and the construction of bridges. 


\title{
XII. ACQUIREMENT OF MINERALS
}

\author{
Quarryixg axd Mixixg
}

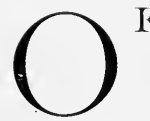

F FIRST importance among the industries of primitive peoples, and of adranced nations as well, is the acquirement of the raw materials of the arts. The mineral kingdom furnishes a large share of these materials: Stone in its various forms-useful, semiprecious, and precious; clay, salt, sulphur, alum, asphaltum, and pigments; gold, silver, copper, tin, quicksilver, meteoric iron, and iron ore, the latter treated and employed always as stone. Little notice was taken by the early pioneers in any part of America of the aboriginal industries connected with the quarrying and shaping of stone and the mining and manipulaLiterature Meager tion of metals. The literature of the subject is extremely meager, and we seek to fill up the wide gaps in the story by study of such traces of the ancient operations as have been spared by the heary hand of time.

The industries involved in the acquirement of these materials, where not already in a state permitting of simple Use of Terms gathering, are known as Quarrying and Mining. "Mining", and There appears to be no essential distinction between the operations and processes implied by these terms. The former is often applied where the materials sought are obtained in open workings, and the latter where they are obtained by deep shafts and by tunneling. Under this definition most of the work of the American tribes would be classed as quarrying. There appears, however, another distinction in common practice, the term "mining" being applied to the getting out of coal, clay, salt, pigments, and the precious and semiprecious stones as well as the metals, no matter whether in open excavation or in subterranean tunnels, the term "quarrying" being restricted to the getting out of stone in bulk, as for building, for monumental work, and for the manufacture of implements and utensils.

In the early stages of culture progress, the stones employed as implements and in the manufacture of implements Beginnings of Quarrying and other articles, as well also as building stone, were gathered at random wherever they happened to be found on the surface of the ground. With advance in culture 
and consequent increase in demand the gathering became an industry in which the communities situated within convenient reach of abundant supplies of the raw material collected systematically and not infrequently employed the surplus product in trade with communities less favorably situated. It may be inferred that the growth of the industry finally led to the opening of quarries of the various kinds of desirable minerals and to the development of trade, which distributed the readily portable products over wide areas, extending far beyond the range of the tribes controlling the source of supply. Instances are recorded in which the possession of desirable quarry sites led to contention and bloodshed between neighboring tribes.

The work of quarrying began with the removal of fragments or masses of desirable material partially buried in the Extent of Opera- ground. It was but a step further to the uncovering
tions and removal of portions wholly buried and but a series of progressive steps to systematic quarrying on a large scale. Ancient excarations where stone was obtained, surrounded by the débris of implement making and the implements employed, are of common occurrence throughout the United States and doubtless throughout America, and the great extent of the operations indicated is in many cases a matter of astonishment.

It is assumed that fire was employed in breaking up the larger and more intractable bodies of rock, when not reUse of Fire in quired in bulk, but the extent of its application in
Quarry Work the mining work can only be conjectured. Naturally, heary, tough stones, as bowlders of quartzite, diorite, and granite, were used as sledges to break up the rock, but these implements would not always serve when large bodies or massive strata were to be worked. In cases where the material sought was embedded in relatively small quantities in solid rock of different constitution, as with native copper, turquoise, and mica, the inclosing rock body

Quarrying of Nodules and Bowlders

had to be broken up and removed bit by bit. The case was different with bowlder and nodule deposits where the matrix was sand, clay, or gravel. In these quarries stone picks and antler points were used in penetrating the deposits, and masses of the material worked were loosened by undermining.

Soapstone and fire clay, after uncovering, were obtained by cutting out suitable masses with picks and chisels of stone; Quarrying of Soap- and the masses of stone required for large utensils, stone and Building Stone

works of sculpture, and building, were hewn out at the expense of great labor with the aid of heary stone

picks and hammers. 
The brittle varieties of stone, such as could be shaped by fracture processes, were in special demand among nearly all Brittle Stone the tribes, since they alone were readily adapted to the manufacture of cutting and piercing implements and weapons. The varieties commonly sought were chert in several of its forms, including novaculite, jasper, agate, and flint; various forms of quartz and quartzite; several metamorphic varieties, and such brittle eruptive rocks as rhyolite and obsidian. In northern America the best known quarries of these rocks are those of Pennsylvania, Ohio, Georgia, Arkansas, Oklahoma, and Wyoming, where massive bodies of the stone were worked; in Kentucky, Indiana, Nodules and Illinois, where nodules were a chief source of supply, and in the Potomac Valley, where bowlder beds were the principal resource of the implement maker. That many others remain undiscovered in the forests and mountains is indicated by the fact that the source of many varieties of stone extensively used by the aborigines has not been determined. Clay for earthenware and fire clay, employed in carving minor artifacts, were mined in many sections. Pipestone was quarried in Minnesota and steatite in many sections throughout northern America. Extensive quarries where cbsidian was obtained occur in Mexico, and the stone quarries, where building stone was gotten out, in southern Mexico and Peru have been visited and briefly described by archeologists.

Iron ore in the form of hematite was mined in Missouri, and red, yellow, and white paint materials were obtained Mining of Metals from the same source. These are the deepest mines known in northern America, the ore body having been extensively tunneled to a depth of 25 feet or more. Copper was mined in the Lake Superior region, and the ancient workings of Isle Royale are the most extensive yet discovered in any part of America.

Little is definitely known of the mining of the precious metals. Gold and silver were in very general use in Middle and South America on the arrival of Europeans, but the literature of the period contains only meager mention of the great industries necessarily connected with their production. The mines were at once taken possession of by the greedy conquerors, and European methods of extracting and treating the metals were introduced. Gold was usually obtained from alluvial deposits by simple methods of panning and sluicing. There seems to have been little knowledge of the reduction of ores, although accounts are preserved of the smelting or melting out of silver in primitive furnaces. 
The principal aboriginal quarries or mines, so far as explored, may be classed as follows:

(a) Quarries of massive stone for sculpture and building.

(b) Quarries of massive deposits of brittle stone.

(c) Quarries of nodules of brittle stone.

(d) Quarries of bowlders of brittle stone.

(e) Quarries of steatite or soapstone.

(f) Quarries or mines of mica.

(g) Quarries of catlinite or red pipestone.

(h) Quarries or mines of turquoise.

(i) Quarries or mines of hematite (iron ore).

(j) Quarries or mines of copper, silver, and gold.

(k) Quarries or mines of clay and fire clay.

(1) Quarries or mines of pigment materials.

(m) Quarries or mines of salt.

(n) Mines of emeralds. 


\section{QUARTZITE BOWLDER QUARRIES, DISTRICT OF COLUMBIA}

HE tribes of the Middle and Northern Atlantic States were
unfortunate in not having plentiful supplies of stone of good
quality for the manufacture of chipped implements. Had such flints as those of the Ohio Valley or the obsidians of California been arailable, the deposits of quartzite bowlders and Inferiority of the the coarse-grained rhyolites and argillites would cer-
saterials

tainly have remained unworked except perhaps for making the heary hammers, picks, and axes, for which purpose these materials are well suited.

In the Potomac and adjacent valleys water-worn stones are found in vast numbers where weathered out of the bluffs Piney Branch and hillsides, and these were utilized for the manu-
Quarries

facture of all classes of implements. So far as shown by exploration, however, they were not extensively quarried except in what is now the District of Columbia, where deposits of cretaceous bowlders, mainly of quartzite and quartz, outcrop along what was once the shore line of the ancient cretaceous sea, and at points of greatest utilization beneath heavy deposits of cretaceous (Potomac formation) sands and gravels. On Piney Branch of Rock Creek, in the northern section of Washington (fig. 43), the The Bowider De- local tribes must have found the bowlders of superior
posits quality for their purpose, for here they carried on quarrying and blade-making operations of astonishing magnitude. The bluffs and gentler slopes facing the creek and its tributaries in the lower half mile of its course rise to the height of 100 feet or more, but are much lower upstream. The Gneissic surface of the ancient ocean bed and the Potomac strata which rest upon it (fig. 44) slope gently toward the east, so that the bowlder deposits which cap the terraced hills next Rock Creek pass beneath the level of the branch east of Sixteenth Street. ${ }^{1}$

\footnotetext{
${ }^{1}$ It is cause for lament that this beautiful valley, the resort for generations of the landscape painters of Washington, is fast being reduced (1910) by deep cutting and filling to the monotonous condition of the ordinary suburb, and the charming rockbordered stream is becoming a deeply buried sewer. In the future it will be known only through incidental references in literature, as here made: and the interesting traces of aboriginal occupation and enterprise will be forever obliterated. In 1892, when the quarries were investigated by the writer, only two dwellings were located within the area of the map (fig. 43), there was but one bridge, and the stream itself had not been molested in any way.
} 
The old quarries are scattered along the bowlder outcrop at favorable points. The most extensive traces of ancient Present A p pear ance of the Quarries

work occur in the face of a ravine on the north side of the creek on about the line of Eighteenth Street. There are but slight superficial traces of the operations, a condition due to the fact that the loosely bedded gravels above crumble rapidly and fill any pittings made on the slope below. The

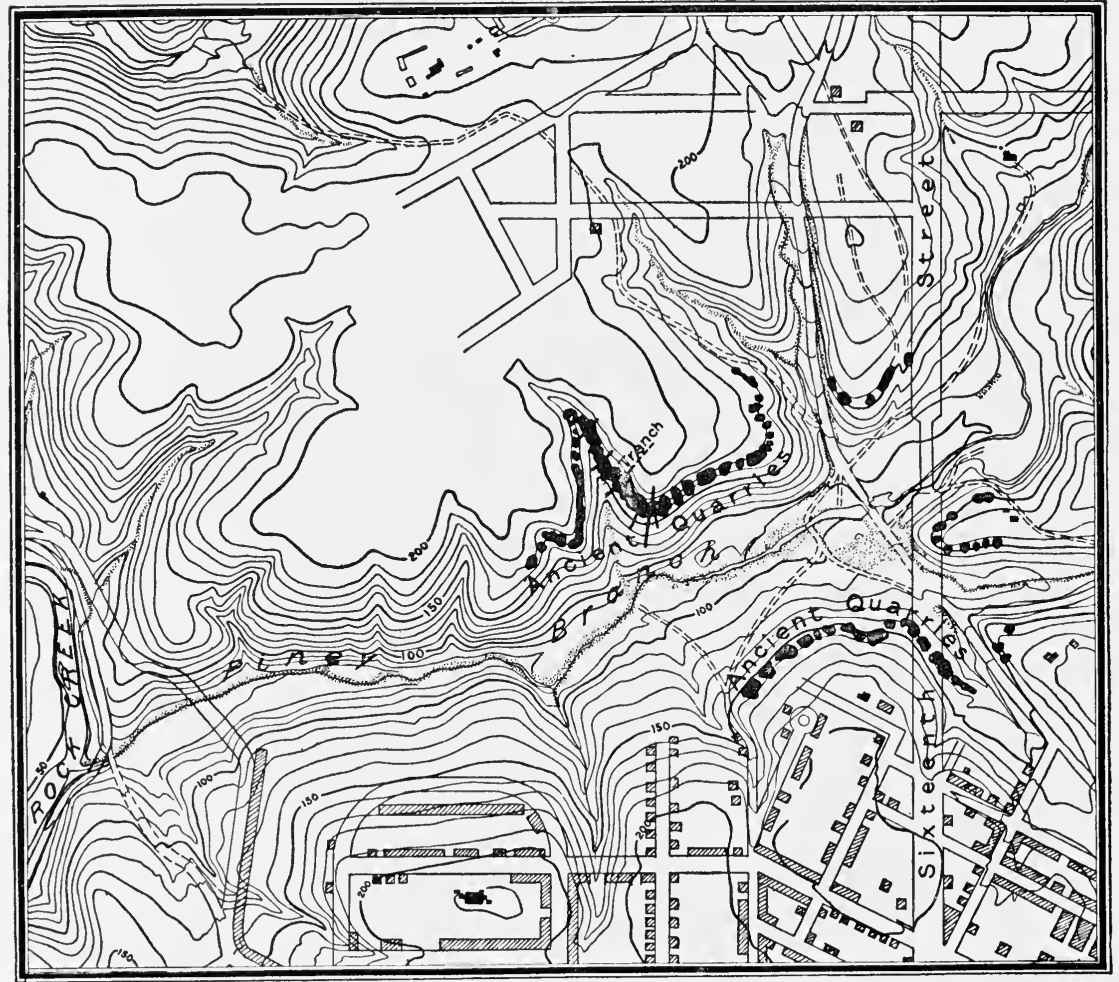

FIG. 43. Map of lower Piney Branch, showing position of bowlder quarries.

several deep trenches carried across the old workshops by the writer were thus obliterated in a short time after the exploration was completed.

The work of getting out the bowlders by the aborigines did not compare in difficulty with the quarrying of the masManner of Quarry- sive varieties of stone as in Ohio and Arkansas, but
ing

nevertheless was a serious task for a primitive people having no metal tools. The face of the bowlder bed in the slopes was readily uncovered, and the bowlders were loosened by means, no doubt, of wooden pikes, and picks of deer and elk antler. Examination of the quarry face where exposed by the recent excavations 
shows that the natives had sometimes entered on the old schistose surface, undermining and knocking down the bowlders above en

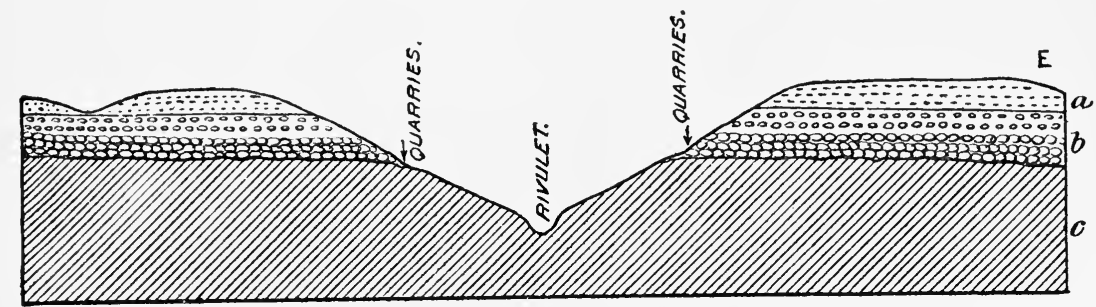

FIg. 44. Section of bluffis showing position of bowlder quarries.

masse (fig. 45). The ordinary profile of the quarry face is shown in figure 46.

The slopes below the bowlder outcrop are deeply covered with quarry refuse and the rejectage of blade making, the The Shaping Work deposits of these materials reaching in places a depth of 10 feet or more. The bowlders were freed from the compact matrix of indurated argillaceous sand and thrown out, and

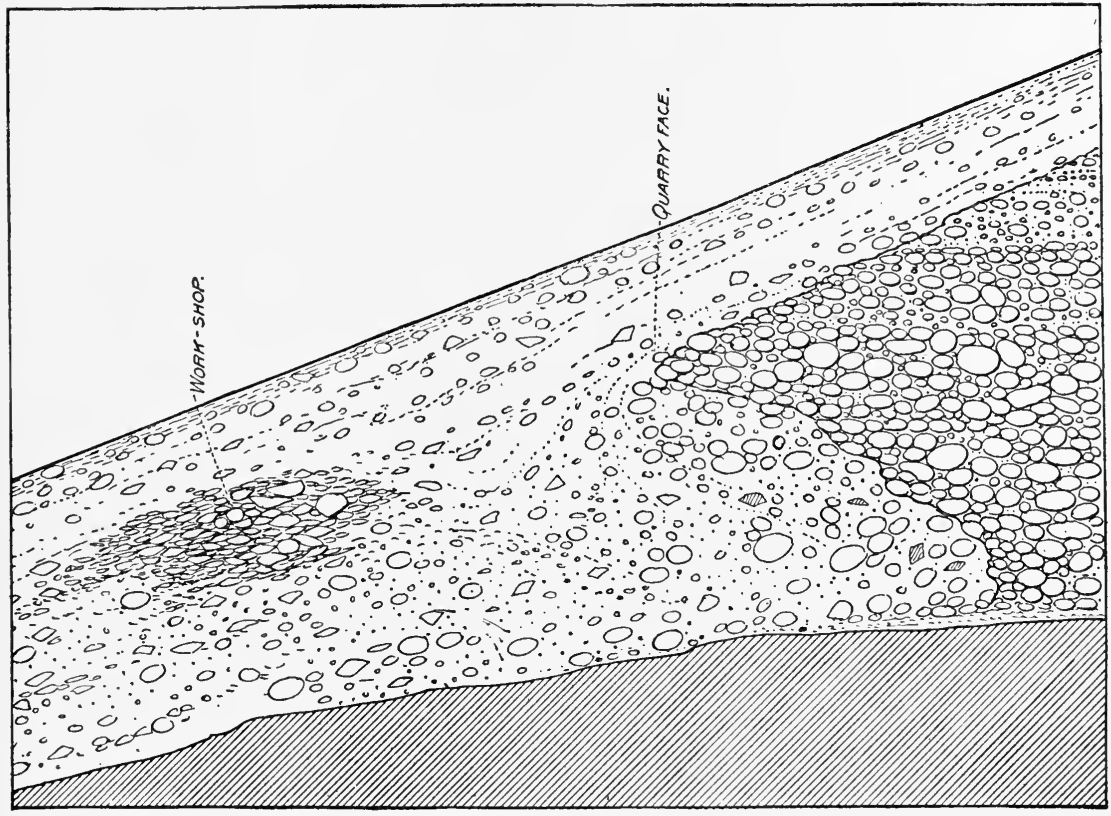

FIG. 45. Section of bowlder quarry showing undermining and a pocket of shop refuse.

the shaping work was begun on the spot. Countless numbers of the bowlders were tested for quality of the material by striking off a few flakes, and being found unsatisfactory, were cast into the refuse (fig. 
47), while those of good quality were reduced by means of bowlder hammers to leaf-like blades of varying sizes, which were carried away for elaboration elsewhere. A characteristic shop deposit showing chips and chipped bowlders appears in firure 48. The work in these shops was directed with great uniformity toward the making of a single blade from each bowlder (fig. 49) as a nucleus by removing flakes by strong strokes of the hammerstone first from one face and then the other, the test of success being a degree of thinness required

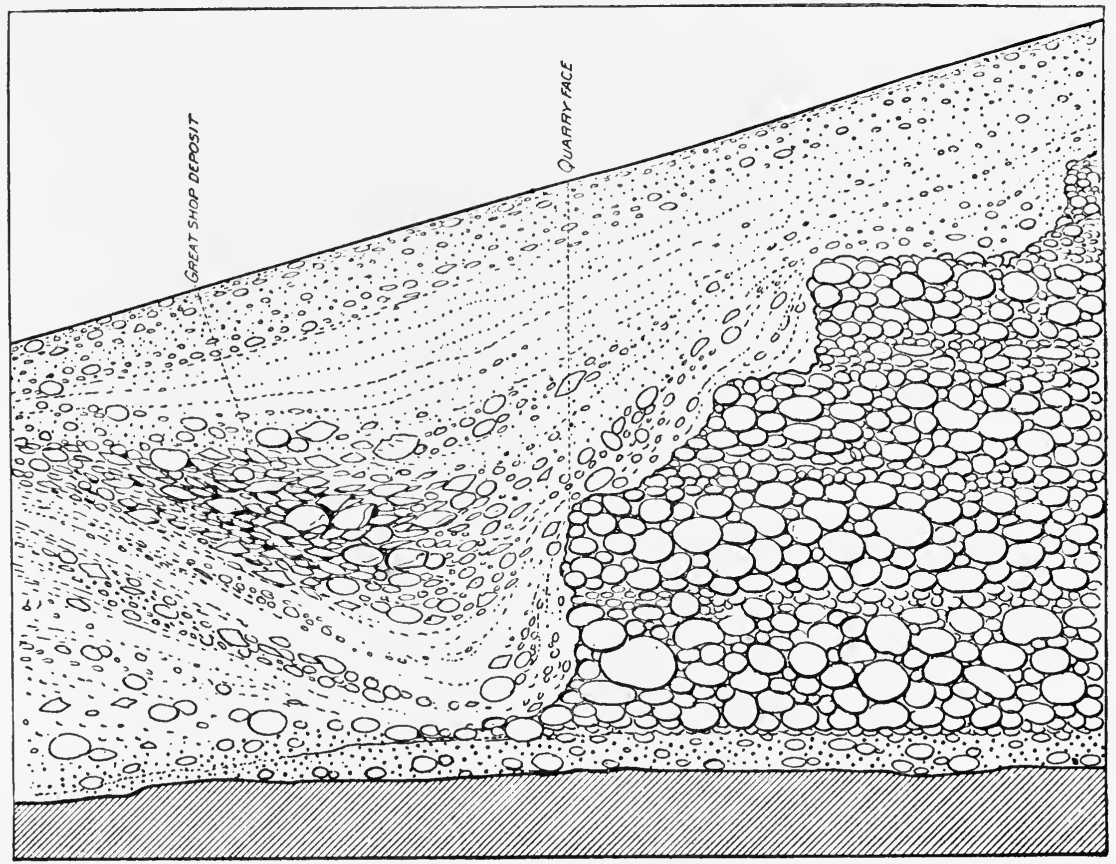

FIG. 46. Section of bowlder quarry showing ordinary quarry face and deposit of shop refuse.

for knife blades and projectile points. Specialization of the blades was not undertaken on the site. Exceptionally large bowlders of good quality were in cases broken up and the more available pieces utilized, but as a rule these are more difficult to treat than the flattishoroid bowlders from 2 to 5 inches in diameter and 1 to 2 inches thick, the kind especially sought by the implement makers.

Although there are on the shop sites no evidences of the specialization of implements, large or small, it may be safely inferred that aside from the leaf-shape blades produced, great numbers of selected fragments and chips were carried away from the quarry to be utilized elsewhere as implements or for the making of implements, especially the smaller projectile points. 


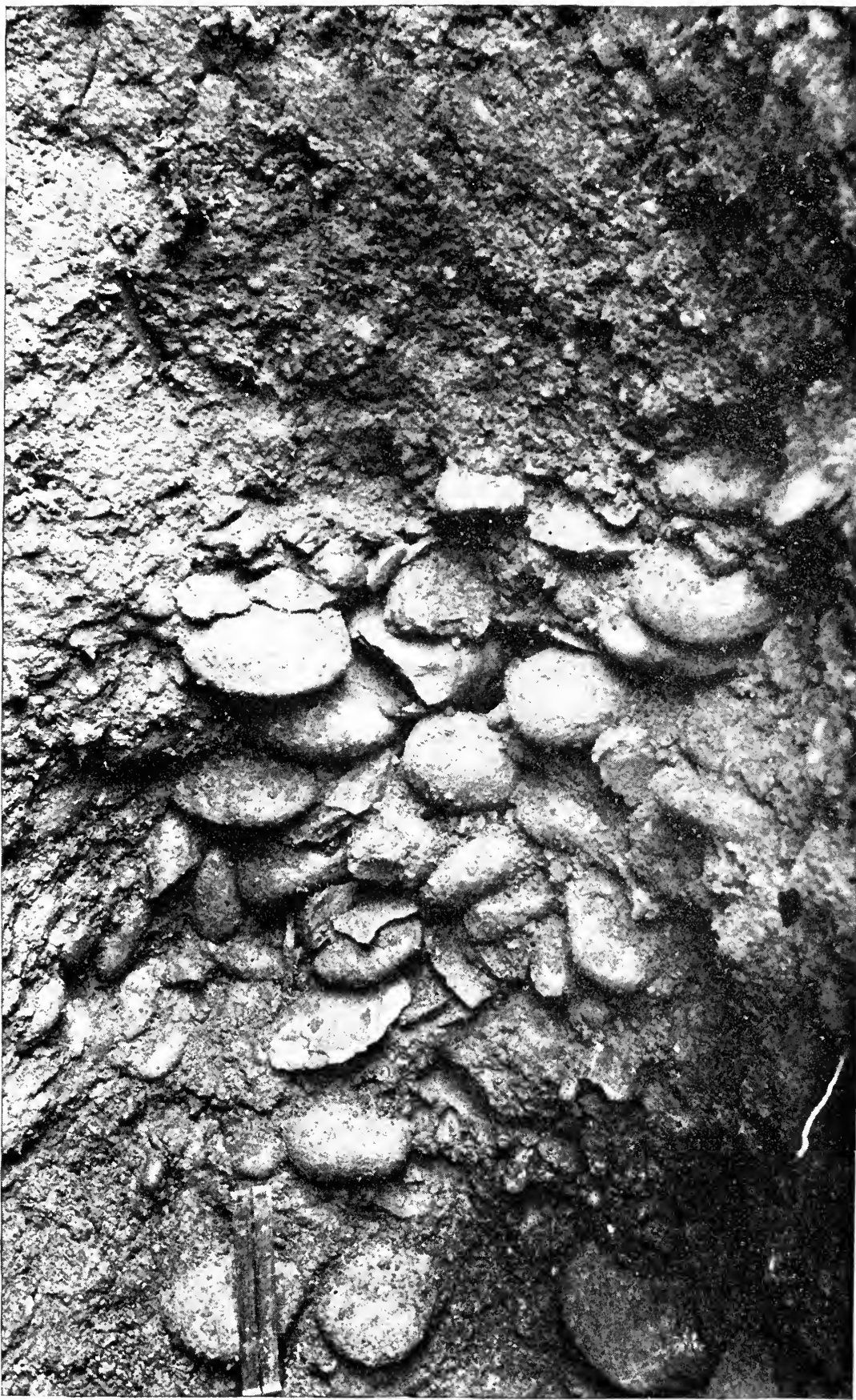

FIG. 47. Character of refuse deposits exposed by trenching. 


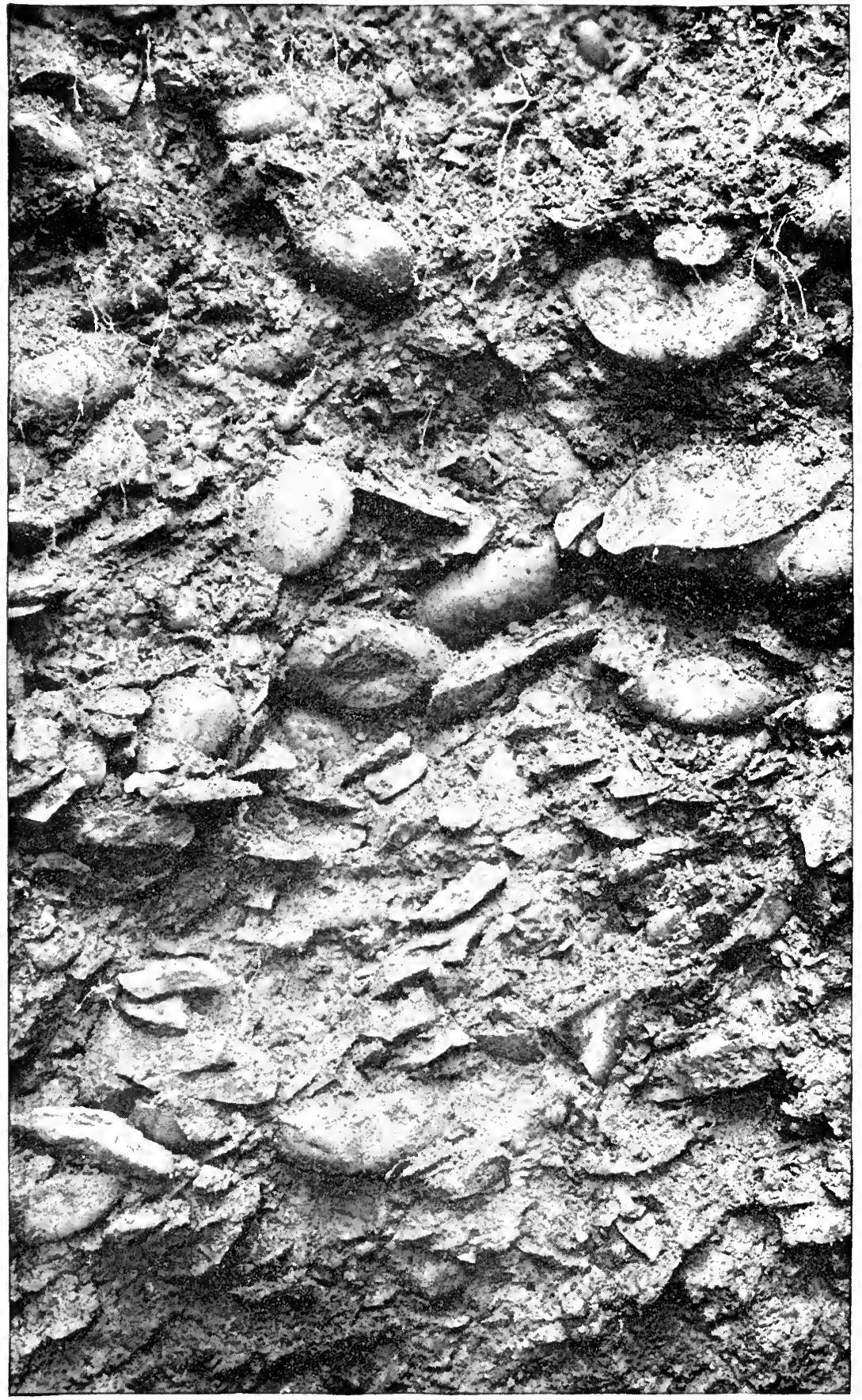

Fig. 48. Part of an extensive deposit of shop refuse near the quarry fare 
The intractability of the stone made failure the rule rather than the exception and resulted in a rast body of parRejectage tially worked, defective, and broken forms. Breakage took place at every stage of the shaping work, and the refuse shows plainly, as already noted, that the only form sought to be
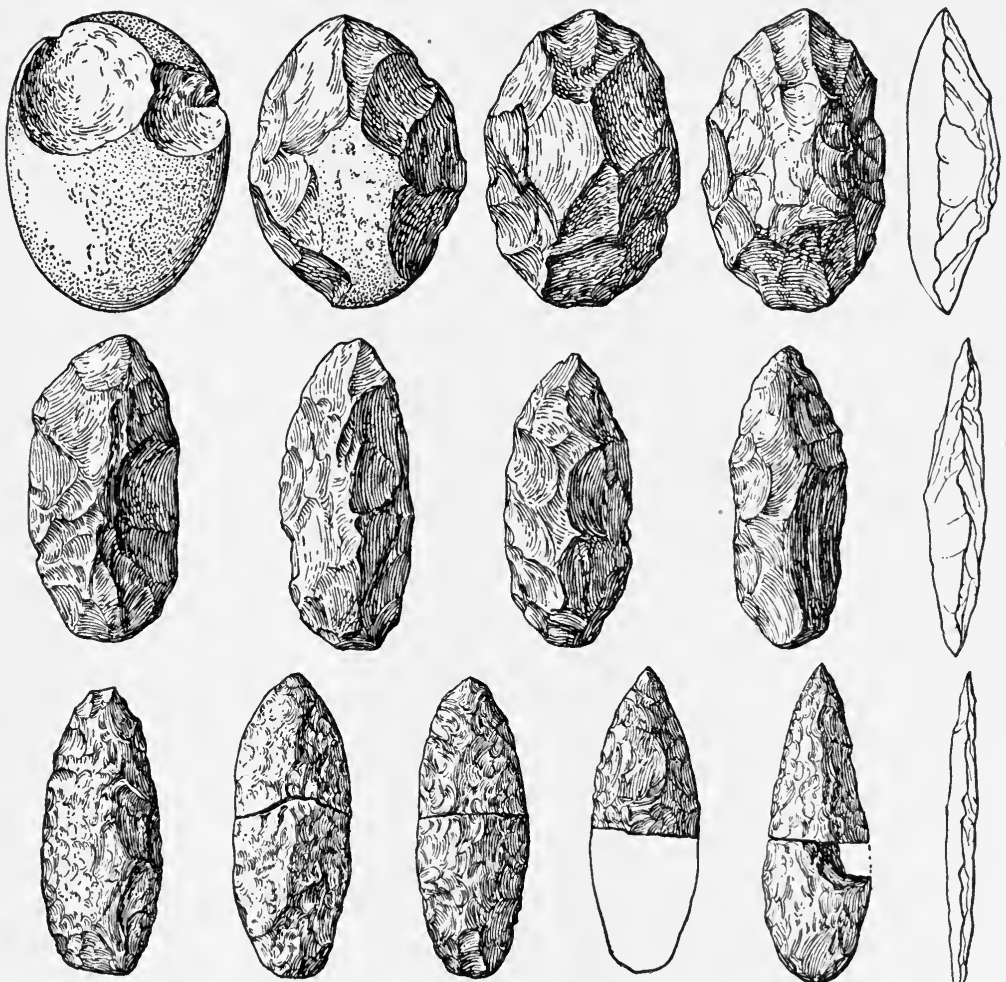

FIG. 49. Relation of a roughed-out, broken blade to the original bowlder.

elaborated in the quarry shops was the thin leaf-blade form best suited for the manufacture of the ordinary chipped implements. $\Lambda$ series of forms representing various successive steps in the progress of blade elaboration from the removal of the first flake to the completion of the knife blades and projectile points is shown in figure 50. In figure 51 are shown typical examples of the blades broken under the hammer strokes at the very moment of completion. The parts of many of such left on the shop sites where dropped when broken were gathered and joined as indicated in the figure. Round bowlders of tough material were used as hammerstones, and a large bowlder employed as an anvil appears in figure 52. Well developed or specialized implements of these classes are rare on the site. It should be noted that the number of well specialized hammers found 

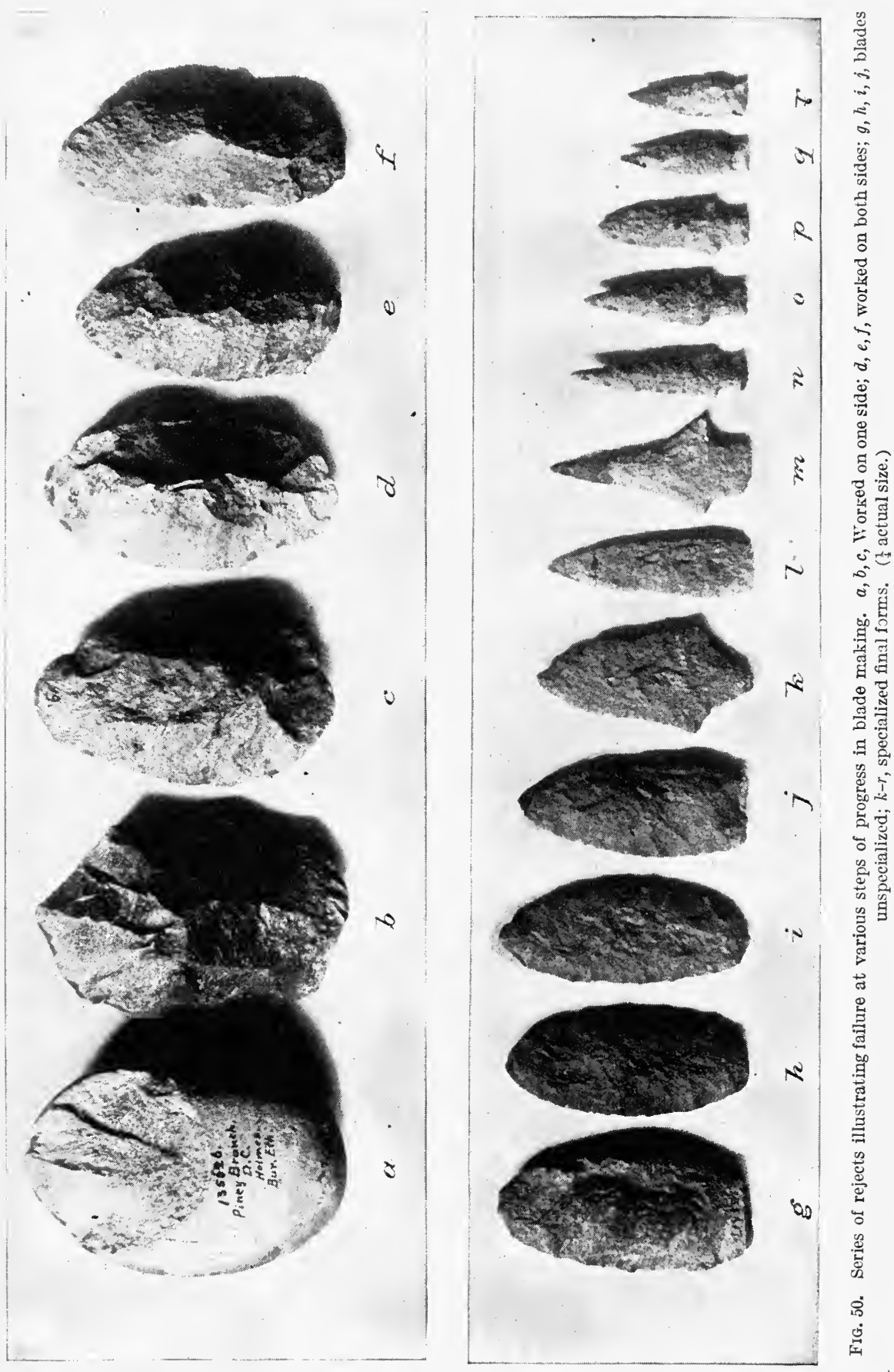
is surprisingly small, and the question has often been raised in vain as to whether any other kind of chipping tool was, or could have been, used.
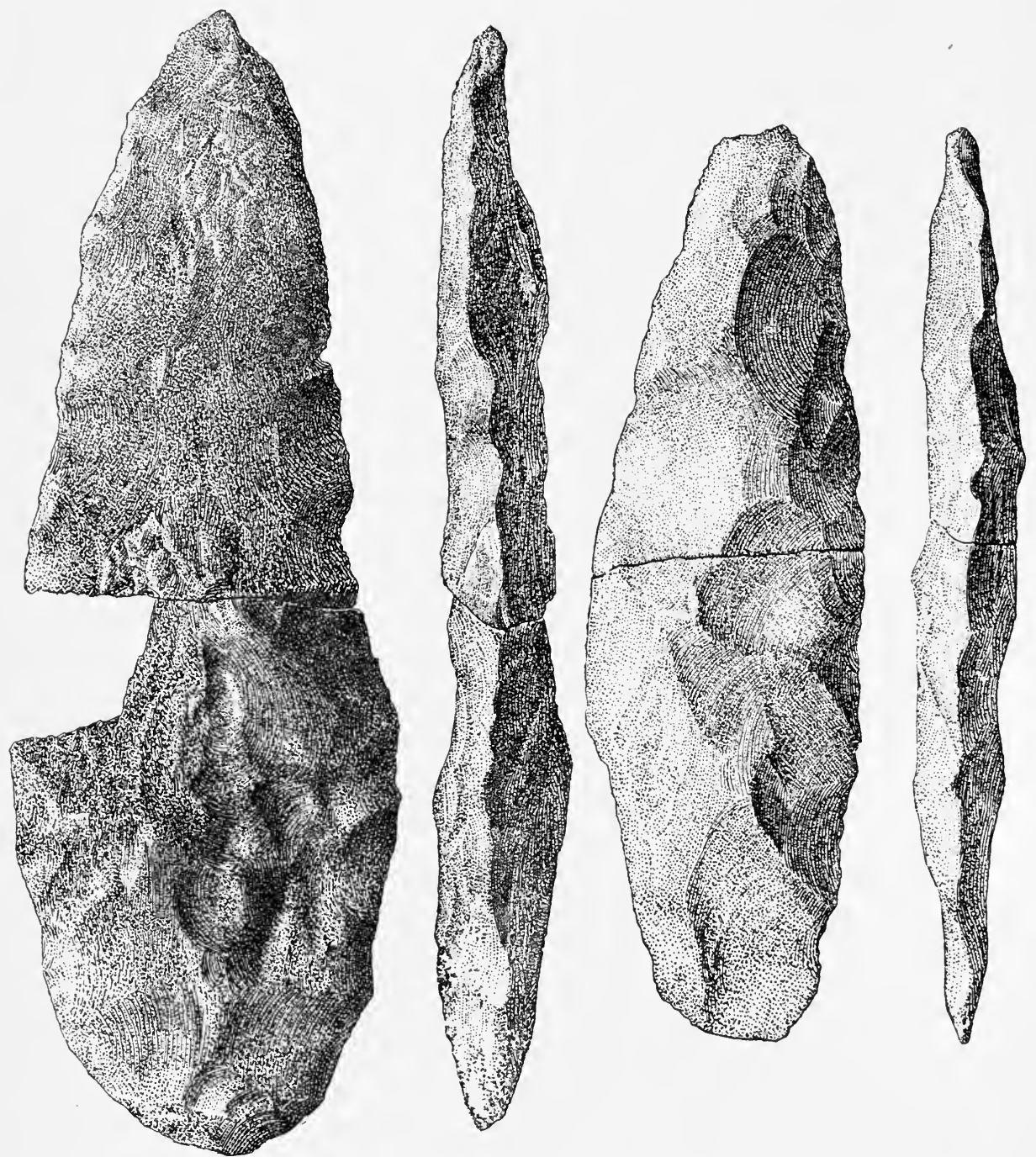

FIG. 51. Examples of blades broken under the hammerstone when nearly finished.

Throughout the bowlder-bearing districts of the Middle Atlantic States the thousands of workshops bear testimony The Distributed to the now well-established fact that the thin leaf
Iroduct blade (fig. 53) was the almost exclusive designed product of the quarry shops and the parent of the several specialized forms (fig. 54), and a stuly of the chipped implements found in countless numbers on village sites and elsewhere fully confirms this 
determination. The unspecialized blades are often found on village sites and in caches far distant from the sources of the raw material, and the specialized projectile points occur throughout tidewater Maryland and Virginia, and in numerous cases are found on the identical sites occupied by Powhatan and other villages of the Poto-

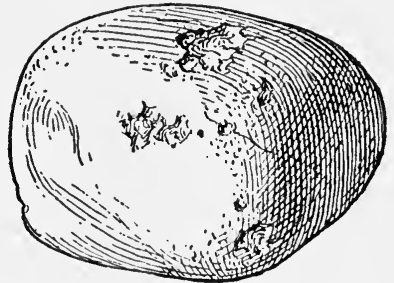

FiG. 52. Bowlder showing marks of use as an anvil. ( 1 actual size.)

mac and James Rivers, with the people of which the early colonists came into familiar contact.

The group of quarry workers illustrated in figure 55, now on exhibition in enlarged form in the National Museum, The Lay-figure illustrates in the most striking manner possible the various features of the quarrying and shaping work as determined by the writer through exhaustive investigations. The scene is laid in the Piney Branch quarries and the figures are costumed according to the only existing information regarding the dress of the tribes of the Middle Atlantic region-the drawings of John White of the Roanoke colony, now preserved in the British Museum. Prominence is given to this group since it represents the most important and essential industry of the native tribes-the manufacture of stone implements-without which little advance could have been made in any branch of material culture.

The question as to the particular period to which the quarry operations should be attributed has been raised, and some writers have rentured the view that the work is very ancient and attributable to very primitive Indian or pre-Indian peoples. This view, however, finds no tangible support. Leaf-shape blades of the type made in such numbers in the quarries are found throughout the tidewater country, associated intimately with the most ordinary remains of the Indian occupancy and on the village sites occupied by the historical peoples. The blades made at the quarry are all of the form through which the millions of specialized arrow and spear heads found everywhere had to pass. If further proof should be called for, it is observed that the quarries with their undisturbed shops are situated on the steep slopes of ravines of comparatively recent origin cut by the rivulets through cretaceous gravels and the 

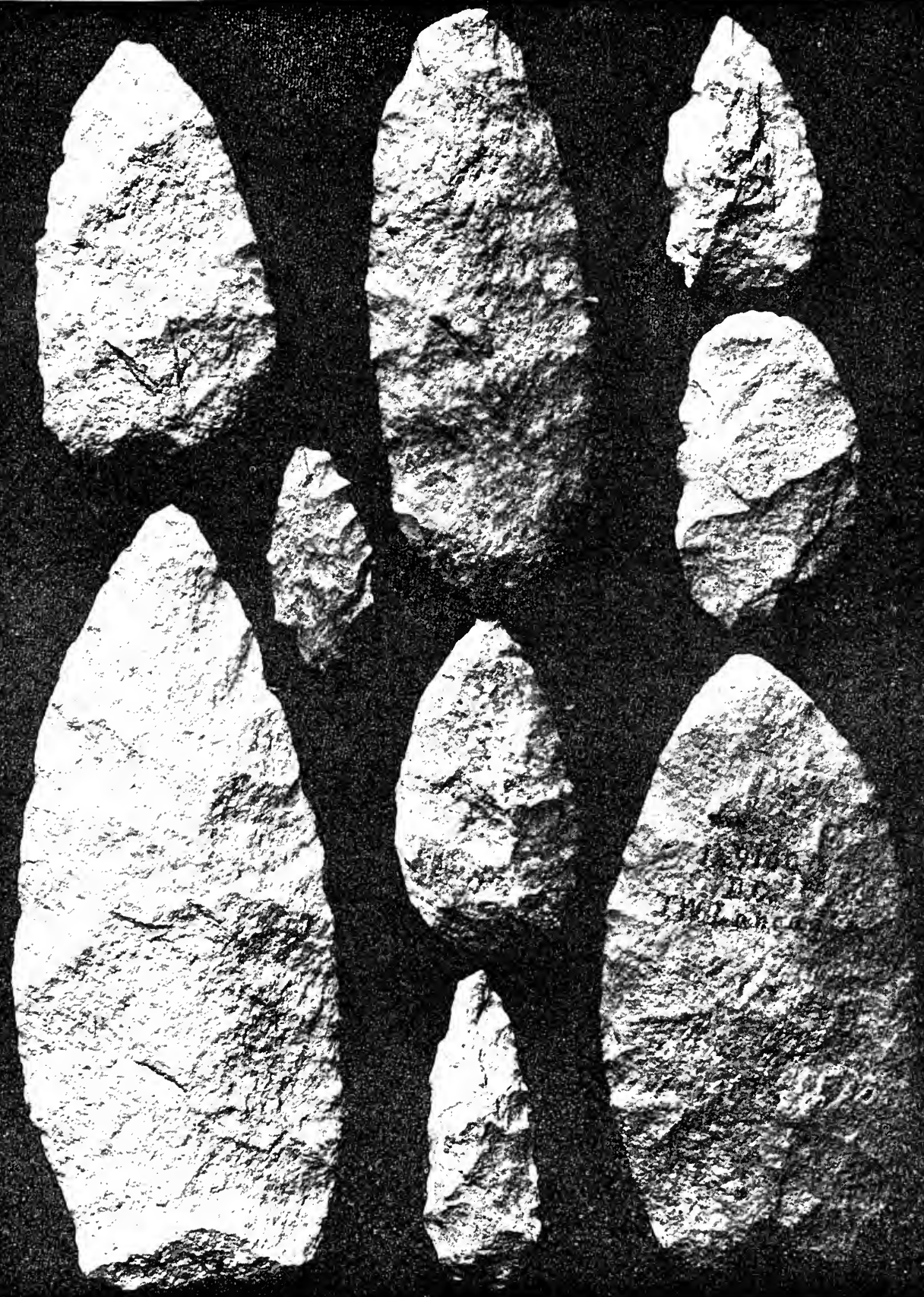


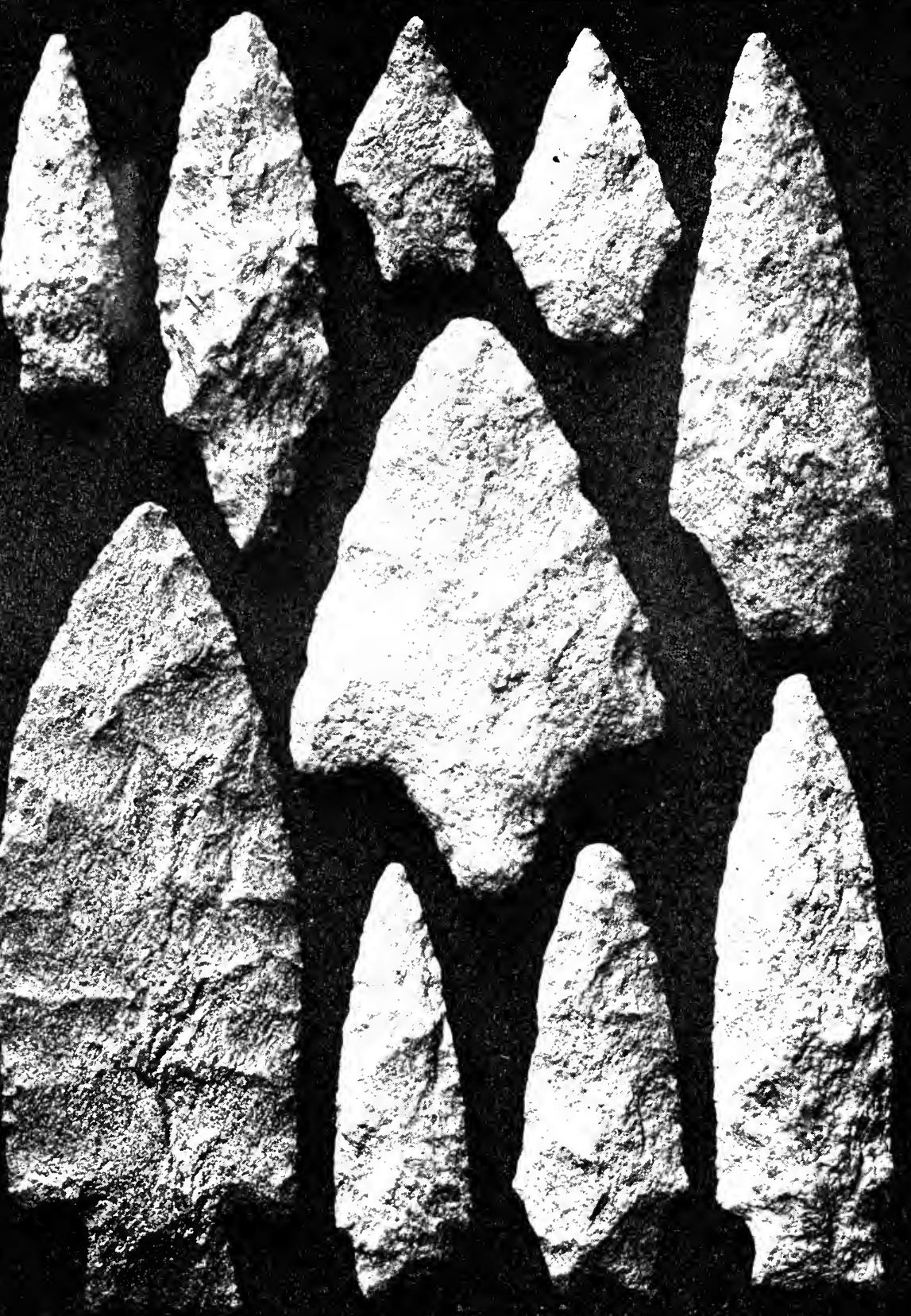

Fli. 5t. Examples of the specialized implements from village sites. (Actual size.) 


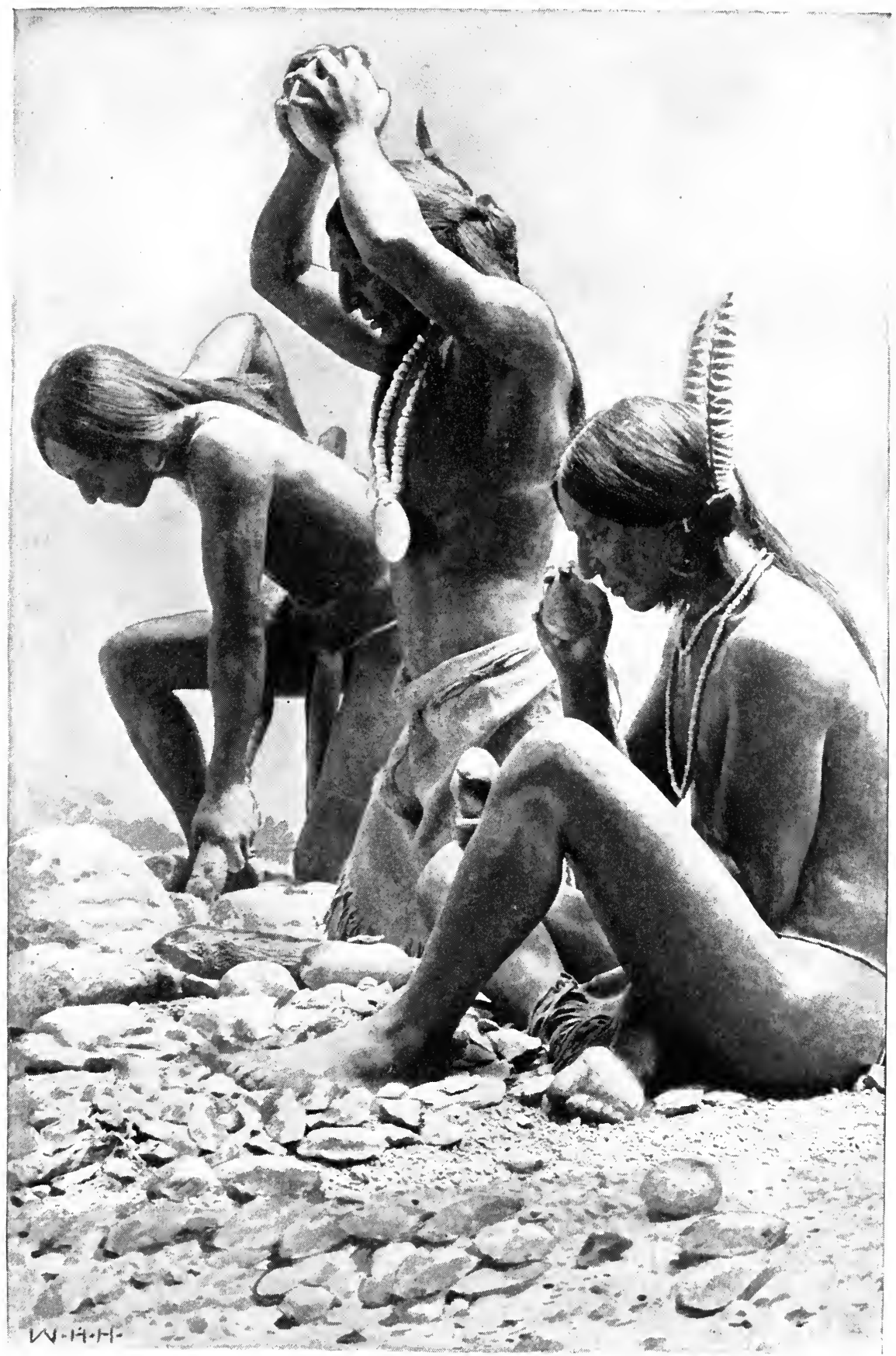

FIG. 55. Lile-size group in plaster of Paris, illustrating the quarry shopwork. (Designed by the author and modeled by U.S. J. Dunbar.) 
underlying schists, and so low on the slopes as to indicate clearly that the gullies were of practically present depth and contour when the quarry operations were in progress. There does not appear either in the character of the work done, the condition of the site, the relation of the quarry product to the types of chipped artifacts of the general region, or the observed order of superposition of types, the least reason for assuming other agencies than the known tribes, difference in culture status, or geological distinctions in time. ${ }^{1}$

${ }^{1}$ For the detailed report on these quarries, see IIolmes, Stone Implements, Fifteenth Aun. Rep. Bur. Amer. Ethn., 1897. 


\section{FLINT RIDGE AND WARSAI QUARRIES, OHIO}

\section{Flin' Ridge Quaries}

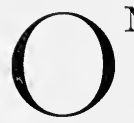

$\mathrm{NE} \mathrm{OF}$ the greatest of the known aboriginal quarries is located on what is commonly called Flint Ridge, a narrow irregular plateau-capped line of hills in Licking and Muskingum Counties, Ohio. The ridge has been known as an aboriginal flint quarry for many years. Hildreth, in the First Annual Report of the Ohio Geological Surrey, under date of 1836, calls attention to the existence and great extent of the quarries. He traced the socalled calcareo-siliceous formations through a number of counties and mentions the presence of ancient mines beginning in Jackson County and extending north into Muskingum County.

In recent years the Flint Ridge quarries have been visited by numerous archeologists, but the first systematic study of the phenomena of the "Ridge" was made by Gerard Fowke, then (1886-87) assistant in the Bureau of Ethnology, and the results of his researches appear in some detail in the Smithsonian Report for 1884 and in his work entitled "The Archæological History of Ohio," 1902.

The extent of the ancient operations is almost beyond belief and can be realized only imperfectly by those who have Extent of Opera- not visited the locality. To say that hundreds of
tions acres of the undulating surface of the plateau have been dug orer and countless trenches and pits opened to the depth of from 5 to 25 feet, often so closely placed as to coalesce within the various groups, does not leave an adequate impression upon the mind. The accompanying map (fig. 56) indicates the general distribution of the flint deposits, and the sketch map (fig. 57) will serve to give a good idea of the superficial arrangement The Pits To-day of the excavations over a small part of the area. The heary stratum or bed of flint, on account of its hardness and continuity, has preserved the general level of the summit, but is or was originally exposed or but slightly obscured along the deeply indented margins, especially on the west: The flint was easily reached along the margins, but farther in, the earth capping in places is 10 or 20 feet in depth or even deeper, hence it presented serious difficulties to the primitive workmen. So pressing, however, was the demand for implement material that this did not discourage the quarrymen, 


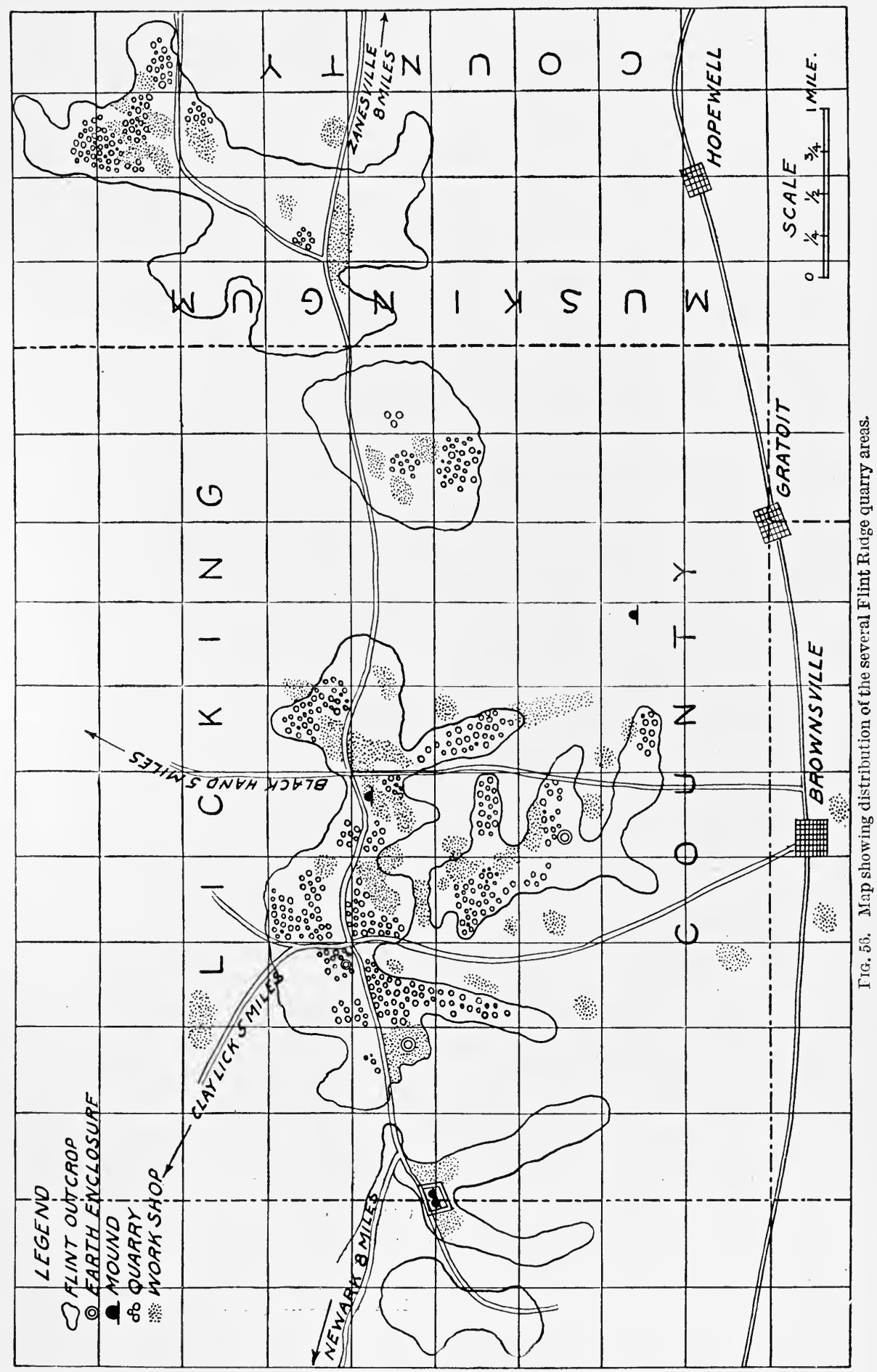




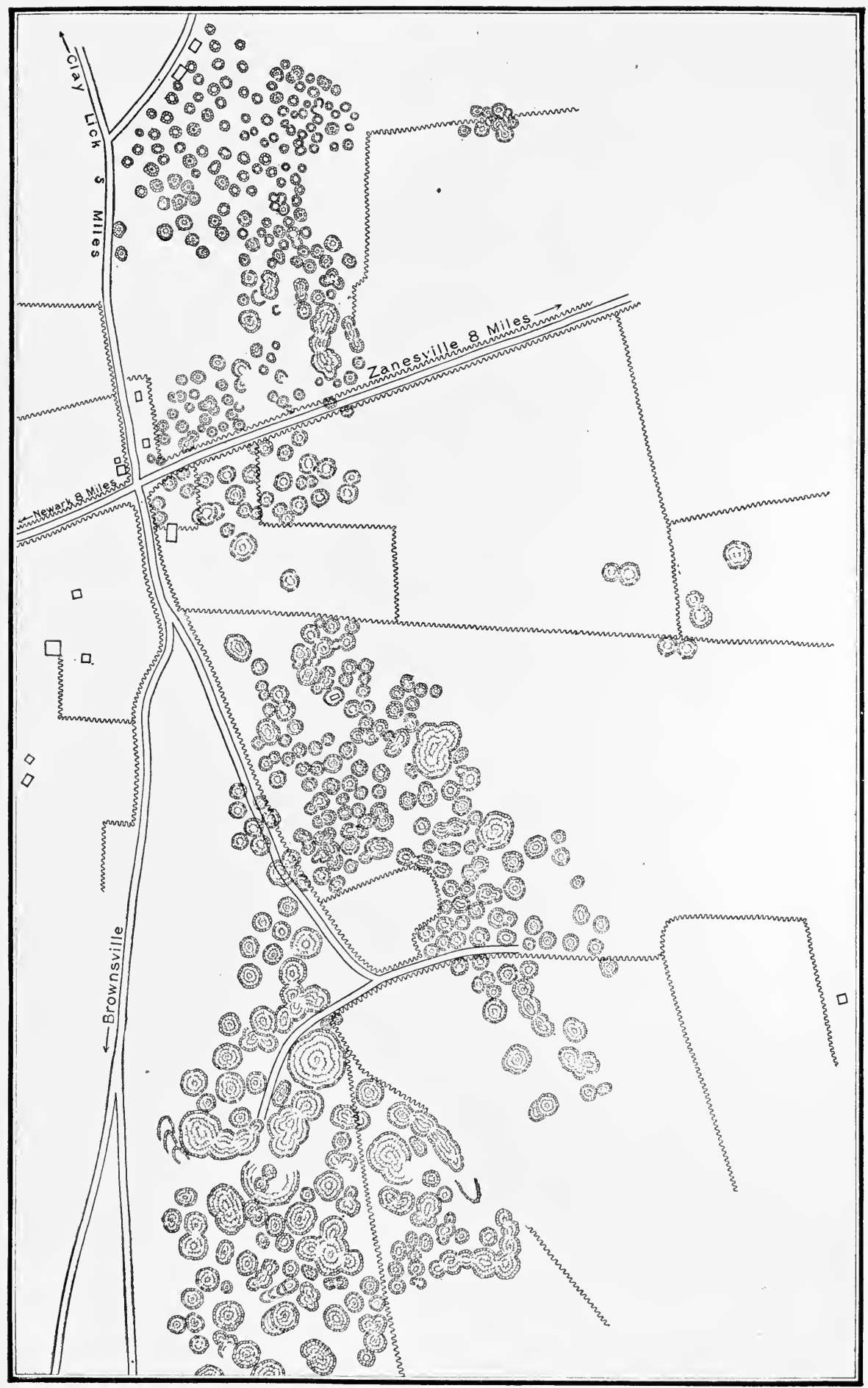

FIG. 57. Detail map of a portion of the Flint Ridge quarries, showing distribution of pittings. $38657^{\circ}-19-$ Bull. 60 , pt I-13 
and the massive flint was uncovered and broken up bit by bit. This work resulted in the accumulation of ridges and heaps of earth about the margins of the pits, and many of the earlier excavations were obliterated by gradual filling. It should not be imagined, however, that evidence of these operations is to-day obliterated or nearly so. Many of the pits are yet as distinct as if made within recent times, and it is not unusual to find them still having a depth of 5 to 10 feet.

The flint stratum is of irregular thickness and uneven quality and does not appear to exceed 7 or 8 feet in thickness at any point. Where the material was found to be of good quality only small sections of the bed remained unworked. Large tracts of the plateau summit, which is some 3 miles in length and nearly 3 in width at the widest part, are so broken up by the ancient work that they are almost wholly lost to agriculture, and on many workshop sites the deposits of shaping refuse are so heavy that the plow can not be used. Naturally the most deeply pitted areas are still in forest, while the soil in such parts as have been invaded by the plow is literally filled with fragments, chips, and other rejectage.

The flint varies greatly at different portions of the deposit. For some distance from the margin on every sicle it is whitish or grayish in color, [The Flint] cellular or porous in structure from the weathering out of small fossils, and makes an excellent buhrstone, for which purpose it was formerly in much demand. Within this border it is more compact, freer from impurities, and possesses all the colors and shades ever seen in such stone. Much of it is a typical chalcelony, blue or grayish-blue and translucent. Large beds exist of banded or ribbon jasper, with alternating stripes of light and dark gray. In places there is a glassy variety ranging from almost perfect transparency to complete opacity, except in very thin flakes, inclucled carbonaceous matter producing every gradation from a slight cloudiness to jet black. Much of this can not be distinguished from moss agate. In the central part of the ridge the chalcedony has weathered into various tints of blue, red, brown, yellow, and white; occasional pieces of green and purple are found. ${ }^{1}$

The great marvel is that the aborigines ever accomplished the work of which such abundant traces remain, and only Method of Quarry- those who have ventured to remove a small mass of
ing the flint from its place can realize the appalling difficulty of the work, even to men with tools of steel, unaided by powerful explosives. The work was done, no doubt, little by little with tools of stone, wood, and buckhorn, aided by fire, as described by Mr. Fowke. A freshly made pit must have presented somewhat the appearance indicated in the sectional view, figure 58.

A pit of which a special study was made by Mr. Fowke was somethirty-two feet in diameter inside of the wall of earth surrounding it, which wall is now 2 feet higher than the general surface around it, and from 20 to 30

1 Fowke, Archæological History of Ohio, pp. 619-621. 
feet across at the base. This form indicates considerable age; as does an oak tree nearly 10 feet in circumference, growing on the top of the wall. In clearing out this pit we could appreciate the patience and industry of the aboriginal excavators. The clay subsoil was as hard and tough as frozen ground; frequently half a dozen blows with a pick were required to break off a clod as large as a man's hand. To remove it with primitive tools seems almost an impossibility. The central part of the pit was filled with material that had washed in from the sides. Several days of steady digging were required, by three men accustomed to such work, to reach the surface of the flint stratum, which was found at a depth of 9 feet. A hole 5 by $8 \frac{1}{2}$ feet had been worked through; clearing this out, we found the layer to be 40 inches thick. It rested directly upon a solid bluish limestone. Both the flint and the limestone showed that they had been subjected to an intense heat. The flint was very solid where not burnt, translucent, and a beautiful light blue in color. On its top, on a corner formed by two seams, was a saucer-shaped depression between 3 and 4

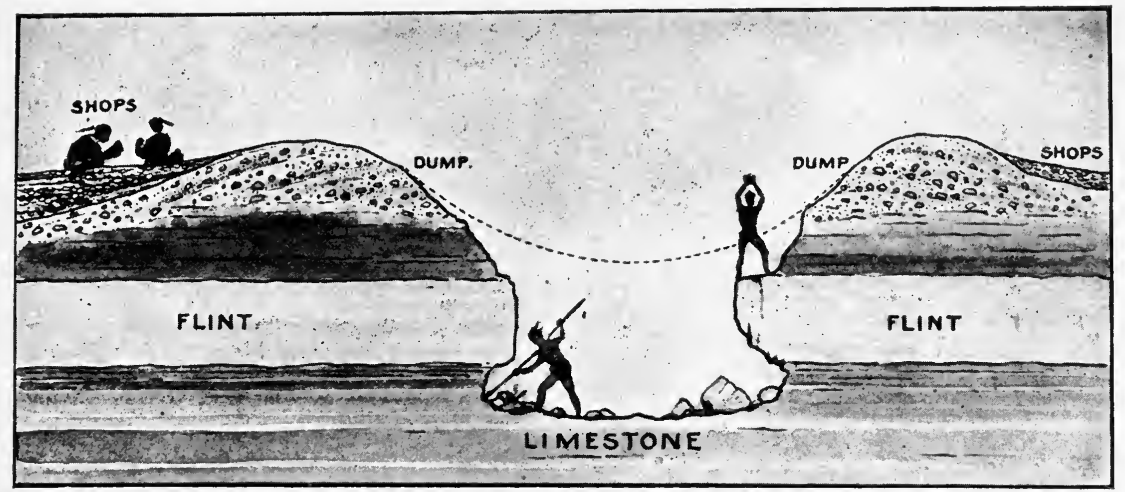

FiG. 58. Section of a quarry excavation, showing work in progress.

inches deep, in the bottom of which was a handful of very fine chips; just such as would result from repeated blows with a large hammerstone, several of which were found scattered through the entire depth cleared out. One of them weighed nearly or quite a hundred pounds.

Careful observation of this pit-and others as well-enables us to follow the prehistoric quarryman in his labors. He selected a spot where he thought the superincumbent earth was not heavy enough to render the task of removing it too tedious, but at the same time was of ample thickness to prevent injury to the stone from weathering. He then sunk a pit, as large as he wished, to the surface of the flint. On this he made a fire; and when the stone was hot he threw water on it, causing it to shatter. Throwing aside the fragments, he repeated the process until he penetrated the underlying limestone to a depth which allowed him sufficient room to work conveniently. The top and freshly made face of the flint was thickly plastered with potter's clay, after which fire and water were again utilized for clearing away the limestone until a cavity was formed beneath the flint layer. Thus a projecting ledge would be left from which the burnt parts were knocked off with heavy stone hammers until the unaltered flint was exposed; in the same manner blocks of this were procured for converting into implements. "Where the flint was well suiter for the purpose intended, or was easily worked, the excavation was carried along in the form of a trench, the waste material being thrown to the rear; under less favorable conditions the spot was abandoned. 
When the blocks thus obtained were reduced with the large hammers to a suitable size for being handled easily, they were carried to [Breaking Up and Selecting]

a convenient spot, which may be designated as a blockingout shop, where the first stages of manufacturing were carried on. These shops are sometimes quite limited in extent, but occasionally they cover an area of 5 to 10 acres. Scattered thickly over the ground in such places are angular fragments of flint, such as would result from knocking off corners and projections from large pieces taken out of the pits and also from breaking them up into smaller pieces. . . Probably nine-tenths of the flint carried from the pits to these blocking-out shops was rejected; the trimming process revealing some flaw or defect that made it unfit for use. The remainder was carried to other places which may be called finishing [Workshops] shops. These are characterized by lighter hammerstones, smaller fragments, thin flakes, and broken implements in all stages of completion. Although never so extensive as the first named, they show a greater amount of work on an equal area. The largest are in the vicinity of the pits and the other workshops; but they may be found, gradually diminishing in extent, at springs, camping places, and village sites, as we travel in any direction, sometimes 50 miles or more from the parent ledge. ${ }^{1}$

There is little indication that the implements were specialized on the local shop sites. The "Ridge," however, is, in large part, a habitable place, and doubtless parties engaged in the mining and shaping work were settled about the springs convenient to the quarries and spent much time there. It is thus not surprising that many finished implements of various classes are found in the vicinity of the quarries and scattered over the ridge.

Fragments of the flint, partially shaped blades rejected because too thick or otherwise defective (fig. 59), and blades broken under the blows of the hammer, together with the nuclei or cores from which flake knife blades were made, as well as great deposits of chips, are found at many points.

The hammerstones employed in the chipping work are very numerous. Some are bowlders picked up in the vicinity Hammerstones or brought from the neighboring streams while many are rough-shaped from tough portions of the flint (fig. 60). Most of the latter are globular or discoidal in form, and many of the larger specimens used in breaking up the flint weigh as much as 50 pounds, while the smaller, with which the finer shaping work was done, are not larger than walnuts. A study of the rejectage makes it plain, however, that the principal output of The Shop Product the shops consisted of leaf-shape blades ranging from 1 to 6 inches in length. These doubtless served in the main for subsequent specialization into knife blades, projectile points, and drills, according to the need of the occasion. Countless implements, recognized by their color and texture as coming from these quarries, are scattered broadcast over a wide area, which in-

1 Fowke, op. cit., pp. 622-623. 


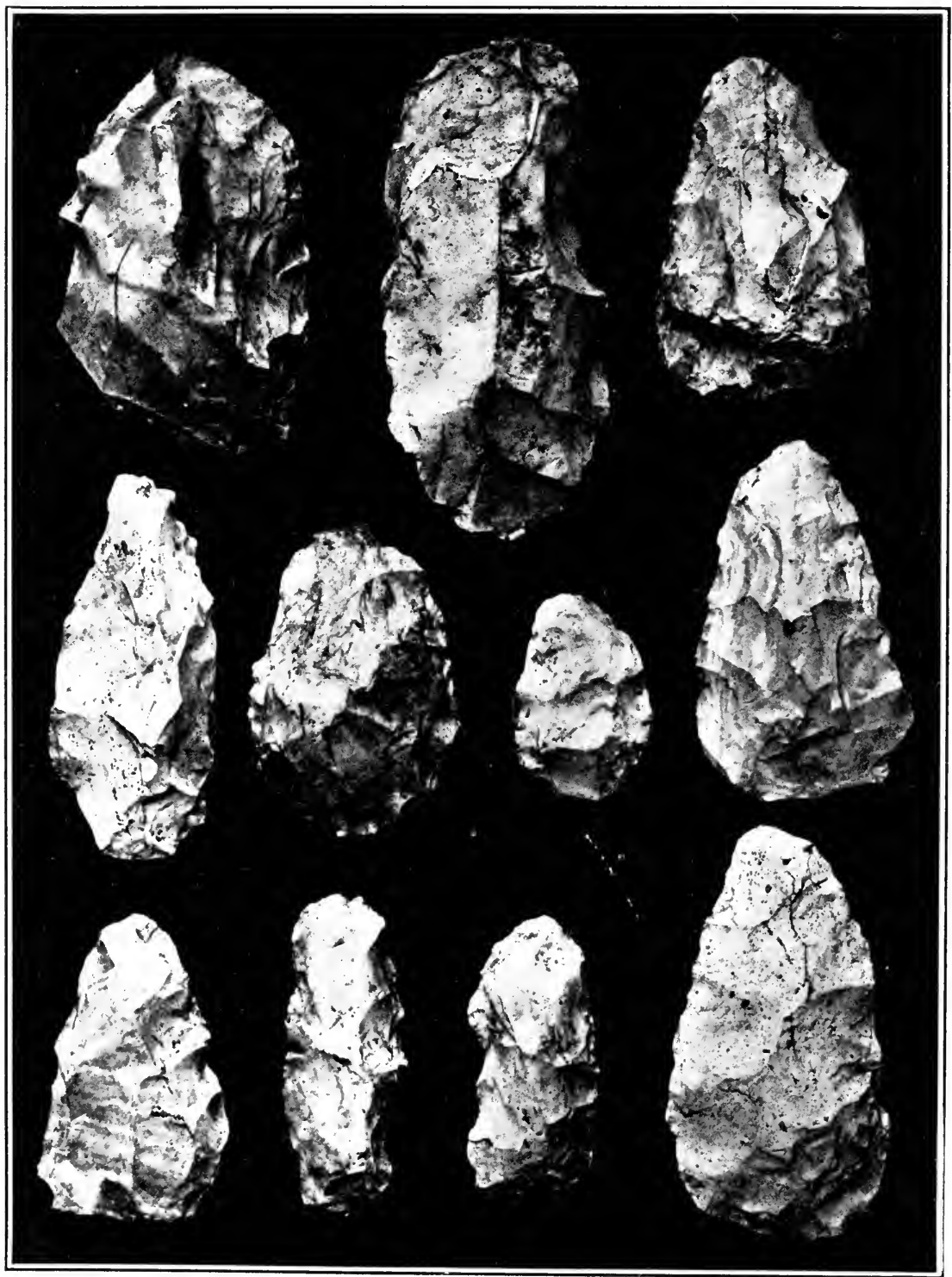

F19. 59. Rejects of blade making due to malformation, too great thickness bein: the principal cause of failure. (One-half actual size.) 


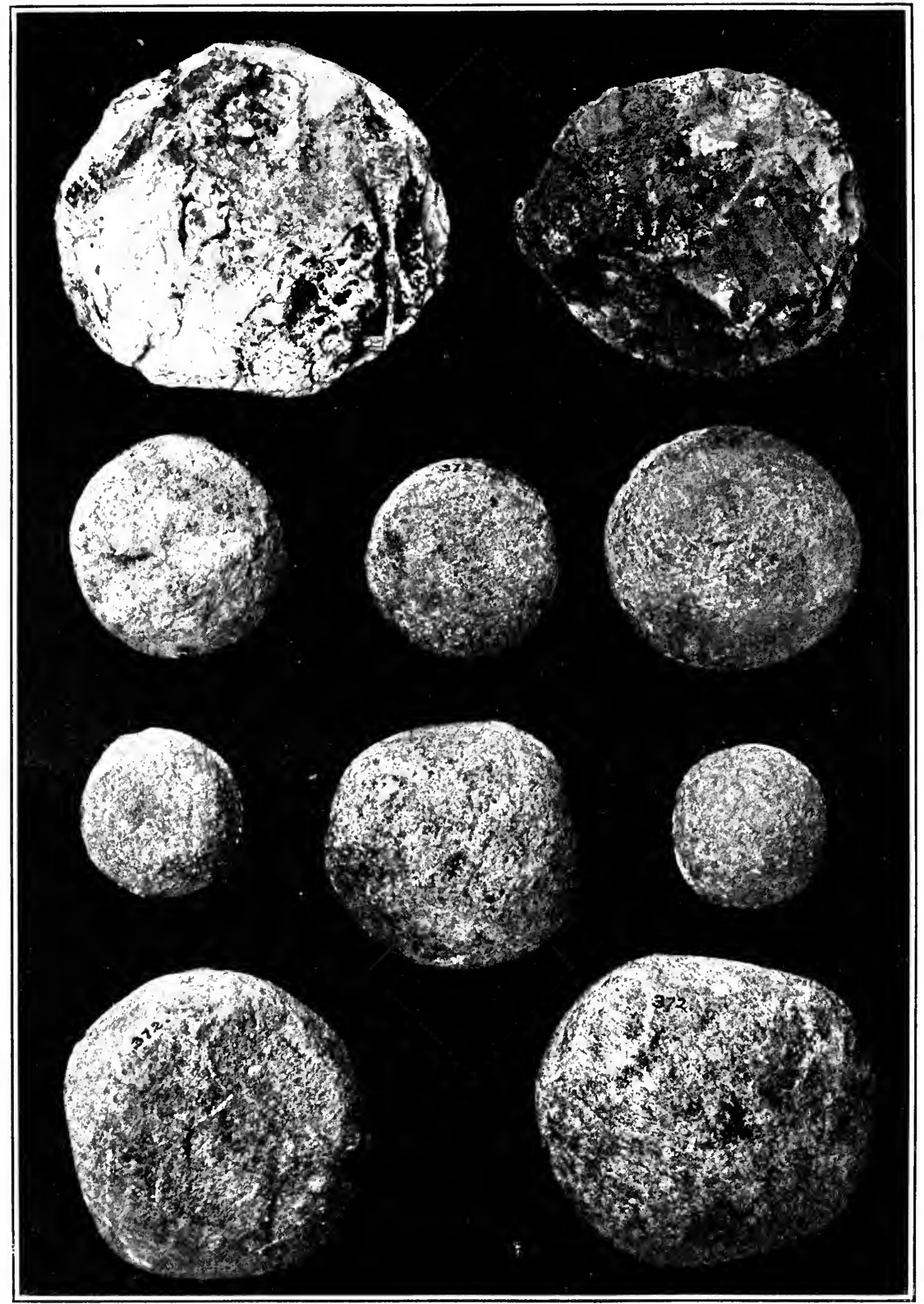

I'IG. 60. Examples of the hammerstones employed in blade making. (One-half actual size.) 
cludes Ohio and parts of Pennsylvania, West Virginia, and Kentucky. Typical examples of the unspecialized blades are shown in figure 61 and of the finished implements in figure 62 .

The presence of large numbers of cores or nuclei (see fig. 87) indicates that a product of much importance consisted of minute flake blades, which probably served as knives. The very fine-grained flint found at certain points on the ridge was perhaps better adapted to this purpose than any other in the eastern half of the country, and this is the only quarry so far studied in which this particular work was extensively carried on.

Other quarries of the Flint Ridge system correspond closely in all important respects with those described above, but none are as representative or as extensive.

\section{Warsaw QUARries}

In Coshocton County, in the vicinity of Warsaw, a number of quarries have been examined with some care. One of these is well characterized by Fowke in the following lines:

Quarries of siliceous stone somewhat similar to those at Flint Ridge exist along the Walhonding River about 3 miles from Warsaw. The flint

[Warsaw Quarries] as originally deposited formed a continuous layer of varying width about 10 or 12 miles long; but subsequently erosion has left only comparatively small detached areas on or near the summits of hills and ridges. At one place a narrow ridge extencis for some distance between the river and a tributary ravine, the flint forming the cap rock beneath a few feet of earth. The aborigines began at the outcrop on one side and dug their way through to the opposite side of the hill, removing all the flint and overlying material, selecting what they could utilize and throwing the residue behind them as they proceeded. The space thus dug over is fully 5 acres. Many circular pits, the largest not less than 100 feet in diameter, are to be seen on the level summits; and much quarrying has been practiced along various outcrops, the work progressing until the removal of overlying rock and earth required an amount of labor too great for the reward. There is much variety in the quality and appearance of the flint at this place. Part of it is cellular, almost spongy, from the weathering out of fossils and various impurities. By insensible gradations it passes into stone as compact and homogeneous as fine agate. Seams of chalcedony, and cavities filled or lined with quartz crystals, occur abundantly. Chert, glossy basanite, and small masses of chalcedony are common. The color runs through various shades of white, black, blue. and red, and there is also the pale amber or "honey color," very rare in this country. Some is almost transparent, and from this it merges into complete opacity. There seems to be no regular order in its arrangement; sometimes there are thick strata of considerable extent with but slight variation in character, while again three or four sorts may be seen in one large block. One color may gradually blend with another or the line of demarcation may be sharply defined without the slightest change in other respects. Only a small proportion of the deposit is of a character suitable for making implements, consequently less digging has been done here than in beds considerably smaller elsewhere. The difficulty of reaching deeply-buried parts has also been a deterrent to extensive working. 


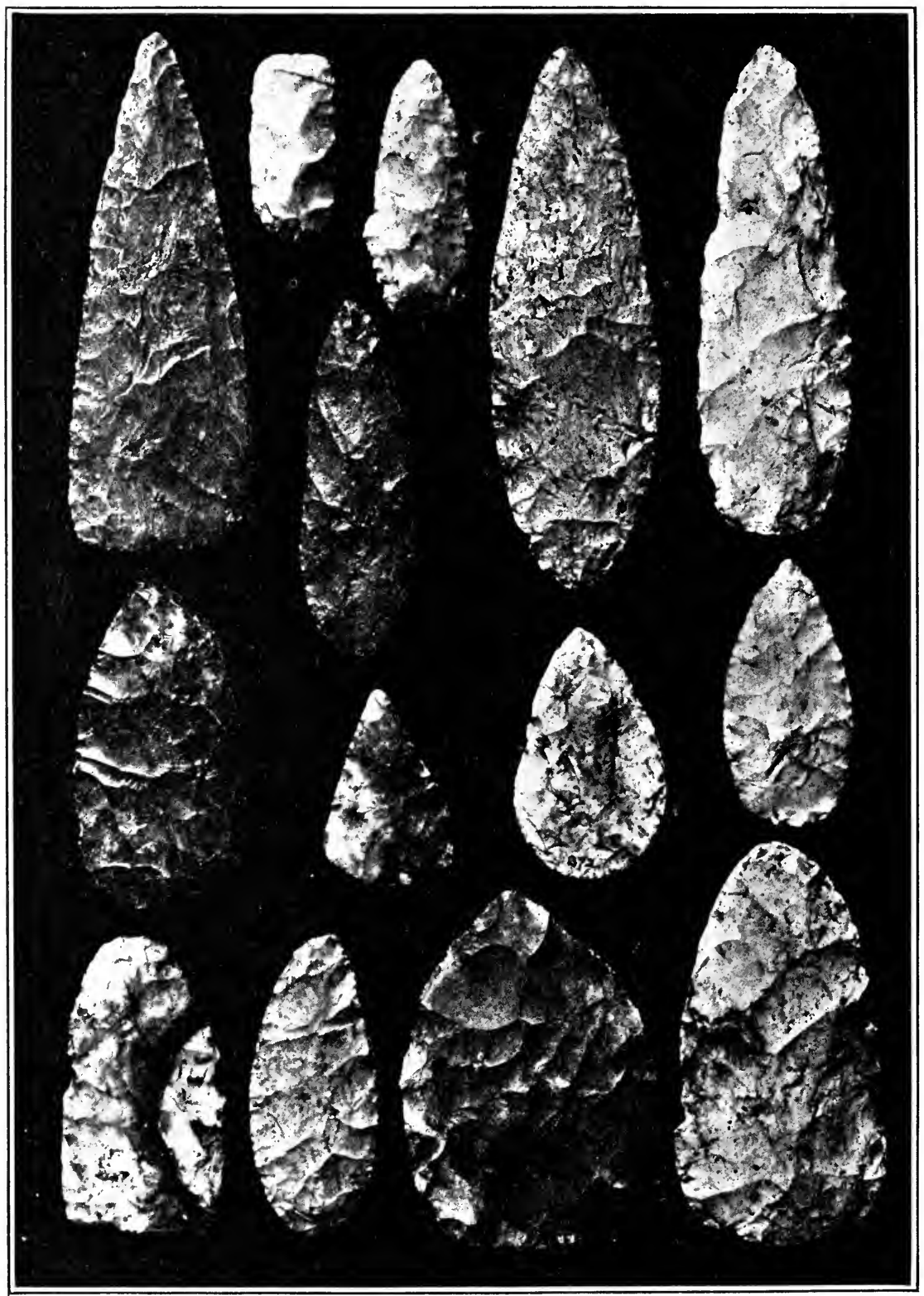

FIG. 61. Types of the blades produced in the quarry shops. (One-half actual size.) 


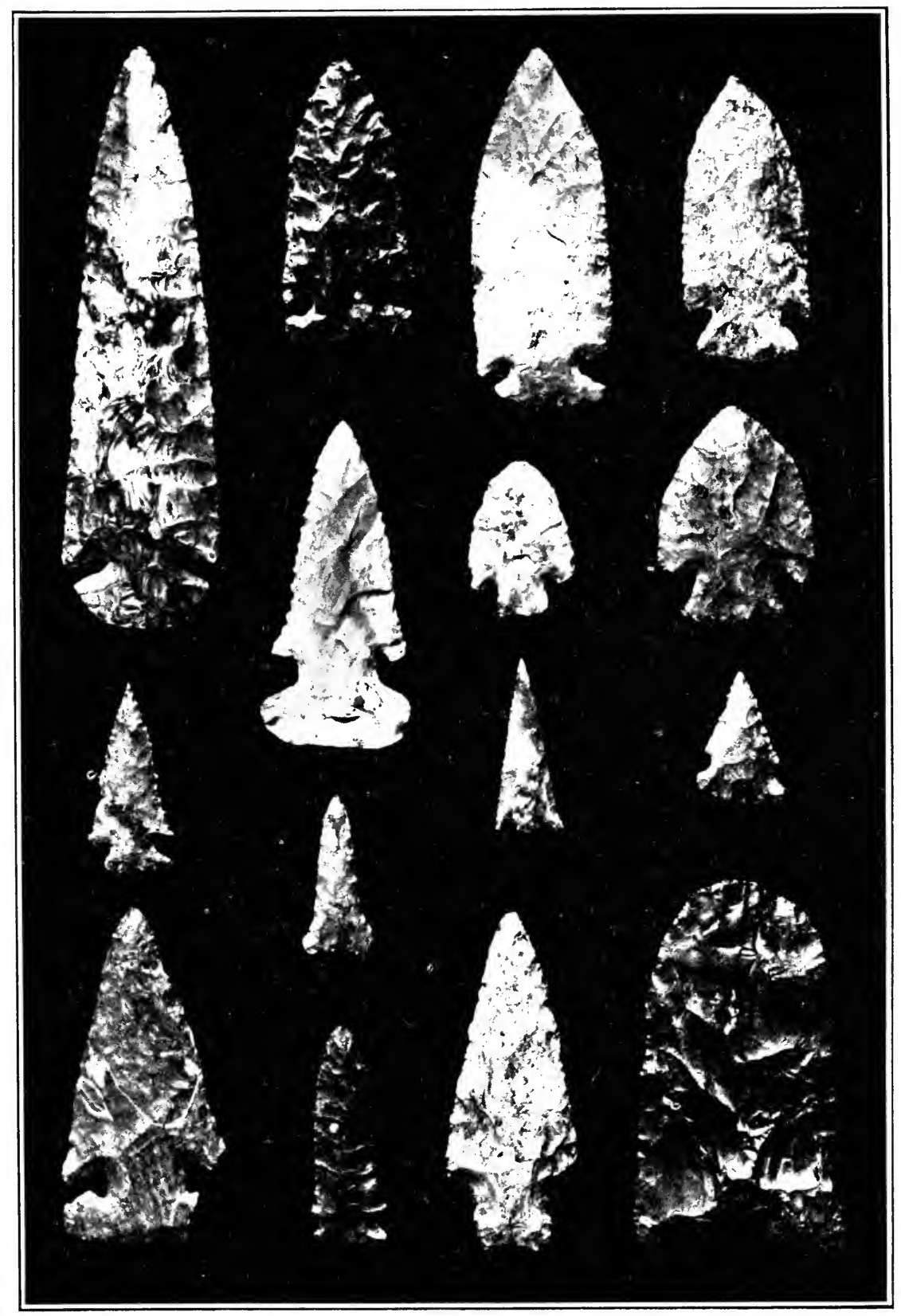

Fra, 62. Types of the implements sperialized for use, one as a scraper, the others as projectile points. (One-half atetual size.) 
Five or six miles west of this a deposit of black flint is reported to occur in a thick stratum. Several acres, in detached areas, have been completely dug over; broken flint, spalls, and unfinished implements are said to almost hide the ground in places. ${ }^{1}$

No one can say at what period the work in these quarries commenced. Many centuries must have elapsed since the Age of the Quar- first flint was obtained frcm the massire beds, and it
ries is altogether probable that the work was continued until the encroachments of Europeans drove the natives from the general region or substituted other materials for' the anciently indispensable flint. 


\section{FLINT QUARRIES: WEST VIRGINIA, KENTUCKY, INDIANA}

7 HE quarries and quarry shops of West Virginia are numerous and correspond closely in every essential feature with those of Ohio. The flint occurs in like manner and is generally blackish in color. Unfortunately their examination has been very superficial.

In some sections of the State, more especially in the middle Kanawha Valley, a dark firm-grained diabase was much used in the manufacture of ordinary leaf-blade forms and also in the making of celts, but the quarries have not been definitely located.

Fowke, who has an extended first-hand knowledge of the distribution of the flint-bearing formations of the Ohio Valley, writes as follows:

It is necessary to pass westward over the different limestone groups that extend from the Ohio coal measures until we reach the sub[Indiana Quarries] carboniferous limestones of southern Indiana before we find other quarries, and we find that the character of the deposits has changed. The regular strata are no longer to be seen, but in their place occur the nodules that pertain to a geological horizon different from that we have above studied. The stone itself is no longer broken and thus released from the bedrock, but the digger attacked the clays that result from the disintegration of the limestone. All the lime has been dissolved by the humic and carbonic acids carried downward by percolating waters which, however, have no effect on the flint, and the nodules are left scattered throughout the clay much in the order as that in which they occurred in the limestone. Frosion caused many of these to roll down to the bottom of the slopes, and here the Indians found them. But they soon learned that this weathered material was not well suited for their tools, and they began digging in the hillsides for fresh, unweathered nodules. The stone they found there was the hard, bluish-gray hornstone that is more easily chipped and worked than any other form of the silicious rock to be found in the central valleys, and the immense amount of quarrying that has been done in almost every spot where the material is abundant, shows that the red man was cognizant of and fully appreciated the wealth that lay beneath his feet. It is only in the vicinity of the Ohio River that the best hornstone is found; as we go northward the stone grallually becomes coarser, until it passes into a chert that is almost spongy.

It may be well here to correct an error that has obtained wille circulation regarling use of flint from the Wyandot cave. It is stated in many books that the Indians resorted to this cave to procure flint, which they broke into small, angular fragments, carrying the latter into the open air to fabricate into 
implements. It is true that they did much excavating in the cave at a distance of a mile or more from its mouth, and that they carried the flint to the outside to work it up. But the quarrying was exactly similar to that carried on on the outside; that is, they dug in the clay for nodules, which they tested by striking off flakes, rejecting such as did not suit their purposes. The angular fragments that have been mistaken for the lébris of the Indian work are pieces that have been released from the ceiling of the cave by the weathering of the limestone, and are not at all suited for manufacture. The stratum from which they come is about 3 inches thick, and the fracture of the stone being at right angles to the line of stratification, produces prisms of a uniform length equal to the thickness of the layer, and varying from the size of a lead pencil to pieces 4 or 5 inches square. ${ }^{1}$

${ }^{1}$ Fowke, Material for Aboriginal Stone Implements, p. 332. 


\section{MILL CREEK QUARRIES, ILLINOIS}

HE lower carboniferous formations of the Ohio Valley, more especially in western Kentucky and southern Illinois, yield 1 chert concretions of different material from those of south-
rn Indiana, which were extensively utilized by the aborigines. The only important quarries of this class thus far discovered and adequately studied are those located in Union and Alexander Counties, in southern Illinois. That there are others scattered through the hills and valleys of the general region is well attested by surface indications of prehistoric diggings and the occurrence of chipped

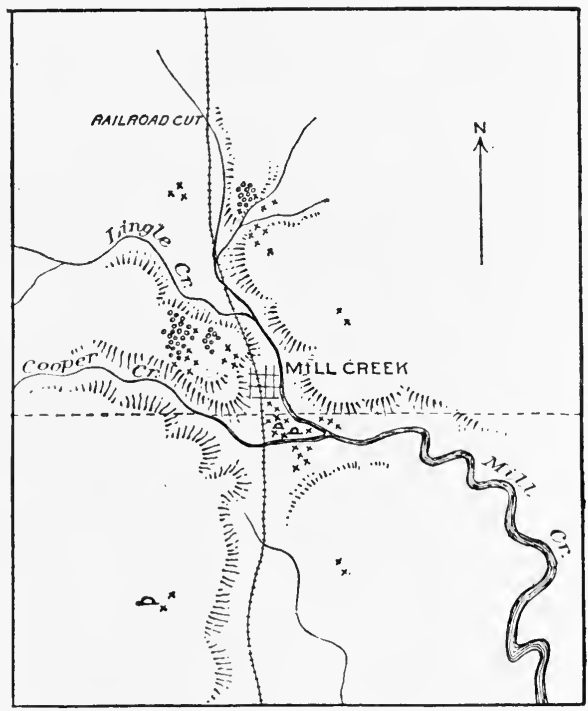

FIg. 63. Map of the Mill Creek quarry site.

implements made of materials other than those derived from the well-known sources.

In the vicinity of Mill Creek village, a station on the Illinois Central Railway, Union County, and extending over Exploration of the into Alexander County on the south (fig. 63), chert
Site

concretions weathered out from the limestone formations were quarried on a large scale. These concretions were especially well suited, on account of their size and shape, for the manufacture of the large chipped blades used as agricultural implements by the aborigines. The site was first visited and examined 
superficially by members of the Bureau of American Ethnology, ${ }^{1}$ and later by Dr. W. A. Phillips, by the present writer, and others. Dr. Phillips made extended examinations of the quarries under the auspices of the Field Museum of Natural History. ${ }^{2}$

The limestone strata, through which the chert ccncretions are distributed in interrupted layers, occupy an approxiGeology of the Lomately horizontal position and have been subject to extensive disintegration by the action of acid-charged cality

waters. In the vicinity of Mill Creek the disintegration and leachingout of the calcareous matter of the superficial strata have been complete, and as a result the underlying Devonian floor is buried beneath extensive bodies of the residual clays (fig. 64). In many places these clays reach a thickness of 25 feet or more, and the chert concretions, not being subject to disintegration, are distributed ir-

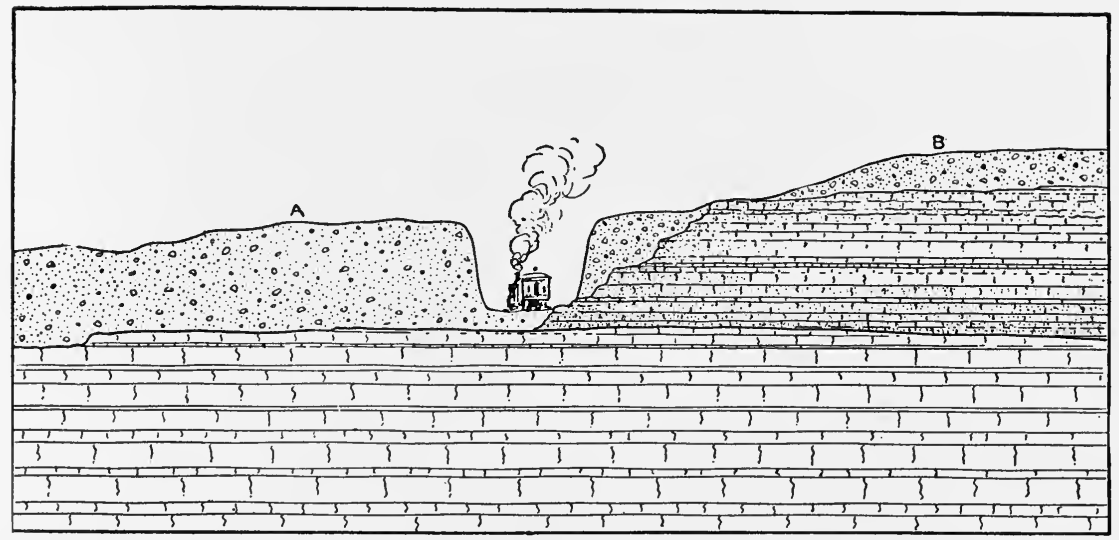

Fig. 64. Section indicating the relation of the residual nodule-bearing deposits to the limestoncs.

regularly throughout the deposits. It is these concretions that the aborigines sought and obtained at enormous cost of time and labor. The manner of the original occurrence of the concretions in the limestone strata is shown in figure 65, and examples The Concretions of typical forms appear in figure 66 . These concretions differ from the prevailing types obtained from the upper carboniferous formations to the north and east in being usually of flattish form and of exceedingly varied outline. They are often joined by irregular necks over considerable areas, but the trans-

\footnotetext{
1 Thomas, Report on Mound Explorations, p. 154.

$2 \mathrm{~A}$ preliminary report of his operations appears in the American Anthropologist, January-March, 1900, and his later investigations, the most thorough yet made of any of the concretion-producing quarries, are in course of preparation for publication by the Field Museum. Dr. Phillips has very generously permitted the writer to embody portions of his data in these pages.
} 
verse section is very uniformly that of a flattened lens, which adapted them especially to the chipping operations of the aborigines.

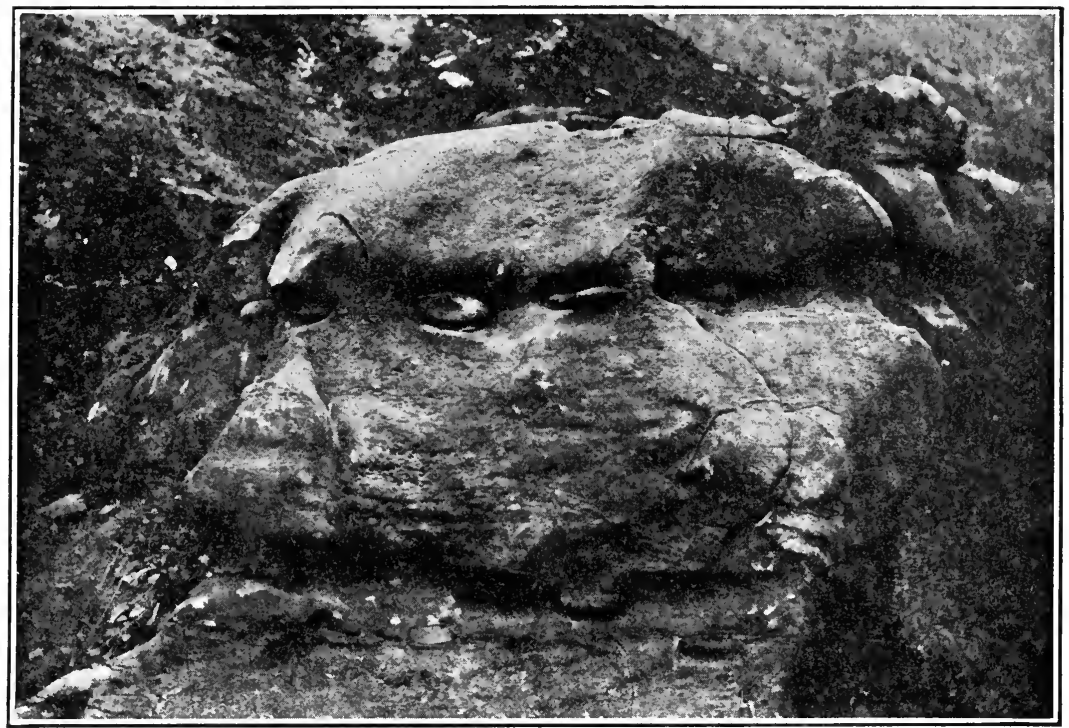

Fig. 65. Manner of occurrence of the chert concretions in the limestone strata.

The ancient pittings are found in several groups or clusters on the hills and slopes in the vicinity of Mill Creek village, and the principal workings examined by Dr. Phillips are distributed along the

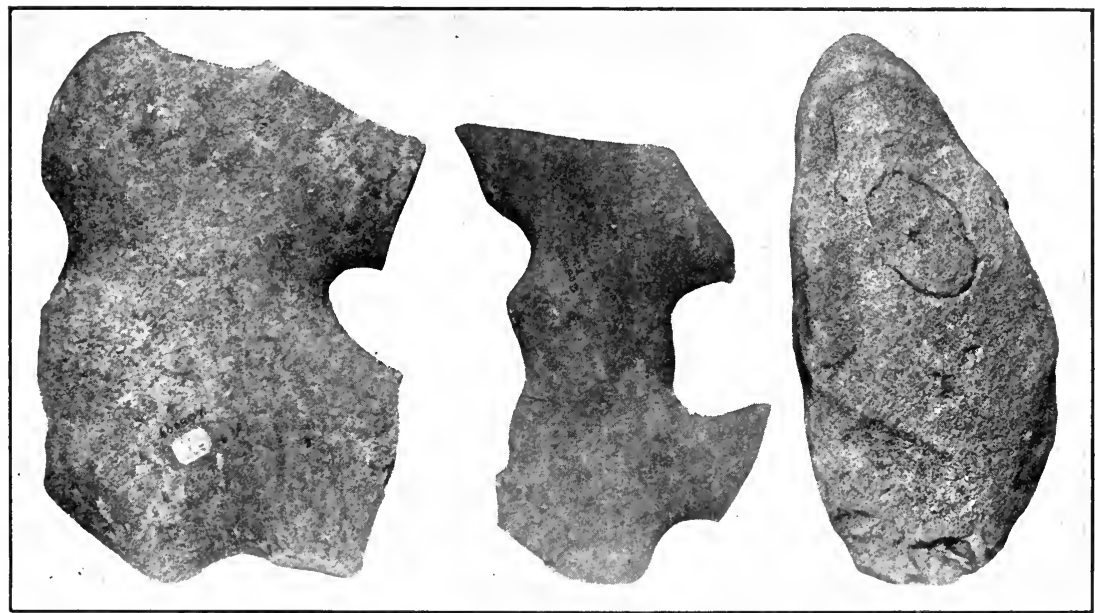

Fig. 66. Examples of the flattish, irregularly shaped chert concretions used in blade making. (One-sixth actual size.)

crest of a ridge which rises to the west. At present, where undisturbed, the old pittings are represented by bowl-shaped or oblong depressions a few feet in depth and in few places exceeding 40 feet in 
diameter. The principal trench opened by Dr. PhilPhillips's Excava- lips in his earlier excavations was about 60 feet in
tions length and passed through three or four of the ancient excavations, which were found to be filled with clay intermingled

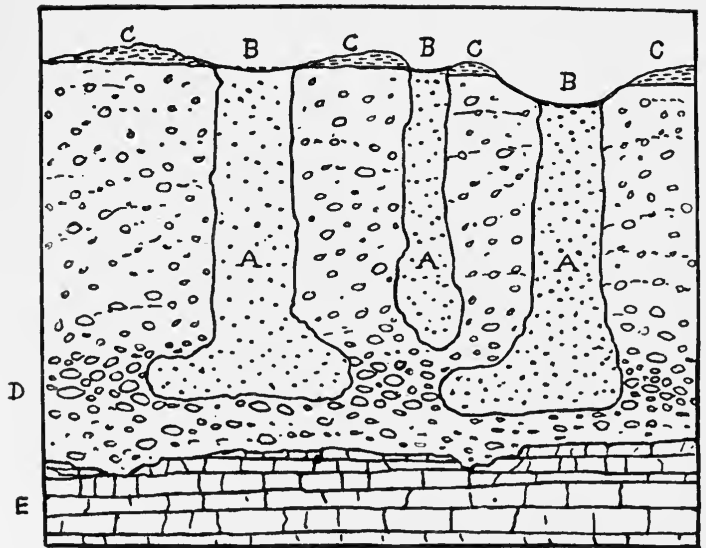

FIg. 67. Section showing the ancient excavations. $A$, The filled pits. $B$, The present surface. $C$, The shop sites. sparsely with quarry implements and shop refuse from the surface. The undisturbed portions of the original deposits consisted of compacted clay comparatively free of concretions until a depth of 20 feet or more was reached, where they occur in numbers. To this level and below to the depth of 25 feet or more the ancient workmen had penetrated and had carried tunnels horizontally in irregular fashion, doubtless at great risk from caving in of the imperfectly solidified materials above. The form of the ancient excavations and the nature of their filling are indicated in figure 67 . The magnitude of the ancient work is almost beyond belief, and we are led to again marvel at the enterprise and perseverance of the quarrymen, who must have been impelled to their task by interests of vital importance to the people of the valley.

The implements employed in the Quarry Imple- quarry work inments clude rude blades resembling the or-

dinary flint hoe of the region, which show traces of wear by use

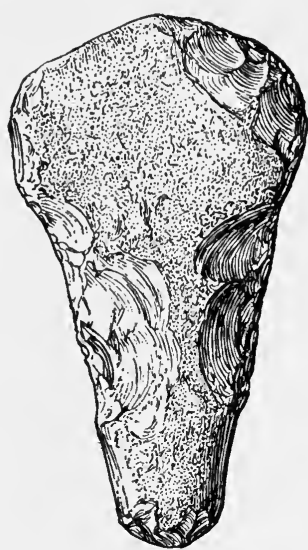

Fig. 68. Clublike implement used in removing the concretions from the matrix.

in digging, and a number of blunt, somewhat paddle or club like tools made from oblong chert concretions by rough chipping a haft at the narrow end and a scraperlike bevel at the broad end (fig. 68). The latter tool appears to have been used in freeing the concretions from the compact matrix by prying and tapping processes, and in 
cases they exhibit traces of wear on one surface, due, apparently, to contact with the thumb, which served as a brace, as indicated in figure 69 .

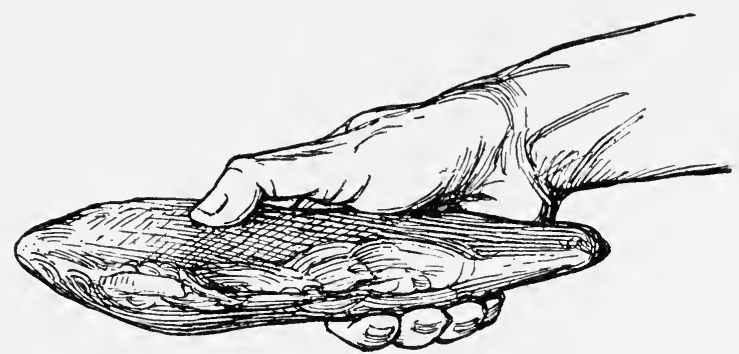

Fig. 69. Suggested manner of holding the quarry implement.

The sites to which the concretions were carried to be worked up are marked by clusters of refuse, generally circular

Lodge-site Workshops

in form, as if accumulated in and about lodge sites. The chipping hammers were roundish nodules or tough portions of chert chipped into convenient form. A study of the refuse shows that the shaping work was directed largely toward
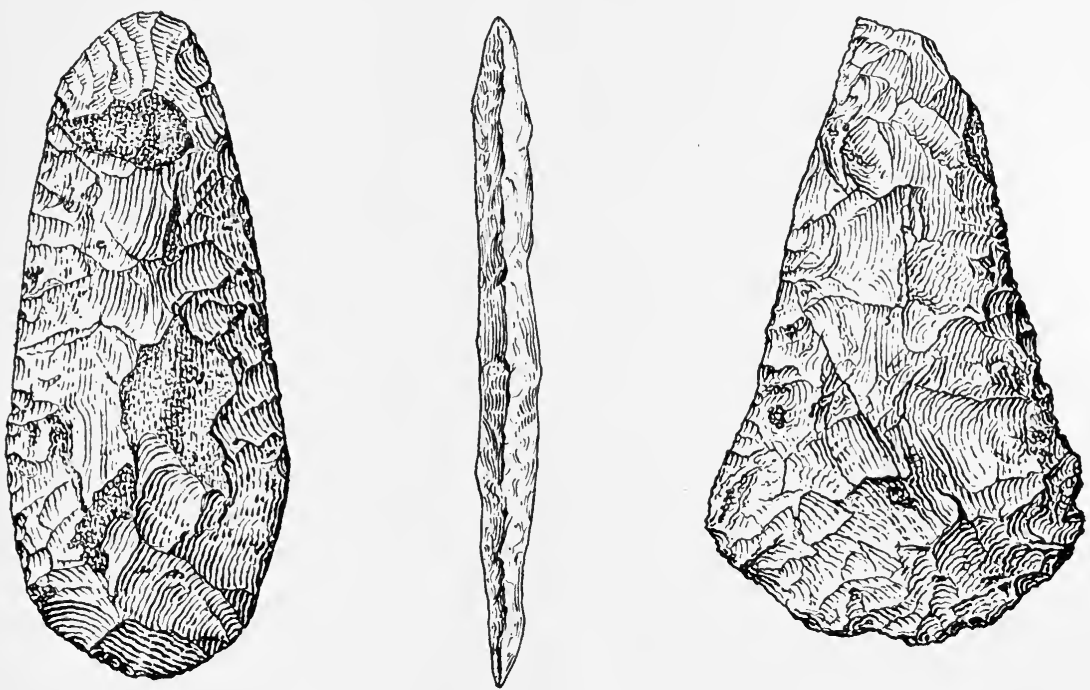

Fig. 70. Examples of the blades produced and ready for hafting as hoes. Length 4 to 8 inches.

the roughing out of implement forms of sereral classes, as follows: (1) Large broad blades, varying from ovate-lanceoForms roduced late to triangular forms, and ranging from 3 to 18 inches in length and from 2 to 7 inches in width (fig. $70)$; (2) wide short blades of diversified outline, notched near the top $38657^{\circ}-19-$ Bull. 60 , pt $\mathrm{I}-14$ 
to facilitate the attachment of a handle (fig. 71$)$; (3) comparatively narrow and thick-bodied blades of chisel, adz, and celt types; (4)
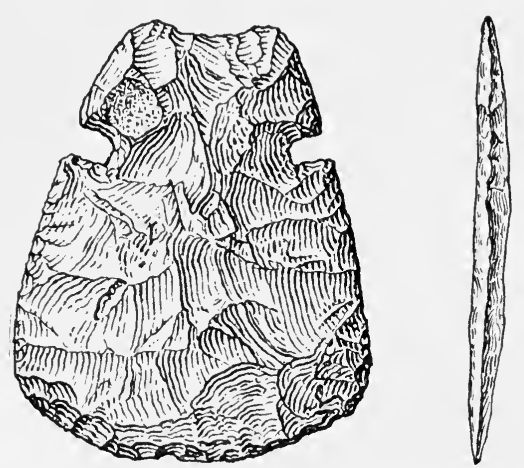

slender blades served as knives and scrapers and for the making of projectile points. Abortive blades, rejected because of malformation or breakage under the strokes of the hammer, are found in vast numbers. On the shop sites numerous examples of flattish masses of chert and even partially worked blades baar traces of use in some kinds of abrading operations (figs. 72, 73).

Fig. 71. Iloe blade specialized to facili- According to Dr. Phillips, a numtate hafting. Length 4 to 8 inches. ber of the chipped blades well advanced toward the final form have been slightly ground along the margin as if to facilitate the secondary chipping. It is thought that the abrading stones may have been devoted to this work.

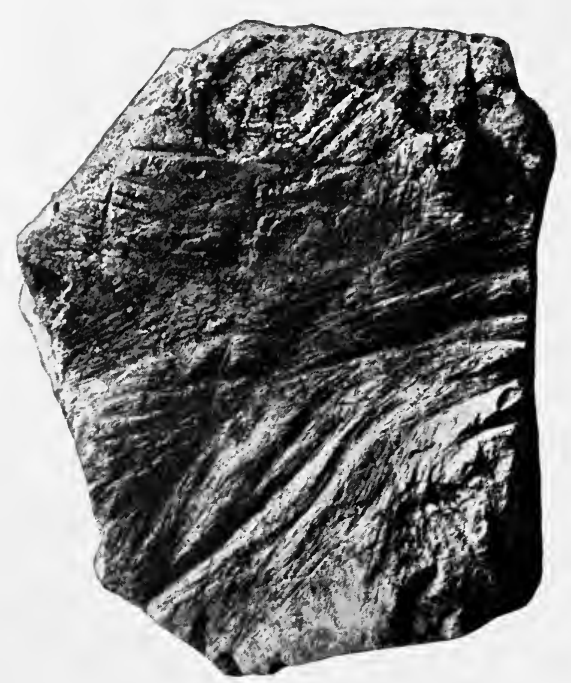

FIG. 72. Much-used abrading stone. (Onefourth actual size.)

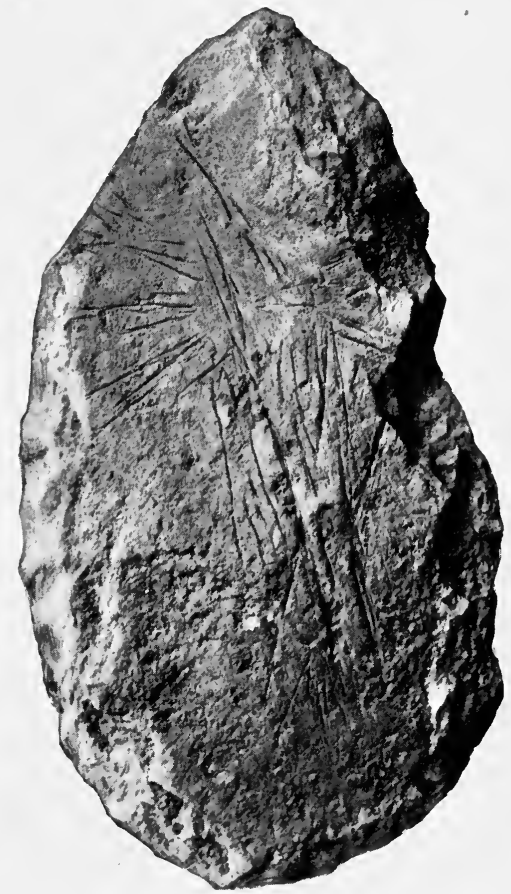

Fig. 73. Rejected blade used as an abrader. (One-fourth actual size.)

There are but slight traces on the quarry-shop sites of the getting out of the smaller blades, but on the Hale place in Village-site Workshop the valley this work appears to have been a leading feature. Here also all other classes of implements 
were trimmed and specialized, and heary beds of chips and other wastage of implement making, including the chipping of implements, are found. It is probable also that much selected raw material from the quarries was carried to this place to be worked up. There are hammerstones of the usual type, as well as numerous chipping tools of deer antler (fig. 74). Many of the latter were discorered by Dr. Phillips in an excavation made through an accumulation of shop refuse near the bank of the creek back of the Hale residence. These implements were probably used rather in the secondary trim-

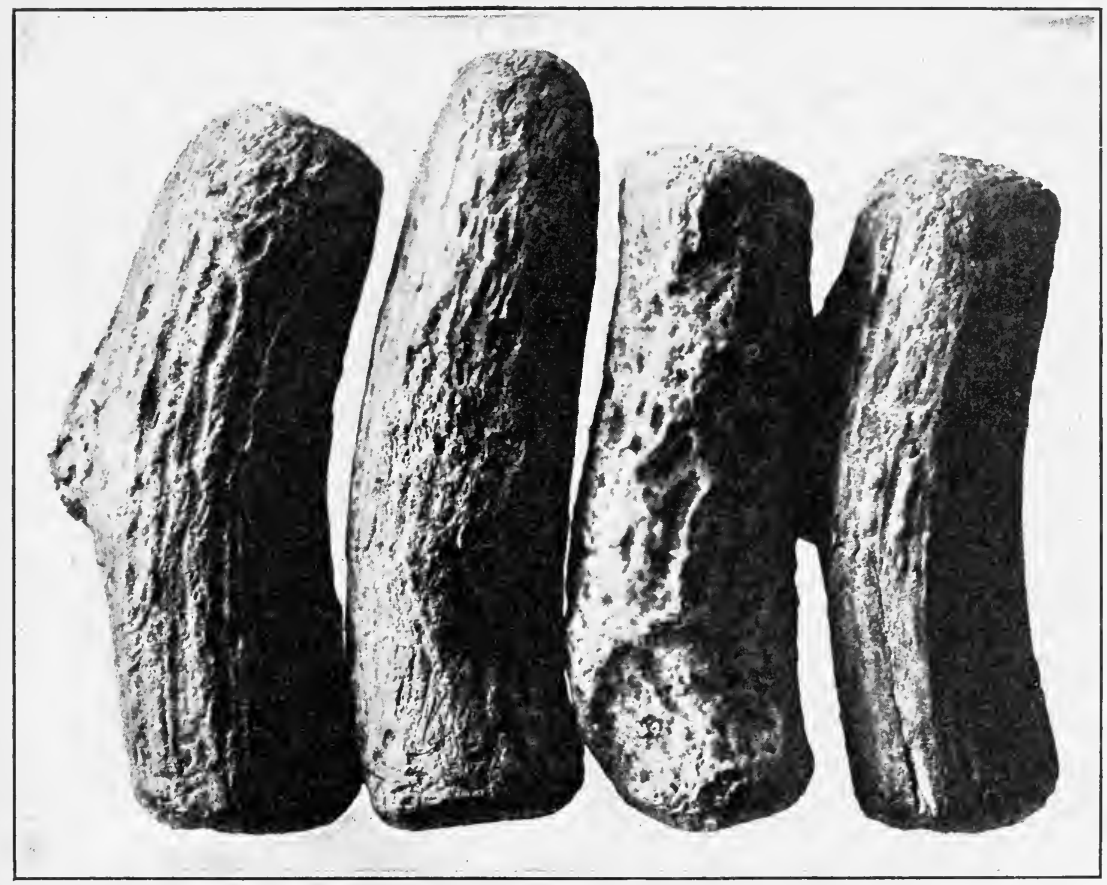

F1G. 74. Chipping implements made of the base of deer antlers. (Three-fourths actual size.)

ming of the blades than in the roughing-out work. The manner of their use is suggested in figures 75 and 76 .

The distribution of the product of the Mill Creek quarries was very wide and specimens assignable to this source Distribution of are found throughout a large area, including por-
product tions of Missouri, Illinois, Indiana, Kentucky, Tennessee, and Ohio, but since closely corresponding materials probably are found at other points somewhat distant from Mill Creek, the range of the Mill Creek material can not be very definitely determined. Concretionary material of the Mill Creek type is said to 
occur as far north as Cobden, Union County, and Sellers states that concretions, which from his description must be closely identical in

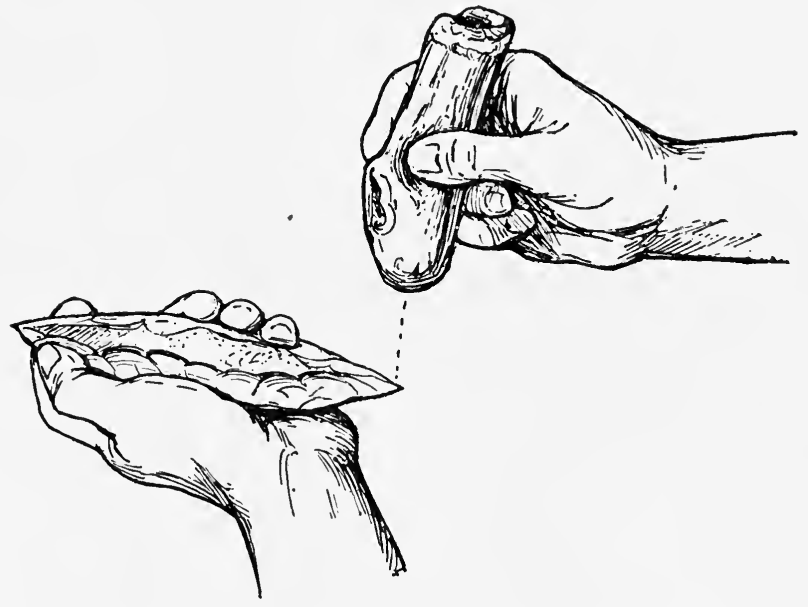

Fig. 75. Manner of using the antler hammer, unhafted.

character, were employed by the tribes of the valley of the Saline far to the east. ${ }^{1}$

Vast numbers of flint blades, of the type produced in the Mill Creek quarry shops, polished by long use in digging, bear ample testimony to the great importance of agriculture among the tribes

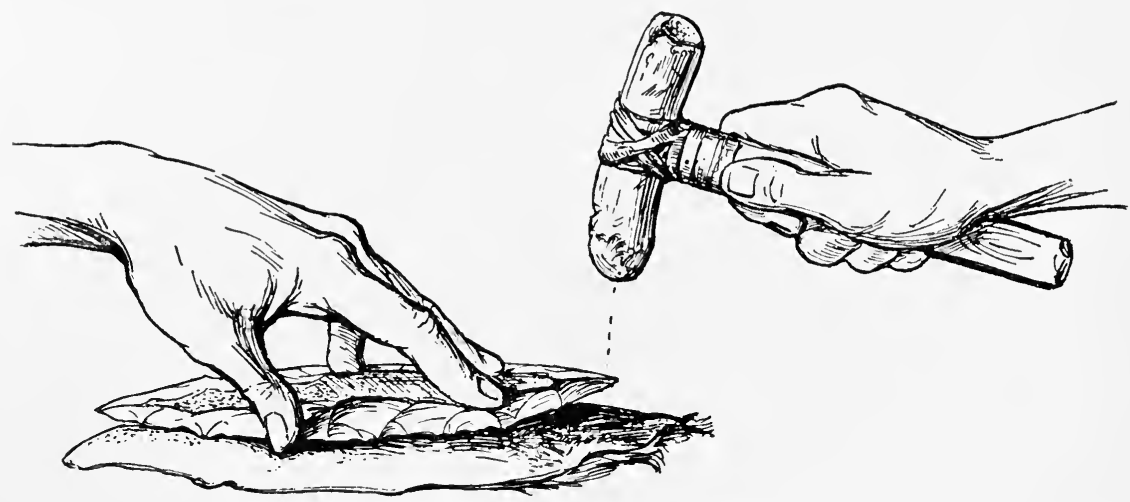

FIG. 76. Manner of using the antler hammer, hafted.

of the middle Mississippi Valley. Many hundreds of choice highly polished specimens are preserved in the collections of Dr. H. M. Whelpley, of St. Louis. 


\section{FLINT QUARRIES NEAR CRESCENT, MO.}

GOOD example of the ancient chert-working sites of the Mis-
souri region is found near the village of Crescent, 25 miles
west of St. Louis. Superficial examinations were made by Mr. Gerard Fowke in 1915 on behalf of the Bureau of American Ethnology. The following paragraphs are extracted from his manuscript report:

The flint-capped ridge, with its windings and spurs, has a general direction

[Crescent, Mo., Quarries]

toward the southeast. The slopes are everywhere covered with an immense quantity of débris, partly from the portion of the deposit still remaining, but mainly from the accumulated flint which has remained when the limestone was carried away, and has settled to lower levels. It has been examined as far to the southward as High Ridge, 7 miles from the Meramec River. Throughout this length the hillsides are scarred with pits, the remains of aboriginal quarries. Most of these pits are near the bottom of the deposit. Very few occur along the top of the ridge, and these only in places where erosion has removed most of the upper portion of the material. As a rule the digging was done along the lowest part of the deposit.

This is because the upper layers, being more influenced by [The Pittings]

woathering, are less suitable for making implements. The most exposed portions are porous from the weathering out of fossils and are also much checked and seamed so that they easily shatter. At the extreme bottom of the series there is a foot or more of very fine-grained, compact stone, which has the texture, color, and chipping quality of chalcedony, and it was this which was most sought. Judging from the amount of waste in the form of spalls and blocks covering the hillsiles below, a vast quantity of the chert was removed and thrown aside in order to reach that which had desirable flaking qualities. After long exposure most of it resembles chalk, though losing none of its hardness or fineness of grain. It weathers into various red or yellowish shades, in some cases, though principally quite white.

The most remarkable feature about this deposit is its extreme thickness. In at least one place it is fully 75 feet from the crest of the rilge to the lowest level of the flint. At this point, too, is the most extensive quarrying; the digging was done at three different levels. The lowest is directly on the surface of a ledge of limestone whose outcrop is several feet thick. After all the wash from above, one quarry here would require at least a thousand yards of earth to fill it to the general slope on either sille, and there is no way of ascertaining how far back it may extend under the talus which has slid down into it.

It is safe to say that the flint sought has been reached and removed over an area of not less than a hunclred acres in the parts of the [Area of Quarries] country examined; and it may well be that this amount is loubled in places not yet examined. Nearly all the chipped implements found within 50 miles of St. Louis in any direction are made of the stone from this deposit-at least it looks exactly like it-and no other deposit is now known from which it could have been derived. This observation, of course, does not apply to the spades and hoes made from the Union County (IIl.) chert, nor to a few of the very long, slender implements or ceremonials, occasionally found which are brought from some other region. 


\section{NOVACULITE QUARRIES, ARK.}

7 HE Arkansas quarries are possibly even more extensive than those of Ohio. The stone in the best-known localities is a fine-grained variety of chert called novaculite, which occurs phenomena of these quarries correspond closely in most respects with those of Flint Ridge. Their examination, howerer, has been superficial, and at best there is little promise of discoveries that will add greatly to our present knowlege. In 1891 the writer visited one of the quarry groups located on a high forest-covered ridge

Quarries Near IIot Springs called Indian Mountain, about 2 miles in a northeasterly direction from the railway station at IIot Springs, Ark. The evidences of quarrying consist of a number of pits and excarations dug in and about the crest of the ridge, which is composed of massively stratified novaculite weathering out in irregular grayish, rough-surfaced outcrops, which protrude from the crest or project on the slopes, forming short broken cliffs 10 to 20 feet in height.

The largest excavation is on the narrow crest of the rilge near the highest point (see map, fig. 75 ). It is almost cirThe Pittings cular in outline and about 150 feet in diameter and 25 feet in depth. The rim of the conical depression is irregular, being higher at the center of the crest of the ridge and lower at the sides. On the eastern sicle the rim is broken down as a result of extensive digging on that side of the crest. The process of excavating this great conical pit was, no doubt, about as follows: An outcrop of particularly desirable rock was discorered and was gradually worked out and followed beneath the surface. As fragments of suitable size and quality were obtained they were thrown or carried to the margin of the pit and broken up and trimmed with hammerstones into approximate shape for the desired tools, the refuse gradually forming heaps

The Rejectage and ridges about the excavation. At the present time the enormous accumulations of shop refuse have (wescended on the interior of the mine, partially filling it, and upon the exterior they form slides of broken bits of the richly colored rock, reaching far down the slopes of the ridge. This encircling wall of refuse is composed largely of chips and partially shaped fragments, the latter representing all stages in the development of 


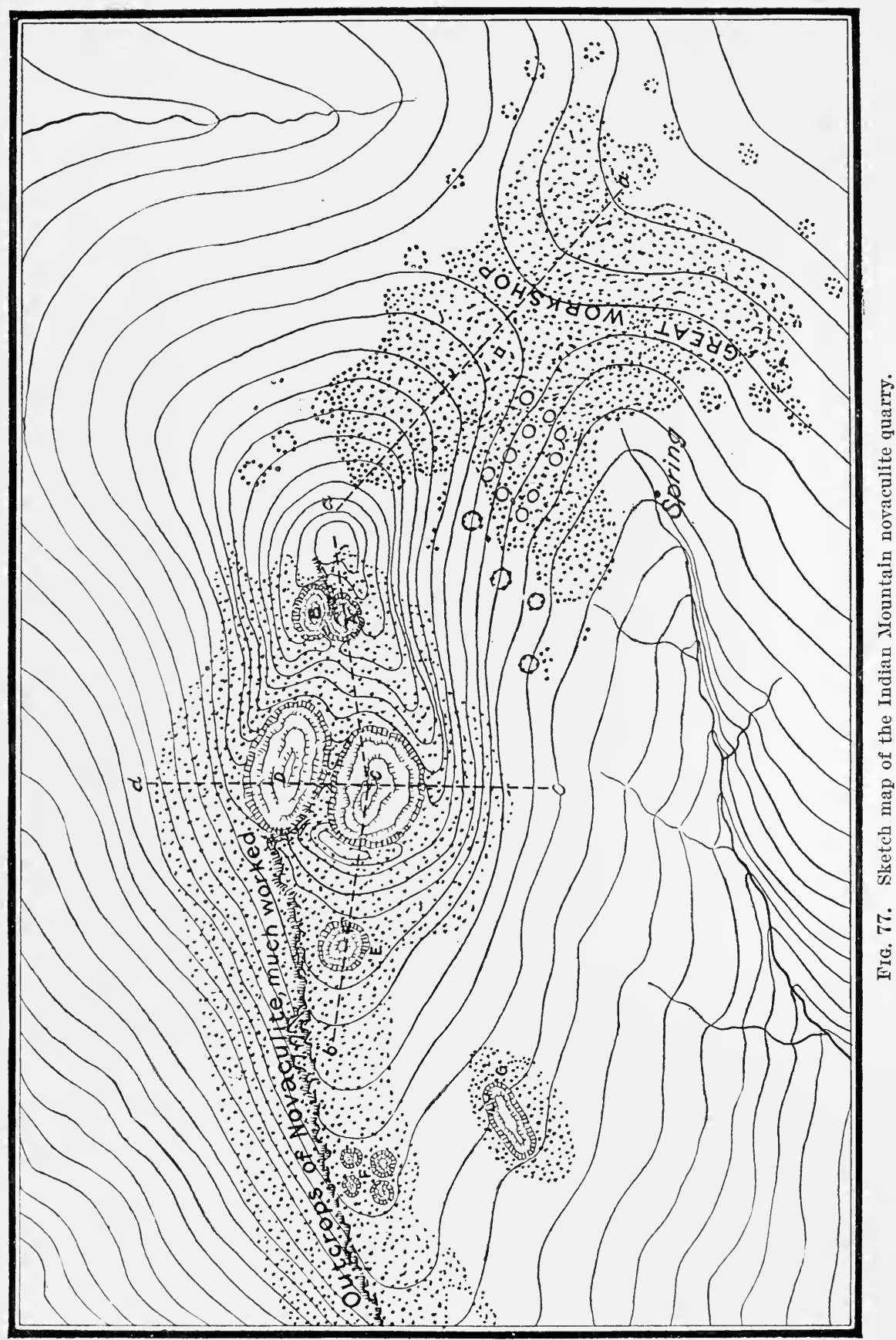


the leaf-shape blades, the form required for final specialization into spearheads, arrow points, knives, scrapers, and Rejectage and l'roduct

drills. Scores of tons of these failures could be collected, while freely intermingled with the refuse are the rude hammers of quartzite made by slightly reshaping bowlders of tough quartzite probably obtained in the valleys Chipping Hammers below. This particular pit was entered by the whites in recent year's and a shaft was sunk in the center for the purpose of determining whether or not the rocks contained gold or other precious metal, for it was popularly beliered that these pits were old Spanish diggings where the early adventurers obtained fabled gold. It would seem that a very slight experience with the barren flinty novaculite must have discouraged the unlucky prospectors. Some of the shaft timbers are still in place in this pit, and the careless observer might readily be led to believe that the excavations were wholly due to modern enterprise.

Recent Digging

That the recent work has not seriously changed the

contour of the ancient quarries is evident from the fact that nearly the entire mass of rejected material, interior and exterior, is composed of artificially shaped materials, the result of the ancient operations.

Seeming evidence of the use of fire in quarrying is found in some of the lateral diggings where there has been underminUse of Fire ing. Here certain faces of the novaculite, protected from the weather by overhanging ledges, display blackened patches which may be due to the ancient fires.

Another very important group of these quarries near Magnet Cove was somewhat hurriedly examined by the writer and Magnet Cove Quar- large collections were made. The sketch map (fig.
ries

78) will convey some definite idea of the vast extent of the work in this place. Later, at his request, a more careful examination was conducted by Prof. W. P. Jenney, from whose unpublished account the following paragraphs are extracted:

These old excavations are located on the top of the divide between the waters of Cove Creek and Pleasant Run, a branch of Ten Mile Creek, about twelve miles east of Hot Springs. They consist of a number of shallow excavations upon the broad, rounded crest of the divide, covering a belt three hundred to six hundred feet in width, the workings following the general strike of the novaculite strata at this point, to wit, N. 60 degrees to 70 degrees E. As far as I followed the divide - for a distance of one and a half miles-these workings continued, and are reported to extend, with breaks at intervals, an extreme distance of four miles southwesterly from this point. They are at present covered with soil and overgrown by oak timber of ordinary size. The excavations are nearly filled by the caving in of the loose waste from the surrounding dumps, but were evidently worked to a depth of fifteen to thirty or forty feet, apparently, as open cuts or trenches, following the purest and most valuable 


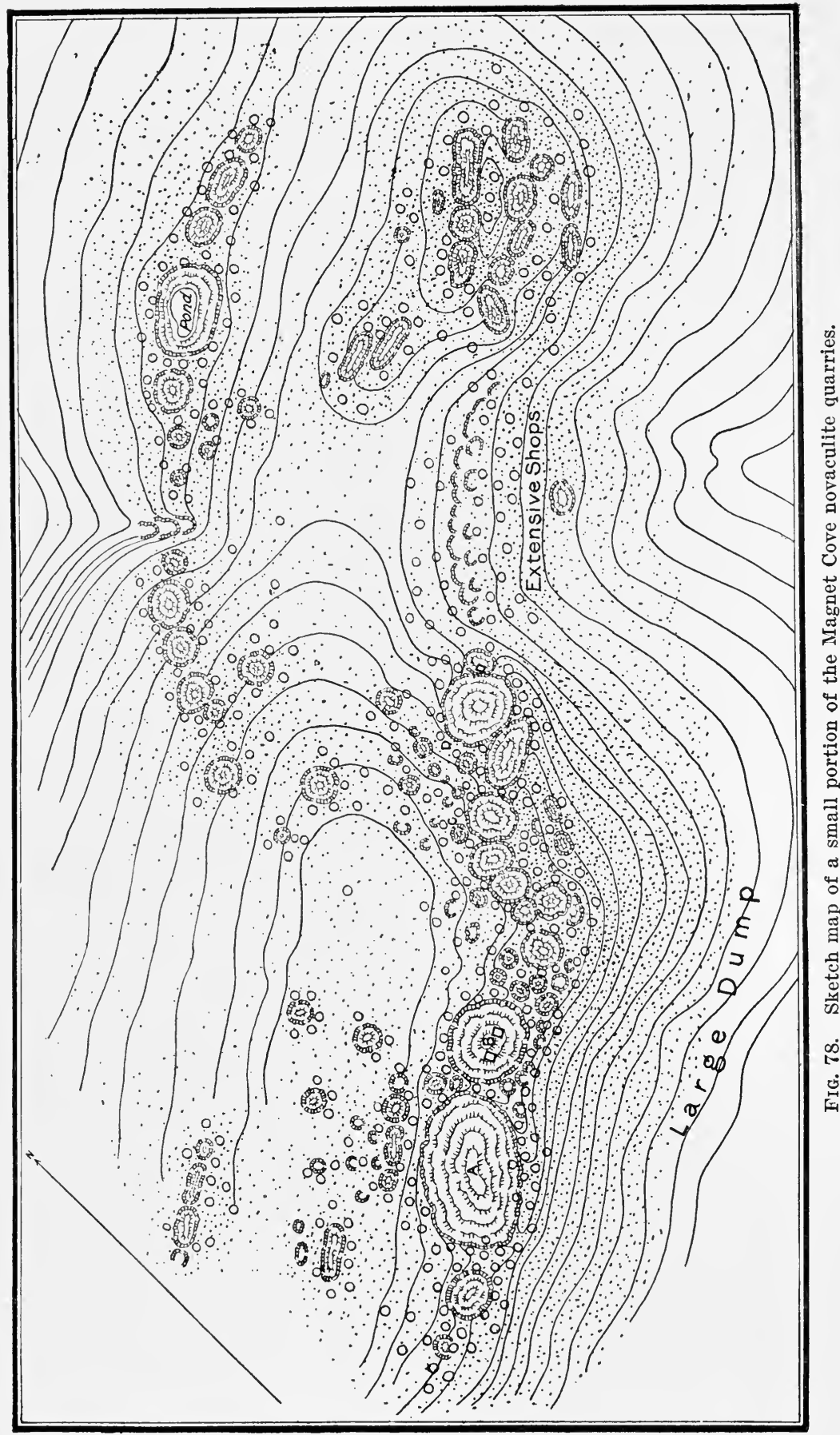


strata of the novaculite. Some are one hundred to three hundred feet in length, but the greater number of these workings consist of shallow pits twenty to fifty feet in length, probably ten to thirty feet in width originally, before caving, and fifteen to twenty-five feet deep, being opened at intervals irregularly along the course of the layers of the novaculite most useful to those doing the work.

The whole ridge is composed of novaculite, with a strike N. 65 degrees E., dipping south at fifty to sixty degrees. Most of the novacu-

[Character of the Novaculite] lite is coarse-grained, impure, and unsuitable for the manufacture of implements. On the crest of the divide several beds of novaculite outcrop, which are of very fine quality and are interbedded with the coarser strata. These pure beds are from five to twenty-five feet in thickness. The rock is white, yellowish, or bluish white in color, breaking readily with a smooth conchoidal fracture. The whole surface of the ridge in the vicinity is covered with chips of pink, red, or white novaculite, rarely darkcolored or black, and always having a fine-grained structure. The pure white agate-like novac'ulite being evidently the most worked and sought for, the waste dumps show that coarse-grained, impure, and much-fractured rock was discarlerl. Many of these flint chips show serrated erlges, as if discarded after an attempt had been made to fashion an arrow head or cutting tool.

The tools used by these ancient miners appear to have been balls of stone or natural bowlders of three sizes, the smallest one and a half [Quarry Sledges] to two and a half inches in diameter, the second size three to four inches, and the largest six to eight inches in diameter; these bowlders or stone hammers are mostly dark grey syenite; some bowlders of hard igneous rocks as well as hard quartzite of grey and brown shades of color. None of these rocks occur in the ridge, these bowlders being evidently brought from the beds of streams draining the area covered by the eruptive rocks to the southeast, the nearest localities from which these tools could have been obtained being some two miles distant.

In the extent of one and a half miles examined on the crest of this divide [Extent of Work] I would estimate the aggregate quantity of material which must have been excavated at 100,000 cubic yards.

The product of these wonderful workings doubtless comprised multitudes of chipped implements, mostly of rather small size, examples of which are found in every valley and on every hill in the region about. The rejected forms and the hammers used are identical with those from the Indian Mountain site. 


\section{CHERT QUARRIES OF THE GREAT PLAINS}

THE hunter tribes of the Great Plains region-the followers of the now vanished herds of buffalo-depended largely 1 on the brittle varieties of stone for their implements and weapons, and the region furnishes vast numbers of all types of these. The hunter was in evidence rather than the cultivator of the soil, but agricultural implements are widely distributed along the fertile valleys tributary to the Mississippi on the west. Vast numbers of chipped implements, especially knives, scrapers, and projectile points, are scattered over the country and not infrequently are recovered from cache deposits where placed possibly as offerings to the gods of the chase. The sources of the several varieties of chert have been imperfectly explored. On the eastern border they extend in a wide belt from north to south through Iowa, eastern Nebraska, Missouri, Kansas, Oklahoma, and Texas, associated always with the carboniferous formations. Farther west the cretaceous quartzites afford a supply of excellent material for implements, and extensive quarries have been located in Wyoming.

\section{OKLamoma}

A single typical example of the quarries of the eastern margin of the great plains area may be described in some detail, although it is olsserved that they correspond closely in all important respects with the quarries of massive flint elsewhere. A somewhat detailed account of this group was published by the present writer in Bulletin 21 of the Bureau of American Ethnology (1894). On what was formerly known as the Peoria Reservation, now included in Ottawa County. Okla., extensive cuarries of a whitish massive chert are located. These were originally known as Spanish diggings and were first reported to the Geological Survey as flint quarries by reputed Spanish Prof. W. P. Jenney, who was engaged in 1891 in Mines spanish the study of the lead mines of the Joplin region. They are located about 7 miles northwest of Seneca, Mo., and some 10 miles southeast of Baxter Springs, Kans. It an early date the whites learned of the ancient digging and work was undertaken by various parties and at long intervals with 
the view of rediscovering the deposits of precious metals supposed to have been worked by the Spanish or other peoples in early times. Several shafts were sunk about the old pits, some to the depth, it is said, of 50 or 60 feet. As a matter of course nothing of value was found. It is reported that some of the explorers discovered iron tools of a primitive type in the ancient pits, but it must be assumed that these were left by our own pioneer miners, since there is no eridence either that the Spanish were ever here, or that the aborigines possessed metal tools.

The beds of chert are of unknown area and of great thickness. They are of upper subcarboniferous age and outcrop about the margins of the shallow stream courses, forming in places a low rounded scarp. The ancient implement-makers doubtless beThe Quarry Work gan work at the more accessible points along the margin of the outcrop and gradually by longcontinued operations carried the pits and trenches far back into the slope. The excavations in the main took the form of roundish pits,

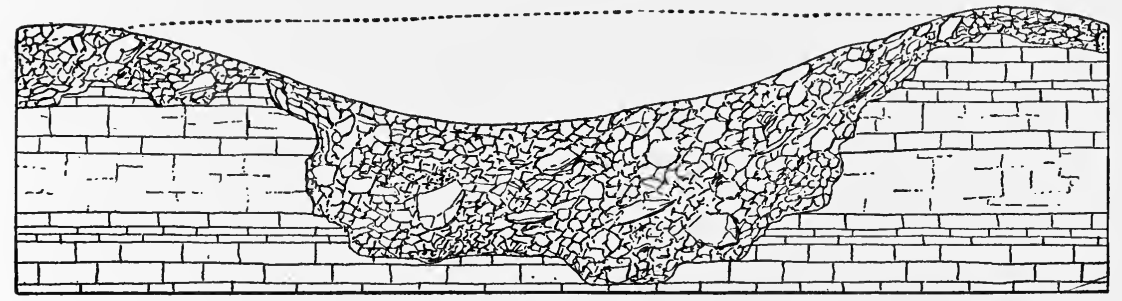

Flg. 79. Section through a single quarry pit well filled with shop débris.

but on the margins of the area trenches in the solid rock a hundred feet or more in length were carried along the ledge. Where the work was deep the refuse about the margins accumulated The Pittings and filled the older excavations (fig. 79). It is not probable that many of the pits were more than 10 or 15 feet deep. At present the greatest depth is about 5 feet and the width of the roundish depressions does not exceed 40 feet.

The story of the working of the quarries and the manipulation of the stcne is to be read with almost as much ease as Workshops if the work had closed but yesterday. The masses of fresh chert were removed from the pits and broken up, and choice fragments were selected for further treatment. Shops were established on the margins of the pits, on the dump heaps, and at convenient points in the vicinity (fig. 80). To-day in numerous cases circular clusters of chert refuse indicate the position of the 
lodges in and about which the work was carried on. In the center is a shallow depression, which was the fireplace of the

Lodge Sites lodge (fig. 81). Around this are accumulations of fragments, flakes, partially worked rejects, and the hammerstones left by the workinen, the whole remaining seemingly undisturbed since the period of occupation. Outside of these circular clusters are heaps of chert masses just as they were brought from the quarry and deposited within reach of the workmen, and in some cases flattish lumps of chert, probably used as seats or anvils, are surrounded by piles of refuse. Not only are these shop phenomena thus fresh and undisturbed, but in some instances the flint seems

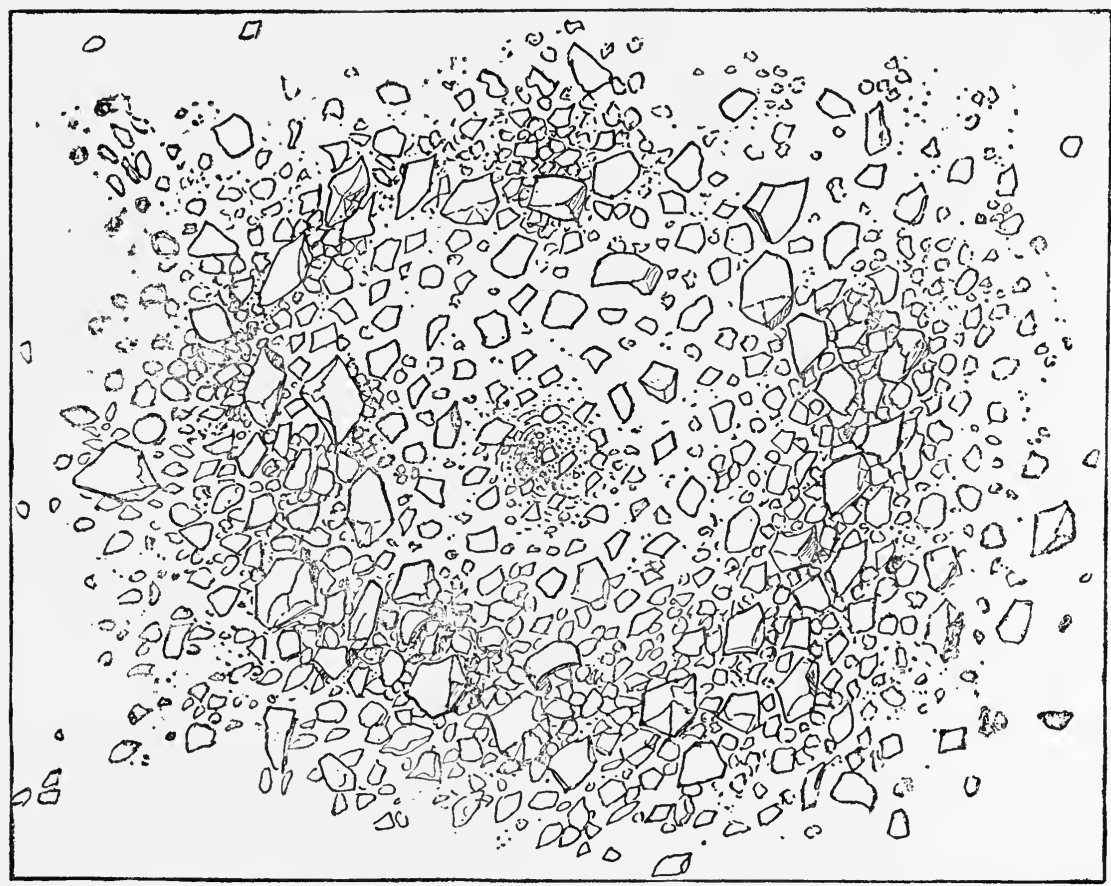

FIG. 80. Plan of lodge shop site showing central fire pit and circle of chert blocks and shaping refuse.

hardly to have changed color or to have suffered in the least from weathering or from the fires which must at times have swept the forest.

The work of quarrying and shaping the stone corresponds in nearly every respect with that of the Flint Ridge and Arkansas quarries already described. The ordinary and almost exclusive product of the shaping work was some form of blade, a The shaped rrod- blank form intended in most cases at least to be subuct

sequently elaborated into implements of more highly specialized type, as hoes, knives, and projectile points. A series of 


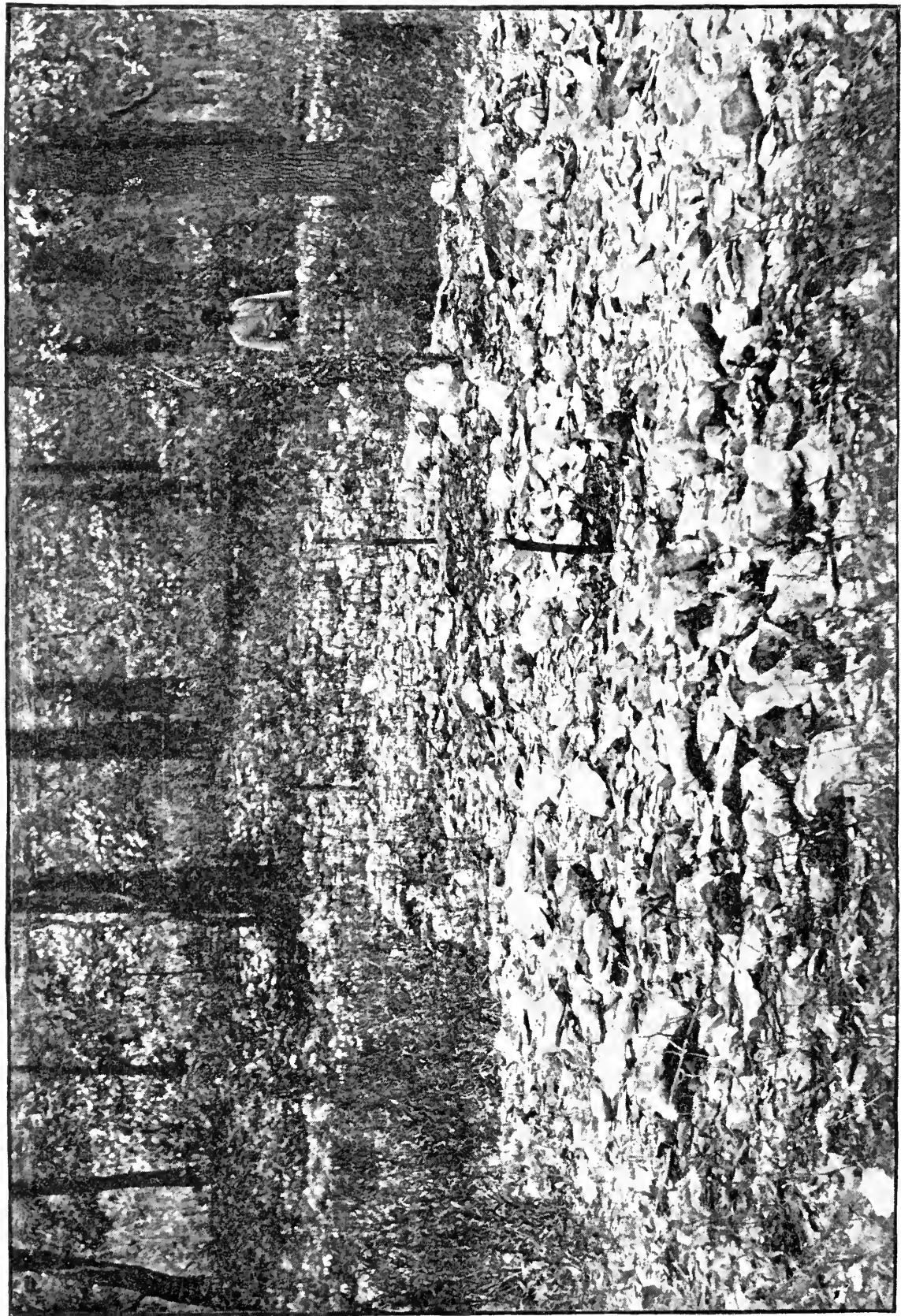


rejects illustrating various degrees of progress in the shaping work is given in figure 82 ; characteristic abortive blades are seen in figures

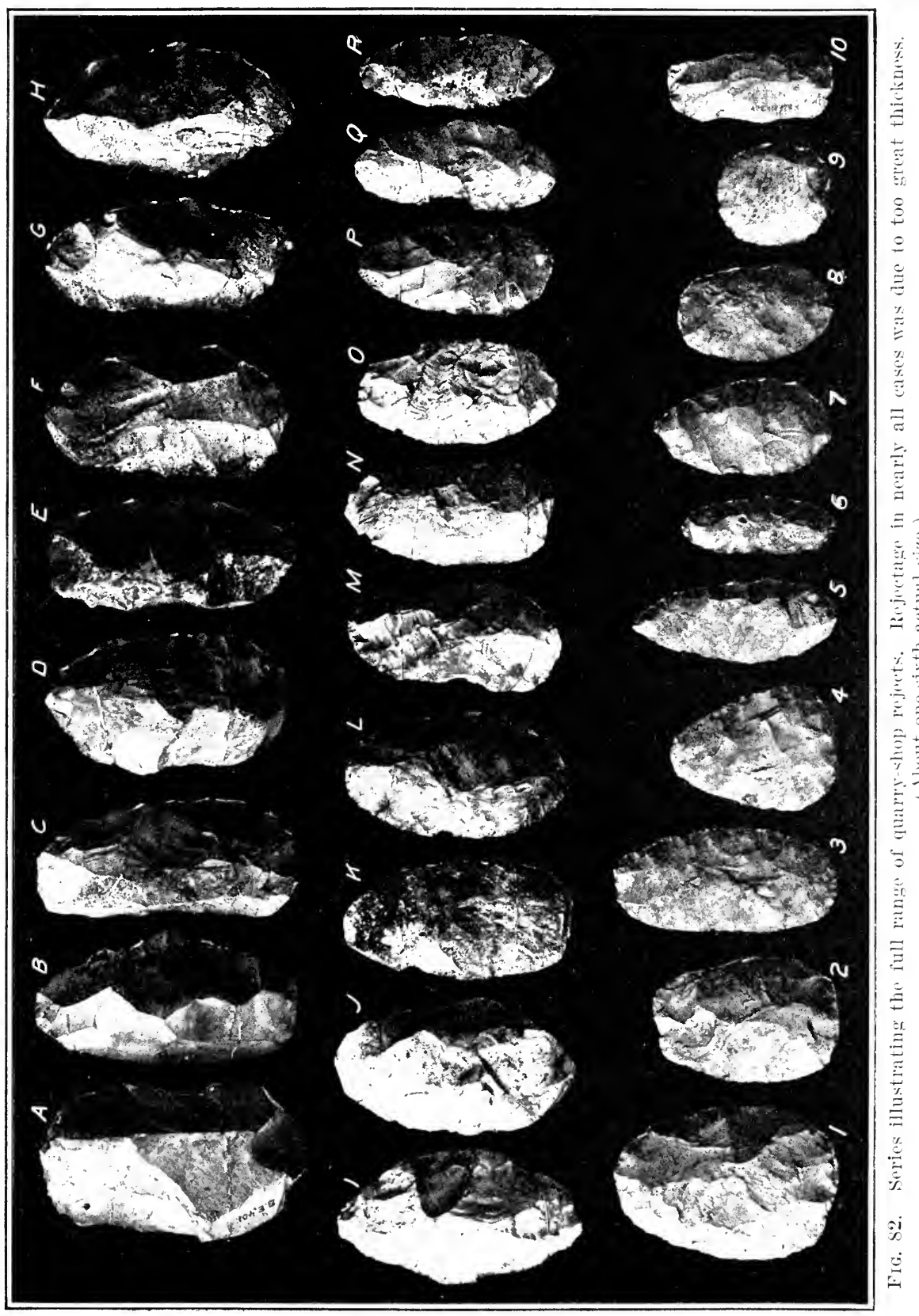

8:3 and 8t. As on all other similar sites where material of suitable quality was worked, large numbers of fragments, spalls, and chips 


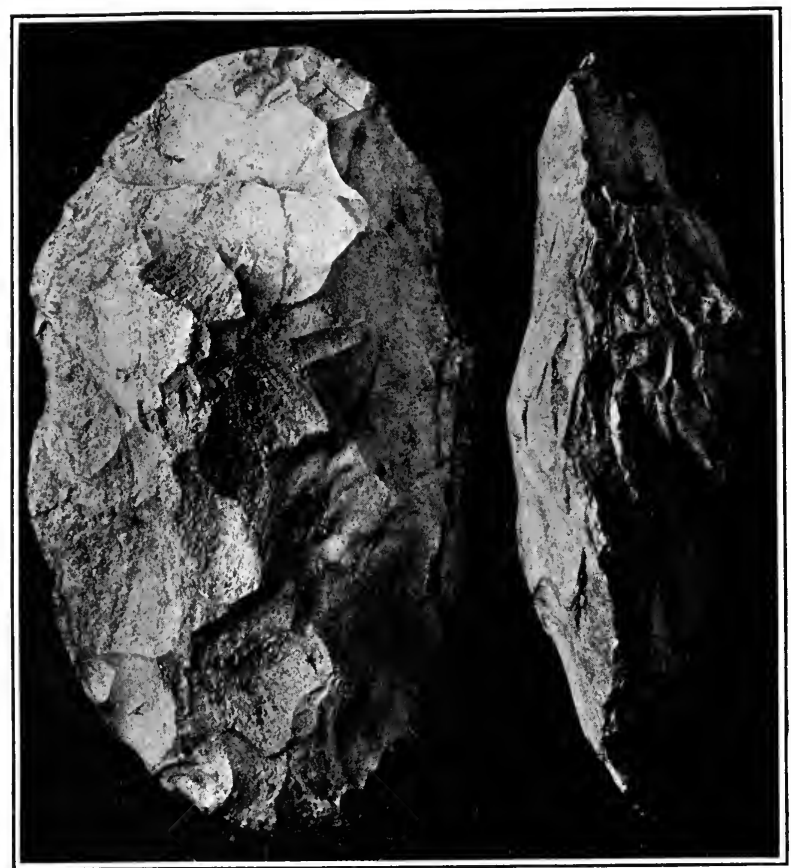

FIG. 83. Prevailing cause of failure. (One-half actual size.)

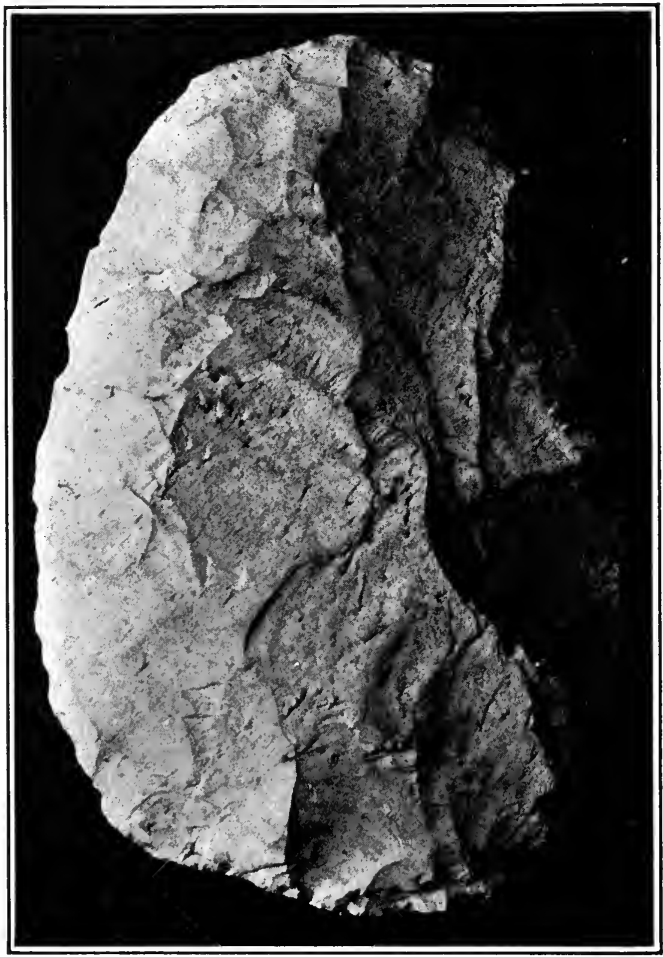

Fig. 84. Comparatively thin blade found among the refuse. (One-half actual size.) 
were doubtless selected and carried away for use in making the different smaller implements and also as implements without further shaping. $\mathrm{As}$ in other cases where dwelling was not associated with the factory site, no specialized implements were found. The nearest approach to the typical completed blade is illustrated by the fragment shown in figure 85. Among the débris a few large thick blades occur, notched in opposite margins as if to be hafted as picks (fig. 86 ), and several fluted cores or nuclei from which thin flakes had
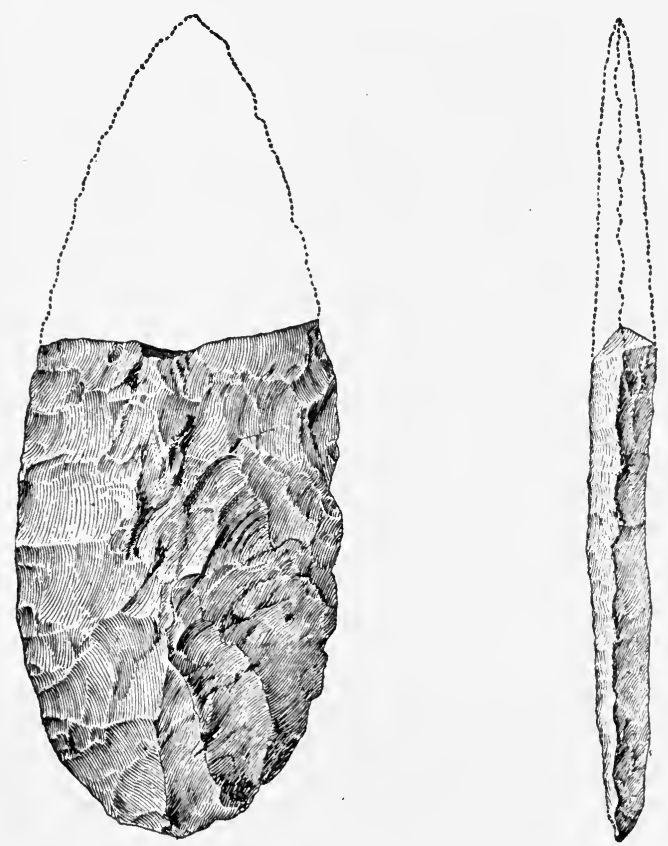

Fig. 85. Blade broken near point of completion. (One-half actual size.)

been detached were found (fig. $8 \tau$ ). Typical hammerstones made of gnarled chert occur in numbers.

The stone is a white and yellowish gray chert of exceptional massiveness and homogeneity but of only moderate fracturing qualities. It is not so well suited for making the smaller implements as is the Flint Ridge material and not so well adapted to the manufacture of very large blades as the Mill Creek chert. However, among the rejectage of the site are many partially worked and abandoned specimens, measuring a foot or more in length, indicating attempts to secure blades of large size. Implements of this material are found scattered over a wide area, but may not be safely traced to this particular locality since there are, doubtless, in the general region, many other quarries and shops where kindred material was worked. Subsequent to the writer's two visits Dr. W. C. Barnard, of Seneca, Mo., had examined this and numerous sites of minor importance in the region and had made valuable collections. 
A remarkable cache of projectile points has recently been discovered in Delaware County, Okla., the number as last reported by

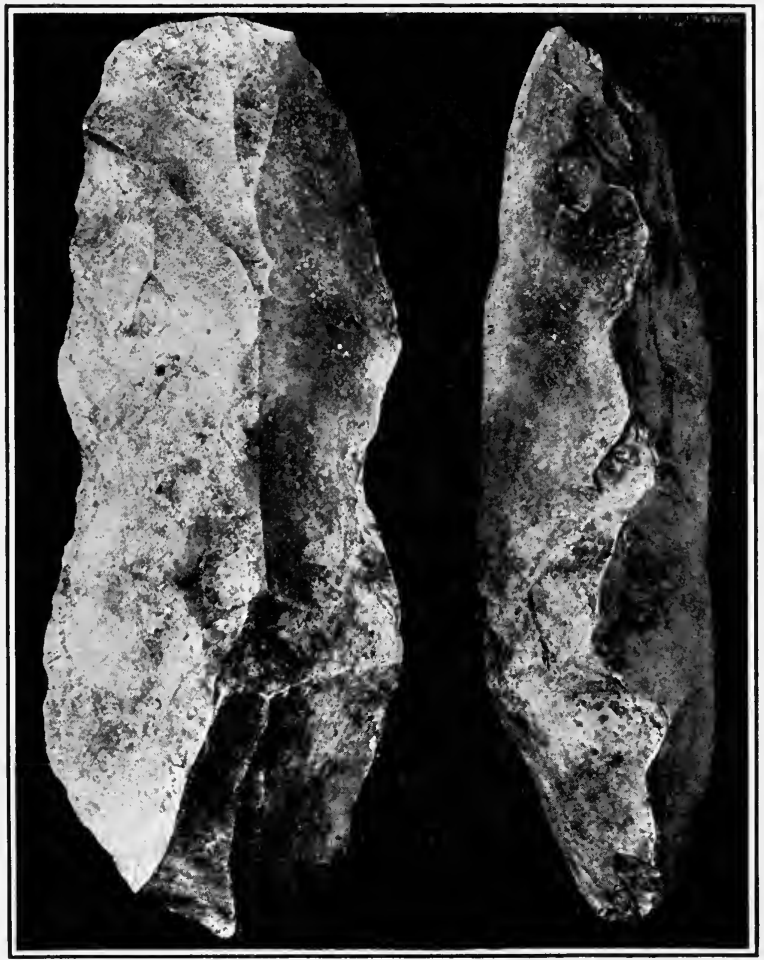

Frg. 86. Slightly notched specimen, possibly used as a pick. (One-half actual size.)

Dr. Barnard reaching the very large total of 22,000 . Those found near the surface in the cache are of the material quarried in the Ottawa County quarries discovered by Dr. Barnard, while those at lower depths are of the flint found in an old river bed near the cache.

In the vicinity of the village of Afton, a few miles to the southwest of the Ottawa County quarries, a most The Afton Cache in teresting cache of projectile points, knives, blades, and other forms of implements, nearly a thousand in all, was obtained by the writer from a sulphur spring, where they had been deposited, doubtless, as an offering to the superior powers. The chert is of

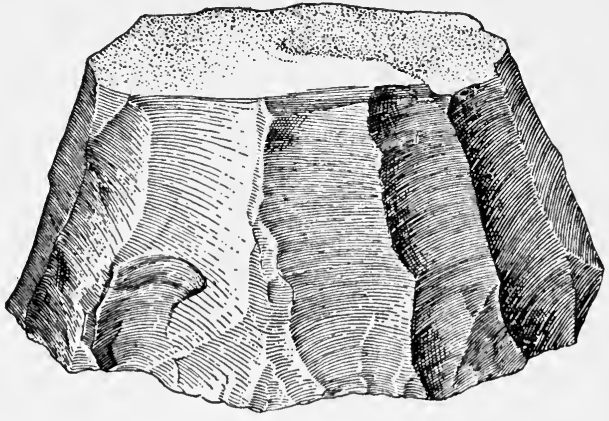

Fig. 87. Nucleus from whlch flake knives have been struck. (One-half actual size.)

fine quality, white or of mottled bluish-grays, and may have been 
derived from quarries in the immediate region. ${ }^{1}$ This site was first reported by Dr. R. H. Harper, of Afton, who generously turned over to the Museum a large number of specimens obtained from the spring deposit previous to the writer's arrival. The implements of this deposit are of mottled tints, a bluish-gray prevailing. It is thus apparent that they could not have come from the Peoria Reservation (Ottawa County) quarries a short distance to the northeast, but were derived rather from other quarries in the vicinity, possibly from certain so-called Spanish diggings reported to occur at Vanita and at other points in the extensive region to the west in which the Permian formations are exposed.

\section{Kansas}

Numerous reports of the occurrence of extensive workshops where chert was obtained and worked up by the aborigines in the State of Kansas have been submitted, but no well-marked quarries have been noted. It is evident that the extensive areas of Permian strata are rich in workable materials, and further exploration will doubtless bring to light the ancient diggings. Very full accounts of the chert-working industry of the region identified as Quivira by J. V. Brower have been published by this enthusiastic explorer, and valuable collections of implements presenting exceptional features of form have been made and preserved in our museums. ${ }^{2}$

${ }^{1}$ IIolmes, Flint Implements, etc., from a Sulphur Spring at Afton, Ind. Ter.

${ }^{2}$ Brower, Memoirs of Explorations in the Basin of the Mississippi, vols. I and II. 


\section{QUARTZITE QUARRIES, WYOMING}

$\mathrm{P}$

ASSING over a broad expanse of prairie and plain and approaching the Rocky Mountain highland, we again encounter traces of ancient activity in the stone-working industry. A large area in eastern Wyoming, which may extend also into Nebraska and Dakota, bears evidence of extensive operations. The best-known quarries of this region are located eastward of the Platte River in the northern part of what was Laramie (now Platte) County, Wyo., and in adjoining parts of Converse County on the north, and are confined to the exposures of quartzite strata of Lower Cretaceous age. Robert F. Gilder, of Omaha, visited the region in 1906 and on one or more subsequent occasions, and published accounts of the remarkable phenomena of the quarries in the Sunday World Herald (Omaha) of September 2, 1906. He prepared a sketch map locating some 20 groups of the ancient diggings, which were originally known locally as Spanish diggings, to which he gave the names of various persons who have taken part in the study of the quarry phenomena here and elsewhere in the United States (fig. 88). The largest of these groups he estimated to cover 40 acres of ground. One of the sites was visited by Dr. George A. Dorsey in 1900, and a number of other persons have made more or less careful observations of the phenomena, among whom are Walter P. Jenney, J. B. Hatcher, Harlan I. Smith, Stewart Culin, and Neil M. Judd.

It is interesting to observe that the phenomena of these quarries and the associated workshops correspond in nearly every respect with those of the more eastern quarries, where kindred forms of material were worked by the aborigines. The following brief account of one of the quarry groups is abstracted in large part from the report of Dr. Dorsey. ${ }^{1}$ This group is located on a rounded eminence in the southern part of Converse County. Here and there over the surface are many pits having a diameter of 20 to 50 feet and a depth of 10 to 30 feet. The walls and bottoms of these excarations are covered with flinty refuse which, although artificially broken up, shows little indication of having been otherwise worked by man. Near the base of the hill on the east side is a deep ravine or wash with vertical walls, which affords an exposure of the massive quartzite of variegated hues 30 or more feet in thickness. In the face 
of this wall are seen rounded or elliptical concretions of fine-grained chert, many taking the form of chalcedony and agate, materials highly prized by the tribes for the manufacture of projectile points, scrapers, and other small chipped implements (figs. 89, 90).

In the more open spaces between the pits, especially on the southern slope of the eminence, are many round tipi circles manifestly

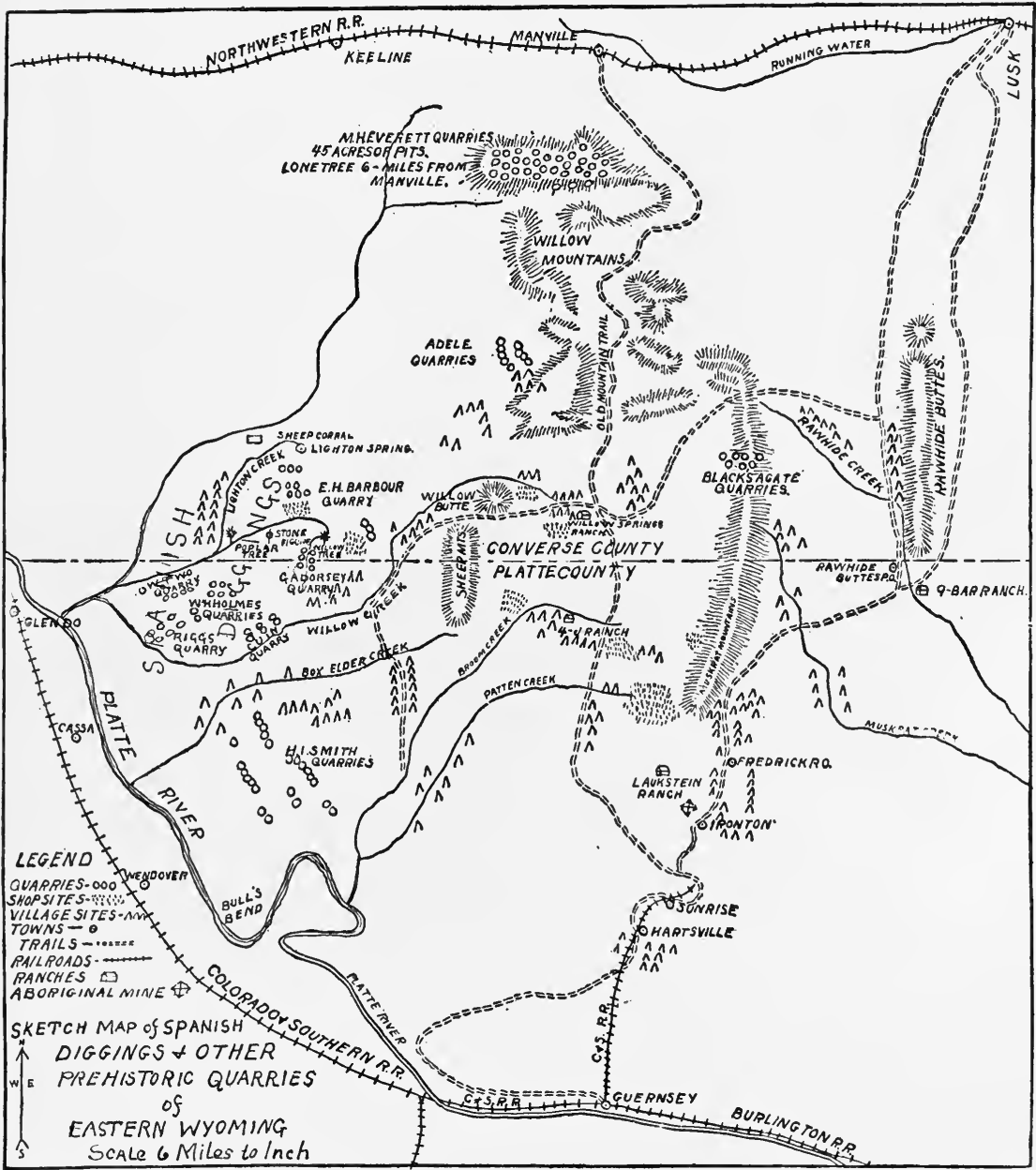

Fig. 88. Sketch map of the Wyoming quartzite quarry area, by R. F. Gilder.

representing recent occupancy of the site. No quarry implements except hammerstones were found, and these were merely rough, irregular masses of quartzite or nodules of other materials which, on account of their hardness and toughness, were suitable for the purpose. Their identification as implements was made possible by the presence of abrasions which could only have come from usage in 


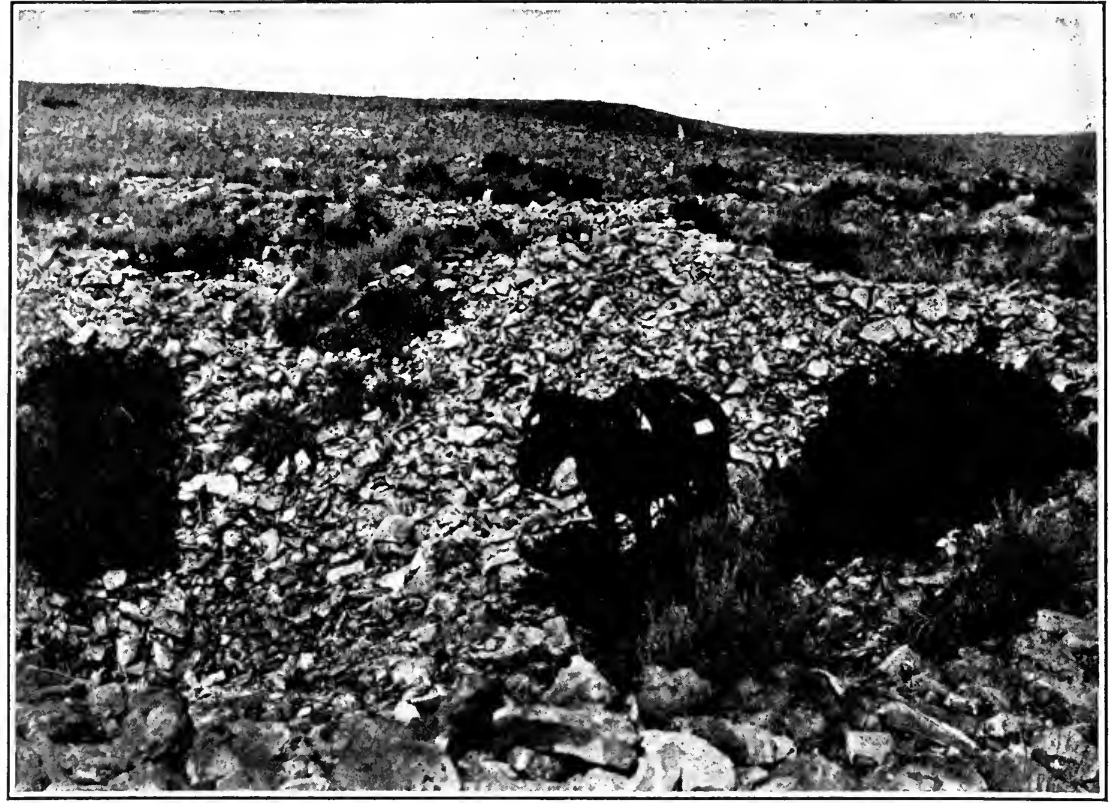

F1G. 89. Present appearance of the Wyoming quartzite quarries.

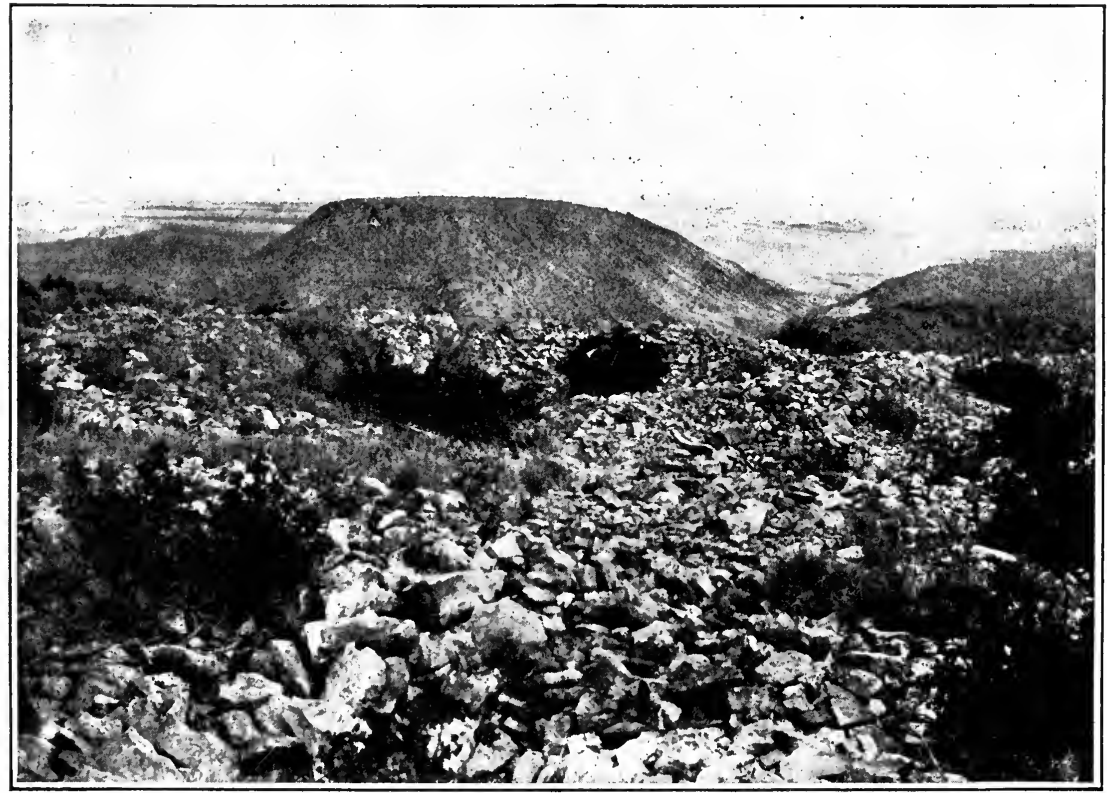

Fig. 90. Present appearance of the Wyoming quartzite quarries. 
breaking up large masses of hard rock and blocking out the forms of implements. An examination of the rejectage of the shaping work about the pits shows that the material most utilized was that which could be worked up into knife blades or long and rather broad lance ${ }^{*}$ heads or into still larger leaf-shape implements, destined, perhaps, for agricultural purposes. Nothing whatever was found in a finished state, and even partially worked specimens were not numerous. The refuse about the pits is characterized by the large size of the partially shaped rejects. No work whatever seems to have been done on the small jasper and chalcedony nodules about the pits, this being reserved for the specializing shops established usually at or near the camping places. As a consequence, on the latter sites numerous small rejects, usually of leaf-shape pattern, occur and small flakes and small hammerstones made from jasper or other nodular material are found in numbers. No single specimen of finished arrowhead was encountered on these sites, nor was any reject discovered from which one could safely predict its destined specialized shape. Small scrapers are met with in surprising quantities, not only about the tipi circles near the quarries, but also in the vicinity of the large circles near the Lauk \& Stein ranch, 30 miles away, and at the innumerable sites encountered on the road between the ranch and the quarry, all of which show evidence of having been workshops. It is remarkable, however, that at none of the shop sites between the ranch and the quarry was any evidence found of the shaping of large leaf-shape implements, the rejectage of which appears plentifully on the quarry sites. This might be taken to indicate that the larger forms after blocking out were carried to distant places in agricultural districts to be worked up.

Dr. Dorsey concludes, however, as the result of his examination, that the work in these quarries was probably done by some of the Plains tribes, within a comparatively recent period, yet previous to the advent of the white race in the region. 


\section{OBSIDIAN MINES}

$\mathrm{O}$

BSIDIAN, a volcanic glass of very diversified characteristics of color and texture, was much utilized by the American aborigines in their arts. It is found in rast deposits in the western half of North America, and in Mexico and Central America. The workings where it was obtained thus far have United States received but meager attention. In 1878 the writer made superficial studies of the remarkable deposits of this material in the Yellowstone National Park, especially in Obsidian Canyon, where cliffs of black, rudely columnar glass rise to the height of 100 feet or more (fig. 91). ${ }^{1}$ The refuse of aboriginal operations observed at a number of points indicate the manufacture of the usual varieties of chipped implements. It is surmised that the aborigines probably worked the deposits of obsidian at many points in the volcanic area of the Yellowstone and Snake River Valleys.

Obsidian was worked somewhat extensively in the mountains of northern New Mexico, in Nerada, and Arizona, and the Pacific States are exceedingly rich in this material, and, although no important quarries have been located, there can be little question that such exist. Among the most remarkable chipped implements in America, and in the world for that matter, are the obsidian knives of California, the largest of which are upward of 30 inches in length and at the same time are of remarkable symmetry and beauty of finish (fig. 92). It is an especially noteworthy fact that the art of working obsidian is practiced successfully as a matter of gain to-day by certain California Indians. A lay-figure group, intended to illustrate the working of obsidian by the ancient Californians and constructed under the writer's supervision for the San Diego Exposition, is shown in figure 93.

Obsidian was quarried extensively in Mexico, and the best known mines are found in the State of Hidalgo, about 12 Mexico miles northeast of the city of Pachuca, on the mountain known as Sierra de las Navajas, the "Mountain of the Knives." It was the writer's good fortune to visit this mountain in 1899. The journey from the City of Mexico was made in company with Prof. G. K. Gilbert, and the trip over the

\footnotetext{
Iolmes, Notes on an Extensive Deposit of Obsidian in the Yellowstone National Park, p. 247.
} 


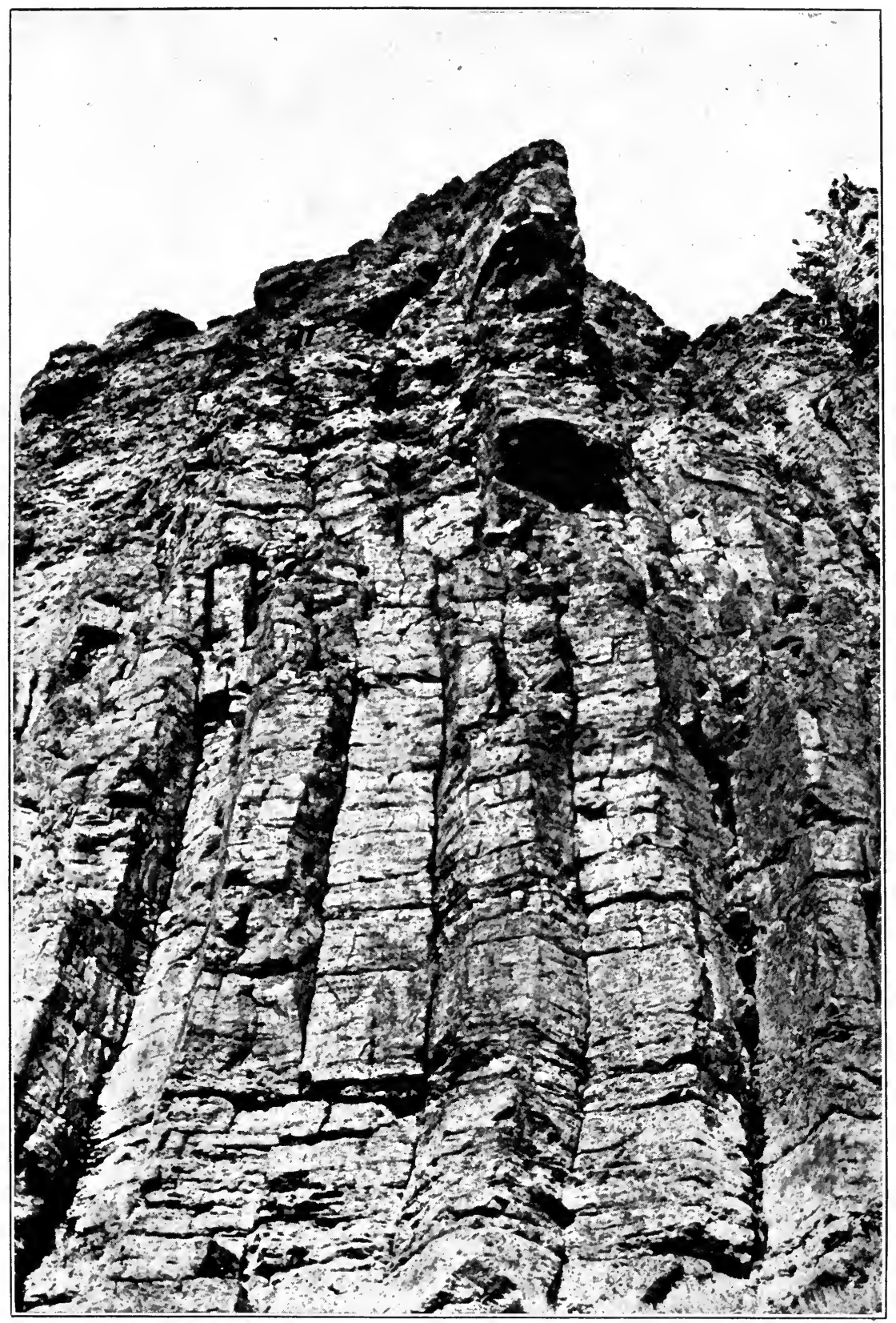

FIG. 91. Giant columns of impure obsidian, Obsidian Canyon, Yellowstone National L'ark. 


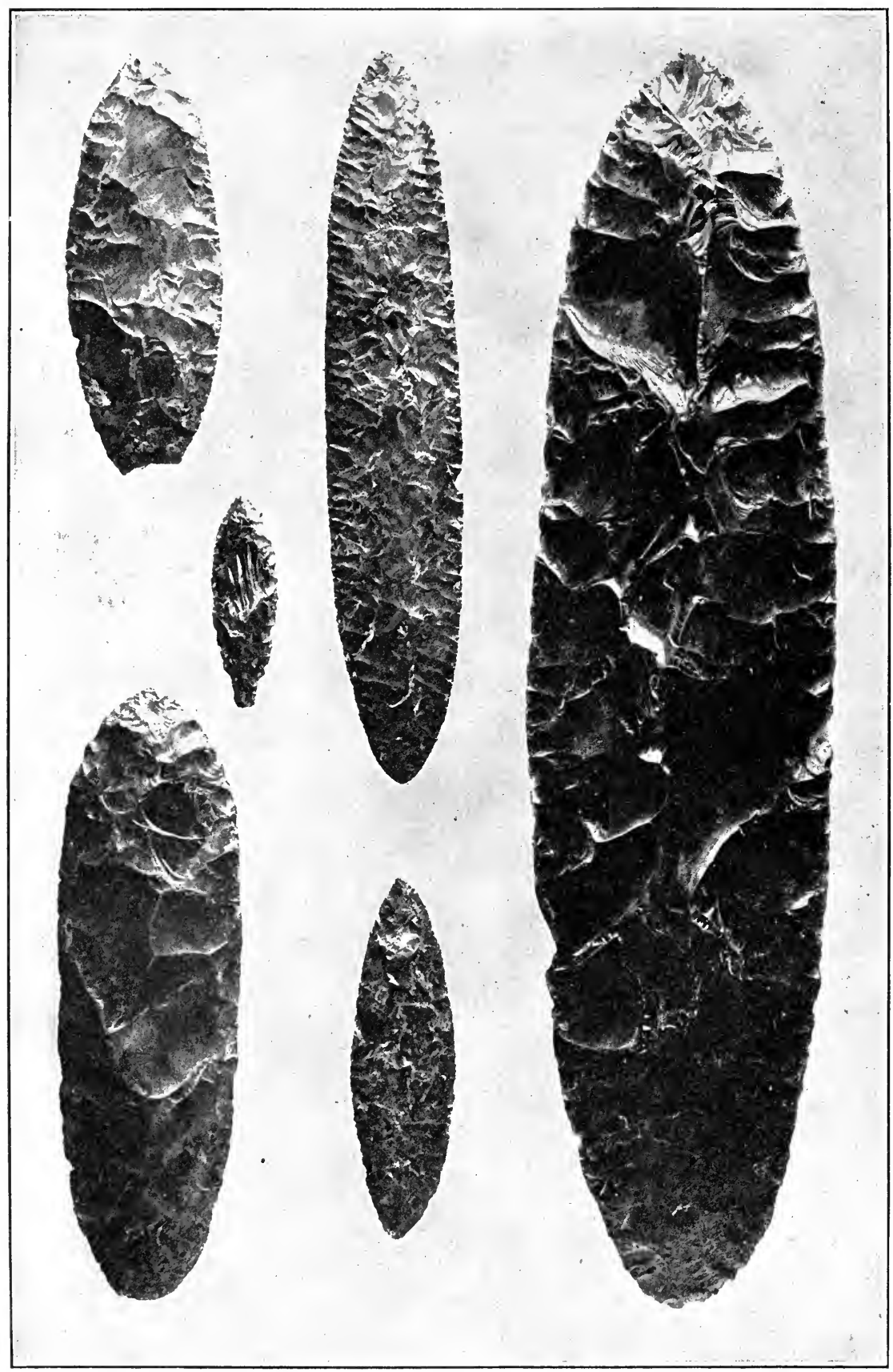

FIG. 92. Obsidian blades from California. (One-third actual size.) 
mountain roads was an extremely rough one. While at the mines we were the guests of Señor Amador, owner of the hacienda on which the Mountain of the Knives is situated. The lower slopes of the mountain are covered with open pine forest, in places overgrown with tall grass and on the steeper parts with underbrush. Everywhere are scattered fragments of obsidian, and groups of irregular mounds, alternating with depressions and pits, extend indefinitely up the forest-covered ridge. The pits and depressions

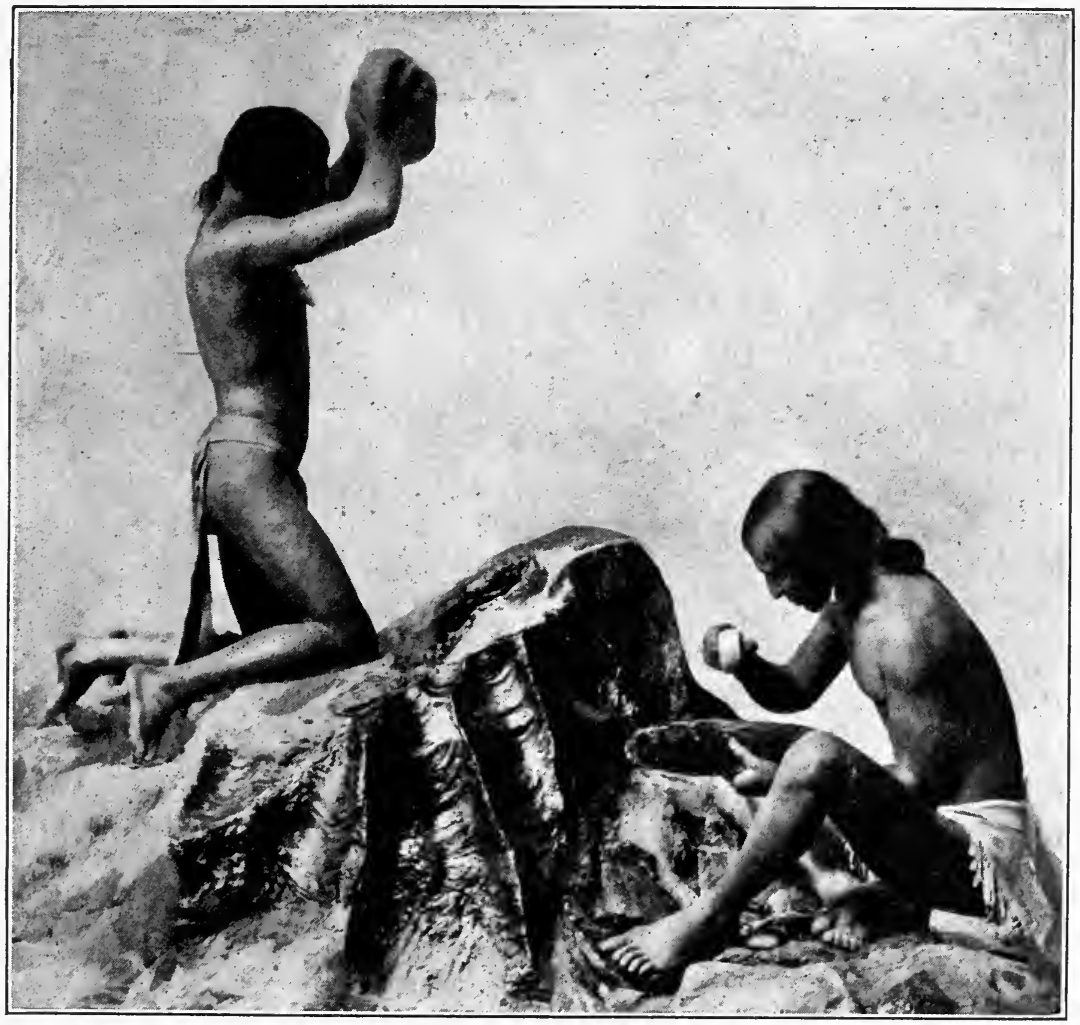

FIG. 93. Obsidian workers in California. From a lay figure model, life size, prepared by the author.

mark the sites of the ancient excarations, while the hillocks are the heaps and ridges of débris thrown out from them.

The enterprising peoples of the valleys below must have operated the mines vigorously for centuries to have thus The rittings worked over hundreds of acres of the mountain side. The deep pittings and heary ridges of excarated débris are practically continuous over an area of a mile or two in length, with a width reaching in places possibly to a fourth of a mile. 
It is not unlikely that there are other worked areas in the vicinity, and extensive workings are reported in the vicinity of Ococingo, several miles toward the east. No outcrops of the obsidian are to be seen on this part of the mountain, and it is apparent that the ancient miners had exploited the entire slope in search of deposits lying at varying depths beneath the surface. The depth of the wider depressions usually does not exceed 6 or 8 feet, but some are deeper, and many take the form of wells from 3 to 10 feet in diameter and 15 or 20 feet deep, with vertical or overhanging walls. Many of these must have been much deeper, for the débris thrown out is more extensive than the present openings would suggest, and there can be no doubt that in numerous cases tunneling was continued horizontally or obliquely for considerable distances along productive layers or bodies of the obsidian. The heaps and ridges of débris thrown out are rarely more than 10 feet in height, but they are well pronounced and abrupt, and the total irregularities of the slope are so great that exploration is tedious and difficult. Very generally the débris is intermingled with broken obsidian, and in many cases it seems to consist almost exclusively of broken fragments and flakes left by the workmen engaged in getting out the forms desired. In places there are large heaps of flakes where the choice fragments of stone were brought from the mines and placed in the hands of the flakers to be worked up.

Extensive areas are covered with these deposits of pure black resonant flakes and fragments. One great heap Deposits of Flak- which lies upon the mountain slope is more than

40 feet in vertical extent and many feet in depth, comprising perhaps 20,000 or 30,000 cubic feet of flakage. Efforts were made to dig into this remarkable deposit (fig. 94), but no headway could be made, as there was no earth to hold the flakes together and the holes dug were immediately filled by sliding, tinkling slivers of glass from above, every piece of which seemed as clean and incisive of edge as when struck off by the workmen perhaps hundreds of years ago. The relation of the deposit of refuse to the mountain slope is suggested in the section, figure 95 .

Being without appliances for descending into the deeper pits, little was learned of the subterranean phenomena, and Hammerstones no traces were discovered of the implements used in the mining and shaping operations, except a number of hammerstones, which are identical in shape with the chipping hammers used in our northern quarries (fig. 96). The larger specimens, 4 or 5 inches in diameter and somewhat discoidal or cheese-shaped, were doubtless employed in breaking the obsidian in the mass, but the smaller, many of which are globular in form, must have been used 


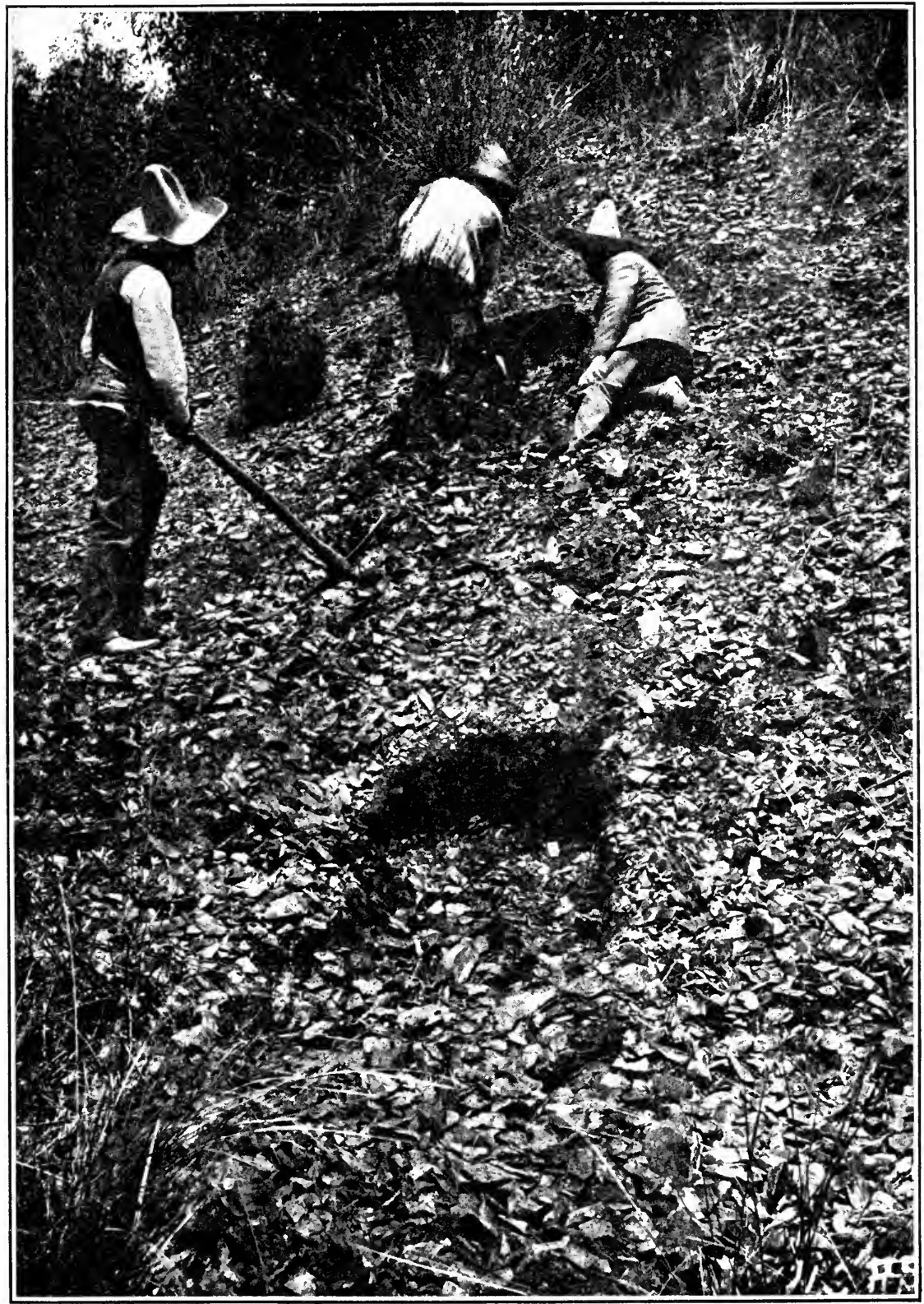

FIg. 94. Great deposits of obsidian flakes and other shop refuse, Mountain of the Knives, Mexico. The author at the right and W. W. Blake at the left. 
in the hand simply, or with a light haft attached, in the work of breaking up the fragments and in trimming them down to the desired contour. Most of the stone is a tough lava, and the peripheries show the usual evidences of battering.

It is well known that the ancient dwelling sites of the general region, including the Valley of Mexico, are strewn Flake Knives with countless knives which have been derived by fracture from faceted cylindrical nuclei, partially exhausted specimens of which are widely distributed, and evidence of the getting out of these nuclei was to be expected on the quarry site. Examination dereloped the fact that here the rejectage deposits abound in abortive nuclei (fig. 97), which were reNuciei for Knife jected because lacking in some of the qualities neces-
Making sary to successful flake blade-making. It was requisite that the material should be fine-grained, flawless, and uniform in texture; the shape had to be roughly cylindrical, and it was essential that

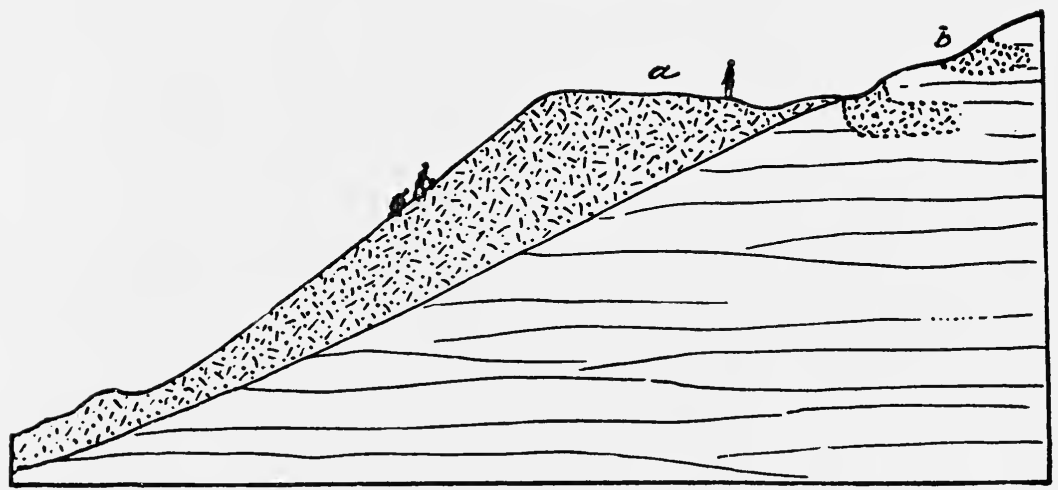

Fig. 95. Section of the great deposit of flakage, obsidian mines, Mountain of the Knives, Mexico.

one end should be smoothly squared off, so that the flaking tool would have the proper surface for receiving the stroke or other form of impact required for removing the long slender blades. Of course, the flake knives were not made on the quarry site, as the edges of the blades were so delicate that transportation would have subjected them to injury; therefore the selected nuclei were carried away, and the knives made by expert workmen, whenever and wherever they were required. It is impossible to form even an approximate estimate of the number of successful nuclei produced and carried away, but the product of the work on this site must have been enormous. Examples of the exhausted cores found widely distributed over the Valley of Mexico are shown in figure 98. 
Besides the rejectage of nuclei making and the hammerstones already referred to, a few other varieties of artifacts were obtained on the quarry site. In some of the heaps of refuse were found a number of scraper-like objects (fig. 99), made by taking a long; thick

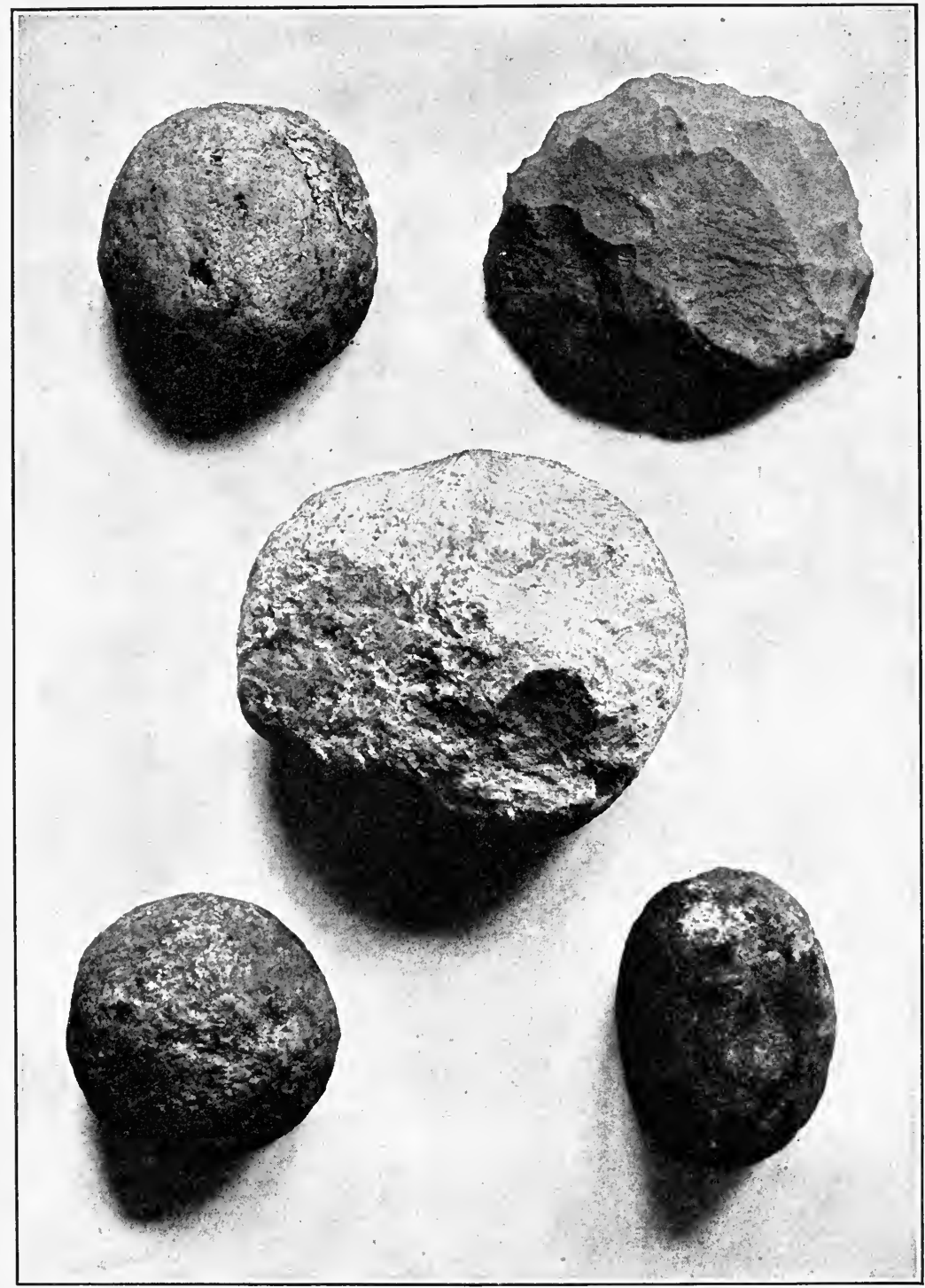

FIg. 96. Hammerstones from the obsidian mines of Mexico. (One-half actual size.)

flake with one smooth, concave side, and removing a few chips around the margin of the wider end on the convex face, giving a keen scraping edge. It is surmised that these were employed in shaping and sharpening the wood and antler tools required in the quarry-shop 


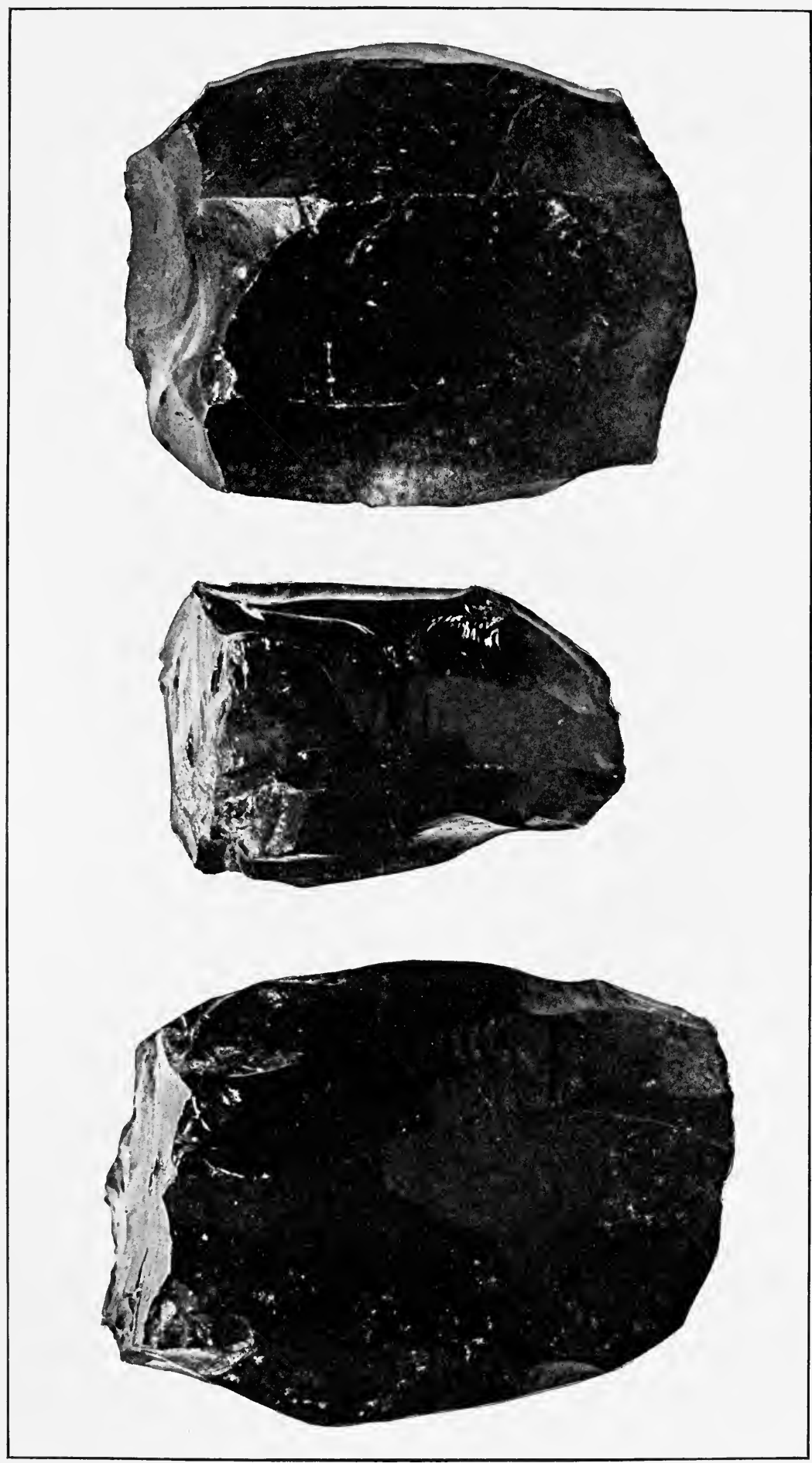

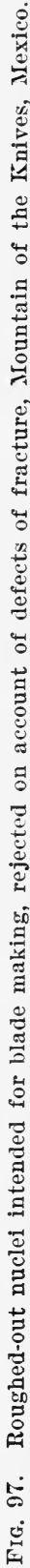




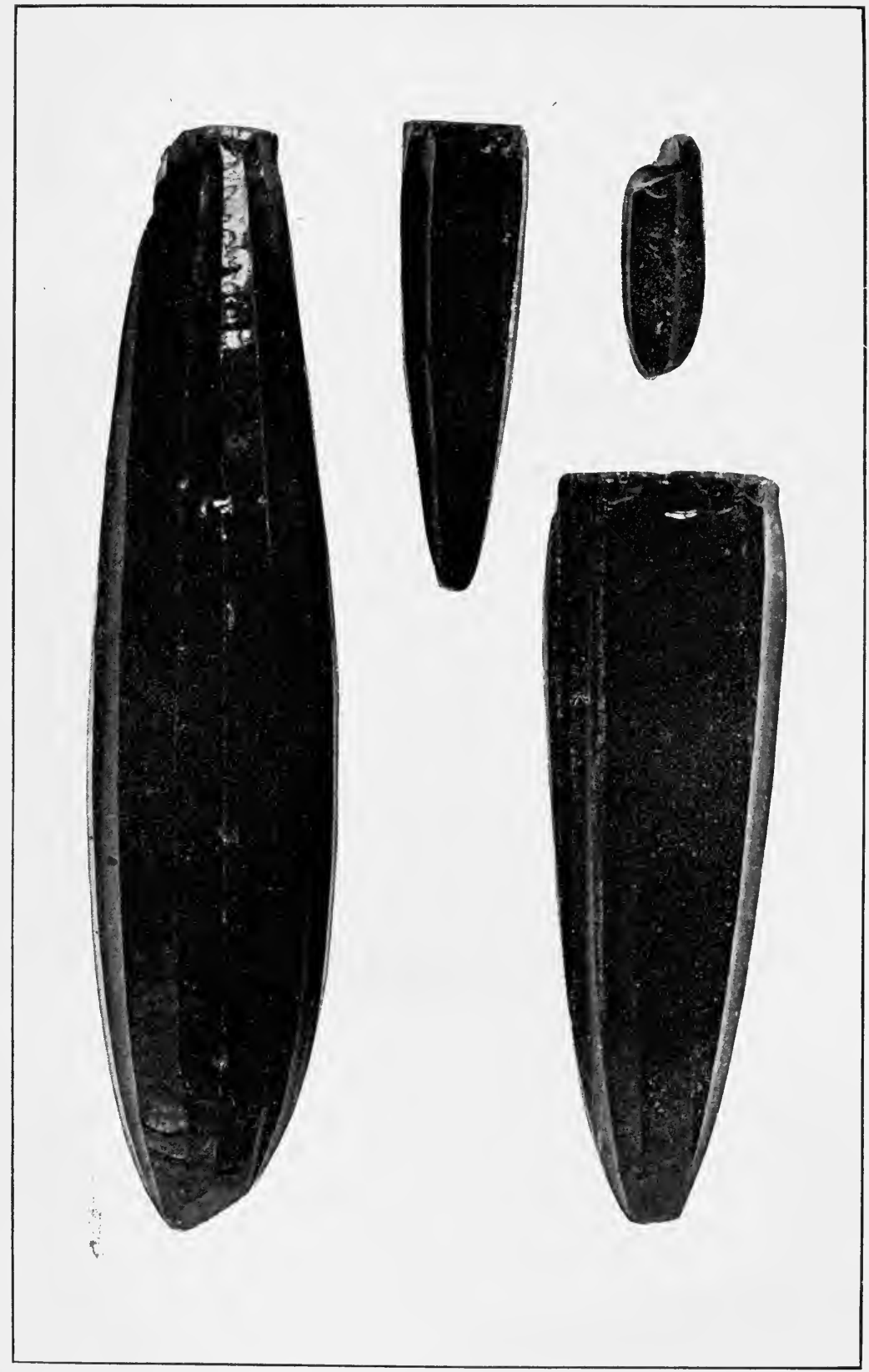

FIG. 98. Exhausted or nearly exhausted nuclei from the Valley of Mexico.

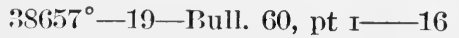




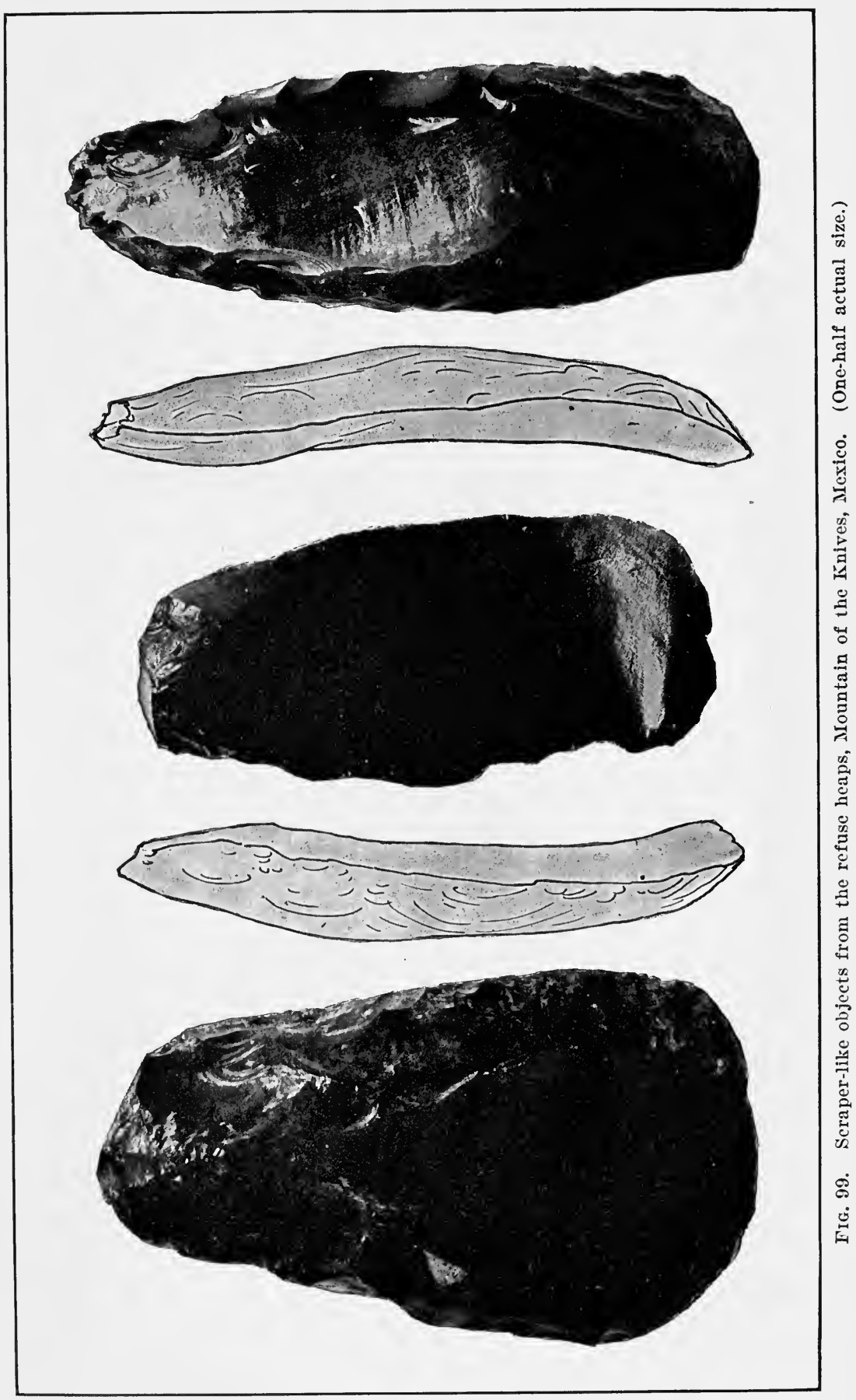


work. Other interesting partially worked implements, the final shape of which could not be determined, are shown in figure 100 . Strangely enough, there seems to be an almost total absence from this site of the manufacture of incipient leaf-blade forms from which knives, spear points, and arrowheads were usually specialized,

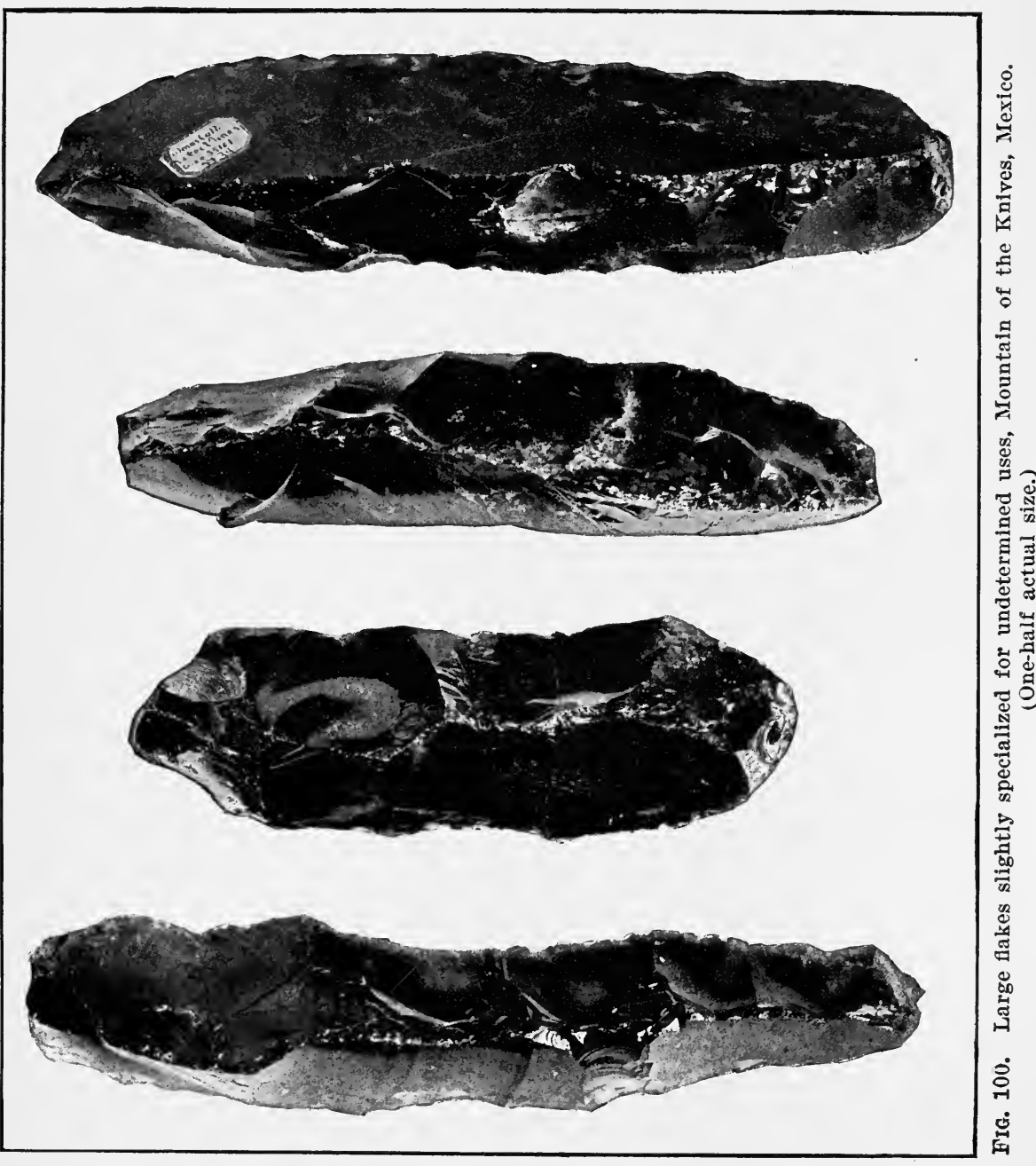

although blade-derived implements are found plentifully in the fields about the base of the mountain (fig. 101). These may have been produced in other quarries than those examined.

It may be difficult to identify the workers of these mines with any particular people, but it is safe to conclude that the Aztecs had a hand in the work. The Spanish invaders found these flake knives 
in universal use by this people, and the inhabited sites of this as well as of other stocks abound in these implements.

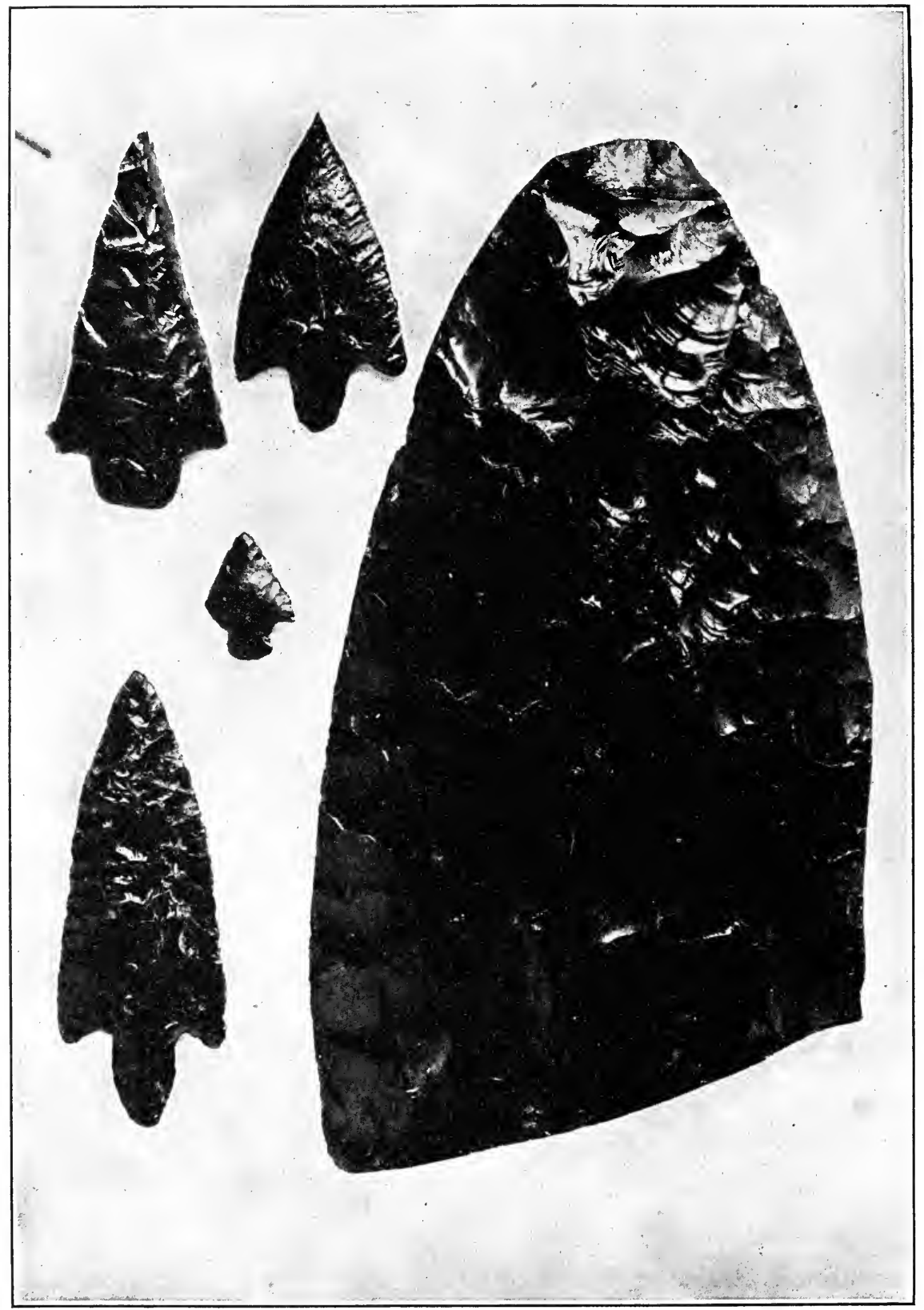

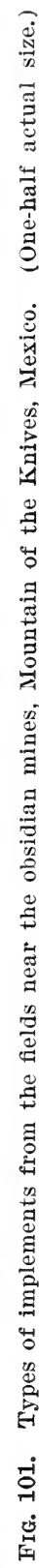

Plentiful evidences of the manufacture of implements of obsidian are found in widely distributed areas in Mexico, but the workings have not been reported on in detail. 
Mention should be made of the fact that the various forms of chipped artifacts referred to above as associated with sites where the raw material was obtained are by no means the only product of the obsidian-working industry in Mexico. Vast numbers of articles of use were produced by the processes of crumbling and abrading as well as by chipping, and even elaborately carred jewelry, vases, and idols were worked out with astonishing elaboration of detail and refinement of finish.

The obsidian product was widely distributed from the mining centers, but in accounting for stray bits and occasional implements of obsidian found in the Mississippi Valley it is not necessary to assume that the ancient peoples visited distant parts or that it came by trade from afar. It is quite reasonable to suppose that fragments of this material may have been carried by flood and ice from the great deposits in the Rocky Mountains of Montana, far down the Yellowstone and Missouri Rivers, to be lodged in the banks and bars of the rivers in what are now Dakota, Minnesota, and even Illinois and Missouri.

The most remarkable instance known of the wide distribution fr $\mathrm{m}$ the quarry source of obsidian artifacts is that of a deposit of knves found in an Ohio mound. Hundreds of carefully chipped blades of medium and large size, now preserved in the Field Museum of Natural History, were obtained from a burial mound in Ross County, the nearest source of supply being the Yellowstone country, upward of 1,500 miles away. It is, however, regarded as probable that these implements, on account of their remarkable forms, were derived from the mines of Mexico, still more distant, rather than from any northern source.

Mr. M. H. Saville, of the Museum of the American Indian (Heye Foundation), on returning from his 1917 researches in Guatemala, reports the occurrence of extensive quarries of obsidian along the line of the Guatemala Railroad at La Joya, about 18 miles east of Guatemala City. The road cuts through the obsidian deposits for a distance of 2 or more miles and the roadbed is ballasted with obsidian. The traces of ancient operations are extensive but, as in the Mexican quarries, the work was confined to the collection of raw material and to the roughing out of cores and implements. Another quarry is reported near Antigua. From this and from the La Joya site, the obsidian, extensively employed by the occupants of the ancient centers of habitation about Guatemala City, was probably obtained. 


\section{STEATITE QUARRIES}

C TEATITE is a soft, tongh, talcose rock, commonly called soapstone, which occurs in massive bodies in association with other metamorphic rocks. It was highly prized by the Indian tribes and served many important purposes in their arts and industries. It has the very desirable quality of A Fireproof Ma- resisting the action of fire and is thus especially adapted for the manufacture of cooking utensils. It is readily carved and susceptible of a high degree of surface finish. The color, when fresh, is usually a somewhat greenish-gray, but when polished and subjected to long-continued handling it becomes almost black, presenting an attractive appearance. The aborigines in their search for materials fitted to serve them in their simple arts probably discovered and attempted to utilize loose masses of this soft tough stone, finding it, however, unsuited for most purposes to which the harder stones were devoted. We may safely infer that step by step the peculiar qualities and adaptabilities of the material became known, and that after the available loose masses were exhausted the rock in place was attacked where it outcropped in the stream beds and on the hillsides.

The manner of conducting the quarry work was substantially as follows: When a sufficient area of the solid stone Quarrying Oyera- had been uncovered, the workmen proceeded with
tions stone picks to detach such portions as were desired. If the surface happened to be uneven, the projections or convexities were utilized, and the cutting was not difficult. Where the rock was massive and the surface flat, a circular groove was cut, outlining the mass to be removed, and the cutting was continued until a depth was reached corresponding to the height of the utensil to be made; then by undercutting the nucleus was detached or the stem so far severed that it could be broken off by means of stone sledges or levers of wood. If the stone happened to be laminated, a circular groove was cut through at right angles to the bedding, and the discoidal mass was removed without the need of undercutting. Where the conditions were favorable, a second disk was cut adjoining the first, and then a third, and so on, pretty much as the housewife cuts up the layer of dough in biscuit making. 
Where the floor and walls of a well-developed quarry are fully exposed, the details of the ancient operations are The Shaping work clearly displayed. In cases it is seen that the task of cutting out the mass was just begun when operations in the quarry closed, while in others it was well under way and the bulbous vessel nucleus now stands out in bold relief (fig. 102). In cases where undercutting has taken place, the rounded form resembles a mushroom on its stem and is ready to be removed by a heavy blow; while in many other cases we see only roundish depressions in the quarry surface, in the bottoms of which are

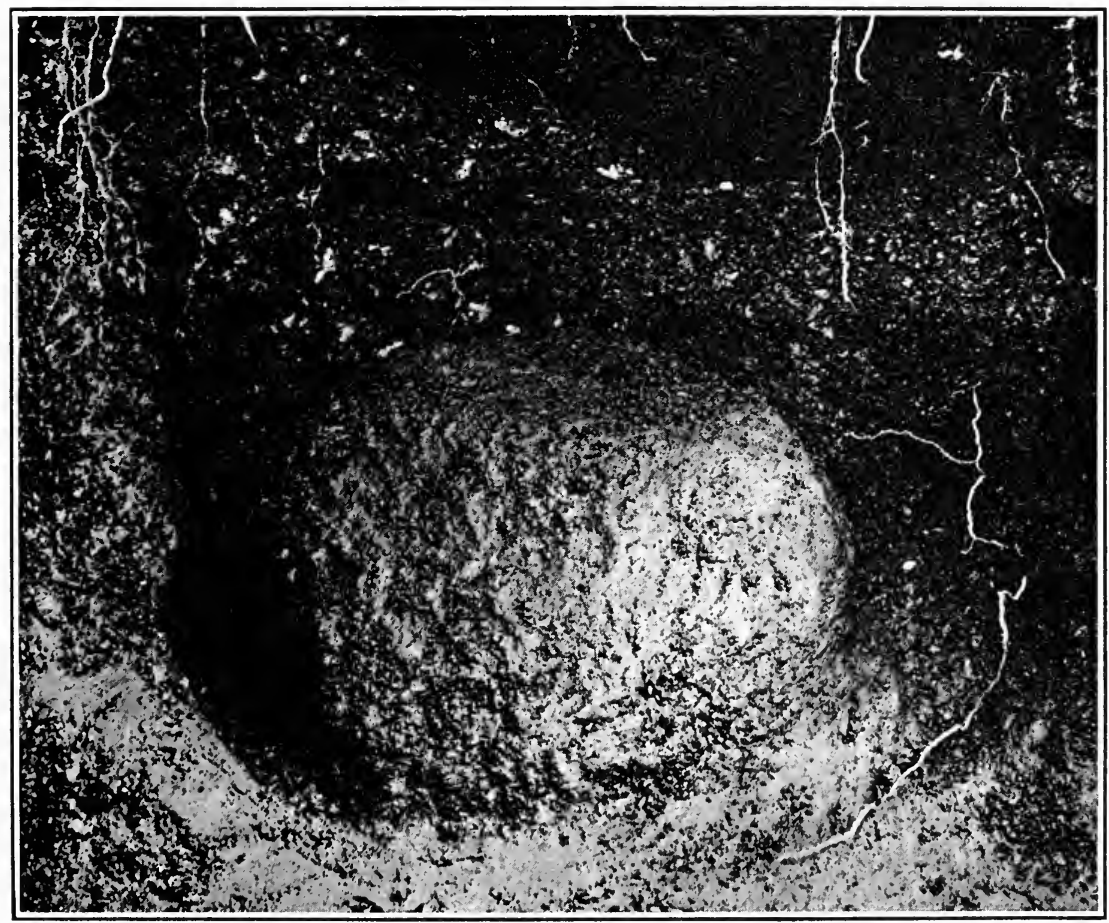

Fig. 102. Lump of soapstone partly cut out of the mass. (Diameter, about 12 inches.)

stumps or scars indicating that removal of the mass has taken place (fig. 103). It often happened that the work was Abortive Work stopped by the discovery of defects in the stone. In very many cases defects were not discovered until late, and the operation of removal at the last moment became abortive; instead of breaking off at the base, as was intended, the cleavage of the stone was such that the body split in two, leaving a portion remaining attached to the stem.

A noteworthy feature of the cutting out of these masses of stone is the attendant shaping of the mass, which was rudely sculptured as the work went on, the contour of the vessel being approximately 
developed. In the eastern United States rude nodes were carred at opposite ends of the mass as incipient handles, and excavation of the bowl was already well under way before the removal took place.

So far as observed, the quarries rarely yield evidence of any other shaping work than that of obtaining the rounded Quarry I'roduct bodies of stone and the partial development of some form of vessel. 'Tobacco pipes, sinker's, baking plates, ceremonial objects, amulets. ornaments, and images were made, mostly no doubt from choice bits of stone carried away for the pur-

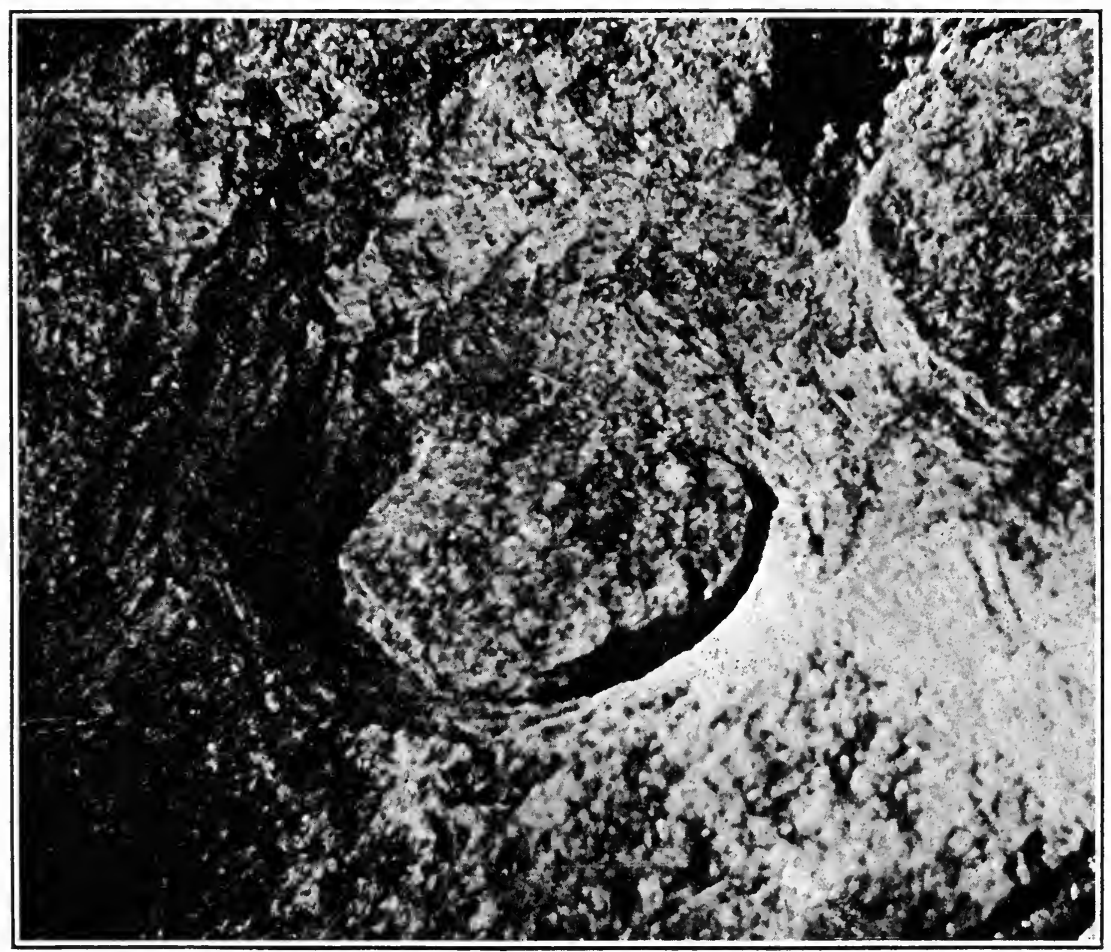

FIG. 103. The stump left by breaking off the globular lump.

pose, or perhaps often from fragments of the thick-walled ressels broken in use.

About the quarries and in the quarry débris are many partly shaped specimens rejected on account of serious defects of fracture, besides many irregular fragments and masses, usually showing some defect of texture, explaining their abandonment.

Steatite is of very general distribution in eastern Canada and the Atlantic States and has been mined by the aborigines Geographical Dis- in numberless localities, especially in New England, tribution of Quar- Pennsylvania, Maryland, District of Columbia, and
ries

the Appalachian regions to the south. Deposits are found in Wyoming and in other States of the Great Divide. In the 
Pacific States it was extensively mined, and to an undetermined extent in the Arctic regions. Little evidence of the presence of mines of this material has been collected in Middle and South America.

In the East two extensively worked quarries have been carefully studied by the writer, one in the suburbs of WashConnecticut Ave- ington City and the other in Fairfax County, Va. These may be taken as types, the manner of operating, the implements used, and the product being much the same everywhere. The former, known as the Rose Hill quarry, is located on Connecticut Avenue 4 miles from the White House. Here steatite of somewhat inferior quality outcropped in the banks of a small stream and in two rounded hills which rise to the right and left. The first account of the superficial features of this site was given by Elmer R. Reynolds in the Twelfth Annual Report of the Peabody Museum of Archeology and Ethnology in 1879. Later, Frank H. Cushing made examinations and collections from the surface, and in 1890 the old pittings were cleared out and exhaustively studied by the present writer. The old excavations were shallow, but extended over considerable areas, and numerous partly worked and rejected ressels and many quarry implements were collected. The abortive vessels illustrated in figure 104 show with remarkable clearness the marks left by the shaping tools. The ordinary form of ressel produced in the eastern quarry shops is shown in figure 105 .

The Clifton quarry had been extensively operated and was opened up and fully cleared out by William Dinwiddie, of the Fairfax County, Bureau of American Ethnology, under the writer's direction, in 1893. The exposure of steatite had been followed into the hillside about 100 feet by the aboriginal miners, and the excavations in places reached a depth of nearly 20 feet in the solid stone, 10,000 or more cubic feet of which had been removed. A general view of the excavations after clearing out is presented in figure 106. It is seen that the entire steatite surface is scarred by the pick work of the quarrymen.

$\Lambda$ number of the implements used in this and other quarries of the region are shown in figures 107-110. They include chisel-like forms made of several varieties of tough stone and groored axes diverted from their normal uses and employed as picks. In many instances the latter are broken, splintered, and modified by reshaping until the original form, excepting the groove, which was protected by the hafting, was lost. The discovery of a longitudinally grooved gouge-form implement (fig. 111) in the Rose Hill quarry near Washington is a noteworthy occurrence, since specimens of this type are rare outside of New England. 

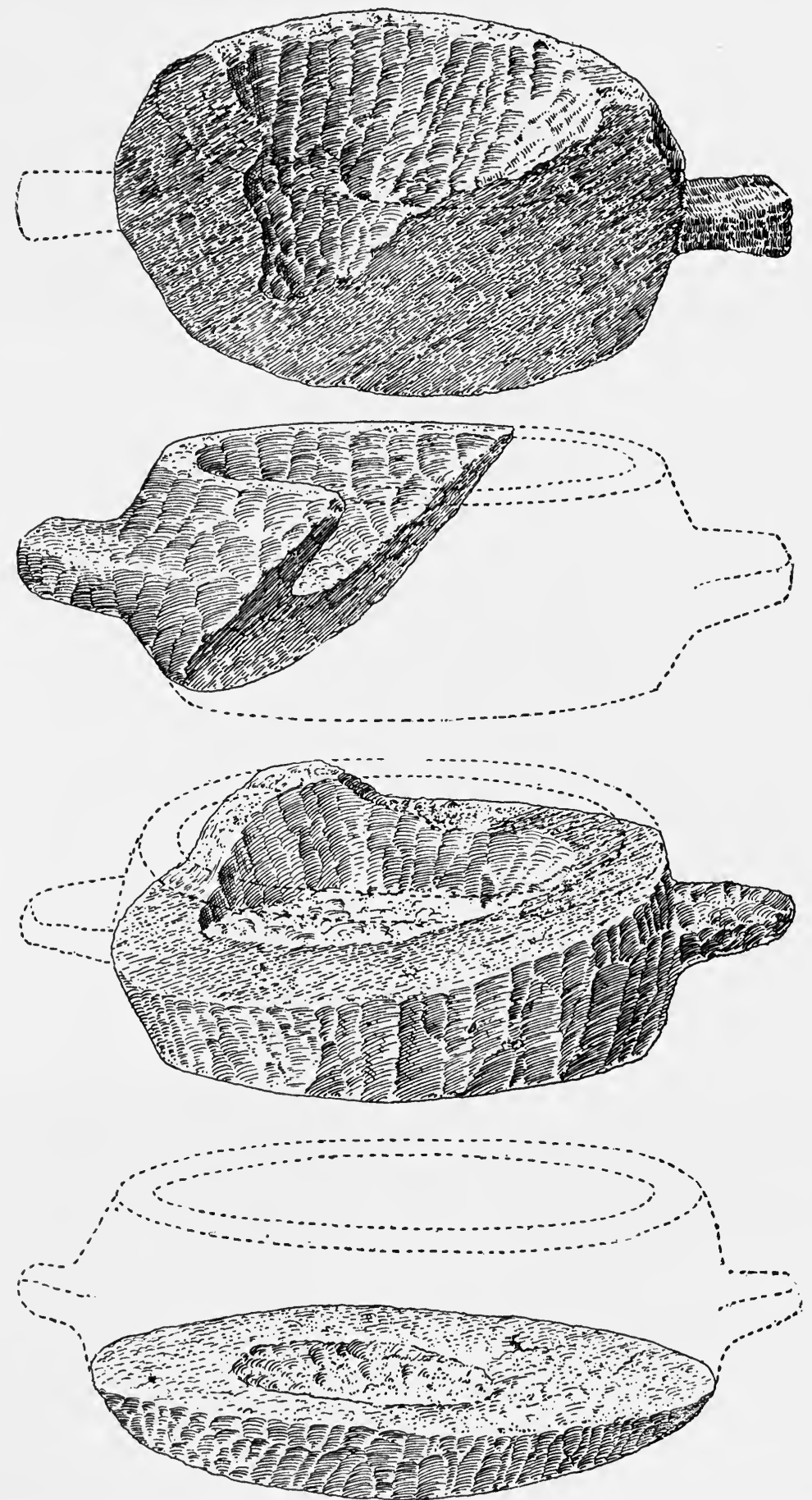

Fig. 104. Unfinished vessels broken during the shaping work. (About one-fourth actual size.) 


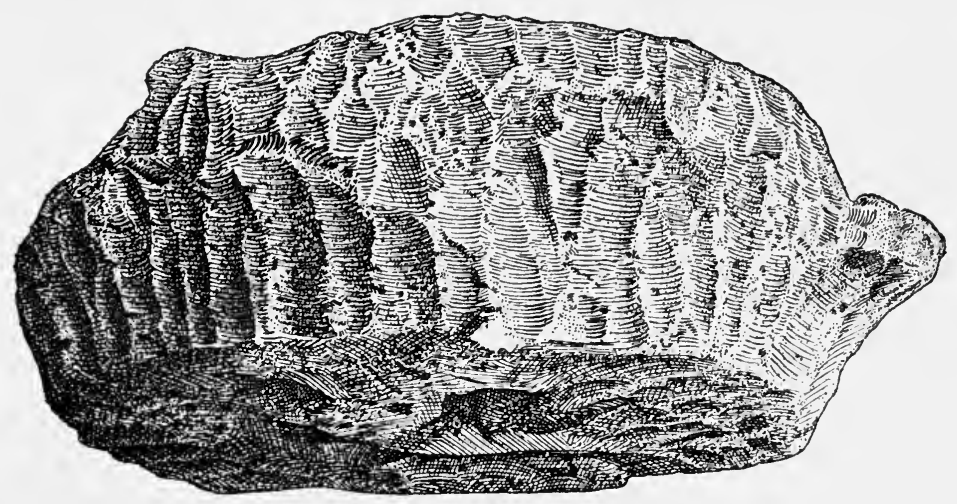

$a$

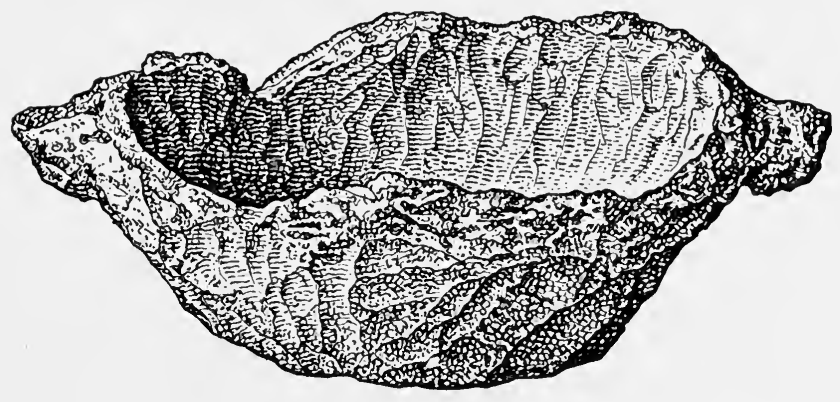

$b$

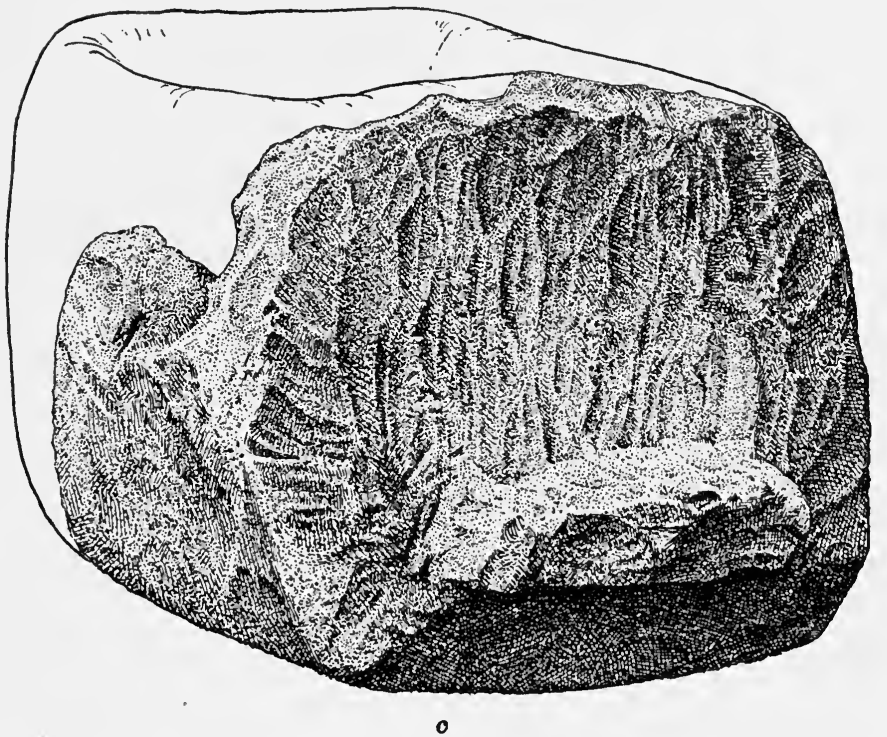

Fig. 105. Rudely finlshed vessels from village sites. 


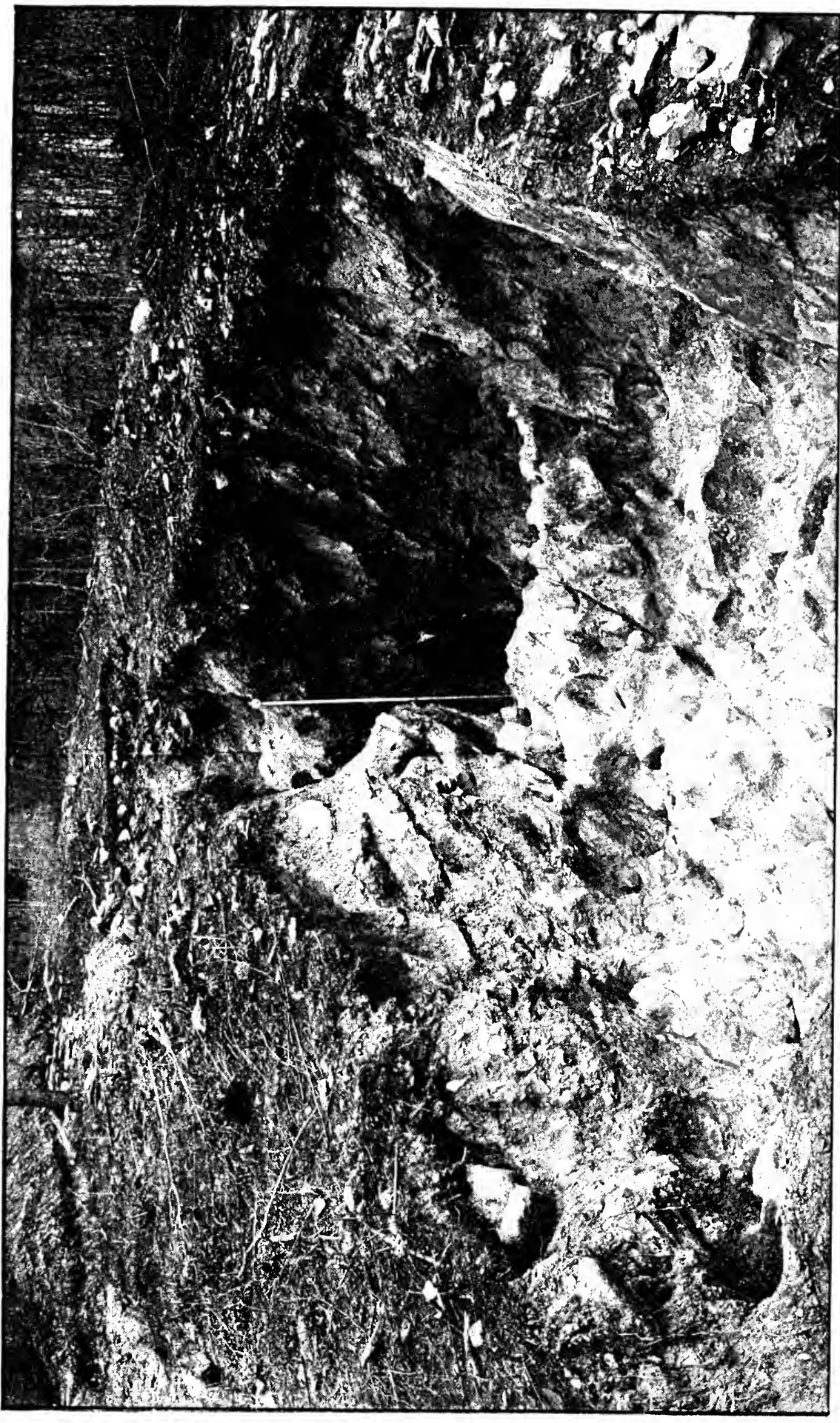



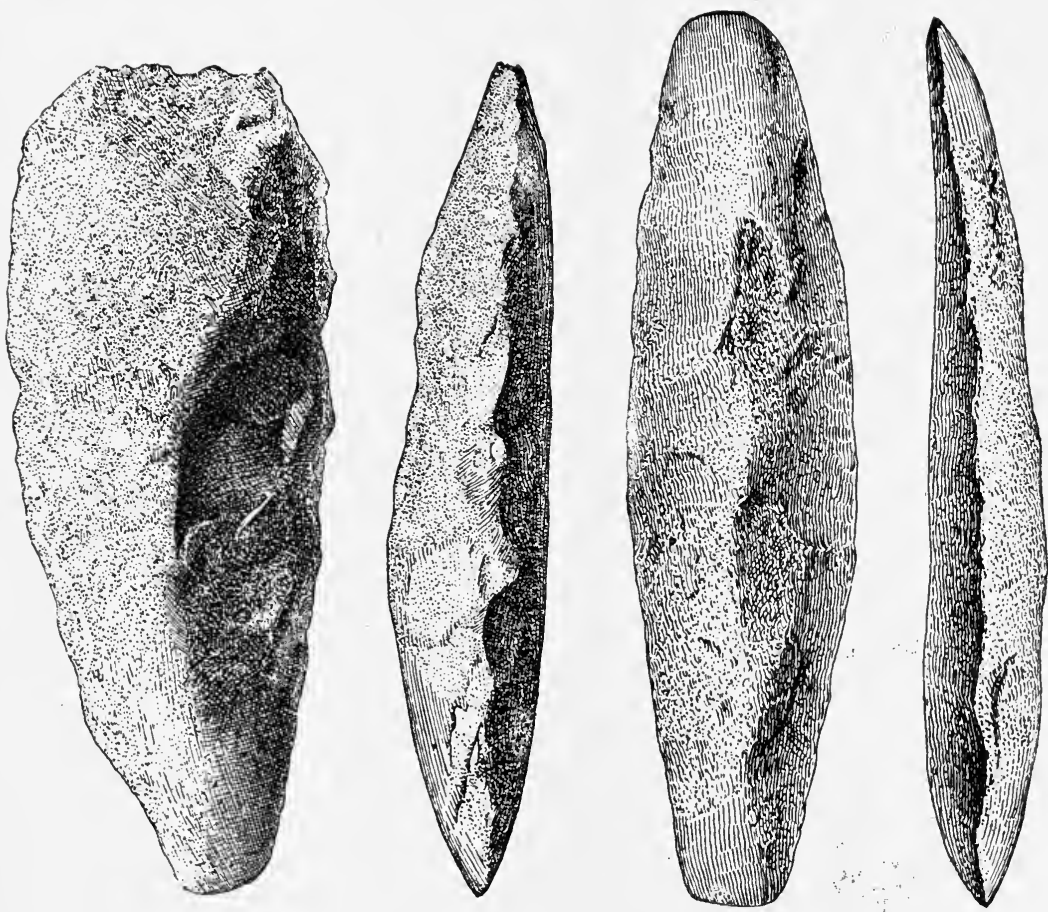

FrG. 107. Chisel and pick like forms of quarry implements. 

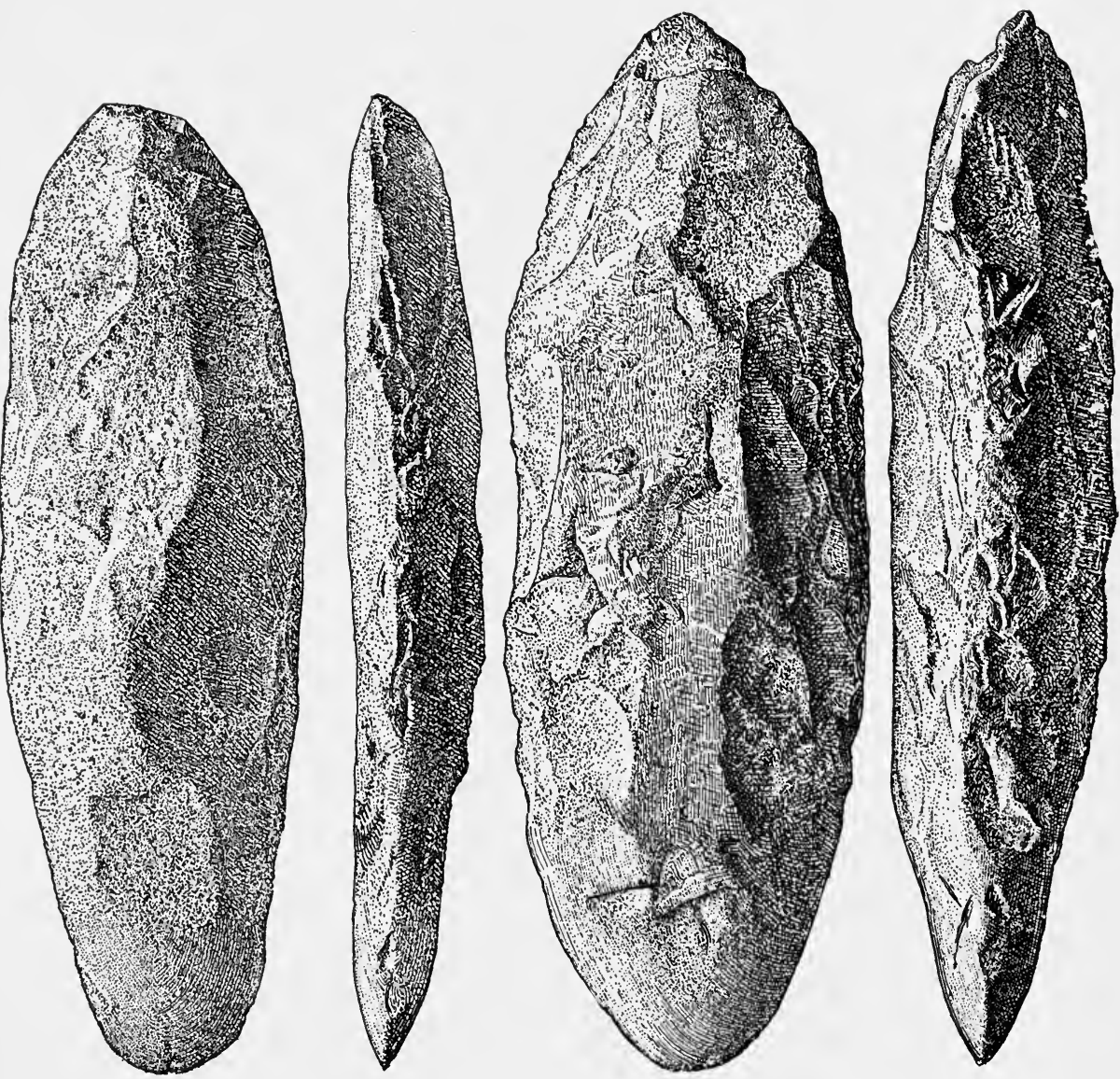

FIG. 108. Chisel and pick like forms of quarry implements. 

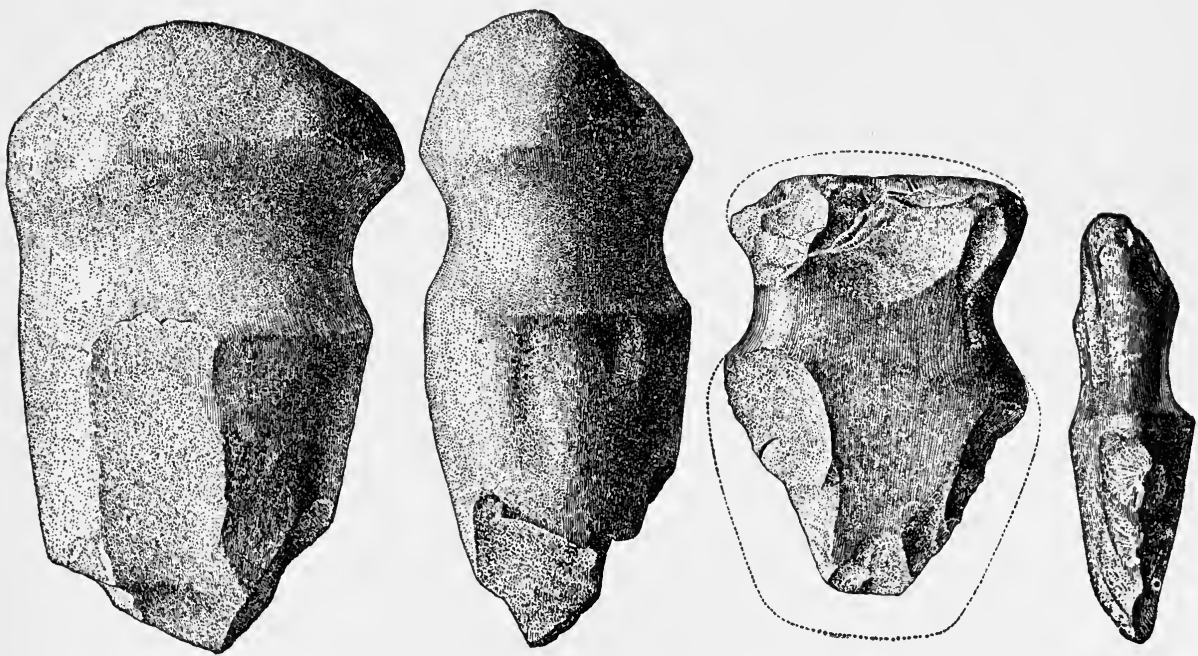

FIG. 109. Grooved axes employed as picks in the quarry work. (One-half actual size.)
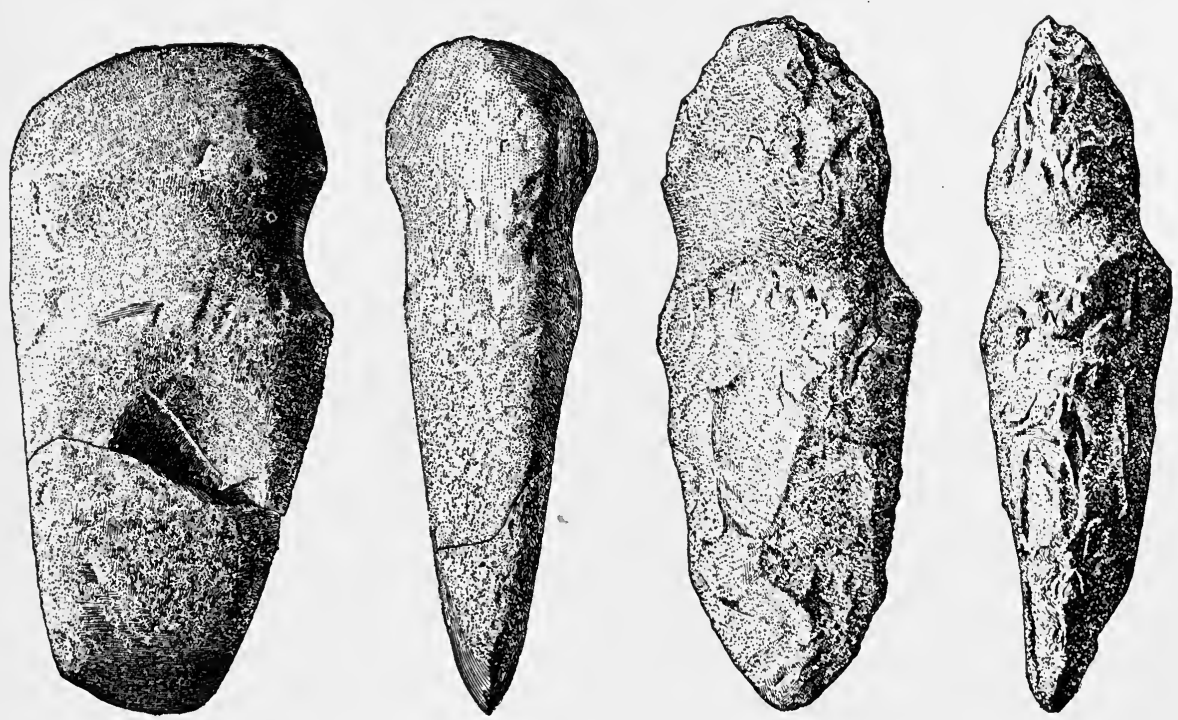

Fig. 110. Grooved axes employed as picks in the quarry work. (One-half actual size.) 
Few other quarries in the South have been carefully examined and those of the Pennsylvania region have received New England only superficial attention, although large collections of the implements and partially worked utensils have been made. Much more thorough examinations have been made in the quarries of New England at Bristol, Conn.; Millbury, North Wilbraham, and Westfield, Mass.; and Johnson, Vt. All, however, present nearly identical features. The manner of operating the
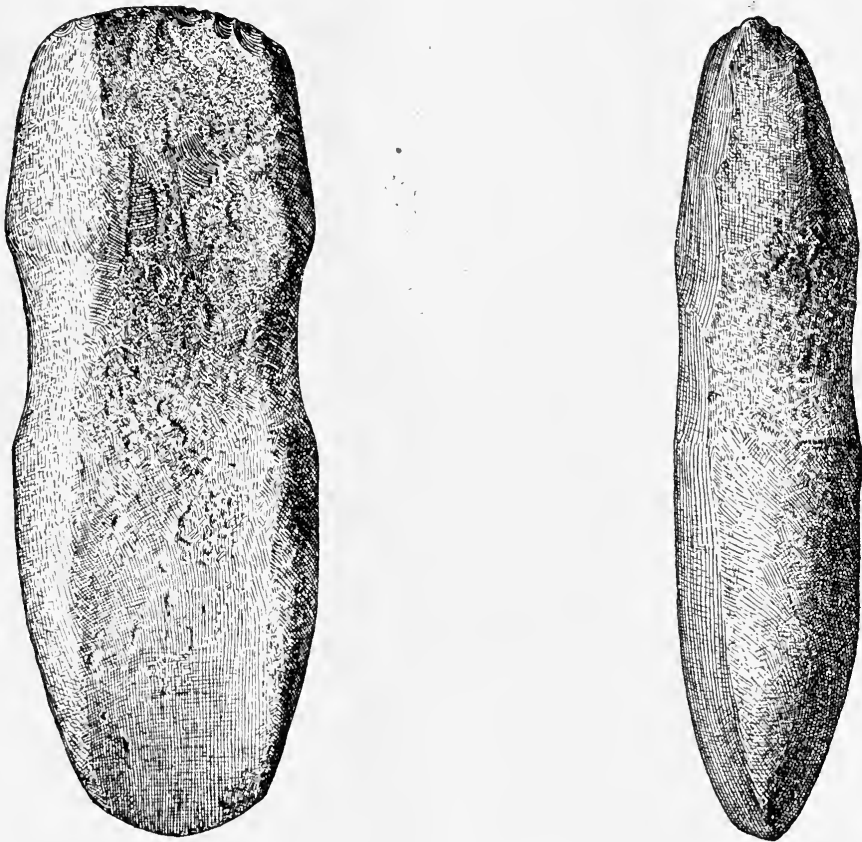

Fig. 111. Gouge of New England type employed in the Connecticut Avenue quarries. (One-half actual size.)

quarries, the traces of shaping work, and the implements employed are much the same everywhere.

Soapstone was worked also in Wyoming, and numerous examples of the articles made have been collected, but the California Quar- (quarries have not been definitely located or de-
ries scriberl. In California, however, the soapstoneworking industry had reached important proportions. The quarries located on the island of Santa Catalina were first examined and described by Schumacher, ${ }^{1}$ and more recently by the present writer. ${ }^{2}$

1 Schumacher, Method of Manufacture of Several Articles by the former Indians of Southern California, p. 260.

2 Holmes, Anthropological Studies in California. 
'The general phenomena of the quarries correspond closely with those of the East, but the articles produced are quite distinct and much more varied in form and often of superior finish. Figure 112 illustrates a small portion of the worked surface of an exposed body of steatite at Pots Valley, Santa Catalina Island. The stumps indicate the removal of several roundish masses of stone, as were required in the shaping of the large globular cooking pots, many fine examples of which have been collected on the islands and the neighboring mainland. A life-size group in plaster, designed to illus-

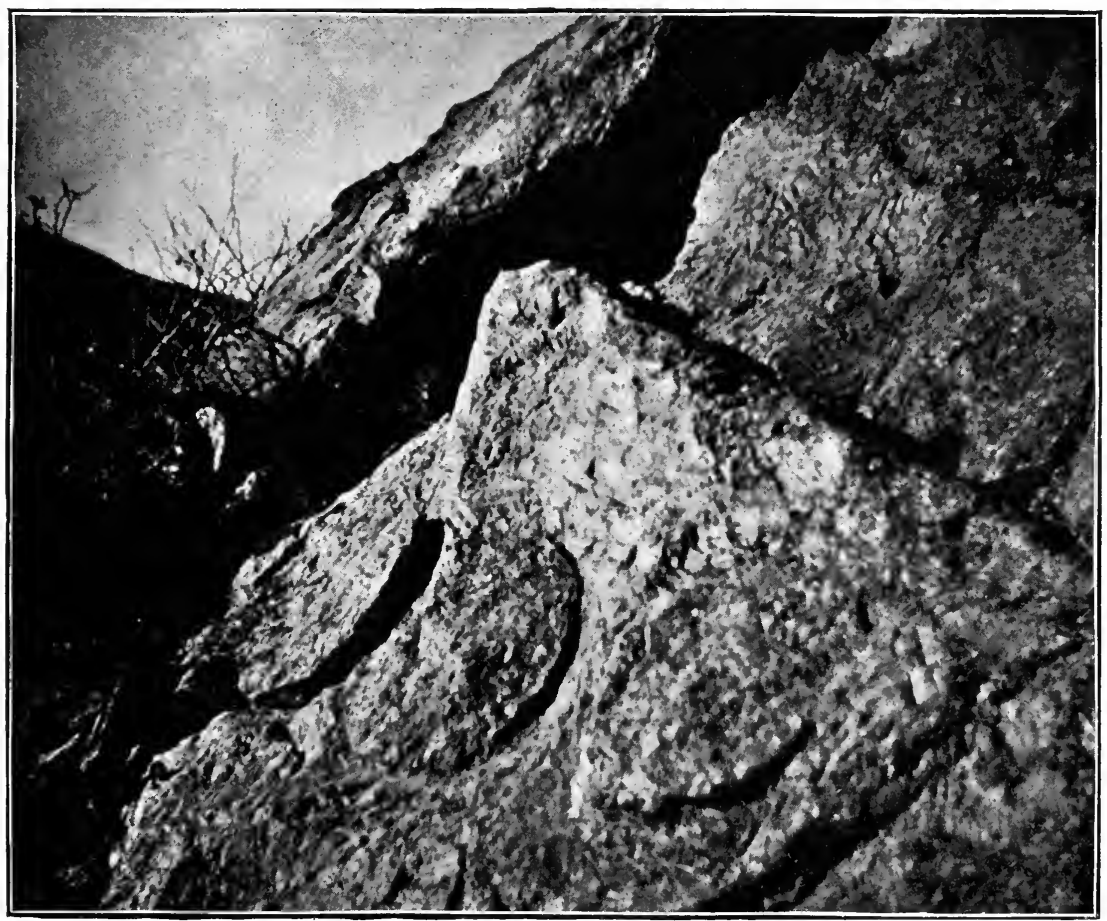

FIG. 112. Traces of aboriginal work in soapstone quarry, Santa Catalina Island.

trate the soapstone-quarry work on Santa Catalina Island, is exhibited in the section of American Archeology, United States National Museum, and is illustrated in figure 113. The exceptional range in form and function of the articles made in this place is indicated by the contents of a grave opened by the writer within a few yards of the quarry face. With the badly crushed skeleton was a shallow dish, two broken pestles, and a number of sculptures and small articles, all of soapstone, and possibly made for the special purpose of burial with the body. 
Steatite was in general use among the Eskimo of the far north, some of the sources of supply being on Cumberland Arctic Steatite Sound, along Wager River, and in Greenland, but the quarries have not been accurately located or described. It was employed more especially in the manufacture of lamps, an essential feature of the Arctic household, but there are found also numerous well-carved cooking vessels and other receptacles.

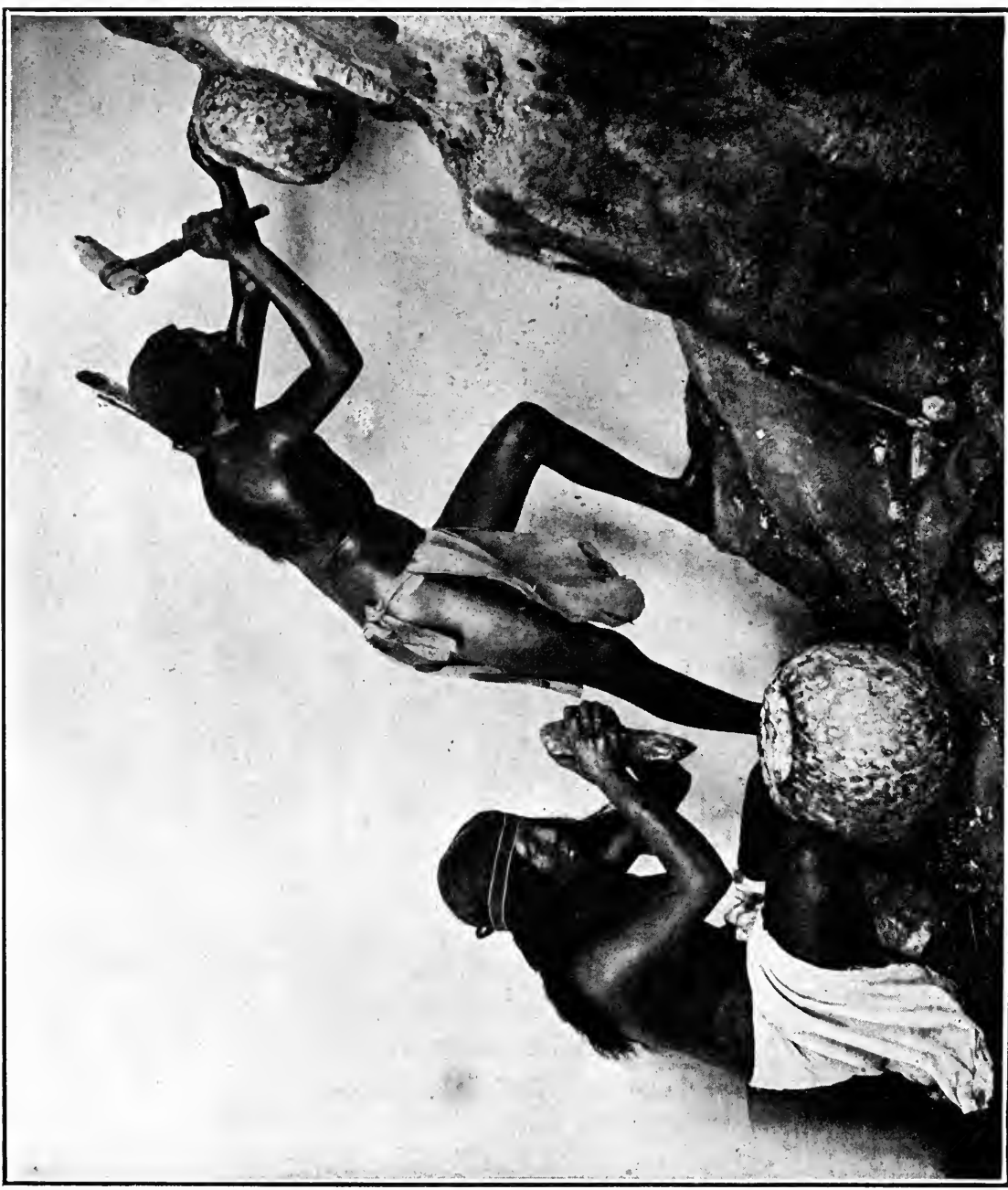

|




\section{MICA MINES}

$\mathrm{M}^{\mathrm{n}}$ ICA was in very general use among the Indian tribes east of the Great Plains and was mined by them at many points in the Appalachian highlands from Georgia to the St. Lawrence River. From these mines it passed by trade or otherwise to remote parts of the country and is found more especially in burial mounds, stone graves, and ordinary burials in the Gulf States and throughout the Mississippi Valley. Mica is found also in workable forms in Dakota and southwestern Arkansas but is not known to have been mined by the aborigines in these sections.

This brilliant mineral is present as crystals embedded in veins of quartz and feldspar which penetrate various early geological formations but more commonly the schistose rocks. The veins are irregullar in thickness and do not conform with the stratification or bedding of the associated formations. The crystals are of diversified shapes and sizes, reaching in cases upward of 3 feet in extreme dimensions. They separate readily into many thin sheets of very attractive appearance, which are transparent or translucent, and display various silvery and amber hues. Although probably servVarious Uses of ing few practical purposes with the aborigines, the sheets were highly prized for the manufacture of personal ornaments and for sacrificial and mortuary purposes. It is stated on very good authority that they were used also as mirrors, and this is doubtless true, since the thick sheets, or the thin sheets properly backed, afford good reflecting surfaces and to the Indian, who spent much time at his toilet, the mirror was a most important desideratum.

The literature of archeological research in the United States, especially that relating to the mound region, abounds in references to the discovery of sheet mica buried with human remains. Atwater describes the discovery in a burial at Circleville, Ohio, of a sheet of mica which measured 36 inches in length by 18 inches in width and $1 \frac{1}{2}$ inches in thickness. ${ }^{1}$ Other similar finds were made by Atwater in the same region. With a skeleton in the Grave Creek mound near Wheeling, W. Va., 150 disks of sheet mica measuring $1 \frac{1}{2}$ to 2 inches in diameter and havOrnaments of Mica ing one or two perforations were found. ${ }^{2}$ These were probably suspended as tinkling pendants on some part of the costume.

\footnotetext{
${ }^{1}$ Atwater, Description of the Antiquities Discovered in the State of Ohio, pp. 178, 225.

2 Schoolcraft, Observations Respecting the Grave Creek Mound in Western Virginia, p. 399 .
} 
Squier and Davis state on the authority of I. Dille, of Newark, Ohio, that in constructing a lock on the Chesapeake Remarkable Burial Deposit

\& Ohio Canal, Licking County, Ohio, an excaration was made, probably in a burial mound, in which were encountered, 4 feet beneath the surface, 14 human skeletons, over which, carefully and regularly disposed, were laid a large number of sheets of mica. Some of these were 8 to 10 inches long by 4 to 5 inches wide and all from $\frac{1}{2}$ to 1 inch in thickness. It was estimated that 15 or 20 bushels of this material were thrown out and built into the support of the lock. ${ }^{1}$

In a sacrificial mound near Chillicothe, Ohio, Squier and Davis discovered a layer of large plates of mica measuring Use in Sacrifice from 10 to 12 inches in diameter, which overlapped one another like the tiles on a roof and were arranged in the shape of a half moon. The excavation disclosed more than half of the crescent, which must have measured at least 20 feet from horn to horn, the greatest width being 5 feet. $^{2}$ It is surmised that this figure had some special religious significance in the minds of the builders of the mound.

An altar in a mortuary mound situated near Chillicothe, Ohio, was filled with fine ashes intermixed with fragments Personal ornament of clay vessels and some small convex copper disks. Over the contents of the altar basin was a layer of mica sheets overlapping one another and serving as a base for a heap of burnt human bones. ${ }^{3}$ These authors also found occasionally in the mounds ornaments of thick sheets of mica cut out very neatly and with great regularity in the shape of scrolls, oval plates, and disks, and pierced with small holes for suspension or attachment. They were doubtless intended for embellishing the dress of persons of distinction. ${ }^{4}$ From the Turner mounds in Clermont County, Ohio, Prof. F. W. Putnam obtained a number of figures neatly cut from sheet mica representing serpents, birds, and other animal forms.

It appears that no definite knowledge of the sources of supply of the mica was obtained until about the year 1868, Discovery of the when they were brought to light by Gen. T. L. Clingman, who undertook to exploit certain artificial pittings in western North Carolina under the impression that they might be ancient silver mines. The mica-bearing veins were discovered in the bottoms of the old excavations, and this led to the working of the mica for commercial purposes not only on the prehistoric sites but in newly discovered veins over wide areas.

\footnotetext{
1 Squier and Davis, Ancient Monuments of the Mississippi Valley, p. 72.

2 Ibid., p. 155.

${ }^{3}$ Ibid., p. 154.

${ }^{4}$ Ibid., pp. 155, 240.
} 
On account of its resistance to the destructive action of heat, sheet mica was used at first by the whites for lights in Uses of Mica stoves and lamps and later for a number of important purposes, among which is the manufacture of electrical apparatus, while the inferior grades are ground up for use in the preparation of lubricants, paints for imparting luster to wall papers, etc.

It is greatly to be regretted that scientific attention was not earlier called to the ancient mines, since all of the diggings Mining Tools have been reopened and worked for commercial purposes, the evidences of the ancient operations being largely and in some cases wholly obliterated. But there is some compensation in the fact that a number of the miners have intelligently
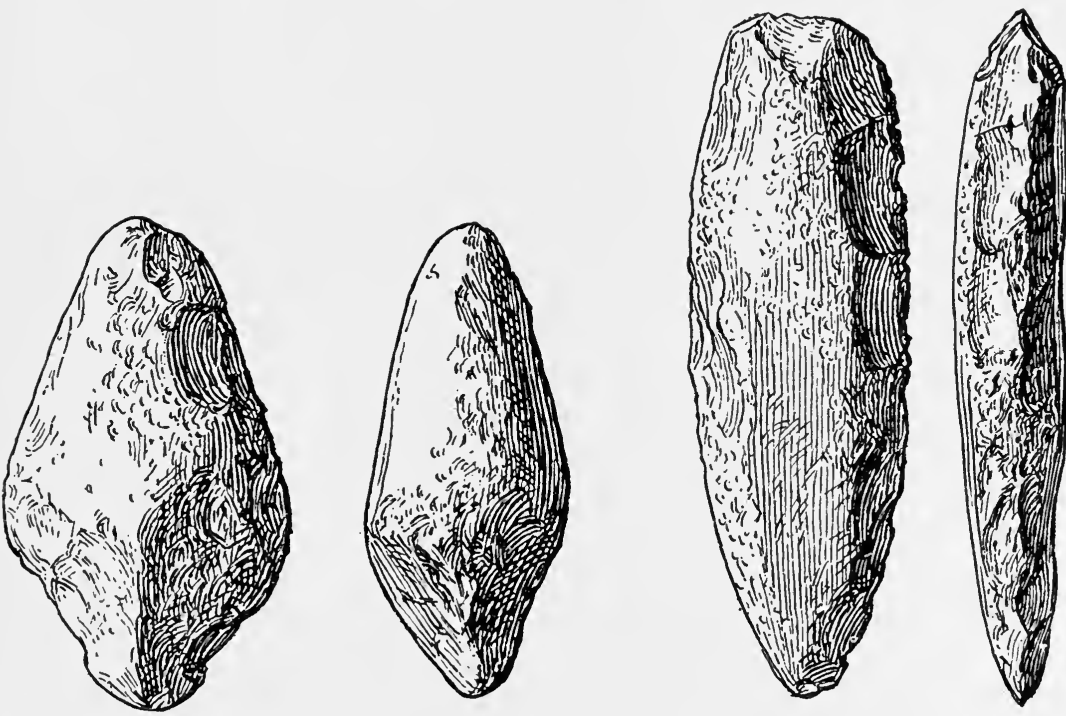

FIG. 114. Stone implements from the ancient mica mines of North Carolina. (Onefourth actual size.)

observed the ancient traces and in a few cases have preserved the tools of stone encountered in the trenches. It is a misfortune, however, that so few of these implements have been preserved, and up to the date of the writer's visit to the mines the National Museum had secured of the digging and fracturing tools only a dozen examples (figs. 114, 115). The rarity of the mining tools, considering the extent of the operations, was at first extremely puzzling, and the white operators of the mines found it difficult to explain this rarity except on the theory that the ancients employed tools of iron or steel, which had subsequently disappeared through disintegration, but examination of the mines by the writer has led to what may be a more satisfactory interpretation. The ancient workings, which penetrated in cases to the depth 
of 40 feet or more, were confined largely to friable and easily worked formations, so that tools of wood and buckhorn served every purpose, tools of stone not being required until the unaltered enclosing rock was encountered, often at a depth beneath the surface of 30 or 40 feet. This theory finds support in the fact that almost all the stone tools found had been abandoned in the bottoms of the deepest diggings, where the feldspar of the veins and the schists of
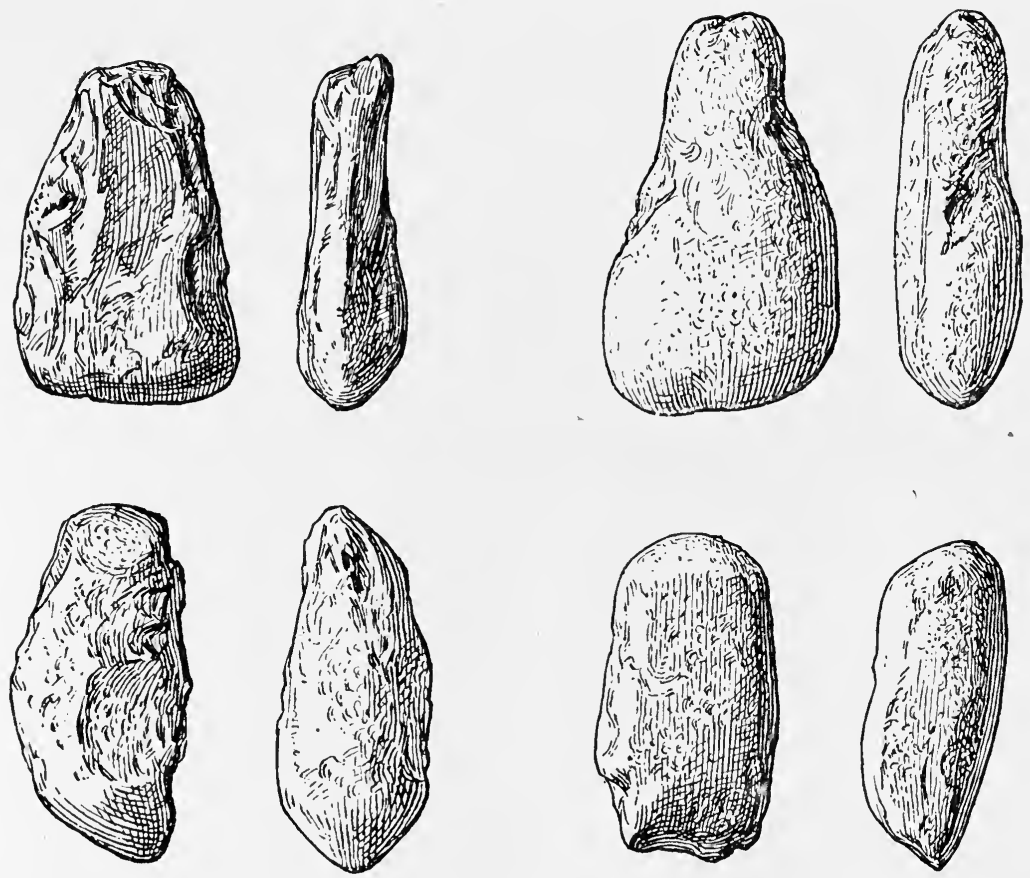

FIG. 115. Stone implements from the ancient mica mines of North Carolina. (Onefourth actual size.)

the vein walls were so hard as to be worked with difficulty, even with steel tools, without the aid of explosives.

No definite idea of the number of ancient diggings can be formed, but that they were numerous and widely distribaboriginal Mining uted over the south Appalachian region can not be questioned, western North Carolina claiming the largest number. The work of uncovering the mica-bearing veins and removing the crystals did not differ essentially in character from that of the mining of copper, steatite, pipestone, and flint. It required the same kind of tools and called for the same superior intelligence and steadfastness of purpose. The veins in which the quartz and mica crystals prevailed resisted the disintegrating and erosive agencies, and as a result were exposed in the slopes of the hills, and were thus 
readily discovered. At first the work would be simple, since the schists which form the walls of the veins are hardly more difficult to handle than well-compacted loam and hence are easily Vein Material worked with hand-wielded tools. The same is true of the feldspar, which constitutes in many places half or more of the vein material. The quartz in large bodies is exceedingly difficult to work, but when forming, as it usually does, only 25 or 30 per cent of the vein mass, it is broken up and removed with comparative ease.

In April, 1913, the writer visited the mines of western North Carolina, making such observations as seemed necesNorth Carolina sary for a reasonable comprehension of the nature
Mines

and extent of the ancient operations. The mines visited are in the vicinity of Spruce Pine, Bandana, and Bakersville, Mitchell County. Some of these were risited in 1893 by Mr. De Lancey Gill, of the Bureau of American Ethnology, under the writer's direction, and valuable information was collected, but his observations have not been published. ${ }^{1}$

Of the several mines in the vicinity of Spruce Pine only two retain traces of the prehistoric operations, and these Spruce-Pine Mines traces are but slight as a result of the recent mining operations, which consisted in entering and deepening the ancient excavations along the mica-bearing veins. Mr. S. E. Bloud, who accompanied the writer to the Deake mines, a mile west of Spruce Pine, pointed out the old pit margins so far as preserved or exposed and described the conditions as they existed before the modern mining began. The aborigines had discovered the outcrop of the mica-bearing rein in the hillside and had followed it for a short distance into the slope, opening a trench just wide enough to enable them to break up and remove the partially decomposed feldspar and the quartz, which form the principal part of the vein material, thus freeing the crystals of mica. The vein as exposed in the quarry face to-day is 4 or 5 feet in thickness. The mica occurs in small and irregularly placed crystals in a matrix consisting of disintegrated whitish feldspar so soft as to be readily worked with the pick, and a small percentage of white quartz. In the deeper mines the feldspar remains so hard as to require blasting.

A second mine, within half a mile of the railway station at Spruce Pine, exhibited somewhat more decided evidence of the old work, and it is said that at the bottom of one of the ancient shafts 25 feet in depth traces were found of branching horizontal tunnels, as if

\footnotetext{
${ }^{1}$ In the Engineering and Mining Jaurnal for March 31, 1877 (p. 121), it is stated that a paper minutely describing the aboriginal mica mines of North Carolina was read lefore the New York Academy of Sciences. It does not appear that this paper has been published.
} 
the miners had been seeking in various directions for pay streaks of the mica-bearing vein.

The "Sink Hole" mines, probably so named before the artificial character of the old pittings had been fully deter-

Sink Hole Mines mined, are located in the hill country near Bandana, Mitchell County, 8 miles northeast of Burnsville and 3 miles north of Boonford, a station on the Carolina, Clinchfiel ' \& Ohio Railway. At Spruce Pine the writer had the good fortune to

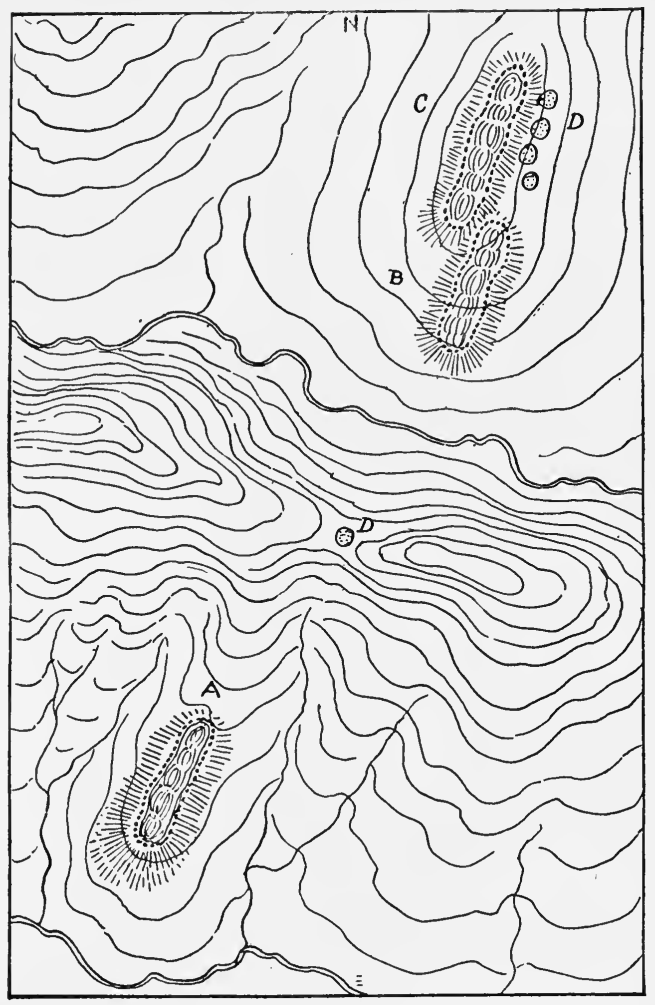

FIG. 116. Sketch map showing the relation of the Robinson and Sink Hole mines. meet William Robinson, part owner and part operator of the mines, who generously volunteered to accompany him to the mines and furnished much information regarding both the original appearance of the aboriginal pittings and the modern work done in them.

Although the mines have been operated extensively in recent years, sufficient traces of the old work remain, coupled with the explanations furnished by Mr. Robinson, to convey a very complete notion of the character and extent of the prehistoric work. There are two main groups of the pittings, as indicated on the sketch map (fig. 116). $A$ is known as the Robinson mine, while $B$ is more commonly referred to merely as the Sink Hole mine.

The Robinson mine is said to be the site of the initial operations by General Clingman. The ancient workings consist The Robinson Mine of a line of excavations extending up the crest of a low rounded spur of the hills a quarter of a mile from Bandana post office. Beginning a few hundred feet north of the creek which drains the valley, the pittings extend with one slight interruption for a distance of 300 to 400 feet up the spur in a north- 
easterly direction. A distant view is shown in figure 117 and a nearer view in figure 118. The pittings are surrounded, except at the upper end, by a somewhat uneven ridge of detritus de-

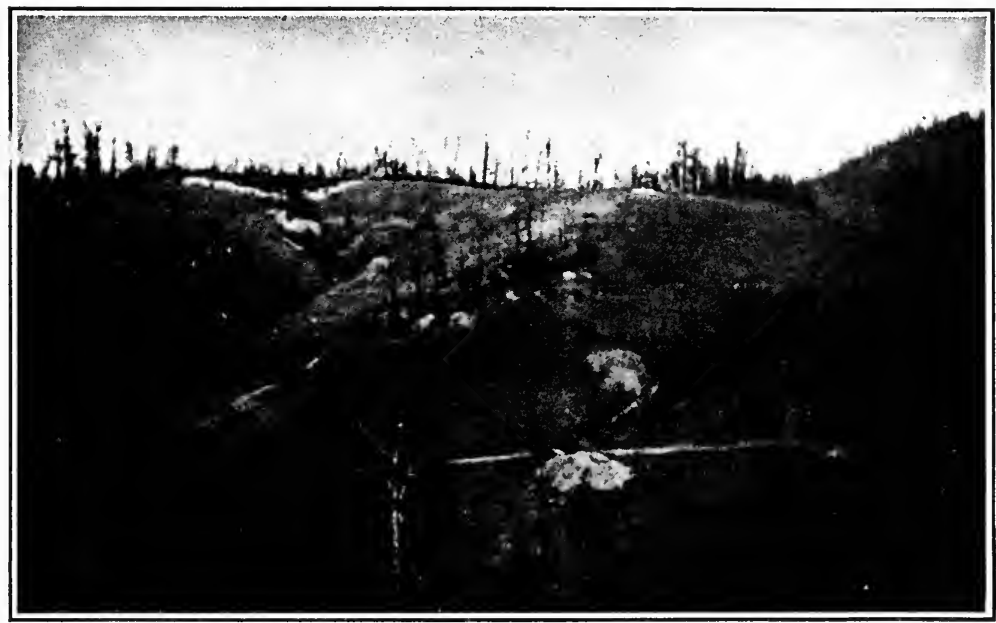

Frg. 117. Distant view of the Robinson mine, center of picture.

rived from the excavation, which has been added to in places by the modern miners, and has been dug into of late years to recover the mica rejected and thrown out by the aborigines. The average width, from crest to crest, of the lateral ridges, which are in places

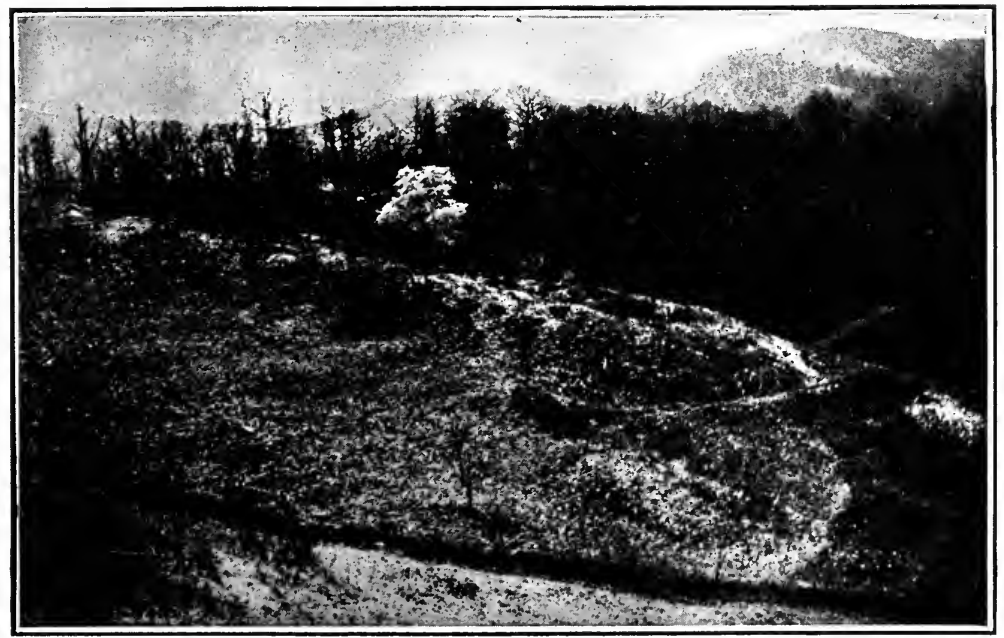

Fig. 118. The Robinson mine, on crest of ridge.

as much as 15 feet in height, is approximately 75 feet (fig. 119), while the depth within, due to the irregular heaping up of material from the deep shafts recently sunk by the whites, rarely reaches 20 feet. 
As developed by the recent operations, it appears that the ancient work along the rein reached in places a depth of 30 to 40 feet, the modern shafts having gone much deeper. In clearing out the old trenches the white miners observed that the ancient excavations were very narrow at the bottom, hardly wider than the vein itself, which varies from 1 to 5 feet in thickness. In descending it was found that the rein dips slightly to the southeast.

The northern or Sink Hole group comprises a remarkable series of ancient pittings, beginning near the base of a low spur a quarter of a mile northeast of the Robinson group, on the same strike, and extending to the crest of the hill and somewhat beyond, a total length of about 1,000 feet. There are two separate and independent lines of the excavations. The lower line corresponds closely in character and extent with the Robinson mine, the pittings left by the aborigines being well filled in places by the material derived from

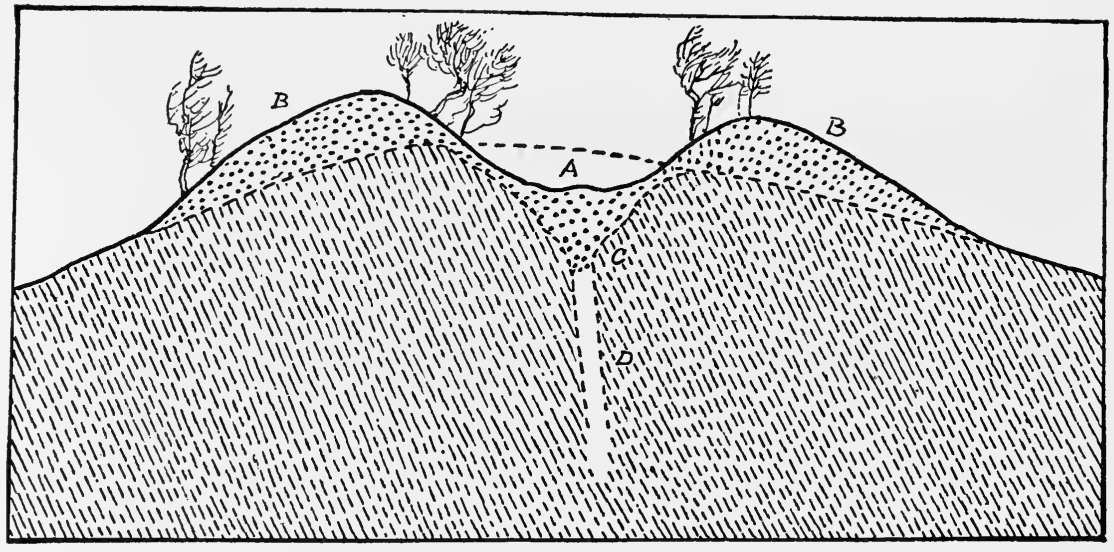

Fig. 119. Section of the Robinson mine.

the deep shafts sunk aiong the vein by the modern miners. The old diggings reached in places 30 to 40 feet in depth, the mica vein averaging from 4 to 8 feet in width and dipping at a steep angle to the southeast. A section of this group corresponds closely with that of the Robinson mine. Just above the upper end of the deep digging is a small round depression 30 feet in diameter and perhaps 15 feet deep, which represents an unsuccessful attempt of the aborigines to discover a continuation of the rein, which, it appears, had been lost at the upper end of the main excavation just described.

The upper line of works is offset from the first as indicated on the map, the distance between the two axes being 30 to 40 feet. It remains a question whether this offsetting is due to the existence of a separately developed rein or to a faulting of a formerly continuous vein. The latter theory is supported by the fact that the upper end of the one appears to coincide with the lower end of the other, there 
being no overlapping so far as developed. The length of this series of excavations is about 800 feet, and the crest of the lateral dumps are in places 80 to 90 feet apart. The ancient pittings are now well filled up with excavated material, old and new. The final digging at the upper end is still 20 feet deep, and the cause of the cessation of work at this point is made clear by the exposure of the quarry face, recently uncovered, where it is seen that the vein is only a few inches in width, showing little quartz and no mica. It is manifestly pinched out at this point, and neither the aborigines nor the whites have been able to find a continuation.

It was in the deep digging near the upper end of this mine that most of the stone implements shown in figure 115 were discovered. They had been abandoned where last used in the bottom of the trench, where they had served, the picks to excavate the softer materials, and the hammerlike tools to break up the harder vein rock.

It is an interesting fact that the sites of workshops to which the crystals of mica were carried and the selected maWorkshops terial prepared for transportation to distant parts are found in the vicinity of both quarries, as indicated in figure $116, D$.

On these sites, which are circular, probably indicating the former presence of lodges, much poor mica was left, and this has been worked over by the whites, who even to-day are engaged in excavating in the dumps for mica rejected by the Indian miners as unsuited to their purposes.

At the house of William Robinson, in the valley a quarter of a mile from the mine, are traces of an ancient village village Site site on which numerous stone implements of ordinary types may still be picked up.

An important site of ancient operations now known as the Clarissa mine is located on the farm of John Buchanan 3 Clarissa Mine miles east of Bakersville, Mitchell County. The excavation occurs in a low, rounded ridge which orerlooks Cane Creek. It is probably the best-preserved and most striking example of the aboriginal workings in this general region and serves to illustrate the importance of the mica industry in prehistoric times. Entering the ridge at an oblique angle (fig. 120), the walls of the excavation are of unequal height, the upper margin being much the higher. The lower margin, as shown in the section (fig. 121), is obscured by heary bodies of ancient dump material, which now supports numerous chestnut trees the trunks of which are 4 to 5 feet in diameter. The modern operators who have worked the vein to the depth, at the upper end, of more than 300 feet, have filled the old trenches to the depth of 30 to 40 feet. When deserted by the original 
workmen, the upper wall was approximately 100 feet in height and the lower 40 feet, the mean depth being, perhaps, 60 feet at the deepest part. The sketch (fig. 120) and the photographs (fig. 122, a, b,c)

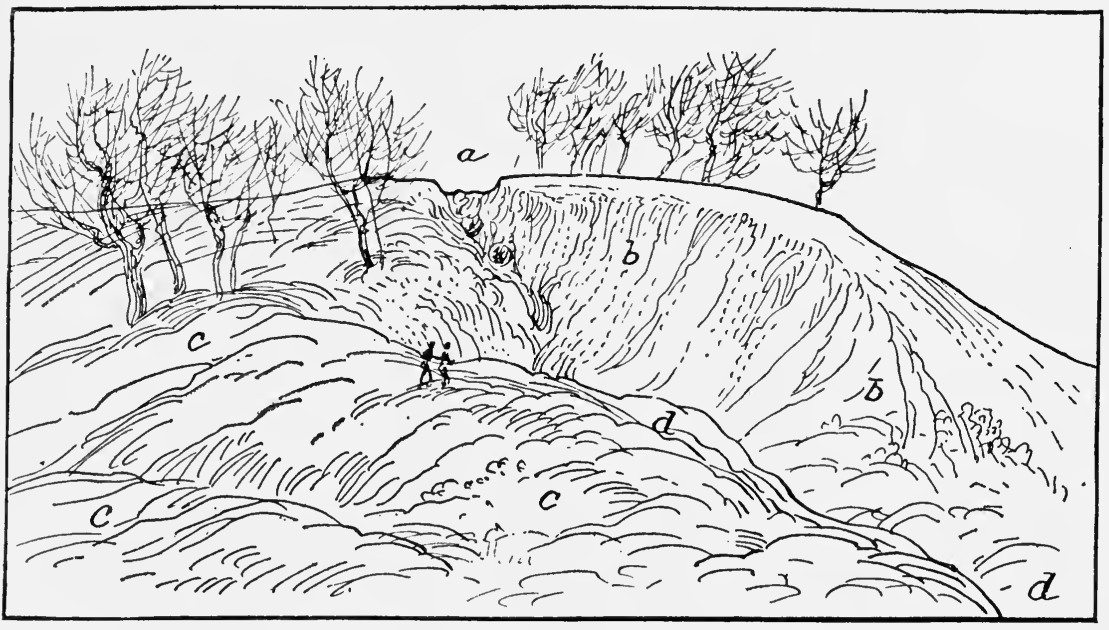

FIG. 120. Sketch indicating the present appearance of the mine.

will convey a definite notion of the present appearance of the excavation.

The vast extent of the aboriginal mica-mining industry is further exemplified by traces found in other sections. An Mines of Macon account of the mines of Macon County, N. C., by
County C. D. Smith, is well worthy of citation in this con-

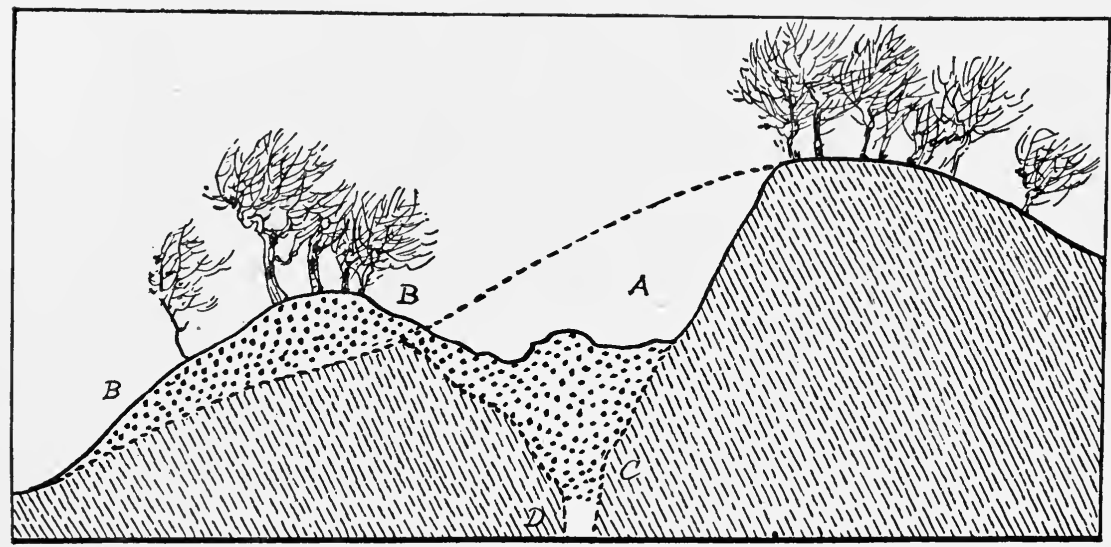

Fig. 121. Section of the Clarissa mine.

nection. It appears from this account that the ancient operations were uniform with those in Mitchell and Yancey Counties.

It is manifest that the ancient miners understood their business well. Indeed, they seldom committed a mistake. In every instance which has come 

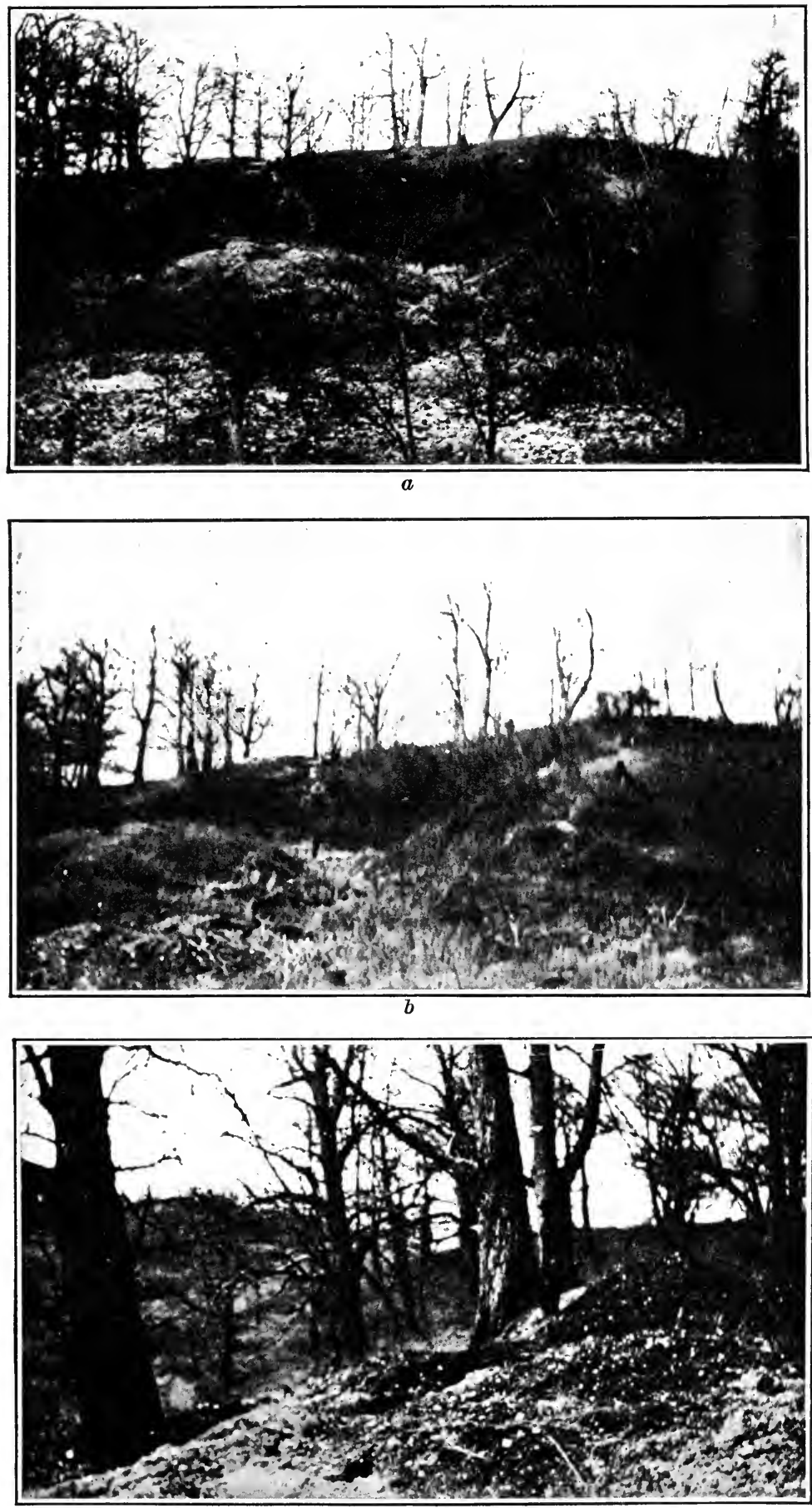

FIG. 122. Photographic views of the Clarissa mine. Large chestnut trees growing on the mine dumps. 
under my observation, where they did work along the mica zone, mica veins have been found by opening the old works. It is also a noteworthy fact that where the old excavations are extensive the veins yield usually large crystals of firm mica of good cleavage and in every way of excellent quality. The mica that they procured in their mining operations has been removed, except the refuse, such as our people generally reject. I have one case to the contrary. In that case the mica had been taken 100 feet, perhaps, and buried. It was found to the amount of several cartloads. It had been packed down with great regularity in an excavation. In this county (Macon) there are a dozen or more of these old diggings known to exist. Most of them have been opened within the last six or seven years and operated upon by our present mica miners. I have had two of these old works opened, one of them upon my own farm. ... The old excavation commences at a small branch and runs at a right angle from it into a ridge that juts down with a gentle slope. The dump-material has been thrown right and left for the first 100 feet. I tunneled in diagonally and struck the vein 60 feet from the branch and have drifted along it 40 feet. Here we reach an immense dump-rim, 65 feet higher than the level of the branch and which seems to have been thrown back upon their works. It forms at this end a circular rim to the continued excavations higher up the ridge. The whole length of the excavation from the branch to the upper end of the cut is about 320 feet. The material removed from the upper part of the cut was carried up the hill as well as down it. The dump on the upper side of this upper part of the cut and at the widest point is about 25 feet above the present bottom of the excavation, and at this point dump and excavation measure about 150 feet across. At the upper end of my tunnel the old digging has been carried down about 30 feet below the surface. If the excavation at the point just mentioned was carried as deep as the work at the upper end of the tunnel, it would make the dump-heap on the upper side 55 feet higher than the bottom of the old works. I have been thus particular in order to show that with mere stone implements it must have required a series of years and a large force to have accomplished such results. ${ }^{1}$

It is impossible to approximate the amount of mica remored by the ancients from the mines, since the yield of the reins is necessarily irregular, but that the vast amount of the crystals obtained should have been carried away to distant points and used by the aborigines is hardly less a marvel than that a primitive people should have accomplished the work of removal from the deep-seated veins.

1 Smith, Ancient Mica Mines in North Carolina, pp. 442-443. 


\section{THE RED PIPESTONE QUARRY}

FAVORITE material for the manufacture of tobacco pipes
and various articles of ornamental, sacred, and ceremonial
use was the red claystone called catlinite, obtained from a quarry in southwestern Minnesota, and so named because it was first brought to the attention of mineralogists by George Catlinite Catlin, the noted traveler and painter of Indians. It is a handsome stone, the color varying from light gray to pale and dark reds, the tints being sometimes so broken and distributed as to give a mottled effect. It is a fine-grained argillaceous sediment, and when freshly quarried is so soft as to be readily carved with stone knives and drilled with primitive hand drills. The analysis made by Dr. Charles F. Jackson, of Boston, who gave the mineral its name, is as follows: Silica, 48.20 ; alumina, 28.20 ; ferric oxide, 5.00 ; carbonate of lime, 2.60 ; manganous oxide, 0.60 ; magnesia, 6.00 ; water, 8.40 ; loss, 1.00. Stone of nearly identical characters, except in the matter of color, is found in many localities, and in cases has been used by the Indians for the manufacture of pipes and other articles, but so far as known it has not been quarried to any considerable extent.

The outcrop of catlinite is found in a broad, shallow prairie valley, on the margin of which is situated the town of PipeLocation stone, county seat of Pipestone County (map, fig. 123). The outcrop was probably discovered by the aborigines where it had been slightly exposed in the bed of the small stream now called Pipestone Creek, which descends into the valley on the east in a charming fall some 20 feet in height, and traverses the shallow basin, passing out to the northwest. Catlin's someThe Pipestone Stratum

what diagrammatic drawing of the quarries is reproduced in figure 124. So far as exposed, the pipestonebearing stratum varies from 10 to 20 inches in thickness, the band of pure, fine-grained stone available for the manufacture of pipes rarely measuring more than 3 or 4 inches in thickness. This stratum is embedded between massive layers of compact quartzite of Huronian age, which dip slightly to the east, so that in working it the overlying quartzite had to be broken up and removed, The Quarry Work the difficulty of this task increasing with every foot of advance. With the rude stone implements in use in aboriginal times the process was a very tedious one, and the exca- 


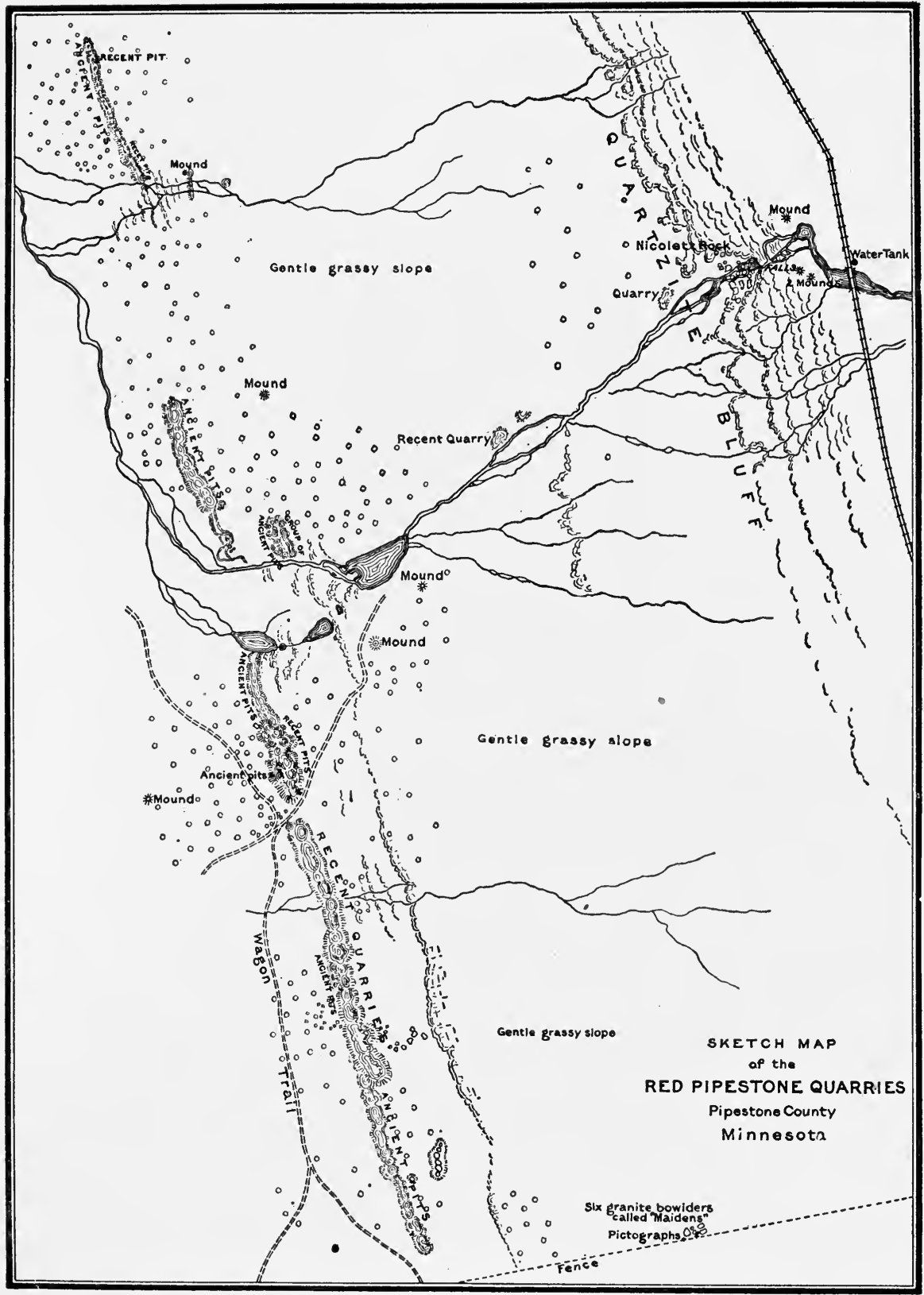

Fig. 123. Sketch map of the pipestone quarry. 
vations were consequently quite shallow. The ledge which crosses the stream approximately at right angles was followed to the right and left by the quarrymen until the line of pittings was nearly a mile in length. These ancient diggings have been almost obModern Operations literated by natural filling (fig. 125) or by the more recent mining operations. The latter, since the advent of the whites, have been greatly accelerated by the introduction of steel sledges, picks, shovels, and crowbars (figs. 126, 127, 128). It is said that with the aid of the whites blasting has been occasionally resorted to. Some of the present excavations are as much as 10 feet in depth, and have advanced 20 feet or more with the dip of the strata to the east. A usual section (fig. 129) now exposed in the

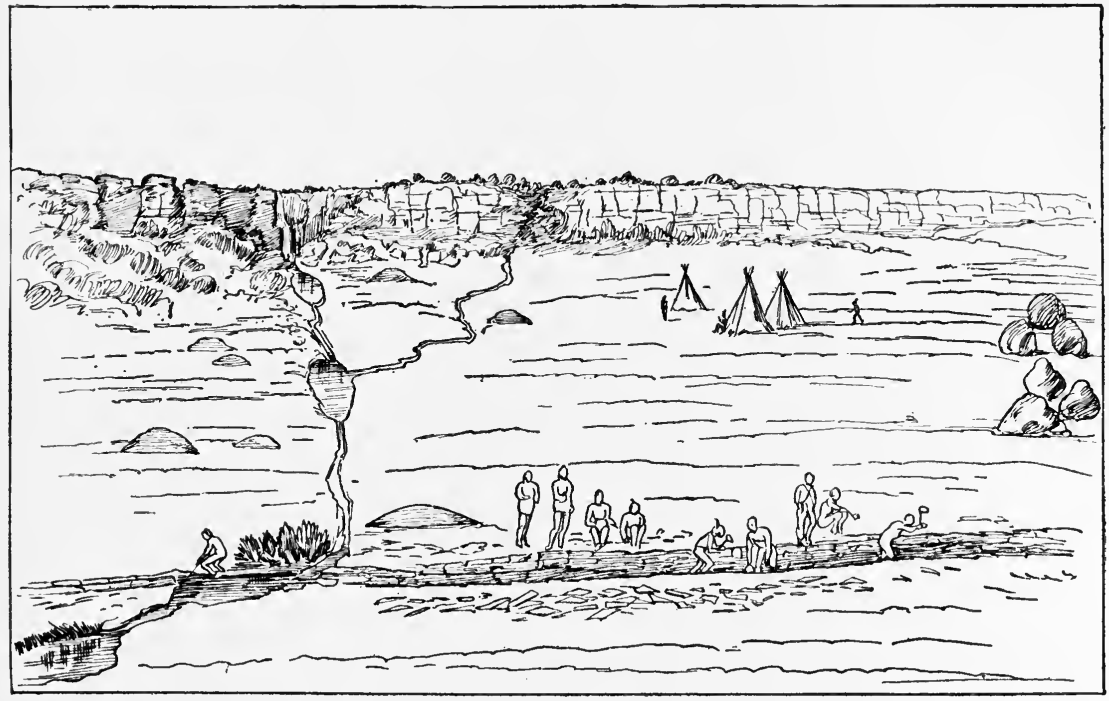

Fig. 124. Catlin's sketch of the pipestone quarry.

deeper excavations beginning above, shows 2 to $t$ feet of soil and beneath this 6 to 8 feet of quartzite, the latter resting on the thin stratum of pipestone, beneath which, forming the bed of the quarry, are compact quartzites. Numerous hanmers of hard stone, some discoidal, other's roughly grooved to facilitate hafting, were founa' about the older pits (fig. 130), and the prairie in the The Implements ricinity is dotted with camp sites and lodge rings,
Used about which are strewn bits of pipestone and other refuse of manufacture along with typical grooved bone-breaking, stake-driving hammers of the Plains tribes (fig. 131). Some of the partially worked pieces of the stone are shown in figure 132.

$38657^{\circ}-19-$ Bull. 60 , pt. $1-18$ 


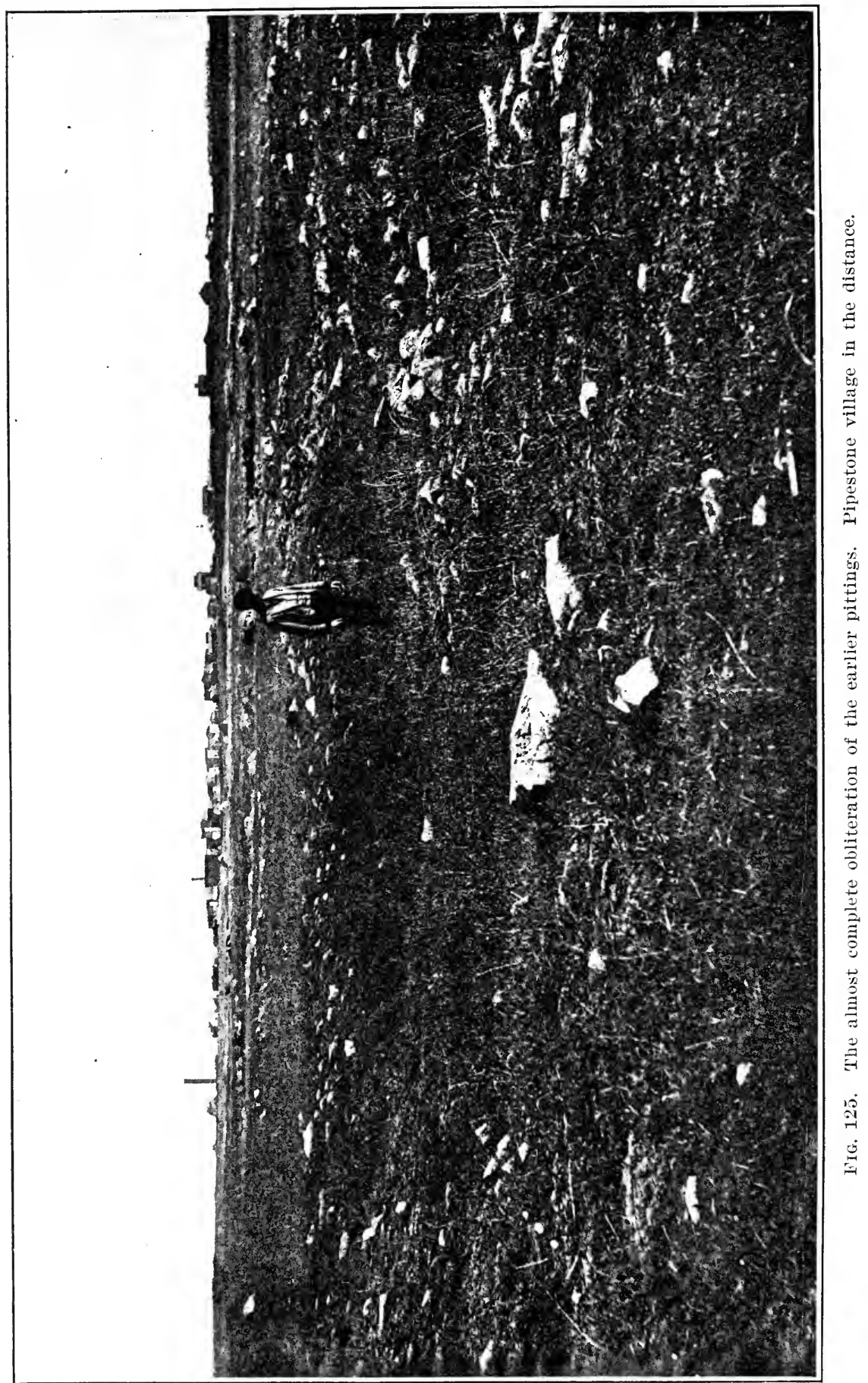




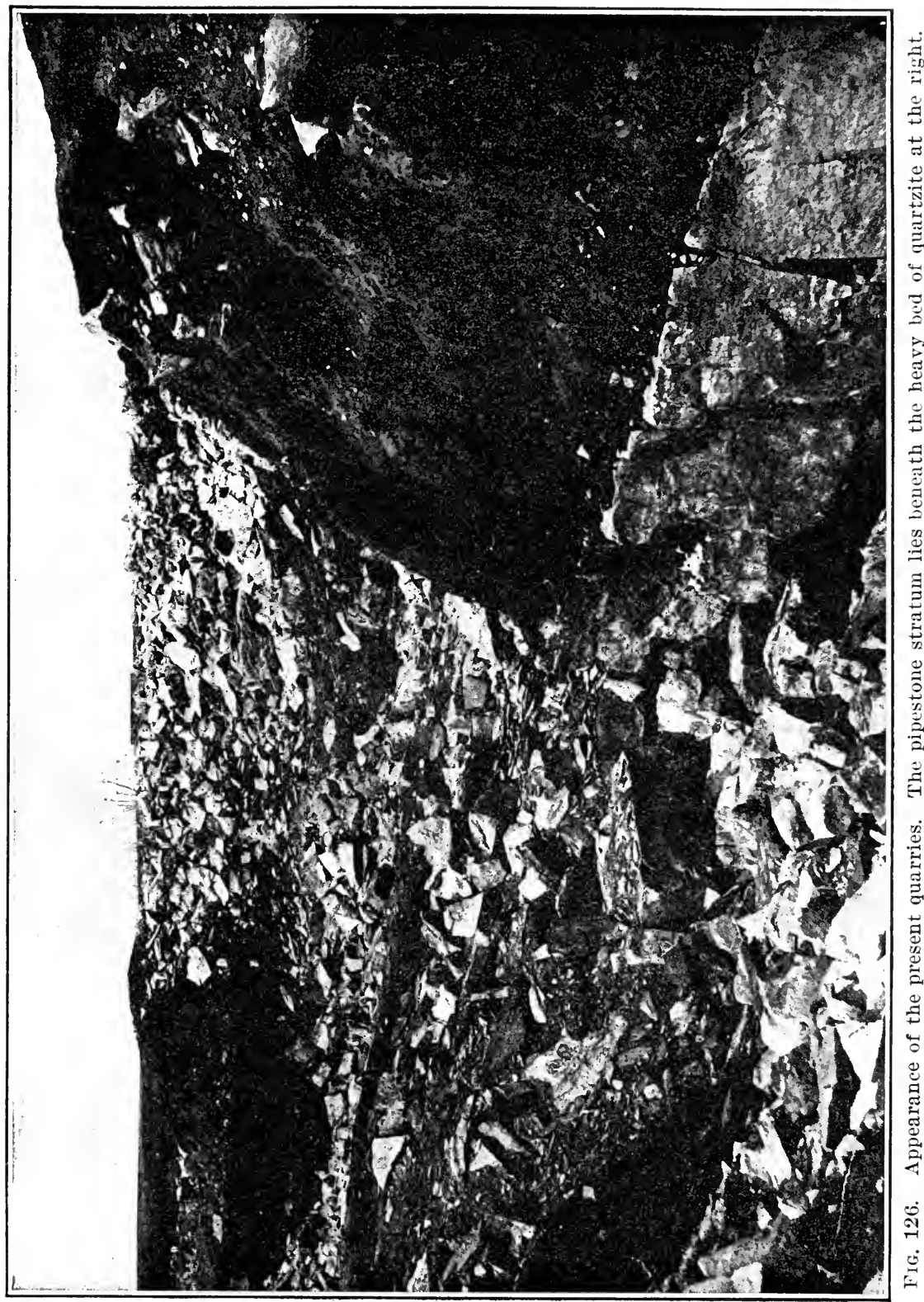




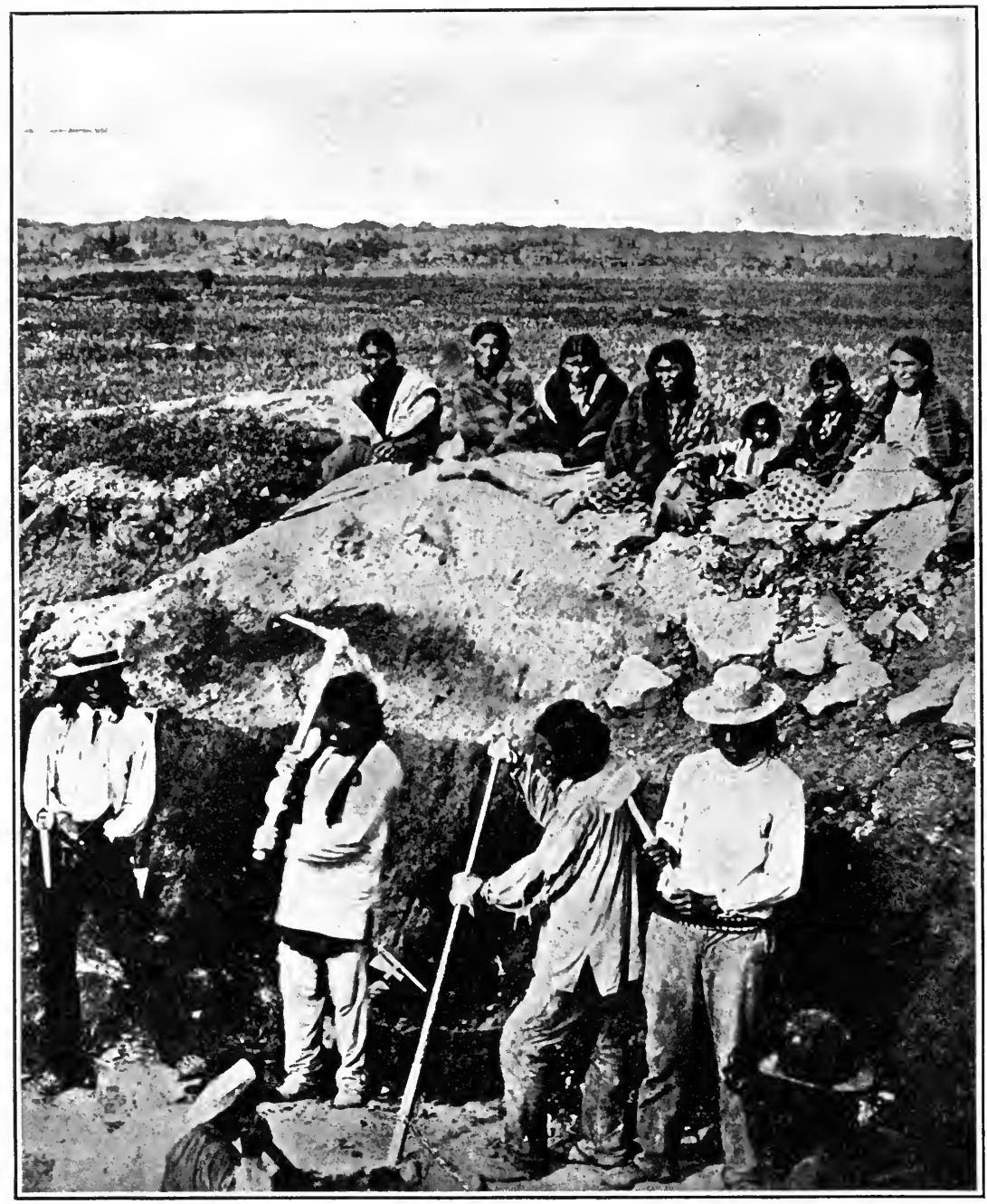

FIg. 127. 'The Sioux at work with steel tools. 


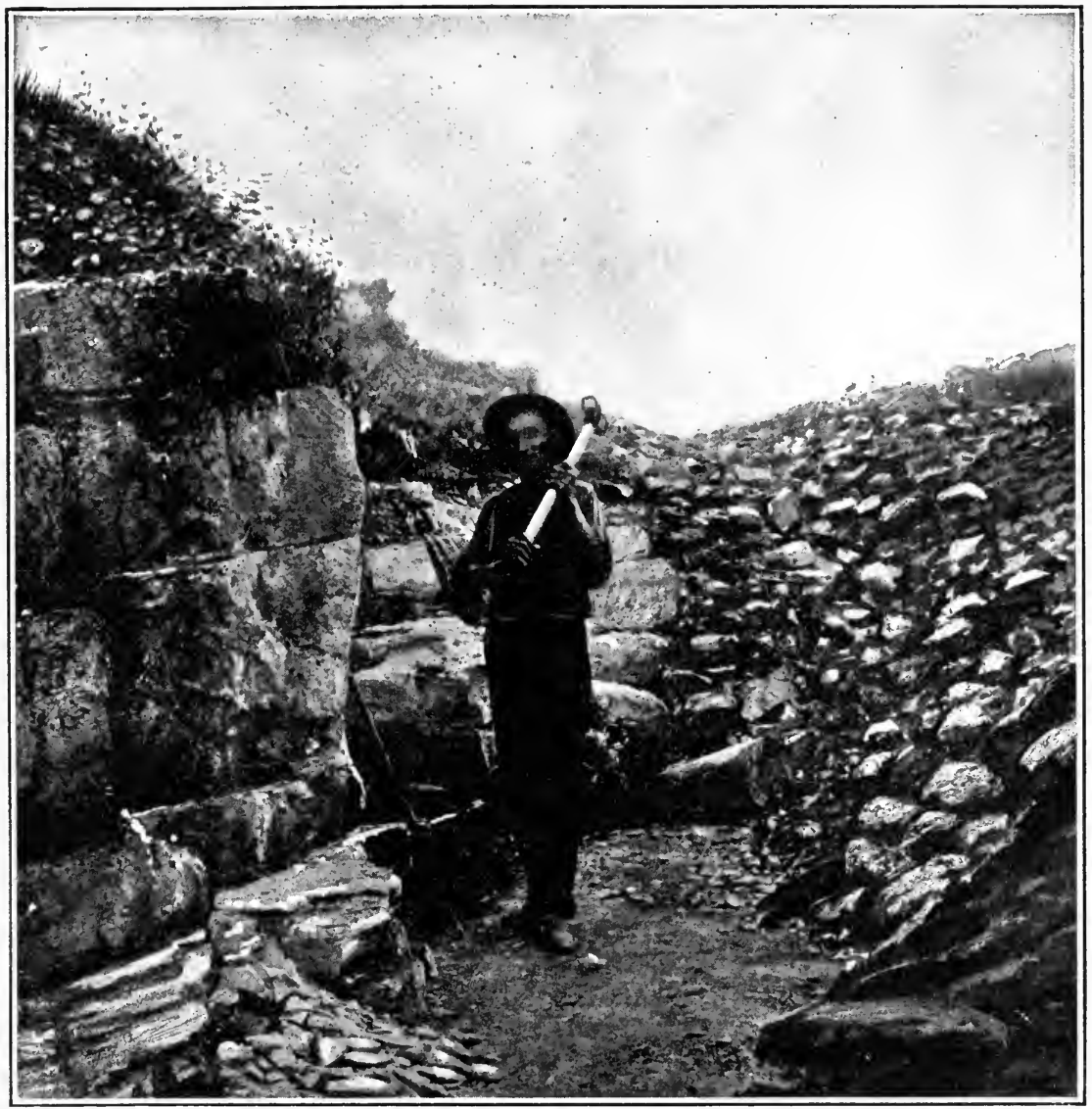

FIG. 128. Indian miner breaking up the exposed margin of the pipestone layer.

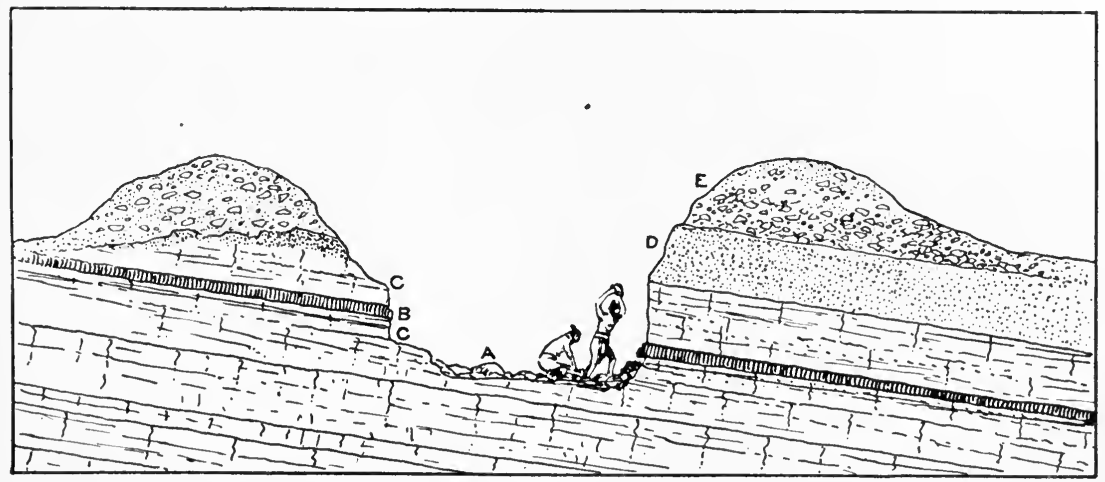

Fig. 129. Section of the pipestone quarry showing the layer of pipestone $B$, the quartzite strata $C C$, the soil $D$, and the dump $E$. 

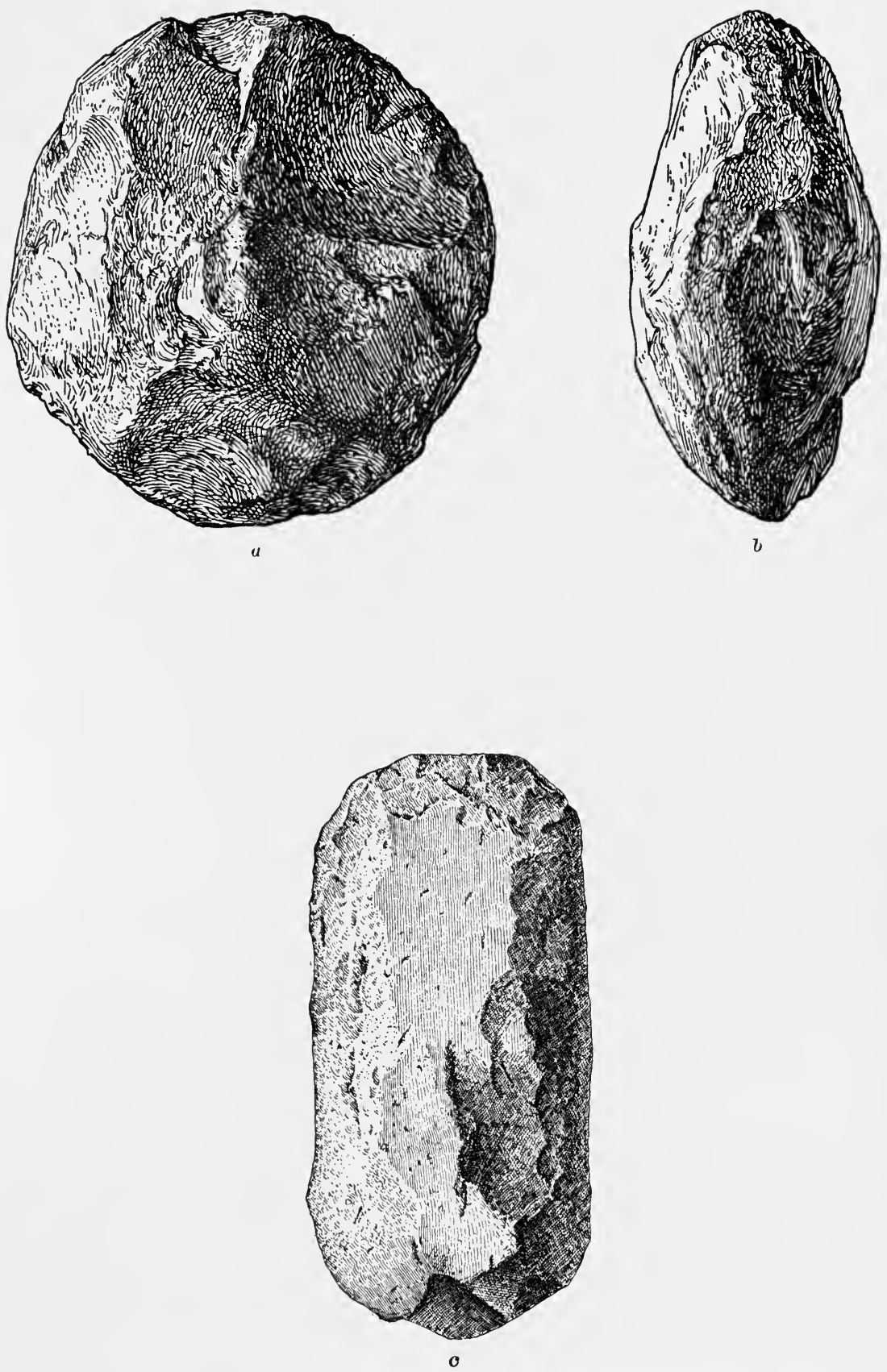

Fig. 130. Ilammerstones used in the quarry work before the acquirement of steel too's. 

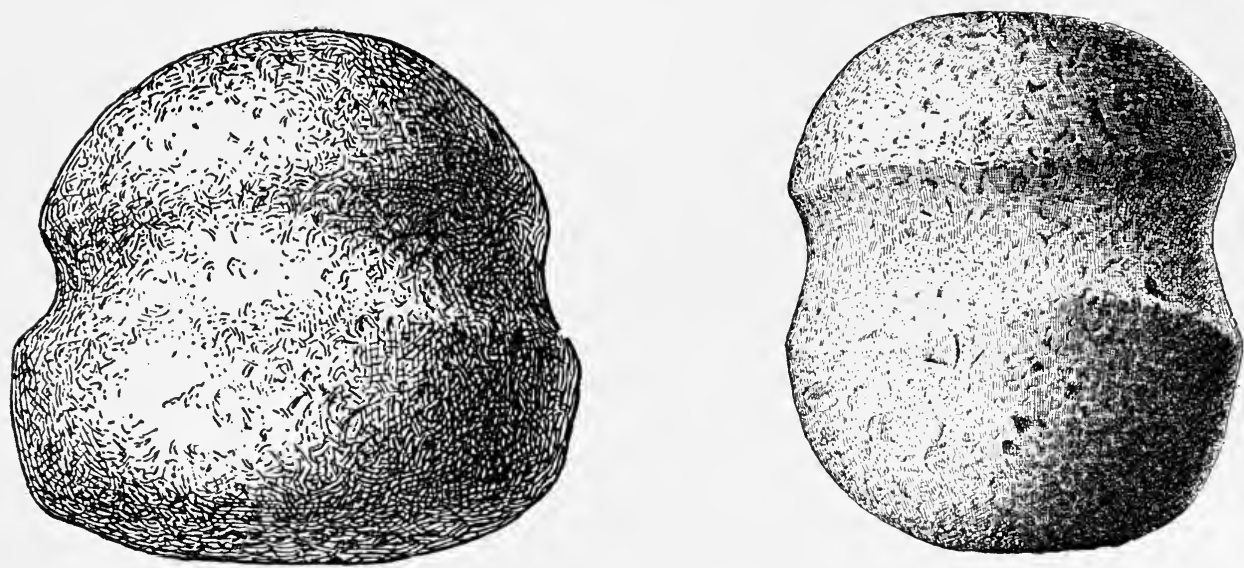

Fig. 131. Grooved sledges of the Plains tribes found on the shop sites. (One-half actual size.)

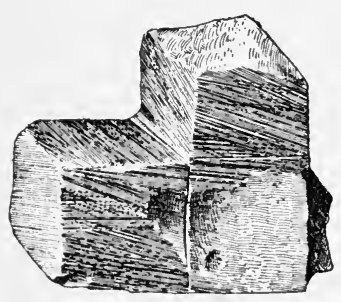

$a$

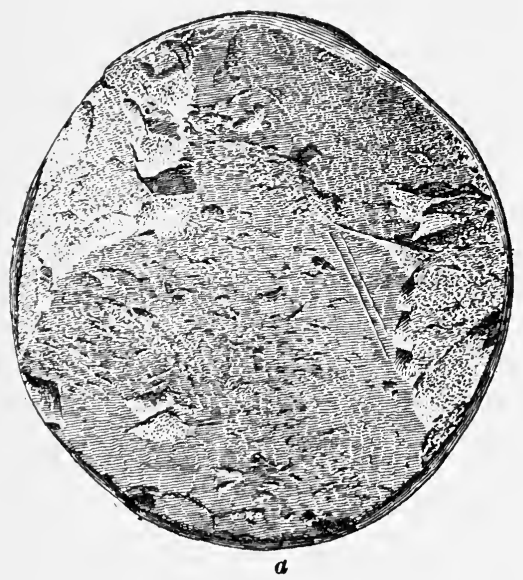

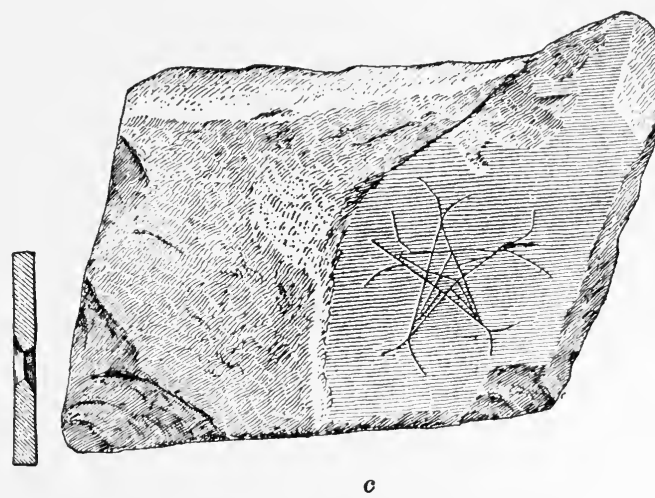

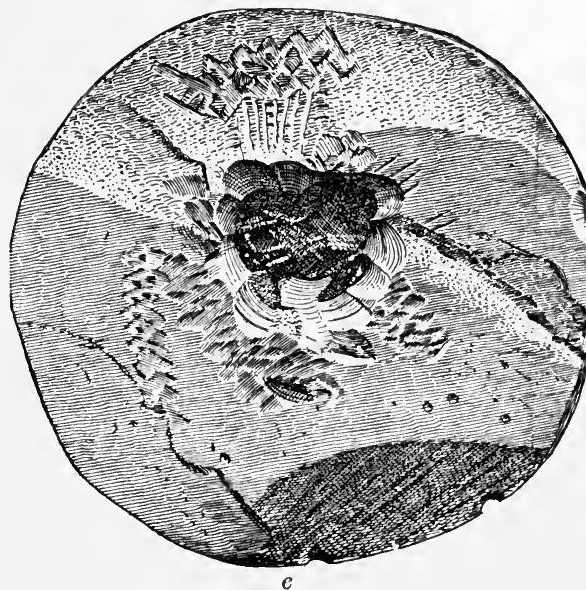

FIG. 132. Examples of worked bits of the pipestone from the camp sites. 
There is a general impression among those who hare written on the subject that the discovery and use of the red Antiquity pipestone by the tribes is of comparatively recent date, and this is no doubt correct; but it is equally certain that it was in use before the arrival of the whites in the Northwest. This is made clear not only by history and tradition but by the appearance of the ancient quarry excarations, and especially by the presence in burial mounds in various sections of the country of pipes and other objects made of the stone by aboriginal methods.

This quarry is usually referred to as the sacred pipestone quarry. According to statements by Catlin and others, the site The Quarry Neutral Ground

was held in much superstitious regard by the aborigines. Traditions of very general distribution lead to the belief that it was, in the words of Catlin-

held and owned in common, and as a neutral ground amongst the different tribes who met here to renew their sicred calumets under some superstition which stayed the tomahawk of natural foes always raised in deadly hate and vengeance in other places. ${ }^{1}$

Nicollet states ${ }^{2}$ that Indians of the surrounding nations made an annual pilgrimage to the quarry unless prevented by Property of the wars or dissensions. Since the earliest visits of the
Sioux

white man to the Coteau des Prairies, however, the site has been occupied exclusively by the Sioux, and Catlin met with strong opposition from them when he attempted to risit the quarry about 1837 .

The following facts regarding the historic occupancy and ownership of the pipestone quary are extracted from a Government Con- statement very generously furnished by Mr. Charles
trol

II. Bennett, of Pipestone:

On April 30, 1803, the region was acquired by the United States through the Louisiana purchase. On July 23, 1851, the lands, including the quarry, were relinquished to the United States by the Sisseton and Wahpeton Sioux, and on August 5 they were relinquished by the Mdewakanton and Wahpekute Sioux, and 64 chiefs and head warriors who had also a claim. A treaty with the Yankton Sioux, ratified April 19, 1858, specifies that "the said Yancton Indians shall be secured in the free, and unrestricted use of the red pipestone quarry, or so much thereof as they have been accustomed to frequent and use for the purpose of procuring stone for pipes; and the United States hereby stipulate and agree to be caused to be surveyed and marked so much thereof as shall be necessary and proper for that purpose, and retain the same and keen it open and free to the Indians to visit and procure stone for pipes, so long as they shall desire." In 1859, 1 square mile, including the quarry, was surveyed as a reservation.

\footnotetext{
${ }^{1}$ Catlin, North American Indians, II, 201.

${ }^{2}$ Report to Illustrate a Map of the Inydrographical Basin of the Upper Mississippi River, p. 15.
} 
The Sioux have no other legal claim to the quarry site than that of quarrying the pipestone, a privilege of which they Recent Work of yearly take advantage to a limited extent. The
the Sioux Yankton Sioux, sometimes accompanied by their friends, the Flandreau Sioux, continue (1900) to visit the quarry and dig pipestone, coming usually in .June or July. They establish their lodges on the reservation near the excavations, and stay from

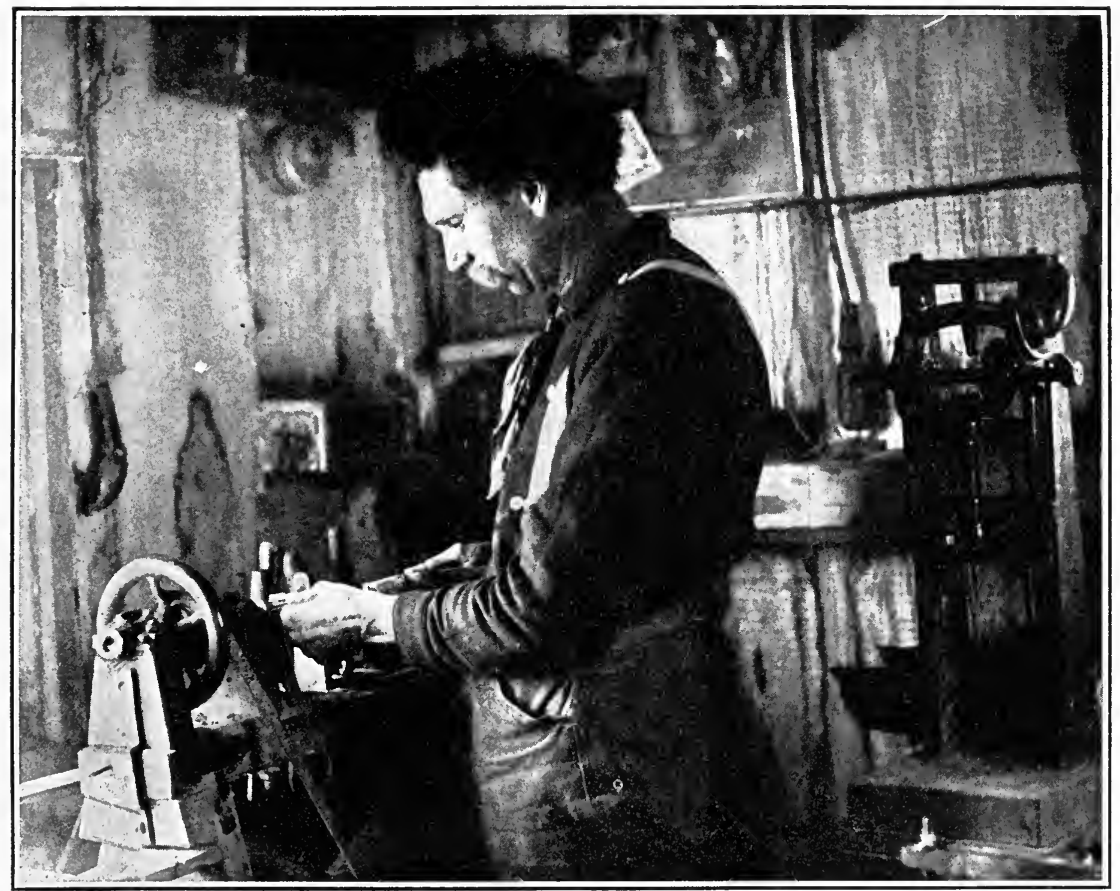

FIg. 133. Commercial pipe and trinket maker at work near the quarries.

one to two weeks, procuring the pipestone, which they manufacture into pipes and trinkets of great variety.

The Indians sell much of the stone to the whites, who have taken up the manufacture of pipes and various utensils and Mrachine-Made trinkets, using lathes and other devices to aid in the work, and in a letter by Mr. Bennett dated 1892 it is stated that not 1 per cent of the pipes then made and disposed of were of Indian manufacture. White traders began the manufacture of pipes from the pipestone many years ago, and according to Dr. F. V. Hayden these were used by the fur companies in trade with the Indians of the Northwest. At a meeting of the American Philosophical Society in 1866 Hayden stated that in the two years just passed the Northwestern Fur Co. had manufactured nearly 2,000 pipes and traded them with the tribes of the upper Missouri.

The pipe maker shown with his lathes and drills in figure 133 was established near the quarry at the time of the writer's visit in 1892, 
and produced a great variety of articles supplied to the trinket market of Pipestone and neighboring towns.

An important feature of the quarry site is a group of large granite bowlders called the maidens (fig. 134), brought from the far north by glacial ice, about the base of which, engraved on the glaciated floor of reddish quartizite, were formerly a number of petroglyphs, representing no doubt mythological beings associated with the locality. Additional interest attaches to the locality on account of an inscription left by the Nicollet exploring party in 1838 . The name of Nicollet and the initials of five other persons, including those of John C. Fremont (C. F. only) are cut in the flinty quartzite rock face near the "leaping rock" at the falls.

The principal explorer's of the site are Nicollet, Catlin, Iayden, Winchell, and the writer. 


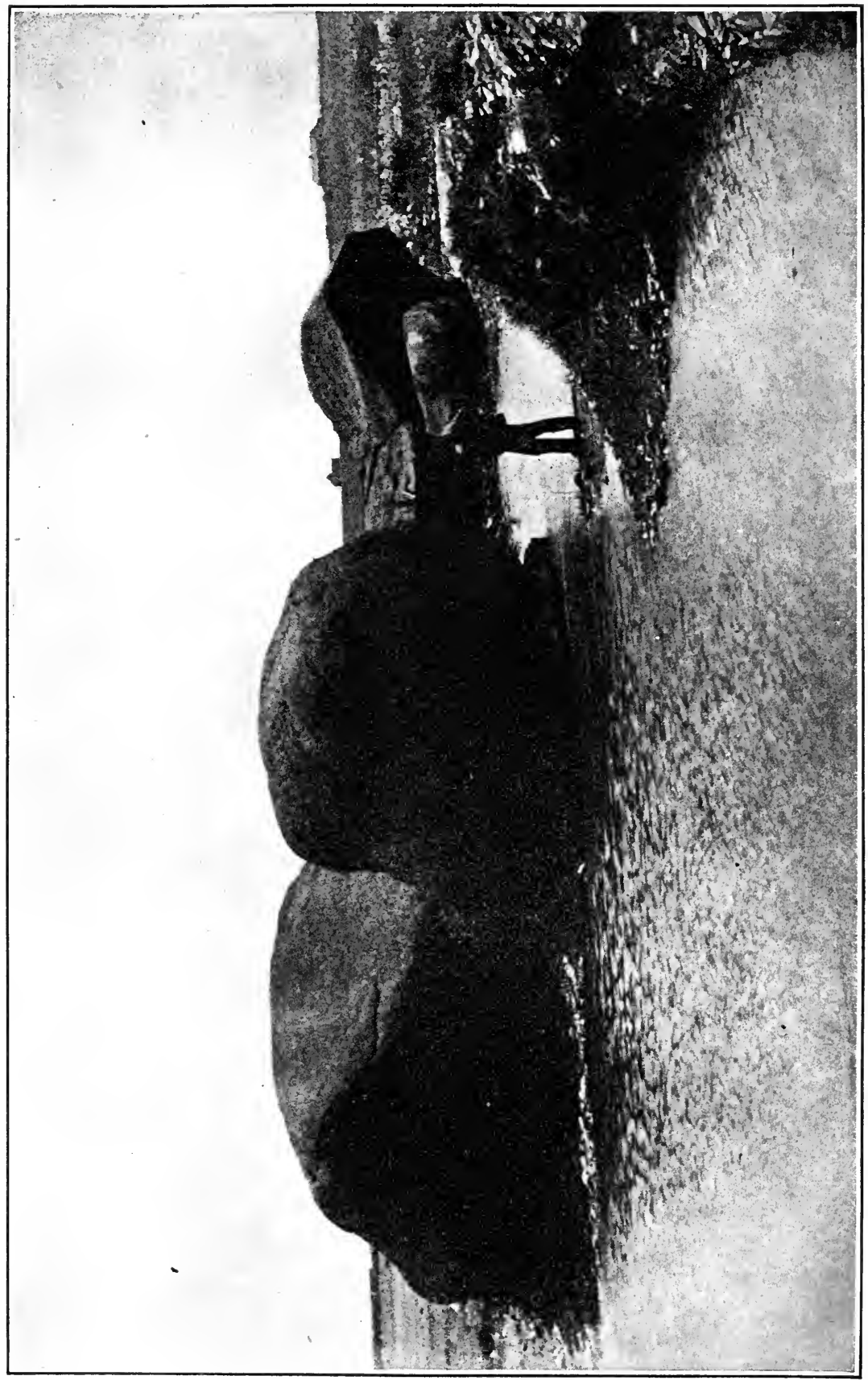

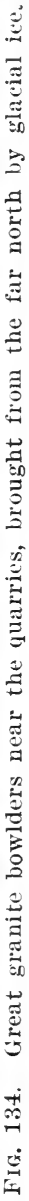




\section{IIEMATITE ORE AND PAIN'T MINE, MISSOURI}

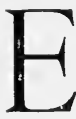

ARLY in the first decade of the present century traces of ancient excavations were observed by miners engaged in opening an iron mine near Leslie, Mo. As the work adranced beneath the surface it was found that the ore had been fairly honeycombed

by some ancient people, the tunnelings extending to Ancient 'Traces the depth of 20 feet or more. There were many partially filled galleries, generally sinuous and often so restricted as to permit the passage of small persons only, but now and then so enlarged as to accommodate standing workmen.

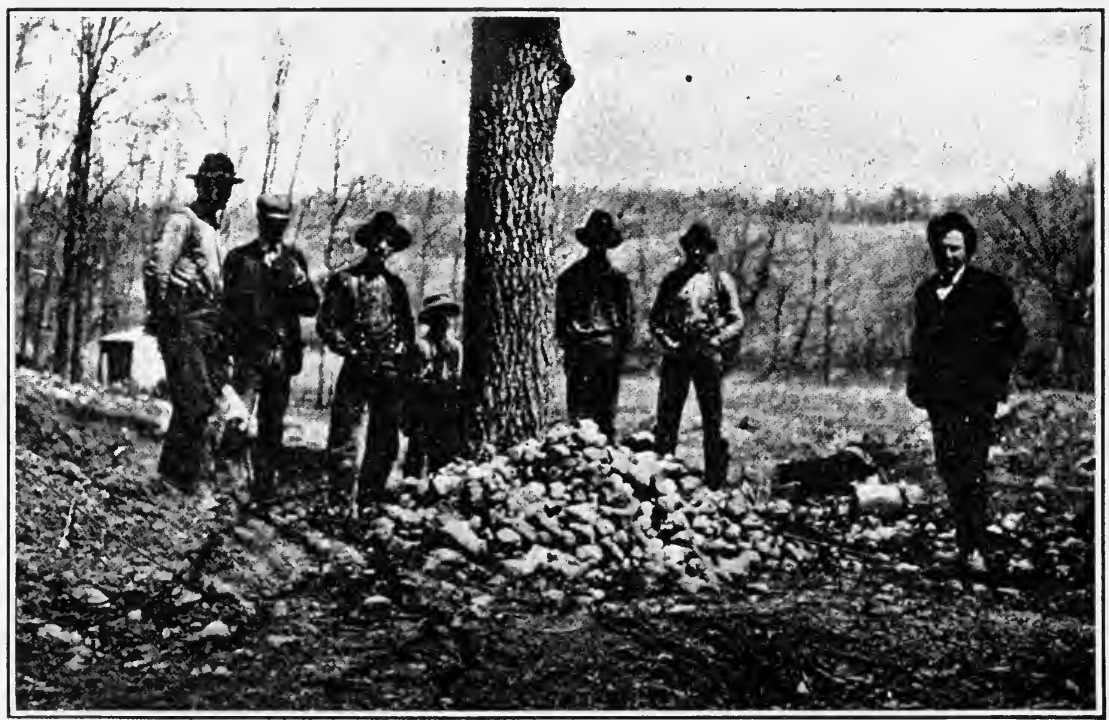

Fig. 135. A heap of ancient mining tools thrown out of the quarry.

All doubt as to the nature of the ancient operations was remored by the discovery in the old excavations of many rude Objects of the Ancient Work

stone implements, and upward of 1,000 of these had been gathered by the miners at the time of the writer's visit, and cast into a heap on the margin of the mine (fig. 135). These implements are exceedingly rude, consisting of masses of hard stone or hematite weighing from 1 to 10 pounds, some picklike in shape and many roughly grooved or notched for the attachment of 
withe handles (fig.136). The great number of these implements made it certain that extensive operations had been carried on by the aborigines, but the exact nature and aim of the work were not readily discernible. The first impression was that the compact masses of hematite were sought for the purpose of manufacturing implements such as were employed by the mound-building and other tribes in many parts of the Mississippi Valley, but few traces of the shaping of this material were found in the mines, although the miners re-

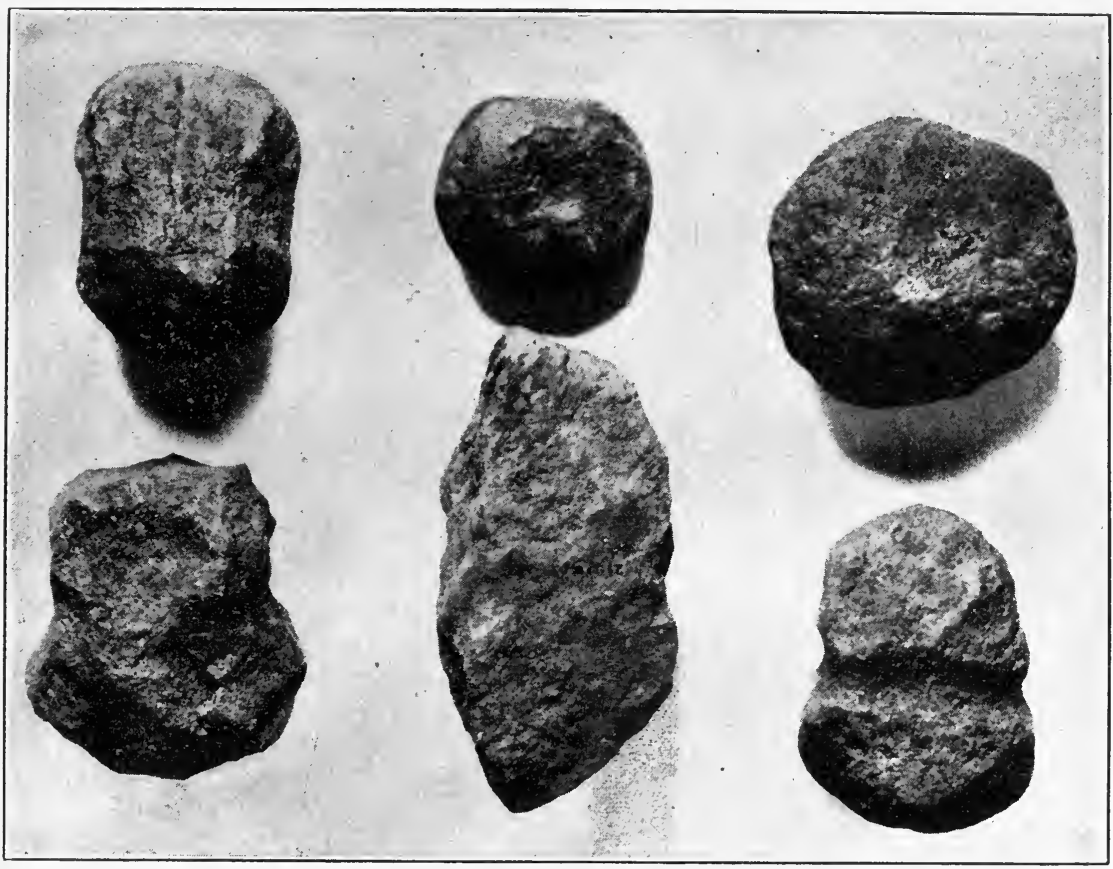

Fig. 136. Examples of the stone sledge heads, picks, and hammers found in the mines.

ported that in beginning operations on the site a large body of chips was encountered near the surface of the ground. Some workable flint was observed in the vicinity of the ore body, Fint Implements and flakes and rejectage of blade making, as well as a number of well-finished projectile points and leafshaped blades, were intermingled in the filling of some of the pits. It is believed that this work was only incidental to the mining of the hematite. Flint is found in large bodies in many sections of the general region and could readily have been obtained in any quantity by the ancient miners.

It was observed that the exposed surfaces of the ore and the ground about were everywhere a brilliant red. The Oxide of Iron Used workmen were red from head to foot, and anyone
as Paint venturing to handle the ore soon found his hands smeared with red oxide, repeated washing being required to remove 
it. The prevalence of the red color suggested at once the idea that the site had been an aboriginal paint mine, and that the red and yellow oxides of iron were mined and carried away to be used as paint-an article of very great importance in the aboriginal economy. ${ }^{1}$

$\Lambda$ s the charges of dynamite used by the miners broke down the walls of the mine, it was observed that the deposits were of irregular hardness, that certain parts of the ore body were very compact and flinty, containing much quartz and often displaying the dark-bluish or purplish hues characteristic of high-grade specular hematite, while the larger part was so highly oxidized as to be easily broken

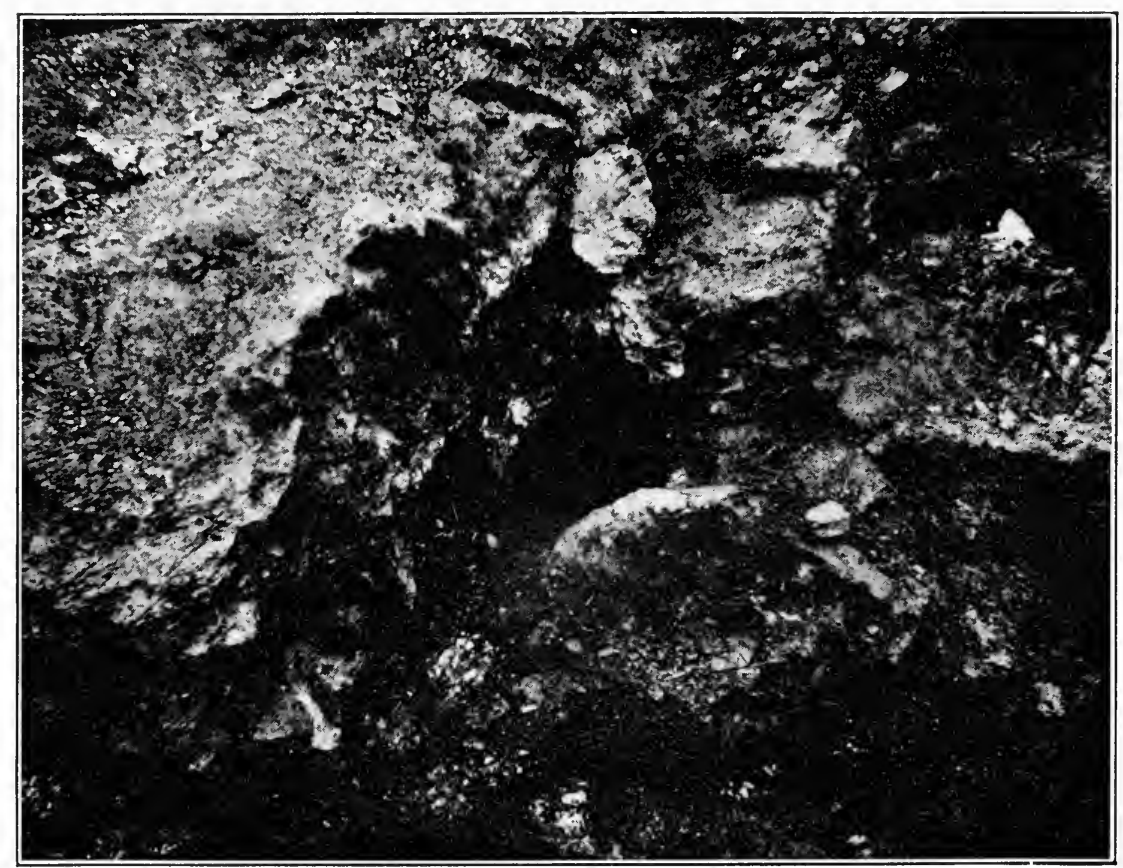

lig. 137. Wall of a modern iron mine, exposing the ancient tunnels.

up. Extending through the ore body in all directions were pockets and seams of soft red and yellow oxides, many of these resembling travertine, and in places there were irregular openings and partially filled carities. Two of these open tunnels are shown in figure 137. Our miners would drill with great difficulty through the hardest ore, to have the drill drop suddenly into a cavity of unknown depth. It was difficult to discover just which of these openings and cavities were

\footnotetext{
1 Two forms of iron ore were used by the aborigines; the anhydrous sesquioxide, to which the name hematite is applied, and the hydrosesquioxide known as limonite. The lematite, in its powdered form, is of a red color. The colors of limonite are less desirable, being yellowish or brown, and it was not so extensively used.
} 
artificial, or whether or not they had all been penetrated by the ancient workers. Changes are constantly taking place in such ore bodies, and percolating waters fill up or clear out passageways. Generally, however, as the walls were broken down by the miners the openings were found to connect with superficial pittings, which were the original openings of the mines, as indicated in figure 138.

It appears certain that the larger tunnels or galleries in which the sledges were found had been opened up or enMethods of Mining larged by the ancient miners, and that in the search for other bodies of the desired product they had followed weak lines and partially filled passageways, removing the projecting masses of hard ore, where these interfered with the work, by means of the sledges or otherwise tunneling around them. It is apparent that the sledges could have had no other function than this, or that of crushing and breaking up the solid masses of ore preparatory to the manufacture of implements. It would seem that in the narrow passages of the mine the use of hafted implements would be inconvenient if not entirely impracticable, and we are left to marvel at the feat accomplished by the ancient workmen in penctrating a compact ore body in dark, sinuous passages hardly roomy enough to admit the body of a man, with the aid of nothing better than the rude hand implements of stone.

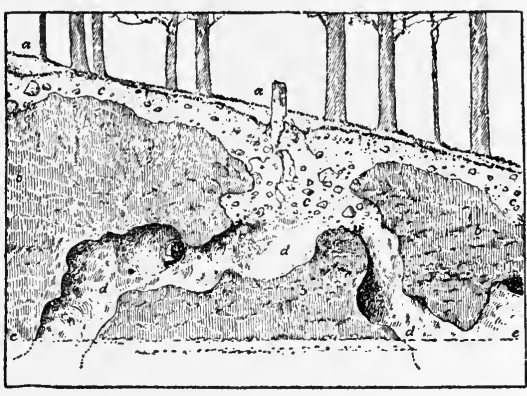

FIG. 138. Section indicating the general character of the ancient tunncling. $(a, a$, Surface traces of ancient pits. $b$, Ore-body. $c$, Filling of excavations. $d$, Borings of the ancient miners. $e$, Floor of mine.) The character of these openings is indicated clearly in figure 137 , which shows the face of the mine as freshly exposed by the mining operations, and figure 138 indicates somewhat imperfectly the manner in which the tunnels or borings penetrate the ore body, comecting with the superficial pits and extending to unknown depths beneath the present floor of the mine.

That paints were in great demand among the tribes is common knowledge, and it is not unlikely that the brilliant pigments obtained from these mines were distributed by trade over a wide area. The solid hematite was in much demand for implements and large number's of axes, celts, plummets, cones, and other objects of use and ceremony are found everywhere in the middle Mississippi Valley.

$\Lambda$ plaster of Paris group, intended to illustrate the remarkable operations carried on by the early tribes in this mine, prepared under the supervision of the writer, is shown in the section of American 
Archeology, United States National Museum. There are two figures, one of which (fig. 139) is seen through the opening in the block of ore, represented as engaged in breaking up the ore with a stone sledge; the other is making his way through a narrow passage carrying a basket of the coveted red and yellow ocher, and is seen in an opening in the block at the opposite end of the case.

It is especially noteworthy that this is a rare example of native enterprise, no instance haring yet been found within the area of

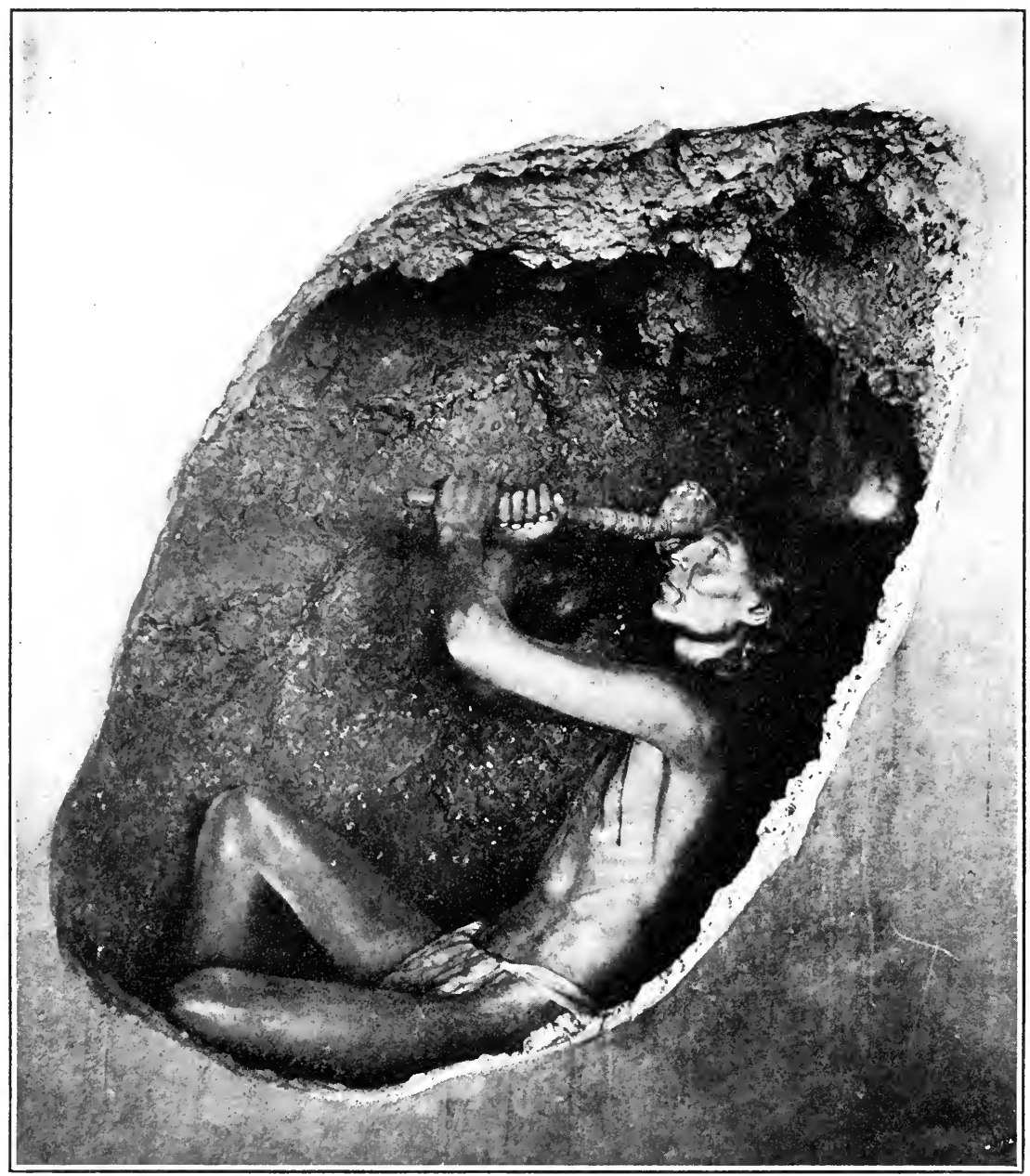

F1G. 139. One of the figures of the model of the hematite workers, prepared by the writer for the Panama California Exposition.

the United States where deep tunneling was undertaken. IIere sinuous passageways were opened to the depth of at least 20 feet in the massive ore body, and no one can say how much farther, nor are we able to say to what extent beyond the observed facts the work was carried on horizontally. 


\section{TURQUOISE MINES}

$\mathrm{T}$

URQUOISE is a precious or semiprecious stone of striking and greatly varied tints of bluish green. Like the other green stones, more particularly jade and emerald, it had a special fascination for the aborigines and was arduously sought and mined in every region in which it was known to exist. Mineralogically it is described as a waxy-appearing sky-blue or apple-green, subtranslucent or opaque hydrous aluminum phosphate colored by a copper phosphate. It is found massive included in metamorphic and eruptive rocks, but in a pure state only in thinly distributed and limited bodies, so that the mining is a difficult and most tedious process, corresponding in difficulties encountered and in the methods required somewhat closely to the mining of native copper. The inclosing rock had to be uncovered and broken up by means of heary sledges of stone, aided on occasion no doubt by applied heat.

Although in general use among the tribes of a vast region which includes our own Southwest and all of Middle Los Cerillos Mines America down to Panama, its occurrence in place is unknown except in the Pueblo region, where it was mined at a number of points: At Los Cerrillos, near Santa Fe, N. Mex.; on Turquoise Mountain, Cochise County, Ariz.; and on Crescent Peak, southern Nevada. These mines were operated by the natives long before the arrival of the Spanish, as is indicated by the extensive pittings and the many rude stone mining tools found associated with them (fig. 140). The Los Cerrillos mines, which seem to have been the most important, were operated also by the Spaniards, and in more recent years in a desultory way are worked by the present inhabitants of the region. Blake, who examined the site about 1885, says:

On reaching the locality I was struck with astonishment at the extent of the excavation. It is an immense pit with precipitous sides of angular rock, projecting in crags, which sustain a growth of pines and shrubs in the fissures. On one side the rocks tower into a precipice and overhang so as to form a cave; at another place the side is low and formed of the broken rocks which were removed. From the top of the cliff the excavation appears to be 200 feet in depth and 300 or more in width. The bottom is funnel-shaped and formed by the sloping banks of the débris of fragments on the sides. On this débris, at the bottom of the pit, pine trees over 100 years old are now growing, and the bank of refuse rock is similarly covered with trees. This great excavation 
is made in the solid rocks, and tens of thousands of tons of rock have been broken out. This is not the only opening; there are several pits in the vicinity more limited in extent, some of them being apparently much more recent. ${ }^{1}$

\section{Silliman speaks of finding in these mines-}

Numerous stone hammers, some to be held in the hand and others swung as sledges, fashioned with wedge-shaped edges and a groove for a handle. A hammer weighing over twenty pounds was found while I was at the Cerrillos, to
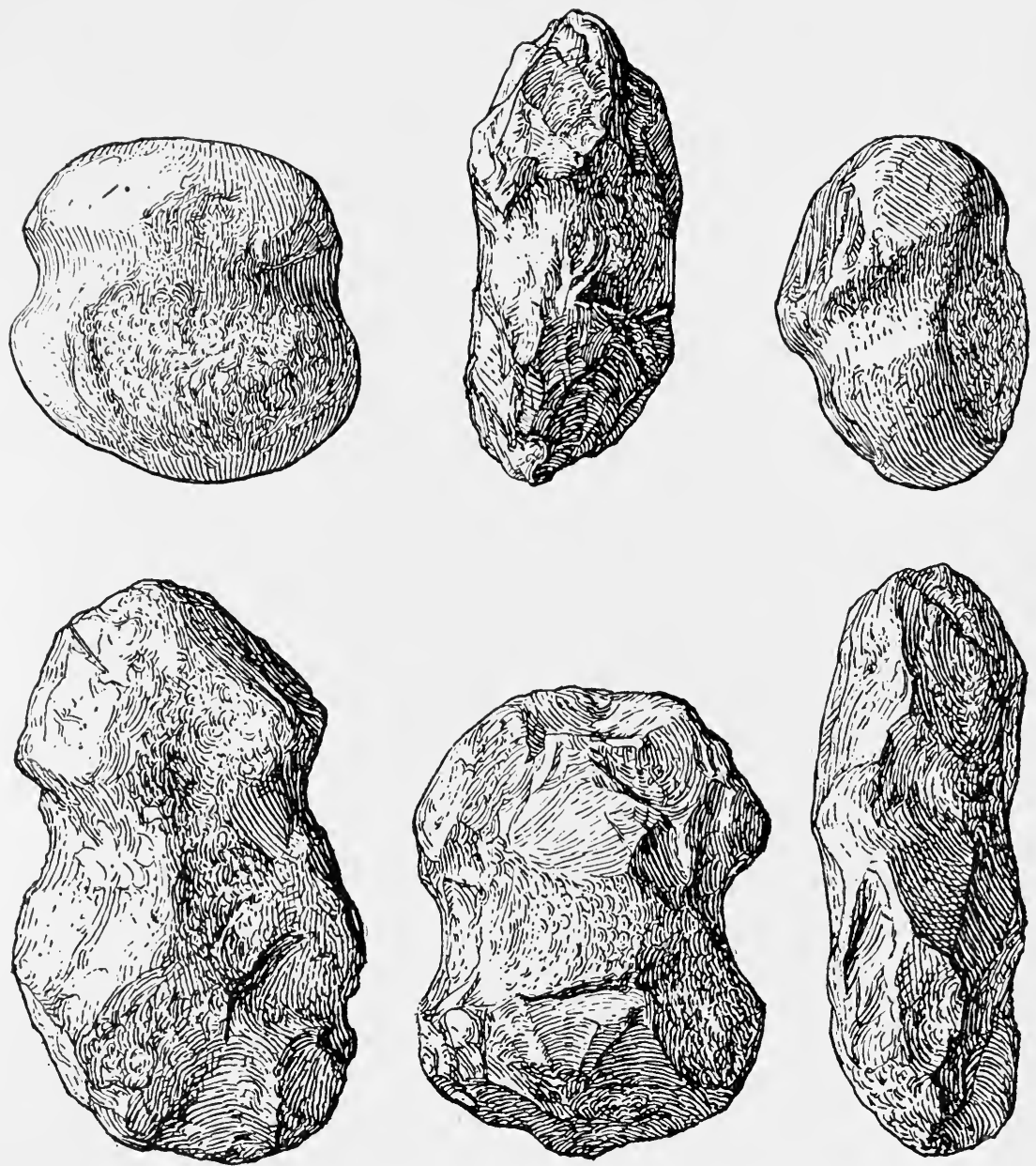

Fis. 140. Stone sledge heads from the ancient turquoise mines at Los Cerrillos, New Mexico.

which the withe was still attached, with its oak handle-the same scrub-oak which is found growing abundantly on the hillsides-now quite well preserved after at leust two centuries of entombment in this perfectly dry rock. The stone used for these hammers is the hard and tough hornblende anclesite, or propylite, which forms the Cerro d'Oro and other Cerrillos IIills. With these

${ }^{1}$ Blake, The Chalchihuitl of the Ancient Mexicans, p. 227. 
rude tools and without iron and steel, using fire in place of explosives, these patient old workers managed to break down and remove the incredible masses of these tufaceous rocks which form the mounds already described. ${ }^{1}$

No satisfactory description of the work in the other quarries has been published, but the stone sledges obtained from them tell identical stories of the laborious extraction of the bits of stone from the compact matrix, and nothing short of a most profound and persistent motive could bring about the results observed. The love of ornament and the fancy for this particular gem doubtless played their part, but superstition was unquestionably the dominant influence. This motive is known to be present among the Pueblo tribes of to-day, and the abundance of the particular stone among ancient remains make clear its use not only for ornament but as a gem to which was attached supernatural attributes of deep significance.

Examples of mining sledges preserved in the National Museum collections purport to have been derived from ancient turquoise mines in California. One locality mentioned is the Himalaya Turquoise Mine, 12 miles east of Silver Lake.

The extensive use of turquoise in Middle America is attested by its historical employment and more especially by its occurrence among the remains of antiquity. The ancient Mexicans employed it in incrusting various works of art, masks, shields, personal ornaments, and the like, and even, in cases, in mural embellishment. It is a remarkable fact that although turquoise was in general use over Mexico and Central and South America, nothing definite has so far been learned regarding the sources of supply. 


\section{QUARRIES OF BUILDING STONE}

$\mathrm{N}$

ORTII of Mexico stone was used in building and for sculpture in numerous centers of culture advancement. The Mound Builders of the Mississippi Valley employed stone in building walls, defensive works, and tombs, and for the carving of images and utensils, and the Pueblo tribes were very skillful

Work of the Mo ou d Bullders and Cliff Dwellers

masons, their pueblos and cliff dwellings displaying much skill in stone construction. In neither region, however, did the quarrying of stone acquire any considerable importance as an industry. Generally the supply of broken stone along outcropping ledges and the faces of cliffs sufficed for all purposes, and there appears to be no record of the systematic quarrying of stone from massive rock bodies with hammers and picks of stone, the only process available to these people, although, as amply shown by the remarkable work done in the flint quarries, there was no lack of energy and skill in kindred work.

In the great centers of native culture, however, the building of cities and the attendant construction of pyramids, Quarries of Mitla temples, fortifications, aqueducts, bridges, and the like, made extensive quarrying from subterranean strata a necessity. Few quarries, however, have had the attention they deserve, and, owing to the long period that has elapsed since they were abandoned they are difficult to locate, being filled with accumulations of soil and overgrown with vegetation. Good examples have been observed at Mitla, in southern Mexico, and the work carried on there is described in a subsequent section, which deals with the pecking-crumbling processes. The native quarrymen did not depend entirely on random blocks or detached masses, but attacked the face of an outcrop or cliff. In some cases the portions to be removed were undermined as far as possible, the upper surface was channeled (fig. 141), and holes were drilled into which wooden wedges were driven. The wedges were then moistened and the swelling of the wood served to fracture the stone.

Stephens refers to a brief visit to the ancient quarries at Copan, Honduras, as follows:

The day after our survey was finished, as a relief we set out for a walk to the old stone quarries of Copan. Very soon we abandoned [Quarries of Copan] the path along the river, and turned off to the left. The ground was broken, the forest thick, and all the way we had an Indian before us with his machete, cutting down branches and saplings. The 
range lie; about 2 miles north from the river, and runs east and west. At the foot of it we crossed a wild stream. The side of the mountain was overgrown with bushes and trees. The top was bare, and commanded a magnificent view of a dense forest, broken only by the winding of the Copan River, and the clearings for the haciendas of Don Gregorio and Don Miguel. The city was buried in forest and entirely hidden from sight. Imagination peopled the quarry with workmen, and laid bare the city to their view. Here, as the sculptor worked, he turned to the theater of his glory, as the Greek did to the Acropolis of Athens, and dreamed of immortal fame. Little did he imagine that the time would come when his works would perish, his race be extinct, his city a desolation and abode

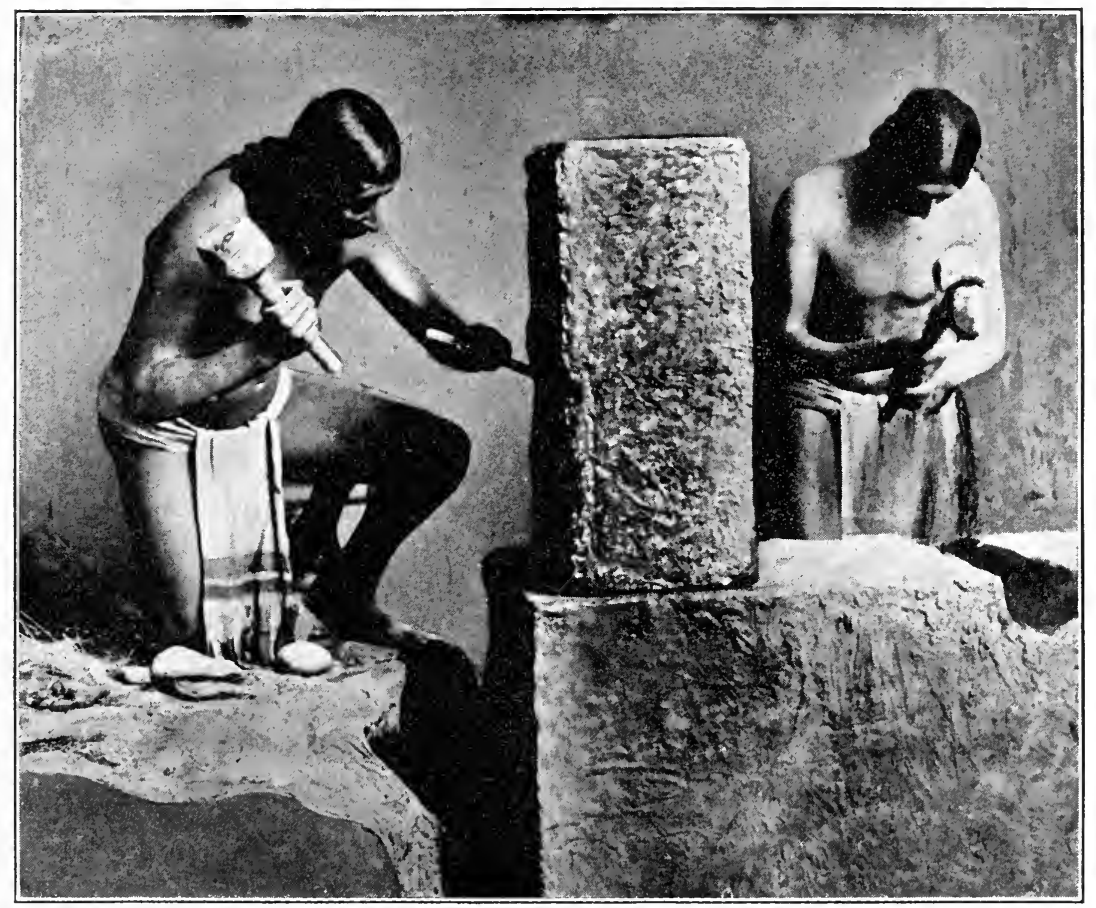

Fig. 141. The stonecutters of Yucatan. From a group in the National Museum.

for reptiles, for strangers to gaze at and wonder by what race it had once been inhabited.

The stone is a soft grit. The range extended a long distance, seemingly unconscious that stone enough had been taken from its sides to build a city. IIow the huge masses were transported over the irregular and broken surface we had crossed, and particularly how one of them was set up on the top of a mountain 2,000 feet high, it was impossible to conjecture. In many places were blocks which had been quarried out and rejected for some defect; and at one spot, midway in a ravine leading toward the river, was a gigantic block, much larger than any we saw in the city, which was probably on its way thither, to be carved and set up as an ornament, when the labors of the workmen were arrested. Like the unfinished blocks in the quarries at Assouan and on the Pentelican Mountain, it remains as a memorial of baffled human plans. 
We remained all day on the top of the range. The close forest in which we had been laboring made us feel more sensibly the beauty of the extended view. On the top of the range was a quarried block. With the chay stone found anong the ruins, and supposed to be the instrument of sculpture, we wrote our names upon it. They stand alone, and few will ever see them. Late in the afternoon we returned, and struck the river about a mile above the ruins, near a stone wall with a circular building and a pit, apparently for a reservoir. ${ }^{1}$

The ancient builders of Peru and Bolivia, the Inca peoples, have bequeathed to us evidence of remarkable enterprise in this field, rivaling in the work accomplished the greatest achievements of the builders of the Old World. Squier has given us a most elaborate and graphic account of the great quarries of Cuzco:

This bolson is separated from that of Oropesa, which is only an extension of that of Cuzco, by a narrow ridge or pass, which formed the [Quarries of Cuzco] southern limit of the dominions of the first Inca, and where stand the massive remains of the works by which it was defended from aggression from the southward. Before reaching these remains we come to great projecting masses of trachytic and basaltic rock, through which the road or path winds tortuously. Here was one of the principal quarries of the Incas, and hence was taken by far the greater part of the stones used in the construction of the edifices of Cuzco. All around are immense heaps of stone chippings, covering more than half a mile square, and among these are scattered, in all directions, blocks of stone of every size and in every stage of progress, from the rongh fragment just broken from the parent mass to the elaborately finished block ready to be put in its assigned place in a building. IIere are the rough stone huts of the quarrymen and also the more pretentious dwelling of the master workman, or overseer, who built a little wall around his house and a terrace in front and otherwise evinced taste and love of comfort.

The whole aspect of things is familiar, and we might readily imagine ourselves in an abandoned quarry at home. Although many of the worked stones have been taken away since the Conquest, yet enough remain to show that the quarries were in full operation at the time of their final interruption, and that the Incas were still actively engaged in enlarging and beautifying their capital. I do not attach much importance to the statements of Cieza de Leon and others that many of the royal palaces and temples of the empire, as far distant as Quito, were wholly or in part built with stones transported from Cuzco, thereby obtaining some degree of sanctity or reverence, as did the soil of the Campo Santo of I'isa, from the fact that some of it was brought from the Holy Land. 'The trachytes of which the edifices of Cuzco are mainly built are by no means uncommon throughout Peru; and the coincidence in materials in any given structure with those of another by no means implies that these materials were obtained from a common source.

Although there is no direct evidence remaining in the quarry as to the manner in which the stones were dressed after being extracted from their beds, yet it seems pretty clear that most of them were picked or hammererl into shape with a pointed instrument of a hammer before passing under the chisel. Of the manner in which the stones were separated from the natural rock there are here, as in other places, abundant illustrations. Excavations were made, where possible, under the masses of rock, so as to leave some portions of them impending. A groove was then cut in the upper surface on the line of desired

1 Stephens, Incidents of Travel in Central America, Chiapas, and Yucatan, I, pp. $146-147$. 
fracture, in which oblong holes were worked to a considerable depth. precisely in the manner now practiced. The presumption is strong that wedges of dry wood were driven into these holes and water turned into the groove. The swelling of the wood would evenly split off the block. This device is probably almost as ancient as the art of stonecutting itself. I found some disks of hard stone in this quarry, with holes through their center, as if for the reception of handles, which may have been used in rough-dressing or hammering the stones into shape.

The distance of this quarry from Cuzco is about 22 miles. How the stones were transported thither is not easy to say ; but as the Incas had no beasts of draft it must have been done through the direct application of human force. With a redundant and disciplined population under absolute control we can understand how the Incas could combine the power of numbers in a most eflicient manner. ${ }^{1}$

In another place Squier's visit to these quarries is graphically described :

This is the old Inca road leading to the porphyry quarries, whence the giant stones of the Fortress of Ollantaytambo were obtained. We follow this to the very extremity and brow of the headland, over which they were toppled, slicling down 2,000 feet into the valley. The plane worn in their descent is distinct, and lying around us are blocks more or less shaped artificially, which the apparition of the Spaniards prevented the ancient workmen from launching down to their destination. How these blocks were got across the swift and turbulent river, in the bed of which some still remain. I do not attempt to explain. Starting back along the ancient quarry road, we constantly encountered blocks of porphyry, entirely or partly hewn, some in the millde of the road and others lying by its sides. ${ }^{2}$

1 Squier, Peru: Incidents of Travel and Exploration in the Land of the Incas, pp. 418-419.

2 Ibid., p. 508. 


\section{THE STONE-SHAPING ARTS}

\section{Synopsis of Processes}

I. FRACTURE PROCESSES

(a) Percussion fracture $\left\{\begin{array}{l}\text { Direct, freehand } \\ \text { Direct, rest } \\ \text { Indirect, freehand } \\ \text { Indirect, rest }\end{array}\right.$

(b) Pressure fracture $\left\{\begin{array}{l}\text { Freehand } \\ \text { Rest }\end{array}\right.$

(c) Heat fracture

(d) Water expansion fracture

II. CRUMBLING PROCESSES

(a) Direct percussion crumbling $\left\{\begin{array}{l}\text { Freehand } \\ \text { Rest }\end{array}\right.$

(b) Indirect percussion crumbling $\left\{\begin{array}{l}\text { Freehand } \\ \text { Rest }\end{array}\right.$

III. ABRADING PROCESSES

(a) Grinding; whetting

(b) Sawing

(c) Scraping

(d) Drilling $\left\{\begin{array}{l}\text { 1. Direct } \\ \text { 2. Rotary }\end{array}\right.$

(e) Engraving

(f) Polishing

(a) Cutting

(b) Shaving

IV. INCISING PROCESSES

V. PIERCING PROCESSES

7 IIE shaping processes, by means of which stone is made to assume artificial forms adapted to human needs, are varied and ingenious, and their mastery has always been a matter of the greatest importance to primitive peoples, as it is also in large Classification of Shaping Processes degree with civilized peoples. These processes are purely mechanical, unless we regard fire, used sometimes in fracturing rock bodies, and perhaps to some extent in minor operations, as a chemical agent. A wide range of manual operations is represented, and these may be conveniently 
arranged in five groups: (1) fracturing, represented by the terms breaking, flaking, chipping, and knapping; (2) crumbling, including such acts as pecking and hammering; (3) abrading, as in rubbing, scraping, boring, sa wing, and polishing; (4) incising, including cutting and shaving; (5) piercing, as with an awl or punch. The processes employed in a given case were determined by the nature and form of the material worked, by the available shaping tools, by the intelligence and skill of the workman, by the character of the object or work designed, and by a number of minor considerations. Fracturing is available to some extent with all varieties of stone, and as a specializing process where the stone to be shaped is measurably brittle, as flint, jasper, and quartz. Heat fracture, although of great service in breaking up bodies of rock, is of little value in the shaping work. The crumbling processes are employed when the materials worked, while readily subject to crumbling and in a measure to fracturing, are capable of resisting fracture by the ordinary shocks of percussion, like the granites, many of the more compact eruptives, fibrolite and jade. All varieties of minerals are susceptible of shaping by abrasion, while simple piercing with a point is but slightly applicable except with such soft and yielding substances as fire clay, soapstone, and mica. Incising is employed where the stone is relatively soft, as soapstone, serpentine, cannel coal, and the like.

The materials employed by the tribes were of many kinds and occurred in many forms. Some attractive varieties, Materials, Shaped being rare and difficult to procure, were regarded as precious, and often as being possessed of exceptional qualities or mysterious attributes. Others were scattered broadcast over the face of the country and were readily obtained, while others occurred in extensive deposits extending beneath the surface and were available only by quarrying or mining. Through long experience the aborigines had acquired extensive and accurate knowledge of the superficial distribution of these materials and of their nature and adaptability to processes and uses. They vary in form, texture, hardness, etc., and these qualities are important factors in deciding the shaping processes used and the character of the art form produced, but detailed discussion of these qualities can add little of real value and will not be taken up in this place. Special studies of the characteristics of fracture have been made by various writers, prominent among whom are Pfeiffer, ${ }^{1}$ and S. Hazzledine Warren. ${ }^{2}$

Having secured the raw materials from the surface or by quarrying, the next step of the primitive implement maker Use of Natural was either to utilize the available product unchanged or to shape it for more effective use. Convenient water-worn forms from the river banks or from gravel beds were 
employed for breaking, driving, grinding, cracking, and killing, and sharp-edged and pointed stones for cutting, scraping, drilling, piercing, and picking; but the archeologist has little to do with the unmodified forms, since it is not easy to say that any given specimen was used at all unless it bears decided marks of use, and if shaped thus by use the stone may be classed with artificial shaping by Use forms, although not the result of design. This is the case with a multitude of mortars, pestles, abraders, hammers, picks, and other implements and utensils in use to-day or discarded upon deserted and ancient sites. Again, many of the simpler forms of artifacts did not call for much Improvised Tools elaboration, as they could be made at once with a few strokes of the hammer. The hunter and warrior were able to supply themselves at slight cost of labor with weapon points as emergency required, and efficient ham mers, axes, knives, picks, scrapers, and the like were made with ease. The more highly specialized forms required Degrees of Implement specialization

time and in many cases no doubt, where there was no need of haste, the work was gradually brought to completion by intermittent labor. Where materials were plentiful and the demand great, implements, and especially implement blanks of certain classes, were often gotten out in numbers, and the sites became workshops or factories, and there was an opporSpecialization of tunity for, and no doubt a tendency toward, specialiLabor

zation of labor. It was more convenient and profitable where separate operations, each requiring special skill, were involved, to have individuals or groups of craftsmen give exclusive attention to the separate steps: First, to quarrying; second, to breaking up the material and selecting choice available pieces in numbers; third, to roughing out blank forms in Steps in special- numbers; and fourth, to the work of trimming, ization of Implements

specializing, and finishing. This would apply more especially to the fracture-made implements. These four well-defined steps gave rise to separate industries carried on by the same individuals at different times or places, or by distinct groups of experts at convenient times and places. It would seem that the second and third steps, whether performed by one or by two groups of workmen, were generally accomplished on the spot yielding the raw material. It would be unprofitable to transport for long distances masses of material of which nine-tenths would finally, from the vicissitudes of fracture, be consigned to the refuse heap. The blank forms of articles to be shaped, worked out so far as tc test thoroughly the material and its capacity for specialization in desired directions, were removed from the sources of supply, to be finisher when convenient or when need demanded. Of course the shaping 
work connected with sculptural and architectural (building) arts, and more especially the industries pertaining thereto, are in a measure distinct from those pertaining to the minor art forms, but these differences will appear with sufficient clearness as the several processes are presented in detail.

Pictography utilized sharp stones and stone surfaces in their natural state, and sculptures generally passed through the same shaping stages and by the same processes as implements and utensils of practical use. The stone gathered for building purposes was employed without change or was dressed by the ordinary shaping processes to suit the needs of the builder, while the quarried material had largely to be freed from the solid beds by the tedious processes of pecking and picking and was dressed and carved by the same implements employed in the shaping of major artifacts generally.

Much has been said regarding the time required for the completion of artifacts of certain classes. The fracturing Time Required in Shaping

operations were usually not prolonged or tedious, and numerous eyewitnesses of the native work testify to the rapidity with which the minor chipped implements, as arrowheads, were made; and experiment has shown that even the most tedious processes, as crumbling and abrading, permit the completion of the more elaborate implements in weeks and months rather than in years or lifetimes. That certain highly specialized and elaborate articles took long periods for their completion is to be accounted for by the fact that the work usually was not carried forward at once, but was taken up at intervals possibly widely separated. Speaking of grooved axes and celts, Lafitau says that they are prepared by the process of grinding on sandstone and finally assume, at the sacrifice of much time and labor, nearly the shape of our axes (the grooved ax) or of a wedge for splitting wood (the celt). The life of a sarage is often insufficient for accomplishing the work, and hence such an implement, however rude and imperfect it may be, is considered a precious heirloom for the children. ${ }^{1}$

McGuire and others who have undertaken experimental work have demonstrated the fact that the most elaborate stone Time Proportioned to Size and Elaboration

$a x$ is not necessarily the work of years but rather of days and weeks (see "Crumbling and Abrading Processes"). However, where large works were undertaken, as in sculpture and architecture, the labor was prolonged and directly in ratio to increase in dimensions. The carving of each of the granite capitals of the Corinthian columns of the portico of the New National Museum, 64 inches in height and 56 inches in diameter, occupied a skilled workman, equipped with the most highly 
perfected electrically driven chisels, 190 days. The magnitude of this work with its high relief, undercutting and diversified floral detail is, however, more than paralleled in magnitude by that of the huge monolithic stelae of Copan and Quirigua, which are marvels of intricate design and bold relief, and carved, it is assumed, without machinery and in the main, no doubt, with implements of stone.

It would appear that the shaping and use of minor artifacts of stone-utensils, implements, ornaments, and objects of religious significance-was carried to a high degree of perfection among most primitive peoples before the larger works of sculpture and architecture were conceived or undertaken, although among exceptional peoples megalithic monuments and cyclopean structures of astounding proportions were erected during very early stages of progress in the shaping arts.

Howsoever important the stone-shaping arts may have been to the implement maker and the carver of minor sculptures generally, their greatest field of accomplishment was in getting out and dressing the vast bodies of solid rock required in the building arts and in carving the colossal sculptures which characterize the culture centers of Middle and South America. Much, however, must remain forever undetermined regarding the means employed by the primitive city-builders in quarrying these monster stones from the unbroken body of living rock.

With regard to the question of the geographical distribution of the various processes here referred to, it may be said that some are widespread or even practically universal, while others are confined apparently to limited areas and represent single communities or tribes. The fundamental processes were doubtless known in one form or another to all the American peoples, either by original discovery or by acculturation, the differences in their operation arising locally as the result of differences in material and needs and varying also with the state of advancement of the people, the difference depending not a little, as with civilized peoples, upon the inventive genius of a few individuals. 


\section{FRACTURE PROCESGES}

$\mathrm{N}$

UMEROUS somewhat distinct methods of shaping stone by fracture processes are described and illustrated in subsequent pages. Many of these methods have been recorded with some degree of fullness by observers of the native work as actually practiced, or as operated by old men who had knowledge of the work in days preceding the coming of the gun, while others are inferred from a study of the implements used, the artifacts made, and the refuse of manufacture. It is not at all likely, however, that the processes cited and described include all of those employed by primitive peoples of the world or even of America alone, but they are sufficient to indicate the wide range of methods available to the Stone Age artisan. During his many years of close association with the Indians Mr. Cushing accumulated a great store of knowledge of the native arts, and in his discussion of the arrow ${ }^{1}$ he enumerates and illustrates several methods of stone working by fracture alone. His account, which describes numerous processes, is introduced later on. The writer has been able to collect more or less definite information regarding a much larger number without going beyond the ordinary range of processes observed in use among primitive peoples. As a matter of fact, the procedure followed out by the experimenter, howsoever carefully he may imitate the native processes as witnessed by him or described by others, will always be found to embody more or less decided individual variations and technical peculiarities.

The fracture processes are of two distinct types: Those which operate by percussion, and those which employ pressure. The former are here presented first for the reason that in the shaping of minor artifacts in which pressure is utilized the shaping work usually begins with percussion. The flakes are made, or blank forms are roughed out by the hammer, preparatory to the use of the bone chipping tool.

\section{Percussion Fracture Processes}

The stone hammer, the greatest of all Stone Age tools, remained imperfectly understood by students of prehistoric culture until within 
recent years. Prof. Sven Nilsson ${ }^{1}$ was probably the first to comprehend its use in shaping by fracture, his experiments having been begun very early in the last century. It remained for various students of the present generation to work out the full range of its application. Its field of usefulness is wonderfully wide. In the shaping arts, besides its universal use in the fracture processes it holds an equally exalted place in the pecking-crumbling arts and was, besides, in one form or another, employed in the household arts and in the arts of war and the chase. Its usefulness in the fracture arts was largely confined to the breaking up of rock masses and the rough shaping of implements and other artifacts. The hammer was in a vast number of cases merely a water-worn bowlder, which assumed artificial shape through use, while where bowlders were not convenient tough, hard bits of stone were collected and roughly shaped to adapt them to the work. Examples are illustrated in figure 142. It is doubtless true that the pitted hammer (fig. 143) was sometimes employed in the chipping work, but examples are rarely found in the quarry shops where this work was extensively carried on. Hammers made of a section of the indurated base of deer and elk antler were in common use in some localities for the lighter chipping work.

The fracture processes in which the hammer is the active agent are summarized as follows:

\section{DIREC'I FREEHAND PERCUSSION}

Fracture by striking the stone to be worked, held in one hand, with another stone held in the other hand, thus purposely shaping the former or obtaining desired fragments.

\section{INDIRECT FREEHAND PERCUSSION}

(a) Chipping brittle stone held in the palm of one hand with a bone punch held between the fingers of the same hand and driven by a hammer held in the other hand.

(b) Chipping brittle stone held in the palm of one hand with a bone punch held in the other hand and driven by a hammer in the hand of another person.

\section{DIRECT REST PERCUSSION}

(a) Fracturing the stone by striking it against another stone, the latter usually of larger size and stationary.

(b) Fracture by casting one stone against another as a missile; employed largely in breaking up masses and more especially in mining and quarrying. 

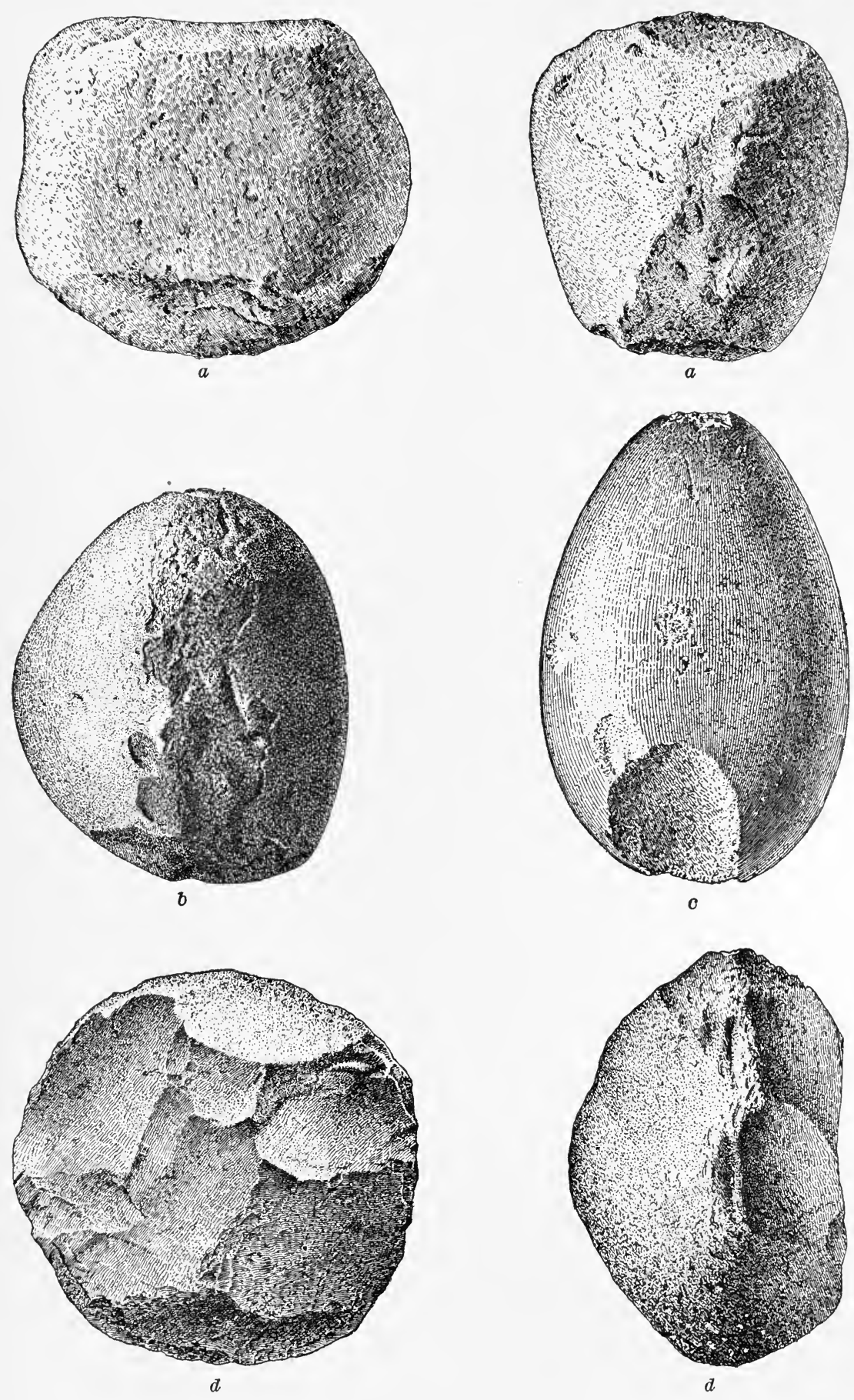

Fig, 142. Types of hammerstones. ( $a, b, c$, Irowlders showing battcring from use; d, hammer (hipped into shape.) 
(c) Fracture by holding the stone to be worked flatwise on a stone or other rest with one hand and striking it with a hammer, thus purposely shaping it or obtaining desired flakes.

(d) Fracture by holding the stone to be shaped edgewise on an anvil-stone and striking it, edge on, with a hammer, thus purposely shaping it or obtaining desired flakes.

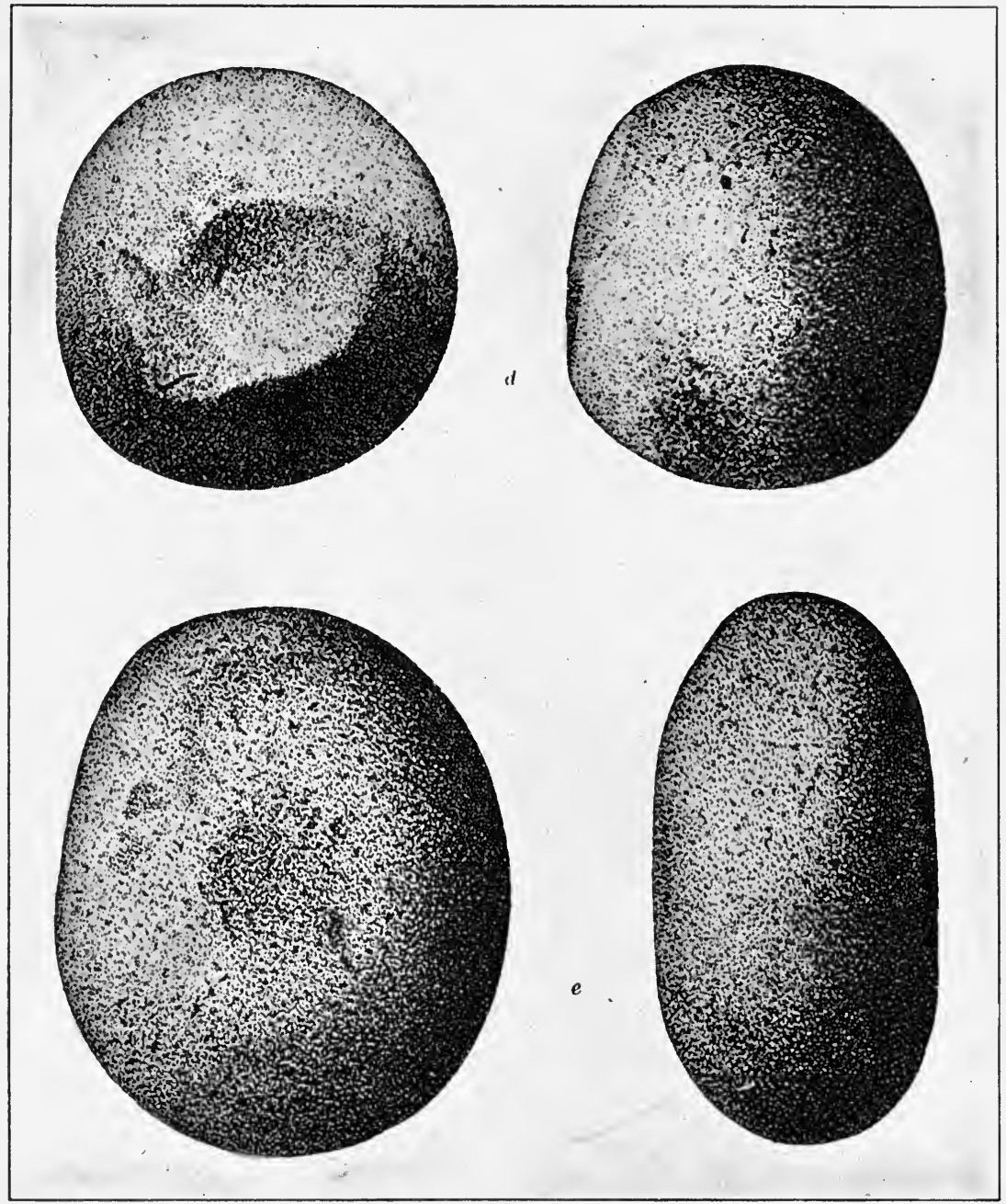

Fig. 143. Pitted hammerstones employed in a wide range of uses, and of very general occurrence.

(e) Fracture by holding the stone to be shaped in a clamp or otherwise fixing it and chipping the exposed margin with a hammer, thus modifying the form. 


\section{INDIRECT REST PERCUSSION}

(a) Fracture by means of a punch of bone or other like material, driven by a hammer, the stone shaped being at rest.

(b) Chipping by placing the thin edge of the stone to be shaped on an anvil and tapping it from above with a hammer.

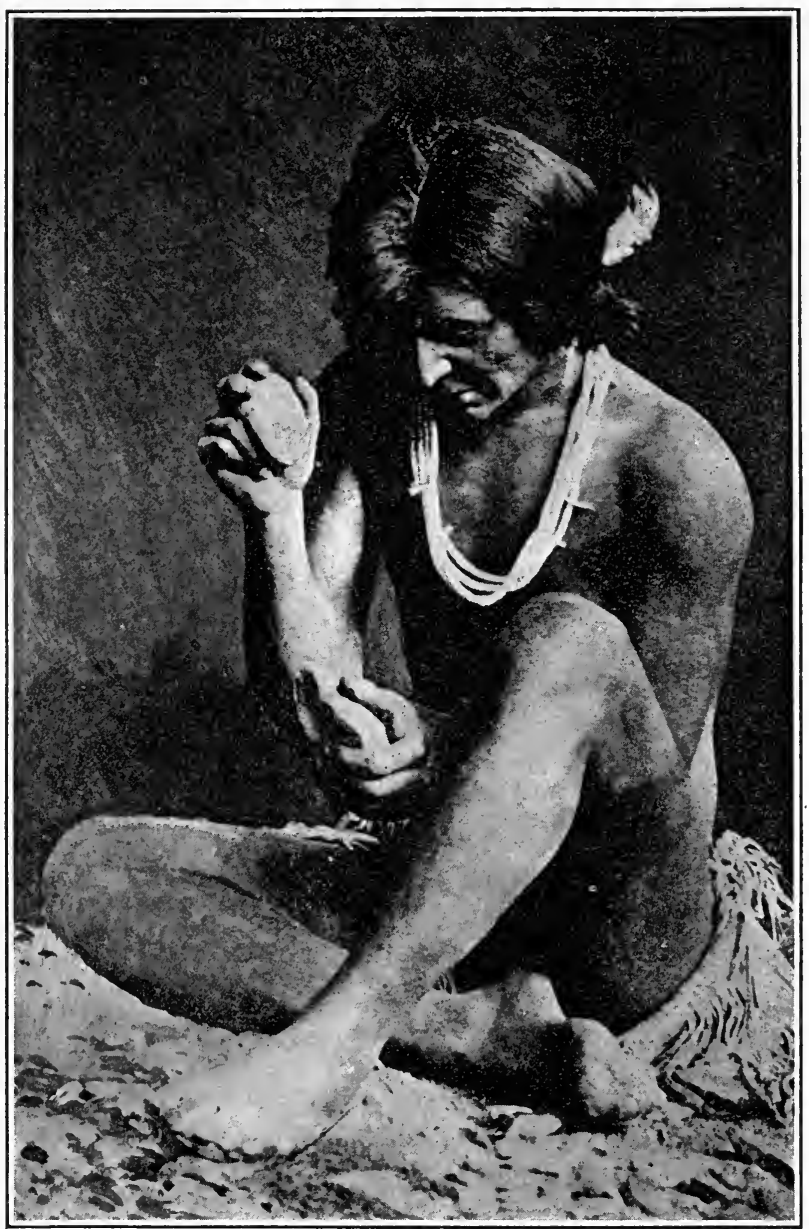

Fig. 144. Free-hand fracture of a bowlder with a bowlder hammer. Figure from the Piney Branch quarry group in the National Museum.

Probably the most generally practiced of the fracture shaping processes in which the stone hammer was employed Direct Free-hand is that referred to as the direct free-hand method.
l'ercussion

Traces of its employment are found in nearly all parts of the habitable world. In its practice the stone to be shaped, necessarily small, was held in one hand, usually the left, and fractured by a hammer of suitable shape and hardness, hafted or unhafted, held in the other hand (fig. 144). It has the special adran- 
Advantagres of the Irocess

tage that the stone to be shaped can be readily and quickly adjusted to the strokes of the hammer, so that the strokes follow one another in rapid succession, and the work in skilled hands progresses with much celerity. The practice of this method has been observed among many tribes of the aborigines, and the refuse of the workshops where chipped

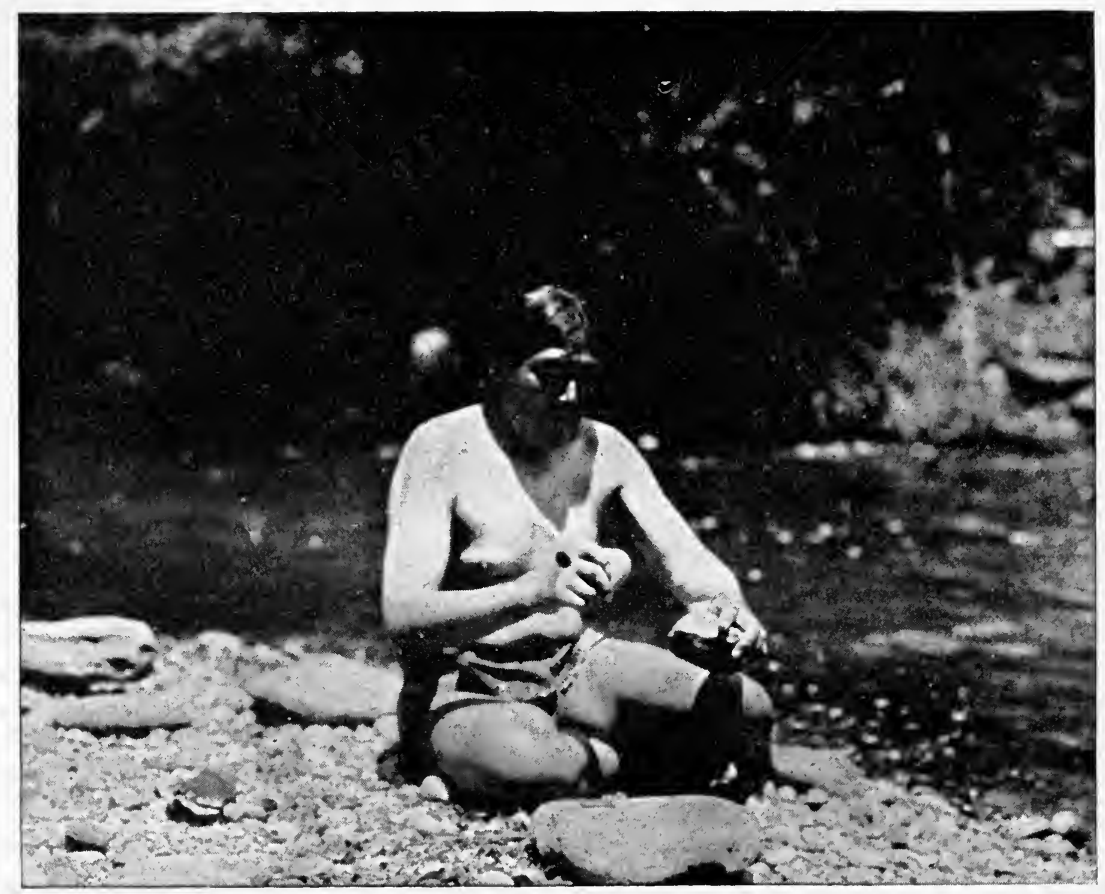

FIG. 145. Flint working by Ishi, a Yahi Indian of California. Nelson, in the Holmes Anniversary Volume, opp. p. 398.

implements were roughed out, especially those associated with the great quarries, afford ample opportunity for the study of the work in all its phases.

We are fortunate in having an example of the practice of this particular process by the Indians of to-day (fig. 145). 
Many kinds of implements were in their less highly specialized forms shaped by free-hand fracture without resort Implements Made to other methods. Among these are knives, scrapers, choppers, hammers, hoes, and picks; and the process was extensively employed, as already noted, in roughing out the forms of many of the smaller articles finished by pecking, grinding, sawing, and drilling, among which are mortars, pestles, mullers, axes, celts, chisels, pipes, ornaments, and diversional and ceremonial objects, as well as sculptures and stones for building.

The results of the writer's prolonged study of the shaping work as carried on by the ancient Potomac Valley tribes Shaping Work in along the bowlder-bearing bluffs of Piney Branch, the l'otomac Valley

D. C., will serve to give a reasonably clear conception of the work of shaping by free-hand fracture, not only where bowlders and pebbles were utilized but with all classes and conditions of materials. ${ }^{1}$ Shaping work in these quarries was almost exclusively fracture by free-hand percussion, the act being a quick, firm stroke with a bowlder hammer, regulated in force by the nature of the resistance to be overcome and by the result desired. Few traces of other kinds of procedure were observed. The bold, irregular style of the chipping precludes the idea that any process capable of accurately adjusting the point of contact between the tool used and the article shaped could have been employed, and rest fracture would hardly be adequate for the reason that in its operation fracture is almost as liable to occur at the rest point as at the point struck by the hammer. Again, it may be noted as decisive in this matter, that neither on Piney Branch nor any of the other great quarry shop sites are there adequate evidences of the use of the rest process, which necessarily leaves large numbers of anvil stones with surfaces scarred or pitted by the impact of the stones worked.

Referring to the Piney Branch quarry shops, it is observed that the process of manufacture and the steps of form development appear to have been about as follows: Crrasping a bowlder in either hand, the first movement was to strike the periphery of the one, which served as the hammer, against the periphery of the other, which was to be shaped, at the proper angle to detach a flake (figs. 144, 145, 146); the second movement and the third were similar, and so on until the circuit was completed. If no false strokes were made, and the stone had the right fracture, these few blows, occupying but as many seconds, gave as a result a typical "turtleThe Turtleback back" - a bowlder with one side faceted by artificial flaking, suggesting the back of the turtle; the 
other side, save through accident, remaining smooth, suggesting the under surface of the turtle (fig. 147, $a, b$ ). If the removal of a single circuit of flakes was not sufficient, the work was continued until the one side was reduced to the proper degree of flatness and the availability of the stone for further elaboration was made apparent. If the result thus far reached proved satisfactory, the stone was reversed in the hand and by a second series of blows the remaining

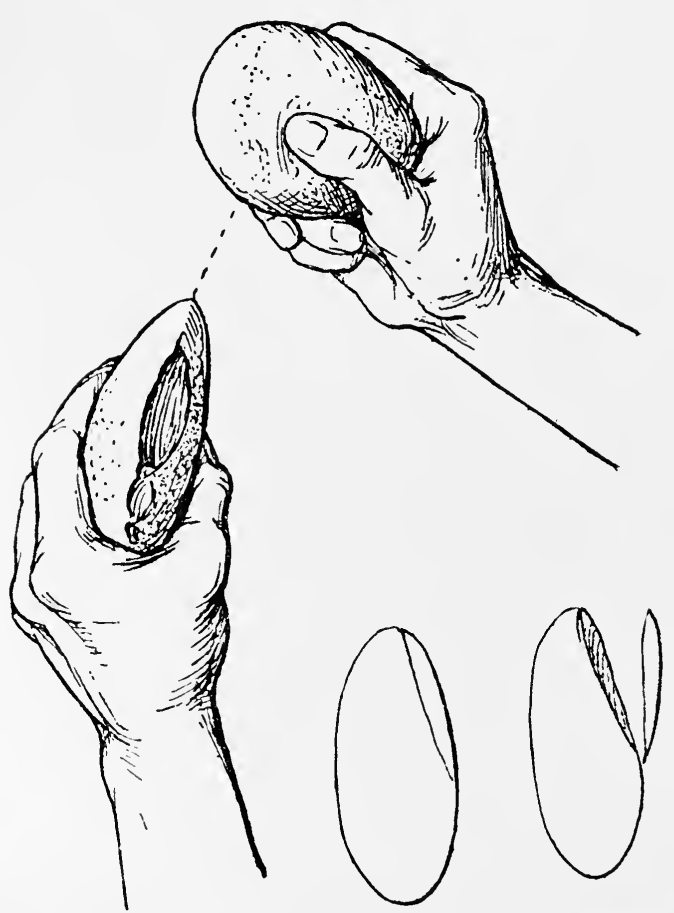

Fig. 146. The first step in the making of a thin blade. smooth side, the under" surface of the "turtle," was flaked away (fig. 148), the result being a double faceted stone (fig. 149). With perhaps a few additional strong strokes the stone assumed the ovate or ovate-lanceolate outline of the implement blank, the principal product of the quarry shops (fig. 150). If at any stage the stone developed serious defects, as too great thickness, crookedness, or humps (fig. 151), that could not be removed, it was thrown away and thus became part of the refuse, and it would appear that all the entire specimens collected included in the refuse, from the quarry shops, since they were included in the refuse, had dereloped some of these shortcomings. The development of too great thickness through failure of flakes to carry well across the specimen was the particular bete noire Causes of Failure of the worker of quartzite and other like tough materials. Another frequent cause of failure and rejectage was cross fracture or shattering under the blows of the hammer, and it is probable, judging by the vast number of transversely broken incipient blades, that one-fourth or more of the blades begun met this fate. Examples are shown in figure 152. These specimens must have been all but completed when the unlucky blow was delivered, for they are apparently more nearly complete than any whole blades left on the site. Many such, associated with the flakes produced in shaping them, were gathered from the Piney Branch shop clusters. 

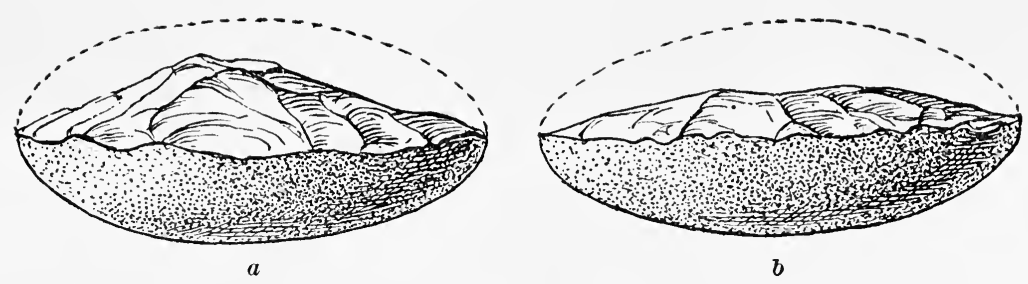

FIg. 147. $a$, One face chipped all around, but unsuccessful because not flat enough-a reject. b, Successful so far because flat enough to insure a thin blade, provided the other side chips equally flat.

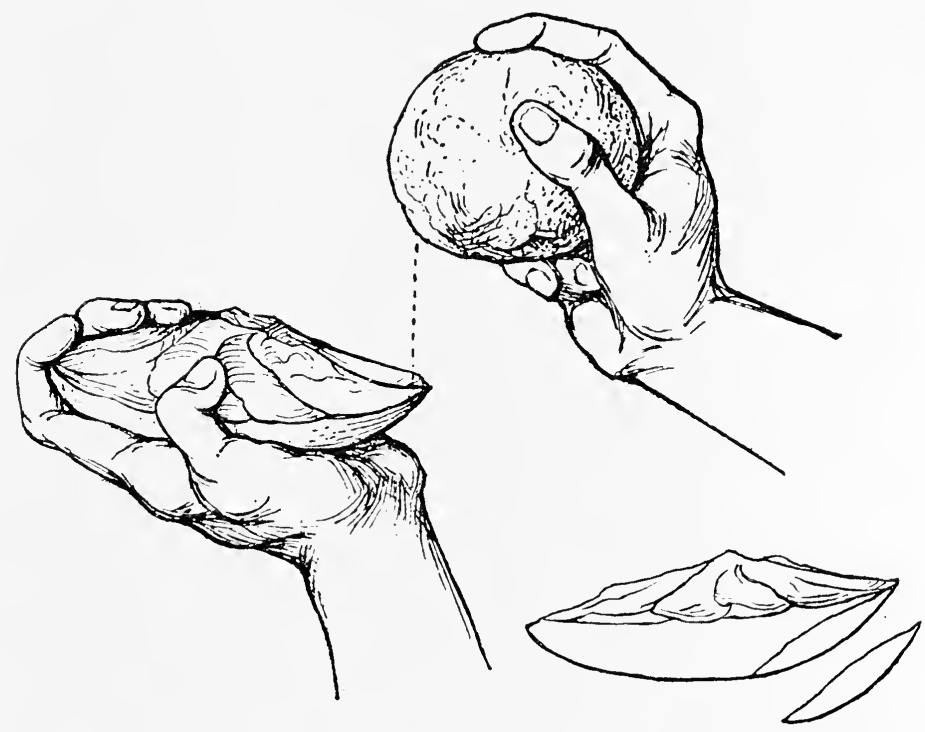

FIG. 148. Peginning of the chipping of the second side of the bowlder. A pad was generally used to protect the hand.
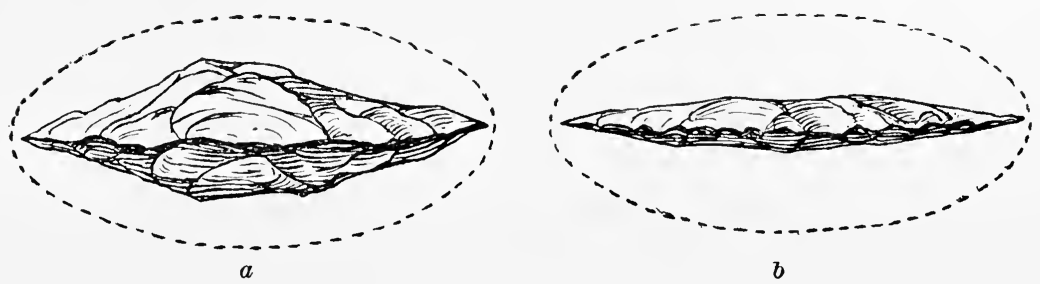

Frs. 149. a, Profile of a blade, unsuccessful because too thick. b, Profile of a blade, successful because thin enough to serve as a knifo or as the blank form for a projectile point. 


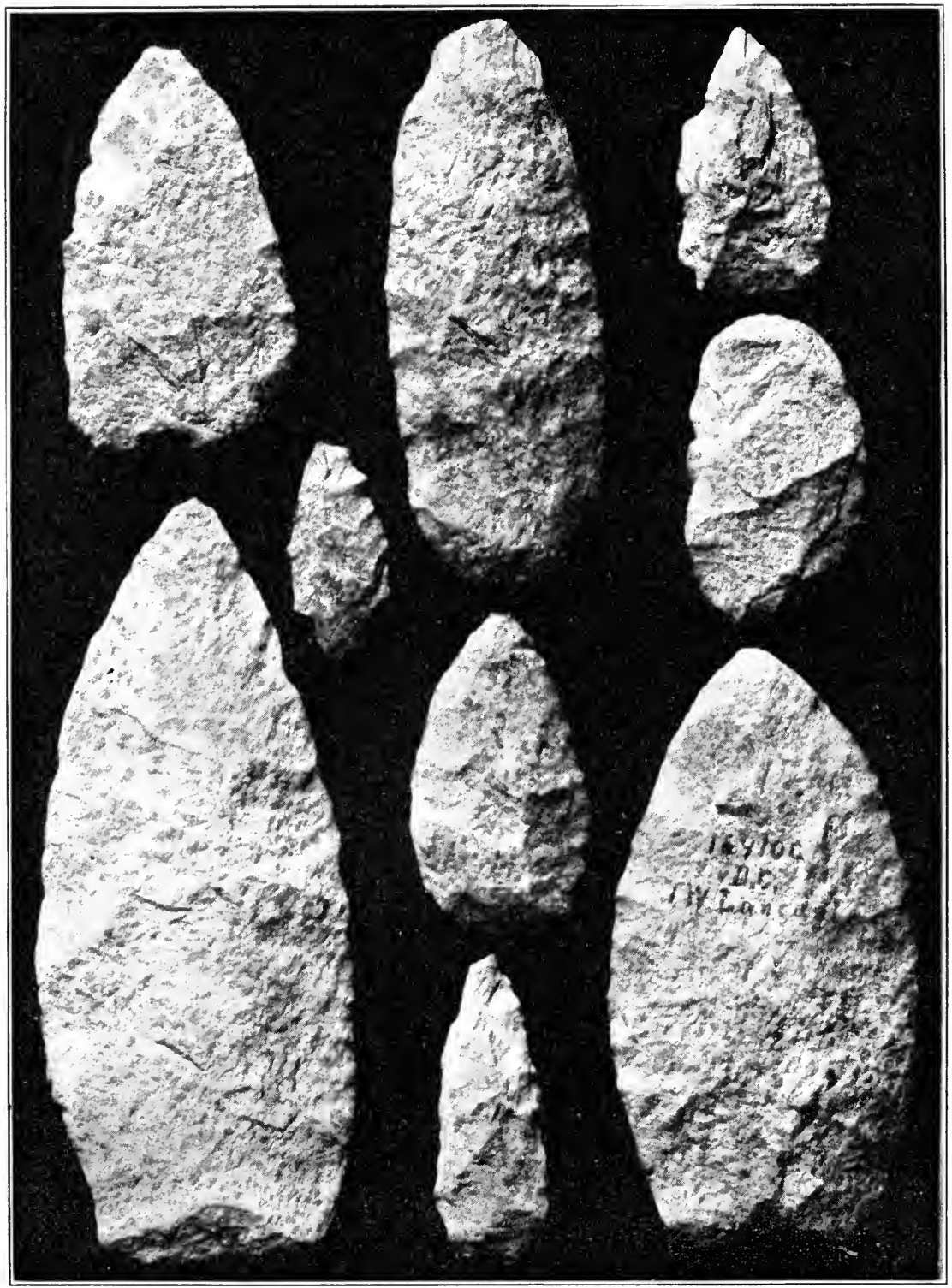

Fic. 150. 'Types of the blades, the blank forms of implements, produced in the quarries. 
A remarkable illustration of the vicissitudes of fracture was brought to light by Dr. Phillips while carrying on explorations
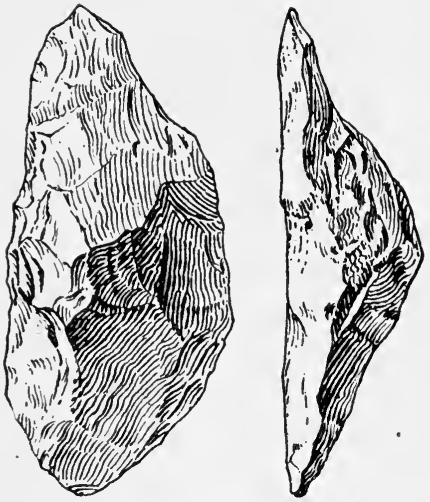

Fig. 151. Example of failure in blade making due to malformation.
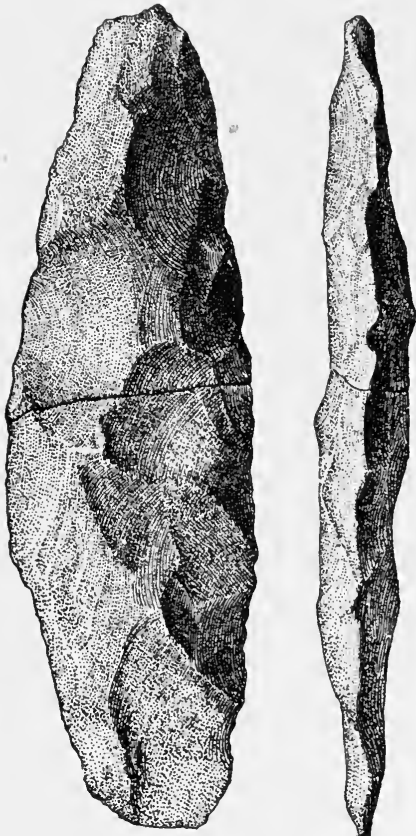

Fig. 152. Example of cross fracture under the hammer near the completion of a blade.

along the southwest shore of Lake Michigan. By patient search he collected, in addition to one-half of an incipient blade, upward of a

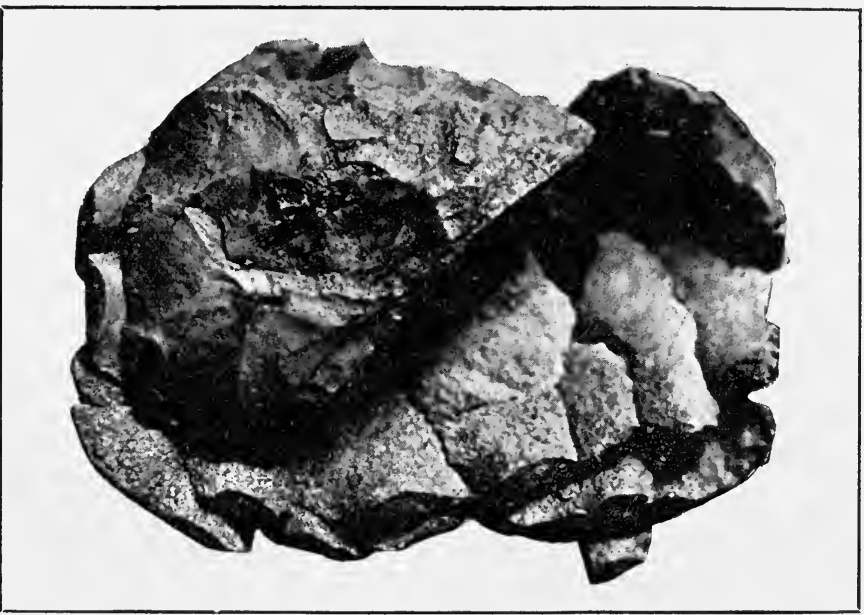

Fig. 153. Cross-fractured blade, one-half of which was found, and also a dozen of the flakes struck from it with the hammer. Flakes set back into place. Each flake represents a blow.

dozen of the flakes removed from it by the hammerstone before the fatal stroke occurred (fig. 153). 
It is important to observe that when the thin leaf-like blade was secured, the work of the quarry shop, the only work of the quarry

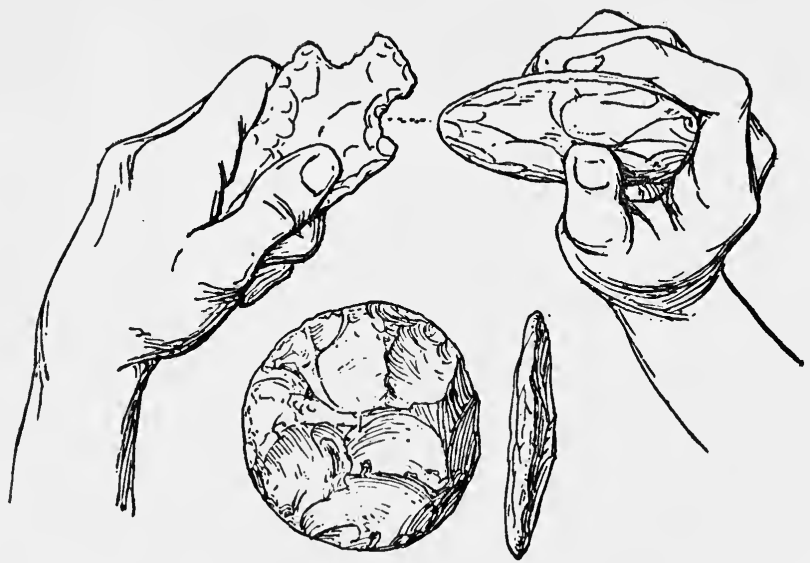

FIG. 154. Limited degree of specialization of the blades, possible by percussion with flat discoidal hammers.

shop so far as shaping is concerned, was ended. The process and the hammer had accomplished all that was asked of them.

It should be stated in this place that a limited degree of specialLimit of Special- ization is possible with
ization

the hammerstone, even with quartzite and like tough materials. It is possible with the aid of thin-edger? hammers to chip out shallow notches and to work out eccentric outlines. Experiment has shown that with the more brittle stones much more can be done. On the flint-shop sites of Georgia numerous thin discoidal hammers are found. These are made of the tougher portions of the flint and are so light that they could not have served for the roughing-out work, and must have been devoted to secondary flaking or to specialization work as shown in figure 154. Figure 155 illustrates a boldly shaped animal form found in Tennessee, the large size and great thickness of which precludes the idea that it could have been shaped by pres-

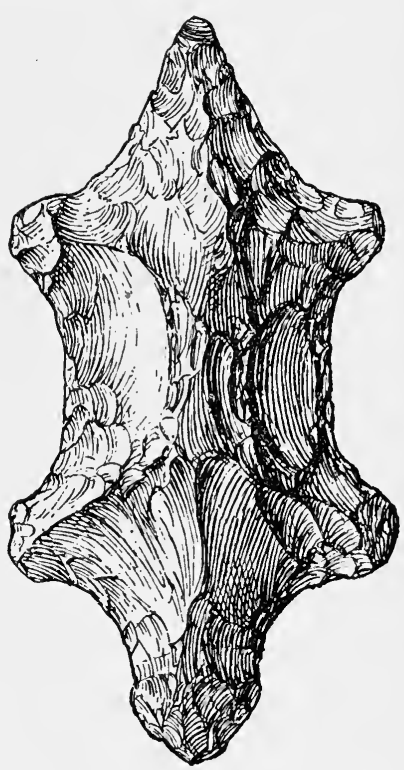

FIG. 155. Large, thick, animalshaped figure of flint, probably specialized exclusively with the hammerstone. sure. It was probably carried to completion as it now stands by the hammerstone and by the free-hand stroke rather than by any rest process. It may be possible that the curiously specialized blade 
shown in figure 156 could hare been produced by the hammerstone, but it is so attenuated that any severe or misplaced stroke would certainly have been disastrous. It may be assumed that in the shaping of such objects some pressure process was employed, at least in the final stages. Caleb Lyon, quoted in detail later, describes the making of small arrowheads by a California Indian, using the hammer alone. He does not make it clear, however, that the shape was specialized beyond the simple outline of the triangular or leaf-shape blade; this much was accomplished with the hammer by all makers of projectile points.

A most remarkable free-hand method of chipping stone by percussion is described by Catlin ${ }^{1}$ in a manner so circumIndirect Free-hand stantial that its practice by at least one of the $\Lambda$ pache
Percussion

tribes can hardly be questioned. The fragments or flakes employed in arrowhead making were obtained as usual by

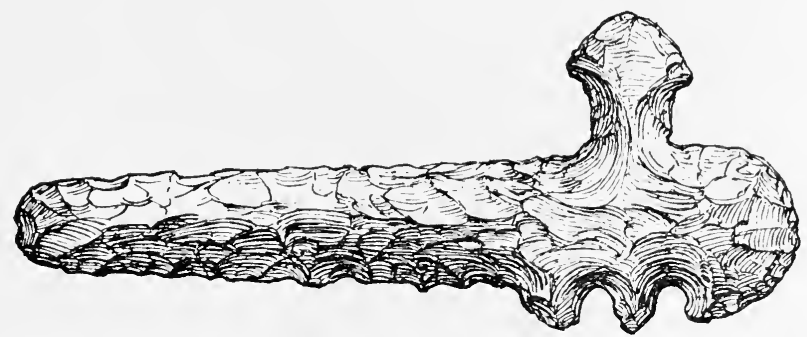

Fig. 156. Flint blade the specialization of which would exceed the capacity of the hammerstone.

direct percussion with the hammerstone. The elaboration of the implement forms is described as follows:

The master workman, seated on the ground, lays one of these flakes on the palm of his left hand, holding it firmly down with two or more fingers of the same hand [fig. 157], and with his right hand, between the thumb and two forefingers, places his chisel (or punch) on the point that is to be broken off, and a co-operator (a striker) sitting in front of him, with a mallet of very hard wood, strikes the chisel (or punch) on the upper end, flaking the flint oft on the under side, below each projecting point that is struck. The flint is then turned and chipped in the same manner from the opposite side, and so turned and chipped until the required shape and dimensions are obtained, all the fractures being mate on the palm of the hand. . . .

The vielding elasticity of the pam of the hand enables the chip to come off without breaking the body of the flint, which would be the case if they were broken on a hard substance. These people have no metallic instruments to work with, and the instrument (punch) which they use, I was told, was a piece of bone; but on examining it $I$ found it to be a substance much harder, mate of the tooth (incisor) of the sperm-whale or sea-lion, which are often stranded on the coast of the Pacific. This punch is alout 6 or 7 inches in length and 1 inch in diameter, with one rounded side and two plane sides; 
therefore presenting one acute and two obtuse angles, to suit the points to be broken. This operation is very curious, both the holder and the striker singing, ancl the strokes of the mallet given exactly in time with the music, with a sharp and rebounding blow, in which, the Indians tell us, is the great medicine (or mystery) of the operation.

According to B. B. Redding, the Wintoons of Cloud River, Oreg, employed a somewhat remarkable method (fig. 158) :

Holding the piece of obsidian in the hollow of the left hand, he placed between the first and second fingers of the same hand the split piece of deerhorn
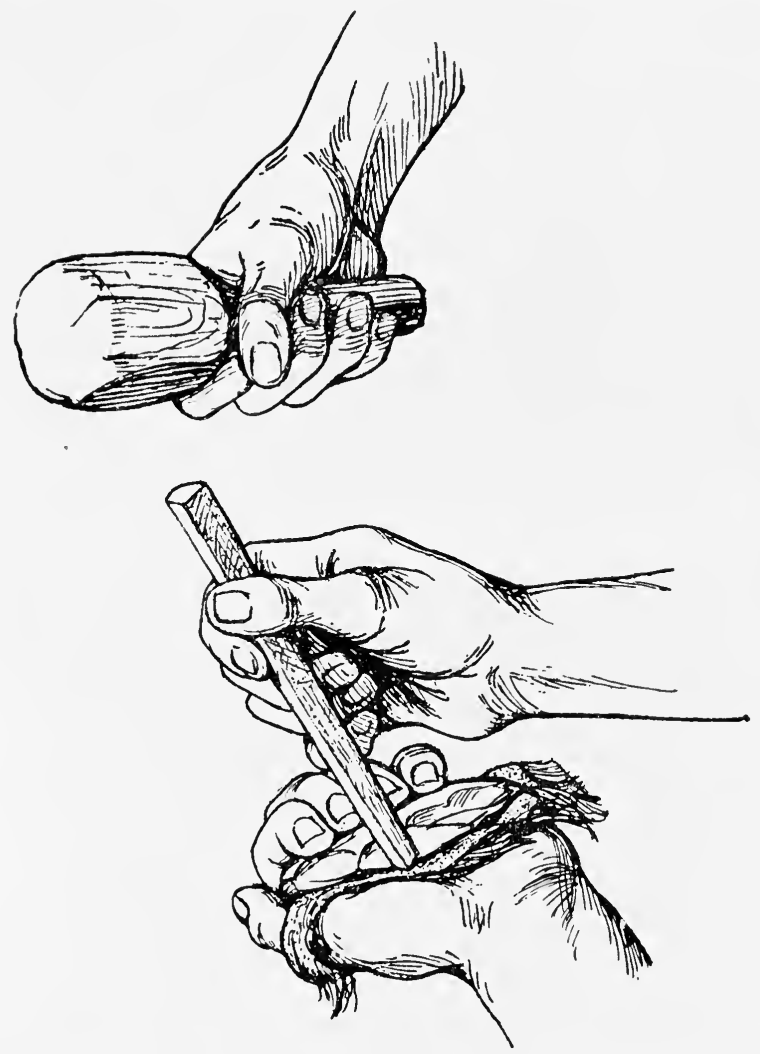

Fig. 157. Indirect percussion; three hands employed.

first described, the straight edge of the split deerhorn resting against about one-fourth of an inch of the edge of the obsidlian-this being about the thickness of the flake he desired to split off; then with a small round water-worn stone which he had selected, weighing perhaps a pound, he, with his right hand, struck the other end of the split deerhorn a sharp blow. The first attempt resulted in failure. A flake was split off, but the blow also shattered the flake at the same time into small framments. He then repeated the operation, apparently holding the split deerhorn more carefully and firmly against the edge of the large piece of obsidian. The next blow was successful. A perfect flake was obtained showing the conchoidal fracture peculiar to obsidian.

1 Redding, IIow Our Ancestors in the Stone Age Made Their Implements, p. G70. 
The work of specialization was then completed by well-known pressure processes.

The very primitive forms of stone craft resulted probably from the use of natural forms in the rude activities of

Direct Rest I'ercussion

primitive times. The stone used for crushing or breaking would be fractured, and the observation that the tool, thus modified, was improved for certain purposes would lead to intentional fracture with a definite purpose in view. But since the stone thus modified was held in the hand it is surmised that the first purposeful attempt at shaping by fracture would probably relate not to the stone struck, but to the stone held in the

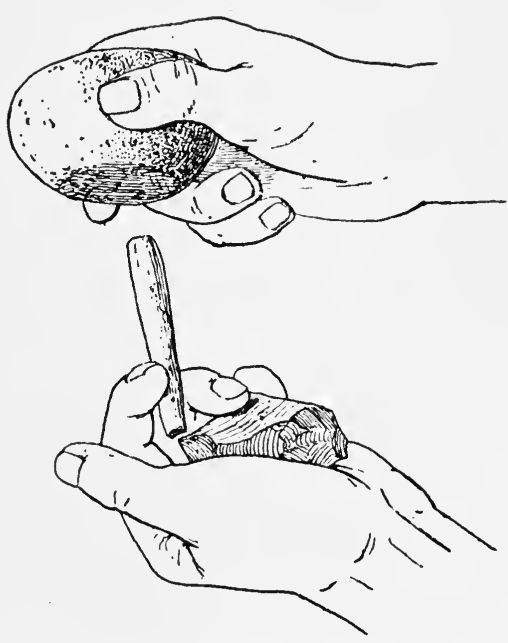

Fig. 15. Frec-hand fracture with hammor and deer-horn punch. (Red(ing.)

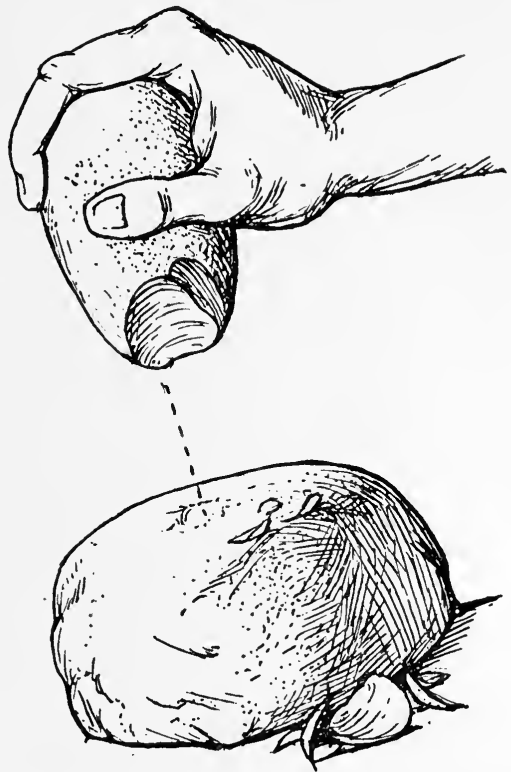

Fig. 159. Fracture of a stone held in the hand by striking it against an anvil stone.

hand, as indicated in figure 159. This form of fracture naturally occurs unintentionally during the practice of stone craft, whatsoever the period, but as a method of shaping its capacity is necessarily limited, and we may reasonably doubt its systematic, purposeful employment by any people.

A second and hardly less elementary form of rest percussion is the crushing or breaking of a stone at rest by striking it with another stone held in the hand or hands and cast as a missile (fig. 160), the purpose being to split or change the shape of the stone or to obtain fragments, splinters, and spalls which would serve as tools. 
This method could have little value in shaping minor artifacts, but must have been of great service at all stages of progress in breaking

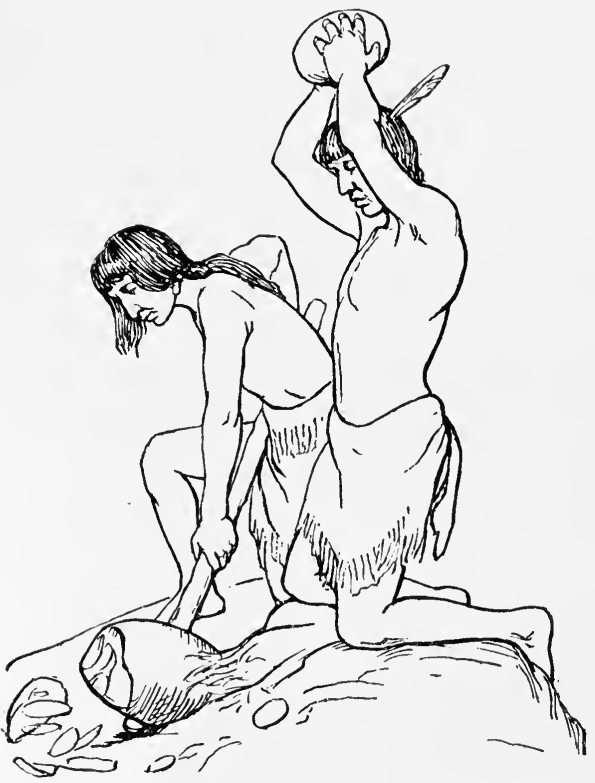

FIG. 160. Fracturing a large stone with a hammerstone cast as a missile.

up stone in the quarries and possibly in rough-shaping stone for building purposes.

Closely akin to the preceding is the use of one stone held in the hand as a hammer, hafted or unhafted, in fracturing another stone at rest, held or not held, to alter its shape or to remove fragments and flakes for use as implements or for the making of implements (fig. 161). This simple process has doubtless been employed by all primitive peoples, and its operation, we may assume, led upward, as skill and intelligence increased, to the development of other and more refined processes of working stone.

Many of the accounts given by casual observers of the use of the hammerstone in implement making by the aborigines are meager

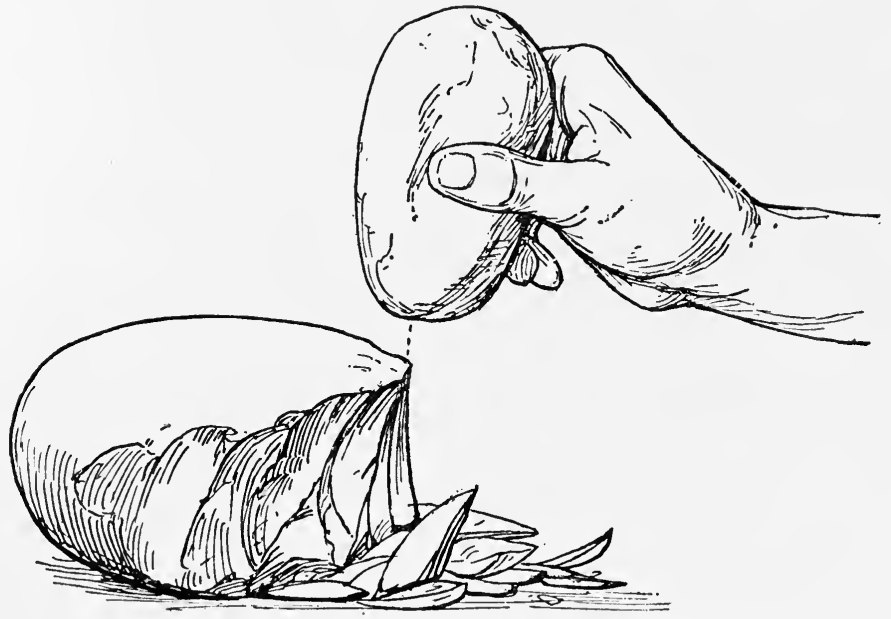

FIG. 161. Use of a hammerstone in making flakes.

and imperfect, and allowance must be made for mistakes and misinterpretations. In some cases it is difficult to determine from the 
descriptions just how the stone under treatment was held. Caleb Lyon some 70 years ago witnessed the making of an obsidian arrowhead by a skilled workman of the Shasta tribe of California. His reference to the work is as follows:

The Shasta Inclian seated himself on the floor, and, placing the stone anvil upon his knee, which was of compact talcose slate, with one blow of his agate chisel he separated the obsidlian pebble into two parts, then giving another blow to the fractured side he split off a slab a fourth of an inch in thickness. Holling the piece against the anvil with the thumb and finger of his left hand, he commenced a series of continuous blows, every one of which chipped off fragments of the brittle substance. It gradually assumed the required shape. After finishing the base of the arrowhead (the whole being only a little over an inch in length), he began striking gentler blows, every one of which I expected would break it into pieces. Yet such was their adroit application, his skill and dexterity, that in little over an hour he proluced a perfect

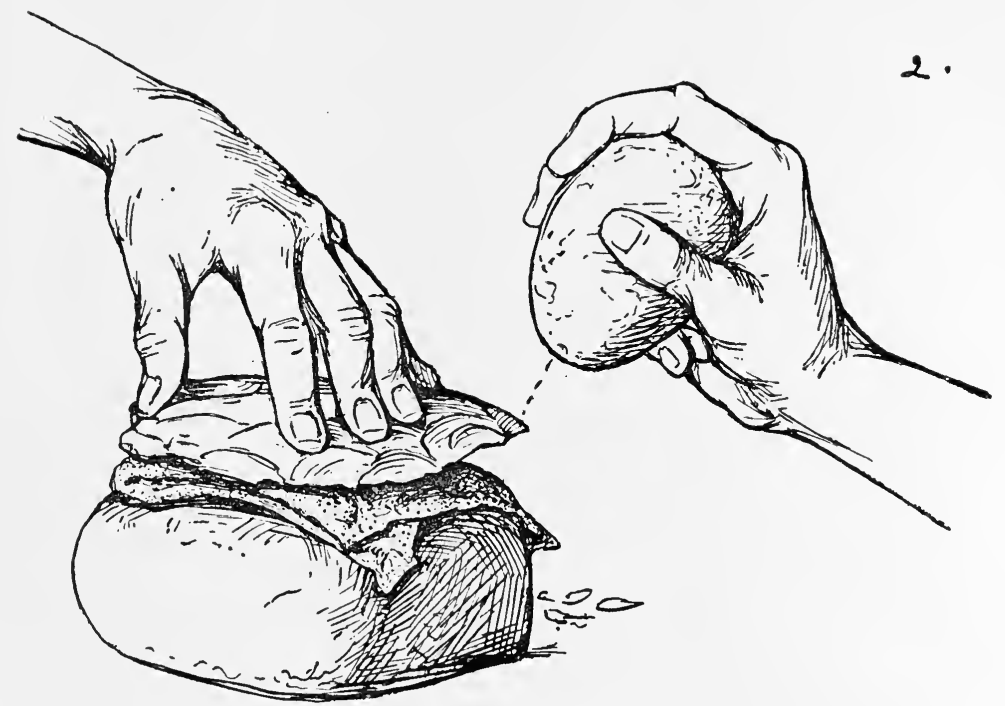

Fig. 162. Shaping a blade at rest by fracture with a hammerstone.

obsiclian arrowhead. I then requested hin to carve me one from the remains of a broken port bottle, which (after two failures) he succeeded in doing. He gave as a reason for his ill success, he did not understand the grain of the grass. No sculptor ever handled a chisel with groater precision, or more carefully measured the weight and effect of every blow, than this ingenious Intian; for, even among them, arrow making is a distinct tratle or profession, which many attempt, but in which few attain excellence. He understood the capacity of the material he wrousht, and, before striking the first blow, by surveying the pebble, he could judge of its availability as well as the sculptor judges of the perfection of a block o1 Parian. ${ }^{1}$

Variants of this rest method are recorded by a number of authors. Snyder witnessed the work as done by a Digger Indian. Holding a quartz splinter flatwise on a smooth bowlder anvil stone with his left hand (fig. 162) he gently tapped the stone first on one edge, then 
on the other, striking off a tiny chip at each stroke until he soon had it reduced approximately to the dimensions required. The work of specialization was completed by pressure with a bone point. ${ }^{1}$

$\Lambda$ fourth form of fracture by rest percussion is that in which the pebble or fragment of stone or partially shaped implement was set edgewise on the anvil stone, where it was held in place by the finger's and thumb while struck edge on with the hammer. The capabilities of this method in the shaping work, however, are found to be limited. It served to split or splinter the stone or to break off spalls and flakes (fig. 163), which served unmodified as implements or for

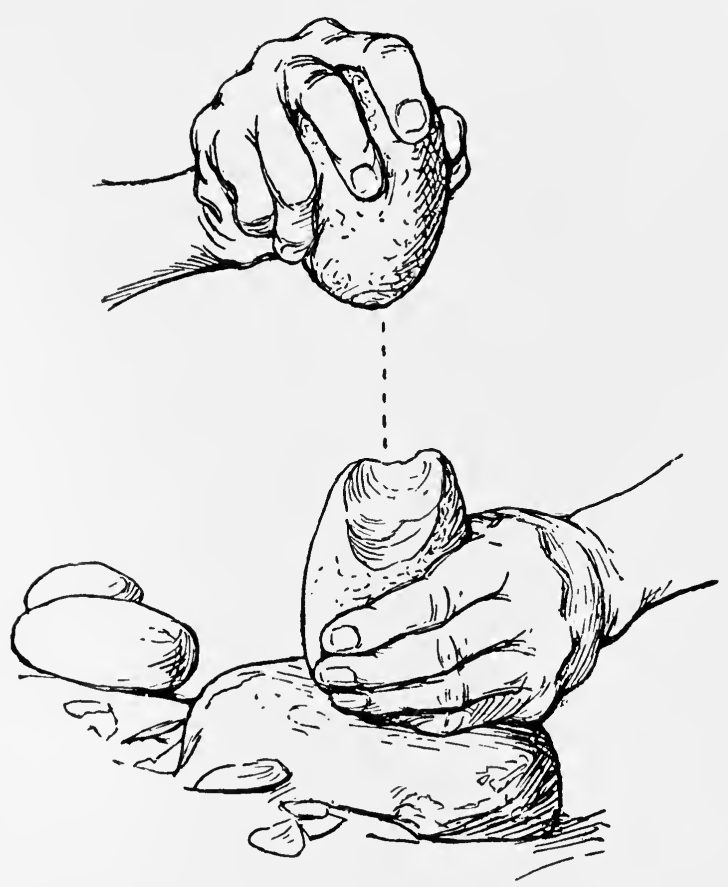

Fig. 163. Chipping a stone held at rest by strokes of a hammerstone. elaboration by more refined processes. The stone thus operated upon assumed fortuitously various shapes readily mistaken by the inexperienced for purposeful forms. The hammer used was any stone suited to the purpose. The method was employed rery extensively along the Atlantic shore of Argentina, where it was regarded by Ameghino as pertaining to a very primitive stage of culture, and the chipped nuclei, regarded as imple. ments, were assigned by him to Tertiary or early Quaternary times. Howerer, the conclusion reached by the writer, based on collections and observations made by Irdlička and Willis along the Pampean coast, is that the work probably pertains to recent times and to the historic tribes. ${ }^{2}$ Examples of the Argentina specimens are presented in figure 164, and the associated hammerstones and anvils displaying their peculiar markings appear in figures 165 and 166 . This process, even in its most refined application, had one serious defect-it was almost as likely when the stone was brittle to result in fracture at the point of con-

\footnotetext{
${ }^{1}$ Snyder, The Method of Making Stone Arrow-points, p. 231.

${ }^{2}$ See IIrdlička, Early Man in South America.
} 

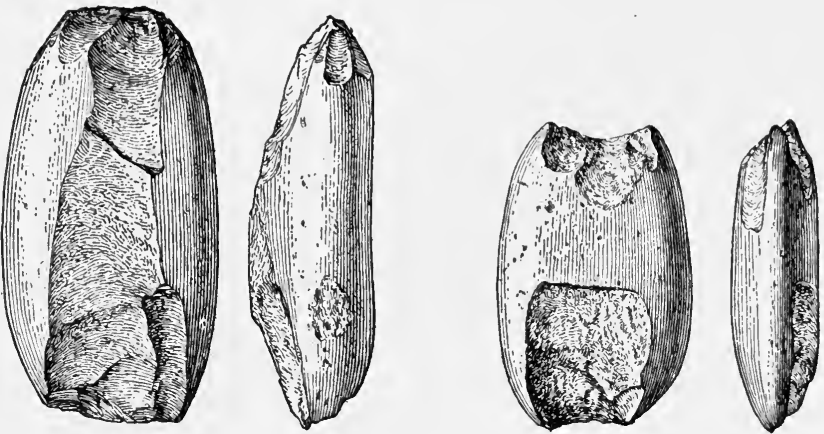

Fig. 164. Pebble from which flakes have been removed by strokes of the hammer.
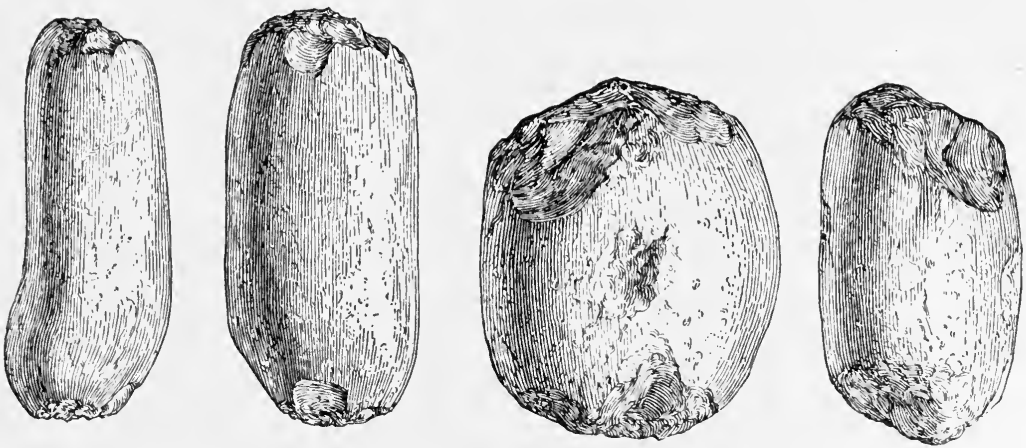

FIG. 165. IIammerstones used also as anvils, as indicated by the scarring.
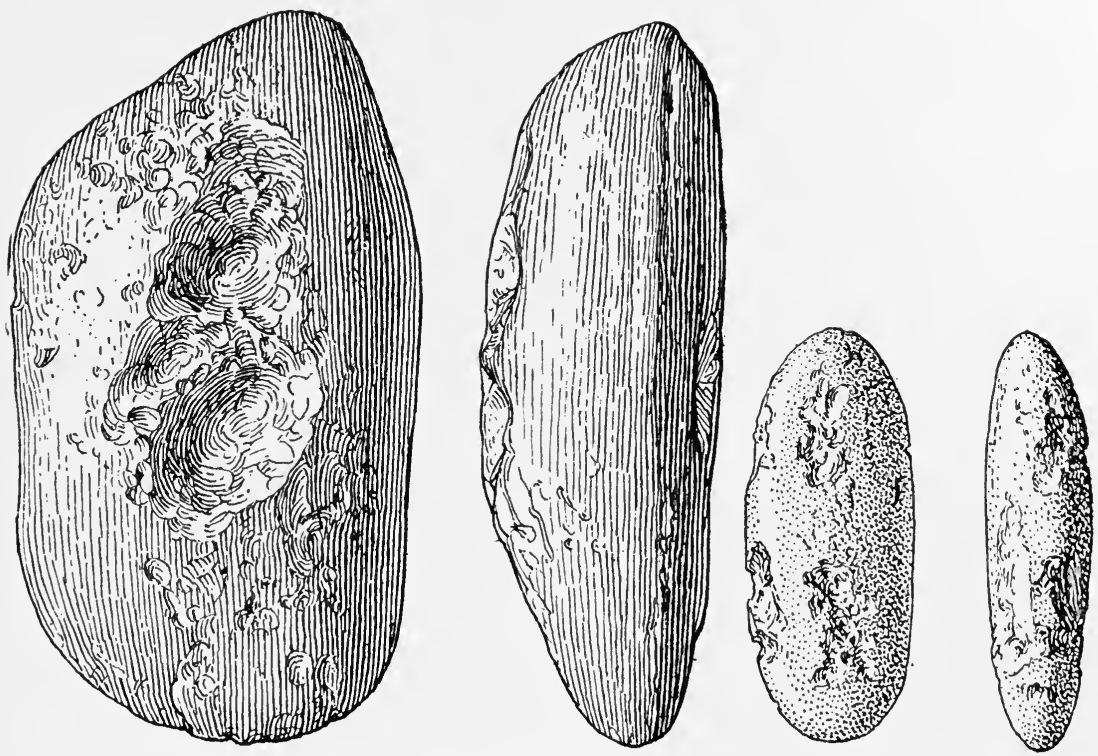

Fig. 166. Hammerstones used also as anvils, as indicated by the scarring. 
tact with the anvil as at the point struck by the hammer. To carry ont any designed specialization except of the simplest kind seems to the writer hardly possible. The most familiar employment of this method of fracture in the United States was in making the so-called "teshoas" of Leidy ${ }^{1}$ (fig. 167), which is a sharp-edged discoidal flake made with a single blow of the hammer upon the convex surface of a bowlder, which may be, when a bowlder hammer is used, either the one held in the hand or the one struck.

A number of obIndirect Rest servers Pereussion have recorded the use of a hammer and punch by the American tribes in flint chipping. An illustration of the free-hand use of these tools is given in figure 158. As employed in the rest method, the bit of stone was held in a
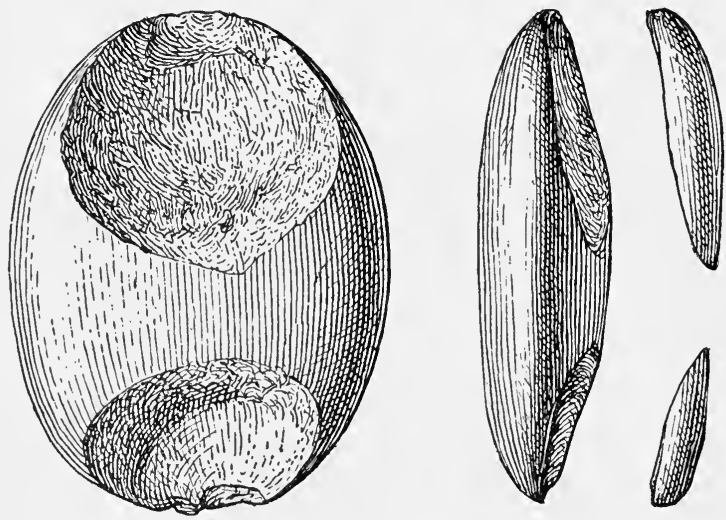

Fig. 167. Flakes made from water-worn bowlders by a single stroke of the hammerstone; used as scrapers, knives, ete., and for the making of various small implements. The name "teshoas" is from the Shoshone language and was given by Dr. Joseph Leidy.

fixed position, as under the knee or in a clamp, and the punch, made of stone, hard bone, or antler, was set upon it at the precise point required to remove a flake of desired thickness, and the opposite end was tapped with a mallet or hammer. Cushing illustrates this

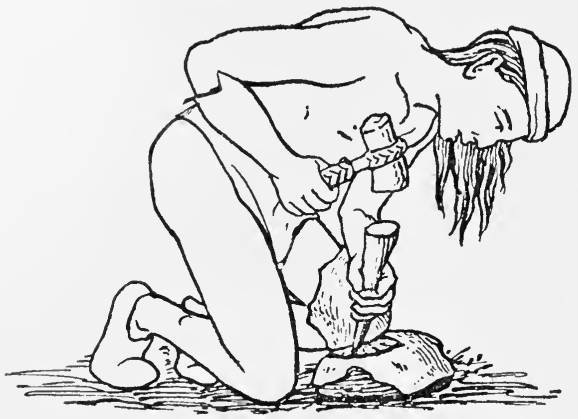

Fig. 168. Rest fracture with hammer and punch. (Cushing.)

work in his paper on the arrow (fig. 168), an extract from which is quoted later. This process is identical with that practiced by civilized peoples, the metal chisel taking the place of the stone or bone fracturing tool.

Another variety of percussive work, accounts of which are not as specific as could be desired, has been noted by a number of observers. The thin edge of the fragment or flake, or the blank form to be further specialized, is laid flatwise on the anvil stone at a suitable angle (fig. 169) and tapped from above with a hammer, minute flakes being thus thrown upward along the margin.

\footnotetext{
${ }^{1}$ Leidy, On Remains of Primitive Art in the Bridger Basin of Southern Wyoming.
} 
This method is capable of trimming the edges of flakes or of blades already well advanced, but apparently is incapable of specialization

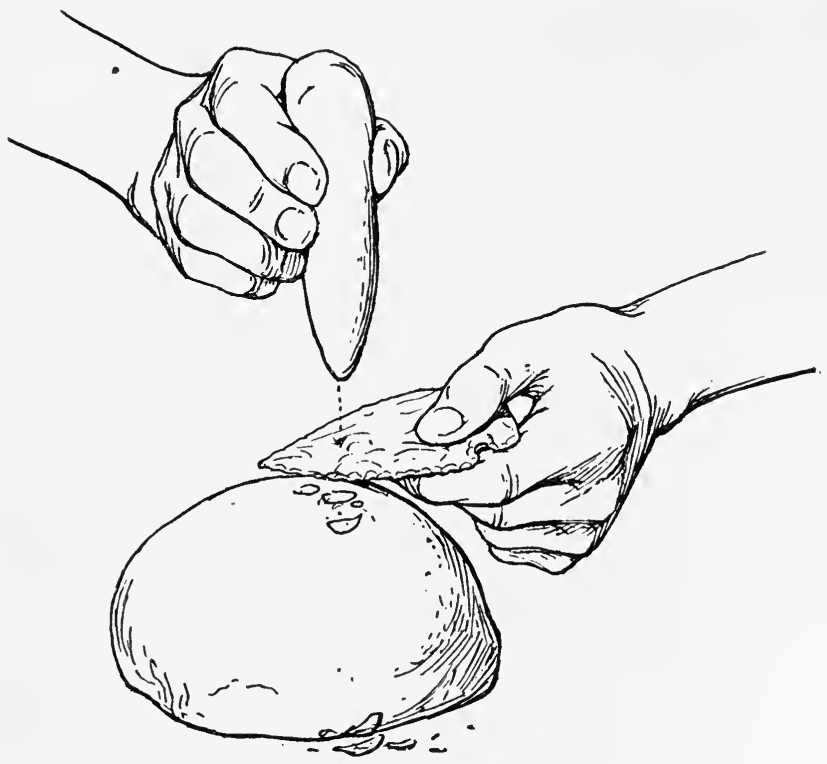

F1G. 169. Fracture by resting a blade upon an anvil and tapping it from above with a hammer.

of any other kind, unless, indeed, a sharp-edged rest is employed as shown in figure 170. By this method it is possible by reversing the

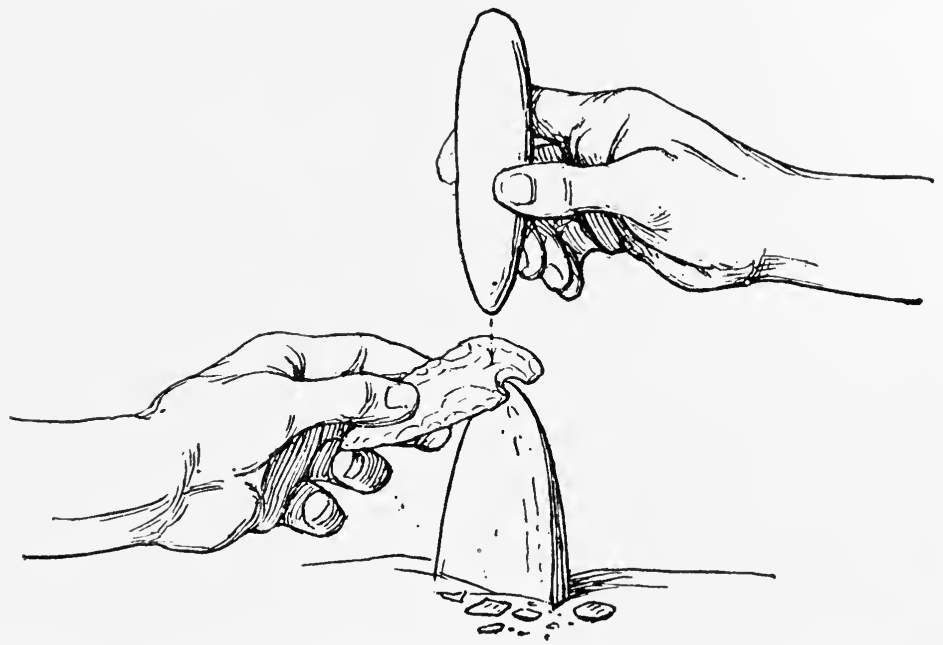

F'1G. 170. Notching a blade by resting it on a sharp-edged anvil and tapping it with a hammer.

piece to be chipped from time to time to chip out notches of considerable depth. 


\section{PRESSURE FRACTURE PROCESSES}

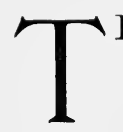

HE statement that stone is susceptible of fracture by pressure and may even be elaborately shaped by pressure processes is usually received with decided incredulity by the uninitiated, and that the work can be done by means of bone tools is still further beyond the limits of ready belief. But primitive man devised numerous methods which enabled him, with the aid of bits of horn, bone, antler, or ivory, to carry the manufacture of objects of brittle stone by means of pressure fracture to a degree of refinement not readily attainable by any other known means. Pressure shaping is limited, however, in its capabilities, since it can be operated successfully only where brittle stone is utilized, and even then with slight success, except with comparatively small objects. The several varieties of pressure processes have been tested in recent years by numerous students, in many cases with marked success. Some have imagined themselves the discoverers of entirely new methods or the rediscoverers of methods practiced in ancient times and now classed among the lost arts. But examination of the literature of pioneer days and the reports of observers who have come into familiar contact with primitive peoples, disclose the fact that most of the now known processes were practiced by the tribes in various parts of America up to the time of the introduction of iron and steel. This is amply shown by the numerous citations brought together in subsequent pages. It may be added that probably a majority of the methods are still practiced by remote tribes in different parts of the world.

Two varieties of the pressure-shaping arts are recognized-the free-hand and the rest processes. These processes are, for the most part, not specifically distinct, since the implement used, so far as its operating point is concerned, is practically the same in all forms of the work, the distinction being due to differences in the mounting and application of the point. In the rest method the fixed position of the stone worked permits of the application of greater force than the free-hand method, while the haft of the implement may be so lengthened as to be set against the chest or under the arm of the operator, thus greatly increasing the fracturing power.

The following brief summary of the several kinds of pressure shaping work will be convenient for reference for those who may not desire to take up the subject in greater detail. 
FREE-IIAND PRESSURE PROCESSES

(a) Chipping thin-edged bits of stone held in one hand by abrupt pressure with a bone tool held in the other hand, thus specializing an implement.

(b) Chipping thin-edged bits of stone held in one hand with a pincerlike or" a notched bone tool held in the other hand and moved with an "impulsive twist," thus specializing an implement.

\section{REST PRESSURE PROCESSES}

(a) Chipping thin-edged bits of stone held in a fixed position by pressure with a bone tool held in the hand, thus specializing an implement.

(b) Chipping thin-edged bits of stone held in a fixed position by pressure with a pincerlike or a notched tool held in the hand, thus specializing an implement.

(c) Chipping thin-edged bits of stone held in a fixed position by pressure with a bonepointed implement mounted in a long shaft, which is set under the arm of the operator to increase the pressure, thus shaping an implement.

(d) Flaking brittle stone held on a rigid surface or otherwise fixed by pressing off flakes with a bonepointed implement mounted in a long shaft, which is set against the chest $\mathrm{or}^{\circ}$

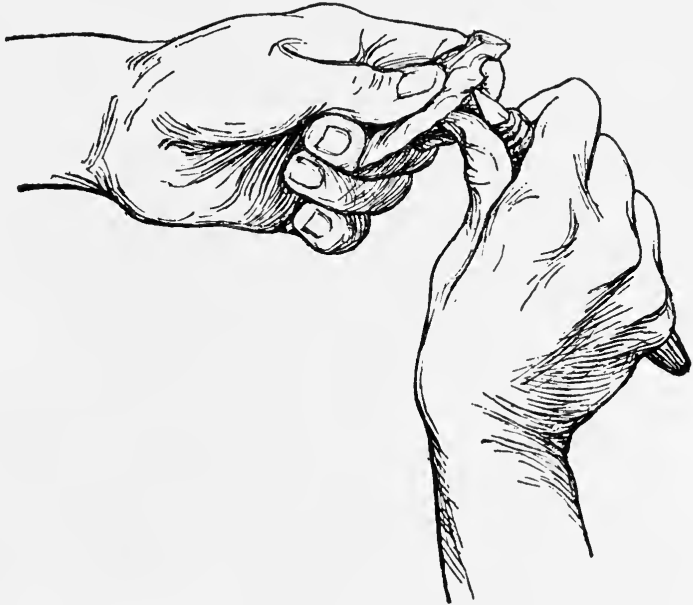

FIG. 171. Fres-hand pressure chipping with a bone point.

shoulder of the operator to increase the pressure, thus producing flake knife blades.

(e) Chipping thin-edged bits of stone by pressing the edge against a sharp-edged bone or other like object at rest, thus specializing an implement.

Free-hand pressure, next to free-hand percussion, is the most important and generally useful of the primitive imFree-hand Pressure plement making fracture processes. It is adapted to the shaping of small objects of brittle stone, and particularly to the specialization and finish of projectile points, knives, drills, scrapers, and the like. The piece of stone shaped, always thinedged, was usually held between the end of the thumb and the tips of two or three fingers of the left hand, as indicated in figure 171, or 
grasped by the finger tips of the left hand against the thumb or the ball of the thumb of that hand, as illustrated in figure 172. In the latter method the hand was always protected from injury by a pad of buckskin or other like device.

Typical examples of the chipping tools are shown in figure 173 and the relation of the bone point to the implement edge operated on in figure 174. The point of the tool was set against the margin of the stone, as here shown, and the chips were forced off by a spasmodic push. It appears that when the point of the tool was rounded, the push was sometimes accompanied by a slight rocking motion. In skilled hands the bone point was quickly moved to the proper point on the margin of the stone for the next flake, and so on until the shaping was complete. The positions illustrated in most of the

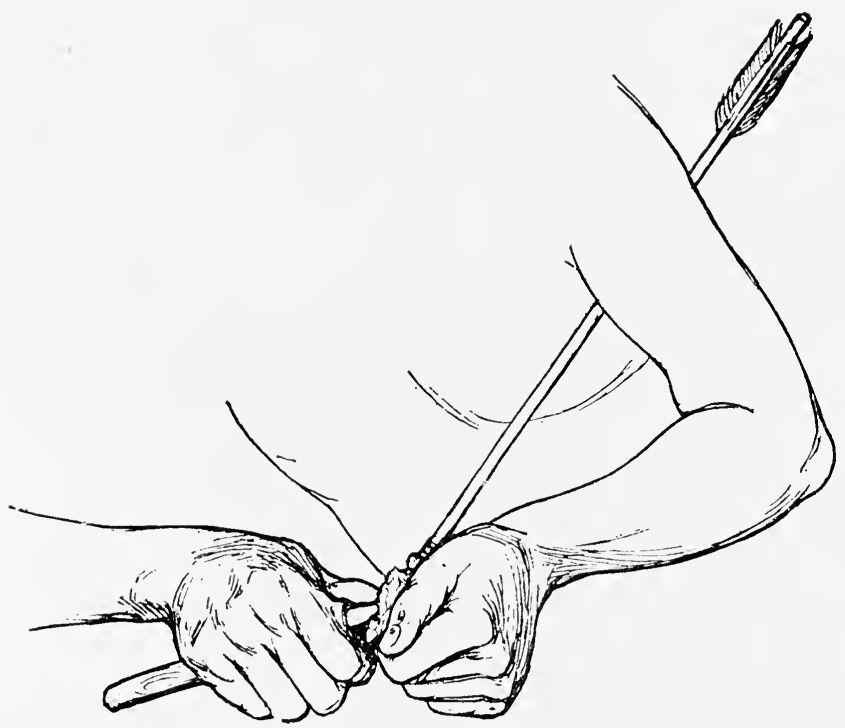

Fig. 172. Sharpening an arrow point by chipping with a bone point.

accompanying drawings are those taken by the writer in demonstrating the various methods recorded by observers of the aboriginal work.

It was the good fortune of Maj. J. W. Powell to witness the operation of this and other processes of shaping stone, as employed among a number of tribes in the Colorado Valley, and his photograph (made by Hillers) of an aged Paiute man demonstrating the manner of holding the chipping implement and the blade under treatment is probably the only record of its kind in existence. This photograph is reproduced in figure 175 , and an enlarged drawing of the 

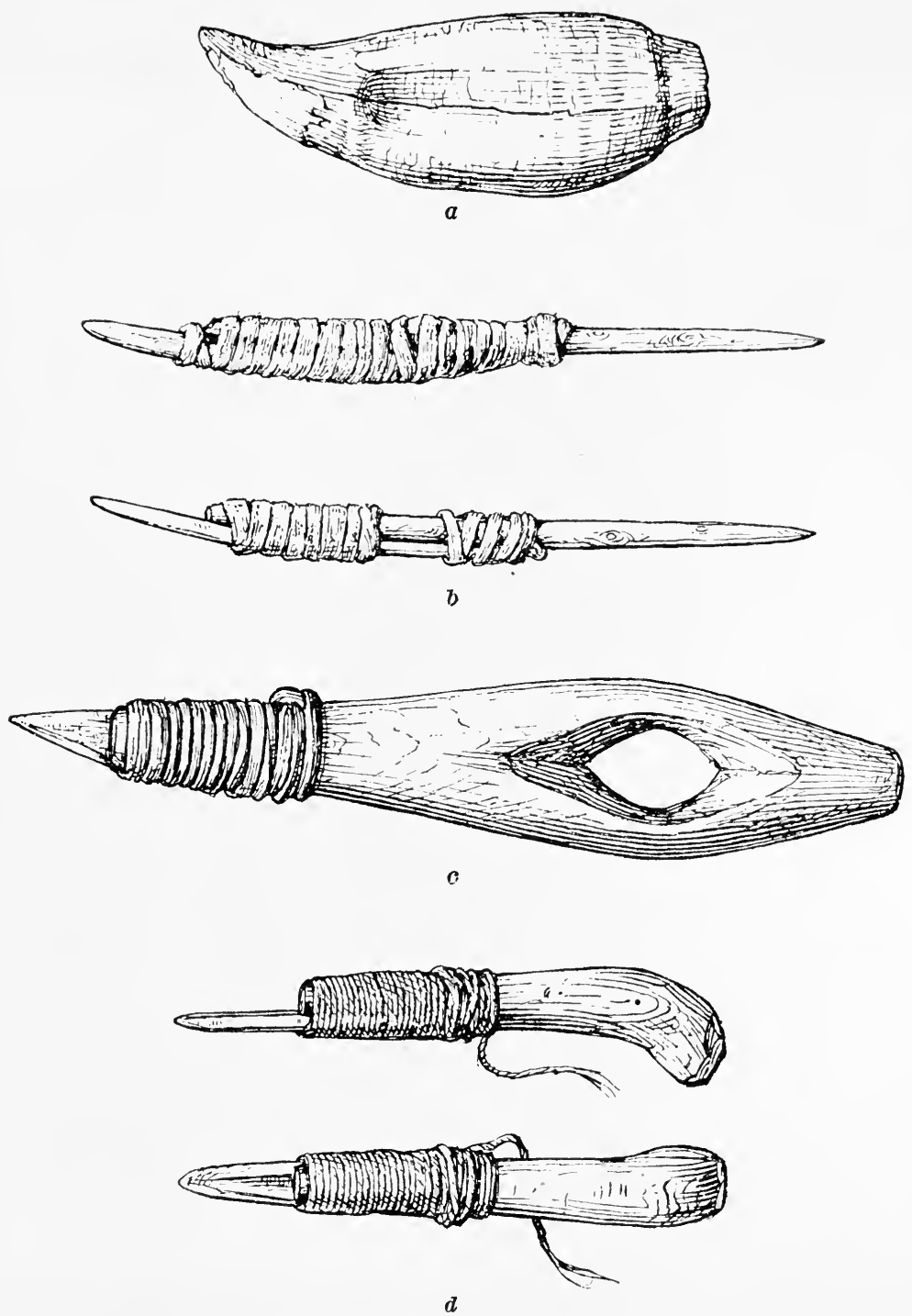

FiG. 173. Examples of pressure chipping tools. 

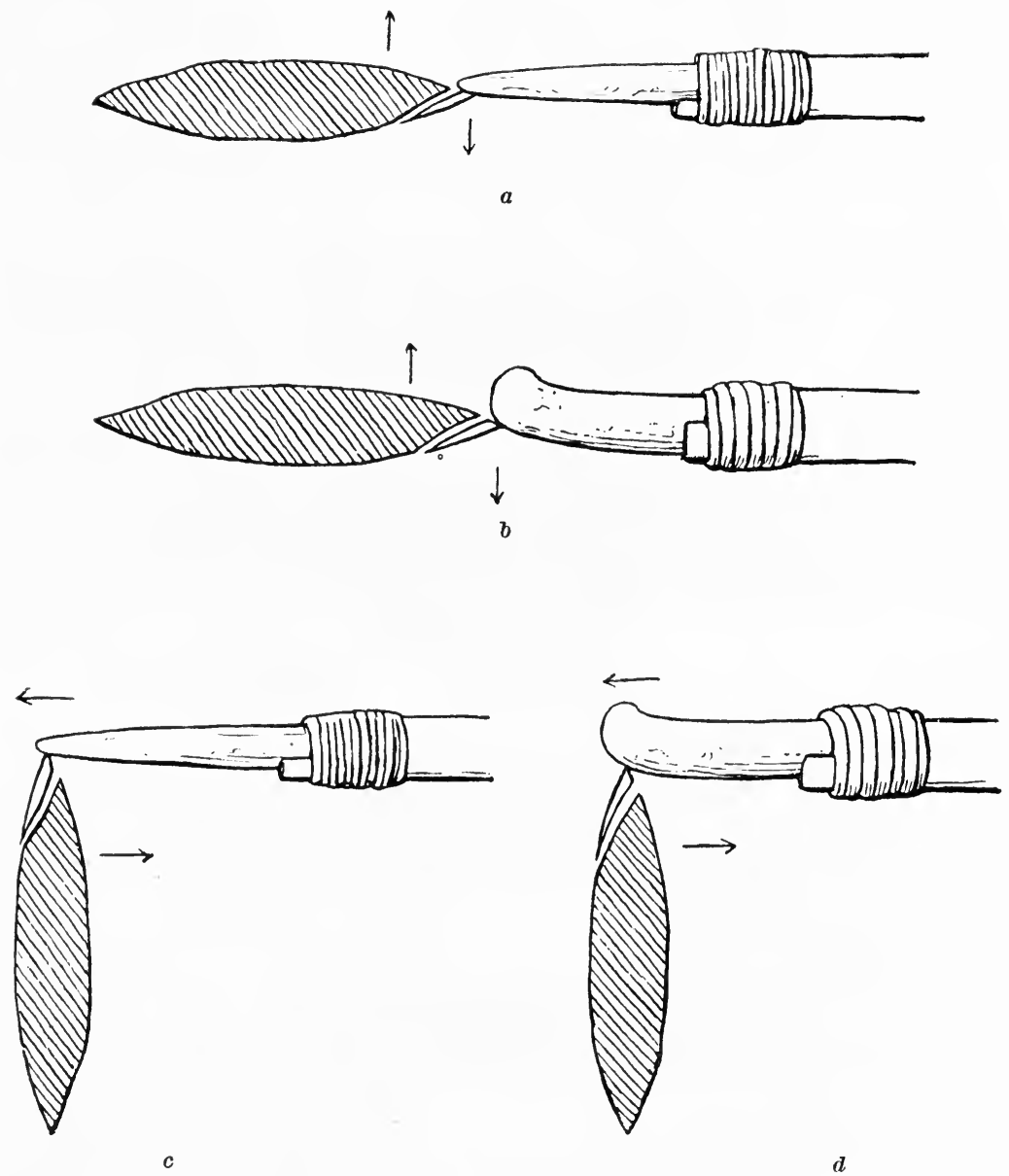

FIG. 174. Positious and movements in pressure chipping. 


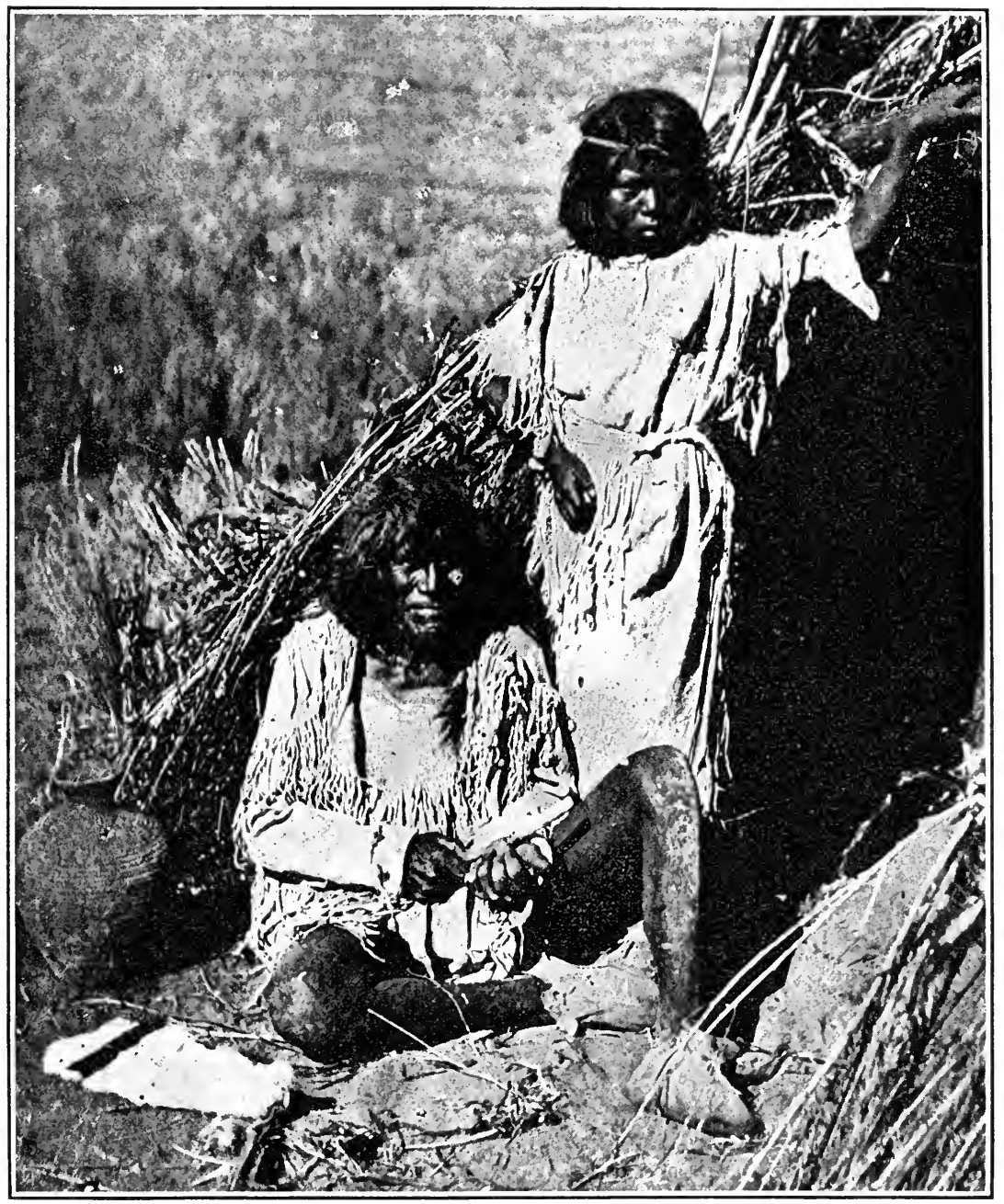

Fig. 175. I'aiute Indian chipping a knife blade with a bone point. (Powell.) 
hands, showing the position of the implements, appears in figure 176 . The flaker held in the right hand is a bone point of usual type, and the implement held in the left is the blade of a hafted flint knife of the kind still in use at that time among the canyon tribes.

Major Powell's reference to the arrow maker's demonstration of the process is as follows:

In a little valley north of the Uinta Mountains a tribe of Shoshoni Indians were found still manufacturing stone arrowheads, stone knives, and [Powell's Account] stone spears. Although a few of them were armed with guns purchased at far-distant trading stores, a greater number of the men and boys were armed with bows and arrows. In the valley which they occupied chalcedony is found in the form popularly called moss-agate. In 1S69 the writer often saw these Inclians manufacturing stone arrow[Shoshoni Arrow Makers]

heads and stone knives. These were made from masses of moss-agate weathering out of the sandy shales of the district. The implements were made by breaking the masses with rucle stone hammers, and selecting favorably shaped fragments to be further fashioned by the use of

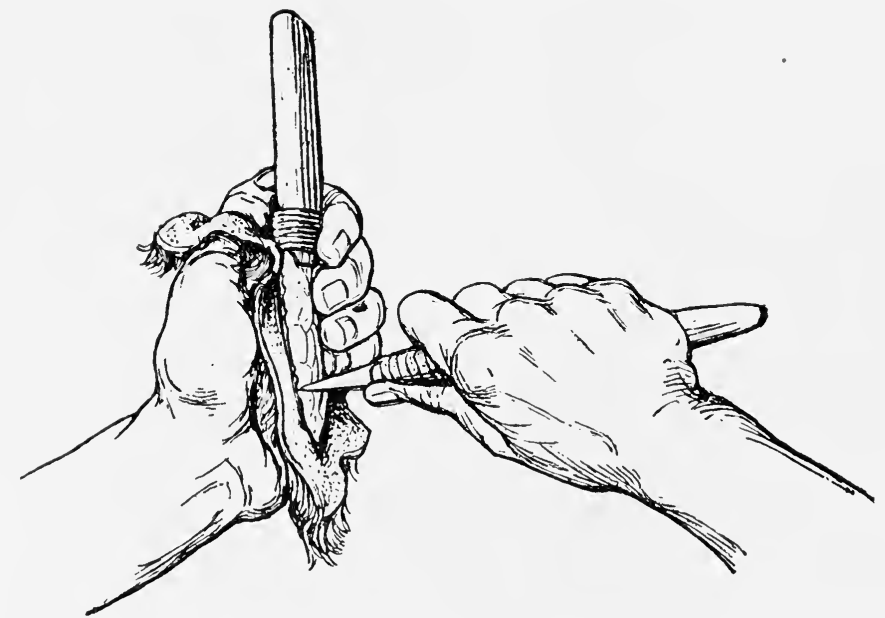

FIg. 176. Relative position of the implements in the hands of the Paiute Indian, figure 175 .

little stone hammers. A fragment held in one hand, protected by a piece of untanned elk skin, was wrought with a hammer held in the other hand. Having somewhat improved the original fragment in this manner, a workman would proceer to give his implement the final shape by using a leerhorn tool from 8 to 12 inches in length and worked down from its original size by grincling, so that its diameter was about five-eighths of an inch. Holding the specinen in one hand, with the implement in the other, he would work the little stone into the desired shape by sudden pressure on its edge with the horn tool and in this manner breaking off small flakes. The arrowheads thus made were small, slender, ancl symmetric, while the stone knives were given keen but somewhat serrated edges. I visited this tribe of Indians many times and lived among them many months and found their camps strewn with the chips, among which were many discarded failures, all having the characteristics of those finds which in the eastern portion of the United States had been called "paleolithic." 1 
Major Powell found the Pahvant tribe of the Wasatch Mountains making stone arrowheads and knives by the proc[Pahvant Arrow Makers] esses of fracturing, pecking, and grinding; the Uintahs employed chipping and grinding, and in the Major's words-

At other times, again and again, for years, I saw the Pagu Indians manufacture stone implements in the Valley of San Iafael, a

[ P a g u $\wedge \mathrm{rrow}$ tributary of the Coloralo flowing from the eastern slope of Makers]

the Wasatch Plateau. These people matle their implements by chipping. A mile above the mouth of the river, in a cottonwood grove, there is a village site which has been occupied intermittently for many years
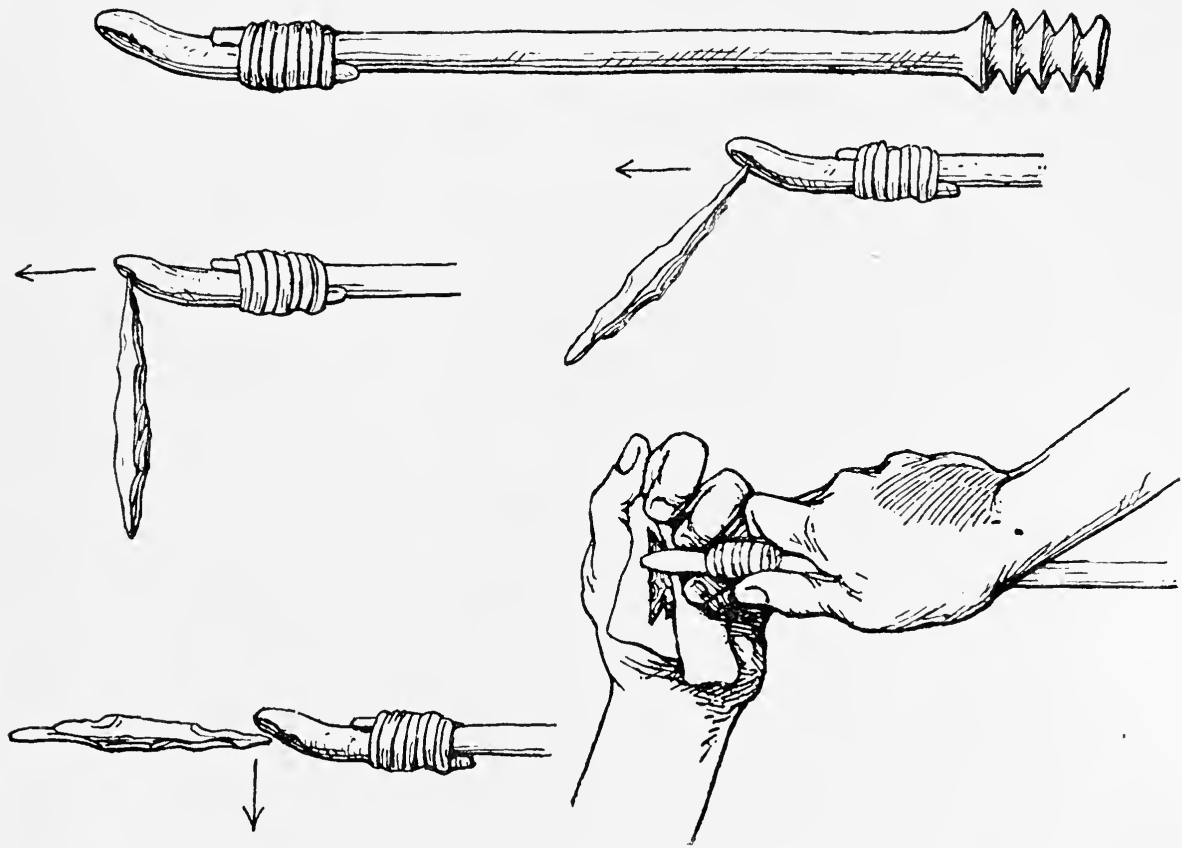

FIG. 177. Free-hand pressure chipping of the Klamath Indians. (Schumacher.)

and probably for many centuries. In the cretaceous lluffs near by great quantities of chert are found, and not far away quantities of moss-agate. From these materials the Indians male their implements by dhipping, and near the village site the flakes, rejects, and accidents may be found in great quantities, measured by wagonloads. ${ }^{1}$

We are indebted to Schumacher for a most lucid account of this schumacher's Ac- process as practiced among the Klamath Indians of count

California (fig. 177). After describing the manner of breaking up the stone by the aid of heat, and the selection of suitable fragments, he states that- 
The fragments are assorted according to shaje and size best corresponding to the weapons desired; the small ones, best fit in shape and

[Klamath Arrow Makers] thickness, are used for arrowheads; similar sherds, but larger in size, for spear points; the long narrow pieces for

borers, and so on. To work the flakes into the desired forms, certain tools are required, one of which is represented in figure $1 .^{1}$ It consists of a stick $(a)$, which is in form and thickness not unlike an arrow shaft and about $1 \frac{1}{2}$ feet in length, to one end of which a point $(b)$ is fastened, of some tough material, as the tooth of the sea lion or the horn of elk, and even iron among the present Klamaths, although the rock does not work as well, and brittles where the edge ought to be sharp. The point is represented in natural size . . . to better illustrate its beveled curve, which form armits a gradual pressure to a limited space in a piece of the sherd. During the operation, the rock is partially enwrapped in a piece of buckskin for botter manipulation, its flat side resting against the fleshy part of the thumb of the left hand, only the edge
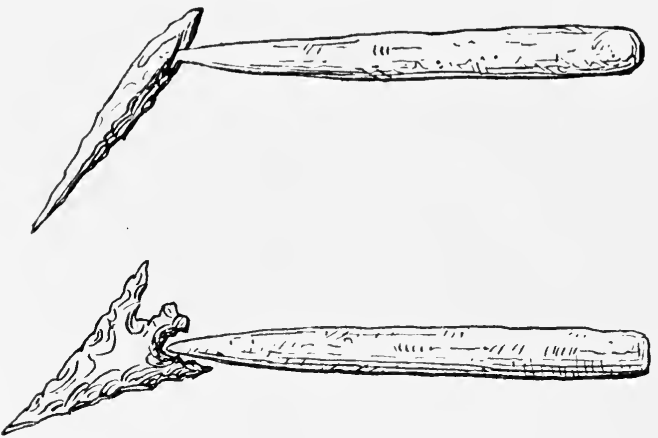

FIG. 178. Free-hand pressure ehipping of the Klamath Indians. (Schumacher.)

to be worked being left exposed (fig. 3). The tool is worked with the right hand, while the lower part of the handle, usually ornamented, is held between the arm and the body so as to guide the instrument with a steady hand. The main movements are shown at $a, b, c$ of figure 4. With the movement as illustrated at $a$ larger flakes are detached, and the rock is roughly shaped into the desired form; while with the movement shown at $b$ long

flakes are broken, which frequently reach the middle of the sherd, producing the ridge of the points or knives; and, with movement illustrated at $c$, the smaller chips of the cutting edge are worked. ${ }^{2}$

The application of the bone tool in notching the arrow point is illustrated in figure 178 .

Speaking of the Indians of California, probably of one of the Shoshonean tribes, Lieut. E. G. Beckwith, who acPaiute: Beckwith's companied the railroad expeditions to the Pacific
Account coast in 1855 , says:

One of them seated himself near me and made from a fragment of quartz, with a simple piece of romul bone, one end of which was somispherical, with a small crease in it (as if worn by a thread) the sixteenth of an inch in depth, an arrowhead which was very sharp and piercing, and such as they use on all their arrows. The skill and rapiclity with which it was made, without a blow, but by simply breaking the sharp edges with the creased bone by the strength of his hands-for the crease merely served to prevent the instrument from slipping, affording no leverage-was renarkable. ${ }^{3}$

1 The original reference figures are retained throughout this citation.

2 Schumachrr, Methods of Making Stone Weapons, p. 547.

${ }^{3}$ Beckwith, Report of Explorations for a Route for the Pacific Railroad, p. 43. 
The crease referred to was possibly merely the notch which the sharp edge of the flint makes in the bone pressed repeatedly upon it, rather than a specially prepared notch such as has been observed by others in a few instances.

One of the fullest and most graphic accounts of the manner of making small arrowheads is that given by J. F. Snyraiute: Snyder's der. A Digger Indian of Eldorado County, Cal.,
statement

having broken his arrowhead in shooting at a rabbit, proceeded in Mr. Snyder's presence to make another to take its place. Searching in the stream bed which was at hand, he quickly obtained a fragment of quartz:

Seating himself on a bowlder near me, his next move was to unfasten and unwrap the sinew thread from the end of the arrow shaft and detach and remove the piece of stone arrowhead remaining in it, for it had broken when it struck the rocky ground. He placed the thread of sinew in his mouth to soften it and rencler it pliable. Then holding the quartz splinter on its edge with his left hand, on a smooth bowlder as an anvil, he gently tapper the stone, first on one edge, then on the other (a percussive process), striking off a tiny chip at each stroke until he soon had it reduced approximately to the dimensions he required. He had before seating himself removed his quiver from his shoulder, and at this stage untied from its strap a buckskin string that suspencled the point of a deer's horn, 7 or 8 inches in length, notched or grooved at its small end in a peculiar manner that I had not before noticerl. The savage saw that $I$ was intensely interested in his work, and executed every movement deliberately and plainly in my view, as though he felt pride in his knowledge of the stone art. Now sprealing the broal tail flap on his quiver in the palm of his left hand, with its inner or dressed side up he placed upon it the quartz splinter he had blocked out, and held it firmly in place with the two smaller fingers of the hand clasped over it. With the point of his horn punch he then, by firm and careful pressure, broke from the elges flake after flake from the point of the embryo arrowhead along to its base. Stopping a moment to inspect the stone, he would reverse it and repeat the cautious pressing on the other edge until directly its outline was that of the orlinary leaf-shaped, flint implement. He now reversed his deerhorn punch, when I noticed that it was ground, at its upper or large end, to an obtuse or diamond point at one side, somewhat like that of a wood carver's bruin. Applying this stout point, by the same mode of pressure as before, to each sicle of the broad end of the stone alternately, the stone now resting for solid support on the heavy muscles at the base of the thumb, he soon chipperl out the indented, lateral notches, defining the shank of the arrowhead, which was now finished as completely, and perfectly proportioned, as any I ever saw. Fitting it in the cloft of the arrow shaft, he took the slender thong from his mouth and soon had the new weapon securely fastened, his horn punch ticl to its place again, and, gathering up his quiver and bow. quickly vanished from view.

The whole process, from his selection of the stone allapted for his purpose to the last tuck of the sinew strand in adjusting the finished implement to its shaft, did not exceed 25 minutes of time. ${ }^{1}$ 
Mr. B. B. Redding has observed and recorded in gratifying detail the method of arrow making among the Wintoons of

Wintoons :

Redding's Obser-

Cloud River, Oreg. Three processes and three types vations

of shaping implements are involved, as follows: $(a)$

Making flakes with hammer and punch; ${ }^{1}(b)$ shaping the blades by free-hand pressure with a large bone flaker; $(c)$ breaking out notches with rocking pressure of a small flaker. The demonstration was made by an old man named Consolulu who-

brought, tied up in a deerskin, a piece of obsidian weighing about a pount, a fragment of a deerhorn split from a prong lengthwise, about 4 inches in'length and half an inch in diameter, and ground off squarely at the ends-this left each end a semicircle, besides two (leer prongs (Cariacus columbiamus) with the points ground down into the shape of a square, sharp-pointed file, one of these

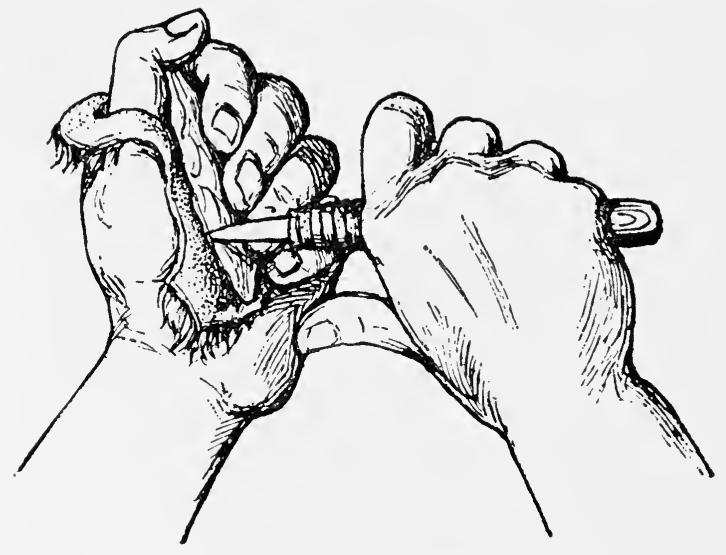

Fig. 179. Position in chipping with a bone point by the Wintoons. (Beckwith.) being much smaller than the other. He had also some pieces of iron wire tied to wooden handles and ground into the same shapes. These, he explained, he used in preference to the deer prongs, since white men came to the country, because they were harder and did not requir e sharpening so frequently.

The first step was to strike off flakes from the obsidian block by percussion, using a hammerstone and a piece of deerhorn. This part of the demonstration has already been given under indirect percussion. Having obtained a suitablo flake, the workman proceeded to shape the arrowhead.

He now squatted on the ground, sitting on his left foot, his right leg extended in a position often assumed by tailors at work. He then placel in the palm of his left hand a piece of thick, well-tanned buckskin, eviolently from the skin of the neck of a deer. It was thick but soft and pliable. On this he latid the flake of obsidian, which he held firmly in its place by the first three fingers of the same hand. He then rested the elbow on the left knee, which gave the left arm and hand holding the flake firm and stealy support. He then took in his right hand the larger of the two deer prongs, which, as has been stated, had its point sharpened in the form of a square file, and holding it as an engraver of wood holds his cutting instrument, he commenced reducing one edge of the circular form of the flake to a straight line. With the thumb of the right hand resting on the edge of the left palm as a fulcrum [fig. 179], the point of the deer prong would be made to rest on about an eighth of an inch or less of the edge of the flake, then with a firm downward pressure of the point, a

${ }^{1}$ Description of this work appears under Percussion Processes, pp. 295-297. 
conchoidal fragment would be broken out almost always of the size desired. The point of the deer prong would then be advanced a short distance and the same operation repeated, until in a few minutes the flake was reduced to a straight line on one edge. As this operation broke all the chips from the under side of the flake, if left in this condition the arrowhead would be unequally proportioned, that is, the two cutting edges would not be in the center. IIe therefore with the side of the deerhorn firmly rubbed back and forth the straight edge he had made on the flake until the sharp edge had been broken and worn down. The flake was now turned end for end in the palm of his hand and the chipping renewed. When completed an equal amount was taken from each side of the edge of the flake and the cutting edge was left in the center. It was now plain that the straight edge thus made was to be one side of the long isosceles triangle, the form of the arrowheads which is used by his tribe.

With the flake of obsidian firmly held in the cushion of the left palm and the point of deerhor'n strongly pressed on the edge of the flake, the

[Notching] effect was the same as the blow which split the flake from the larger piece. While, however, he was not always sure of the effect of the blow in splitting off the large flakes out of which to make the arrowheads, he in no instance appeared to fail in breaking out with the point of deer prong the exact piece desired. The soft, thick, pliable piece of tanned deerskin on which the flake in his left palm was held, may have added to the cushion, but seemed to serve no other purpose than to save his hand from being cut by the countless sharp chips as they were broken off. One of the long sides of the arrowhead having been thus formed, the flake was turned over and the other side formed in the same manner. As, however, very much more of the obsidian had to be chipped away, he brought more pressure upon the point and broke out larger chips until the flake began to assume the shape desired, when the same care was exercised as when the first straight erlge was made. In breaking out large or small chips the process was always the same. The pressure of the point of deerhorn on the upper edge of the flake never appeared to break out a piece, which, on the upper side, reached beyond where the point rested, while on the under side the chip broken out might leave a space of twice the distance. Invariably when a line of these chips had been broken out the sharp elge was rubbed down, the flake turned end for end, and the chipping renewed on the other side. By this process the cutting elges of the arrowhead were kept in the same line. The base was formed in the same mamner. No lines were drawn but he would occusionally look at his work as it progressed and (hip) on one sirle or the other to keep their proportions equal. The base of the arrowhear-opposite the point-when finished, is inserted in a slot mate in the end of the wooden shaft, and is firmly tied to it by the tendons of a deer. To hold the arrowhead firmly to the shaft and to prevent the thread of deer tendon from interfering with the penetrating power of the arrow, a slot about onefourth of an inch deep is chipped into both cutting elges of the arrowhead about one-fourth of an inch above the base. This causes the arrowhead to look as if it were barbed, but the object seems only to be to provide means by which the arrowhead may be firmly fastened to the shaft, at the same time avoiding the making of any obstruction to the penetrating or cutting power of the arrowhead. The chipping out of these slots was the last operation to be performed. It seems to me more difficult than any other part of the work, and I thought that in this would be the danger of the loss of all the patient labor that hat been expended. In practical operation it was the simplest. safest, and most rapid of all his work. He now held the point of the well-shaped arrowhead 
between the thumb and first finger of his left hand with the edge of the arrowhead upward, the base resting edgewise on the deerskin cushion in the palm. IIe then used the smaller deer prong, which had been sharpened in the same form as the larger one, but all its proportions, in every respect, were very nuch smaller; its point could not have been larger than one-sixteenth of an inch square. He rested this point on the edge of the arrowliead where he desired to make the slot, and commenced sawing back and forth with a [Rocking Motion of rocking motion, the fine chips flew from each side, the point of Flaker]

the deerhorn descended, and in less than a minute the slot was

cut. The arrowhead was turned over and the same operation repeated on the other edge. It seemed that by this process, if he desired, the arrowhead could have been cut in two in a very few minutes. He now examined his work in the strong sunlight and, being satisfied, handed me the completed arrowhead. It had taken him 40 minutes to split the two flakes from the large piece of obsidian and chip one of them into the arrowhead. ${ }^{1}$

The practice of this method of chipping at present by the California Indians is illustrated in figure 180.

John Smith, who had an intimate acquaintance with the Indian tribes of the Virginia region, gives a brief but explicrt

Towhatans account of the ordinary method of providing arrowheads among the tribes of Virginia: "His arrowhead he quickly maketh with a little bone, which he ever weareth at his bracert, of any splint of a stone, or glasse in the forme of a heart, and these they glew to the end of their arrowes." ${ }^{2}$

Sellers, referring to observations made by Titian R. Peale, who accompanied Lewis and Clark on their exploration Western Tribes to the Pacific, contributes the following:

Mr. Peale said he had seen squaws chipping flakes into small arrow points, holding the flake in their left hand, grasped between a piece of bent leather, and chipping off small flakes by pressure, using a small pointed bone in the right hand for that purpose. From this it was evident that John Smith's story was no mytlı. ${ }^{3}$

A similar process, identical with the blade-making process described by Beckwith, was demonstrated by an aged Shoshone Washoe Indian for the benefit of Mr. S. L. Lee, who described it in a letter addressed to Prof. O. T. Mason, dated Carson City, Nev., 1904. The chipping implements were two points, a large and a small one, made of buckhorn reinforced with a piece of "rabbit brush" and wrapped with buckskin. These articles were later presented to the Museum by Mr. Lee and are illustrated in figure $173, b$.

That stone, on account of its hardness and brittleness, was unsuited for the making of chipping implements is entirely apparent, but its use, probably in the absence of more suitable materials, is recorded

\footnotetext{
${ }^{1}$ Redding, How Our Ancestors in the Stone Age Made Their Implements, pp. 671-674.

2 Smith, True Travels, Adventures, and Observations, vol. I, p. 132.

3 Sellers, Observations on Stone-chipping, pp. 872-873.
} 

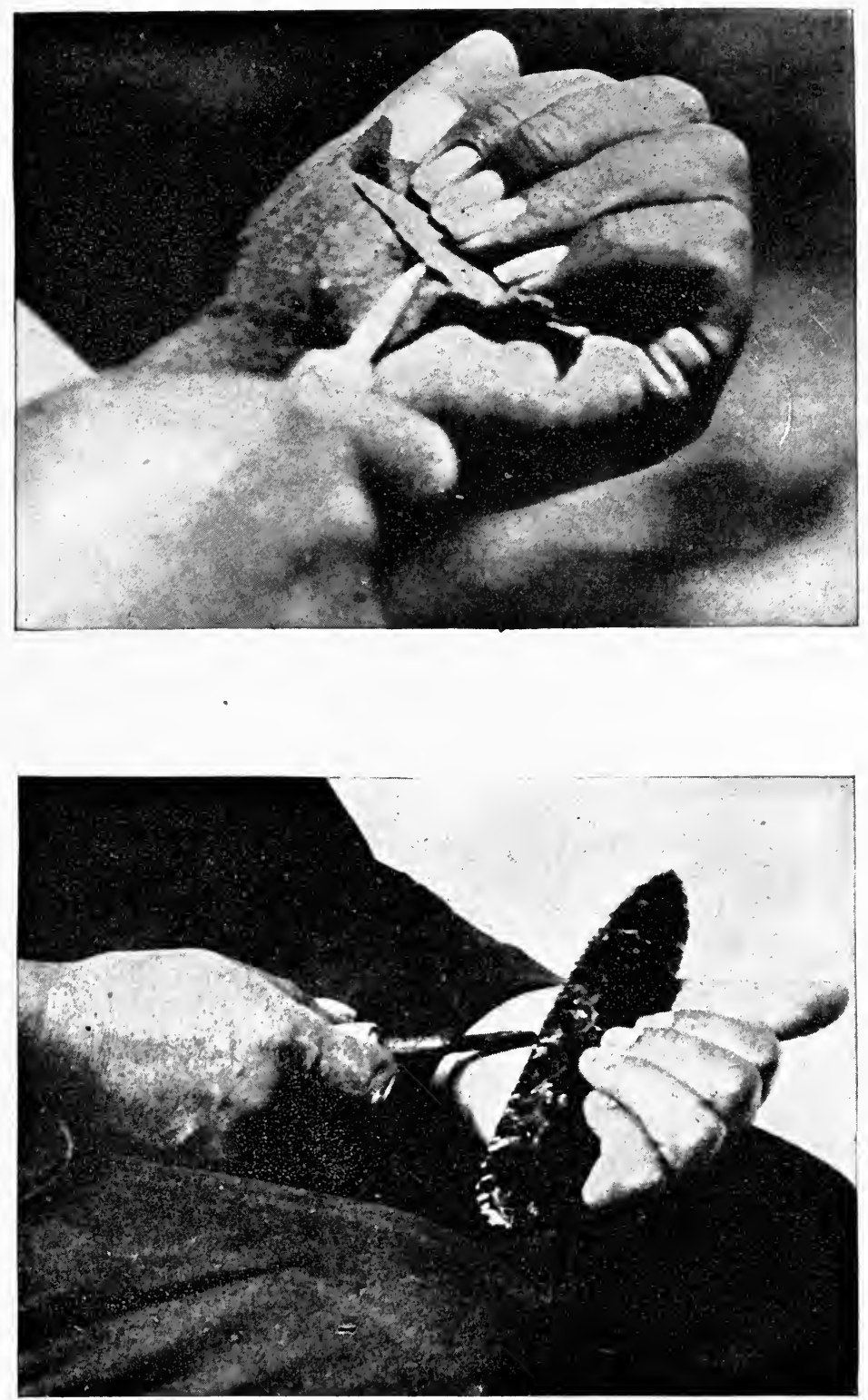

Fig. 180. Flint working by Ishi. (Nelson, in the Holmes Anniversary Volume, opp. p. 400.) 
by a number of writers. Father Morice, the learned student of the western Déné, furnishes the following account of their work:

The material chosen in preference to fashion arrow or spear heads with was loose, broken pieces of the rock, such as were found on the

[ Hené] surface. Of course, these were confined to a few localities only, wherein were situated sorts of quarries which were very jealously guarded against any person, even of the same tribe, whose right to share in their contents was not fully established. A violation of this traditional law was often considered a casus bclli between the co-clansmen of the trespasser and those of the proprietors of the quarry.

The first operation consisted in roughly blocking off with a hard stone the pieces of the flint, the removal of which was necessary to [Stone Flaker] obtain a vague resemblance to the intended weapon. Then grasping the flint lengthwise with the closed fingers of the left hand (fig. 44), the arrow smith carefully pressed off the flakes with an elongated stone held in his right hand until the desired form and finish were obtained. A piece of buckskin served as a pad to protect the hand against the asperities of the point.

I owe these details to an old chief who has been an eyewitness to the operation. I should add that in not a few cases a moose molar tooth replaced the long chipping stone. I know also of a very few points the sharp edges of which liave been polished off by friction. ${ }^{1}$

Mr. II. C. Dulog published in Forest and Stream a brief account" of pressure chipping by the Indians of Clear Lake, Clear Lake, Call- Cal., as follows:
fornia

The old expert put on his left hand a piece of buckskin with a hole cut in it to let the thumb pass through, something like the "palm" used by sailmakers. This was, of course, to protect his hand while at work. In his right hand he took a tool of bone ground down to a blunt point. These tools, matle often from the leg bone of a deer, are assorted in sizes, large ones being used for coarse work and small ones for fine work. A piece of obsidian of the right size was held in the loft hand, then the right thumb was pressed on the tol) of the stone, while the point of the bone was strongly pressed against the under edge of the proposed arrowhead and a little splinter of obsidian worked off.

Numerous explorers have observed and recorded the flaking processes as practiced among the Eskimo. The stone is broken up and the forms roughed out in the usual manner with stone hammers. The specializing work is done with well-made implements of bone, antler, and ivory, usually of highly specialized type. A typical example is illustrated in figure 181 .

Murdoch, an exceptionally discriminating observer, writes as follows of the flint working of the Eskimo of Point Barrow :

These people still retain the art of making flint arrow and spear heads, and other implements, such as the blades for the skin scrapers, to [ Eskimo] be hereafter described. Many of the flint arrowheads and spear points already described were made at Nuwr̆k and

Utkiarwĩn especially for sale to us and are as finely formed and neatly finished

${ }^{1}$ Morice, Notes on the Western Dénés, p. 6.5.

2 Quoted by Mason, North American Bows, Arrows, and Quivers, p. 658. 
as any of the ancient ones. The flints, in many cases water-worn pebbles, appea. to have been splintered by percussion into fragments of suitable sizes, and these sharp-edged spalls are flaked into shape by means of a little instrument consisting of a short, straight rod of some hard material mounted in a short curved haft. We collected nine of these tools (kI' gli), of which two have no blades. No. 89262 (1223) figured in Point Barrow Report, Ethnology, plate iii, figure 7, has been selected as the type. The handle is of walrus ivory 7.8 inches long, straight and nearly cylindrical for about $4 \frac{1}{2}$ inches, then bending down like a saw handle and spread out into a spatulate butt. Fitted into a deep groove on the top of the handle so that its tip projects 1.8 inches beyond the tip of the latter is a slender four-sided rod of whale's bone, 4.7 inches long. This is held in place by two simple lashings, one of cotton twine and the other of seal thong. The flint to be flaked is held in the left hand and pressed against the fleshy part of the palm, which serves as a cushion and is protected by wearing a thick leerskin mitten. The tool is firmly grasped well forward in the right hand, with the
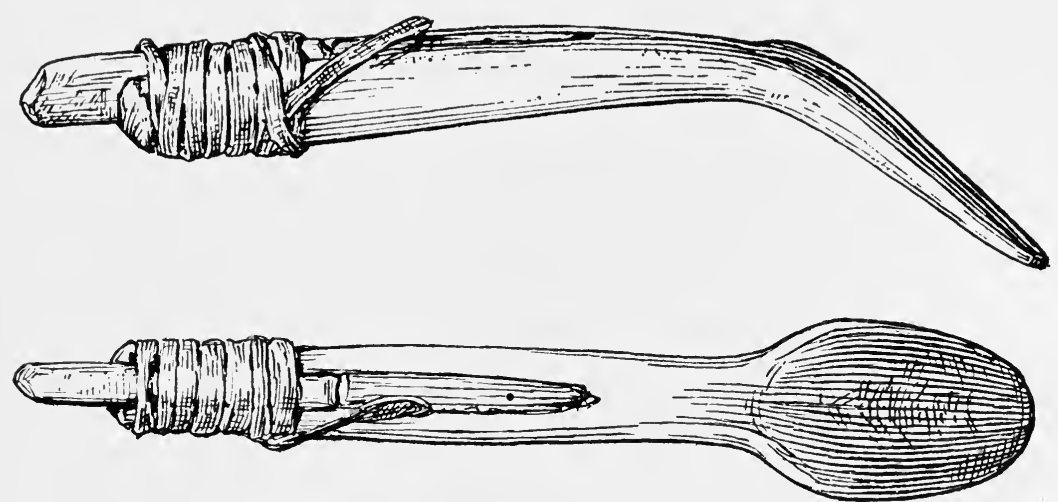

FIG. 181. Bone chipping implement of the Eskimo. (Murdoch.)

thumb on top of the blade, and by pressing the point steadily on the edge of the flint flakes of the desired size are made to fly off from the under surface.

These tools vary little in pattern, but are made of different materials. Hard bone appears to have been the commonest inaterial for the blade, as three out of the seven blades are of this substance. One specimen (No. 89263 [796] from Ctkiarwiñ) lais a blade of iron of the same shape but only 2 inches long. ${ }^{1}$

Nelson appears not to have witnessed the making of flint implements during his protracted stay among the western Eskimo Eskimo, but states that "flint knives, spearheads, and arrowpoints are made by flaking. The flakers are made of smail, rodlike pieces of deerhorn, wood, or ivory, fastened into a slot at the end of a handle, usually of ivory or deerhorn, with wrappings of sinew or rawhide cord." The specimens collected by Nelson from Kotzebue Sound, Hotham Inlet, and Point Hope are identical in type with those observed among the Eskimo elsewhere. ${ }^{2}$

- Murdoch, Ethnological Results of the Point Barrow Expedition, pp. 287-288.

${ }^{2}$ Nelson, The Eskimo About Bering Strait, p. 91. $38657^{\circ}-19-$ Bull. 60 , pt I -22 


\section{The following is quoted from Dr. Franz Boas:}

Capt. Comer collected a number of interesting objects anong the tribe whom he met with on the southwest coast of Southampton Island. [Eskimo] The natives still use bow and arrow. They have no guns, and they possess very little iron. The points of their arrows and harpoons are made of flint, which is chipped with a bone flaker (Fig. S3), the hamdle of which is made rough so as to give a firm grip. In one specimen the handle is wrapped with semnit in order to give a firm hold. A pad made of sealskin folded in several layers belongs to this implement; and attached to one specimen by a string is a wide ring of leather, which is worn over the joint of the fourth finger of the right hand. The flint which is to be worked is placed on the skin pad in the hollow of the left hand. The flaker is firmly grasped by the right so that the fourth finger is near its tapering end. Then flakes are removed from the flint by pressure, the second joint of the fourtl finger, which would strike the flint, being protected by the ring. Arrow points, harpoon and lance points, and knives, are made of this material. It would seem that the Eskimo first made the diamond-shaped forms, shown in Fig. 84, 2-d. By flaking the base of these, arrow points with slender stems are made (Fig. 84, 4-1). The elongated points (Fig. 84, r, s) may have been used as knives. A supply of these points wrapped simply in a long strip of seal intestine, and the flaker, are generally carried in the tool pouch of the quiver, which is of the same type as that of Cumberland Sound and Smith Sound. ${ }^{1}$

It would appear that the highly specialized curved flaker handle ased by the Eskimo (fig. 181) was in use as far south as California.

In describing the Ray collection from the Hupa of California, Mason quotes Ray as follows:

The arrowheads used for war and for big game are usually made from flint and obsidian, and more recently of iron and steel. The

[IIupa ] flakes for the stone heads are knocked off by means of a chipping tool of deer antler. The stone heads are male with a chipper composed of a crooked handle to which is lashed a short piece of antler precisely similar to those which I collected at Point Barrow. The work is held in the left hand on a pad and flaked off by pressure with the tool in the rigint hand, in exactly the same manner as I found the Innuits doing in northern Alaska. ${ }^{2}$

According to Cherer, a free-hand pressure method of chipping of somewhat exceptional character was practiced by certain California tribes:

The stone arrowheads are made with great care, and the materials from which they are made are often brought from long distances.

[California ] Obsidian and agate are probably selected not so much for beauty of coloring as for their close grain, which admits of more careful shaping. They use a tool with its working edge shaped like the [Notched Flaker] side of a glazier's diamond. The arrowhead is held in the nipper to chip off small fragments. ${ }^{3}$

Since it does not appear that Mr. Chever actually witnessed the use of the nipper described and illustrated by him, it seems possible

${ }^{1}$ Boas, Eskimo of Baffin Land and IIudson Bay, pp. 62-64.

${ }^{2}$ Mason, The Ray Collection from IIupa Reservation, pp. 228-229.

${ }^{3}$ Chever, The Indians of California, pp. 139-140. 
that the notch may be nothing more than the shallow groove produced by continued use of the flaker on the sharp edges of the stone worked.

A second distinctive or exceptional method of free-hand pressure shaping practiced by the California Indians is described by Power's:

It was often a source of wonder to me how the delicate arrowheals used on war arrows, with their long, thin points, could be male [Viard: Powers] without breaking them to pieces. The Viard proceed in the following manner: Taking a piece of jasper, chert, obsiclian, or common flint, which breaks sharp-cornered and with a conchoidal fracture, they heat it in the fire and then cool it slowly, which splits [Fracture by Ileat] it in flakes. The arrow maker then takes a flake and gives it an approximate rough shape by striking it with a kind of hammer. He then slips over his left hand a piece of buckskin, with a hole to fit over the thumb (this buckskin is to prevent the hand from being wounded), and in his right hand he takes a pair of buckhorn pincers, tied together at the point with a thong. Holding the piece of flint in his left hand, he breals off? from the elge of it a tiny fragment with the pincers by a twisting or wrenching motion. The piece is often reversed in the hand, so that it mal be worked away symmetrically. Arrowhead manufacture is a specialty, just as arrow making, medicine, and other arts. ${ }^{1}$

Belcher, who witnessed arrow making among the Eskimo of Icy Cape, gives the following account of the work:

Possibly, had I not witnessed the operation and had been at the time one of the first Europeans with whom they ever had communica[Rest Pressure : Eskimo] tion, the idea would have remained undisputed that they owed their formation to the stroke of the hammer. Being a working amateur mechanic myself, and having practiced in a very similar manner on glass with a penny piece in $\mathbf{1 8 1 5}$, I was not at all surprised at witnessing the modus operandi. Selecting a $\log$ of wood in which a spoon-shaped cavity was cut, they placed the splinter to be worked over it, and [F 1 a k ing in a by pressing gently along the margin vertically, first on one spoon-shaped Cavity ]

side and then on the other, as one would set a saw, they splintered off alternate fragments until the object thus properly outlined presented the spear or arrow head form, with two cutting serrated elges.

This instrument has a graceful outline. The handle is of fine fossil ivory. That would be too soft to deal with the flint or chert in the manner required. But they discovered that the point of the leerhorn is harder and also more stubborn; therefore, in a slit, like lead in our pencils, they introduced a slip of this substance and secured it by a strong thong, put on wet, but which on drying became very rigid. Here we can not fail to trace ingenuity, ability, and a view to ornament. It is the point of the deerhorn which, refusing to yield, arives off the fine conchoidal splinters from the chert.

I can not here omit remarking that the very same process is pursued by the Indians of Mexican origin in California with the obsidian [Pacific Isiands] points for their arrows; and also in the North and South Pacific-at Sandwich Islands $\left(21^{\circ}\right.$ north $)$, and Tahiti $\left(18^{\circ}\right.$ south $)-39^{\circ}$ or 2,340 miles asunder-similar indentations or chippings are car- 
ried out in forming their axes from basaltic lava, but probably performed in the latter instances with stone hammers. I myself witnessed at the convent of Monterey the captured Indians forming their arrowheads out of obsidian similarly to the mode practiced by the Eskimos. ${ }^{1}$

Sellers, who has contributed largely to our knowledge of the flint working of the aborigines, obtained from George Catlin much interesting matter regarding the processes in vogue among the tribes of the middle and far West.

He [Catlin] considered making flakes much more of an art than the shaping them into arrow or spear points, for a thorough knowledge [Western Tribes] of the nature of the stone to be flaked was essential, as a slight difference in its quality necessitated a totally different mode of treatment. The principal source of supply for what he termed homemade flakes was the coarse gravel bars of the rivers, where large pebbles are found; those most easily worked into flakes for small arrow points were chalcedony, jasper, and agate. Most of the tribes had men who were expert at flaking, and who could decide at sight the best mode of working. Some of these pebbles would split into tolerably good flakes by quick and sharp blows striking on the same point; others would break by a cross fracture into two or more pieces; these were preferred, as good flakes could be split from their clean fractured surface by what Mr. Catlin called impulsive pressure, the tool used being a shaft or stick of between 2 and 3 inches diameter, varying in length from 30 inches to 4 feet, according to the manner of using them. These shafts were pointed with bone or buckhorn, inserted in the working end as represented in figure 1 , bound with sinews, or rawhide thongs, to prevent splitting. For some kinds of work the bone or horn tips were scraped to a rather blunt point, others with a slightly rounded end [Methods of Holding the Stone]

of about one-half inch in diameter. He described various ways of holding the stone while the pressure was being applied. A water-worn pebble broken transversely was commonly held by [ Embedded in Clay ]

being sufficiently embedded in hard earth to prevent its slipping when held by the foot as the pressure was applied. Large blocks of obsidian or any easily flaked stones were held between the feet of the operator while sitting on the ground, the impulsive pressure being given to the tool grasped in both hands, a crosspiece on the upper. end resting against the chest, the bone end against the stone in a slight indentation, previously prepared, to give the proper angle and to prevent slipping.

In some cases the stone operated on was secured between two pieces or strips of wood like the jaws of a vise, bound together by cords or [Clamp] thongs of rawhide; on these strips the operator would stand as he applied the pressure of his weight by impulse.

The best flakes, outside of the homemade, were a subject of commerce, and came from certain localities where the chert of the best quality was quarried in sheets or blocks, as it occurs in almost continuous seams in the intercalated limestones of the Coal Measures. These seams are mostly cracked or broken into blocks, that show the nature of the cross fracture, which is taken advantage of by the operators, who seemed to have reduced the art of flaking to almost an absolute science, with division of labor; one set of men being expert in quarrying and selecting the stone, others in preparing the blocks

1 Belcher, quoted by Wilson, Arrowpoints, Spearheads, and Knives of Prehistoric Times, p. 986 . 
for the flaker. This was done when the blocks were nearly right angled at the corners by striking off the corner where the flaking was to commence, and, with a properly directed blow with a hard pebble stone, knock off of the upper elge a small flake, making a seat for the point of the flaking tool. Sometimes these blows were carried entirely across the front upper elge of the block, making a groove entirely across the edge, when the first row of flakes have been thrown off. It is the work of this operator to prepare seats for a second row and so on. What was meant by almost absolute science was a knowledge and skill that would give the proper direction to the pressure to throw off the kind of flake required.

Figure 2 represents, as nearly as I recollect, the rude sketches made of the flaking tool used to throw off massive flakes, when

rCombined Pres s u re and Percussion] a sudklen percussive pressure was required in adclition to the impulsive pressure the man could give. The staffs of these flaking tools were selected from young hardwood saplings of vigorous growth. A lower branch was utilized, as shown at $a$ in figure 2, to form the crotch in which the blow was struck. Another branch on the opposite side, $a$, was used to secure a heavy stone to give weight and increase the pressure. When the stone to be flaked was firmly held, the point adjusted to give the pressure in the required direction, the staff firmly grasped, the upper end against the chest of the operator, he would throw his weight on it in successive thrusts, and if the flake did not fly off, a man standing opposite would simultaneously with the thrust give a sharp blow with a heary club represented in cross section $b$ in figure 2 , it being so shaped that its force is downward close in the crotch. It has been represented to me that a single blow rarely failed to throw off the flake, frequently the entire lepth of the block of stone, sometimes as much as 10 or 12

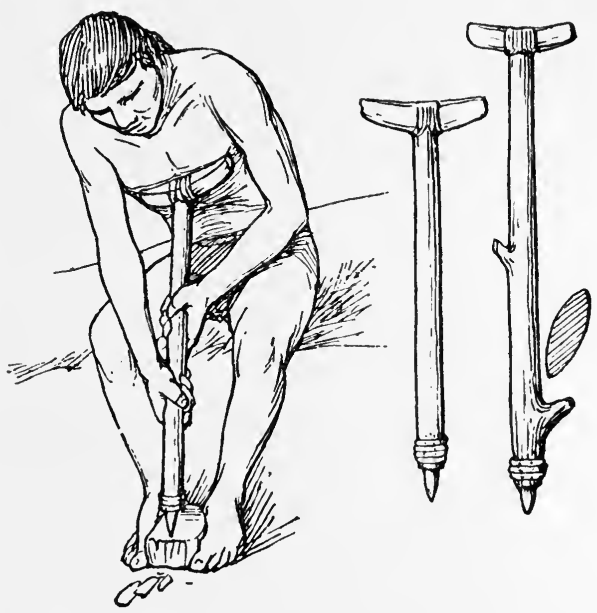

Frg. 182. Method of flaking by Mexican Indians as described by Torquemada, and by western United States tribes as described by Catlin.

inches. The tooth or tusk of the walrus was highly prized for the tips of the flakers. ${ }^{1}$

Figure 182 shows the two implements described by Catlin and illustrated by Sellers, and also the figure of a workman using one of the implements in the manner described. This figure presents equally well the method of making obsidian knives by the Aztecs, as described by Torquemada:

They had, and still have, workmen who make knives of a certain black stone or flint, which it is a most wonderful and admirable

[Aztec Method] thing to see them make out of the stone; and the ingenuity which invented this art is much to be praised. They 
are made and got out of the stone (if one can explain it) in this manner: One of these Indian workmen sits down upon the ground and takes a piece of this black stone, which is like jet, and hard as flint, and is a stone which might be called precious, more beautiful and brilliant than alabaster or jasper, so much so that of it are made tablets and mirrors. The piece they take is about 8 inches long, or rather more, and as thick as one's leg or rather less, and cylindrical. They have a stick as large as the shaft of a lance, and 3 cubits, or rather more, in length, and at the end of it they fasten firmly another piece of wool 8 inches long, to give more weight to this part, then pressing their naked feet together, they hold the stones as with a pair of pincers or the vise of a carpenter's bench. They take the stick (which is cut off smooth at the end) with both hands, and set well home against the edge of the front of the stone, which also is cut smooth in that part; and then they press it against their breast, and with the force of the pressure there flies off a knife, with its point and edge on each side, as neatly as if one were to make them of a turnip with a sharp knife, or of iron in the fire. Then they sharpen it on a stone, using a hone to give it a very fine edge; and in a very short time these workmen will make more than 20 knives in the aforesaid manner. They come out of the same shape as our barbers' lancets, except that they have a rib up the middle, and have a slight graceful curve toward the point. They will cut and shave the hair the first time they are used, at the first cut nearly as well as a steel razor, but they lose their edge at the second cut; and so to finish shaving one's beard or hair, one after another has to be used; though indeed they are cheap, and spoiling them is of no consequence. Many Spaniards, both regular and secular clergy, have been shaved with them, especially at the beginning of the colonization of these realms, when there was no such abundance as now of the necessary instruments and people who gain their livelihood by practicing this occupation. But $I$ conclude by saying that it is an admirable thing to see them made, and no small argument for the capacity of the men who found out such an invention. ${ }^{1}$

The Mexicans are said to have held a piece of obsidian in the left hand and pressed it against the point of a small goat's horn held in the right; moving it gently in different directions, they chipped off small flakes until the arrow was complete. This is a mere variant of the simple free-hand method of pressing the bone implement against the edge of the stone. This work corresponds closely to the process employed by the Australians as described by Balfour, which, however, is a rest process and is thus classed with the rest pressure processes.

The Australians, according to Balfour, used-

(a) a water-worn pebble of some hard, close-grained rock, of irregular shape, rounded on one face, flattened on the other ; the upper end is rounded and fits the hollow of the hand comfortably, the lower end is blunt edged. The shape is purely natural. The weight of the pebble is $3 \frac{1}{2}$ ounces. (b) A piece about 4 inches long, of the leg bone of a sheep, which has been roughly broken across. The stone is abraded at the lower end, the abrasions extending some way up the convex face of the pebble. It was used for striking off and pressing off

1 Torquemada, quoted by Wilson, Arrowpoints, Spearheads, and Knives of Prehistoric Times, p. 988. 
flakes from the glass, presumably during the earlier stages in the fashioning of the spearhearl. Such abraded stones frequently occur amongst neolithic finds. The bone was used in the final shaping of the spearhead, and to some extent at least in the manner which is represented in the photograph [fig. 183]. This was not taken on the spot, but was arranged in accordance with a sketch which Dr. Clement gave to me. The developing spearhead was held in both hands in the position shown in the photograph, and the edges pressed with a slightly rotary movement against the elges of the broken end of the bone, which was held down with the fingers of the left hand. In this manner flakes were detached with considerable accuracy, and the serrated edges of the blade were formed by flaking deeper at regular intervals. The edges of the bone have been partially smoothed by rubbing, presumably to improve their shape for the process of flaking the glass. ${ }^{1}$

The observer who has knowledge only of the processes required in the making of arrowheads of obsidian may be very far from having any adequate conception of the methods required and used in

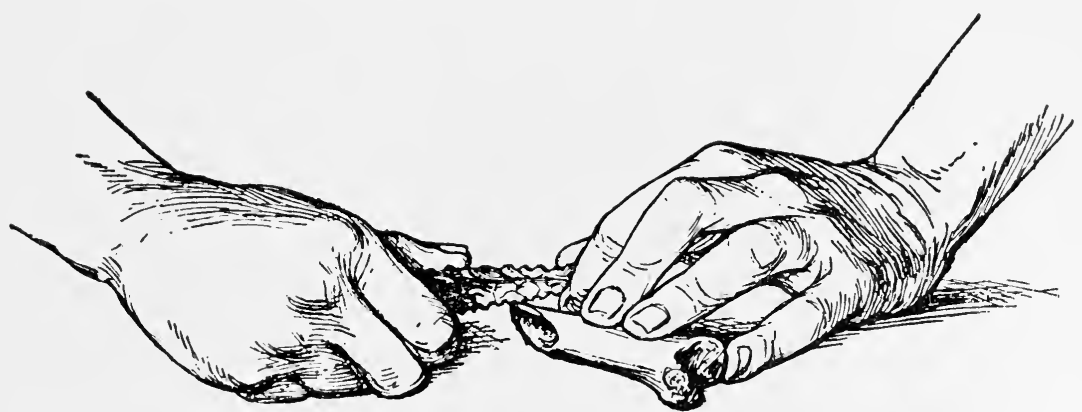

Fig. 183. Australian method of chipping as described by Balfour.

shaping like forms from tough and hard material, as quartzite or diorite, and he will be still further from understanding the processes required in evolving the long spearheads, and knives, and the highly specialized blades and other objects found in many sections of the country. With obsidian the hammer makes the flake and thins down thick edges, and the bone point shapes the arrowhead with ease; with the tougher materials, especially when the objects are large, the range of the stone hammer's work is much greater, and, indeed, the hone point by free-hand methods is often available only in the refinements of finish and in many cases not at all.

A most valuable contribution to our knowledge of the native methods of working brittle stone is furnished by Nels C. Nelson. ${ }^{2}$ He records with the greatest fullness the work of Ishi, a Yahi Indian of southern California, who kept up the practice of the art until his

\footnotetext{
${ }^{1}$ Balfour, On the Method Employed by the Natives of N. W. Australia in the Manufacture of Glass Spear-heads, p. 65.

${ }^{2}$ Flint working by Ishi, pp. 398-402.
} 
death in 1916, not, however, with the original tools, which were of bone, but with tools of iron, which he found to have certain advantages, the rate of wear doubtless being a first consideration. The chipping work is described by Nelson as follows:

Given a nodule of flint or a lump of obsidian, Ishi, in making a notched arrow point, let us say, employs three distinct processes, for each of which special tools ordinarily are required. The first process involves the division or breaking up of the obsidian mass to obtain suitable thin and straight flakes; the second process consists in chipping the selected flake to the size and shape of the arrow point desired; and the third and final process embodies, among other things, the notching of the base of the point to facilitate its attachment to the arrow shaft.

For the first process, that of dividing the obsidian mass, an ordinary hard, water-worn bowlder may do, especially if only small flakes are wanted, the obsidian being broken up or a flake struck from it by a direct blow. But if a large spear point or knife blade is ultimately desired, an intermediate tool is needed. This is apparently (Ishi never made one for me to see) a short, stout, blunt-pointed piece of bone or wood serving as a sort of punch and sometimes as a lever. As a matter of fact, what is wanted in the case of producing a large implement is not the division of the obsidian mass, but the trimming down of this mass by the detachment from it of all unnecessary portions. A direct blow with a hammerstone might be fatal to the obsidian core being thus shaped, while an indirect blow, delivered through this punch, the same being held at a selected spot and angle, has some chance of success in removing the superfluous portions without shattering the whole piece to bits. A hammerstone, then, or a hammerstone together with a punch, are the tools required for the preliminary rough work, namely, the production of flakes or of a flaked core.

For the secondary flaking, or, as it will be termed in this paper, chipping, a tool was made as follows: Ishi on one occasion took a common spike and at another time a piece of iron rod about the size of a lead pencil. He ground one end down about equally on two opposing sides, making a curving, chisel-like cutting edge, lenticular in cross section-a tool of a nature halfway between an awl and a chisel. Around the butt end a bit of cloth was wrapped to ease the handhold, and the chipping tool was finished. The notching tool was practically a duplicate of the preceding, but much smaller. A slender nail was sharpened as before, and, being too small to be held in the hand as it was, the butt end was inserted into an improvised wooden handle. The whole tool was nothing more or less than a common awl. The two implements are shown in figure 1 [184].

Another necessary item was a piece of leather or hide with which to protect the hand holding the obsidian during the chipping and notching processes.

Five things, therefore, seem to constitute the full complement of tools and accessories used in making the average chipped artifact, but more or fewer tools may no doubt be employed under extreme conditions.

The breaking up of stone to be utilized and the production of desired flakes or fragments with strokes of a hammerstone, the first step in implement making, as described by Mr. Nelson, do not differ in any way from the usual methods already fully described. The pressure chipping is proceeded with as follows: 
Having selected a suitable flake, Ishi assumes the new pose shown in plate I, b [fig. 185]. * * * The actual disposition of flake and tool is better indicater in the detail views of plate II [fig. 180]. The flake to be worked will be observed resting on a bit of leather and placed transversely across the proximal fleshy part of the left palm and there held by one or more of the finger tips. The chipping tool, grasped firmly with the right hand, is placed on the upper side of the flake, very close to the edge, and by a quick, downward pressure a chip is removed from the underside of the flake. That much of this seemingly simple act will be noticed by any casual observer, but it may be well to analyze the act a little so as to show that it is, after all, not so simple as it looks. There is, so to speak, some knack about it. First of all, we may note the fact, well shown in the illustration, that the axis of the tool used and the edge of the obsidian to be worked do not meet at a right angle, although they are in nearly the same plane. Secondly-and this does not show well in the illustration-the chipping tool is so
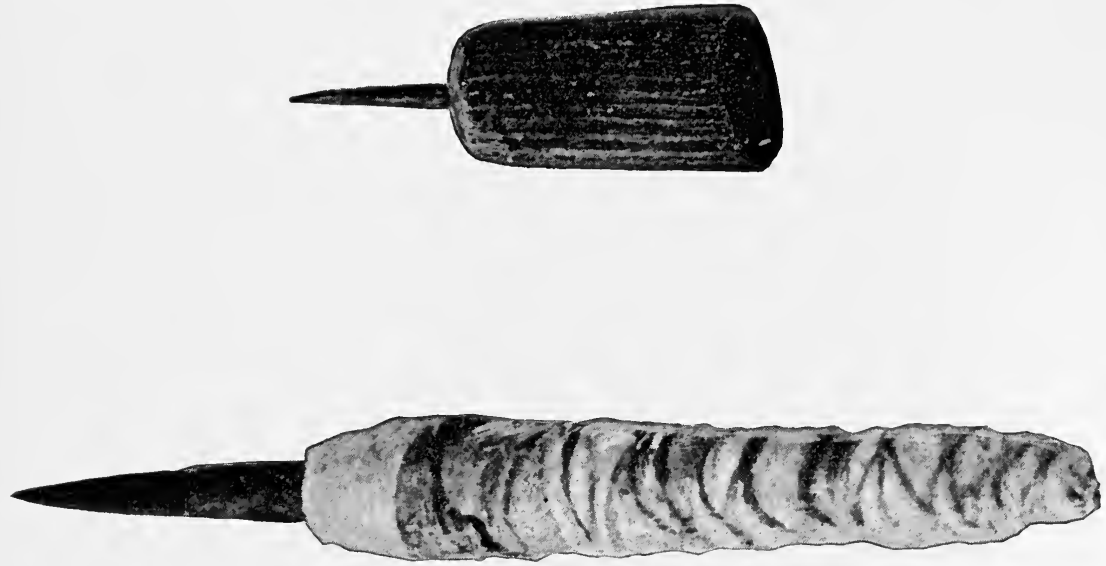

FIG. 184. Flaking and notching tools used by Ishi.

turned on its axis that the plane of its cutting edge meets the plane of the flake to be worked at nearly, if not quite, a right angle. That this turn of the chipping tool is necessary, or at least deliberate. is certain, because Ishi employs it invariably in the later stages. * * * Not having experimented very much, I am unable to say why Ishi proceeds as he does, but he gets results which I can not imitate, try as I will. Ishi removes thin and fairly slender chips that extend two-thirds or more across the face of the flake, while my chips are thick and short. Consequently his arrowpoints when finished are thin and shapely, while mine, much to his disgust, are thick and clumsy affairs. My work resembles the abrupt Mousterian retouch, while Ishi's is the true Solu. trian technique.

As to the actual movements involved in chipping, these. would be rather diflicult to describe. The pressure exerted, if not too great, comes mostly from a wrist action; but if greater weight is needed the leverage is thrown back to the elbow and shoulder. The precision of the movement in the later and more delicate stage of the work is guided by placing the index finger of the tool 
hand against the edge of the palm on which the flake lies. The pressure is down, of course, rather than up, mainly in order to avoid the flying chips, and the chips being left in the palm of the hand, absolutely necessitates the leather parl. Ishi works rapidly, reversing the flake often or not as conditions roquire. He begins chipping at the point on the flake nearest the tool and gradually works toward the farther end, and his best work appears to be done when he is chipping in a direction from the point end of the arrowpoint toward the base rather than when, on reversal, he must work in the opposite direction-i. e., from the base of the arrowpoint toward the point. Working in this manner Ishi can finish an arrowpoint of average size in half an hour, more or

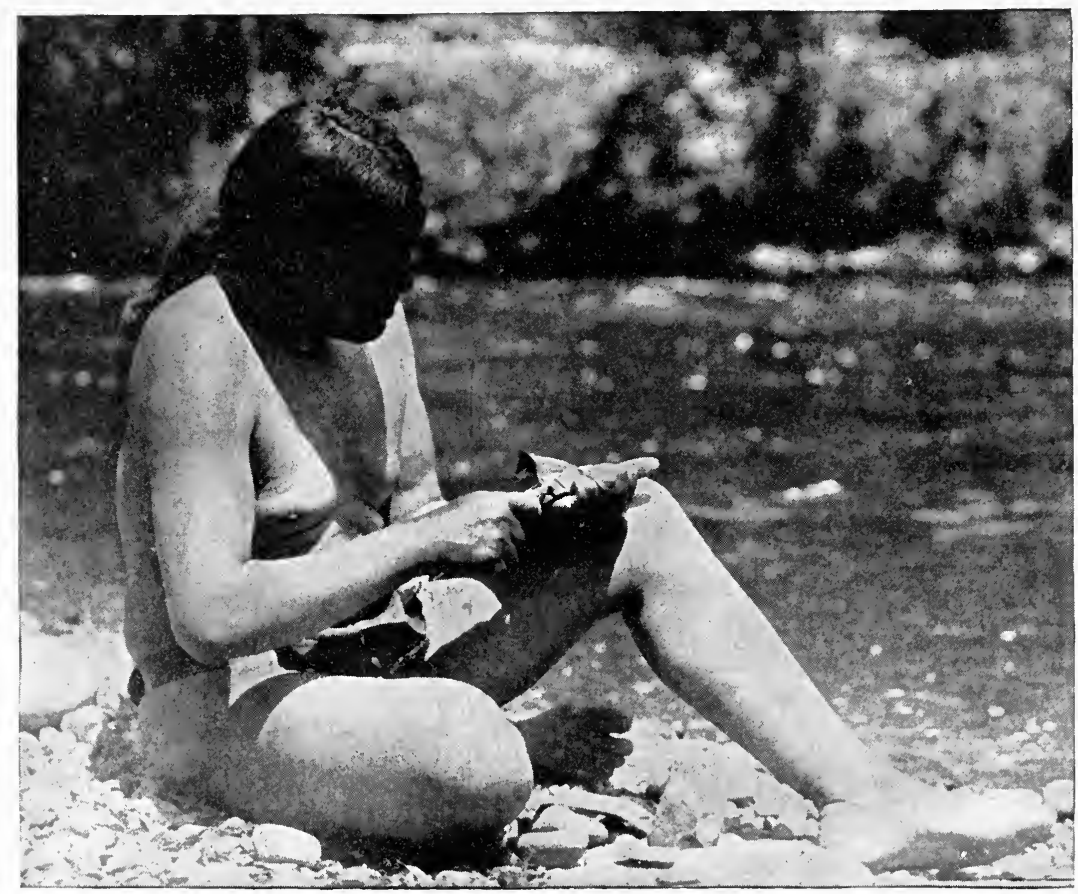

Fig. 185. The secondary process-chipping the obsidian.

less, accorling to the nature of the substance he is working and also according to the adaptability of the flake originally selected. Having finished, he procoesls to the final step.

First of all, Ishi takes his leather pad, doubles it over the end of his left thumb, and ties it in place with a string. Then he grips the arrowpoint near the base, holding it firmly between the end of the protected thumb and adjoining intlex finger. With the right hand he directs the point of the notching tool against the elge of the arrowpoint at the place where the notch is to be, and by a slight pressure removes a small chip. The fool, as shown in plate II [fig. 186], is held perpendicular to the plane of the arrowpoint and is pushed forward as if to be driven into the end of the thumb. For each minute chip thus re- 
moved the arrowpoint is reversed until the notch is of the lepth desired. The successful act requires some deftness, or the stem is sure to be severed from the blade of the arrowpoint. Ishi seldom fails, however, especially when working

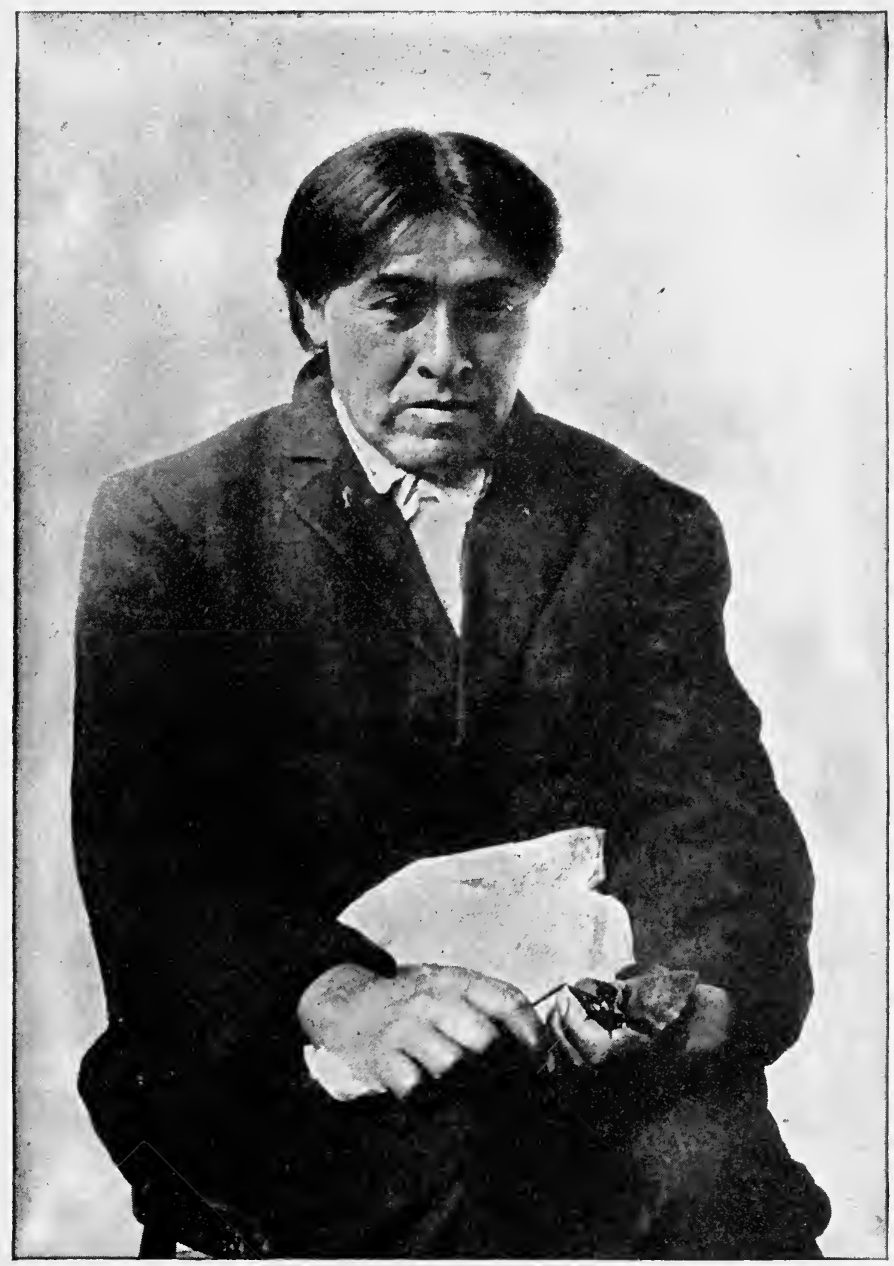

FIG. 186. The process of notching and serrating.

with glass, and he completes the two notches often in about half a minute's time. If the edge of the arrowpoint was to be serrated, Ishi would doubtless proceed in the same way, although I never asked him to try. 


\section{CRUMBLING PROCESSES}

\section{Dirfect Free-hand Percussion}

Crumbling the surface of the stone treated with a hammerstone, pick, or kindred tool, hafted or unhafted, held in one hand, the stone worked being held in the other hand.

\section{Direct Rest Percussion}

Crumbling the surface of the stone treated with a hammer, pick, or kindred tool, hafted or unhafted, held in one or both hands, the stone worked being stationary.

\section{Indirect Rest Percussion}

Crumbling the surface of the stone under treatment by means of a chisel, drill, or like tool, hafted or unhafted, held in one hand and driven by a hammer or mallet held in the other hand, the stone being stationary.

7 IIE evolution of the crumbling processes has been considered briefly in a preceding section, and further reference to this particular phase of the subject need not be made here. These processes are, however, of great technical interest, and it would be hard to overestimate their importance to Stone Age Importance of the peoples, and indeed to peoples of all times and cul-
Irocess ture grades down to the present day. The higher manifestations of implement making, sculpture, and the building arts everywhere must be placed largely to the credit of these processes. When, with the advance of culture, hard metals took the place of stone as the material for implements, the processes remained practically the same, although in civilization mechanical devices for operating were greatly improved. The edge or point of the electrically driven drill of steel does not differ in type from the edge or point of the stone chisel or pick. It is to be noted that the crumbling processes are closely allied with and shade into incising, abrading, and piercing, as when a certain pointed or narrow-edged tool is used at one moment as a pick to crumble or cut, at the next as a drill to abrade, and again as an awl or punch to pierce. 
The shaping acts in this class of operations are pereussive, and the impact of the implement results in the crumbling of The Crumbling minute portions of the surface of the stone, which

disappear as dust. 'The implements are necessarily hard and tough, while the stone shaped is sufficiently tough practically to preclude fracture by the ordinary blow. Should the implement be so used as to dislodge considerable portions of the stone the operation would have to be classed with the fracture processes. No specialized tool was necessary for the primitive artisan in the simpler crumbling work, though such came in time to be made or were developed through modifications due to long use in the practice of the arts. The several crumbling acts are expressed by the terms pecking, battering, chiseling, and percussive drilling, the term peck-

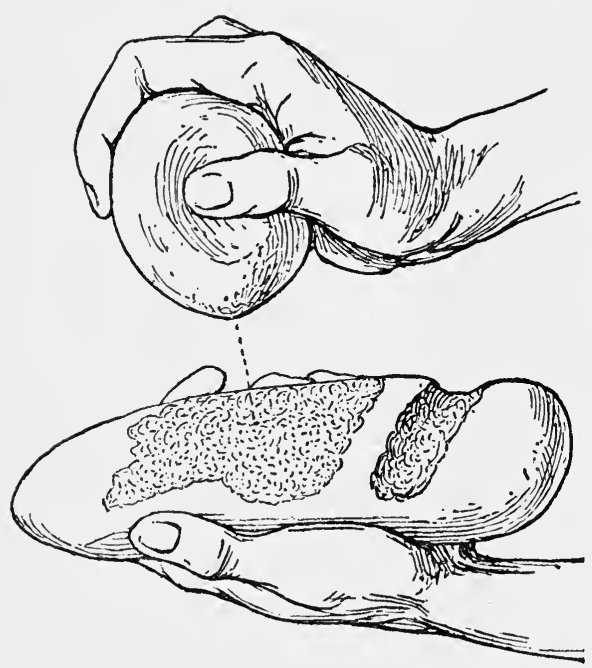

116. 187. Shaping a stone ax by the pecking (crumbling) process.
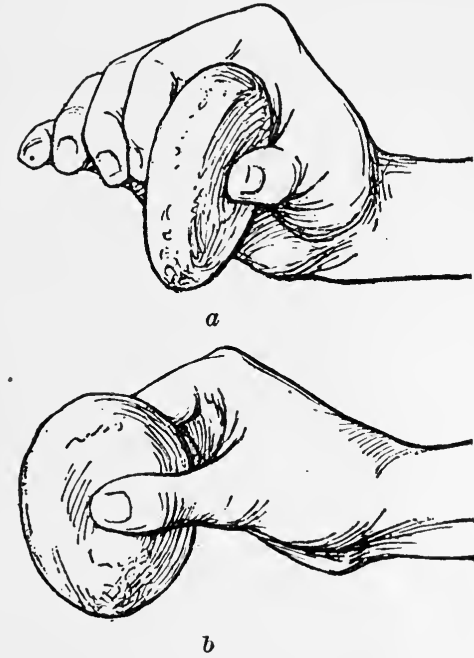

Fig. 188. Method of holding the discoidal hammerstone.

ing being commonly employed for the operation by which shaping was more usually accomplished by the aborigines.

The method most effective for the shaping of minor artifacts is illustrated in figure 187. The implement under treat-

Direct Free-hand l'ercussion ment in this case is an ordinary grooved ax in process of elaboration from an ovoid bowlder. The blade is being reduced to desired thinness by strokes of the discoidal hammer. Held thus in the hand, the incipient ax is readily turned to meet the blows of the hammer, which are rapidly delivered, and the elasticity of the hand support prevents breakage under strokes which, were the ax stationary, would shatter it. Figure $188, a, b$, illustrates the man- 
ner of holding the hammer suspended between the thumb and finger tips, thus minimizing the jar and strain.

Examples of hammerstones regarded as especially adapted to the work of shaping minor artifacts by crumbling are The Implements shown in figure 189, $a, b$. 'These are specialized by more or less decided flattening of the face or by slight indentations. Doubtless these discoidal forms, which are in some localities very numerous, served on occasion for other purposes. Although the discoidal pitted hammer is regarded by some students of the subject as the pecking tool par excellence, it is observed that in very many cases the periphery bears no traces of the battering which necessarily results from this use. It is also true that stones of other available shapes were employed in the crumbling work. The pitted disk may have been a favorite form in some sections, especially for minor work, but deep carving required pointed tools, and the

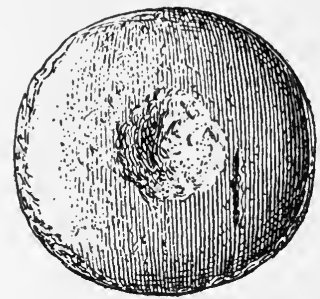

$a$

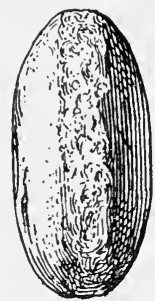

Frg. 189. Typical discoidal hammerstones.
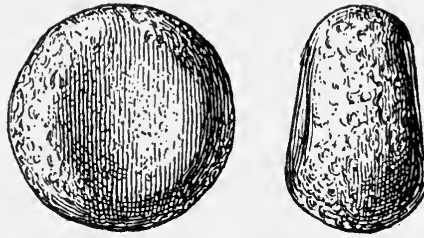

$b$

(One-half actual size.)

greater work of sculpture and building was accomplished with heary tools, grooved or otherwise suitably shaped for attaching a haft. It is more than probable that celts, axes, picks, and chisels normally devoted to other uses were often direrted, as the need arose, to stone cutting and sculpture.

Rough shaping by pecking usually precedes the grinding-polishing processes and is preparatory to them, although multitudes of implements and utensils are deroted to their respective uses without the finishing treatment or with but slight grinding to sharpen the edges and points. The technical history of individual polished artifacts is thus usually complex and often obscure, since they have passed generally through stages involving two or more processes. When in such cases the finishing processes are complete, traces of the earlier stages are obliterated. However, there is no longer any mystery about the processes, which are now fully removed from the category of lost arts. This result has been brought about largely by intelligent experiment and by the study of sites of manufacture where the shop 
rejectage, as in the chipping arts, records the various operations with accuracy if not with entire fullness.

Eximples of implements reduced to approximate form by pecking are illustrated in figures 190 and 191. The specimen shown in figure 187 is an incipient grooved ax. The general form is well developed, but the groove has not been commenced. The specimen shown in $b$, originally a water-worn bowlder, was specialized in the rough by pecking, the blade and the groove being well advanced and ready for the polishing tool.
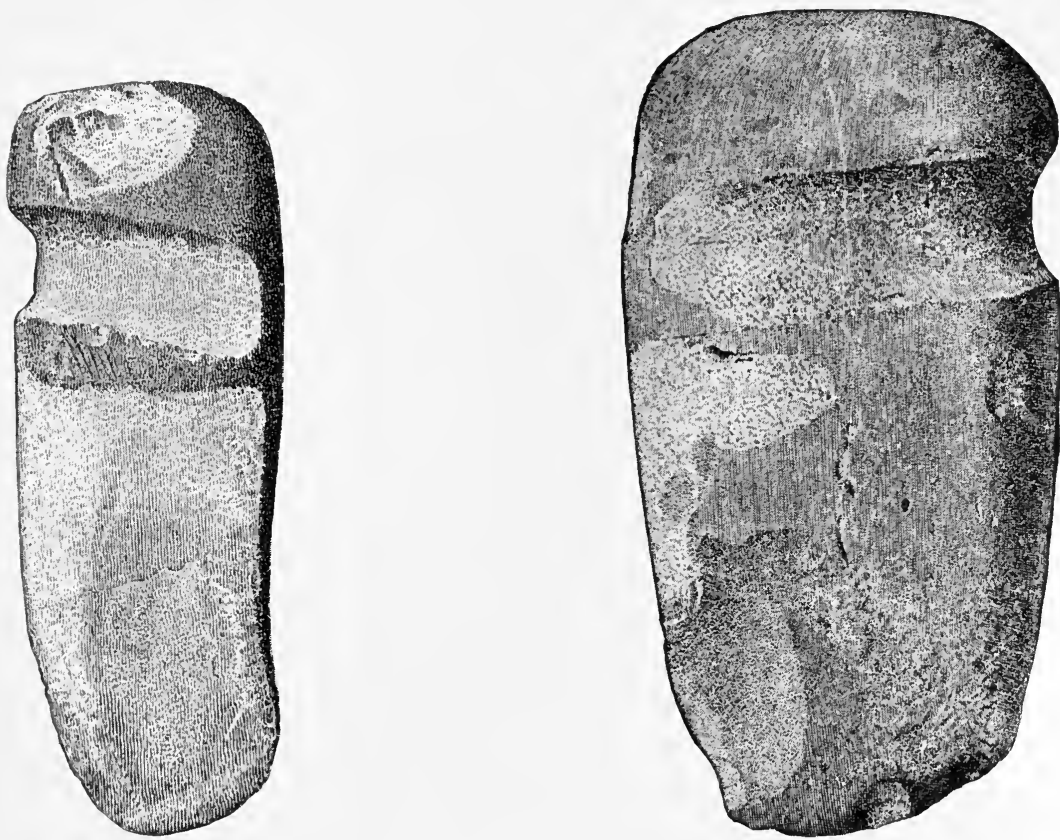

Fig. 190. Stone axes in process of manufacture by pecking (crumbling) with hammerstones.

The P'otomac Valley, a field studied in much detail by the writer, affords plentiful evidence bearing on the practice of Implement Manu- the crumbling processes as applied to the manufac-
facture ture of stone implements. Here a favorite variety of stone for the manufacture of celts and axes was a compact, greenishgray trap or traplike contact rock, occurring originally in the highland of Maryland and Virginia, but obtained by the aborigines very largely from the bowlder beds deposited by the rivers near their exit from the highland, or at other points higher up the streams where 
partially rounded fragments are found in large numbers. The most striking example of this class of site yet observed is Luray, va., Work- located in Page County, Va., near the village of
shops

Luray. It occupies several acres of bottom land on the right bank of Pass Creek, a few hundred yards above its confluence with Hawksbill Creek. The materials utilized by the inhabitants of this site were derived from great accumulations of pebbles,
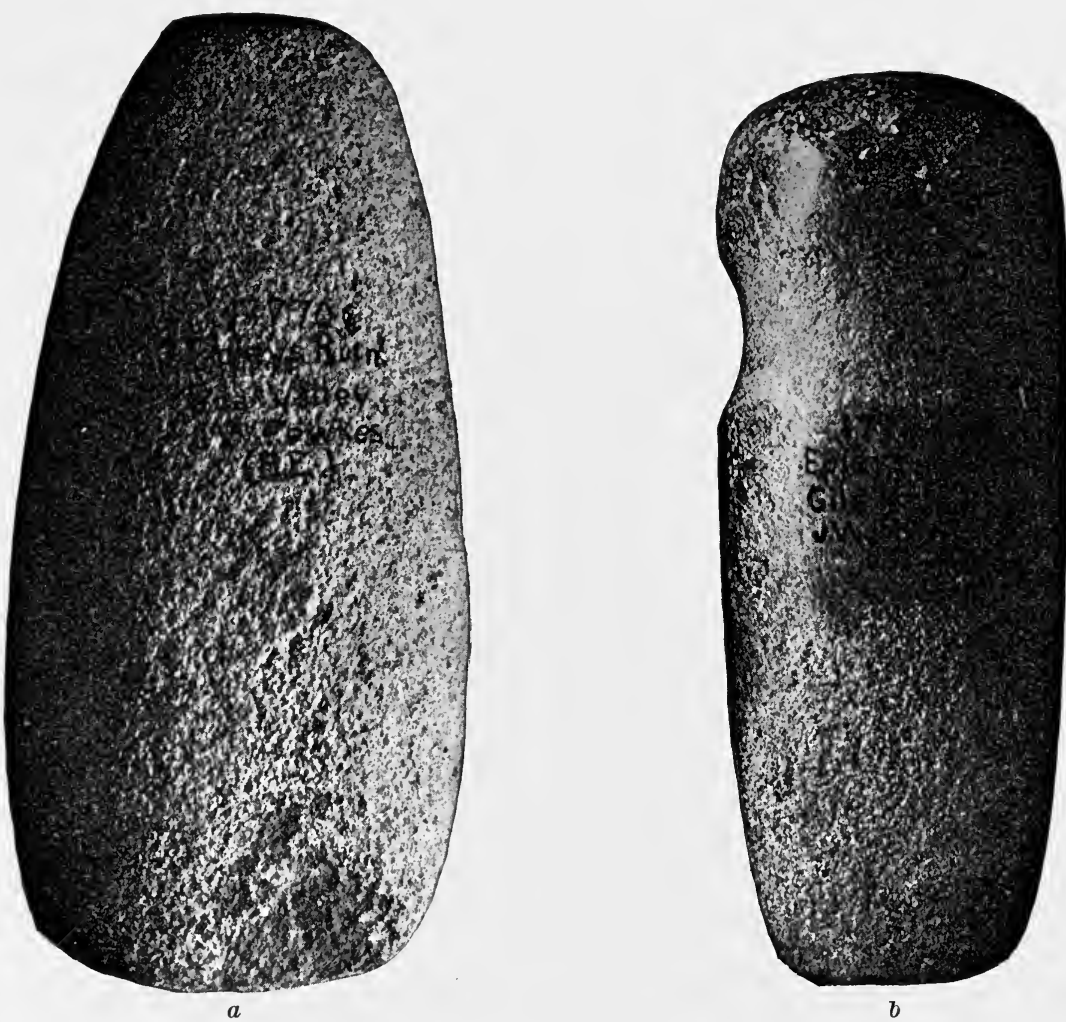

FIg. 191. Incipient grooved axes showing the effects of pecking (crumbling) with a hammerstone.

bowlders, and partly water-worn fragments of dioritic rock present in the banks and bed of the stream, and now exposed where freshets have torn channels through the alluvial bottom. On the village site about a low central mound the phenomena of manufacture are more or less confused with those of utilization, but separation of the varied features is in the main possible and easy. It was found by study of the shop refuse that in very many cases the work of shaping by the pecking process was preceded by chipping and followed by grinding. Abortive forms representing all stages of the work were 
found in numbers. Here is the bowlder, with a few chips removed in testing the material, or the shattered fragments resulting from breakage under the preliminary blows of the hammer. Here are hundreds of rejects (fig. 192) representing various stages of manipulation-the roughly chipped forms $a$ and $b$, the more adranced shapes in which the pecking is begun, $c$, and blades approximating closely the final form, $d$. Here also are many pieces broken transversely under the hammer at different stages of the work, and finally here are examples of the completed implements in which the grinding process has obliterated to a large degree the conchoids of chipping as well as the indentations due to the crumbling tool. ${ }^{1}$

Extended experimentation in the work of shaping stone implements and utensils by the pecking process was undertaken by Mr.

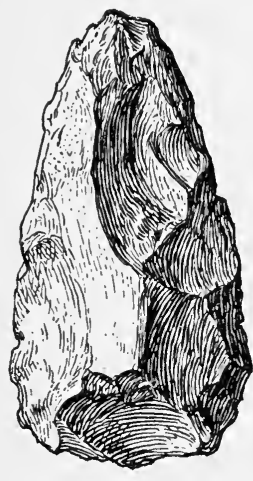

$a$

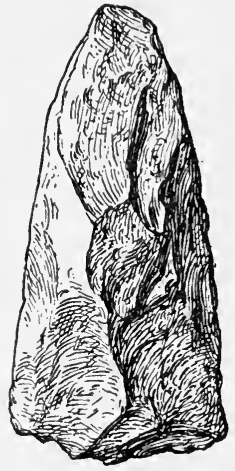

b

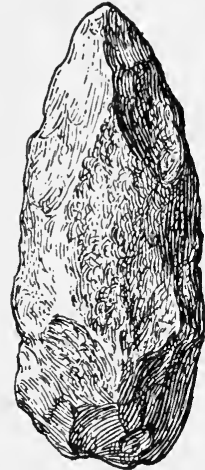

c

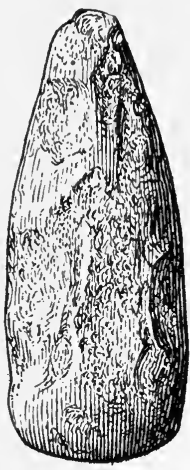

$d$

Fig. 192. Specimens illustrating successive steps in shaping hatchet blades by fracture, crumbling, and grinding.

J. D. McGuire at the National Museum some years ago, and the valuable results of his work are available. ${ }^{2}$

The crumbling processes had, howerer, a much wider field than that of shaping implements and utensils by pecking Wide Range of with a hammer. Vast numbers of petroglyphs
I'rocesses I'rocesses appear on slabs, bowlders, and broad rock faces throughout America, displaying great diversity in manner of execution and finish. Hammerstones of ordinary form were doubtless employed, but pointed picklike implements, hafted or unhafted, were better suited to the purpose (fig. 193). Figure 194 is intended to illustrate the probable method of carving the minor relics of hard stone, many of which are elaborately embellished with symbolic

${ }^{1}$ IIolmes, Manufacture of Pecked-abraded Stone Implements.

2 See his two memoirs entitled "The Stone IIammer and Its Various Uses" and "Materials, Apparatus, and Processes of the Aboriginal Lapidary."

$38657^{\circ}-19-$ Bull. 60 , pt I- 23 
figures in low and high relief, or even in part in the full round. The question naturally arises as to the kind of tool employed in this work, since so few are found seemingly well adapted to it. The chisel-

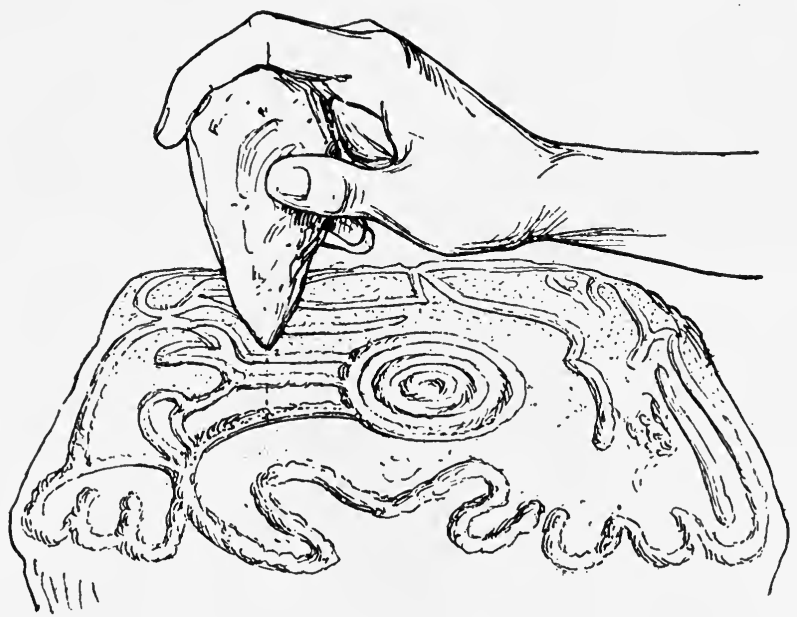

Fig. 193. Carving with a pointed bit of stone held in the hand.

like implement of flint (fig. 195), obtained somewhere in Yucatan, properly hafted, would have been effective. It seems probable that the abrading process must have been called into service for this class of sculpture more fully than we are accustomed to allow. The

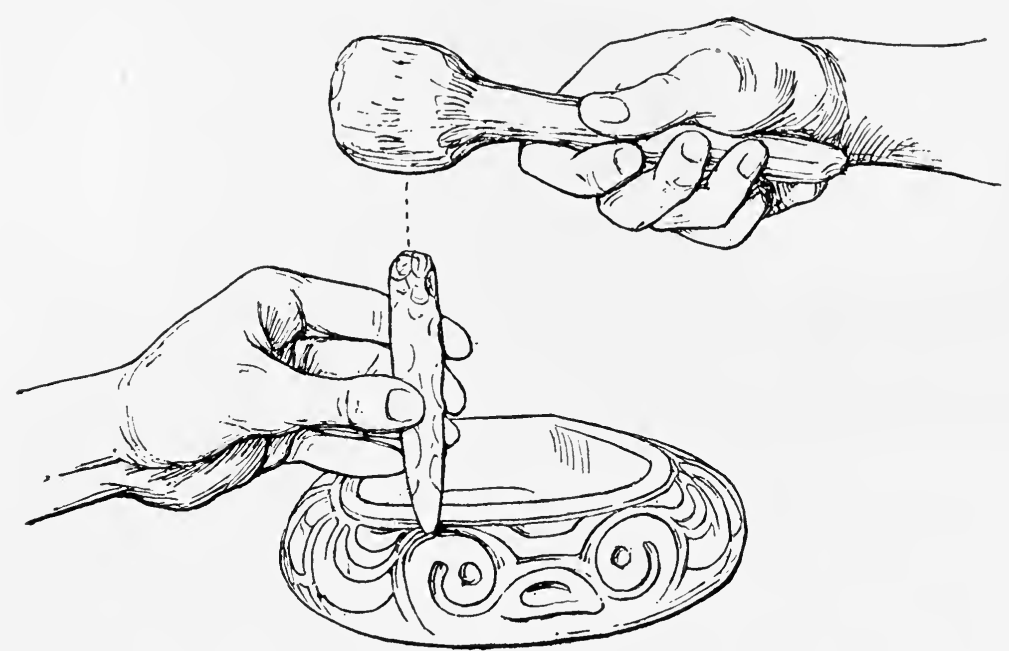

Fig. 194. Probable manner of employing the chisel in carving stone.

drawing reproduced in figure 196 serves to indicate three variants of the crumbling processes probably in more or less general use amon: the stone workers of Middle America. 
Still more important was the work of the bruising-crumbling tool in getting out and dressing Quarrying Stone the stone employed in the building and sculptural arts. Vast supplies of the requisite materials were hewn from the massive formations of the earth's crust by the man with the pick and hammer. The task of cutting out the steatite from the northern quarries was more difficult and laborious than the shaping of the many artifacts made from it, the processes and tools, however, being in large part the same. Far more arduous was the task of extracting the blocks of limestones, trachytes, granites, and other hard and massive rocks from the undisturbed beds in the hills. Under the face of a cliff near Mitla the writer came upon a partially hewn block of trachyte (fig. 197) which had been abandoned by the workmen while the labor of separating it into three parts was in progress. The rude hammers and picks, one a much battered celt, with which, it is as-
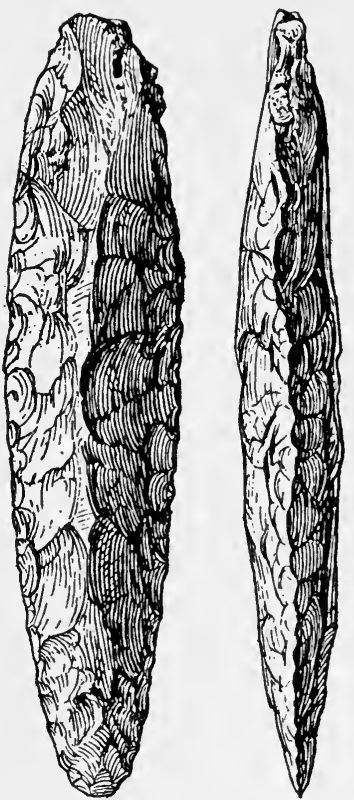

Fig. 195. A chisel-like blade of flint from Yucatan. sumed, the channels were being crumbled through the mass, were scattered about in profusion (fig. 198). On the mountain side above the

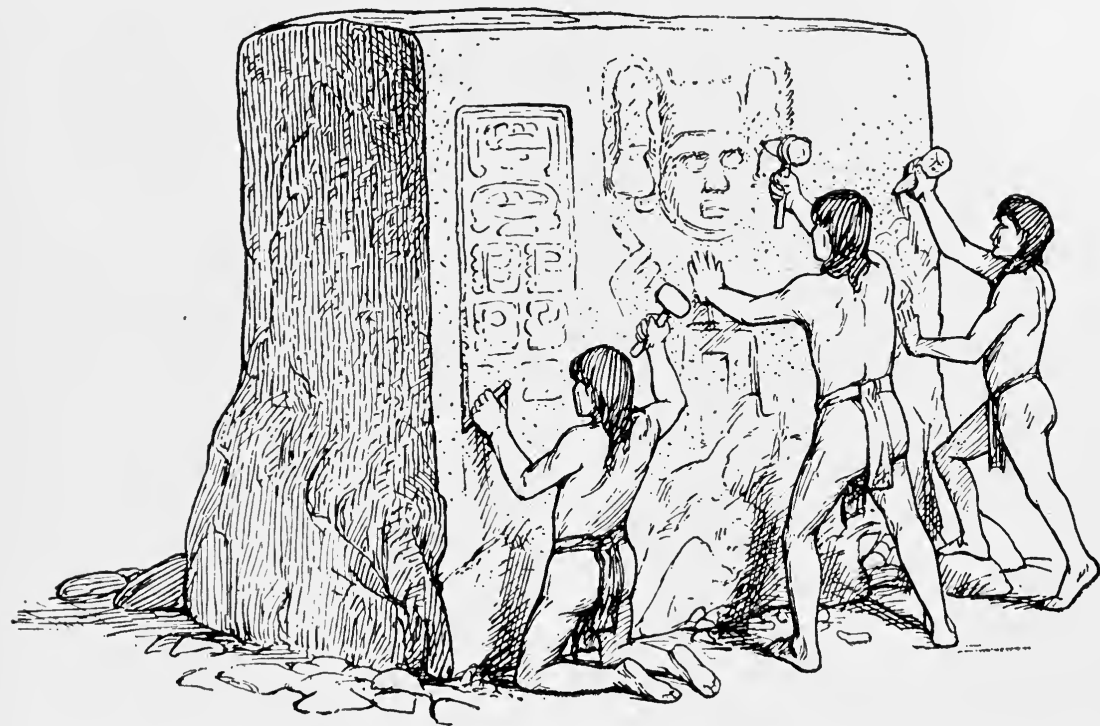

Fig. 196. Three forms of the crumbling-carving process-with mallet and chisel, with hafted pick, and with pick held in the hand. 
writer's companion, Mr. Edward H. Thompson, encountered traces of more extended work where the great blocks had been cut out of the face

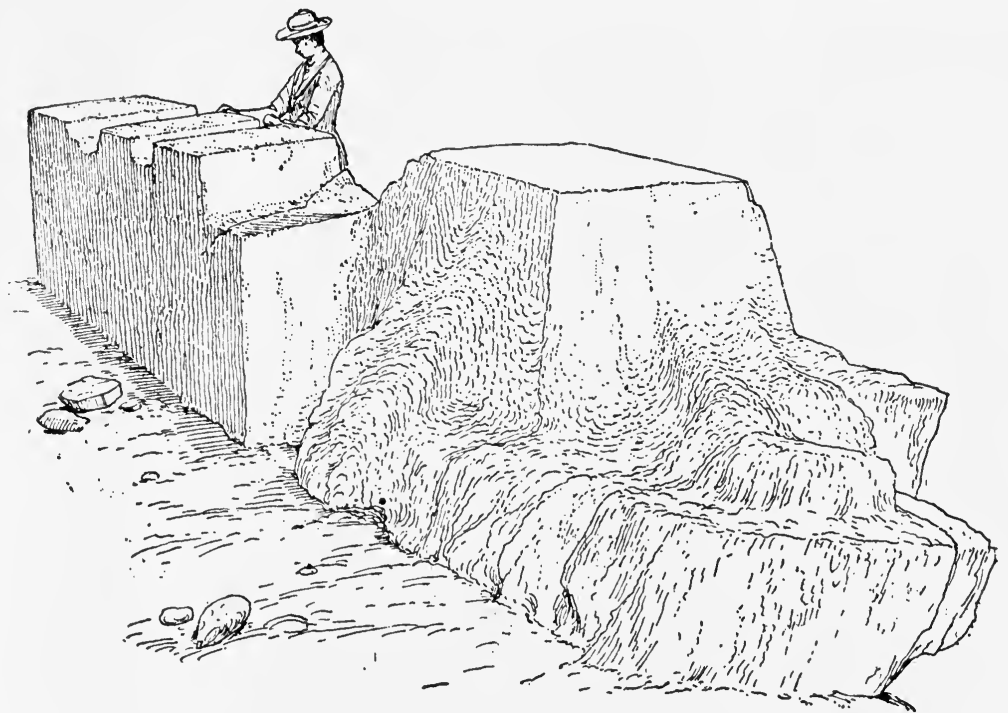

Fig. 197. Partially dressed blocks of sione in an ancient quarry at Mitla, Mexico.

of the living rock, to be transported, no one knows how, and built into the temples and tombs of Mitla. The time and labor involved in
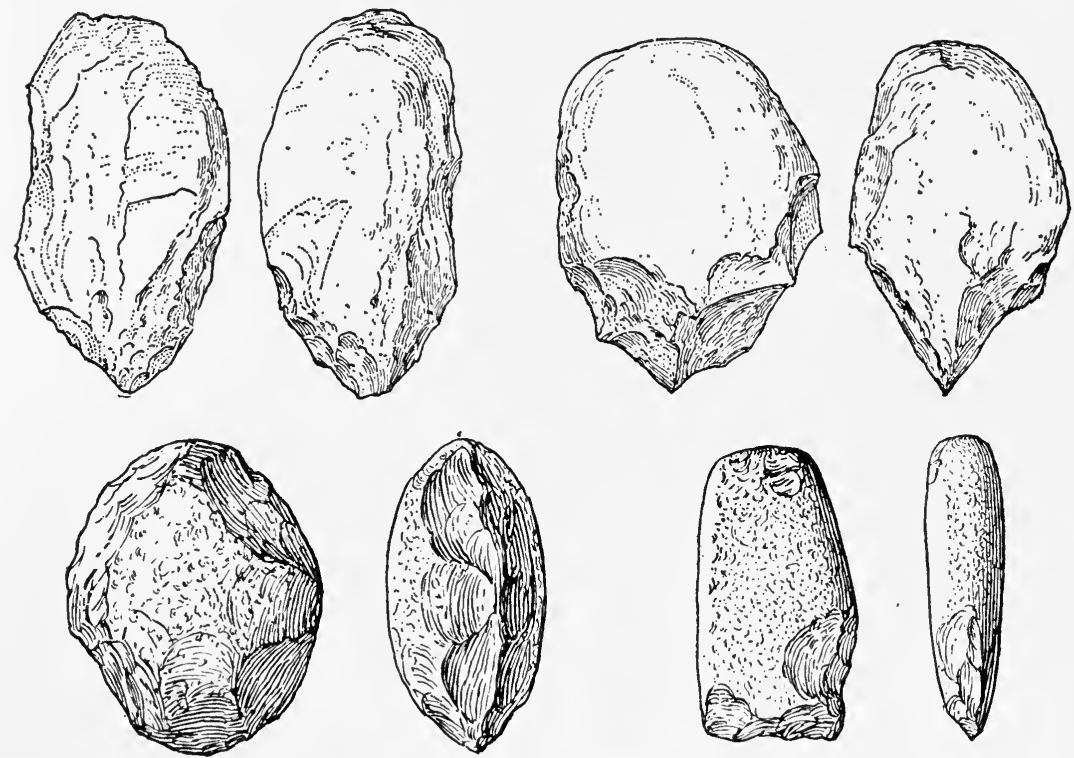

FIG. 198. Rude stone-cutting (crumbling) implements found on a quarry site at Mitla, Mexico.

this initial phase of the stone-using arts can hardly be justly estimated by those who know only the methods of civilization. Figure 
141 represents a life-size group, recently constructed in the National Museum under the direction of the writer, to illustrate graphically our understanding of the methods of stone working practiced by the more civilized peoples of Middle and South America.

The marvel grows when gradually we come to realize the vastness of the monumental remains of hewn stone which II on u m e n t a 1 ITorks

mark the culture centers of the ancient peoples of Middle and South America. Not only did the huge blocks employed in the building of a hundred cities have to be pecked out and hewn and fitted into their places, but the countless sculptured embellishments, the massive stelæ, and the individual sculptures in relief and the round, which are the marvel of the western world, had to be wrought into shape by the tedious process of crumbling. When the imagination traverses the field from Central Mexico to Argentina and recalls the traces of former enterprises in such centers as Chichen Itza, Uxmal, Palenque, Quirigua, Copan, Tiahuanaco, Cuzco, Machu Picchu, and the rest, the magnitude of the industrial achievement of a Stone Age people is borne in on us with almost overwhelming force.

At Tiahuanaco the writer gazed with wonder on the huge monoliths assembled on the site, brought no one knows whence or how far, but apparently never built into the structures for which they were intended, for if once placed in orderly form what force or agency could have arranged them as they appear to-day? All had to be hewn from the quarry with picks of stone or bronze, a work followed by transportation in which marvelous difficulties were overcome, and finished by crumbling and abrasive methods. The vast achievements of the ancient Peruvians in quarrying and dressing the great stones employed in their Cyclopean structures, as described by Squier and others, attest the efficiency and possibilities of the crumbling process. Describing the fortress of Olantaytambo, Squier writes as follows:

The stones composing it or lying scattered over its area are of a hard red porphyry, brought from quarries more than 2 leagues distant, upward of 3,000 feet above the valley, and on the opposite sicle from the fortress. They are nearly all hewn into shape and realy to be fitted, and among them I noticed several having places cut in them for the reception of the $\mathbf{T}$ clamp, which $\mathbf{I}$ have mentioned in describing the remains of Tiahuanuco. One of these porphyry blocks, built in the wall of what appeared to be the beginning of a square builling, is 18 feet long by 5 broad and 4 deep, not only perfectly squared but finely polished on every face, as are also the stones adjoining it, to which it fits with scarcely perceptible joints.

The most interesting series of stones, however, are six great upright slabs of porphyry supporting a terrace, against which they slightly incline. It will be observed that they stand a little apart, and that the spaces between them are accurately filled in with other thin stones, in sections. The sides of these, as well as of the larger slabs which they adjoin, are polished. The following 
table gives the dimensions of the slabs in feet and tenths, commencing with the one at the left:

\begin{tabular}{|c|c|c|c|c|c|c|}
\hline & $\begin{array}{c}\text { No. } \\
1 .\end{array}$ & $\begin{array}{c}\text { No. } \\
2 .\end{array}$ & $\begin{array}{c}\text { No. } \\
3 .\end{array}$ & $\begin{array}{c}\text { No. } \\
4 .\end{array}$ & $\begin{array}{c}\text { No. } \\
5 .\end{array}$ & $\begin{array}{l}\text { No. } \\
6 .\end{array}$ \\
\hline 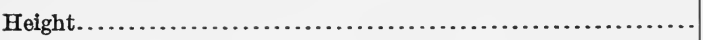 & 11.5 & 10.7 & 12.8 & 12.1 & 12.4 & 13.3 \\
\hline Width at base.................................. & 6.2 & 4.7 & 3. 7 & 5.7 & 7.0 & 7.1 \\
\hline 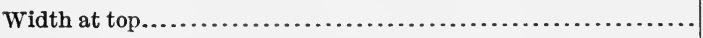 & 5.4 & 4.4 & 4.2 & 6.0 & 6.8 & 6.4 \\
\hline 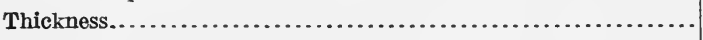 & 4.0 & 3.5 & 2.3 & 2.6 & 2.5 & 5.9 \\
\hline
\end{tabular}

The faces of these slabs are not hewn entirely smooth, but have several projections, indicating that the work of accurately facing them was never completed. No. 4 shows traces of the same kind of ornamentation observed on some of the blocks at Tiahuanuco, only here the ornament is in relief. But gigantic as are these blocks, they are small in comparison with the "Tired Stones" lying on the inclined plane leading to the fortress or at its foot, as if abandoned there by the ancient workmen. One of these is 21 feet 6 inches long, by 15 feet broad. It is partly embedded in the ground, but shows a thickness of 5 feet above the soil. ${ }^{1}$

The traces of the ancient work at Cuzco as described by Squier are equally marvelous:

The stones composing the walls are massive blocks of blue limestone, irregular in size and shape, and the work is altogether without doubt the grandest specimen of the style called Cyclopean extant in America. The outer wall, as I have said, is heaviest. Each salient terminates in an immense block of stone, sometimes as high as the level of the terrace which it supports, but generally sustaining one or more great stones only less in size than itself. One of these stones is 27 feet high, 14 broad, and 12 in thickness. Stones of 15 feet length, 12 in width, and 10 in thickness are common in the outer walls. They are all slightly beveled on the face, and near the joints chamfered down sharply to the contiguous faces. The joints-what with the lapse of time, and under the effects of violence, earthquakes, and the weather-are not now, if they ever were, so perfect as represented by the chroniclers. They are, nevertheless, wonderfully close, and cut with a precision rarely seen in modern fortifications. The inner walls are composed of smaller and more regular stones, and are less impressive. ${ }^{2}$

Garcilasso de la Vega, as quoted by Squier, writes of the marvelous structures of Cuzco as follows:

This was the greatest and most superb of the edifices that the Incas raised to demonstrate their majesty and power. Its greatness is incredible to those who have not seen it; and those who have seen it, and studied it with attention, will be led not alone to imagine, but to believe, that it was reared by enchantment-by demons, and not by men, because of the number and size of the stones placed in the three walls, which are rather cliffs than walls, and which it is impossible to believe were cut out of quarries, since the Indians had neither iron nor steel wherewith to extract or shape them. And how they were brought

1 Squier, Peru : Incidents of Travel and Exploration in the Land of the Incas, pp. 500 501.

2 Ibid., pp. 471-472. 
together is a thing equally wonderful, since the Indians had neither carts nor oxen nor ropes wherewith to drag them by main force. Nor were there level roads over which to transport them, but, on the contrary, steep mountains and abrupt declivities to be overcome by the simple force of men. Many of the stones were brought from 10 to 15 leagues, and especially the stone, or rather

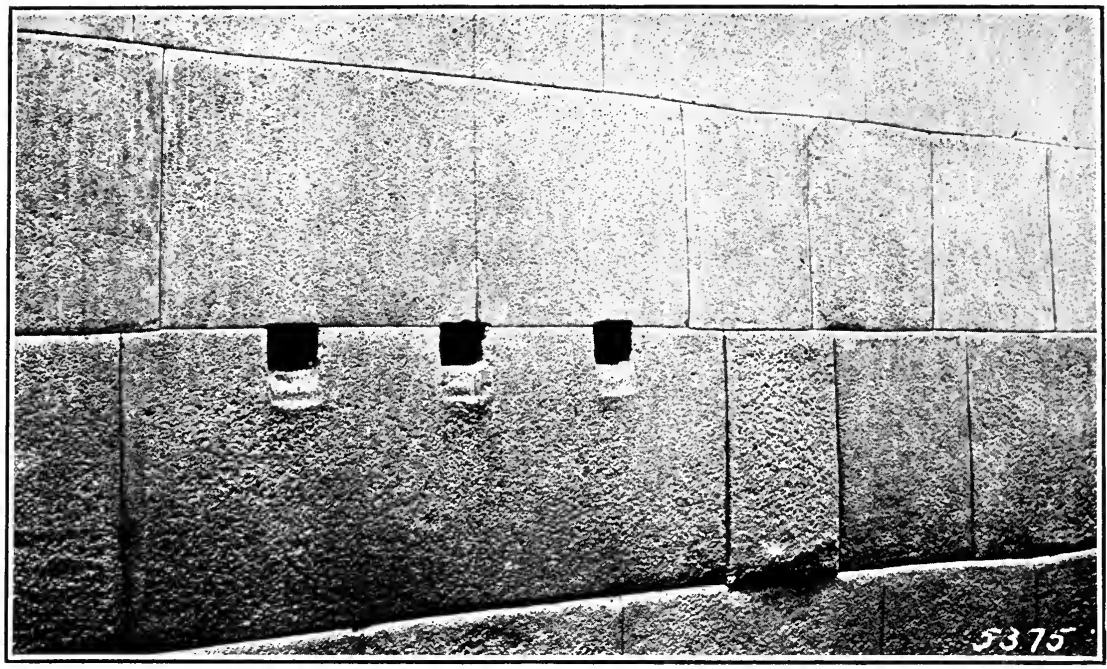

$a$

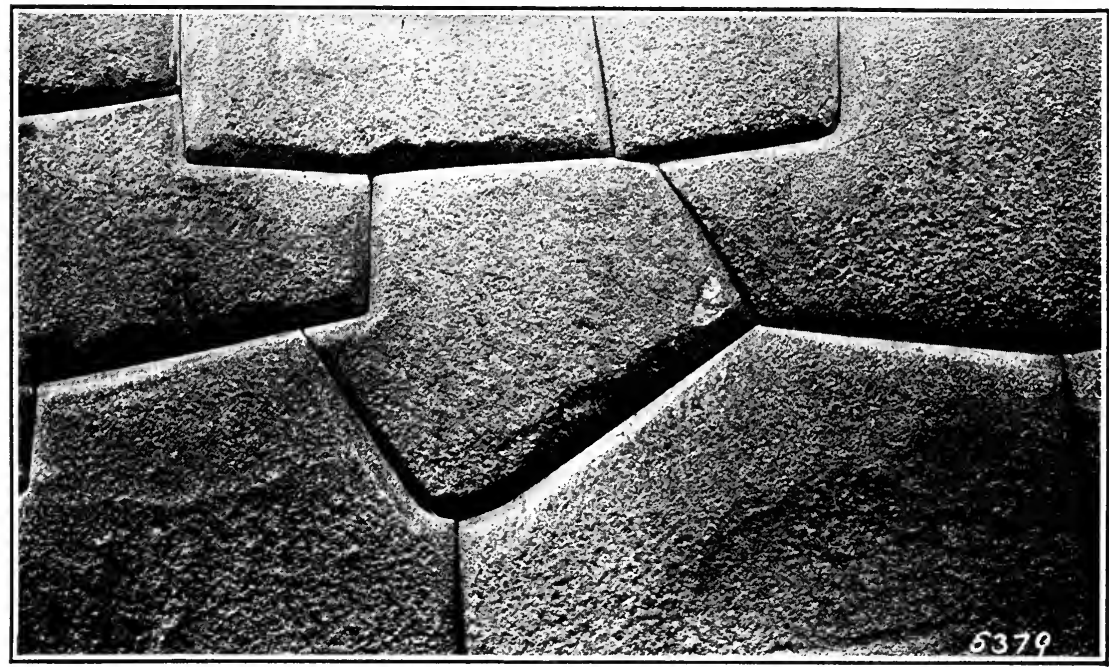

$b$

FIG. 199. $a, b$, Marvelous mural masonry of the ancient Peruvians.

the rock, called Saycusca, or the "Tired Stone," because it never reached the structure, and which it is known was brought a distance of 15 leagues, from beyond the river of Yucay, which is little less in size than the Guadalquivir at Cordova. The stones obtained nearest were from Muyna, 5 leagues from Cuzco. It passes the power of imagination to conceive how so many and so great stones 
conld be so accurately fitted together as scarcely to admit the insertion of the point of a knife between them. Many are indeed so well fitted that the joint can hardly be discovered. And all this is the more wonterful as they had no squares or levels to place on the stones and ascertain if they would fit together.

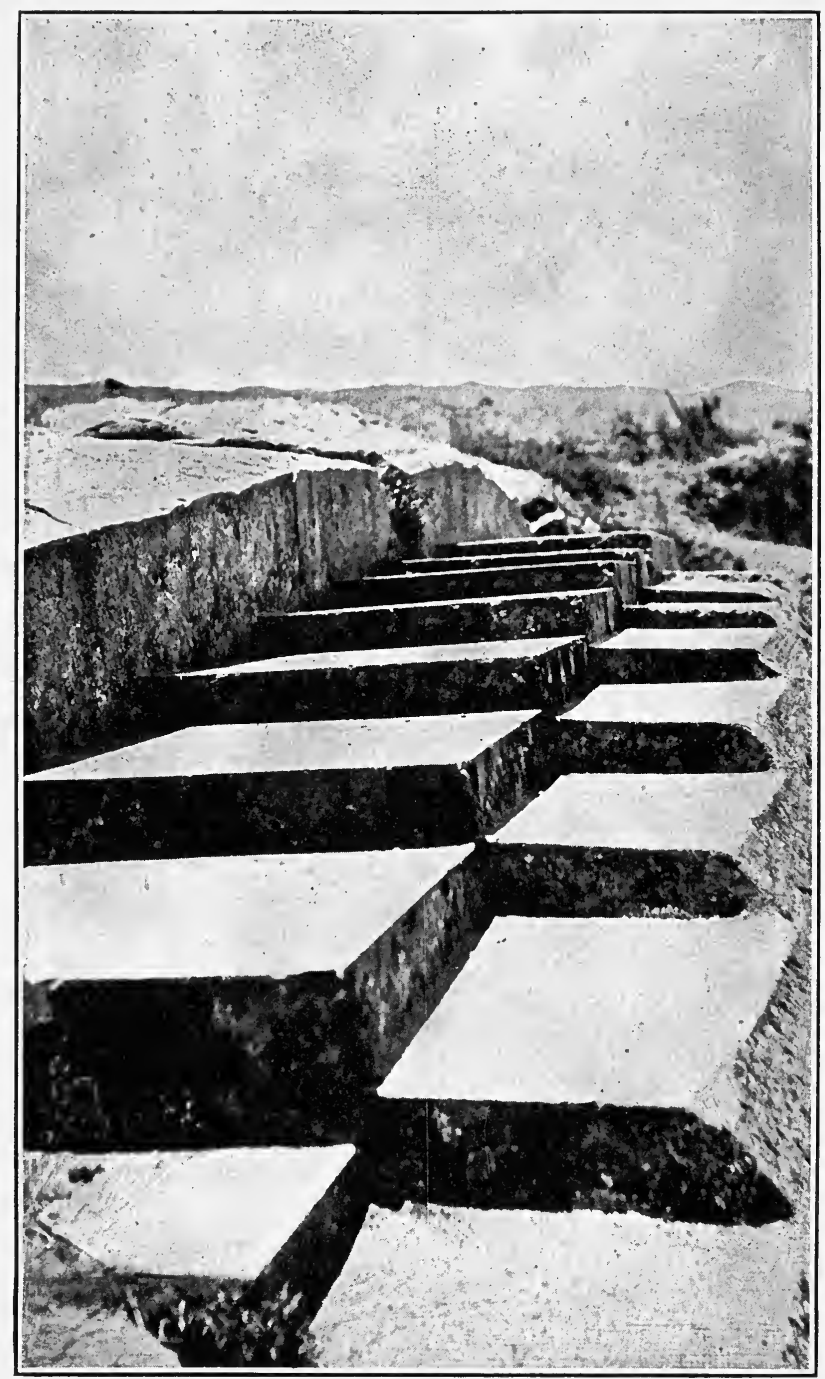

Fig. 200. Carving of the massive rock in place by the ancient Peruvians.

How often must they have taken up and put down the stones to ascertain if the joints were perfect! Nor had they cranes, or pulleys, or other machinery whatever. . . I Int what is most marvelous of the edifice is the incredible size of the stones, and the astonishing labor of bringing them together and placing them. ${ }^{1}$

1 Squier, Peru: Incidents of Travel and Exploration in the Land of the Incas, pp. $468-469$ 
The perfection of the mural masonry of the Incas is shown by the examples illustrated in figure 199, $a, b$. This superb work, executed by the crumbling process, supplemented by the abrading process, is not confined to a few limited examples, but extends to great buildings, fortresses, embankments, aqueducts, and bridges of vast extent.

This marvelous hewing of mural surfaces was not all. The builders of the Cuzco Valley extended their passion for sculpture to the elaborate carving of the massive rock in place, a good specimen of this work being shown in figure 200, selected from numerous equally noteworthy examples illustrated by Bingham. The purpose of the carving of great rock masses and even the massive outcrops of the mountain sides is not determined, but that it was the result of a most serious purpose and executed with primitive tools and at the expense of great labor is beyond dispute.

Hardly less to be wondered at as products of primitive handicraft than these strange traces of sculptural and architectural enterprise are the multifarious products of the lapidarian art-the personal ornaments, amulets, idols, and the like, made of jade, agate, turquoise, emerald, and other precious and semiprecious stones recovered by tens of thousands from dwelling sites and burial places throughout America, all or nearly all of which had to pass through the crumbling stage of elaboration before the abrading-polishing processes could proceed with the work. 


\section{ABRADING PROCESSES}

THE abrading processes, as employed in stone-shaping by primitive peoples, are very generally supplementary to frac1 turing and crumbling. They may be assembled for descriptive purposes in seven principal groups:

\section{Grinding, Whetting}

Simple manual abrasion, the stone abraded being held in the hand and rubbed on another stone or abraded by another stone held in the hand. In large work the abrader may have been in some cases hafted or otherwise mounted to increase its efficacy.

\section{SAWING}

Simple manual abrasion with edges, plain or notched, or filaments employed, often with the aid of sand, in channeling and dividing.

\section{Scraping}

Abrasion of comparatively soft stone with scraping implements of various types held in the hand.

\section{Engraving}

Abrasion with a point as in engraving.

\section{Drilling}

Abrasion with simple manual or machine revolved drill points, solid or tubular.

\section{Scouring, Rasping}

Abrasion by scouring with sand moved beneath or held embedded in a somewhat yielding surface, as of leather.

\section{Polishing}

Abrasion with hard or soft surfaces variously applied to give finish and polish. 
The abrading crafts employ a wide range of implements and mechanical appliances and are of vast importance in the economy of all peoples in all stages of progress. It is observed that they are applicable in the treatment of all materials in degrees varying with the nature of the material. Abrasion in its simplest form consists of rubbing one object, as of stone, against another with such force as to remove small particles from one or both, but in the practice of the art for ages, abrading implements and devices of many kinds have been evolved and their operation is expressed by such terms as grinding, whetting, scraping, scratching, engraving, sawing, drilling, boring, and rubbing. Even the polishing arts, howsoever delicate, act by the removal of exceedingly minute particles. All varieties of stone are abradable, and all stones can be made to serve in the active operation of abrading. Gritty textured varieties serve for the rougher reducing and surfacing, and the finer-grained, even agates, jades, and the like, for whetting and smoothing, and sand and finely pulverized minerals of many kinds are employed in various ways as shaping and finishing agents.

Many forms of abrading work have been observed in actual operation among the tribes, and not a few are in use to-day; in fact, the processes are in use among other than primitive peoples, and the higher forms of abrading arts in use among lapidaries, sculptors, and builders of to-day do not differ from the primitive forms in principle but rather in the improved mechanical devices employed.

Grinding and whetting implements are exceedingly numerous among prehistoric relics, and their use and manner Grinding, whet - of use can be inferred in many cases from their shape
ting and the traces of use which they bear. It can not be said with certainty, however, whether a particular form was employed exclusively or even partially in the shaping of stone, and many of the implements probably served for the treatment of other materials, as shell, bone, wood, and metal, as occasion required, and even in the manipulation of pliable materials, as Irincipal Use hides and filaments, but their greatest field of usefulness was, no doubt, in the shaping and finishing of minor artifacts and in giving surface finish to sculptures generally and to building stone. Grinding and whetting stones of three distinct types are shown in figures 201, 202, and 203. An instructive series of illustrations of the use in abrading work of Flake Abraders simple spalls struck from bowlders by the ancient occupants of the shores of Lake Michigan is given by Phillips. ${ }^{1}$ The various positions and movements are determined by observing traces of the work and wear displayed by the specimens themselves (fig. 204).

${ }^{1}$ Phillips, Stone Implements from the Southern Shores of Lake Michigan, p. 587. 
The abrading work was by no means limited to hand-wielded im-
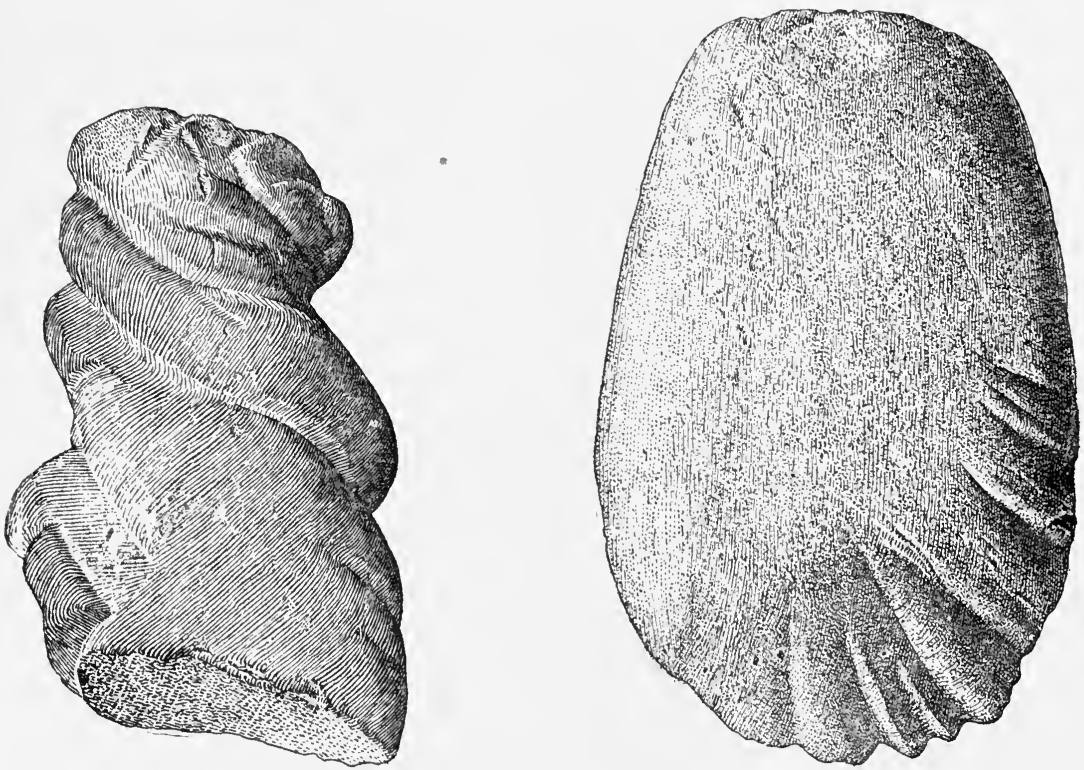

Fig. 201. Common forms of abrading stones from the Atlantic States.

plements as applied to artifacts under treatment. Hand-held objects in process of manufacture were rubbed on stationary grindstones (fig. 205 ), and numerous examples hare been observed where depressions and grooves are worn in the surfaces of rock bodies in situ (fig. 206).

Edged scraping tools of varied forms were in univerScraping sal use by primitive peoples, but little can be said regarding their use in the treatment of stone. There can be no doubt, however, that stone scrapers as well as knires of stone and metal served in shaping the softer stones, as catlinite, soapstone, cannel coal, and fire clay. Artifacts made of these materials bear unmistakable traces of the employment of implements of this

type. Sharp-pointed Engraving implements were employed in engraving figures on stone surfaces, as countless examples indicate, but the particular.

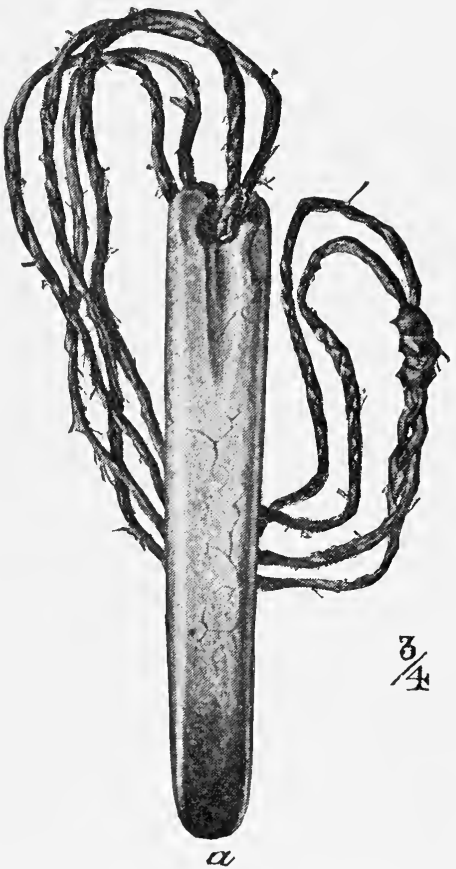

Fig. 202. Type of whetstone of jade in common use among the western Eskimo. tools employed are not readily identified. 


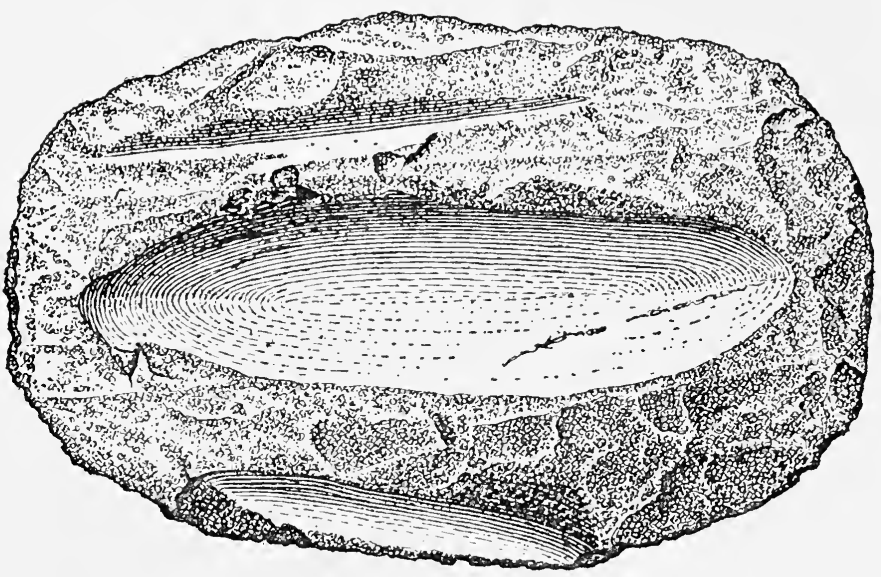

Fig. 203. Grooves produced by the abrasion of implements.
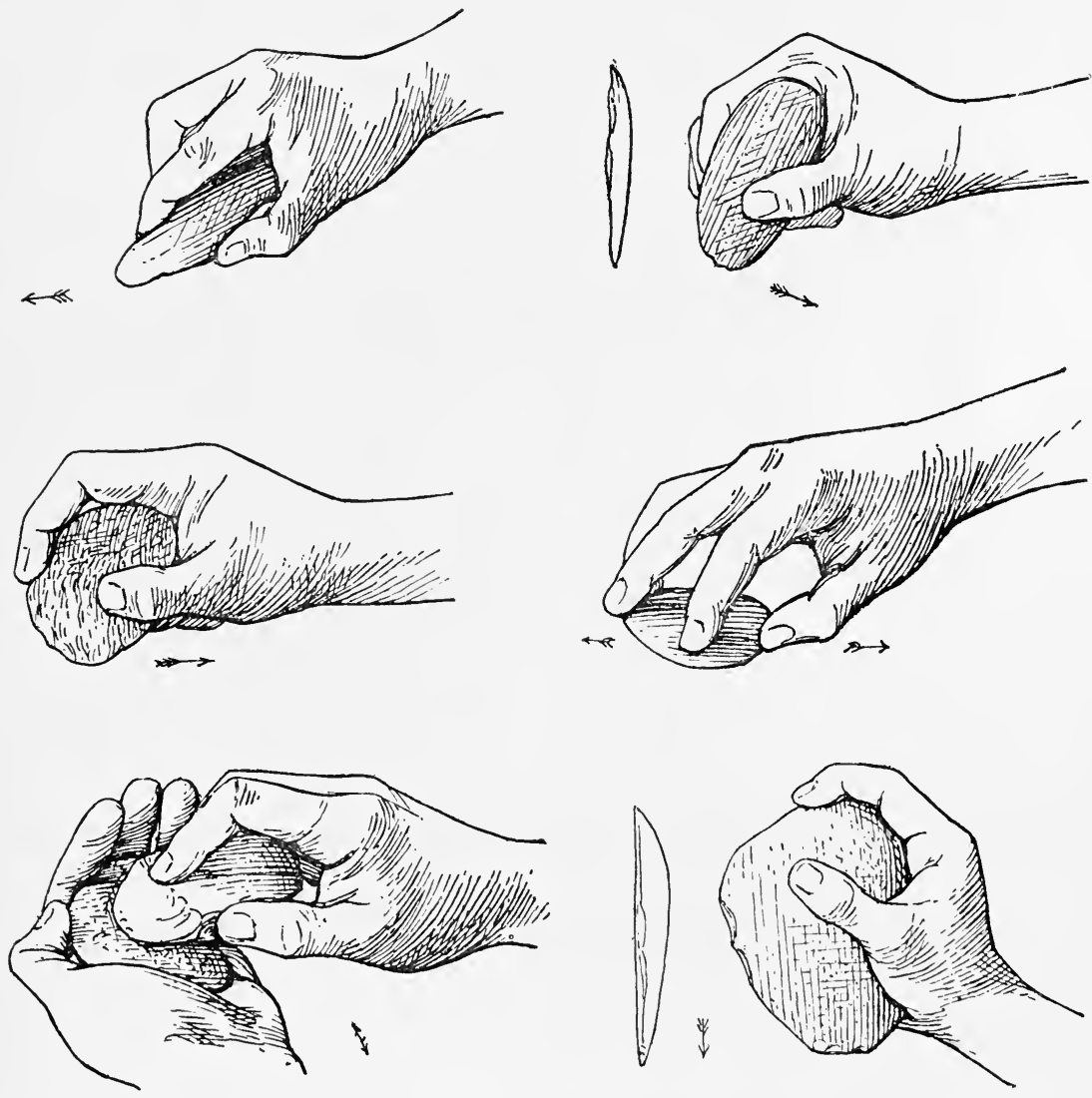

Fig. 204. Series of positions illustrating abrading work with a small hand implement. 
The primitive shaping crafts, classed for convenience under the term "sawing," were in universal use by the aboSawing Processes rigines for dividing bits or masses of the raw material intended for further elaboration. The process does not necessarily imply a saw-a toothed or notched implement-but rather any thin-bladed implement employed in grooving or dividing

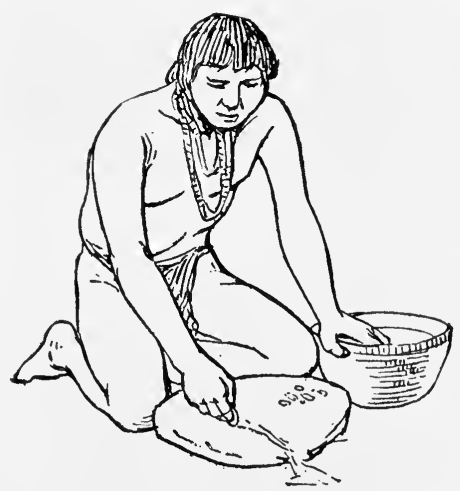

Fig. 205. A California Indian grinding shell ornaments on a flat stone.

stone by a sawing morement. These implements may be of stone or metal or of less durable materials, as bone, or wood, or eren copper uscd with sand as the abrading agent. A distinct variety of the sawing-abrading process occasionally referred to is that in which a cord or a strip of rawhide, aided by sand, is employed. It is not

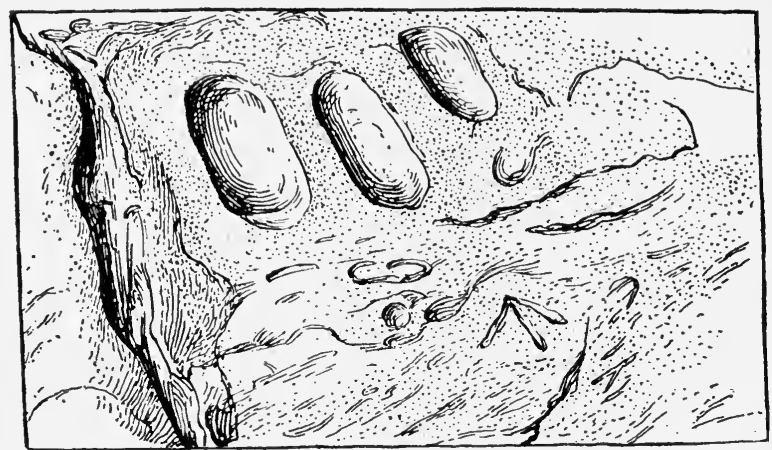

FIG. 206. Traces of abrading work left in rock bodies in place.

probable, however, that this method was ever in general use by any people.

Although the sawing processes, as practiced by the aborigines, appear not to have been observed and recorded in detail by anyone, the evidence furnished by worked stones and stone implements which retain traces of the work sufficiently elucidate the operation if not 
the exact implements and devices employed. So far as known, the work was purely manual, the sawing implement, hafted or unhafted, being held in the hand without mechanical device for operating. 'The probable manner of use of the thin stone blade as a saw-abrader

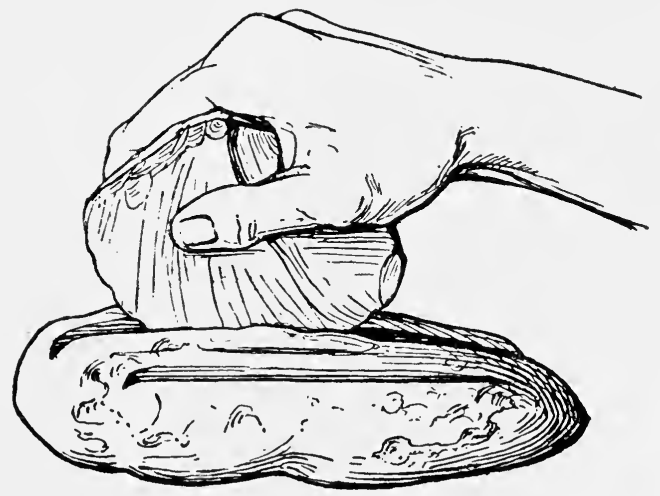

Fig. 207. Use of the saw-abrader.

is indicated in figure 207 , and examples of the traces left in the stone treated appear in figure 208.

Whether the semicivilized peoples of Middle and South America employed more highly developed methods and devices and on a scale
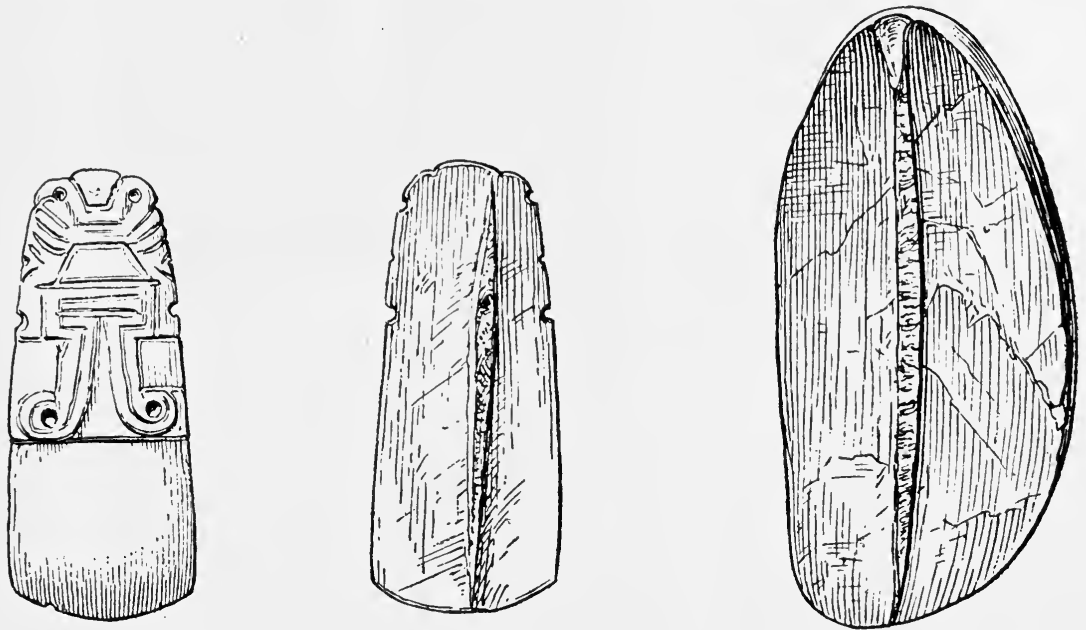

FIG. 208. Showing the result of sawing from opposite sides and breaking the thin septum.

commensurate with the magnitude of their building and sculpture work is not known, but it is probable that the pecking, chiseling, and abrading processes with simple stone tools were everywhere the chief stone-working agencies. The extent to which copper and 
bronze were employed in Middle and South America for such purposes can not be determined. Analyses of bronzes found in Peru, for example, indicate a wide range of hardness. The harder would have served in the direct operation of sawing stone of all kinds, while the softer, as well as copper, would have served in sawing the softer stones, and even the harder with the aid of sand.

The primitive drilling arts were of prime importance to the aborigines and are of exceeding interest to the stuRotative Abrasion dent of primitive technics. Stone was rough carved by picking, pecking, chipping, and gouging, where particular depth or relief were not called for, but for deep excavation and perforation the rotary processes were especially effective.

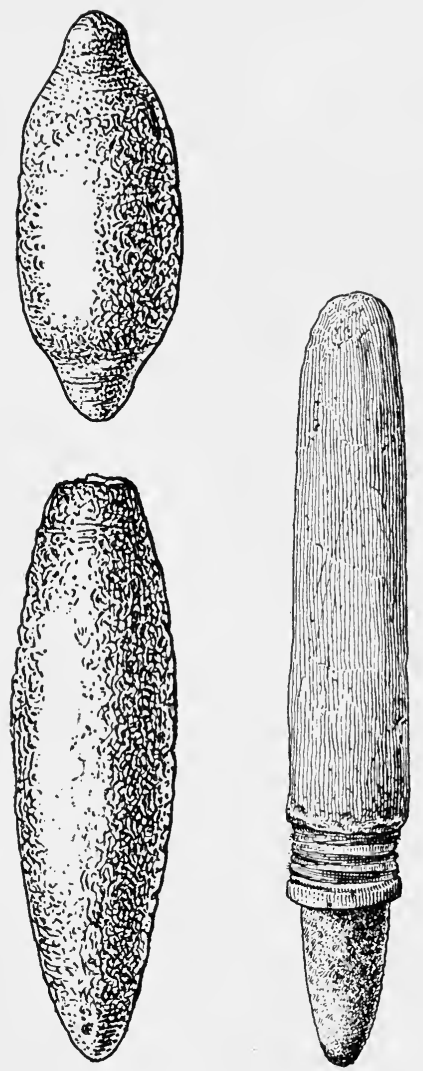

Fig. 209. Solid stone drill points.

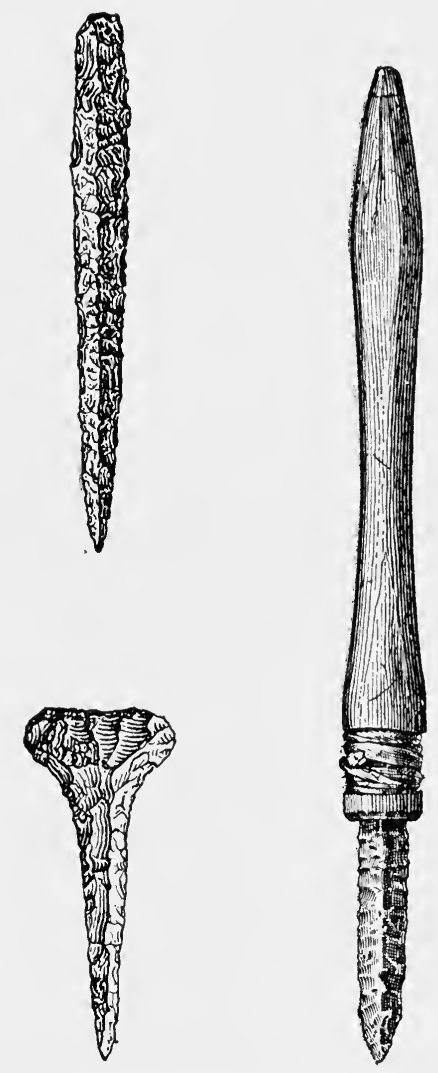

FIG. 210. Drill points of chipped flint.

Drill points are of two distinct types, the solid and the tubular. The solid points may be any sharp or pointed stone, as illustrated in figures 209 and 210, or other softer materials, mineral, animal, or vegetal, utilizing sand as the abrading agent. The tubular forms 
may be of copper (fig. 211), bronze, bone, or wood, all employed with sand as the abrading agent. Joints of cane and the hollow bones of birds were often utilized.

That tubular drills were in general use in boring stone as well as other softer materials is attested by many specimens, finished and unfinished. An excellent example is seen in the unfinished travertine vase shown in figure 212. ${ }^{1}$ Here the boring out of the bowl was in progress when the work was discontinued, and an illustration of exceptional interest is that of a pendant-shaped tablet of travertine, now preserved in the Field Museum of Natural History. The remarkable and entirely unexampled occurrence is the presence of the bone drill point in the bore.

About the year 1895 there was brought to light by workmen digging an irrigating canal at Ixtapaluco, near Chalco, in

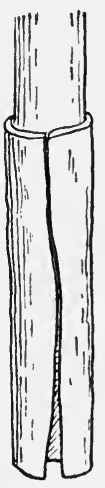

FIG. 211. Tubular drill of copper and section of bore. the Valley of Mexico, an engraved tablet of remarkable character and, as it happens, of unique interest [fig. 213]. It is a keystone-shaped slab of onyx $11 \frac{1}{2}$ inches long, $6 \frac{1}{2}$ inches wide at the wider end, and $1 \frac{1}{2}$ inches thick; it is drilled longitudinally and has four pairs of biconical perforations along the upper margin. . . .

Pouring water into the perforation to dampen the dark earth that clung to the sides and served to fix the bone tube in its place, I was at once able to press the implement back into the stone and, as the other end of the opening was larger, to remove it with ease. The finely comminuted earth was carefully saved for examination under the microscope. The hollow bone $[$ fig. $213, a] \ldots$
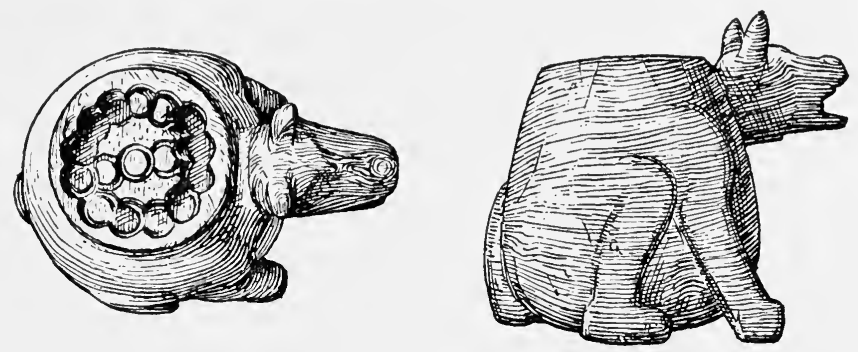

FIG. 212. Bowl of travertine vase partially excavated by tubular drill. (About one-fifth actual size.)

probably from the leg of a crane or other large bird, is $2 \frac{3}{4}$ inches long and three-eighths of an inch in diameter. It is shattered and worn at the upper end, while the lower end or point has the appearance of having been freshly cut off. This latter feature was a matter of some surprise, as a drill point might be expected to show decided evidence of abrasion by use. I found, however, on the other hand, that the exterior surface of the tube was scratched and striated as 
if by attrition with fine sand. On washing out the bore in the larger piece of stone I discovered that the bone tube had not extended to the end of the boring from below; that, in fact, it reached only half way, and that the size of the hole diminished, so that it could not enter any farther. On cleaning out the earth the fact was developed that the borings from opposite ends of the tablet had not met accurately, as indicated in figure $[213, a] \ldots$ and the conclusion was at once reached that the drill was probably being employed, when the work ceased, to enlarge the bore, with the intention of making more complete connection from end to end. The use of the tubular drill of cane, bone, or native metal by primitive peoples, and even by many well-advanced nations, is well known. The tube was twirled by rolling between the hanls or by a pump or bow drill, and sand of suitable fineness and hardness was employed as the cutting agent. That a tubular drill was used in the present case is proved by the presence of a well-dereloped core at the base of the boring from the upper
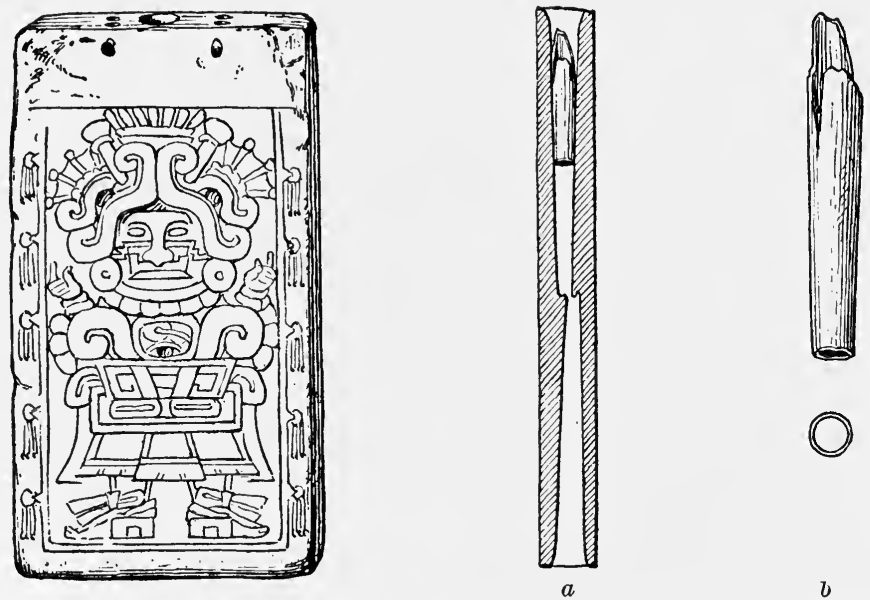

FIg. 213. Alabaster tablet with the bone drill found in place. $a$, Section of tablet. $b$, Drill (one-half actual size).

end, . . . and, though the proof may not be absolute that this piece of bone was actually in use as a drill, the probabilities are strongly in favor of the correctness of the assumption that it was so used, and it is also highly probable that in addition we have here a correct suggestion of the manner in which the tubular drill was employed in enlarging and straightening defective borings, a measure often necessary where devices were of such imperfect construction. ${ }^{1}$

The earth removed from the bore of this specimen was submitted to Prof. O. C. Farrington, of the Field Museum of Natural History, for examination. He reported that although finely comminuted bits of bone and travertine were found, it contained grains of a variety of minerals, including some of the hardness of 7 . The latter would have been effective in the abrading work.

${ }^{1}$ Holmes, Archeological Studies Among the Ancient Cities of Mexico, pp. 304-308. 
The simplest form of unhafted rotary drill is the pointed stone held between the thumb and finger tips and twirled Drill ${ }_{\text {Thumb }}$ and back and forth (fig. 214), or an implement of somewhat $T$ shape (fig. 215), held in the hand as a gimlet and twirled back and forth with pressure, producing the desired bore. The ordinary form of shafted revolving drill (fig. 216) is rotated back and forth between the palms of the The Palm Drill hands after the manner of the fire drill, or between one palm and the thigh. These methods were in com-

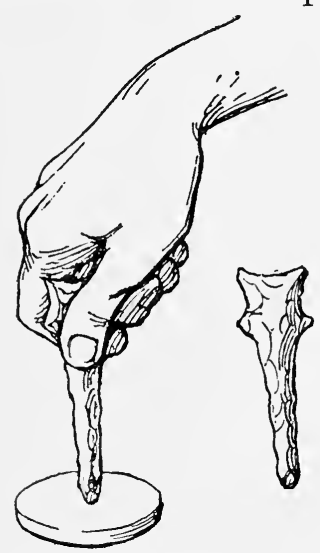

FIG. 214. Primitive method of drilling.

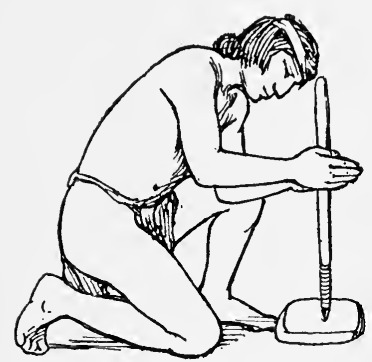

Frg. 216. Primitive method of drilling.
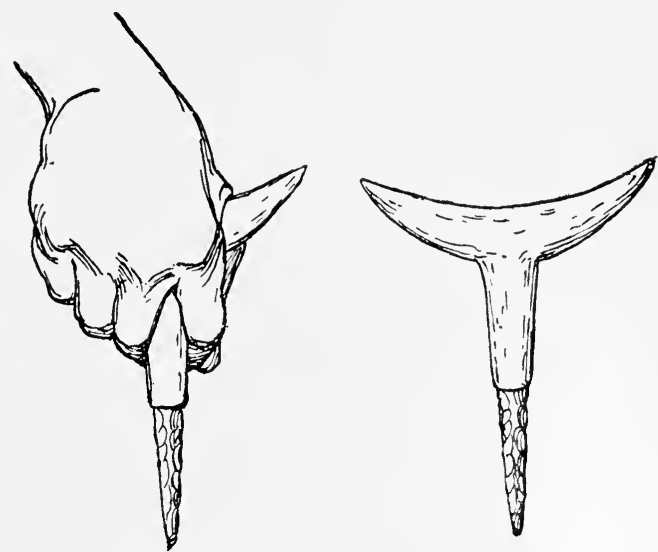

Fig. 215. Primitive method of drilling.

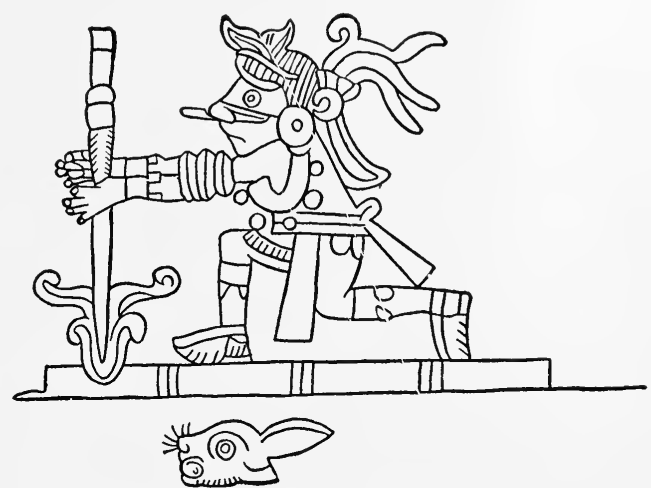

FIG. 217. Primitive method of drilling.

mon use throughout America, and McGuire questions whether any other more efficient form of mechanical device for mounting and operating the drill point than this was in use among the tribes south of Alaska in pre-Columbian times. Drawings representing drills, found in the ancient Mexican codices, all represent the one type (fig. 217). Other devices for revolving the drill have been found in 
use by the aborigines, although it may not now be possible to determine whether or not they were of recent introduction. These implements are known as the pump, strap, bow, and disk drills.

The pump drill consists of a shaft which passes through a disk of stone, pottery, or wood, and a crosspiece through Pump Drill which the shaft also runs. To each end of the crosspiece is attached a cord or thong having sufficient play to allow it to pass over the top of the shaft, permitting the crosspiece to reach close to the disk. In setting the device in motion the disk is turned to wind the string about the shaft; this raises the crosspiece. By pressing down quickly upon the crosspiece, the wrapped end of the string unwinds and the shaft is made to revolve, the disk thus acquiring sufficient momentum to rewind the string the moment the pressure on the crosspiece is removed. By successive pressure and release the reciprocal movement is kept up (fig. 218).

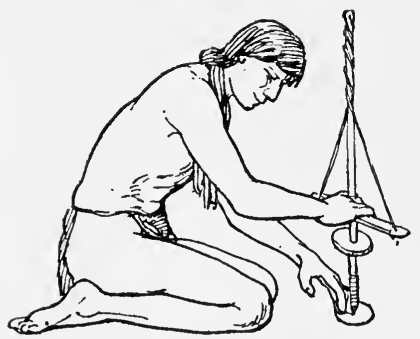

FIG. 218. Primitive method of drilling.

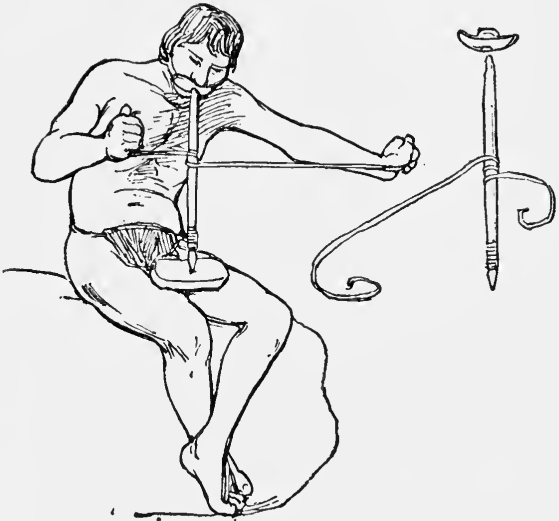

Fig. 219. Primitive method of drilling.

The speed attained by this drill is much greater than that of the bow or the strap drill and has the advantage that one hand is left free to hold the object to be drilled.

The strap drill was in use among the Eskimo and Aleuts in early, possibly in pre-Columbian, times. The shaft is kept

Strap Drill

in position by means of a headpiece of wood, which is held between the teeth, as well illustrated in the drawing (fig. 219). A strap or thong is wound once around the shaft, one end being held in each hand, and is pulled alternately to the right and left, revolving the shaft. The thong was sometimes furnished with a hand piece of wood, bone, or ivory, to give a firmer grip. The chief advantage of this contrivance was that pressure could be regulated by pressure of the teeth on the mouthpiece. In some re- 
gions instead of the mouthpiece the top of the shaft was held by an assistant, and as much pressure applied as was needed (fig. 220).

The bow drill is closely related to the strap drill. The headpiece is held in position with the left hand, while the strap Bow Drill is attached to the two ends of the bow and after wrapping around the shaft, is revolved by a backward and forward movement of the bow held in the right hand (fig. 221).

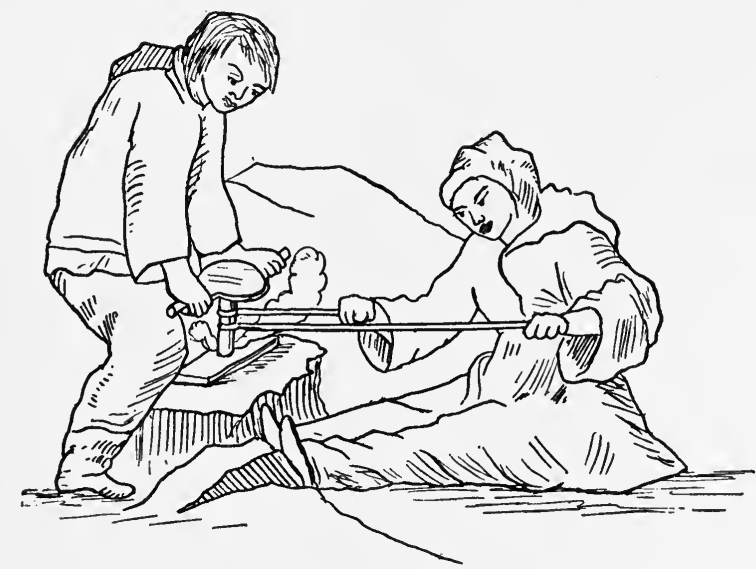

Fig. 220. Primitive method of drilling.

The disk drill, which apears to be confined to the tribes of California, is a variant of the pump drill. The fixed Disk Drill disk of the pump drill is omitted, and a wide movable disk takes the place of the movable crosspiece. Through holes in opposite margins of the disk thongs are passed and attached, one end to the top of the shaft and the other to

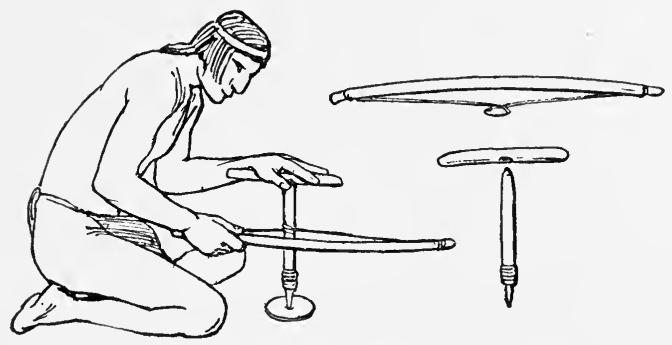

FIG. 221. Primitive method of drilling.

the base near the drill point. The revolving motion is started by turning the disk until the thongs are twisted around the shaft, becoming taut. The disk is then released and pressed suddenly downward, when the strands unwind, revolving the shaft, the momentum 
acquired winding them taut the other way. Sudden removal of the pressure on the disk causes the unwinding of the strands below, twirling the shaft in the opposite direction. By quick repetition of these movements the motion is kept up and the work goes steadily on.

According to Chapman, ${ }^{1}$ the New Zealanders attached weights to the dirill shaft to increase the boring capacity (fig. 222, a). (McGuire.) Again the shaft was weighted by spool or top-shaped bits of heary wood (fig. 222, b). (McGuire.)

Dr. Rau seems to have been the first to demonstrate the primitive methods of drilling stone, but his success in the beginning was not flattering. ${ }^{2}$ Others since have met with more gratifying success. So far as published accounts go, Mr. J. D. McGuire seems to have ac-
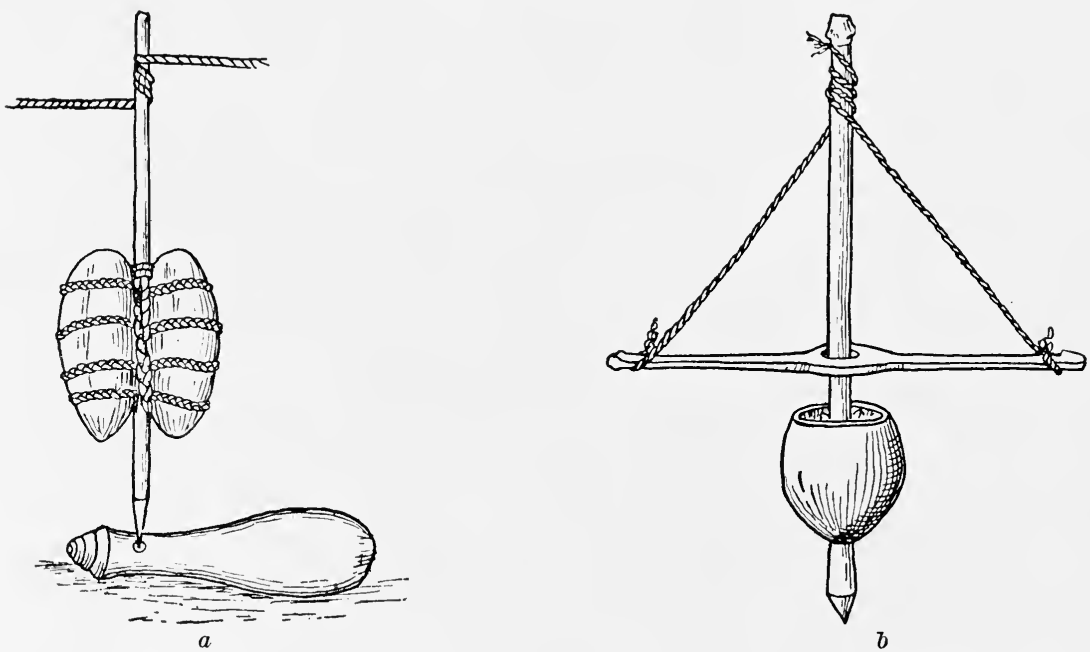

F1G. 222. Weighted drills.

complished the most. Describing his experiments in drilling catlinite with bow and pump drills, Mr. McGuire states ${ }^{3}$ that in starting the hole the point of the drill, if of copper or stone, readily took hold of the stone, but that wood and bone did not do so unless supplemented by sand. Trouble was caused by choking from the powdered stone and sand before the hole was very deep. By working with the stone under water the smaller particles floated off, a condition which made it possible for the cutting to proceed to advantage. The jasper point was found most effective, and its effectiveness was much enhanced by the use of water. The drill point, however, required frequent sharpening. A hole 5 inches deep in a piece of catlinite was drilled in about three hours with a pump drill. A jasper point was

1 Chapman, On the Working of Greenstone or Nephrite by the Maoris, p. 496.

2 Rau, Drilling in Stone with Metals, p. 392 ; also, Aboriginal Stone Drilling, p. 536. Palenque Tablet. (Evans, Kellar.)

${ }^{3}$ McGuire, Materials, Apparatus, and Processes of the Aboriginal Lapidary, p. 172. 
first used, but it began to choke when the hole was one-half or threefourths of an inch deep. A pine drill was then used with dry sand, but the point wore away very fast. The addition of water made matters worse, for it softened the wood, and the dust from the catlinite formed a puttylike mass, which choked the drill. A shaft of ash wood was substituted for the pine and dry sand instead of wet, whereupon the drill ran smoothly, and by giving a slight jumping motion to the shaft a great deal of dust was expelled with the sand and work progressed satisfactorily. A proper drill of copper would have cut the same hole, possibly, in an hour; one of jasper with sand would have done the work, probably, in two hours. On the jasper the three drills were used with all kinds of available points, including quartz, nephrite, and copper; even hard steel drills were tried. All were equally unsuccessful, nothing penetrating this obdurate material. A copper point on a pump drill used with emery, however, started the work and in time would have completed it.

McGuire's experiments demonstrated the wide range of devices and materials arailable to the primitive lapidary and the absolute need of long, intelligent experiment to find out the available and effective combinations for each and all. When we consider the difficulties met with by McGuire in his experiments the drilling feats of the aborigines become a source of wonderment.

The processes of manufacture and the implements employed must be considered, at least briefly, in connection with the descriptions of the separate classes of artifacts in subsequent volumes, but this repetition occurs only in cases in which the implements were employed in stone shaping, and involves little real duplication. 


\section{INCISING PROCESSES}

\section{Pressure Incising}

(a) Cutting or shaving the stone to be shaped by pressure with a sharp, laterally-edged tool held in the hand as a knife.

(b) Chiseling the stone to be shaped with a terminally-edged implement, hafted or unhafted, held in the hand and pushed.

\section{Percussion Incisivg}

(a) Chiseling the stone to be shaped with a terminally-edged implement, hafted or unhafted, forcibly driven with a hammer or mallet.

(b) Chopping the stone to be shaped with a terminally-edged tool, as an ax or adz, a chisel, hatchet, pick, or gouge, hafted or unhafted.

7 HE incising processes shape material by means of a cutting edge, which implies the use of a hard, edged implement and

1 a substance to be shaped of decidedly inferior hardness. Generally speaking, stone is not well adapted for the making of cutting implements, yet edged tools of stone were of Incising Tools necessity a chief reliance of Stone Age peoples in their diversified manual activities. They included knives, axes, hatchets, adzes, chisels, and gouges, and are much diversified in form, ranging in each type from selected natural forms to implements of wholly artificial conformation. The edge was obtained by chipping, crumbling, or grinding, or by the one supplemented by one or both of the others. Simple fracture of glassy stone, as obsidian, gave the keenest possible edge, and all the finer grained stones were capable of taking an excellent edge by grinding, as is well illustrated by the slate and jade knives of the Arctic peoples.

The grooved ax, celt-hatchet, chisel, and gouge were given edges by grinding capable of cutting and dressing wood and Soapstone Working the softer stones, but very ineffective as compared with steel tools of corresponding type. The flint klade, sharpened by chipping, was in universal use by the tribes, but was little adapted to the shaping of stone. Soapstone, the principal and most generally available mineral readily worked by incising methods, was hewn out of the quarry and shaped into implements, 
utensils, and other artifacts chiefly by means of the pick, gouge, and chisel, the incising edge being generally quite narrow and merging into the pointed pick, the process at the same time merging into the crumbling type. These tools were used hafted or unhafted and were operated by pushing and striking or by indirect percussion, as with the aid of a mallet.

Our principal information regarding the shaping of stone by incising methods is obtained from prehistoric sources, especially from the soapstone quarries, which are found in great numbers in the Appalachian Ranges and to a lesser extent in other regions throughout Northern America.

The quarry excavations where the stone was hewn from its native bed and the refuse of manufacture left on the shop sites near at hand furnish ample data for the student, and the utensils made of this material and left on dwelling sites where used and abandoned, bear traces of the methods employed in their production, often obscured, howerer, by reshaping and wear. But the quarry faces from which the material was cut and the refuse of the shops left practically untouched since abandoned by the workmen afford traces of the most satisfactory kind. The markings are so perfectly preserved that the size and kind of cutting edges employed are at once apparent. The tools themselves scattered about, often in large numbers, serve to complete the story. We are even able to say with reasonable certainty that the work of blocking out the articles made was often done with hafted rather than unhafted implements, since the deep, direct incisions (fig. 223, a) could hardly have resulted from less forcible methods. There is no doubt, howerer, that the tools were on occasions held in the hand and wielded chisel fashion merely, producing effects such as appear in figure $223, b$. Many of the implements employed in the quarries and shops were improvised natural forms, while others were made especially for the particular purpose. Some were edged tools employed originally for other purposes, as the ax, celt, and gouge.

No clear distinction is to be drawn between the implements used in quarrying and cutting out the soapstone masses Quarrying and in the quarry and those employed in shaping the
Shaping Implements

artifacts made of these masses, yet it may be assumed that in general the heavier, ruder tools associated with quarry sites were used in excavating and quarrying, and that the more delicate sharp-edged and pointed tools served for shaping and finishing. One variety of pick is roughly grooved by chipping and pecking, while another has a plain shaft, in many specimens slightly curved, as if to be attached to a handle, somewhat as are our picks and adzes. In several of the quarries there have been 


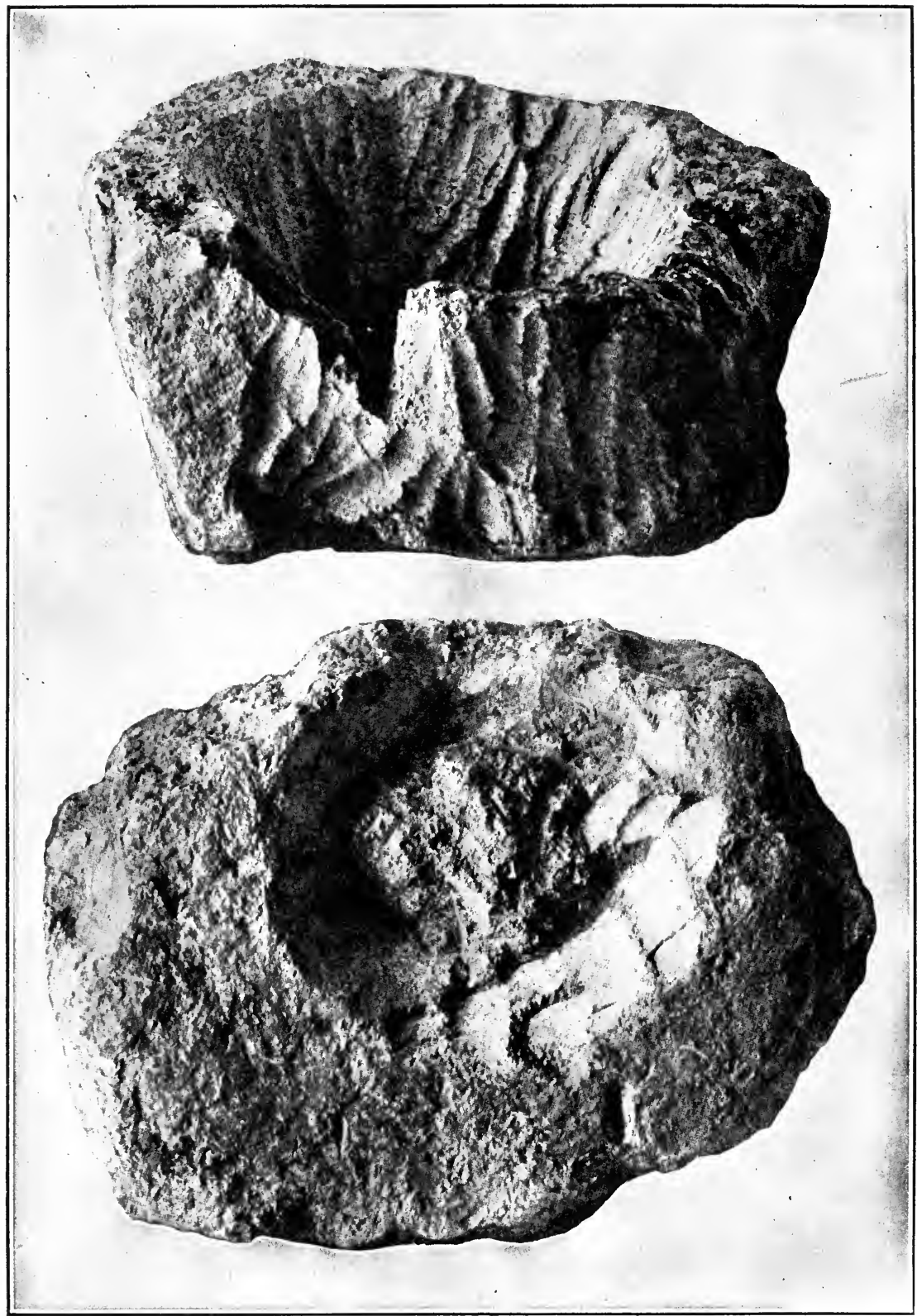

FIG. 223. $a$, Use of strong strokes by a broad-pointed implement, probably hafted. $b$, Use of a narrow-pointed implement, probably unhafted. 
found ordinary grooved axes, most of them remodeled or resharpened by chipping to increase their efficiency as cutting tools; then there is a large class of chisel-like tools of varied sizes and shapes, some improvised from stones of approximate proportions slightly flaked or ground to effective points, some chipped out of the inchoate raw material and well finished by grinding. These steatite working tools are very numerous in places. Around a single pit located in a plowed field on Patuxent River, Md., and nearly obliterated by successive plowings, the writer found during a single visit some 30 entire and broken implements, and from the excavation in the quarry near Clifton, Va., cleared out by Mr. William Dinwiddie, nearly four dozen of the chisel-like tools, some broken and some entire, were found.

There are three or four ways in which these cutting tools were utilized. The simplest was that of using the impleManner of Using ment as a chisel or gouge held in the hand or hands. Another suggested method was that of setthe Tools

ting the sharpened stone or chisel in a short handle of buckhorn and striking this with a stone or billet of wood. The chisel marks left in many cases suggest this method, and the heary end of the tool was found in cases furnished with a short and rough-chipped point or stem suitable for setting in a haft socket. Many specimens of these implements found in the quarry shops are too minute to be utilized unhafted. A third method is that of hafting the pointed stone as an $\mathrm{adz}$ or ax is hafted. The grooved tools were undoubtedly used in this way, and many of the grooveless forms could have been attached as in the ordinary primitive adz.

That incising tools were used in the shaping of other of the softer materials is amply indicated by the traces left on unfinished specimens of pipes and other objects carved from slate, catlinite, cannel coal, chalk, tufa, and the various indurated clays, and sheets of mica were neatly cut into ornamental forms for personal embellishment. Catlinite was employed in the manufacture of many articles of use and ceremony. When first extracted from the quarry this stone is soft enough to be cut or shaved with a keen edge, but on exposure it becomes too hard to be cut effectively except with tools of steel. The same is true of various kindred materials employed to a lesser extent by the tribes. The black slates of the northwest coast, of which material a vast number of interesting carvings have been made, may be cut with comparative ease when fresh from the bed, but it does not seem probable that in this case or even in that of catlinite the incisive methods were much employed before the introduction of iron; fracture, crumbling, and abrasion, in the absence of efficient keen-edged tools, served every purpose. Indurated clays, clay slates, 
cannel coal, and fire clay are readily carved with stone tools while fresh from the ground.

Cutting tools of copper were doubtless in general use among the more advanced peoples, but were not effective for the working of hard stone. Bronze was in use in Middle and South America, and the Incas especially understood the manufacture and use of this alloy; yet to what extent cutting tools of this material took the place of stone in the great work of hewing building stone and of sculpture can not now be determined.

It is observed that the processes employed in stone cutting and sculpture generally, where hard stone is employed, are mainly the fracture and crumbling processes. The chisel used in working marble, granite, and the like, although a keen-edged tool, does not cut the stone but fractures or crumbles it. 


\section{PIERCING PROCESSES}

(a) Piercing comparatively soft stone by simple pressure with a hard, pointed tool, hafted or unhafted, as with an awl or punch.

(b) Piercing comparatively soft stone with a hard, pointed tool, hafted or unhafted, by twirling under pressure.

(c) Piercing comparatively soft stone with a hard, pointed tool, hafted or unhafted, by direct percussion, as with a pick.

(d) Piercing comparatively soft stone with a pointed tool driven by a mallet or hammer.

7 HE needle, awl, punch, and pick penetrate by direct pressure or by direct or indirect percussion. The distinction between the operation of these tools and that of a drill is that the latter accomplishes its results by the removal of particles howsoever minute, torn from the substance bored, while the piercing implement is forced through the substance bored without necessarily removing particles, although portions of the stone may be dislodged. A pointed or edged pick may perforate thus simply, but in its ordinary use it crumbles or cuts.

Piercing implements may be operated by simple direct pressure, by twirling under pressure, or by direct or indirect percussion, the latter implying the use of a driving implement. In general the piercing implement is of harder material than the stone pierced, but a thorn or a pointed bone may be made to penetrate soft stone or indurated clay or sheets of mica. Such implements may pierce but would not be expected to abrade or crumble.

This process has little value as a shaping agent, its use being confined to simple penetration. It is in a sense related to incising, since an edge may penetrate a soft substance without removing particles, the result being an oblong, instead of a round or somewhat round, puncture. 


\section{FIRE FRACTURE PROCESSES}

7 HE use of fire in fracturing stone is well known and was widely practiced by the aborigines. The process was employed ex1 tensively in quarrying, as in the copper and flint mines, to break up large bodies of rock and also in fracturing smaller masses for the purpose of obtaining fragments and spalls, for use as implements or for the manufacture of implements. In general, however, the action of fire is destructive to stone, and if not very discreetly employed will so flaw the stone as to make it unfit for most uses. Fowke tells us how this destructive tendency was probably avoided by the ancient quarrymen of Flint Ridge. ${ }^{1}$ According to his determination, fire was built upon the surface of the flint body, such portions of the purer stone as were desired for use being protected from the action of the heat by layers of moist clay.

References to the employment of heat in shaping stone, which is a very different matter from merely breaking it up, Fire or Heat Frac- are numerous but generally lacking in fullness, and
turing very few of the available accounts appear to be based on first-hand observation. Speaking of the Klamath Indian method of fracturing stone, Schumacher says that in obtaining suitable fragments of stone for arrow making, "The rock is first exposed to fire and after a thorough heating, rapidly cooled off, when it flakes readily into sherds of different sizes under well-directed blows at its cleavage." ${ }_{2}$ Although this author had the good fortune to meet the last arrow maker of the tribe, it does not appear that he witnessed the use of fire as described.

Mabel L. Miller states ${ }^{3}$ that the Diggers (Maidu) on the eastern side of the Sacramento River heated the stone and then chipped it "with a spikelike stone implement, which was dipped in cold water, placed quickly on the hot flint, and the necessary stroke given." A rough stone was used to grind points and edges into shape.

A remarkable account of the use of fire in chipping flint implements is furnished by Thomas H. Fraser, who states in a recent publication that he-

was informed by Chief Paul, the head of a remnant of the Mic-mac tribe, resident on the northern coast of Nova Scotia, that in his grandfather's time, flint arrow-heads were made by the systematic application of fire and water, and I still have in my possession an arrow-head made according to the process described by him.

1 Fowke, Archæological History of Ohio, pp. 622-623.

${ }^{2}$ Schumacher, Methods of Making Stone Weapons, p. 547.

${ }^{3}$ Miller, The so-called California “Diggers," p. 207. 
This author also describes in detail a method of arrowhead making employed by the Seri Indians of western Sonora, Mexico:

I watched this particular artist for several hours, until he had completed an arrow-head that now reposes in my desk, and here is a description of the manner of his labor. Putting three small pieces of flint among the coals of a hot fire on the ground, he places a small stone basin containing a little water within his reach; beside this are placed several straws or reeds of different sizes, together with a few smaller stems of native grass. Presently the first piece of flint placed in the fire is dragged out upon a flat stone by means of a hooked stick, and as the end of the larger straw or reed is dipped in the basin, it will be observed that a drop of water clings thereto; this is lightly touched to the thoroughly heated stone and a small chip flies from the surface. This performance is repeated with astonishing rapidity, until the stone refuses to respond to the touch, when it is returned to the fire and the second stone is treated in the same way, the chips always flying fast and furious. As the work progresses, and the stones are reduced in size and begin to assume the required shape, smaller straws are used, until the final pointing, sharpening, and smoothing is done with the small grasses that pick up a very tiny drop of water and safely remove a very diminutive chip. ${ }^{1}$

That several hours should have been consumed in the work is difficult to understand, considering the rapidity with which the work was carried forward. A much shorter time would ordinarily be required in producing a like result with hammerstone and bone flaker. A small arrowhead can be made from a good quality of stone in a few minutes, while larger ones usually require a somewhat longer time.

According to Wilfred Powell, a most remarkable process was employed in perforating stone club heads by the natives of New Britain. His account is as follows:

The native first takes a piece of suitable granite, which he places in a slow fire of cocoa-nut shells, which give an immense heat, and allows it to become red hot. He then, by the aid of a split bamboo in the place of tongs, removes it from the fire and begins to drop water on it drop by drop, each drop falling exactly on the same place.

That portion of the stone on which the water falls begins to fly and crack off, until the heat has gone out of the stone. He then repeats the operation, until an irregular hole is formed through the center; he then fixes a stick through it and takes it off to a place where there is a large granite rock in which is a dent like a small basin. He hits the stone upon the rock until all the rough corners are knocked off and it is worn fairly round; then takes the end of the stick, and pressing the stone down into the hollow of the rock makes the stick revolve rapidly between his hands, weighting it with other stones fastened to the top of the stick, until that side of the stone is worn perfectly smooth and round. He then shifts the other side of the stone downward and works at that until both are smooth and even, choosing a handle of tough wood, about four feet long, on to which he fixes the stone with gum from the bread-fruit tree, leaving about four inches protruding at one end beyond the stone. ${ }^{2}$

1 Fraser, Touching Aboriginal History, p. 68.

${ }^{2}$ Powell, Wanderings in a Wild Country, pp. 161-162. 


\section{CUSHING'S ACCOUNT OF SHAPING PROCESSES}

$7 \mathrm{HE}$ following very interesting account of the flint-working processes is extracted from F. H. Cushing's memoir entitled 1 "The Arrow." It appears that this account does not relate
to the stone-shaping work of any particular tribe but is rather a composite account, embodying all the processes familiar to Mr. Cushing, who had intimate acquaintance with the aboriginal handicrafts, and experimented extensively and with exceptional acumen in every kind of process known to him.

Long before I went to the Smithsonian or lived in Zuñi I had elaborated from the simple beginning I have chronicled here, some seven or eight totally distinct methods of working flintlike substances with Stone Age apparatus, and subsequently have found that all save two of those processes were absolutely similar to processes now known to have been sometime in vogue with one people or another of the ancient world. ...

They first sought the material, mined it arduously from buried ledges with fire, mauls, and skids, or preferably, when the country [Quarrying] afforded, sought it in banks of bowlder pebbles, digging such as were fit freshly from the soil, if possible, and at once blocking out from them, blanks for their blacles by splitting the pebbles into suitable spalls, not by free-handed percussion, but by lolding them edgewise on a hard base and hitting them sharply and almost directly on [Making Spalls] the peripheries, but with a one-sided twist or turn of the maul or battering stone with each left stroke. The spalls, sometimes 20 from a single cobble or block of moderate size, were with almost incredible rapidity trimmed to the leaf-shape basis of all primitive chipped tools by knapping them with a horn, bone, or very soft, tough, granular stone hammer mounted in a light handle. For this the spall was [Roughing Out] placed flatwise on the knee or on a padded hammer stone, so called, and held down by the base of the thumb of one hand and rapidly struck along the edge transversely and obliquely to its axis lengthwise, with the outwardly twisting kind of blows used in the splitting. The blanks thus formed were then carried home for leisurely or opportune finishing, and carefully buried in damp soil, not to hide them, as has been usually supposed, but to keep them even-tempered or uniformly [Transportation] saturated ("full of sap and life" these ancients thought); whence the so-called caches of numerous leaf-shape blades which are now and then found, for example, throughout old Indian ranges.

In finally forming arrow points from these trimmed blanks, the smallest of them only were chosen. The first care in fashioning one of these was to remove protuberant points from its edge and sides and to thin it down by 
means of a pitching tool of buckhorn. This was effected in several ways, usually by clamping it in a folded pad of buckskin under

[Use of Hammer and Punch] the knee against a hammer stone (anvil stone) or notched wooden block, so that the projecting edge rested orer the margin or else over the pit of the stone, or notch if a block or log were used and with one hand holding the point of the pitching tool very lightly and slantingly and at a wide angle against or just over the points to be chipped, sharply tapping the tool with a maul or with a knapping hammer. Thus the blade was quickly thinned down and made almost even edged. It was now further shaped, sharpened, nocked, or barbed or serrated, [Specializing with a Bone] according to intended use, and tanged with a rounded, flat bodkin of horn (seized to a stick or handle for leverage at one end and tapering therefrom to a curved, blunt point), either by laying it on a folded buckskin, over the hollow of a hammer stone or the palm of the left hand, pressing it downward along the edges at nearly right angles, and always slantingly to its length, or else holding it edge up between the thumb and all the fingers of the left hand and freely flaking it, with the rod held in the right hand, with handle braced against the ribs for steadying, by pressing the sharp edges until they caught in the point or blade of the bodkin, and twistingly wrenching them off by a most dextrous motion, which I can exhibit but not adequately describe or illustrate.

All this sounds complicated and tedious, but I have succeeded, from the time I found a suitable pebble of fine-grained, ringing, cold, and fresh quartzite, in making seven finished knife and arrow blades in exactly 38 minutes, ancl I have often made from obsidian or glass a very small and delicate arrow point-the most easily made, by the way-in less than 2 minutes. ${ }^{1}$

${ }^{1}$ Cushing, The Arrow, pp. 205-210.

$38657^{\circ}-19-$ Bull. 60 , pt $\mathrm{I} \longrightarrow 25$ 


\section{BIBLIOGRAPHY}

Aввотт, C. C. The Stone Age in New Jersey. Smithson. Rept. for 1875, pp. 246-380, Washington, 1876.

Atwater, Caleb. Description of the antiquities discovered in the State of Ohio. Trans. and Colls. Amer. Antiq. Soc. (Archreologia Americana), vol. I, pp. 105-267, Worcester, 1820.

Babbits, Franc E. Vestiges of glacial man in Minnesota. Amer. Nat., vol. ximI, nos. 6 and 7, pp. 594-605, 697-708, Phila., 1884.

BAEGert, JACOB. An account of the aboriginal inhabitants of the California peninsula. Translated by Charles Rau. Smithsonian Repts. for 1863, pp. 352-369, and 186/, pp. 378-399, Washington, 1864-65.

Baird, S. F. On the bone caves of Pennsylvania. Proc. Amer. Asso. Adv. Sci. for 18.9, pp. 352-355, Boston, 1850. Reprint, Salem, 1885.

Balfour, Hexry. On the method employed by the natives of northwestern Australia in the manufacture of glass spear-heads. Man, vol. III, p. 65, London, 1903.

Bancroft, Hubert Howe. The native races. Vols. I-v. San Francisco, 1886.

Becker, George F. Antiquities from under Tuolumne Table Mountain in California. Bull. Geol. Soe. Amer., vol. II, pp. 189-198, Rochester, 1891.

Beckwith, E. G. Report of explorations for a route for the Pacific Railroad on the line of the forty-first parallel. Repts. of Explor. and Surv. for a R. R. from the Miss. River to the Pacific Ocean, 1853-4, vol. II, pp. 1-66, Washington, 1855.

Bingham, Hikam. Preliminary report of the Yale Peruvian expedition. Bull. Amer. Geog. Soc., vol. xuIv, pp. 20-26, New York, 1912.

Blake, W. P. The chalchihuitl of the ancient Mexicans. Amer. Journ. Sci. and Arts, 2nd ser., vol. xxv, pp. 227-232, New Haven, 1858.

BoAs, Franz. The Eskimo of Baffin Land and Hudson Bay. Bull. Amer. Mus. Nat. Hist., vol. xv, pt. 1, New York, 1901.

Bolles, T. Dix. Chinese relics in Alaska. Proc. U. S. Nat. Mus. for 1892, vol. xv, p. 221, Washington, 1893.

Bowen, Benjamin. America discovered by the Welsh in 1170 A. D. Phila., 1876.

Brinton, Daniel G. The American race. New York, 1891.

Brower, J. V. Quivira. Memoirs of Explorations in the Basin of the Mississippi, vol. I, St. Paul, 1898.

- Harahey. Ibid., vol. II, 1899.

Kakabikansing. Ibicl., vol. v, 1902.

Catuin, Georec. Letters and notes on the manners, customs, and condition of

the North American Indians. Vols. I-II. 4th ed. London, 1844.

Last rambles amongst the Indlians. London and Edinburgh, n. d.

Chamberlin, T. C. The geologic relitions of the human relics of Lansing, Kansas. Journ. Geol., vol. x, no. 7, pp. 745-777, Chicago, 1902.

Editorial. Ibicl., p. 793.

Review of Kakabikansing. Ibid., pp. 794-798. 
Chaparan, F. R. On the working of greenstone or nephrite by the Maoris. Trans. and Proc. New Zealand Inst., vol. xxiv, pp. 479-539, Wellington, 1892.

Charnay, Désire. The ancient cities of the New World. New York, 1887.

Chever, Edward E. The Indians of California. Amer. Nat., vol. iv, no. 3, pp. 129-148, Salem, 1870.

Claypoole, E. W. Human relics in the drift of Ohio. Amer. Geol, vol. xvirI, no. 5, pp. 302-314, Minneapolis, 1896.

Cushing, Frank Hammton. The arrow. Proe. Amer. Asso. Adv. Sei., vol. xLIV, pp. 199-240, Salem, 1896; also in Amer. Anthrop., vol. vin, no. 4, pp. 307-349, Washington, 1895.

DALL, IV. H. On succession in the shell-heaps of the Aleutian Islands. Cont. N. Amer. Ethn., vol. I, pp. 41-91, Washington, 1877.

De Mortillet, A. L'Age du bronze en Chine. Revue Anthropologique, VingtTroisieme Annee, no. 12, Décembre, 1913.

Donsey, GEoRge A. An aboriginal quartzite quarry in eastern Wyoming. Field Col. IIus. Pubs., Anthrop. ser., vol. II, no. 4, Chicago, 1900.

Fenner, Clarence N. See Hrdlička, Aleš, and others.

Fowke, Gerard. Material for aboriginal stone implements. The Archoologist, vol. II, no. 11, pp. 328-335, Waterloo, Ind., 1894.

- Archaeological history of Ohio. Columbus, Ohio, 1902.

Fraser, Thomas H. Touching aboriginal history. Sports Aficld, vol. xL, no. 1, pp. 67-69, Chicago, Jan. 1908.

Geikie, James. Fragments of earth lore. Edinburgh, 1893.

Gilbert, G. K. The geological history of a prehistoric hearth found in western New York. Amer. Anthrop., vol. II, no. 2, pp. 173-174, Washington, 1889.

Gondon, George B. The double axe and some other symbols. Univ. Pa. Mus. Joúrn., vol. vII, no. 1, pp. 46-68, Phila., 1916.

Handbook of American Indians north of Mexico. Bull. 30, Bur. Amcr. Ethn., pts. 1-2, Washington, 1907-10.

Haven, Samuel F. Archaeology of the United States. Smithson. Cont. to Knovvledge, vol. vrr, pp. 1-159, Washington, 1856.

Нinth, Friedrich, and Rockhill, W. W. (trans.) Chau-Ju-kua: his work on the Chinese and Arab trade in the Twelfth and Thirteenth centuries, entitled Chu-fan-chï. St. Petersburg, 1911.

Holmes, W. H. Notes on an extensive deposit of obsidian in the Yellowstone National Park. Amer. Nat., vol. xiII, no. 4, pp. 247-250, Phila., 1879.

Are there traces of glacial man in the Trenton gravels? Journ. Geol., vol. I, no. 1, pp. 15-37, Chicago, 1893.

- Traces of giacial man in Ohio. Journ. Geol., vol. I, no. 2, pp. 147-163, Chicago, 1893.

- Vestiges of early man in Minnesota. Amer. Geol., vol. xi, no. 4, pp. 219-240, Minneapolis, 1893.

- Archeological studies among the ancient cities of Mexico. Ficld Col. Irus., Anthrop. ser., vol. I, Chicago, 1895.

- Manufacture of pecked-abraded stone implements-a study of the rejectage. Amcr. Antiquarian, vol. xvıı, no. 6, pp. 309-313, Chicago, 1896.

- Primitive man in the Delaware valley. Seience, n. s. vol. vi, pp. 824-829, New York, Dec. 3, 1897.

- Review of the evidence relating to auriferous gravel man in California. Smithson. Rept. for 1899, pp. 419-472, Washington, 1901.

Anthropological studies in California. Rept, U. S. Nat, IIus. for 1900, pp. 155-187, Washington, 1902. 
Holmes, W. H. Flint implements and fossil remains from a sulphur spring at Afton, Indian Territory. Rept. U. S. Nat. Mus. for 1901, pp. 237-252, Washington, 1903.

- Fossil human remains found near Lansing, Kansas. Smithsonian Rept. for 1902, pp. 455-462, Washington, 1903.

- On a nephrite statuette from San Andres Tuxtla, Vera Cruz, Mexico. Amer. Anthrop., n. s. vol. Ix, No. 4, pp. 691-701, Lancaster, 1907.

See Hrdlička, Aleš, and others.

Hrdurčka, Aleš. The Lansing Skeleton. Amer. Anthrop., n. s. vol. v, no. 2, pp. 323-330, Lancaster, 1903.

- Skeletal remains suggesting or attributed to early man in North America. Bull. 33, Bur. Amer. Ethn., Washington, 1907.

(in collaboration with W. H. Holmes, Bailey Willis, Fred. Eugene Wright, and Clarence N. Fenner). Early man in South America. Bull. 52, Bur. Amer. Ethn., Washington, 1912.

Lafitau, Joseph François. Mœurs des sauvages ameriquains. Vols. I-II. Paris, 1724.

LeIDY, Joseph. On remains of primitive art in the Bridger Basin of southern

Wyoming. Sixth Ann. Rept. U. S. Geol. Surv. Terr., pp. 651-653, Washington, 1873.

- Notice and description of fossils in caves and crevices of the limestone rocks of Pennsylvania. Ann. Rept. Geol. Surv. Pa. for 188\%, pp. 1-20, Harrisburg, 1889.

Leterett, Frani. Supposed glacial man in southwestern Ohio. Amer. Geol., vol. xr, no. 3, pp. 186-189, Minneapolis, 1893.

Lyon, Caleb. [Extract from letter of] Bull. Amer. Ethn. Woe., vol. I, p. 39, New York, 1861.

MICGEE, W J. An obsidian implement from Pleistocene deposits in Nevarla. Amer. Anthrox:, vol. II, no. 4, pp. 301-312, Washington, 1889.

- The Seri Indians. Seventeenth Ann. Rept. Bur. Amer. Ethn., pt. 1, pp. 1-344, Washington, 1898.

- Archaeology, American. The International Year Book, pp. 48-51, New York, 1902.

MICGurre, J. D. The stone hammer and its various uses. Amer. Anthrop., vol. Iv, no. 4, pp. 301-312, Washington, 1891.

- Materials, apparatus, and processes of the aboriginal lapidary. Ibid., vol. v, no. 2 , pp. 165-176, 1892.

Mason, Otis Tufton. The Ray collection from Hupa reservation. Smithson. Rept. for 1886, pt. 1, pp. 205-239, Washington, 1889.

- North American bows, arrows, and quivers. Smithson. Rept. for 1893, pp. 631-679, Washington, 1894.

Mercer, H. C. Pebbles chipped by modern Indians as an aid to the study of the Trenton gravel implements. [Abstract.] Proc. Amer. Asso. Adr. Sci., vol. XLI, pp. 287-289, Salem, 1892.

Jasper and stalagmite quarried by Indians in the Wyandotte care.

Proe. Amer. Philos. Soc., vol. xxxiv, pp. 396-400, Phila., 1895.

- The hill-caves of Yucatan. I'hila., 1896.

Researches upon the antiquity of man in the Delaware Valley and the Eastern United States. Pubs. Univ. Pa., Ser. in Philol., Lit., and Archaeol., vol. vi, pp. 1-85, Phila., 1897.

- An exploration of Durham Cave, Bucks County, Pennsylvania, in 1893. Ibid., pp. 149-178.

- The bone cave at Port Kennedy, Pennsylvania, and its partial excavation in 1894, 1895, and 1896. Journ. Acad. Nat. Sci. of Phila., vol xI, pt. 2, pp. 269-286, Phila., 1899. 
Merriam, John C. Recent cave exploration in California. Amer. Anthrop., n. s. vol. viII, no. 2, pp. 221-228, Lancaster, 1906.

Mrlmer, Mabel L. The so-called California “Diggers." Pop. Sei. Monthly, vol. L, pp. 201-214, New York, 1897.

Mooney, JAmes. The growth of a myth. Amer. Anthrop., vol. Iv, no. 4, pp. 393-394, Washington, 1891.

Morice, A. G. Notes on the Western Dénés. Trans. Can. Inst., vol. iv, pp. 1-222, Toronto, 1895.

Murdoci, John. Ethnological results of the Point Barrow expedition. Ninth Ann. Rept. Bur. Amer. Ethn., pp. 19-441, Washington, 1892.

Nelson, Edward William. The Eskimo about Bering Strait. Eighteenth Ann. Rept. Bur. Amer. Ethn., pt. 1, Washington, 1899.

Nelsox, Nels C. Flint working by Ishi. Holmes Anniversary Volume, pp. 397-402, Washington, 1916.

Nelson, Sven. The primitive inhabitants of Scandinavia. London, 1868.

Nicollet, I. N. Report intended to illustrate a map of the hydrographical basin of the Upper Mississippi River, 1841. Sen. Doc. 23\%, 26th Cong., 2nd sess., Washington, 1843.

Peabody, Charles. The exploration of Bushey cavern, near Cavetown, Maryland. Phillips Acad., Dept. Archaeol., Bull. iv, pt. 1, Andover, Mass., 1908.

Pfeiffer, Ludwig. Die steinzeitliche Technik. Jena, 1912.

Phillips, W. A. A new group of stone implements from the southern shores of Lake Michigan. Smithson. Rept. for 1897, pp. 587-600, Washington, 1898.

- Aboriginal quarries and shops at Mill Creek, Illinois. Amer. Anthrop., n. s. vol. II, no. 1, pp. 37-52, New York, 1900.

Powell, J. W. Are there evidences of man in the glacial gravels? Pop. Sei. IIonthly, vol. xumI, pp. 316-326, New York, July, 1893.

- Stone art in America. Amer. Anthrop., vol. vin, no. 1, pp. 1-7, Washington, 1895.

Poweld, Wilfred. Wanderings in a wild country; or three years amongst the cannibals of New Britain. London, 1884.

Powers, Stephen. Tribes of California. Cont. N. Amer. Ethn., vol. III, Washington, 1877.

Putsair, F. W. On a collection of palaeolithic implements from America and Europe. Proc. Boston Soc. Nat. Hist., vol. xxir, pt. iv, pp. 421-424, Boston, 1888 .

Riu, Charles. Drilling in stone without metal. Smithson. Rept. for 1868, pp. 392-400, Washington, 1869.

- Aboriginal stone drilling. Amer. Nat., vol xv, no. 7, pp. 536-542, Phila., 1881.

Reding, B. B. How our ancestors in the Stone Age made their implements. Ibid., vol. XIII, no. 11, pp. 667-674, 1879.

Savilie, M. H. An onyx jar from Mexico, in process of manufacture. Bull. Amer. Mus. Nat. Hist., vol. xIII, pp. 105-107, New York, 1900.

Schoolcraft, Henry R. Observations respecting the Grave Creek Mound in western Virginia. Trans. Amer. Ethn. Soc., vol. I, pp. 369-420, New York, 1845.

Schumacher, Paul. Methods of making stone weapons. Bull. U. S. Geol. and Geog. Surv. Terr., vol. III, pp. 547-549, Washington, 1877.

- The method of manufacture of several articles by the former Indians of southern California. Eleventh Rept. Peabody IIus., vol. II, no. 2, pp. 258-268, Cambridge, 1878.

Selders, George Ercol. Observations on stone-chipping. Smithson. Rept. for 1885, pt. 1, pp. 871-891, Washington, 1886. 
Shaler, N. S. Nature and man in America. New York, 1891.

Man and the Glacial Period. Antiquity of man in eastern North America. Amer. Gcol., vol. xı, no. 3, pp. 180-184, Minneapolis, 1893.

Sildiman, Bendamin. Turquoise of New Mexico. Engincering and Mining Journal, vol. xxxrr, no. 11, p. 169, New York, Sept. 10, 1881.

Sмiтн, C. D. Ancient mica mines in North Carolina. Smithson. Rept. for 1876 , pp. 441-443, Washington, 1877.

Sмгтн, John. The true travels, adventures and observations of Captaine John Smith. Vols. I-Ir. London, 1629. Reprint, Richmond, 1819.

SNyder, J. F. The method of making stone arrow-points. The Antiquarian, vol. I, pt. 9, pp. 231-234, Columbus, O., 1897.

Spinden, Herrert J. A study of Maya art. Mems. Peabody Mus. Amer. Archaeol. and Ethn., vol. vi, Cambridge, 1913.

Squier, E. George. Peru: Incidents of travel and exploration in the land of the Incas. New York, 1Sit.

Squier, E. G., and Davis, E. H. Ancient monuments of the Mississippi valley. Smithsonian Cont. to Knowledgc, vol. I, Washington, 1848.

Stephens, John L. Incidents of travel in Central America, Chiapas, and Yucatan. Vols. I-II. 12th ed. New York, 1843.

Thomas, Crrus. Report on the mound explorations of the Bureau of Ethnology. Twolfth Ann. Rept. Bur. Amer. Ethn., Washington, 1894.

UpHaM, Warren. Primitive man and his stone implements in the North American loess. Amer. Antiquarian, vol, xxrv, pp. 413-420, Chịcago, 1902.

- Man in the Ice Age at Lansing, Kansas, and Little Falls, Minnesota. Amer. Gcol., vol. xxx, no. 3, pp. 135-150, Minneapolis, 1902.

Volk, Ernest. The archaeology of the Delaware valley. Papers Peabody IIus. Amer. Archaeol. and E'thn., vol. v, Cambridge, Mass., 1911.

Warren, S. Hazzledine. The experimental investigation of flint fracture and its application to problems of human implements. Journ. Royal Anthrop. Inst., vol. xuIv, pp. 412-450, London, 1914.

Whitney, J. D. Auriferous gravels of the Sierra Nevada of California. $M \mathrm{~cm}$. Mus. Comp. Zool. at Hartard, vol. vi, no. 1, Cambridge, 1880.

Willis, BaIley. See Hrdlička, Aleš, and others.

Willistox, S. W. A fossil man from Kansas. Scienec, n. s. vol. xvi, New York, Aug. 1, 1902.

Wilsox, Thomas. Arrowpoints, spearheads, and knives of prehistoric times. Rept. U. S. Nat. Mus. for 1897, pp. 811-988, Washington, 1899.

Winsor, Justin. Narrative and critical history of America. Vols. I-vilI, Boston and New York. 1884-89.

Wrightr, Fred. Eugene. See Hrdlička, Aleš, and others.

Wright, G. Frederick. Climatic condition of the Glacial Period: the Nampa image. Proc. Boston Soc. Nat. Hist., vol. xxiv, pts. iii and iv, pp. 425-450, Boston, 1890.

- Additional notes concerning the Nampa image. Ibid., vol. xxv, pt. ii, pp. 242-246, Boston, 1891.

Evidences of glacial man in Ohio. Pop. Sci. Honthly, vol. xuII, pp. 29-39, New York, May, 1893.

- Man and the glacial period. 2nd ed. New York, 1895.

The Ice Age in North America. 5th ed. Oberlin, Ohio, 1911. 


\section{N D E X}

A BRADING Processes of STONE-ShapING... Page A BRADING STONES............. 192, $345,346,347$ Activities, classification of antiquities by ... 150 ADZ, stone, of the northwest coast ......... 29 $\Lambda$ FTON, OKLA., flint implements from....... A griculture of the INCAS.............. AlaBASTER TABLET, showing use of drill..... AlEutLAN IsLands, as a route of migration..

"A MAZON A XE".

A MEgHino, data collected by.

A MERICAN ANTIQUARIAN Soctety, investigations of.

ANALOGIES IN CULTURE, value of . .......... ANTHROPOLOGY -

branches of

definition of

ANTIQUities-

classification of

rare in northern interior area $\ldots . . . . . .$.

ANTIQUITY OF MAN-

in California, evidence of............ - 61

in Columbia Valley.................. 118

in Mississippi Valley area............. 105

ANTIQUITY OF MAN IN AMERICA............ 16,19

arguments against great . ..............

arguments in favor of great ............

geological evidence of.

problems of.

value of archeological material in deter-

mining

ANVIL STONES................. 297, 300, 301, 303

APACHE METHOD OF IMPLEMENT MA KING..... 295

ARAWAK CULTURE

142,145

ARCHEOLOGY -

not limited to antiquity

range of.

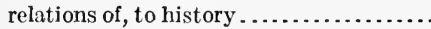

research in, scope of . . . . . . . . . . . . .

ultimate purpose of...................

Archeology oF WESTERN HeMisPHEREsources of information ...............

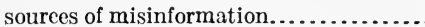

A RCHITECTURE OF THE INCA PERIOD . . . . . . . . See Building; Dwellings.

A RGENTINA, explorations conducted by.....

A RGILLITE, significance of use of . . . . . . . . .

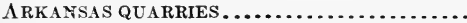

ARROWIIEADS-

eache of.

method of making-

by Dené.

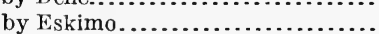

by Hupa.........................

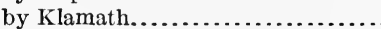

by Pahvant ...................... 311

by Paiute . ................. $310,312,313$

by Powhatan.................. 316

by Shasta......................... 299

by western tribes............... 322

by Wintoon ......................... 314

described by Cushing..............
ASIA -

Page

early intercourse between eastern and western.......................... 27

origin of A merican race in ........... 20

A thantis, myth of.................. 14, 33

A twater, Caleb, paper by ............ 15

A Uriferous gravels OF CALIFORNIA, relics

found in....................... 61,116

A USTRALIAN METHOD OF CHIPPING......... 324

Ax, Chinese bronze.................... 28

Ax, stone

drilled........................... 23

fluted............................ 109

method of shaping................ 331, 333

possible origin..................... 24

time required in making.............. 281

type of, in South America........... 105

AxEs, grooved stone................... 237, 334

from supposed glacial deposits......... 83

rare in Georgia-Florida area............ 103

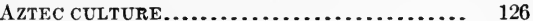

effect of environment on............. 48

AZTEC METHOD OF MAKING KNIVES......... 323

AZTEC PROBABLE WORKERS OF OBSIDIAN MINES........................ 225

BАввітт, F. E., discoveries of . ........... 85

BAIRD, S. F., discoveryof remains in Pennsylvania cave by.

BAlfour, HENRY, on Australian method of chipping .......................... 324

BANNER STONES.................... 23, 24

BARNARD, W. C., collections of ........... 207

BASKETRY OF CALIFORNIA AREA .......... 116

BECKWITH, E. G., on the making of arrowheads.

BELCHER, E., on Eskimo method of arrow-

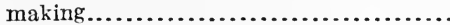

BenNetT, Cilarles H., on pipestone quarr:

BERING Strait as A RoUte of MIGRATION . . .

BIG Bone Cave, fossil found in............. Bingham, Hiram, Peruvian expedition of...

BLADE FROM LOVELAND, OHIO.............. 82

BLADE FROM NEWCOMERSTOWN, OHIO ....... 80

BLADE MAKING........ 161, 165, 179, 191, 290, 291, 293

BLADEs, types of . .................. 182, 292

BLAKE, W. P., on turquoise mines......... 271

BoAs, Franz, on Eskimo method of arrowmaking...

BOAT-SHAPED STONES FROM AURIFEROUS

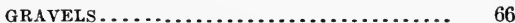

Bolivis, ancient builders of . ........... 276

BONE CHIPPING IM PLEMENT............... 319

BONE FRAGMENTS RESEMBLING IMPLEMENTS 92

Bow DRILL.......................... 355

BowMAN, I., on age of Cuzeo remains...... 60

BRAZIL-

explorations conducted by ........... $\quad 16$

researches in caves of ................ 93

BRIDGES OF TIIE INCAS................. 139

Brower, J. V., excavations made by ...... 85 
BUFFALo, effect of, on culture in Mississippi

Valley..............................

BuIr.DING-

materialsused for, in North Atlantic area. stone used for.

BUILDINGS-

of Inca area ........................... 139

of stone in Colombia.................. 135

types of, in arid region................ 112

BURIAL CUSTOMS-

of Georgia-Florida arca................ 104

of Middle Andcan-Pacific area.......... 137

of Mississippi Valley region ........... 106

See Mortuary offerings.

BURIAL DEPOSITS..................... 227, 242

BurIal VASES OF MARAJO............... 141

Caches of stone im Plements . . . . . . . . . 107 at Afton, Okla.................... 111,208

in Delaware County, Okla.......... 111, 208

in Ohio mound.................... 227

Calendar, development of, in South Mexico . 129

California-

antiquity of man in ............... 61

caves, researches in .................. 92

Indians, arrow making by ............ 311,

$313,318,320,321,326$

Cannibalism in South AM EricA . . . . . . . . . 142

Carib culture....................... 143, 145

CARving-

implements used in................ . 336, 337

methods of ........................ 337

See Sculpture.

Catrin, George-

on implement making

on pipestone quarry.

Catlinite-

pipes of ....................... 109, 263

quarries of ..................... 109, 253

See Pipestone.

Cattle UNKNowN IN PRE-COLUMBIAN

AMERICA .......................... 20

Cave explorations................ 89, 91,92

CAvetown, MD., exploration in cave at.... 91

Celts-

abundant in Georgia-Florida area ....... 103

faceted ............................ 109

petaloid polished ................... $\quad 25$

used in sculpture ................... $\quad 337$

Ceramic art of Chiriqui . . . . . . . . . . . 132

Ceramics-

arid region........................ 114

North Atlantic area ................. 100

See Earthenware; Pottery.

Chamberlin, T. C.-

on Lansing skeleton...

on work of J. V. Brower.

CHerT-

character of, in Oklahoma quarries..... 207 concretions quarricd at Mill Creek.... 187, 188 deposits in Mississippi Valley region..... 106

Chert QUarRIES-

of Great Plains...................... 201

of Kansas. . . . . . . . . . . . . . . . . . . . 209

of Oklahoma........................ 201

Chever, E. E., on arrow making by Cali-

fornia Indians.....................

ChIlcat Mask With ChINese coINS.......

30
CiIle, explorations conducted by..........

Chinese bronze AXES................ 29

CiInese coIns IN Chilcat MASK.......... 30

CirIPPING, im plements used in.. 193, 194, 198, 306, 307

Cirsel, manner of using . . . . . . . . . . . . 336, 337

Chisels, stone................... 235, 236

ChroNologY-

classification of data bearing on........ 52

geological ........................ 16

glyphic.......................... 52

Chulpas. See Tombs.

Clarissa mine........................ 249

Claypole, E. W., quoted on implementsfrom

Ohio Valley . ........................ 83,84

ClifF DWEllers, popular fallacy concerning . 13

Cliff DWELliNGS OF THE ARID REGION..... 112

early records of .................... 16

Clifton QUARrY...................... 231, 234

ClnngmaN, T. L., discovery of mica mines by. 242

CLUB, stone, of the Samoan Islands. . . . . . . . 29

Club Heads, method of perforating........ 365

COLLARS-

sacrificial, of eastern Mexico........... 127

stone, of West Indies.................. 146

Collections, archeologic, of the National

Museum ....................... XIV

COMMUNAL HOUSES OF THE GEORGIA-FLORIDA

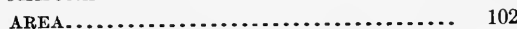

CoPan, quarries of ..................... 274

CopE, E. D., cave excavations by .......... 90

COPPER DRILL........................ 351

COPPER MINES OF LAKE SUPERIOR REGION.. 109

COPPER WORK FROM MOUNDS IN GEORGIA

AND IlLINOIS. ...................... 107

COPPER WORKING OF NORTHWEST COAST

AREA. . ............................ 120

CORES FOUND ON QUARRY SITES ......... 178

$181,208,220,222,223$

Costa RICA, explorations conducted by ..... 16

CRESCENT QUARRIES.................... 195

CRUMBLING METHOD OF STONE WORKING... 330

Culture-

aboriginal American, views of initial

status of .........................

agencies which affect .................

chronology and .....................

influenced by geography ............... 120

modified by environment ........... 45,95

phenomena not uniform................ 99

relations of old and new worlds . . . . . . . 20-21

status of Georgia-Florida area......... 105

status of Lower Mississippi Valley arca.. 108

status of North Atlantic area. ......... 99

value of analogies in................. 21

Cushing, F. H.-

finds of, on Key Marco................ 103

on arrowhead making ............... 366

on methods of stone fracture.......... $2 \& 3$

work of . ..................... XIV

work of, in soapstone quarry .......... 231

Cuzco, quarries of ..................... 376

stone work at .............. 341

DEER HORN USED AS A PUNCH........... 296, 297

DEGENERACY, theory of, not sustained..... 14

DELAWARE VALLEY-

relics of ........................ 101 stages of culture in..................... 77

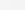

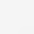

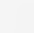

6

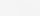

9

5

27

330

44

56

5

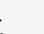

8

9

3

03

6

1

41


Page

DENÉ METHOD OF ARROW MAKING.

DigGer INDIANs, use of fire by, in chipping

implements.......................... 36

DIGGER METHOD OF MAKING ARROWHEADS. 299, 313

DIORITE, collars or yokes of............ 127

DISK DRILL.......................... 355

Domestic ANIMALS.................. 20, 138

DoRSEY, GEO. A., report of, on Wyoming quarries............................. 210

DRAKE, DANIEL, paper by .............. 15

DRILL POINTS-

bone............................. 351, 352

metal................................ 351

stone.............................. 350

DrILLING, primitive methods of....... 344, 350, 353

Drills, tubular......................... $\quad 351$

Dulog, H. C., on Clear Lake Indian method of arrow making .......................

DURHA M CAVE, exploration of, by Mercer...

DWELIINGS-

communal

material used in construction of.........

of Arctic area........................

of California area ......................

of Lower Mississippi Valley region......

of North Atlantic area..................

of Plains tribes........................

EARTHENWARE-

of Georgia-Florida area................ 103

of north Mexican area................. 125

See Pottery; Ceramics.

EARTHWORKS-

of Mississippi Valley.

of Wisconsin

See Mounds.

ENGRAVING ON STONE.

344,346

ENVIRONMENT, culture modified by....... 45, 95

Eskimo-

culture of, compared with other groups.. 122 method of making arrowheads. . .. 318, 320, 321

EXPLORERS-

of the A mazon delta area..............

of Arctic coast area.....................

of arid area............................

of California area......................

of Central American-Isthmian region....

of Columbia-Fraser area.................

of Georgia-Florida area................

of Great Plains and Rocky Mountain area.

of Maya-Quiché area ..................

of Middle and Lower Mississippi Valley

area...............................

of Middle Mexican area...............

of North Atlantic area.................

of North Mexican area..................

of northern interior area . .............

of northwest coast area. ................

of primitive South America.............

of South Andean-Pacific area...........

of south Mexico area...................

of upper Mississippi and Great Lakes area of West Indian area.

Fetishes, carved animal..................

Fewkes, J. WaLter, rescarches of..........

FiguRINE OF JADE BEARING OLDEST DATE....
FIrE-

Page

use of, for shaping stone............... 364

use of, for stone fracture.............. 364

use of, in quarrying.............. 156, 176, 198

FLAKING TOOLS..................... 327, 323

FLINT-

deposits, distribution of............... 173

disks from Ohio mound............... 107

implements in Georgia................ 103, 104

quarries of Indiana ................. 185

quarries of Missouri................... 195

use of, in Arctic area.................. 121

working by California Indian ......... 288, 325

working by Ishi ................... 288, 325

Flint Ridge QUarRIES.................... 173

FLORIDA, antiquity of man in........... 104

FOOD RESOURCES-

of California area ................... 116

of northwest coast area................ 119

FosSIL MAN IN FLORIDA................... 104

Fowke, GERARD-

explorations of, in Wyandotte cave,

Indiana.......................... 91

on flint quarries in Missouri.............. 195

on Flint Ridge quarries............... 176

on Indiana quarries................... 185

on Warsaw quarries................. 185

researches of....................... 173

FRACTURE OF STONE, processes employed... 283

Fraser, T. H., on use of fire in chipping

flint............................. 364,365

Fremont, JoHn C., initials of, cut in pipe-

stone quarry.......................... 264

FUSANG, story of...................... 33

GARCILASSO DE LA VEGA, on structures of

Cuzco............................ 340

GILBERT, G. K., quoted on prehistoric hearth 79

GILDER, ROBERT F., work of ............. 210

"GLACIAL PERIOD," significance of the term.. 73

GLYPHIC CHARACTERS, earliest date recorded

in .................................. 51

GLYPHIC INSCRIPTIONS OF MAYA-QUICHÉ

AREA ................................ 130

GLYPHIC RECORDS..................... 51

GLYPHIC WRITING, development of, in South

Mexico........................... 129

GOLD ORNAMENTS FOUND IN FLORIDA...... 104

GoUGE, stone................... 22, 23, 231, 238

Graves. See Burial customs.

GREenstone, grooved ax of, from supposed

glacial deposits ....................... 83

GRINDING, whetting..................... 344

GRINDING IMPLEMENTS, use of........... 345

HAMMERS-

discoidal............................ 294

made of deer antler.................. 193

stone ............................... 283

HAMM ERSTONES... 178, 180, 207, 218, 221, 260, 285, 286

discoidal......................... 331, 332

use of............................ 298,301

HANDBOOK SERIES OF BUREAU OF AMERICAN

EthNoLoGY......................... XII

HARPER, R. H., gift of, to National Museum.. 209

HARPOON HEADS, slate .................. 24

IIATCHET BLADES, method of shaping...... 335

HaWAIIAN IsLaNDS, antiquities of ......... xvII 
HEADS, carved stone, of Columbia-Fraser area ....................................

HEARTH, discovery of prehistoric...........

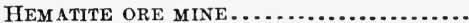

HISTORY, HUMAN-

fortuitous records of.

intentional records of

relation of, to archeology ................

sources of information..................

written and unwritten

HOE BLADES.

HORN IMPLEMENTS

Houses, communal, of the Georgia-Florida

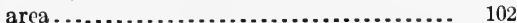

HRDLIČKA, ALEŠ-

collections made by .

investigations of

on finds in caves of Brazil . . . . .

HUPA METHOD OF ARROW MAKING..........

IlLINOIS, quarries of .......................

IMPLEMENTS-

making of, by free-hand fracture........

making of, described by Catlin..........

making of, dessribed by Redding.........

making of, first step in .................

making of, in Potomac Valley ...........

of Aretic area..........................

of arid region ...........................

of California area .......................

of Central America ......................

of Columbia-Fraser arca...............

of Great Northern Interior area..........

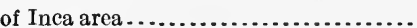

of Mississippi Valley region.............

of North Atlantic area.................

of Plains tribes.........................

of primitive South America .............

of South Andean-Pacific area .............

of Upper Mississippi Valley .............

shaped by use .........................

specialization of

time required in shaping................ 281

used in chipping ......... 193, 194, 198, 306, 307

used in drilling...................... 350

used in grinding...................... 345

used in incising ...................... 358

used in mining.................. 243,266,272

used in piercing ....................... 363

used in quarrying ................... 190,255

used in sawing ........................ 348

varieties of $\ldots \ldots \ldots \ldots \ldots \ldots \ldots \ldots \ldots \ldots . .289$

INCAS-

dominance of, in Middle Andean-Pacific

area ................................

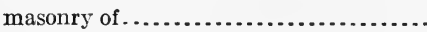

service to mummified bodies by ..........

stone buildings of .........

INCISING TOOLS, manner of using ........... 358, 361

Indian Mountain QUARRY, map of........ 197

INDLANA, flint quarries of................. 185

IsHI, flint working by $\ldots \ldots \ldots \ldots \ldots \ldots \ldots . .317,325$

JADE-

figurine bearing oldest date.

implements and ornaments in Northwest

Coast area ..................................

use of, in Arctic area..................
JASPER-

in Pennsylvania....................... 101

spatulate implements of ............... $\quad 113$

JenNey, W. P.-

on Magnet Cove quarries.............. 198

work of............................. 201

Key Marco, finds on ................... 103, 104

KrTCHEN MIDDENS on the coast of South

America.

KLAMATH INDIANS-

method of arrow making

312

method of fracturing stone............. 364

KNIFE BLADE, obsidian, from Nevada ....... 68

KNIVES, OBSIDIAN-

Aztec method of making............. 220, 323

of California area ..................... $\quad 115$

LADLE FROM AURIFEROUS GRAVELS......... 66

LAM PS, soapstone....................... 121

of Arctic region....................... $\quad 239$

LANGUAGES, diversity of, in chronology ...... 55

LANSING SKELETON................... 71, 106

LEE, S. L., on Washoe method of arrow making.

LEIDY, JOSEPH-

exploration of Pennsylvania caves by....

on teshoas.............................

LEVERETT, FraNk, quoted on finds in glacial gravels................................

LINGUISTIC STOCKS-

of arid area

of Georgia-Florida area.................

of Great Plains and Rocky Mountain area

of Middle Andean-Pacific area.

of Middle and Lower Mississippi Valley area.............................

of Middle Mexican area...................

of North Atlantic area.................

of North Mexican area...................

of Upper Mississippi and Great Lakes area.

Literature of AMERICAN ANTIQUITIES .... 145 See Explorers.

Little Falls, Minn., finds at............. 84

LODGE SITES NEAR QUARRIES............. 203

LOS CERLLLOS TURQUOISE MINES........... 271

"LOST TRIBES OF ISRAEL," supposed analo-

gies with aborigines.................... 14

LOVELAND, OHIO, chipped stone blade from.. $\quad 82$

Lund, P. W., work of, in caves of Brazil..... 93

LURAY, VA., workshop at.................. 334

LYON, CALEB, on arrowhead making........ 299

MCGEE, W J-

on finds in Trenton gravels.............. $\quad 77$

on obsidian bladefrom Nevada........... $\quad 68$

MCGuire, J. D., experiments of-

in drilling........................... 356

in stone shaping...................... 335

Madisonville, OHIO, chipped stonefrom.... 82

MAGNET Cove QUARRIES.................. 198, 199

Marajo bURIal vases................... 141

Mask, Chilcat, with Chinesecoins........... $\quad 30$

MAsks, snouted, of Maya sculpture.......... $\quad 26$

MASONRY-

of the Incas........................ 340,342

of the Maya......................... $\quad 130$ 
Page

Masterman, Elmer E., discovery of stone implements by

MAYA-

culture affected by environment.

culture, decadence of . . ................ culture, development of............ 129, 131

history recorded in glyphs.............

pottery.

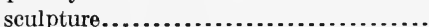

MEgALITHS..

Mercer, H. C.-

exploration of, in Durham cave.

on argillite implements of the Delaware

Valley.

on Big Bone Cave .....................

on caves of Ohio Valley.

on Port Kennedy Cave................

MERE, or stone club, of Samoan Island.......

Merriam, John C., on work in Shasta caves.

METAL WORK-

from the Florida peninsula............

of arid region ..........................

of Central America.....................

of Middle Andean-Pacific area...........

of North Andean-Pacific area.

\section{MEXICO-}

architectural remains of...............

culture of.............................

explorations conducted by..............

$\mathrm{MICA}$

method of stone flaking in ............ $\quad 323$

discovery of mines of ................. 242

mines of.......................... 101,107

uses of............................ 241, 243

MicMaC METHOD OF CHIPPING FLINT......... 364

MIDDEN DEPosits, investigation of, to estab-

lish a chronology .......................

Migration-

difficulties of . . ..................... 37,41

effect of, on culture................... 40

from Old to New World............... 55,56

necessarily slow ..................... 39,42

over Central America................... 133

over Great Northern Interior area....... 123

over North Mexican area............. 124

probable routes of...................... $\quad 32$

problems of........................... 36

the result of pressure $\ldots \ldots \ldots \ldots \ldots \ldots \ldots . \quad 38$

Mill Creek quarries.................... 187

Miller, Mabel L., on Digger method of chipping.............................

Mills, W.C., chipped stone object discovered

by $\ldots \ldots \ldots \ldots \ldots \ldots \ldots \ldots \ldots \ldots \ldots \ldots \ldots \ldots, 80,81$

MINING-

implements used in.

$243,266,272$

methods of.

$244,245,269$

of metals.

157

use of term.......................... 155

Missouri QUARrIEs..................... 195

MitLA, buildings of..................... 128 quarrying at...................... 274,338

Monoliths at Tiailuanaco.............. 340

MONTEZUMA, offerings of ................. 15

Monumental works of Middle and Souti

AMERICA .

MOORE, C. B., collection of.
Morice, A. G., on Dené method of arrow making............................. 318

MORTARS-

stone............................. 65, 109

wooden............................. 104

Mortars AND PESTLES-

from auriferous gravels............... 65

from Georgia-Florida area............. 104

of California..................... 115, 116

MoRTUARY OFfERINGS................. 107

MOSAIC WORK, turquoise used for .......... 114

MOUND BUILDERS...................... 105

effect of environment on culture of...... $\quad 47$

popular fallacy concerning.............. 13

relation of, to Indian tribes............. 15

Mounds-

in Columbia-Fraser area.............. 117

sacrificial, in Ohio..................... $\quad 242$

Mountain of the KnIVEs............... 214

MUMMIES-

from caves of North Mexican area...... 124

service to, by Incas....................

MURDOCH, JOHN, on Eskimo method of arrow

making............................... 318

MUSEUM OF AMERICAN INDIAN, work of staff

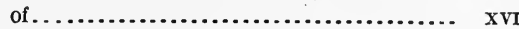

NAMPA IMAGE..................... 69, 70,111

NELson, E. W., on Eskimo arrow making... $\quad 319$

Nelson, Nels C., on flint working......... 325

NEW BRITAIN, method of perforating stone in. 365

Newcomerstown, OHo, supposed paleo-

lithic implement from .................. 80,81

New London, OHIO, discovery of stone implements at........................... 83

NEW ZEALAND METHOD OF DRILLING....... 356

NiCOLLET EXPLORING PARTY, inscription left

by.................................. 264

Nilsson, SveN-

experiments of, in stone fracture....... 284

on "Amazon Axe".................... 23

North Carolina, mica mines of .......... 245, 250

NotcIIng TOOL...................... 327

Novaculite-

character of, in Magnet Cove quarries.... 200

quarries........................... 196

OAXACA, ruins of ........................ 128

OBSIDIAN-

arrowheads, method of making........ $\quad 299$

articles made of....................... $\quad 227$

distribution of....................... 227

implement from Nevada................ $\quad 68$

implements from Ohio mound.......... $\quad 107$

knives, Aztec, method of making........ 323

knives of California area......... 115, 214, 216

mines in United States................ 214

mines of Mexico....................... 214

mines of middle Mexican area......... 127

quarries in Guatemala................. $\quad 227$

OHIO VÁLLEY -

archeological researches in ............ 80, 83

cave explorations..................... 89

OLANTAYTAMBO, fortress of .............. 340

ORIGIN-

Asiatic, of $A$ merican race........... 19, 56

of American aborigines.............. 14, 31

of human race..................... 18 
ORNAMENTS-

Page

of Arctic area.

of mica.............................. 242

OXIDES OF IRON, yellow and red, used as

paint.

OZARE REGION, explorations in caves of ...

PAHVANT METHOD OF MAKING ARROWHEADS.

Paint Mine in Missouri.................

PAIUTE METHOD OF MAKLNG ARROWHEADS ... 306, $310,312,313$

PALENQUe, evidence of age................

"Palmas" Carvings of Mexico........... 127

Peabody, Charles-

explorations of, at Cavetown, $\mathbf{M d}$ explorations of in Ozark region ......

Peabody Museum, collection of implements by..

Pectolite, use of, in Aretic area.

PERCUSSION PROCESS OF STONE FRACTURE... Causes of failure in....................

Perforating Stone, method of............

PERU-

ancient builders of.................... explorations conducted by............... practice of Incas of..................... See Incas.

Pestles, stone...................... 62,63,65 of the Northwest Coast................ 29 See Mortars and pestles.

Petroglypis-

implements used in carving............ of Chile............................. of North Atlantic area. of Northwest Coast area.................

Pfeifer, LudwiG, studies of, in stone frac-

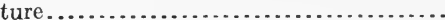

PhILlIPS, W. A., work of, in Mill Creek quarries................................

PICTOGRAPHIC RECORDS.........................

PictographS OF SOUTH AMERICA ...........

Piercing implements....................

PINEY BRANCH QUARRIES, shaping work in. .

PIPES-

manufacture of, from pipestone.........

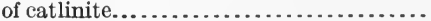
of Mississippi Valley area.............. of North Atlantic area.................. steatite, of California..................

Pipestone, red, prehistoric use of ........... PIPESTONE QUARRIES................... 109, 253 PIPESTONE QUARRY, explorers of............ 264 Polished STONE ARTIFACTS, processes of

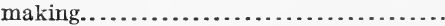

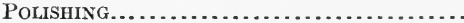
Port Kennedy Cave excavation... . . . . . . "Postglacial," significance of the term... Ротомac Valley, implement making in.... PotTery-

head from Vera Cruz

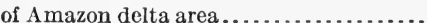

of Aretic area. ........................

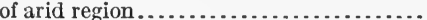

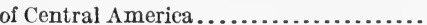

of Ecuador..........................

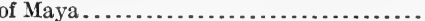

of Maya-Quiché area.................

of North Mexican area................
PotTERY - Continued.

Page

of primitive South $A$ merica............ 144

of South Mexican area................ 129

of Upper Mississippi region............ 109

of West Indies....................... 146

See Ceramics; Earthenware.

POWELL, J. W.-

on arrow making............... 306,310,311

studies of......................... Xv

POWELL, WILFRED, on perforating stone.... 365

Powers, StePHen, on arrow making by Cal-

ifornia Indians..................... 321

Powhatan METHOD of ARROW MAKING.... 316

Pressure PROCESS OF STONE FRACTURE... 304, 308

PROBLEMS OF ANTIQUITY ..................... XV

Publications Rei.ating to COLlections of

National Museum .................. xiv

Pueblo culture, influence of environment on................................ 47

Pueblos-

early records of ................. 16

lowland, practically fortifications....... 112

PUMP DRILL........................... 354

PUtNaM, F. W., archeologieal work of...... 242

Pyramids, Middle Mexican area........... 126

QUARRIES-

classifleation of $\ldots \ldots \ldots \ldots \ldots \ldots \ldots \ldots \ldots \ldots 158$

of Arkansas........................ 196

of Indiana......................... 185

of Missouri........................ 195

of Piney Branch, D. C................ 159

QUARRY WORKERS, group of, in National

Museum ........................ 168,171

QUARRYING......................... 155

implements used in................. 190, 255

methods of ...................... 156,

$160,176,196,202,228,253$,

$255,274,276,282,337,359$

QUARTZ-

objects from gravel deposits at Little

Falls, Minn.................... 84, 86

quarries in the District of Columbia..... 101

use of, in its bearing on problems of age.. $\quad 84$

QUARTZITE QUARRIES, Wyoming.......... 210

QUIPU OF PERU....................... 7

RaU, Charles-

experiments of, in drilling ............. 356

work of........................... xiv

RECORDS-

fortuitous......................... 51

intentional......................... 51

"RED PAINT PEOPLE," origin of the name.... 100 REDDING, B. B., on implement making.... 296, 314 REJECTAGE-of blade making........ 165, 179, 196 of quarry shops................. 205, 206

REJECTS MISTAKEN FOR PAIEOLITHIC IMPLEMENTS.............................. 75

RELIGION, effeet of, on culture............. $\quad 49$

RESEARCH IN ARCHEOLOGY, scope of....... 18

REYNOLDS, E. R., work of, in soapstone quarry ............................ 231

Rhyolite in Pennsylvania .............. 101

ROADS OF THE INCA DOMINION............ 138

RoBinson, WILLIAM, assistance of, to author. $\quad 246$ RoBINSON MINE..................... 246, 248

ROME, written and unwritten histcry of..... 5

ROSE HILL QUARRY .................... 231 
RUins-

of arid region

of Maya citios.

SAILING CRAFT UNKNOWN IN PRE-COLUMBIAN

A Merica ..............................

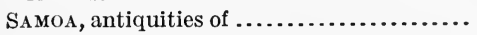

SAMOAN CLUB ............................

SAN JUAN TEOTIHUACAN, ruins of..........

SANTA Catalina soapstone QUARRIES .... 238, 239

SAVILle, M. H., researches of, in Guatemala. 227

SAWING ............................. 344

SA WING IMPLEMENTS . . .................. 348

Schumacher, Paul-

on Klamath arrow making.

on stone fracture.

SCOURING.

SCrapERs, stone, use of.

SCULPTURE-

in California area.

in Central American-Isthmian area.

in eastern Mexico......................

in Maya-Quiché arca..................

in Northwest Coast area................

of the Maya.

SCULPTURES-

Central American

destruction of..

SEllers, G. E., on arrow making by western

tribes................................ 316, 322

SEMINOLE IN FlORIDA TO-DAY............... 102

SERI INDIAN METHOD OF MAKING ARROW-

IIEADS...............................

SERPENTINE, bowls and cups of............

SHALER, N.S.-

on influence of buffalo on culture in Mississippi Valley......................

on Ohio Valley cave explorations.........

SHASTA METHOD OF MAKING ARROWHEADS...

SHEEP UNKNOWN IN PRE-COLUMBIAN AMER-

ICA.

SHELl HEAPS-

of the Georgia-Florida area..............

of the Pacific coast

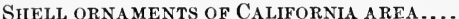

SHIPs, giant, of the Mediterranean........... SILliman, BENJA MIN, on mining implements. SILVER ORNAMENTS FOUND IN FLORIDA......

SINK Hole MINES................... 246, 248

Sroux INDIANS-

as quarry workers.

SLATE-

owners of pipestone quarry . .......... 262, 263

carvings of Northwest Coast area....... 119

use of, in Aretic area................. 121

SledGES, stone................ 261, 267, 272, 273

SмiтH, C. D., on mica mines of North Caro-

lina...................................

SMITH, JoIn, on Powhatan method of mak-

ing arrowheads......................... 316

SNYDER, J. F., on the making of arrowheads 299,313

SOAPSTONE-

carvings in California area ............. 115

deposits of............................ 101

lamps made of....................... 121

lamps of the $A$ retic region . . ............ $\quad 239$

quarries. 228,229
SoAPSTONE-Continued. Page

quarries in California................. 238

quarries in Wyoming................. 238

vessels.......................... 232,233

working............................ 358

SPANISH DIGGINGS............. 198, 201, 209, 210

SPEARHEADS-

Australian method of shaping.......... $\quad 325$

of slate.............................. 24

SPRUCE-PINE MINES.................... 245

Squier, E. G.--

expedition of........................ 16

on fortress of Olantaytambo........... 340

on quarries of Cuzco................. $\quad 276$

on stonework at Cuzco............... 341

SquiER AND Davis, researches of........... 15

Statuette from Vera Cruz, earliest date recorded on ............................

Statuette. See Nampa Image.

STEATITE, pipes made of.................. 115 Sce Soapstone.

STELE-

of Copan and Quirigua.

of Guatemala suggest sculptures of Far

East............................

Stephens, John L.-

expedition of.

on quarries at Copan . .................

STONE, use of, in building. ...............

STONE AGE, scope of .....................

STONE-BUILDING ART OF ARID REGION......

STONE BUILDINGS NOT AN EVIDENCE OF GREAT ANTIQUITY.

STONE SHAPING-

by fracture.

processes, classification of

work in Potomac Valley ...............

StRAP DRILL......................... 354

TERRA-COTtA FigURINE FroM NAMPA, IDAHO. 69,70

Teshoas................................. 302

TEXTILES OF ARID REGION ................. 114

Toltec Remains...................... 126

ToMBS of stone..................... 139

Tools. See Implements.

TORQUEMADA ON AZTEC METHOD OF MAKING

KNIVES..................... 324

TOY CHARIOT FROM MEXICO ............ 20,21

TRANSPORTATION ....................... 153

of stone blocks...................... 277

Travertine vase, showing use of drill.... 351

Trenton, N. J., archeological work in vicin-

ity of $\ldots \ldots \ldots \ldots \ldots \ldots \ldots \ldots \ldots \ldots \ldots \ldots \ldots, \quad 76$

Trill, Charles F., work of............ xiv

TURner MOUNDS, mica figures from........ 242

TURQUOISE, use of...................... 273

TURQUOISE MINES.................... 114

TURQUOISE MINING................... 271

TURTLEBACKS.......................... 289

U. S. National MUSeUmcollection of implements by............ 75 work conducted by, near Cumberland, Md. $\quad 91$

UtEnsILS, stone, of California area......... 115

VIARD METIOD OF ARROW MAKING........ 321

VILlage site, sand-buried, on Chesapeake Bay ...............................

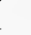

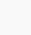

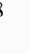

16
274

99

Xv

14

57

283

78

9

(1)

26
139

4

1
7

351

6

V

3

71

289

115


WARREN, S. HAzzLedine, studies of, in stone

fracture..............................

WARSAW QUARRIES......................

WASHingtoN, D. C., written and unwritten

history of............................

WELSH SETTLEMENT IN AMERICA, myth concerning.

WEST INDIES, culture of.

WHEELED TOY FROM MEXiCO.

WhELPLEY, II. M., collections of .

WHETSTONE OF JADE

WILLIS, BAILEY-

collections made by

investigations of.

Wilson, Thomas, work of.............. xiv

WINTOON METHOD OF IMPLEMENT MAKING. 296,314

\section{Page}

279

181

5

5

14

XVI

20,21

194

346

300

59

XIV
WOOD CARVING-

of Northwest Coast area............... $\quad 119$

of West Indies...................... 147

WORKSIIOP AT LURAY, VA.............. 334

WoRKsIIOPS-

quarry.............. 161, 162, 191, 202, 204, 24?

village-site........................ 192

Writers on American antiquities. See

Explorers.

WYANDOTTE CAVE, explorations in......... 91

Wyoming, quartzite quarries of . .......... 210

YANI INDIAN, flint working by ............ 325

YUCATAN-

caves, researches in.................. 93

stonecutters........................ 275 






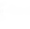




$$
1293169 x
$$





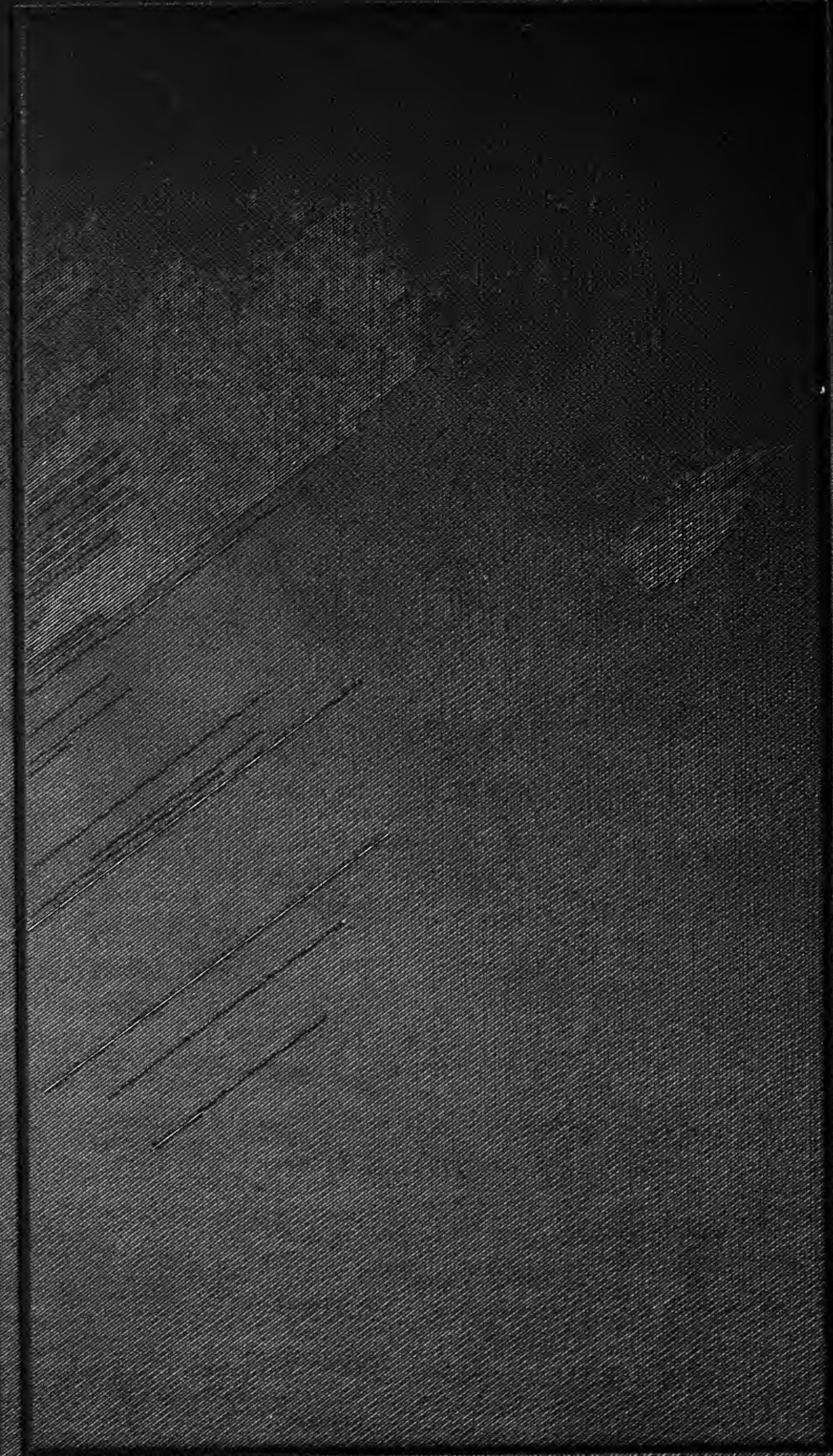

